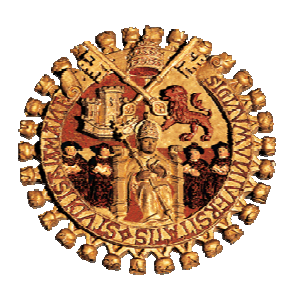

UNIVERSIDAD DE SALAMANCA

FACULTAD DE FARMACIA

DEPARTAMENTO DE QUíMICA FARMACÉUTICA

\title{
DESARROLLO DE NUEVOS AGENTES \\ ANTIMITÓTICOS RELACIONADOS CON \\ COMBRETASTATINAS Y FENSTATINAS
}

TESIS DOCTORAL

RAQUel ÁlVAREZ LOZANo

Junio 2009

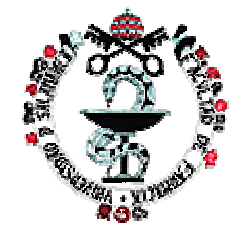





\section{UNIVERSIDAD DE SALAMANCA \\ FACULTAD DE FARMACIA \\ DEPARTAMENTO DE QUÍMIICA FARMACÉUTICA}

Trabajo Presentado Para Optar al Grado de Doctor en Farmacia por:

Raquel Álvarez Lozano

$\mathbf{V}^{\mathbf{o}} \mathbf{B}^{\mathbf{o}}$

Profesor Arturo San Feliciano

Director del Departamento de Química Farmacéutica 

Manuel Medarde Agustín, Catedrático de Química Orgánica y Rafael Peláez Lamamié de Clairac Arroyo, Profesor Titular de Química Orgánica, del Departamento de Química Farmacéutica, de la Facultad de Farmacia, de la Universidad de Salamanca,

\section{CERTIFICAN:}

Que la licenciada en Farmacia por la Universidad de Salamanca, D ${ }^{\mathbf{a}}$ Raquel Álvarez Lozano, ha realizado en este Departamento, bajo su dirección, el trabajo titulado "Desarrollo de nuevos agentes antimitóticos relacionados con combretastatinas y fenstatinas", para optar al grado de Doctor en Farmacia por la Universidad de Salamanca. Considerándolo finalizado, autorizan su presentación para que sea juzgado por el tribunal correspondiente.

Salamanca, Marzo de 2009

Fdo. Manuel Medarde

Fdo. Rafael Peláez 

La investigación realizada sobre los compuestos 16, 17, 73 y 74 se llevó a cabo bajo la supervisión del Dr. Andrew Westwell durante la estancia en la Universidad de Cardiff.

La financiación de la investigación en este trabajo de Tesis Doctoral ha procedido de los siguientes proyectos:

-Nuevos agentes quimioterápicos. Síntesis, estudios de actividad e interacción con tubulina. CTQ-2004-00369/BQU (Ministerio de Educación y Ciencia 2004-2007).

-Diseño, síntesis y evaluación de análogos macrocíclicos de combretastatinas y fenstatinas como agentes citotóxicos inhibidores de la polimerización de tubulina. SA090A06 (Junta de Castilla y León 2006-2008).

-Compuestos antineoplásicos y su unión a tubulina. Estudio de la interacción proteína-ligando. USAL2005-002 (Universidad de Salamanca 2006-2007).

-Síntesis y evaluación de nuevos agentes antitumorales basados en combretastatinas y fenstatinas: vectorización y modificación del mecanismo de acción. SAF20080424. (Ministerio de Ciencia e Innovación. DGPTC-SGPI 2008-2011).

Su realización ha sido posible gracias a:

-Beca para la realización de tesis doctorales de la Fundación Ramón Areces (2005).

-Beca-contrato FPU del Ministerio de Educación y Ciencia. (2006-2007).

-Contrato de ayudante de la Universidad de Salamanca (2007-). 

Una parte de los resultados presentados en esta memoria, han sido publicados en los siguientes artículos:

-"Synthesis and biological activity of naphthalene analogues of phenstatins: Naphthylphenstatins” Bioorg. Med. Chem. Lett. 2007, 17, 3417-3420.

-“Conformationally restricted macrocyclic analogues of combretastatins" Bioorg. Med. Chem. Lett. 2007, 17, 6316-6320.

-"Diarylmethyloxime and hydrazone derivatives with 5-indolyl moieties as potent inhibitors of tubulin polymerization" Bioorg. Med. Chem. 2008, 16, 5952-5961.

-"Naphthylphenstatins as tubulin ligands: Synthesis and biological evaluation" Bioorg. Med. Chem. 2008, 16, 8999-9008. 

Quiero expresar mi agradecimiento a todas las personas que con su ayuda y apoyo han contribuido a la realización de este trabajo:

A mis directores, Manolo y Rafa, por todo lo que me han enseñado profesional y personalmente. Por tener siempre la puerta de su despacho abierta, dispuestos a ayudar en todo lo necesario. Por su dedicación y paciencia, muchas gracias.

A los doctores Andrew Westwell y Andrea Brancale, por hacerme sentir una más durante mi estancia en Cardiff y por sus aportaciones a la última parte experimental de este trabajo.

Al Prof. Adam Nelson por brindarme la oportunidad de realizar una estancia en la Universidad de Leeds.

A todos los profesores y compañeros del departamento, por hacer del laboratorio un agradable lugar de trabajo y orientarme cuando lo he necesitado.

A Consta y Rosa, por su inestimable ayuda y por hacer de su despacho nuestra segunda casa, sin olvidar el "momento pincho" de cada día, que hace que todos volvamos con una sonrisa al trabajo.

A todos mis amigos, Blanca, Elena, Lauri, Pilar, Manu, Andrés, Alex, Mieke, Diego, Raquel, Sonia, Pablo, Marta... por todos los buenos momentos compartidos durante estos años.

A mi familia, porque sin su apoyo, cariño y comprensión, no habría podido llegar hasta aquí. Y en especial, a mis padres y hermana, que han sufrido la distancia tanto como yo y a los que quiero y admiro tanto, que no puedo explicarlo con palabras.

A Fernando, por estar siempre ahí, tendiéndome su mano en los malos momentos y disfrutando juntos de los buenos. Por enseñarme a valorar y apreciar esas pequeñas cosas que, a veces, sin darnos cuenta, dejamos pasar.

Muchas gracias a todos. 


I.1. REA DE COMBRETASTATINAS 27

I.1.A. Modificaciones en el anillo $A \quad 27$

I.1.B. Modificaciones en el anillo B 28

I.1.C. Modificaciones en el puente 29

I.1.D. Otras modificaciones 30

I.2. REA DE FENSTATINAS 31

I.3. FARMACÓFORO Y ESTRUCTURA DE RAYOS X 32

II. PLANTEAMIENTO Y OBJETIVOS 35

II.1. PUENTE OLEFÍNICO 37

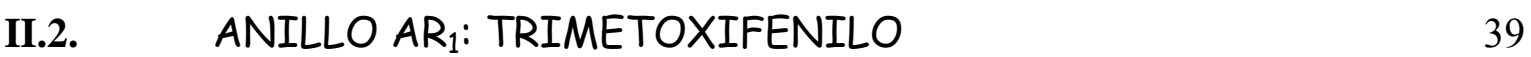

II.3. ANILLO AR2: DERIVADO DE 5-INDOLILO $\quad 39$

II.4. OBJETIVOS 40

III. MÉTODOS Y RESULTADOS 43

III.1. SÍNTESIS DE COMPUESTOS NO MACROCÍCLICOS $\quad$ ST

III.1.A. Síntesis de isocombretastatinas $\quad 47$

III.1.A.1. $\quad$ Materiales de partida 48

Obtención de los compuestos 11 y 12

Obtención de $N$-metil-5-bromo-1H-indol (10) $\quad 49$

III.1.A.2. Síntesis de diarilmetanoles 50

III.1.A.3. Síntesis de fenstatinas 53

III.1.A.4. Síntesis de isocombretastatinas $\quad 55$

III.1.A.5. Modificaciones del anillo aromático $\mathrm{Ar}_{2} \quad 56$

III.1.A.5.1. Modificaciones en los restos fenilo 56

Reducciones de grupo nitro a amino $\quad 56$

Desprotección de alcoholes $\quad 58$

III.1.A.5.2. Modificaciones en la posición 3 del indol $\quad 58$

Formilaciones $\quad 59$

Reducciones del aldehído $\quad 61$

Formación de oximas $\quad 62$

Formación de hidrazonas $\quad 62$

Tratamiento de oximas con anh. acético 63

III.1.A.6. Modificación del puente $\quad 64$ 
Reducción de la olefina del puente $\quad 64$

III.1.B. Síntesis de derivados de fenstatina con otros heterociclos 67

$\begin{array}{lll}\text { III.1.B.1. } & \text { Materiales de partida } & 67\end{array}$

Obtención de benzimidazoles 14 y 15

Obtención de 5-bromo-1,3-benzoxazol (17) 68

$\begin{array}{lll}\text { III.1.B.2. } & \text { Síntesis de diarilmetanoles } & 69\end{array}$

Obtención de los compuestos 69 y 70

Obtención del compuesto 73 70

III.1.B.3. Síntesis de fenstatinas $\quad 71$

III.1.C. $\quad$ Síntesis de derivados de combretastatinas 73

III.1.C.1. Materiales de partida 74

Obtención de 1-metil-1H-indol-5-carbaldehído (4) 74

Obtención de 1-etil-1H-indol-3,5-dicarbaldehído (3) 74

Obtención de benzimidazol carbaldehídos 7 y $8 \quad 75$

III.1.C.2. Síntesis de análogos de combretastatinas 76

Obtención del 1H-indol-3-carbaldehído $75 \quad 77$

Obtención de los derivados de benzimidazol 79 y $80 \quad 78$

Obtención del derivado de indol $\mathbf{7 6} \quad 78$

Obtención de los derivados 77 y 80

III.2. SÍNTESIS DE COMPUESTOS MACROCÍCLICOS $\quad 81$

III.2.A. Intermedios monoarílicos y diarílicos 85

III.2.B. $\quad$ Compuestos macrocíclicos 87

III.3. ANÁLISIS ESPECTROSCÓPICO DE COMPUESTOS MACROCÍCLICOS 91

III.3.A. $\quad$ Olefinas 91

III.3.B. $\quad$ Dioles y acetatos 92

III.4. ANÁLISIS CONFORMACIONAL DE COMPUESTOS MACROCÍCLICOS 97

III.4.A. Olefinas $\quad 99$

III.4.A.1. Análisis de conformaciones 99

Olefinas macrocíclica con dos restos fenilo. Equilibrio conformacional 103

Olefinas macrocíclica con un resto fenilo simétrico y otro asimétrico. Equilibrio conformacional de 0D, 0E y 0F 106

Olefinas macrocíclica con un resto indolilo.

Análisis conformacional de 84 y 87

III.4.A.2. Estudios de mecánica molecular y dinámica molecular de las olefinas 84 y 87

$\underline{\text { Mecánica molecular }}$ 
Dinámica molecular

III.4.A.3. Justificación de la apariencia de los espectros de RMN de las olefinas 84 y 87

$\begin{array}{lll}\text { III.4.B. } & \text { Dioles y diacetatos } & 139\end{array}$

III.4.B.1. Análisis de conformaciones 139

Análisis de conformaciones de dioles con dos restos fenilo 139

Análisis de conformaciones de dioles con un resto indolilo 144

III.4.B.2. Estudios de mecánica molecular y dinámica molecular de dioles y diacetatos 149

Mecánica molecular. Análisis de resultados $\quad 155$

Dinámica molecular 163

III.4.B.3. Justificación de la apariencia de los espectros de RMN de dioles y acetatos

Giro rápido del puente-Interconversión de conformaciones sinclinales.

Giro lento del puente. Interconversiones lentas de conformaciones sinclinales.

III.5. ACTIVIDAD BIOLÓGICA. 185

III.5.A. $\quad$ Actividad inhibidora de la polimerización de tubulina 185

III.5.A.1. Aislamiento de la proteína 186

III.5.A.2. Ensayos de la actividad inhibitoria de polimerización de tubulina de los compuestos. 187

III.5.A.3. Determinación de la $\mathrm{IC}_{50}$ de los compuestos seleccionados $\quad 189$

$\begin{array}{lll}\text { III.5.B. } & \text { Citotoxicidad } & 191\end{array}$

III.5.C. Discusión de los resultados de actividad. 193

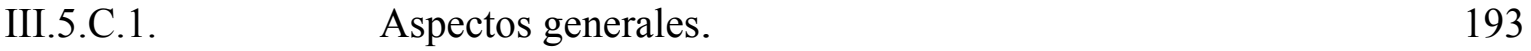

$\begin{array}{ll}\text { III.5.C.2. } & \text { Consideraciones estructurales generales. }\end{array}$

III.5.C.3. Análisis de la contribución de elementos estructurales individuales. 203

IV. PARTE EXPERIMENTAL $\quad 211$

IV.1. TÉCNICAS GENERALES 213

IV.2. MÉTOODOS GENERALES 217

IV.3. SÍNTESIS DE COMPUESTOS NO MACROCÍCLICOS 223

IV.3.A. Materiales de partida. 223

IV.3.B. Síntesis de fenstatinas e isocombretastatinas difenílicas 233

IV.3.C. Sintesis de fenstatinas e isocombretastatinas con un resto indolilo. 255

IV.3.D. $\quad$ Síntesis de fenstatinas con un heterociclo distinto de indol 277

IV.3.E. $\quad$ Síntesis de combretastatinas. 281 
IV.4. SÍNTESIS DE COMPUESTOS MACROCÍCLICOS 287

$\begin{array}{lll}\text { IV.4.A. } & \text { Materiales de partida } & 287\end{array}$

IV.4.B. $\quad$ Macrociclos 291

IV.5. ACTIVIDAD BIOLÓGICA 299

IV.5.A. Aislamiento de proteína microtubular 299

IV.5.B. Determinación de la actividad inhibitoria de la polimerización de tubulina de los compuestos a una concentración $\quad 301$

IV.5.C. Determinación de la $I C_{50}$ de inhibición de polimerización de tubulina 


\section{LISTA DE SÍMBOLOS, ABREVIATURAS Y ACRÓNIMOS}

\begin{tabular}{|c|c|}
\hline Ac & Acetilo \\
\hline $\mathrm{Ac}_{2} \mathrm{O}$ & Anhidrido acético \\
\hline AcOEt & Acetato de etilo \\
\hline $\mathrm{AcOH}$ & Ácido acético \\
\hline Ar & Arilo \\
\hline $\mathrm{BI}$ & Benzimidazol \\
\hline BSA & Seroalbúmina bovina \\
\hline $\mathrm{Bu}_{4} \mathrm{~N}^{+} \mathrm{HSO}_{4}^{-}$ & Hidrogenosulfato de tetrabutilamonio \\
\hline C & Cuartete \\
\hline CA-4 & Combretastatina A4 \\
\hline $\mathrm{CC}$ & Cromatografía de columna \\
\hline $\mathrm{CCF}$ & Cromatografía en capa fina \\
\hline$d$ & Doblete \\
\hline$d a$ & Doblete ancho \\
\hline DAMA- & $N$-diacetil- $N$-(2-mercaptoacetil)- \\
\hline$d d$ & Doble doblete \\
\hline$d d d$ & Doble doble doblete \\
\hline $\mathrm{DE}$ & Disolución de extracción \\
\hline $\mathrm{DMF}$ & $N, N$-Dimetilformamida \\
\hline DMSO & Dimetilsulfóxido \\
\hline$d t$ & Doble triplete \\
\hline DT & Disolución de transporte \\
\hline EDTA & Ácido etilendiaminotetracético \\
\hline EGTA & Ácido etilenglicol-bis(diaminoetiléter)-N,N,N',N'-tetraacético \\
\hline EM & Espectro de masas \\
\hline $\mathrm{EtBr}$ & Bromuro de etilo \\
\hline Et & Etilo \\
\hline $\mathrm{EtOH}$ & Etanol \\
\hline Fig. & Figura \\
\hline GTP & Trifosfato de guanosina \\
\hline Hex & Hexano \\
\hline HPLC & Cromatografía líquida de alta eficacia \\
\hline $\mathrm{Hz}$ & Hercios \\
\hline $\mathrm{IC}_{50}$ & Concentración inhibitroria 50 \\
\hline IPT & Inhibición de la polimerización de tubulina \\
\hline IR & Infrarrojo \\
\hline$J$ & Constante de acoplamiento \\
\hline $\mathrm{K}$ & Grados Kelvin \\
\hline Kcal & Kilocaloría \\
\hline$m$ & Multiplete \\
\hline $\mathrm{M}^{+}$ & Ion molecular \\
\hline MAPs & Proteínas asociadas a microtúbulos \\
\hline $\mathrm{Me}$ & Metilo \\
\hline MeI & Yoduro de metilo \\
\hline mmol & Milimoles \\
\hline $\mathrm{MeO}$ & Metoxilo. \\
\hline
\end{tabular}




\begin{tabular}{|c|c|}
\hline $\mathrm{MeOH}$ & Metanol \\
\hline MTP & Proteína microtubular \\
\hline $\mathrm{N}_{2}$ & Atmósfera de nitrógeno \\
\hline$n \mathrm{BuLi}$ & $n$-butillitio \\
\hline $\mathrm{nm}$ & Nanómetros \\
\hline NMeIND & N-metil-5-indolilo \\
\hline nOe & Efecto nuclear Overhauser \\
\hline ns & Nanosegundos \\
\hline $\mathrm{OMe}$ & Metoxilo \\
\hline${ }^{\circ} \mathrm{C}$ & Grado Celsius \\
\hline $\mathrm{P}$ & Grupo fosfato \\
\hline $\mathrm{Pd} / \mathrm{C}$ & Paladio sobre carbono \\
\hline PDC & Dicromato de piridinio \\
\hline P.f. & Punto de fusión \\
\hline $\mathrm{Ph}$ & Fenilo \\
\hline PMSF & Fluoruro de fenilmetanosulfonilo \\
\hline $\mathrm{PPh}_{3}$ & Trifenilfosfina \\
\hline ppm & Partes por millón \\
\hline ps & Picosegundos \\
\hline pyr & Piridina \\
\hline REA & Relación estructura actividad \\
\hline $\mathrm{RMN}{ }^{13} \mathrm{C}$ & Resonancia magnética nuclear de carbono 13 \\
\hline $\mathrm{RMN}{ }^{1} \mathrm{H}$ & Resonancia magnética nuclear de protón \\
\hline rpm & Revoluciones por minuto \\
\hline$S$ & Singlete \\
\hline sa & Singlete ancho \\
\hline $\mathrm{SC}$ & Sinclinal \\
\hline$t$ & Triplete \\
\hline t.a. & Temperatura ambiente \\
\hline TBAF & Fluoruro de tetrabutilamonio \\
\hline TBDMS & tercButildimetilsililo \\
\hline TBDMSiCl & Cloruro de tercbutildimetilsililo \\
\hline TBDPS & tercButildifenilsililo \\
\hline TBDPSiCl & Cloruro de tercbutildifenilsililo \\
\hline TEA & Trietilamina \\
\hline THF & Tetrahidrofurano \\
\hline TM & 3,4,5-Trimetoxifenilo \\
\hline TMG & 2,3,4-Trimetoxifenilo \\
\hline$t_{R}$ & Tiempo de retención \\
\hline$\delta$ & Desplazamiento químico \\
\hline UV & Ultravioleta \\
\hline$\mu \mathrm{M}$ & Micromolar \\
\hline
\end{tabular}




\section{RESUMEN}

Una de las estrategias empleadas en la lucha contra el cáncer es la búsqueda y desarrollo de nuevos fármacos capaces de inhibir la polimerización de tubulina y frenar, así, el crecimiento de las células cancerosas.

En nuestro grupo de investigación se ha optado por la síntesis y evaluación de nuevos agentes antimitóticos capaces de unirse a la tubulina en el sitio de la colchicina. Tomando como referencia la combretastatina A-4, durante los últimos años se han realizado modificaciones en ambos anillos aromáticos y en el puente.

La disposición cisoide de los anillos aromáticos es una de las características estructurales clave para mantener la actividad antimitótica en estos compuestos. En este trabajo se han seguido dos estrategias diferentes para conseguir este objetivo:

- Sintetizar análogos macrocíclicos de combretastatina, que además restringen la movilidad de los anillos aromáticos.

- Obtener compuestos con estructura de 1,1-diarileteno, isómeros de combretastatina que poseen la ventaja de no sufrir isomerizaciones cistrans.

En todos estos compuestos se ha mantenido la presencia de un anillo de trimetoxifenilo, y se han introducido variaciones en el segundo anillo aromático. Principalmente se ha estudiado el efecto en la actividad que produce el empleo de restos $N$ metil-5-indolilo diferentemente sustituido en la posición C-3.

Finalmente, se ha evaluado, in vitro, la capacidad inhibitoria de polimerización de tubulina de todos los compuestos obtenidos y su actividad citotóxica frente a cuatro líneas celulares neoplásicas (HL-60, A-549, HeLa y HT-29). 


\section{ABSTRACT}

The search and development of new inhibitors of tubulin polymerization drugs that stop cancer cell growing, is one of the present strategies to fight against the cancer.

Our research group has chosen for the synthesis and evaluation of new antimitotic agents that are able to bind to the tubulin in the colchicine site. In the last few years, several modifications of both aromatic rings and the bridge have been performed using the combretastatin A-4 as a model.

Keeping the cisoid disposition of the rings is one of the structural keys to preserve the antimitotic activity. This $\mathrm{Ph}$. D. work has followed two different strategies to reach this objective:

- Synthesizing macrocyclic analogues of combretastatins, which also restrict the mobility of the aromatic rings.

- Obtaining compounds with 1,1-diarylethene structure. These isomers of combretastatins have the advantage of not suffering cis-trans isomerizations.

All these compounds have maintained a trimethoxyphenyl moiety and have different modifications on the other aromatic ring. Mainly, it has been studied the effect on the activity of several substitutions at the C-3 position of $N$-methyl-5-indolyl moiety.

Finally, all the synthesized compounds have been assayed in vitro to check their tubulin polymerization inhibitory activity and their cytotoxicity against four neoplasic cell lines (HL-60, A-549, HeLa and HT-29). 

El cáncer es un conjunto heterogéneo de enfermedades que puede afectar a todos los órganos del cuerpo y que consiste en la aparición de células cuyos mecanismos de proliferación se encuentran descontrolados. Estas células poseen una capacidad de división y crecimiento que supera los límites normales y pueden llegar a invadir los tejidos vecinos o incluso a diseminarse por todo el organismo a través del torrente sanguíneo o linfático (metástasis) ${ }^{1}$.

En la actualidad, el cáncer es la segunda causa de mortalidad en los países desarrollados, por detrás de las enfermedades cardiovasculares. En España, las enfermedades cardiovasculares siguen siendo la primera causa de muerte entre las mujeres, mientras que en los hombres el cáncer las ha superado y es la primera causa de defunción ${ }^{2}$.

Uno de los posibles tratamientos desarrollados para combatir el cáncer es la quimioterapia. Tomando como base que las células cancerosas presentan una elevada frecuencia de división celular, el desarrollo de numerosos fármacos se ha dirigido a la interrupción de la mitosis (fase del ciclo celular durante la cual se produce la división celular).

\footnotetext{
Nota: Las referencias bibliográficas se han incluido como notas a pie de página, no repitiendo las citas en cada capítulo (aunque sí en capítulos diferentes).

${ }^{1}$ www.cancer.gov/espanol, página web del Instituto Nacional del Cáncer.

2 Datos del año 2006 recogidos en las encuestas realizadas por el INE y publicados en 2008. Disponibles en http://www.ine.es/prensa/np490.pdf.
} 
Los microtúbulos son un componente básico del citoesqueleto y juegan un papel importante durante la mitosis, además de participar en otros procesos como el transporte y los movimientos celulares. Los microtúbulos son cilindros huecos formados por 13 protofilamentos que, a su vez, están compuestos por heterodímeros de subunidades $\alpha / \beta$ de tubulina. Se puede decir que los microtúbulos presentan cierta polaridad y una dinámica inestable, ya que existe un equilibrio con dímeros que están constantemente adicionándose a uno de los extremos del microtúbulo (extremo +) y liberándose por el otro (extremo -) y se alternan procesos de polimerización de tubulina o crecimiento y despolimerización o acortamiento. ${ }^{3}$

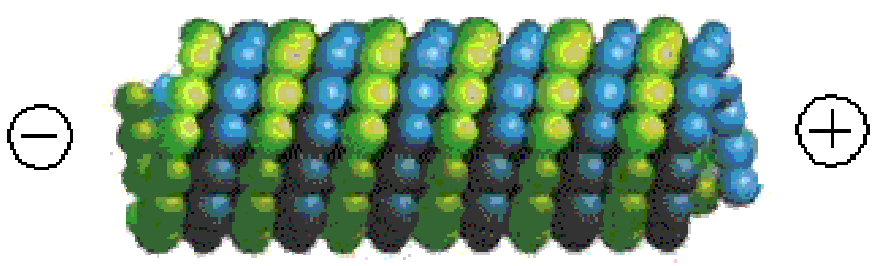

Figura 1. Representación gráfica de un microtúbulo con las subunidades $\alpha$ en verde y las $\beta$ en azul.

La estructura tridimensional de los dímeros de tubulina es conocida y sobre ella se han identificado al menos cinco sitios de unión de ligandos: el sitio de unión del taxol, el sitio de unión de los alcaloides de la vinca minor, el sitio de unión de la colchicina y dos sitios de unión para GTP (uno intercambiable, sitio E, y otro no intecambiable, sitio N). Además cada mol de tubulina se encuentra unido a un mol de $\mathrm{Mg}^{2+}$.

Mientras que el taxol ejerce su acción antimitótica a través de la estabilización de los microtúbulos, los compuestos que se unen al sitio de la vinca y de la colchicina actúan bloqueando la polimerización de la tubulina. ${ }^{4}$ En ambos casos se produce una alteración de la funcionalidad de los microtúbulos.

\footnotetext{
${ }^{3}$ Hyams, J.; Lloyd, C. W. Microtubules; Wiley-Liss: New York, 1994.

4 a) Jordan, M. A.; Wilson, L. Microtubules as a target for anticancer drugs. Nature Reviews Cancer, 2004, 4, 253-265. b) Li, Q.; Sham, H. L. Discovery and development of antimitotic agents that inhibit tubulin polymerisation for the treatment of cancer. Expert Opin. Ther. Patents 2002, 12, 1663-1702.
} 


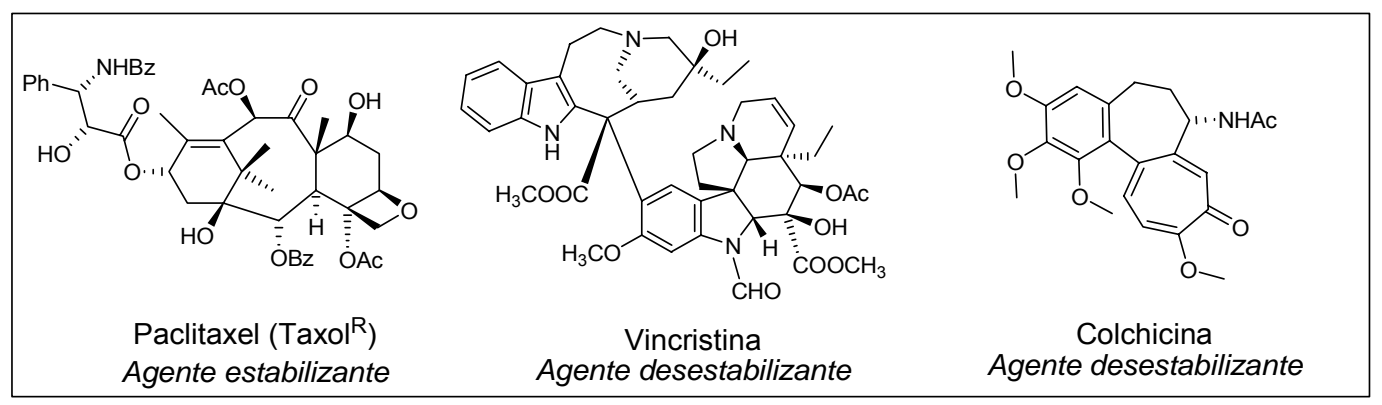

Figura 2. Estructuras de paclitaxel, vincristina y colchicina.

Existe una amplia variedad estructural entre los compuestos naturales y sintéticos que se unen a tubulina en el sitio de la colchicina. ${ }^{5}$ Además de ésta, se han descrito flavonoles, quinolonas, lignanos, combretastatinas, el 2-metoxiestradiol, bifenilos, chalconas, benzofenonas, etc. En general, estas familias de compuestos presentan dos anillos aromáticos no coplanares unidos por un puente de entre 0 y 4 átomos de carbono. Además, en muchos de los casos, uno de los anillo es un trimetoxifenilo.<smiles>COc1ccc(-c2oc3cc(O)c(OC)c(O)c3c(=O)c2OC)cc1O</smiles><smiles>COc1ccc(/C=C\c2ccc(OC)c(OC)c2)cc1OC</smiles><smiles>COc1cccc(-c2cc(=O)c3cc(N4CCCC4)ccc3[nH]2)c1</smiles><smiles>COc1cc([C@H]2c3cc4c(cc3[C@@H](O)[C@@H]3COC(=O)[C@H]23)OCO4)cc(OC)c1OC</smiles>

Podofilotoxina (lignano)<smiles>COc1ccc(OC)c(C(=O)/C(C)=C/c2ccc(N(C)C)cc2)c1</smiles><smiles>COc1ccc(-c2ccc(OC)c(=O)cc2)c(OC)c1OC</smiles><smiles>COc1ccc(C(=O)c2cc(OC)c(OC)c(OCC(=O)O)c2)cc1O</smiles>

Figura 3. Compuestos que se unen al sitio de la colchicina.

\footnotetext{
${ }^{5}$ Jordan, A.; Hadfield, J. A.; Lawrence, N. J.; McGown, A. T. Tubulin as a target for anticancer drugs: agents which interact with the mitotic spindle. Med. Res. Rev. 1998, 18, 259-296.
} 
Nuestro grupo de investigación se ha centrado en el estudio de algunas de estas familias (principalmente combretastatinas $^{6}$ y fenstatinas $^{7}$ ) y ha descrito algunos compuestos que inhiben la polimerización de tubulina en el rango submicromolar. A continuación se comentarán brevemente las relaciones estructura-actividad conocidas para estas familias.

\footnotetext{
${ }^{6}$ Maya, A. B. S.; Pérez-Melero, C.; Mateo, C.; Alonso, D.; Fernández, J. L.; Gajate, C.; Mollinedo, F.; Peláez, R.; Caballero, E.; Medarde, M. Further Naphthylcombretastatins. An Investigation on the Role of the Naphthalene Moiety. J. Med. Chem. 2005, 48, 556-568.

7 a) Álvarez, C.; Álvarez, R.; Corchete, P.; Pérez-Melero, C.; Peláez, R.; Medarde, M.. Synthesis and biological activity of naphthalene analogues of phenstatins: naphthylphenstatins. Bioorg. Med. Chem. Lett. 2007, 17, 3417-3420. b) Álvarez, C.; Álvarez, R.; Corchete, P.; Pérez-Melero, C.; Peláez, R.; Medarde, M. Naphthylphenstatins as tubulin ligands: synthesis and biological evaluation. Bioorg. Med. Chem. 2008, 16, 8999-9008. c) Álvarez, C.; Álvarez, R.; Corchete, P.; López, J.L.; Pérez-Melero, C.; Peláez, R.; Medarde, M. Diarylmethoxime and hydrazone derivatives with 5-indolyl moieties as potent inhibitors of tubulin polymerization. Bioorg. Med. Chem. 2008, 16, 5952-5961.
} 


\section{I.1. REA DE COMBRETASTATINAS.}

Las combretastatinas son un grupo de productos naturales que fueron aislados por el grupo de Pettit de la corteza de Combretum caffrum, ${ }^{8}$ un árbol que se encuentra en las regiones tropicales de África e India. Entre ellas, el compuesto que ha presentado mayor citotoxicidad ha sido la combretastatina A-4, que ha sido tomada como molécula de referencia y cuya estructura puede servir como base para establecer las relaciones estructura actividad de esta familia de compuestos y los numerosos análogos sintéticos que han ido apareciendo.<smiles>COc1ccc(/C=C\c2cc(OC)c(OC)c(OC)c2)cc1O</smiles>

COMBRETASTATINA A-4 (CA-4)

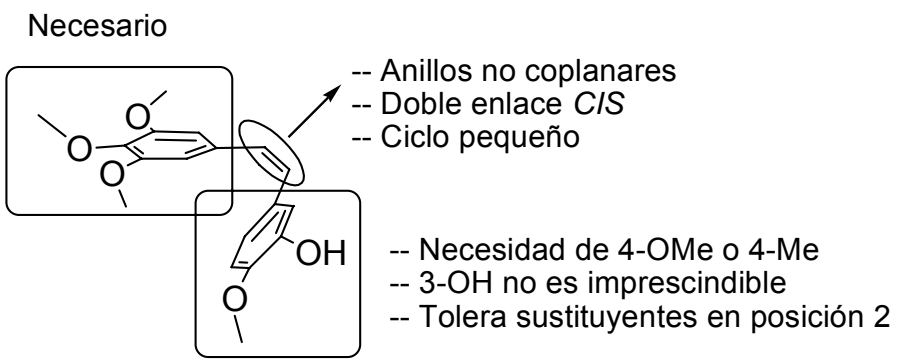

Figura 4. Estructura de la combretastatina A-4 a la izquierda y esquema de REA de combretastatinas.

\section{I.1.A Modificaciones en el anillo $A$.}

El anillo de trimetoxifenilo parece imprescindible para la citotoxicidad y la actividad inhibidora de polimerización de tubulina, ya que su sustitución conduce siempre a compuestos de menor potencia. ${ }^{9}$

\footnotetext{
${ }^{8}$ a) Pettit, G. R.; Cragg, G. M.; Singh, S. B. Antineoplastic agents. 122. Constituents of Combretum caffrum. J. Nat. Prod. 1987, 50, 386-391.

${ }^{9}$ Gaukroger, K.; Hadfield, J. A.; Lawrence, N. J.; Nolan, S.; McGown, A. T. Structural requirements for the interaction of combretastatins with tubulin: how important is the trimethoxy unit? Org. Biomol. Chem. 2003, 1, 3033-3037.
} 


\section{I.1.B. Modificaciones en el anillo B.}

El anillo de guayacol, por el contrario, permite mayor número de modificaciones. ${ }^{10}$ Mientras que el cambio del grupo metoxilo en para no conduce a compuestos más activos, las modificaciones en las posiciones 2 y 3 del anillo han llevado a la obtención de compuestos de igual o mayor potencia citotóxica. Así, la sustitución del grupo hidroxilo en meta por un bromo mantiene la potencia antimitótica y la introducción de grupos amino la aumenta a la vez que mejora su solubilidad acuosa. Cabe destacar que los compuestos en los que el hidroxilo ha sido protegido con un grupo fosfato (CA-4P) o sustituido por un grupo amino (AVE-8062) se encuentran actualmente en ensayos clínicos. ${ }^{11}$

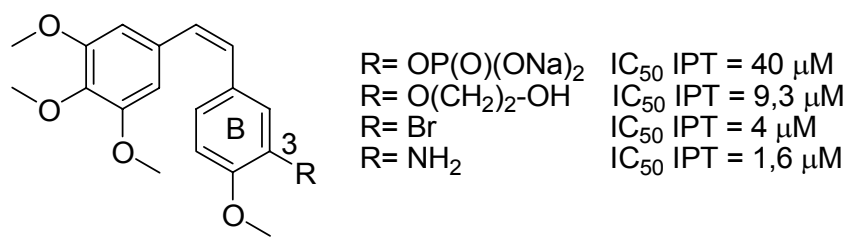

Figura 5. Modificaciones de la posición 3 del anillo B que mantienen la potencia como inhibidores de polimerización de tubulina

La sustitución del anillo $\mathrm{B}$ por anillos de menos de 6 miembros conlleva una pérdida de actividad. Sin embargo, su reemplazo por sistemas bicíclicos como naftaleno o indol no conlleva una importante disminución de la actividad. ${ }^{6}$<smiles>COc1cc(/C=C\c2ccc3c(ccn3C)c2)cc(OC)c1OC</smiles><smiles>COc1cc(/C=C\c2ccc3ccccc3c2)cc(OC)c1OC</smiles>

Figura 6. Sustitución del anillo de guayacol por sistemas bicíclicos.

\footnotetext{
${ }^{10}$ a) Nam, N. H. Combretastatin A-4 analogues as antimitotic antitumor agents. Curr. Med. Chem. 2003, 10, 1697-1722. b) Pinney, K. G.; Mejia, M. P.; Villalobos, V. M.; Rosenquist, B. E.; Pettit, G. R.; VerdierPinard, P.; Hamel, E. Synthesis and biological evaluation of aryl azide derivatives of combretastatin A-4 as molecular probes for tubulin. Bioorg. Med. Chem. 2000, 8, 2417-2425. c) Ohsumi, K.; Nakagawa, R.; Fukuda, Y.; Hatanaka, T.; Morinaga, Y; Nihei, Y.; Ohishi, K.; Suga, Y.; Akiyama, Y.; Tsuji, T. Novel combretastatin analogues effective against murine solid tumors: design and structure-activity relationships. $J$. Med. Chem. 1998, 41, 3022-3032.

${ }^{11}$ Tron, G. C.; Pirali, T.; Sorba, G.; Pagliai, F.; Busacca, S.; Genazzani, A. Medicinal chemistry of combretastatin A4: present and future directions. J. Med. Chem. 2006, 49, 3033-3044.
} 


\section{I.1.C. Modificaciones en el puente.}

Se ha visto que la distancia entre ambos anillos aromáticos es un factor determinante, ya que los compuestos con un puente formado por uno o dos carbonos presentan mayor potencia que los que poseen puentes de 3 o 4 átomos. Además, son los compuestos con disposición cis los que presentan mayor actividad antimitótica frente a sus isómeros trans, que en general son menos potentes. De esta manera, la reducción del doble enlace también reduce la actividad ${ }^{12}$ al aumentar la flexibilidad del puente, permitiendo al compuesto adoptar conformaciones equivalentes a ambas olefinas.

Una estrategia para mantener la disposición cis de los anillos ha sido la síntesis de compuestos que presentan un ciclo en el puente. La introducción de heterociclos de cinco miembros en el puente ha sido estudiada por diversos grupos de investigación y ha conducido a la aparición de análogos de combretastatina capaces de mantener la inhibición de polimerización de tubulina. ${ }^{6,13}$ En el caso de la introducción de un dioxolano, se observa la importancia de la quiralidad, ya que solo el isómero $S, S$ es capaz de mantener la actividad antimitótica.<smiles>COc1ccc(C2OCOC2c2cc(OC)c(O)c(OC)c2)cc1OC</smiles><smiles>COc1ccc([C@H]2OCOC2c2cc(OC)c(OC(C)C)c(OC)c2)cc1OC</smiles>

Figura 7. Valores de IPT de distintos dioxolanos quirales.

\footnotetext{
${ }^{12}$ Cushman, M.; Nagarathnam, D.; Gopal, D.; Chakraborti, A. K.; Lin, C. M.; Hamel, E. Synthesis and evaluation of stilbene and dihydrostilbene derivatives as potential anticancer agents that inhibit tubulin polymerization. J. Med. Chem. 1991, 34, 2579-2588.

a) Ohsumi, K.; Hatanaka, T.; Fujita, K.; Nakagawa, R.; Fukuda, Y; Nihei, Y; Suga, Y; Morinaga, Y; Akiyama, Y. Syntheses and antitumor activity of cis-restricted combretastatins: 5-membered heterocyclic analogues. Bioorg. Med. Chem. Lett.. 1998, 8, 3153-3158. b) Shirai, R.; Okabe, T.; Iwasaki, S. Synthesis of conformationary restricted combretastatins. Heterocycles 1997, 46, 145-148. c) Nam, N.; Kim, Y.; You, Y.; Hong, D.; Kim, H.; Ahn, B. Combretoxazolones: Synthesis, Cytotoxicity and Antitumor Activity. Bioorg. Med. Chem. Lett. 2001, 11, 3073-3076. d) Wang, L.; Woods, K. W.; Li, Q.; Barr, K. J.; McCroskey, R. W.; Hannick, S. M.; Gherke, L.; Credo, R. B.; Hui, Y.; Marsh, K.; Warner, R.; Lee, J. Y.; Mozng, N.; Frost, D.; Rosenberg, S. H.; Sham, H. L. Potent, orally active heterocycle-based Combretastatin A-4 analogues: Synthesis, structure-activity relationship, pharmacokinetics, and in vivo antitumor activity evaluation. J. Med. Chem. 2002, 45, 1697-1711.
} 


\section{I.1.D. Otras modificaciones.}

Otra estrategia para mantener la disposición cis de las combretastatinas es la preparación de derivados macrocíclicos, conectando los anillos aromáticos a través de un puente adicional. Esta ciclación puede permitir incrementar la rigidez y la selectividad de compuestos bioactivos. Así, recientemente, en nuestro grupo de investigación se han sintetizado varias combretastatinas macrocíclicas que, si bien no mantienen la potencia de sus análogos no macrocíclicos, han aportado información acerca de las diferentes conformaciones que pueden adoptar las combretastatinas. ${ }^{14}$
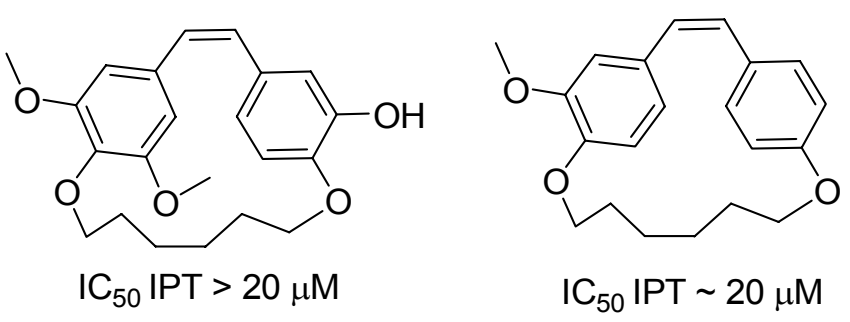

Figura 8. Análogos macrocíclicos de Combretastatina A-4.

\footnotetext{
14 a) Mateo, C.; Pérez-Melero, C.; Peláez, R.; Medarde, M. Synthesis of a conformationally restricted polyoxygenated crownophane. Tetrahedron Lett. 2005, 46, 7055-7057. b) Mateo, C.; Pérez-Melero, C.; Peláez, R.; Medarde, M. Stilbenophane Analogues of Deoxycombretastatin A-4. J. Org. Chem. 2005, 70, 6544-6547. c) Mateo, C.; López, V.; Medarde, M.; Peláez, R. Synthesis and conformational analysis of macrocyclic hydroxystilbenes linked between the para-para positions. Chem. Eur. J. 2007, 13, 7246-7256. d) Mateo, C.; Álvarez, R.; Pérez-Melero, C.; Peláez, R.; Medarde, M. Conformationally restricted macrocyclic analogues of combretastatins. Bioorg. Med. Chem. Lett. 2007, 17, 6316-6320.
} 


\section{I.2. REA DE FENSTATINAS.}

Las fenstatinas son derivados de benzofenona sintetizados, inicialmente, para estudiar el efecto que producía, en la actividad citotóxica, la disminución en un átomo de la separación entre los anillos aromáticos de las combretastatinas. ${ }^{15}$ El desarrollo de esta familia de compuestos se ha visto impulsado por la aparición de derivados antimitóticos muy potentes que mejoran la solubilidad acuosa de las combretastatinas, uno de los principales problemas que plantea su uso clínico.

En general, las REA de fenstatinas siguen las mismas directrices que las de combretastatinas. $^{15,16}$ La presencia de un anillo de trimetoxifenilo es necesaria para mantener la actividad, el puente carbonílico obliga a los anillos aromáticos a adoptar una disposición similar a los $Z$ estilbenos y el anillo $\mathrm{B}$ es el que admite mayor número de modificaciones.

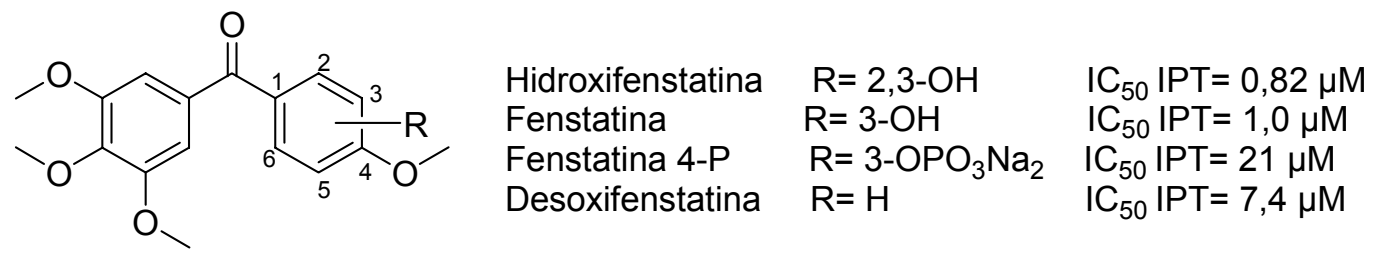

Figura 9. Estructura e inhibición de polimerización de tubulina de fenstatinas análogas a combretastatinas.

Sin embargo, existen modificaciones y determinados grupos funcionales que no ejercen la misma acción sobre la actividad de estas dos familias, como es el caso de la sustitución del anillo de guayacol por un resto indolilo unido por la posición $3^{17}$.

\footnotetext{
${ }^{15}$ a) Cushman, M.; Nagarathnam, D.; Gopal, D.; He, H. M.; Lin, C. M.; Hamel, E. Synthesis and evaluation of analogues of (Z)-1-(4-methoxyphenyl)-2-(3,4,5-trimethoxyphenyl)ethene as potential cytotoxic and antimitotic agents. J. Med. Chem. 1992, 35, 2293-2306. b) Pettit, G. R.; Toki, B.; Herald, D. L.; VerdierPinard, P.; Boyd, M. R.; Michael R.; Hamel, E.; Pettit, R. K. Antineoplastic agents. 379. Synthesis of phenstatin phosphate. .J. Med. Chem. 1998, 41, 1688-1695.

${ }^{16}$ a) Pettit, G. R.; Grealish, M. P.; Herald, D. L.; Boyd, M. R.; Hamel, E. Pettit, R. K. Antineoplastic agents. 443. Synthesis of the cancer cell growth inhibitor hydroxyphenstatin and its sodium diphosphate prodrug. $J$. Med. Chem. 2000, 43, 2731-2737. b) Liou, J. P.; Chang, C. W.; Song, J. S.; Yang, Y. N.; Yeh, C. F; Tseng, H. Y.; Lo, Y. K; Chang, Y. L.; Hsieh, H. P. Synthesis and structure-activity relationship of 2aminobenzophenone derivatives as antimitotic agents. J. Med. Chem. 2002, 45, 2556-2562.

${ }^{17}$ Liou, J. P.; Chang, Y. L.; Kuo, F. M.; Chang, C. W.; Tseng, H. Y; Wang, C. C; Yang, Y. N; Chang, J. Y; Lee, S. J; Hsieh, H. P. Concise synthesis and structure-activity relationships of combretastatin A-4 analogues, 1-aroylindoles and 3-aroylindoles, as novel classes of potent antitubulin agents. J. Med. Chem. 2004, 47, 4247-4257.
} 
Otra característica que se ha observado para diversos análogos de fenstatina es la inexistencia de una correlación directa entre la potencia presentada en inhibición de polimerización de tubulina y citotoxicidad. De esta manera, las fenstatinas suelen mejorar la potencia en inhibición de polimerización de tubulina respecto a las combretastatinas y presentar una menor citotoxicidad.

\section{I.3. FARMACÓFORO Y ESTRUCTURA DE RAYOS X DE} LA TUBULINA.

Recientemente, a partir de una selección de compuestos que muestran la diversidad estructural de las moléculas que se unen al sitio de la colchicina, se ha propuesto un farmacóforo definido por siete posibles puntos de unión al sitio: tres aceptores de enlaces de hidrógeno (A1, A2, A3), un dador de enlaces de hidrógeno (D1), dos centros hidrofóbicos (H1, H2) y un grupo plano (R1). ${ }^{18}$

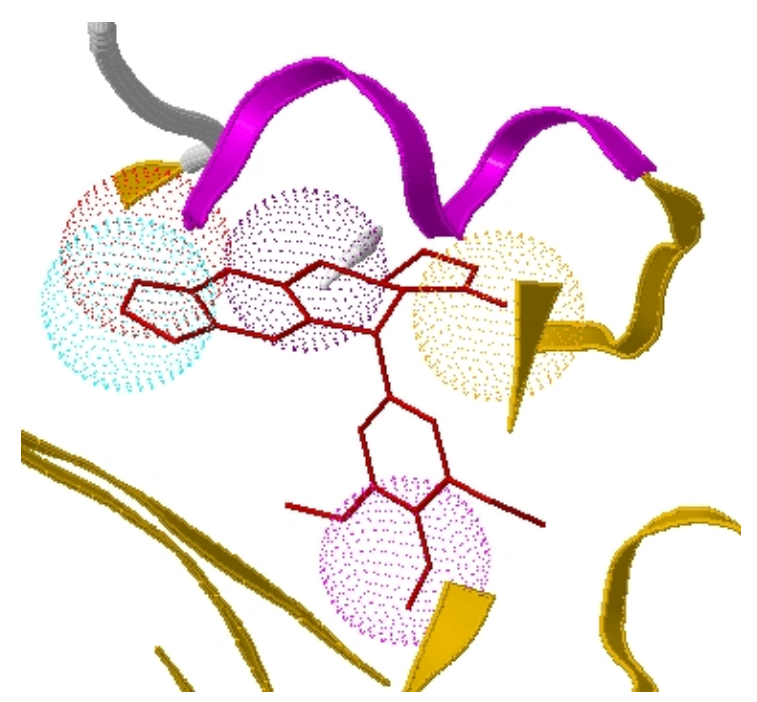

Figura 10a. Representación de la podofilotoxina en el sitio de la colchicina. Los puntos A1, A2, A3, D1 y H1 del farmacóforo están indicados por esferas punteadas del color correspondiente.

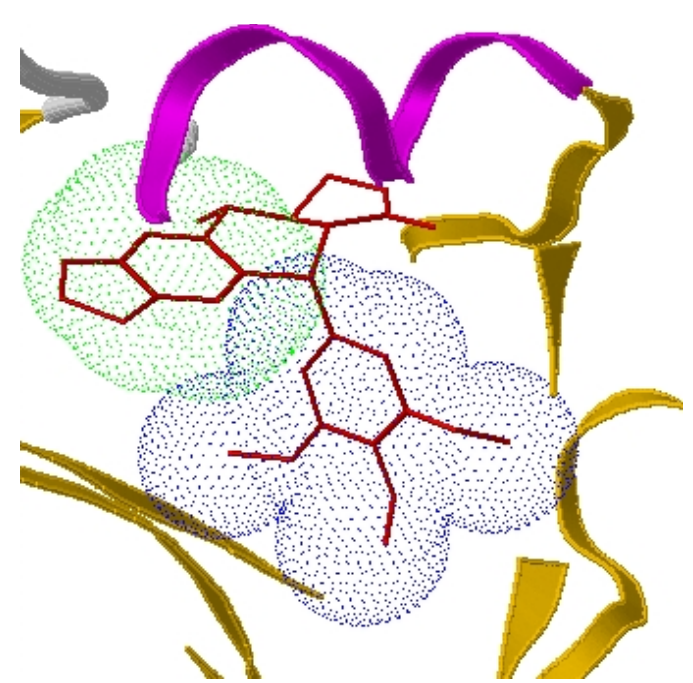

Figura 10b. Representación de la podofilotoxina en el sitio de la colchicina. Los puntos H2 y R1 del farmacóforo están indicados por esferas punteadas del color correspondiente.

\footnotetext{
${ }^{18}$ Nguyen, T. L.; McGrath, C.; Hermone, A. R.; Burnett, J. C.; Zaharevitz, D. W.; Day, B. W.; Wipf, P.; Hamel, E; Gussio, R. A common pharmacophore for a diverse set of colchicine site inhibitors using a structure-based approach. J. Med. Chem. 2005, 48, 6107-6116.
} 
Según este modelo de farmacóforo, la mayor potencia que presentan algunas fenstatinas, respecto a sus correspondientes combretastatinas, se explicaría por la presencia de un punto farmacofórico extra (A3) que permitiría la posibilidad de establecer un enlace de hidrógeno adicional con la tubulina.
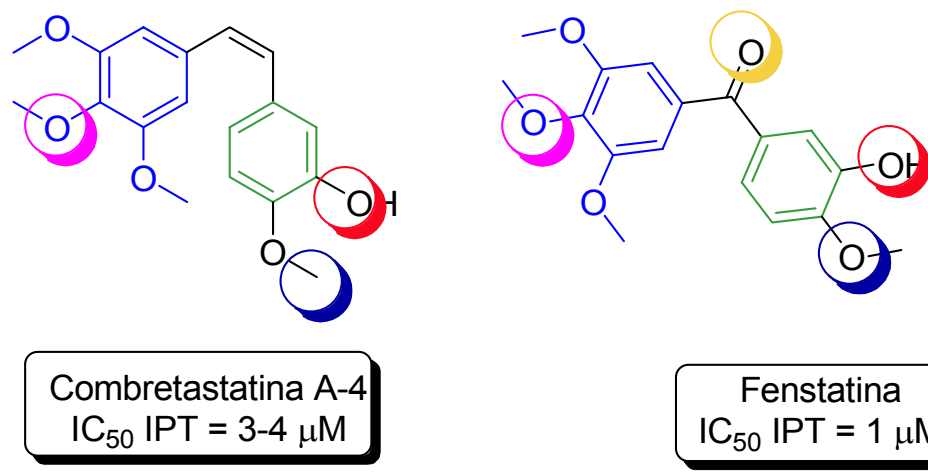

\section{A1 A2 A3 D1 H1 H2 R1}

Figura 11. Representación de los puntos del farmacóforo presentes en la combretastatina A-4 y la fenstatina.

La descripción de este farmacóforo puede, por lo tanto, ayudar a predecir la capacidad para inhibir la polimerización de tubulina de los ligandos que se unen en el sitio de la colchicina. Sin embargo, como podremos comprobar en este trabajo doctoral, no todos los ligandos de la tubulina en el sitio de la colchicina están de acuerdo con este modelo.

Finalmente, cabe destacar las estructuras de rayos $\mathrm{X}$ de los complejos formados por $\alpha, \beta$-tubulina con podofilotoxina y DAMA-colchicina, descritas recientemente por el grupo del profesor Ravelli. ${ }^{19}$ Aunque existe una gran variabilidad estructural para los ligandos del sitio de la colchicina, debido a la plasticidad de la proteína, se dispone de una herramienta con la que analizar los resultados de la actividad y racionalizar los efectos que diversas variaciones estructurales producen sobre la misma.

\footnotetext{
${ }^{19}$ Ravelli, R. B.; Gigant, B.; Curmi, P. A.; Jourdain, I.; Lachkar, S.; Sobel, A.; Knossow, M. Insight into tubulin regulation from a complex with colchicine and a stathmin-like domain. Nature 2004, 428, $198-202$.
} 


El objetivo general de este trabajo es la síntesis y evaluación de nuevos agentes antimitóticos que combinen los siguientes elementos estructurales: un anillo de trimetoxifenilo, un anillo derivado de un resto 5-indolilo y un puente olefínico. Para ello, se han tomado como base los resultados obtenidos por nuestro grupo de investigación en la síntesis de análogos de combretastatinas y fenstatinas.

La selección de dichos elementos estructurales y las diversas modificaciones de los mismos, se ha efectuado en base a los antecedentes existentes, según se discute a continuación:

\section{II.1. PUENTE OLEFÍNICO.}

Estudios de REA, realizados anteriormente en combretastatinas y fenstatinas, muestran como éstas últimas poseen, en numerosas ocasiones, una mayor potencia en la inhibición de polimerización de tubulina respecto a las combretastatinas que poseen igual patrón de sustitución en los anillos aromáticos $\mathrm{Ar}_{1} \mathrm{y}_{\mathrm{Ar}_{2}}{ }^{20}$

\footnotetext{
${ }^{20}$ a) Cushman, M.; Nagarathnam, D.; Gopal, D.; He, H. M.; Lin, C. M.; Hamel, E. Synthesis and evaluation of analogues of (Z)-1-(4-methoxyphenyl)-2-(3,4,5-trimethoxyphenyl)ethene as potential cytotoxic and antimitotic agents. J. Med. Chem. 1992, 35, 2293-2306. b) Pettit, G. R.; Toki, B.; Herald, D. L.; VerdierPinard, P.; Boyd, M. R.; Michael R.; Hamel, E.; Pettit, R. K. Antineoplastic agents. 379. Synthesis of phenstatin phosphate. .J. Med. Chem. 1998, 41, 1688-1695. c) Pettit, G. R.; Grealish, M. P.; Herald, D. L.; Boyd, M. R.; Hamel, E. Pettit, R. K. Antineoplastic agents. 443. Synthesis of the cancer cell growth inhibitor hydroxyphenstatin and its sodium diphosphate prodrug. J. Med. Chem. 2000, 43, 2731-2737. d) Liou, J. P.; Chang, C. W.; Song, J. S.; Yang, Y. N.; Yeh, C. F.; Tseng, H. Y.; Lo, Y. K.; Chang, Y. L.; Hsieh, H. P. Synthesis and structure-activity relationship of 2-aminobenzophenone derivatives as antimitotic agents. $J$. Med. Chem. 2002, 45, 2556-2562.
} 
Este hecho concuerda con los datos aportados por el farmacóforo ${ }^{21}$ que ha sido descrito a partir de los estudios de docking realizados con diversos ligandos, estructuralmente diferentes, del sito de la colchicina. De acuerdo con dicho estudio, el aumento de potencia de las fenstatinas vendría dado por la posibilidad de que se establezca un enlace de hidrógeno adicional, entre el oxígeno del puente y un grupo $\mathrm{NH}$ de los residuos $\beta 248-\beta 249-\beta 250$ de la cadena proteica.

En nuestro grupo de trabajo se han sintetizado recientemente compuestos en los que el oxígeno del puente es sustituido por un metileno. ${ }^{22}$ Estos compuestos, llamados isocombretastatinas por ser isómeros estructurales de las mismas, inhiben la polimerización de tubulina de forma más potente que sus fenstatinas correspondientes. Por ello, en este trabajo se ha planteado la síntesis y evaluación de un amplio número de compuestos con estructura de isocombretastatina (1,1diariletenos).

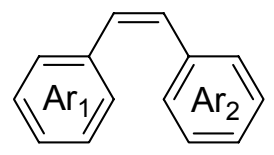

Combretastatinas

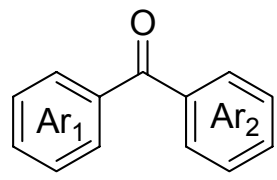

Fenstatinas

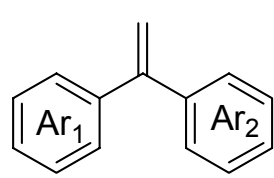

Isocombretastatinas

21 T. L. Nguyen, C. McGrath, A. R. Hermone, J. C. Burnett, D. W. Zaharevitz, B. W. Day, P. Wipf, E Hamel, R. Gussio. A common pharmacophore for a diverse set of colchicine site inhibitors using a structurebased approach. J. Med. Chem. 2005, 48, 6107-6116.

${ }^{22}$ Álvarez, C. Tesis Doctoral, Universidad de Salamanca, 2006. 


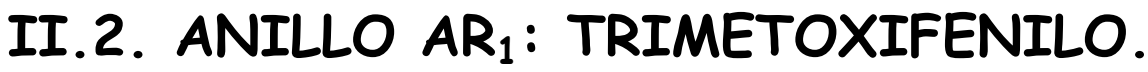

El anillo de 3,4,5-trimetoxifenilo es prácticamente imprescindible, tanto en fenstatinas como en combretastatinas, ya que su sustitución suele conllevar una disminución en la actividad antimitótica. ${ }^{23}$ No obstante, se han sintetizado fenstatinas en las que su reemplazo por el anillo de 2,3,4-trimetoxifenilo confiere una mayor selectividad frente a determinadas líneas celulares cancerosas sensibles. ${ }^{24}$ Así, se ha optado por emplear ambos en la síntesis de los compuestos de este trabajo.

\section{II.3. ANILLO AR2: DERIVADOS DE 5- INDOLILO.}

El resto indol ha demostrado ser un buen sustituto del anillo de guayacol en combretastatinas y fenstatinas, ${ }^{25}$ especialmente los derivados 5-indolilo $\mathrm{N}$ sustituidos con un resto metilo. ${ }^{26}$ En consecuencia, el sistema $N$-metil-5-indolilo ha sido tomado como base para realizar diversas modificaciones en el anillo $\operatorname{Ar}_{2}$. Benzimidazoles y benzoxazoles pueden considerarse como aza- y oxa- análogos del indol, por lo que también se incluirán algunos representantes con estos sistemas.

\footnotetext{
${ }^{23}$ Gaukroger, K.; Hadfield, J. A.; Lawrence, N. J.; Nolan S.; McGown, A. T. Structural requirements for the interaction of combretastatins with tubulin: how important is the trimethoxy unit? Org Biomol Chem. 2003, 1,3033-3037.

${ }^{24}$ a) Álvarez, C.; Álvarez, R.; Corchete, P.; Pérez-Melero, C.; Peláez, R.; Medarde, M. Synthesis and biological activity of naphthalene analogues of phenstatins: naphthylphenstatins. Bioorg. Med. Chem. Lett. 2007, 17, 3417-3420.

${ }^{25}$ Brancale, A.; Silvestri, R. Indole, a core nucleus for potent inhibitors of tubulin polymerization. Med. Res. Rev. 2007, 27, 209-238.

${ }^{26}$ a) Maya, A. B.; Pérez-Melero, C.; Mateo, C.; Alonso, D.; Fernández, J. L.; Gajate, C.; Mollinedo, F.; Peláez, R.; Caballero, E.; Medarde, M. Further Naphthylcombretastatins. An Investigation on the Role of the Naphthalene Moiety J. Med. Chem. 2005, 48, 556-568. b) Liou, J. P.; Wu, C.Y.; Hsieh, H. P.; Chang, C. Y.; Chen, C. M.; Kuo, C. C.; Chang, J. Y. 4- and 5-Aroylindoles as novel classes of potent antitubulin agents. J. Med. Chem. 2007, 50, 4548-4552.
} 


\section{II.4. OBJETIVOS.}

Una vez establecidos estos antecedentes, los objetivos concretos que se ha planteado alcanzar durante la realización de esta Tesis Doctoral se detallan a continuación:

Síntesis de una serie de isocombretastatinas que combinen un anillo de trimetoxifenilo y un resto fenílico con los mejores patrones de sustitución de combretastatinas y fenstatinas.<smiles>[R]c1cc(C(=C)c2cc([X])c(OC)c(OC)c2[Y])ccc1OC</smiles>

$\mathrm{X}=\mathrm{OMe}, \mathrm{Y}=\mathrm{H}, \mathrm{R}=\mathrm{H}, \mathrm{OH}, \mathrm{NO}_{2}, \mathrm{NH}_{2}$. $\mathrm{X}=\mathrm{H}, \mathrm{Y}=\mathrm{OMe}, \mathrm{R}=\mathrm{H}, \mathrm{OH}, \mathrm{NO}_{2}, \mathrm{NH}_{2}$.

Este primer objetivo permitirá establecer el efecto que cada puente produce sobre la actividad, al comparar compuestos cuya estructura difenílica comparten las tres familias. Los resultados obtenidos servirán como referencia para los compuestos que adicionalmente presenten variaciones en los anillos aromáticos.

Como segundo objetivo, se plantea la síntesis de isocombretastatinas que combinen los dos anillos trimetoxifenílicos con derivados indólicos que presenten modificaciones en la posición 3, ya que es la más accesible sintéticamente. De este modo, se introducirán diferentes grupos polares (aldehídos, alcoholes, oximas, hidrazonas...) que, previsiblemente, aumentarán la solubilidad acuosa de los compuestos y que podrían aumentar la interacción con la tubulina mediante la formación de algún enlace de hidrógeno adicional.<smiles>[X]c1cc(C(=C)c2ccc3c(c2)c([R])cn3C)c([Y])c(OC)c1OC</smiles> 
Se han seleccionado algunas de las modificaciones del resto indolilo para realizar la síntesis de las correspondientes combretastatinas y fenstatinas, de manera que permita establecer comparaciones con las isocombretastatinas equivalentes. Adicionalmente, se plantea la síntesis de algunos derivados de fenstatina y combretastatina en los que el anillo $\mathrm{Ar}_{2}$ sea reemplazado por un resto benzimidazolilo o benzoxazolilo, de manera que la modificación del carbono 3 del resto indolilo consista en su sustitución por un heteroátomo. La realización de estas dos partes completaría el tercer objetivo.

Recientemente, en nuestro grupo de trabajo se ha realizado la síntesis de análogos de combretastatina que presentan un espaciador entre los anillos aromáticos. ${ }^{27}$ Estos compuestos macrocíclicos fuerzan la disposición cisoide requerida de los dos anillos aromáticos y restringen notablemente su rotación, y por tanto, el número de conformaciones posibles. Se ha decidido continuar este estudio con la sustitución del anillo $\mathrm{Ar}_{2}$ por un resto 5-indolilo y analizar el efecto sobre la potencia y la selectividad que estas restricciones confieren a estos agentes antimitóticos. De esta forma se ha definido el cuarto objetivo como la síntesis y el análisis conformacional de los análogos macrocíclicos que se muestran en la siguiente figura:<smiles></smiles><smiles>[R]c1cccc([C@@H](O)[C@@H](O)c2ccc3c(ccn3CCCCCCOc3ccc(OC)cc3[R])c2)c1</smiles><smiles>[R]c1cccc([C@@H](OC(C)C)[C@@H](OC(C)=O)c2ccc3c(ccn3CCCCCCCOc3cc(OC)c(OC)cc3[R])c2)c1</smiles>

$\mathrm{R}=\mathrm{H}, \mathrm{OMe}$

El quinto y último objetivo consiste en la realización de los ensayos de inhibición de polimerización de tubulina de todos los compuestos sintetizados.

\footnotetext{
${ }^{27}$ a) Mateo, C.; Pérez-Melero, C.; Peláez, R.; Medarde, M. Synthesis of a conformationally restricted polyoxygenated crownophane. Tetrahedron Lett. 2005, 46, 7055-7057. b) Mateo, C.; Pérez-Melero, C.; Peláez, R.; Medarde, M. Stilbenophane Analogues of Deoxycombretastatin A-4. J. Org.Chem. 2005, 70, 6544-6547. c) Mateo, C.; López, V.; Medarde, M.; Peláez, R. Synthesis and conformational analysis of macrocyclic hydroxystilbenes linked between the para-para positions. Chem. Eur. J. 2007, 13, 7246-7256. d) Mateo, C.; Álvarez, R.; Pérez-Melero, C.; Peláez, R.; Medarde, M. Conformationally restricted macrocyclic analogues of combretastatins. Bioorg. Med. Chem. Lett. 2007, 17, 6316-6320. e) Mateo, C. Tesis doctoral, Universidad de Salamanca, 2006. f) Ramos, V. Tesis doctoral, Universidad de Salamanca, 2007.
} 




\section{III.1. SÍNTESIS DE COMPUESTOS NO MACROCÍCLICOS.}

Como se ha descrito en el apartado de planteamiento y objetivos, en esta tesis se pretende sintetizar nuevos y potentes agentes antimitóticos relacionados con combretastatinas y fenstatinas, que incluyan un puente vinilénico y/o un resto 5-indolilo, además de un anillo de trimetoxifenilo.

Los compuestos no macrocíclicos obtenidos en este trabajo se pueden clasificar en función del puente que une los dos anillos aromáticos. De este modo, podemos diferenciar entre:
A. Isocombretastatinas o 1,1-diariletenos
B. Fenstatinas o 1,1-diarilmetanonas
C. Combretastatinas o 1,2-diariletenos

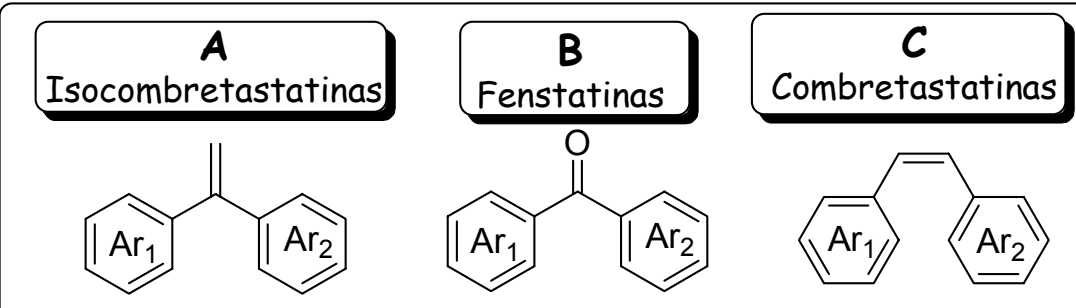

Figura 12. Clasificación de compuestos no macrocíclicos. 



\section{III.1.A. Sintesis de isocombretastatinas.}

Los objetivos 1 y 2 de este trabajo comprenden la síntesis de dos familias de isocombretastatinas. Ambas poseen en todos sus compuestos un anillo de trimetoxifenilo, por las razones ya descritas. La estructura del anillo $\mathrm{Ar}_{2}$ en la primera de las familias corresponde a derivados de fenilo que suelen aparecer frecuentemente en combretastatinas y análogos, mientras que en la segunda el anillo $\mathrm{Ar}_{2}$ estará formado por diferentes restos $\mathrm{N}$ metil-5-indolilo.

El planteamiento general para la síntesis de estos compuestos consiste en la obtención de los 1,1-diariletenos, con los anillos aromáticos seleccionados, a partir de las benzofenonas obtenidas por oxidación de los diarilmetanoles correspondientes. La ventaja de éste método, frente a otros como la acilación de Friedel-Crafts, ${ }^{28}$ reside en la obtención de productos con regioquímica definida. Una vez formadas las isocombretastatinas base, se introducen las modificaciones del anillo aromático $\mathrm{Ar}_{2}$. El acoplamiento entre un derivado organometálico (arilmagnesio, arillitio) y un aldehído aromático ha sido el método elegido para la obtención de los derivados metanólicos.

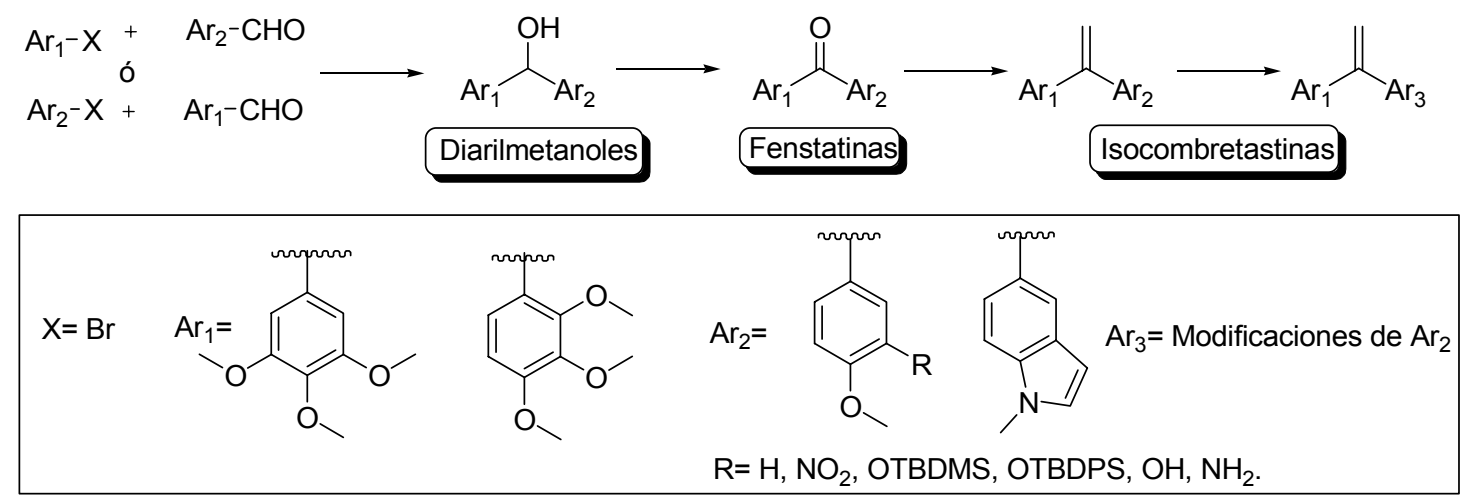

Esquema 1. Esquema general de síntesis de isocombretastatinas.

\footnotetext{
${ }^{28}$ March, J. Advanced Organic Chemistry. J. Willey \& Sons, Inc.; New York, 2001, 1324.
} 


\section{III.1.A.1. Materiales de partida.}

La mayoría de los materiales de partida utilizados para la síntesis de las isocombretastatinas son comerciales, a excepción de los que se describen a continuación.

Obtención de 4-metoxi-3-tercbutildifenilsiloxibenzaldehído (11) y de 4-metoxi-3tercbutildimetilsiloxibenzaldehído (12).

La protección del grupo hidroxilo mediante la formación de un silil éter permite la realización de reacciones de acoplamiento, sin que se produzcan reacciones indeseadas entre el grupo fenólico ácido y el organometálico.

La reacción se produce mediante la adición de una base (trietilamina) que facilita la formación del anión ariloxi que, en presencia del cloroderivado de silicio correspondiente (TBDPSiCl o TBDMSiCl), da lugar a los silil éteres. ${ }^{29}$

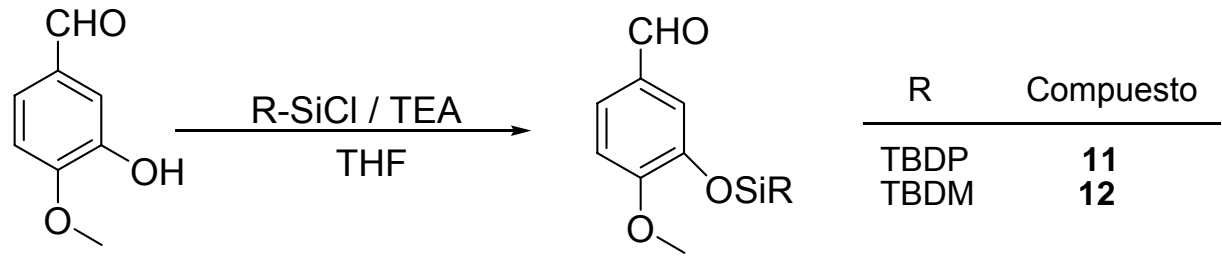

Figura 13. Obtención de silil éteres.

En los espectros de RMN ${ }^{1} \mathrm{H}$ del compuesto 11 se observa una señal que resuena como singlete a 1,12 ppm, correspondiente a los $9 \mathrm{H}$ del grupo tercbutilo, y dos señales en la zona aromática, que resuenan como multipletes a 7,38 y 7,68, que corresponden a los hidrógenos de los dos difenilos introducidos. Asimismo, en el espectro de RMN ${ }^{1} \mathrm{H}$ del compuesto 12 se observan 2 señales que resuenan como singlete a 0,17 ppm y 1,00 ppm, que se corresponden con los hidrógenos del dimetilsililo y del tercbutilsililo respectivamente.

\footnotetext{
${ }^{29}$ Greene, T.; Wuts, P. Protective groups in organic synthesis. J. Willey \& Sons, Inc.; New York 1999.
} 


\section{Obtención de $N$-metil-5-bromo-1H-indol (10).}

El carácter ácido del protón del NH del 5-bromoindol hace necesaria su protección con el fin de evitar reacciones indeseadas. En este trabajo se ha decidido introducir un grupo metilo sobre el $\mathrm{N}$ del indol, debido a que estudios previos en combretastatinas y fenstatinas muestran que la presencia del metilo no sólo no disminuye la inhibición de polimerización de tubulina de los compuestos sino que la aumenta. ${ }^{30}$ Además, la presencia de un grupo $\mathrm{N}$-alquilo mejora la manipulación y el rendimiento de las reacciones implicadas.

Debido al carácter ácido del indol, la alquilación se produce mediante la formación del anión por tratamiento con bases, en presencia de un catalizador de transferencia de fase, y la posterior adición del electrófilo requerido en esa posición. ${ }^{28}$ Mediante este procedimiento se obtienen los productos de $\mathrm{N}$-alquilación con buenos rendimientos.

En nuestro caso, la reacción se lleva a cabo utilizando hidróxido sódico como base e hidrogenosulfato de tetrabutilamonio como catalizador de transferencia de fase, desprotonándose de esta forma el $\mathrm{NH}$ del indol. La posterior adición de yoduro de metilo da lugar al indol metilado con un $86 \%$ de rendimiento.

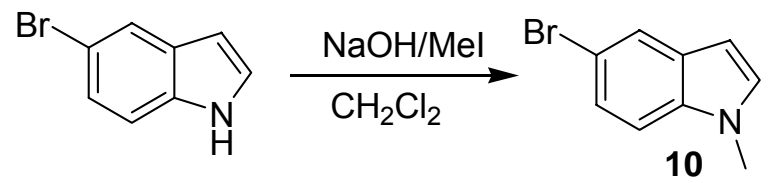

Figura 14. Obtención de 5-bromo- $N$-metil-1H-indol.

La señal característica del metilo del indol se observa a 3,77 ppm en el espectro de RMN ${ }^{1} \mathrm{H}$ y a 32,8 ppm en el espectro de $\mathrm{RMN}{ }^{13} \mathrm{C}$.

\footnotetext{
${ }^{30}$ a) Maya, A. B.; Pérez-Melero, C.; Mateo, C.; Alonso, D.; Fernández, J. L.; Gajate, C.; Mollinedo, F.; Peláez, R.; Caballero, E.; Medarde, M. Further Naphthylcombretastatins. An Investigation on the Role of the Naphthalene Moiety J. Med. Chem. 2005, 48, 556-568. b) Liou, J. P.; Wu, C. Y.; Hsieh, H. P.; Chang, C. Y.; Chen, C. M.; Kuo, C. C.; Chang, J. Y. 4- and 5-Aroylindoles as novel classes of potent antitubulin agents. J. Med. Chem. 2007, 50, 4548-4552.
} 


\section{III.1.A.2. Síntesis de diarilmetanoles.}

La preparación de los derivados alcohólicos se ha realizado siguiendo tres metodologías diferentes en función de los materiales de partida utilizados.

Para la síntesis de los compuestos difenílicos (Figuras 15a y 15b) se decidió formar el derivado organometálico del trimetoxifenilo, que se hizo reaccionar con los aldehídos cuyo patrón de sustitución correspondía con el anillo $\mathrm{Ar}_{2}$, ya que estos aldehídos eran más accesibles que los derivados bromados correspondientes.<smiles>COc1cc(Br)cc(OC)c1OCC(C)C(C)F</smiles><smiles>[R]c1cc(C=O)ccc1OCC</smiles><smiles>[R]c1cc(C(O)c2cc(OC)c(OC)c(OC)c2)ccc1OC</smiles>

$21 \mathrm{R}=\mathrm{NO}_{2}$ 28 R=OTBDPS

Figura 15a. Obtención de los compuestos 18, 21 y 28.

La síntesis de los derivados que contienen el resto 3,4,5-trimetoxifenilo se ha llevado a cabo mediante la formación del magnesiano por adición sobre el derivado bromado en posición 5 , en THF a $0{ }^{\circ} \mathrm{C}$, de magnesio y unas virutas de yodo. Una vez formado, el reactivo de Grignard se adiciona sobre una disolución en THF del aldehído correspondiente, dando lugar al alcohol (Figura 15a).

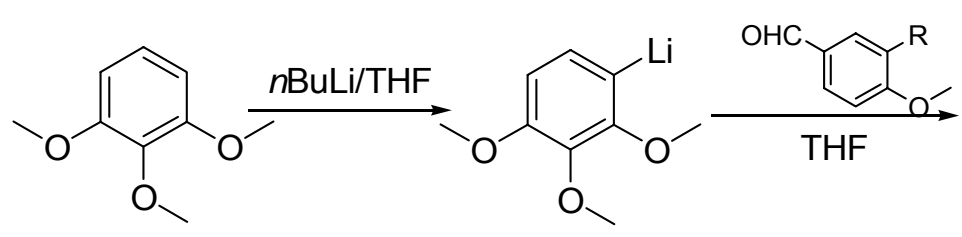

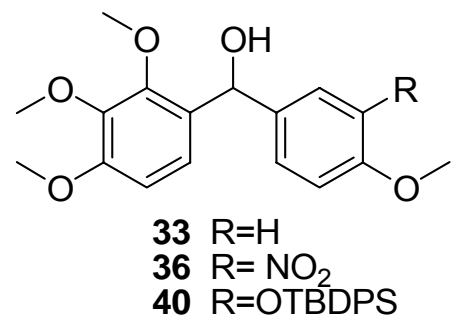

Figura 15b. Obtención de los compuestos 33, 36 y 40. 
En el caso de los derivados con la agrupación 2,3,4-trimetoxifenilo, se decidió partir del 1,2,3-trimetoxibenceno (Figura 15b), ya que la adición de $n B u L i$ genera el derivado organolitiado en la posición requerida, disminuyendo en un paso la síntesis (ya que no es necesaria la bromación).

La coordinación del litio con el oxígeno del metoxilo adyacente aumenta la estabilidad del derivado organometálico y, por tanto, favorece la litiación en posición orto de los metoxilos. ${ }^{31}$ De este modo, la adición de 0,9 mol de $n$ BuLi por cada mol de 1,2,3trimetoxibenceno disuelto en THF a $0{ }^{\circ} \mathrm{C}$ produce el derivado litiado, sobre el que se añade lentamente el aldehído correspondiente para la formación del alcohol.

La presencia de un exceso de 1,2,3-trimetoxibenceno no es un problema ya que, por su reducida polaridad, se elimina con facilidad por percolación sobre gel de sílice.

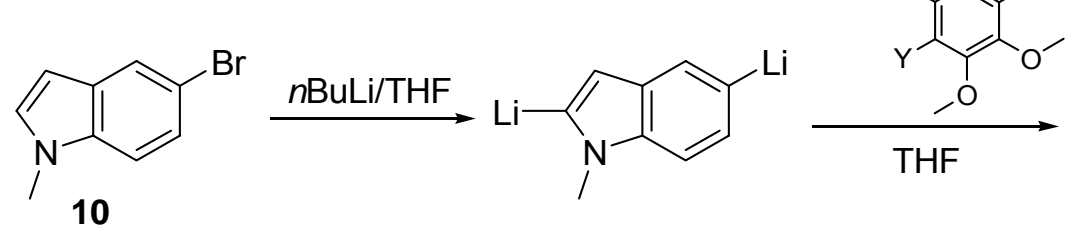

Figura 15c. Obtención de los compuestos 44 y 57.<smiles>[Y]c1c(C(O)c2ccc3c(ccn3C)c2)cc([X]#[Y])c(OC)c1OC</smiles>

Para la obtención de los compuestos que contienen el resto $N$-metilindolilo (Figura 15c) se ha partido del bromoderivado de indol y del aldehído de los trimetoxifenilos, debido a que el coste de los materiales de partida es inferior y los rendimientos son parecidos a los que se obtienen a partir del $N$-metil- $1 H$-indol-5-carbaldehído y el 5-bromo1,2,3-trimetoxibenceno o el 1,2,3-trimetoxibenceno. ${ }^{32}$ La síntesis se ha llevado a cabo mediante la formación del derivado organolítico a partir del derivado halogenado aromático por tratamiento con $n B u L i$ en THF seco y a $-78^{\circ} \mathrm{C}$. A continuación se añade el aldehído correspondiente, disuelto también en THF, dando lugar al alcohol. ${ }^{32,33}$

\footnotetext{
${ }^{31}$ Rigolet, S.; McCort, I.; Le Merrer, Y. Efficient access to ATP mimics, potential FGF receptor tyrosine kinase inhibitors. Tetrahedron Lett., 2002, 43, 8129-8132.

32 Álvarez, R. resultados sin publicar.

${ }^{33}$ Mahboobi, S.; Pongratz, H.; Hufsky, H.; Hockemeyer, J.; Frieser, M.; Lyssenko, A.; Paper, D. H.; Bürgermeister, J.; Böhmer, F. D.; Fiebig, H. H.; Burger, A. M.; Baasner, S.; Beckers, T. Synthetic 2aroylindole derivatives as a new class of potent tubulin-inhibitory, antimitotic agents. J Med Chem, 2001, 44, 4535-4553.
} 
En trabajos anteriores, ${ }^{34}$ se había observado que cuando se utilizan derivados de indol, se producen transmetalaciones entre los carbonos 2 y 5 (Esquema 2). La utilización de 2 equivalentes de $n \mathrm{BuLi}$ por cada uno de 5-bromoindol evita la aparición de derivados unidos a través de la posición 2 del indol. De esta manera se forma el dianión (en las posiciones 2 y 5) y el aldehído reacciona con la posición 5, que es la más reactiva, dando lugar al alcohol.

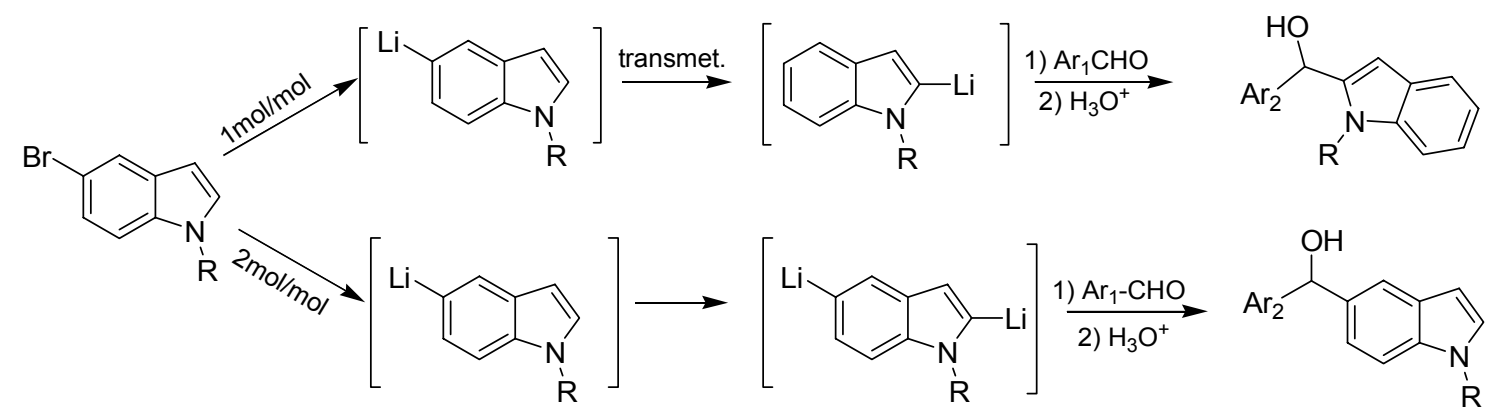

Esquema 2 - Formación de organolíticos en los derivados de indol.

En general, los rendimientos obtenidos son de buenos a muy buenos y adecuados para la preparación de los diarilmetanoles como materiales de partida de los restantes compuestos sintetizados en este trabajo. En la tabla siguiente se recogen los rendimientos obtenidos junto con la señal característica en el espectro de $\mathrm{RMN}{ }^{1} \mathrm{H}$ del metino del puente, muy desapantallada por efecto de los anillos aromáticos contiguos.

\begin{tabular}{|c|c|c|c|c|}
\hline Producto & $A r_{1}$ & $A r_{2}$ & $\begin{array}{c}\text { Rendimiento } \\
\text { (\%) }\end{array}$ & $\begin{array}{c}R M N^{1} H \\
C H O H \\
(\mathrm{ppm})\end{array}$ \\
\hline 18 & $\mathrm{TM}$ & 4-MeO-Ph & 91 & 5,7 \\
\hline 21 & TM & $\begin{array}{c}4-\mathrm{MeO}-3-\mathrm{NO}_{2}- \\
\mathrm{Ph}\end{array}$ & - & 5,7 \\
\hline 28 & TM & $\begin{array}{c}\text { 4-MeO-3- } \\
\text { OTBDPS-Ph }\end{array}$ & 94 & 5,4 \\
\hline 33 & TMG & 4-MeO-Ph & $>90$ & 5,9 \\
\hline 36 & TMG & $\begin{array}{c}4-\mathrm{MeO}-3-\mathrm{NO}_{2}- \\
\mathrm{Ph}\end{array}$ & $32(\mathrm{CC})$ & 5,9 \\
\hline 40 & TMG & $\begin{array}{c}\text { 4-MeO-3- } \\
\text { OTBDPS-Ph }\end{array}$ & $74(\mathrm{CC})$ & 5,8 \\
\hline 44 & TM & $N M e I N D$ & $50(\mathrm{CC})$ & 5,9 \\
\hline 57 & TMG & $N M e I N D$ & $71(\mathrm{CC})$ & 6,1 \\
\hline
\end{tabular}

Tabla 1. Rendimiento y señales características de los derivados metanólicos sintetizados.

\footnotetext{
${ }^{34}$ Álvarez, R. Trabajo de Grado. Universidad de Salamanca. 2005.
} 


\section{III.1.A.3. Síntesis de fenstatinas.}

De acuerdo con el esquema planteado, el siguiente paso para la preparación de fenstatinas y compuestos derivados de las mismas, como isocombretastatinas, es la oxidación de los diarilmetanoles a diarilcetonas.

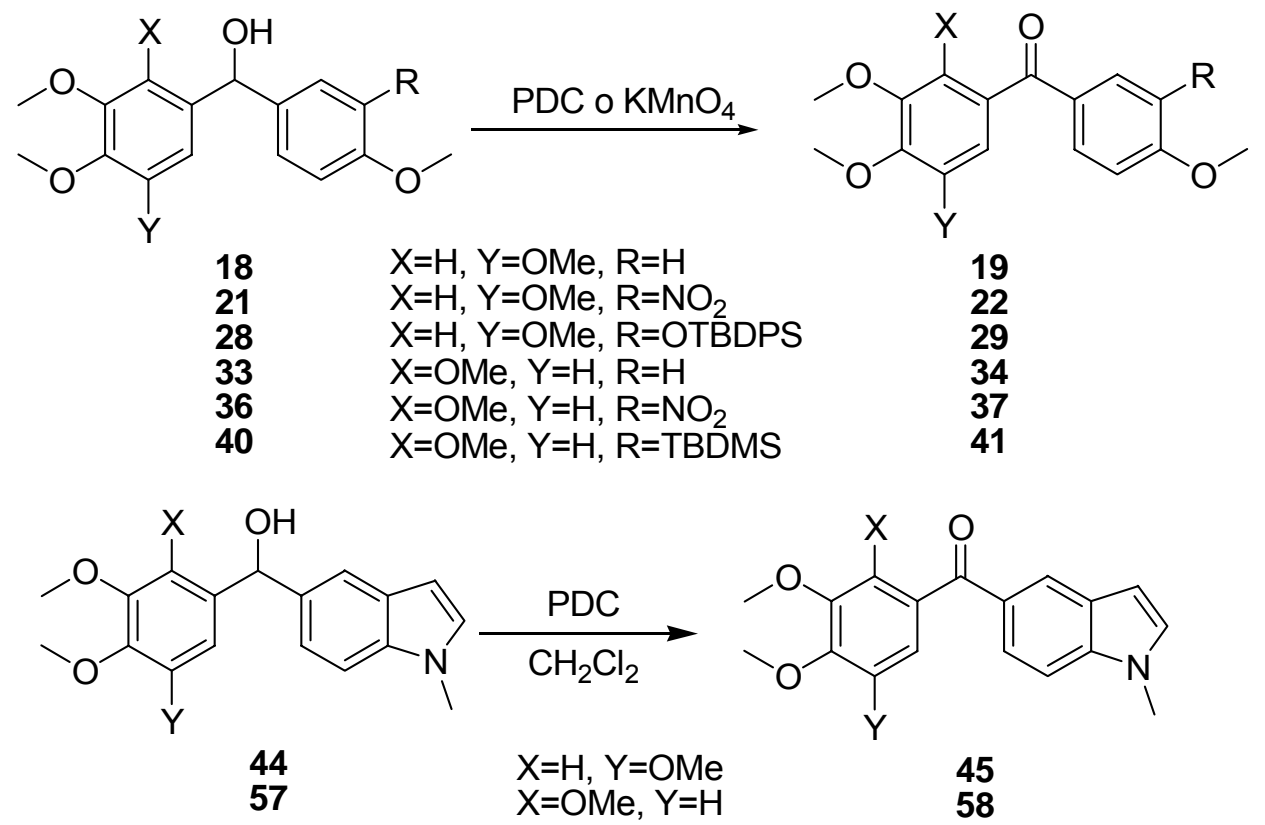

Figura 16. Obtención de los compuestos 19, 22, 29, 34, 37, 41, 45 y 58.

El agente oxidante más utilizado para efectuar la oxidación de alcoholes a cetonas durante la síntesis de fenstatinas es el PDC. ${ }^{35}$ Sin embargo, la utilización de este reactivo en la oxidación de los diarilmetanoles con el resto 2,3,4-trimetoxifenilo provocaba la rotura de la molécula, observándose la aparición de las señales características del 2,3,4trimetoxibenzaldehído en el espectro de $\mathrm{RMN}{ }^{1} \mathrm{H}$. Por ello, se decidió utilizar para la oxidación de estos compuestos otras condiciones, ya utilizadas en nuestro grupo de investigación, en las que se emplea $\mathrm{KMnO}_{4}$ como agente oxidante y bromuro de tetrabutilamonio como catalizador de transferencia de fase. ${ }^{34}$

${ }^{35}$ Collins, J. C.; Hess W. W. Aldehydes from primary alcohols by oxidation with chromium trioxide: Heptanal. Org. Synth. 1988, 644. 
Sin embargo, debido a los bajos rendimientos obtenidos con $\mathrm{KMnO}_{4}$, se decidió volver a probar la oxidación con PDC en condiciones más suaves con los derivados con 2,3,4-trimetoxifenilo. De este modo se observa que la realización de la reacción a $0{ }^{\circ} \mathrm{C}$, durante $4 \mathrm{~h}$ y protegida de la luz, da como resultado la oxidación del alcohol, sin rotura de la molécula, con un rendimiento del 50\%.

\begin{tabular}{|c|c|c|c|c|c|}
\hline Producto & $A r_{1}$ & $\mathrm{Ar}_{2}$ & Condiciones & $\begin{array}{c}\text { Rendimiento } \\
\text { (\%) }\end{array}$ & $\begin{array}{c}R M N^{1} H \\
\text { (ppm) }\end{array}$ \\
\hline 19 & $\mathrm{TM}$ & 4-MeO-Ph & PDC 24h & 97 & 7,8 \\
\hline 22 & $\mathrm{TM}$ & $4-\mathrm{MeO}-3-\mathrm{NO}_{2}-\mathrm{Ph}$ & PDC 24h & 36 & 8,3 \\
\hline 29 & $\mathrm{TM}$ & $\begin{array}{c}\text { 4-MeO-3- } \\
\text { OTBDPS-Ph }\end{array}$ & PDC 24h & 85 & n.a ${ }^{*}$ \\
\hline 34 & TMG & 4-MeO-Ph & PDC 4h & 17 & 7,7 \\
\hline 37 & TMG & 4-MeO-3- $\mathrm{NO}_{2}-\mathrm{Ph}$ & $\mathrm{KMnO}_{4} 24 \mathrm{~h}$ & 39 (CC) & 8,2 \\
\hline 41 & TMG & $\begin{array}{c}\text { 4-MeO-3- } \\
\text { OTBDPS-Ph }\end{array}$ & $\mathrm{KMnO}_{4} 24 \mathrm{~h}$ & 92 & n.a \\
\hline 45 & TM & $N M e I N D$ & PDC $24 \mathrm{~h}$ & $65(\mathrm{CC})$ & 8,1 \\
\hline 58 & TMG & NMeIND & PDC 4h & $47(\mathrm{CC})$ & 8,1 \\
\hline
\end{tabular}

Tabla 2. Condiciones de oxidación y rendimientos obtenidos. *n.a. $=$ señales no asignadas.

En el análisis espectroscópico de $\mathrm{RMN}{ }^{1} \mathrm{H}$ cabe destacar el desapantallamiento de la señal H-2 del resto fenilo y H-4 del resto indolilo, como se observa en la figura 7 y se recoge en la tabla 2.<smiles>[R19]c1cc(C(C)=O)ccc1OC</smiles>

Figura 17.- Desapantallamiento de los protones aromáticos. 


\section{III.1.A.4. Síntesis de isocombretastatinas.}

La metodología empleada para la síntesis de estos derivados es la reacción de Wittig, ${ }^{28}$ utilizada habitualmente como primera opción para la formación de dobles enlaces carbono-carbono. La reacción entre un carbonilo y un iluro de fósforo suele producir rendimientos aceptables en presencia de grupos metoxilo, trialquilsiloxi y nitro como los presentes en los grupos arilo utilizados.

En nuestro caso, la reacción de Wittig ha sido realizada entre las diarilcetonas y ioduro de trifenilmetilfosfonio. La formación del iluso, utilizando como base $n \mathrm{BuLi}$, se pone de manifiesto por una coloración anaranjada intensa de la reacción. Posteriormente, se añade la cetona disuelta en THF seco y se deja subir espontáneamente la temperatura hasta alcanzar temperatura ambiente.
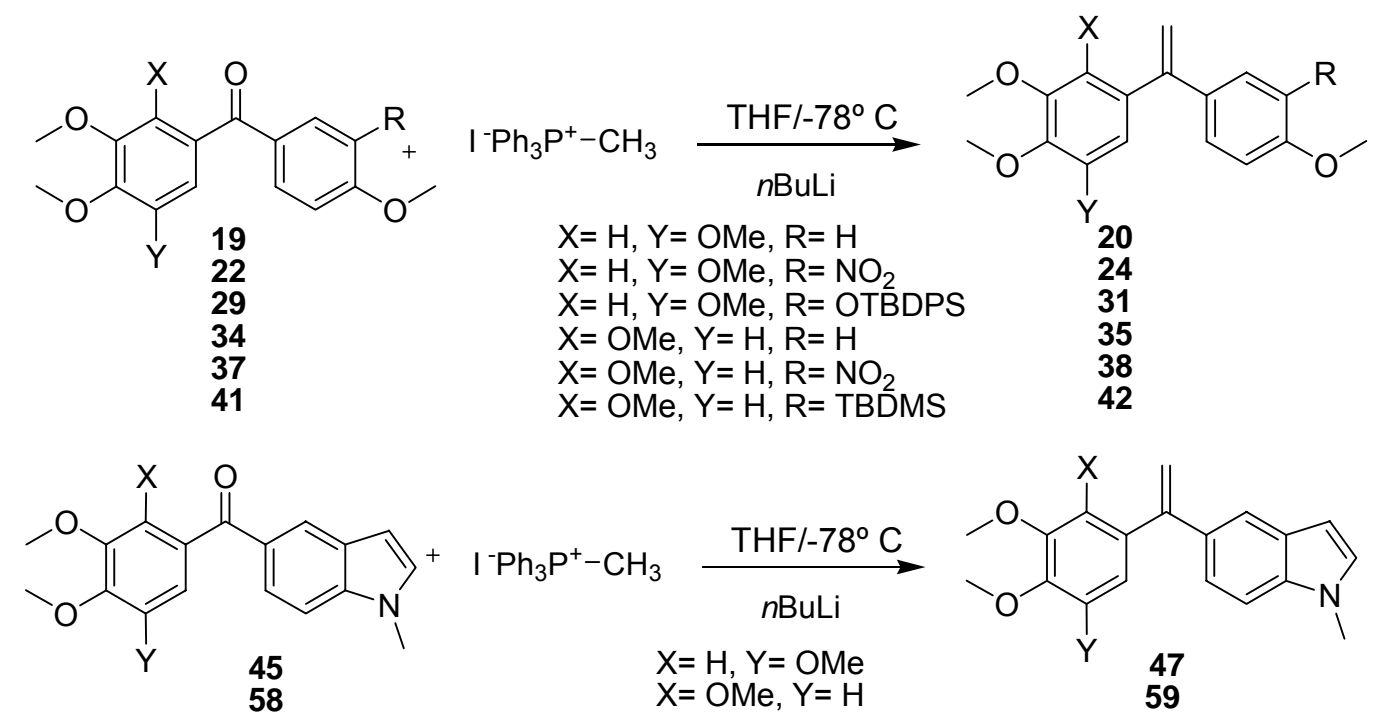

Figura 18. Obtención de las isocombretastatinas 20, 24, 31, 35, 38, 42, 47 y 59.

Las isocombretastatinas obtenidas por este método se purifican mediante cromatografía en columna obteniéndose rendimientos que oscilan entre el 20 y el $84 \%$.

Las señales espectroscópicas características de estos compuestos son las correspondientes a los protones del $\mathrm{CH}_{2}$ del puente y cabe destacar que, en los compuestos con el grupo 3,4,5-trimetoxifenilo, ambos protones presentan una diferencia de desplazamiento entre 0,05 y $0,07 \mathrm{ppm}$, mientras que en los compuestos que contienen el grupo 2,3,4-trimetoxifenilo, esta diferencia oscila entre 0,3 y 0,4 ppm. 


\begin{tabular}{|c|c|c|c|c|}
\hline Producto & $A r_{1}$ & $A r_{2}$ & $\begin{array}{c}\text { Rendimiento } \\
(\%)\end{array}$ & $\begin{array}{c}R M N^{1} H \\
C=C H_{2}(\mathrm{ppm})\end{array}$ \\
\hline 20 & TM & 4-MeO-Ph & $25(\mathrm{CC})$ & 5,$32 ; 5,37$ \\
\hline 24 & TM & $\begin{array}{c}4-\mathrm{MeO}-3-\mathrm{NO}_{2}- \\
\mathrm{Ph}\end{array}$ & $58(\mathrm{CC})$ & 5,$27 ; 5,34$ \\
\hline 31 & $\mathrm{TM}$ & $\begin{array}{c}\text { 4-MeO-3- } \\
\text { OTBDPS-Ph }\end{array}$ & $57(\mathrm{CC})$ & 5,$10 ; 5,15$ \\
\hline 35 & TMG & 4-MeO-Ph & 20 (CC) & 5,$18 ; 5,54$ \\
\hline 38 & TMG & $\begin{array}{c}4-\mathrm{MeO}-3-\mathrm{NO}_{2-}- \\
\mathrm{Ph}\end{array}$ & 27 (CC) & 5,$30 ; 5,58$ \\
\hline 42 & TMG & $\begin{array}{c}\text { 4-MeO-3- } \\
\text { OTBDPS-Ph }\end{array}$ & $8(\mathrm{CC})$ & 5,$17 ; 5,51$ \\
\hline 47 & $\mathrm{TM}$ & NMeIND & $84(\mathrm{CC})$ & 5,$36 ; 5,43$ \\
\hline 59 & TMG & NMeIND & 66 (CC) & 5,$27 ; 5,66$ \\
\hline
\end{tabular}

Tabla 3. Rendimiento y señales características de las isocombretastatinas obtenidas.

\section{III.1.A.5. Modificaciones del anillo aromático $\mathrm{Ar}_{2}$.}

Una vez obtenidas las estructuras base de fenstatina e isocombretastatina se procedió a realizar diversas modificaciones, con vista a la preparación de compuestos que ampliaran el conocimiento de las relaciones estructura-actividad de estos compuestos. El grupo trimetoxifenilo se ha mantenido en todos las casos ya que su presencia, aunque no absolutamente necesaria, siempre conduce a compuestos más potentes que su ausencia. Por tanto, las modificaciones posteriores se han centrado en el otro anillo aromático, afectando a la posición 3 del grupo fenilo $\left(\mathrm{NO}_{2}, \mathrm{OR}\right)$ y a la posición 3 del sistema 5-indolilo (introducción de diversos sustituyentes).

\section{III.1.A.5.1. Modificaciones en los restos fenilo.}

\section{$\underline{\text { Reducciones de grupo nitro a grupo amino. }}$}

Las reducciones de grupo nitro a grupo amino han sido ampliamente detalladas, principalmente para compuestos aromáticos. Entre todos los agentes reductores posibles, se recomienda la utilización de metales en medio ácido. En este trabajo se decidió usar Zinc en $\mathrm{AcOH}$, obteniéndose de forma cuantitativa los productos 25 y 39. 


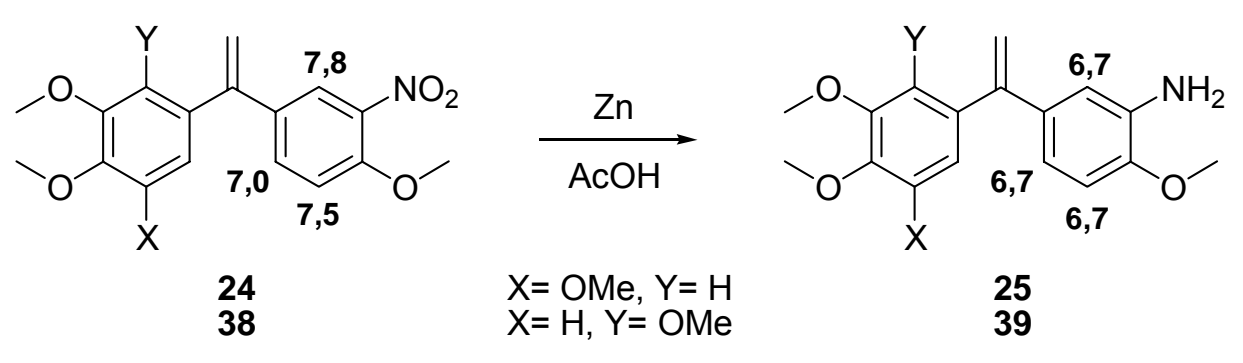

Figura 19. Señales espectroscópicas características de los productos oxidados y reducidos.

En el espectro de RMN ${ }^{1} \mathrm{H}$ se observa cómo las señales del anillo que soporta el grupo amino resuenan como una única señal a 6,7 ppm. El grupo amino también es detectado en IR por la aparición de una banda ancha en torno a $3300 \mathrm{~cm}^{-1}$.

Adicionalmente, se realizó la reducción del compuesto 22 para obtener la aminofenstatina 23, idéntica a la descrita en bibliografía, ${ }^{36}$ con el fin de poder realizar los ensayos de actividad en las mismas condiciones utilizadas en este trabajo y efectuar las comparaciones oportunas. La utilización de Zinc en este caso provoca, simultáneamente, la reducción de la cetona del puente a su alcohol. Por ello, se decidió usar Fe en medio ácido, metodología habitual para la síntesis de este compuesto. ${ }^{36}$<smiles>COc1ccc(C(=O)c2cc(OC)c(OC)c(OC)c2)cc1[N+](=O)[O-]</smiles><smiles>COc1cc(C(=O)c2cc(OC)c(OCC(=O)O)c(OC)c2)cc(OC)c1N</smiles>

Figura 20. Señales características de la aminofenstatina.

Al igual que en los casos anteriores se produce un apantallamiento de las señales de protón del anillo $\mathrm{Ar}_{2}$.

\footnotetext{
${ }^{36}$ Liou, J. P.; Chang, J. Y.; Chang, C. W.; Chang, C. Y.; Mahindroo, N.; Kuo, F. M.; Hsiehet, H. P. Synthesis and structure-activity relationships of 3-aminobenzophenones as antimitotic agents. J. Med. Chem. 2004, 47, 2897-2905.
} 
Desprotección de los sililéteres.

Para la obtención de los fenoles 32 y 43 se utilizó TBAF en THF. ${ }^{29}$ Se puede comprobar la liberación del alcohol por la aparición de una banda a $\sim 3400 \mathrm{~cm}^{-1}$ en el espectro de IR.

Del mismo modo, por desprotección del compuesto 29 con TBAF se obtiene la fenstatina $30,{ }^{37}$ que se utiliza como referencia en los ensayos de actividad.

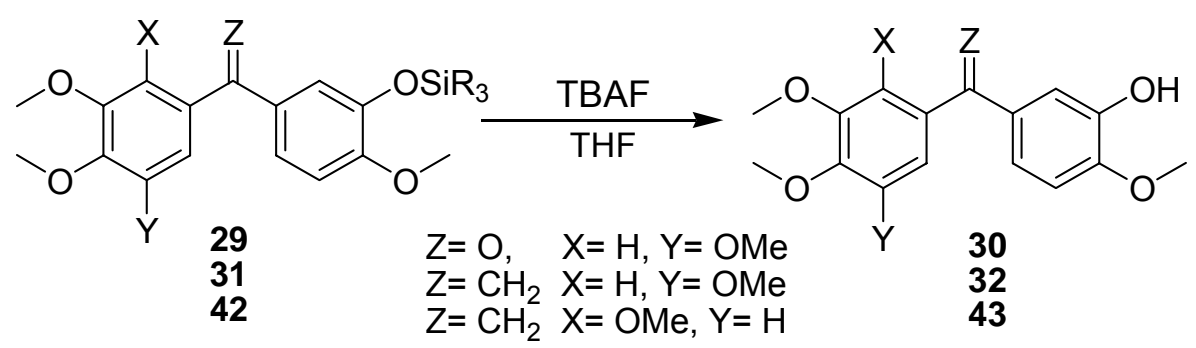

Figura 21. Obtención de los compuestos 30, 32 y 43.

\section{III.1.A.5.2. Modificaciones en la posición 3 del indol.}

El sistema indol parece muy adecuado para la preparación de antimitóticos ${ }^{38}$ cuando se combina con un sistema 3,4,5-trimetoxifenilo a través de diferentes puentes, según se ha comentado en el apartado de planteamiento y objetivos.

Además el sistema indol permite la introducción controlada de sustituyentes en diversas posiciones, obteniéndose derivados que pueden considerarse análogos rígidos en el anillo $\mathrm{Ar}_{2}$ de fenstatinas. La posición 3 parece la más adecuada para la preparación de derivados de indol debido a su reactividad y a la localización de los sustituyentes en el sistema.

\footnotetext{
${ }^{37}$ Pettit, G. R.; Toki, B.; Herald, D. L.; Verdier-Pinard, P.; Boyd, M. R.; Michael R.; Hamel, E.; Pettit, R. K. Antineoplastic agents. 379. Synthesis of phenstatin phosphate. .J. Med. Chem. 1998, 41, 1688-1695.

${ }^{38}$ Brancale, A.; Silvestri, R. Indole, a core nucleus for potent inhibitors of tubulin polymerization. Med. Res. Rev. 2007, 27, 209-238.
} 
Las reacciones de sustitución electrofílica aromática, en general, y especialmente la formilación, que pueden servir de punto de partida para la preparación de diversos derivados, se producen con gran facilidad en dicha posición. Aunque otras sustituciones pueden ser de interés, el pequeño tamaño, reactividad y posibilidad de preparación de derivados nitrogenados, hicieron aconsejable preparar los derivados formilados en este primer estudio.

En lo referente a la localización del sustituyente, la posición 3 viene a ser equiparable a la posición ocupada por los sustituyentes en el $\mathrm{O}$ o el $\mathrm{N}$ en 3 de fenstatina y aminofenstatina.<smiles>[R][Z]c1cc(C(=O)c2cc([Y])c(OC)c(OC)c2[X])ccc1OC</smiles><smiles>[Y]c1cc(C(=O)c2ccc3c(c2)c([R])cn3C)c([X])c(OC)c1OC</smiles>

Figura 22. Comparación de fenstatinas clásicas e indolofenstatinas.

Esta posición ha sido utilizada en agentes antimitóticos que se unen al sitio de la colchicina para incrementar las interacciones con el mismo y para preparar profármacos de interés como el fosfato de la CA-4 que se encuentra en ensayos clínicos. ${ }^{39}$

\section{Formilaciones.}

Una vez sintetizadas las isocombretastatinas con el resto $N$-metilindolilo, se procedió a realizar las modificaciones en la posición 3 del mismo, que se inician con una reacción de formilación de Vilsmeier-Haack. Los compuestos obtenidos con el grupo formilo serán los materiales de partida para el resto de las modificaciones.

La reacción se lleva a cabo en dimetilformamida, que en presencia de oxicloruro de fósforo $\left(\mathrm{POCl}_{3}\right)$ produce un catión iminio. Este catión es el encargado de realizar la sustitución electrofílica aromática generando un intermedio que se hidroliza para dar el aldehído aromático. ${ }^{40}$

\footnotetext{
${ }^{39}$ Tron, G. C.; Pirali, T.; Sorba, G.; Pagliai, F.; Busacca, S.; Genazzani, A. A. Medicinal chemistry of combretastatin A4: present and future directions. J. Med. Chem. 2006, 49, 3033-3044.

${ }^{40}$ Campaigne, E.; Archer, W. L. Formylation of dimethylaniline. Org. Syn. Coll. 1963, 4, 331.
} 
La formilación en la posición 3 del indol se ha realizado usando un exceso de DMF y $1 \mathrm{mmol}$ de $\mathrm{POCl}_{3}$ por cada mmol de compuesto de partida. El catión iminio se genera a 0 ${ }^{\circ} \mathrm{C}$ y posteriormente se calienta la reacción durante 2 horas, tras las cuales se hidroliza el intermedio formado con una solución acuosa de acetato sódico. En estas condiciones se obtuvieron, además de los productos esperados, otros derivados doblemente formilados. La aparición de estos derivados disminuye si se reduce el tiempo de reacción.

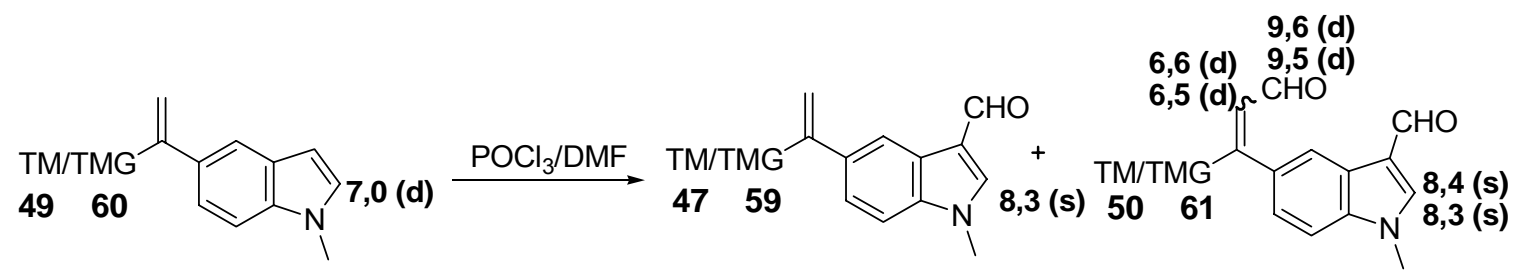

Figura 23. Señales caractrísticas de los monoaldehídos y los dialdehídos.

En el espectro de $\mathrm{RMN}{ }^{1} \mathrm{H}$ de los compuestos formulados en 3 es característico el desapantallamiento que sufre la señal del hidrógeno de la posición 2 del indol: $\mathrm{Su}$ desplazamiento químico en $\mathrm{RMN}{ }^{1} \mathrm{H}$ se diferencia en más de 1 ppm del de los compuestos de partida y pasa a resonar como singlete en vez de como doblete.

En el espectro de $\mathrm{RMN}{ }^{13} \mathrm{C}$ de los derivados doblemente formilados se observa la desaparición de la señal del metileno olefínico del puente. En el espectro de RMN ${ }^{1} \mathrm{H}$ se observa que la desaparición de estos protones está acompañada por la aparición de dos señales que resuenan como dobletes con una constante de acoplamiento de $8 \mathrm{~Hz}$, una a 9,6 ppm y otra 6,6 ppm. Estos cambios se atribuyen a la formilación del grupo vinilideno $\left(>\mathrm{C}=\mathrm{CH}_{2}\right)$, que se transforma en un aldehído conjugado $(>\mathrm{C}=\mathrm{CH}-\mathrm{CHO})$. La formación de dos derivados de doble formilación se explica por la existencia de los isómeros $\boldsymbol{Z}$ y $\boldsymbol{E}$ como resultado de la formilación del puente. Los isómeros $\boldsymbol{Z}$ y $\boldsymbol{E}$ no se separan por cromatografía en columna, pero fue posible purificar por cristalización el isómero $\mathbf{Z}$ del derivado que contiene el 3,4,5-trimetoxifenilo (50Z), cuya estereoquímica se asignó mediante espectros de diferencia de nOe.

Adicionalmente, se realizó la formilación de la fenstatina 45 usando la misma metodología, para comprobar si la formilación del resto indolilo induce el mismo efecto antimitótico en fenstatinas que en isocombretastatinas. 


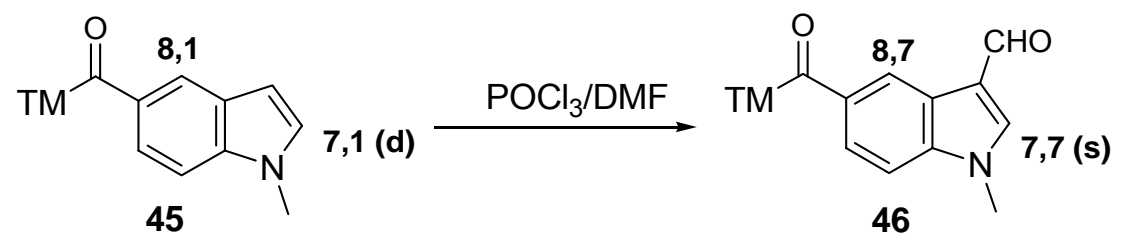

Figura 24. Obtención del compuesto 46.

Como se observa en la figura, en este caso, el análisis de $\mathrm{RMN}{ }^{1} \mathrm{H}$ refleja un desapantallamiento de 0,6 ppm de las señales del protón $\mathrm{H}-2$ y del protón $\mathrm{H}-4$ del resto indolilo.

\section{$\underline{\text { Reducciones de los aldehídos. }}$}

Debido a que las reducciones de compuestos carbonílicos con hidruros de metal suelen dar sus correspondientes alcoholes con buenos rendimientos, se decidió preparar los 3-indolilmetanoles en primer lugar. En este caso se optó por emplear borohidruro de sodio que, aunque menos reactivo que otros hidruros (como por ejemplo el hidruro de aluminio y litio), presenta mayor estabilidad al aire y a la humedad. De este modo, se realizó la reducción en $\mathrm{MeOH}$ usando un exceso de $\mathrm{NaBH}_{4}$.
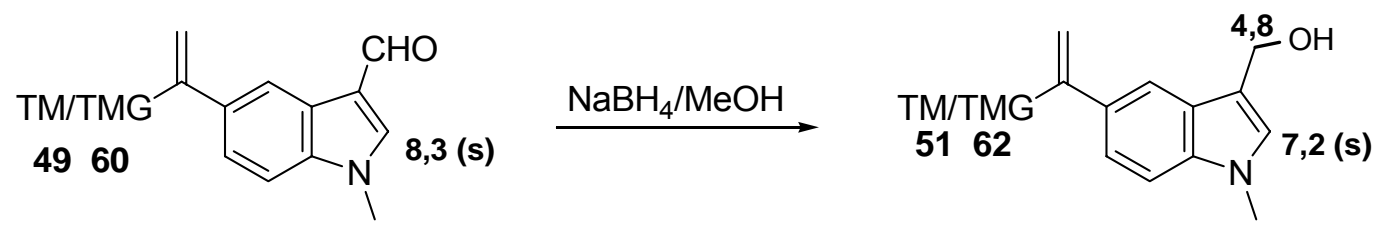

Figura 25. Obtención de los compuestos 51 y 62.

En el análisis espectroscópico de $\mathrm{RMN}{ }^{1} \mathrm{H}$ se observa la aparición de una señal que resuena como singlete a 4,8 ppm, correspondiente al metileno hidroxilado y el apantallamiento de la señal del protón H-2 del resto indolilo. 


\section{Formación de oximas.}

Las oximas son también derivados de interés debido a que aumentan la posibilidad de establecer enlaces de hidrógeno, de interaccionar con la proteína y de preparar derivados como las acetoximas. Las oximas se han preparado de forma satisfactoria en la obtención de derivados de fenstatinas, mediante la introducción de dicha agrupación en el puente carbonílico, ${ }^{41}$ dando lugar a compuestos muy potentes, con elevados rendimientos. En este caso, las oximas se han obtenido por reacción de los aldehídos con clorhidrato de hidroxilamina usando como disolvente metanol y piridina. De este modo, se obtiene las oximas como una mezcla de los isómeros $\boldsymbol{Z}$ y $\boldsymbol{E}$, con alto rendimiento y sin necesidad de purificación por cromatografía en columna. La separación de los isómeros fue posible mediante cromatografía en columna. Sin embargo, la identificación de cada uno de ellos no pudo completarse ya que en disolución se isomerizan rápidamente para dar una mezcla 1:1 idéntica a la obtenida directamente como crudo de reacción.<smiles>C=C(C)c1ccc2c(c1)c(C=O)cn2C</smiles>

Figura 26. Obtención de los compuestos 53 y 64.

Formación de hidrazonas.

Debido a las semejanzas y diferencias existentes entre el grupo oxima e hidrazona, la preparación de estos últimas es una prolongación aconsejable durante un estudio inicial sobre las relaciones estructura actividad de estos compuestos.

\footnotetext{
${ }^{41}$ a) Álvarez, C.; Álvarez, R.; Corchete, P.; Pérez-Melero, C.; Peláez, R.; Medarde, M., Naphthylphenstatins as tubulin ligands: synthesis and biological evaluation. Bioorg. Med. Chem. 2008, 16, 8999-9008.

b) Álvarez, C.; Álvarez, R.; Corchete, P.; Lopez, J. L.; Pérez-Melero, C.; Peláez, R.; Medarde, M., Diarylmethyloxime and hydrazone derivatives with 5-indolyl moieties as potent inhibitors of tubulin polymerization. Bioorg. Med. Chem. 2008, 16, 5952-5961.
} 
La preparación de las hidrazonas se ha realizado a partir de los aldehídos por reacción con hidracina en metanol con unas gotas de ácido acético. Durante la reacción se produce, además, la reducción del doble enlace del puente. En el caso de los compuestos con un resto 2,3,4-trimetoxifenilo, éstos son los únicos productos obtenidos. Las hidrazonas se han obtenido con buenos rendimientos como mezcla de los isómeros $\mathbf{Z}$ y $\boldsymbol{E}$, los cuales no fue posible separar mediante cromatografía de columna en gel de sílice.<smiles>[R4]C(=C)c1ccc2c(c1)c(C=O)cn2C</smiles><smiles>[Y19]C(=C)c1ccc2c(c1)c(/C=N\N)cn2C</smiles><smiles>C=C(C)c1ccc2c(c1)c(C=O)cn2C</smiles><smiles>CC(C)c1ccc2c(c1)c(/C=N\N)cn2C</smiles>

Figura 27. Obtención de los compuestos 56 y $\mathbf{6 8}$.

\section{$\underline{\text { Tratamiento de las oximas con anhídrido acético. }}$}

Con el fin de obtener las acetoximas, se realizó el tratamiento de las oximas con anhídrido acético y piridina resultando en las dos series un producto complejo. El crudo de reacción se purificó mediante cromatografía de columna obteniéndose en la serie con 3,4,5-trimetoxifenilo el carbonitrilo (54) con un 30-35\% de rendimiento y una mezcla de los isómeros $55 \mathbf{Z}$ y $\boldsymbol{E}$ de las acetoximas en un $20 \%$ de rendimiento. En el derivado que contiene 2,3,4 trimetoxifenilo, adicionalmente se obtuvo un $7 \%$ del compuesto 66 (fenstatina con nitrilo en 3 del indol) probablemente debido a la existencia de restos de la cetona correspondiente (58) durante la reacción de acetilación.

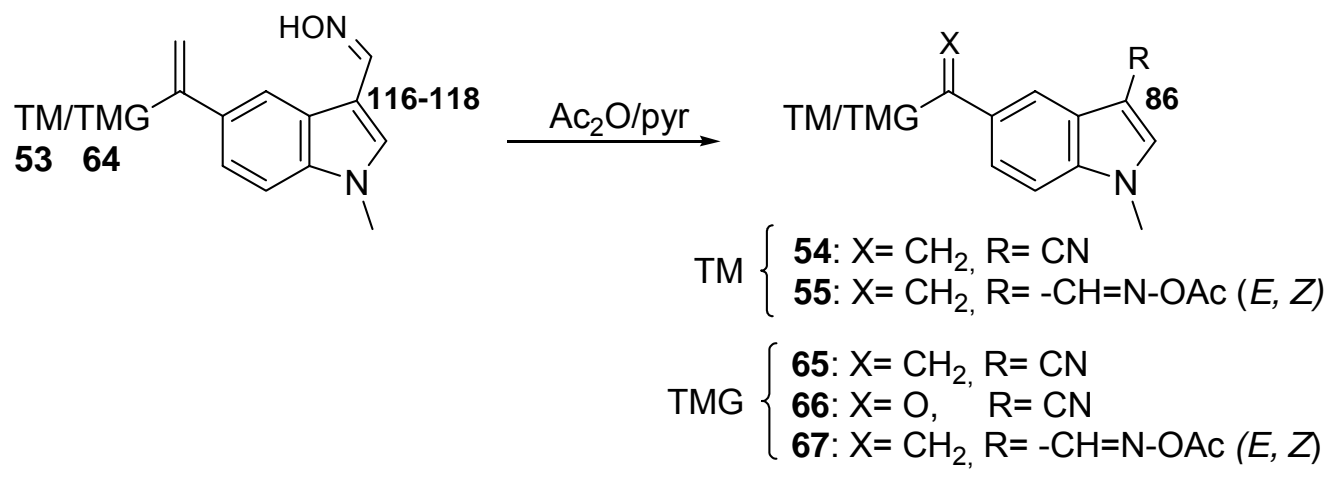

Figura 28. Obtención de los compuestos 54, 55, 65, 66 y 67. 
En el espectro de $\mathrm{RMN}{ }^{13} \mathrm{C}$ destaca el apantallamiento que sufre el carbono del sustituyente en posición 3 que pasa de resonar a 117 ppm en la oxima a hacerlo a 86 ppm en el nitrilo (Figura 28). Los acetatos obtenidos no pudieron ser caracterizados ya que se degradan rápidamente en disolución.

\section{III.1.A.6. Modificación del puente.}

La introducción de sustituyentes en el puente, a no ser que sean de pequeño tamaño, producen efectos negativos sobre la actividad. Por otra parte, la hidrogenación de las combretastatinas, que les hace perder rigidez y cambiar sus disposiciones preferidas, produce una disminución notable de la citotoxicidad y de la inhibición de polimerización de tubulina. En las isocombretastatinas, la hidrogenación del puente sólo produce una pequeña alteración en la geometría de la molécula, no modifica los grados de libertad de la misma y, prácticamente, no afecta al tamaño. Por lo tanto, la preparación de derivados hidrogenados de isocombretastatinas (1,1-diariletanos) parece una modificación útil para añadir información sobre el efecto de las modificaciones del puente de las fenstatinas.

\section{$\underline{\text { Reducción de la olefina del puente. }}$}

Así pues, con el fin de comprobar si la hibridación $\mathrm{sp}^{2}$ del carbono del puente es indispensable para la actividad antimitótica (al igual que ocurre en los derivados de fenstatinas en los que la reducción del carbonilo del puente conlleva una disminución de la potencia) o si, por el contrario, podría sustituirse por un carbono $\mathrm{sp}^{3}$, se decidió realizar la reducción de algunas de las isocombretastatinas sintetizadas.

Las reacciones se llevaron a cabo en atmósfera de hidrógeno utilizando como catalizador paladio sobre carbono y etanol como disolvente. 
Para la hidrogenación del puente se seleccionaron cuatro isocombretastatinas en las que $\mathrm{Ar}_{1}$ corresponde a un resto 3,4,5-trimetoxifenilo (de las cuales, dos poseen un fenilo sustituido como $\mathrm{Ar}_{2}$ y dos un resto 5-indolilo) y una en la que los dos anillos aromáticos los forman el resto 2,3,4,-trimetoxifenilo y el resto $N$-metil-5-indolilo.
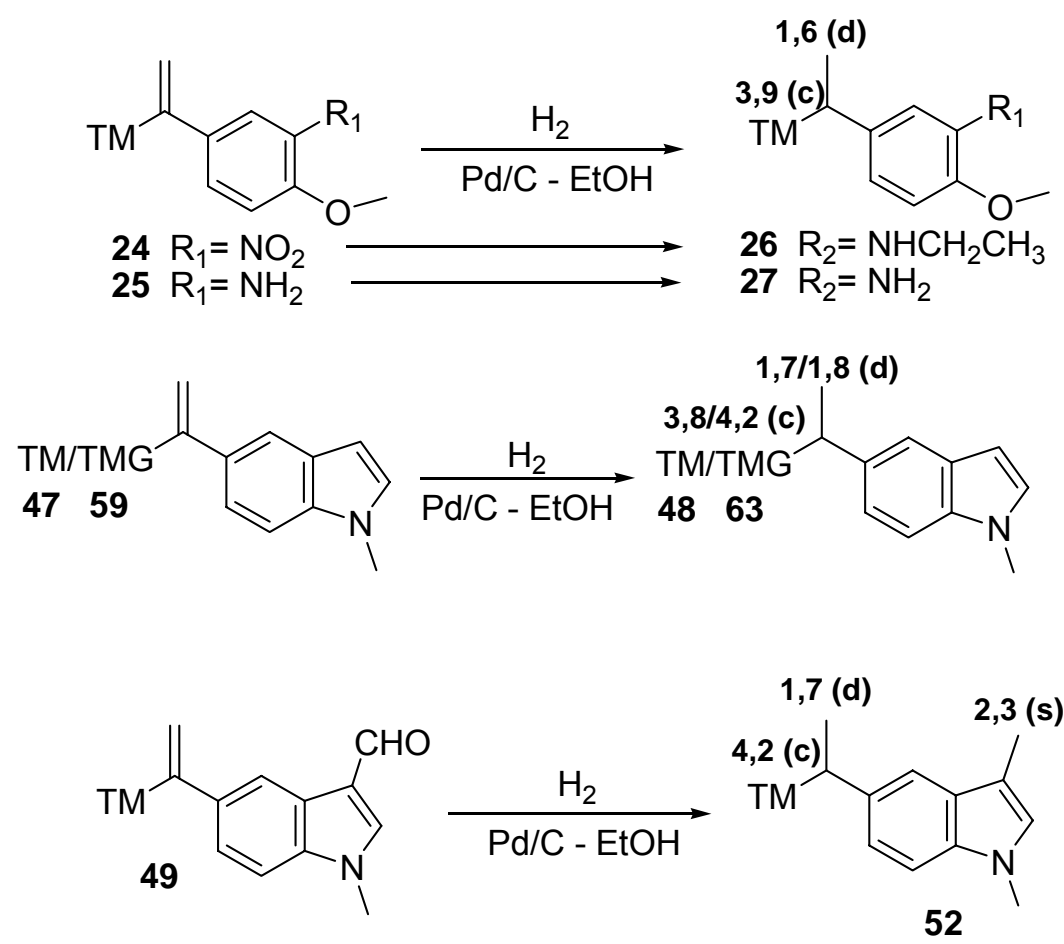

Figura 29. Obtención de los compuestos 26, 27, 48, 52 y 63.

Son características de estos compuestos las señales de $\mathrm{RMN}{ }^{1} \mathrm{H}$ del grupo $\mathrm{CHCH}_{3}$. El $\mathrm{H}$ del carbono bisbencílico resuena como cuartete en torno a $4 \mathrm{ppm}$ y el metilo resuena como doblete a 1,6-1,8 ppm.

Cuando se hidrogena la isocombretastatina formilada, también se reduce el aldehído hasta metilo. Así, desparece la señal de $\mathrm{RMN}{ }^{1} \mathrm{H}$ característica a $10 \mathrm{ppm}$ del protón del aldehído y se observa un singlete a 2,3 ppm correspondiente al metilo.

En el caso de la isocombretastatina que posee un grupo nitro, éste también se reduce en las condiciones de reacción y, adicionalmente, se introduce un etilo sobre el nitrógeno. La formación de este compuesto (26) se observa claramente en el espectro de masas y en los espectros de $\mathrm{RMN}{ }^{1} \mathrm{H}$ y de $\mathrm{RMN}{ }^{13} \mathrm{C}$. 



\section{III.1.B. Sintesis de derivados de fenstatina con otros heterociclos.}

Dentro de los objetivos de este trabajo, se planteó la sustitución del anillo 5-indolilo por otros heterociclos. Debido a los buenos resultados obtenidos con los derivados indólicos, se seleccionaron anillos benzofusionados, de estructura similar al indol, que incorporaran un heteroátomo adicional en posición 3. De este modo, se decidió sintetizar las fenstatinas que combinan un resto 3,4,5-trimetoxifenilo y un resto 1,3-benzoxazolilo o $1 H$-benzimidazolilo utilizando la metodología descrita en el apartado anterior.

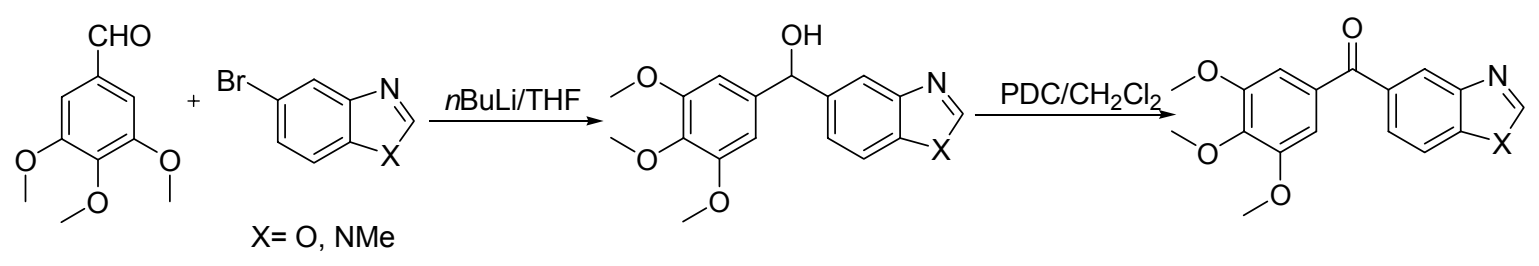

Esquema 3. Procedimiento de síntesis de fenstatinas con benzimidazol y benzoxazol.

\section{III.1.B.1. Materiales de partida.}

Los derivados bromados de los heterociclos seleccionados no son comerciales, por lo que se sintetizaron previamente a la reacción de acoplamiento con 3,4,5trimetoxibenzaldehído.

Obtención de 5-bromo-1-metil-1H-benzimidazol (14) y 6-bromo-1-metil-1Hbenzimidazol (15).

A partir de 4-bromobenceno-1,2-diamina, por tratamiento con ortoformiato de trimetilo en medio ácido, ${ }^{42}$ se obtiene de forma cuantitativa el 5-bromobenzimidazol. En el espectro RMN ${ }^{1} \mathrm{H}$ se observa la aparición de la señal correspondiente al H-2 que resuena como singlete a 7,99 ppm.

\footnotetext{
${ }^{42}$ Roberts, R. M.; Vogt, P. J. N-Ethyl-p-chloroaniline. Org. Syn. Coll. 1963, 4, 420-422.
} 
Una vez obtenido el benzimidazol bromado, se procedió a la alquilación del $\mathrm{NH}$, tanto para evitar la presencia de hidrógenos ácidos durante la reacción de acoplamiento como para mantener el grupo metilo presente en indolil-fenstatinas potentes obtenidas con anterioridad. En este caso se obtiene la mezcla de dos isómeros (14 y 15) debido a la deslocalización de la carga negativa entre los dos nitrógenos, que se produce cuando tratamos el benzimidazol-5-carbaldehído con una base $(\mathrm{NaOH})$. Tras cromatografía en columna de gel de sílice no fue posible la separación de los dos isómeros, por lo que se utilizó la mezcla 1:1 (obtenida con un rendimiento del 53\%) en el acoplamiento con 3,4,5trimetoxibenzaldehído.

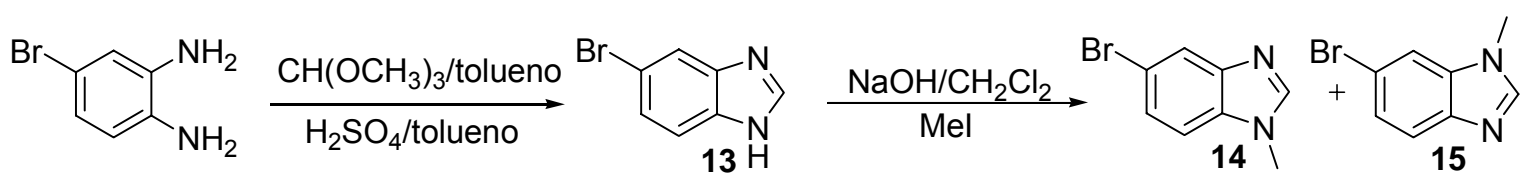

Figura 30. Procedimiento de obtención de los benzimidazoles metilados.

\section{Obtención de 5-bromo-1,3-benzoxazol (17).}

La preparación del 5-bromo-1,3-benzoxazol se efectúa por el mismo procedimiento anterior, utilizando como material de partida el aminofenol obtenido mediante la reducción de 4-bromo-2-nitrofenol con cloruro de estaño. El producto se hizo reaccionar con ortoformiato de trimetilo en medio ácido para obtener 5-bromo-1,3-benzoxazol, que se caracteriza por la aparición de la señal del protón $\mathrm{H}-2$ en el espectro $\mathrm{RMN}{ }^{1} \mathrm{H}$ a 8,05 ppm. El rendimiento obtenido tras los dos pasos es del $32 \%$.

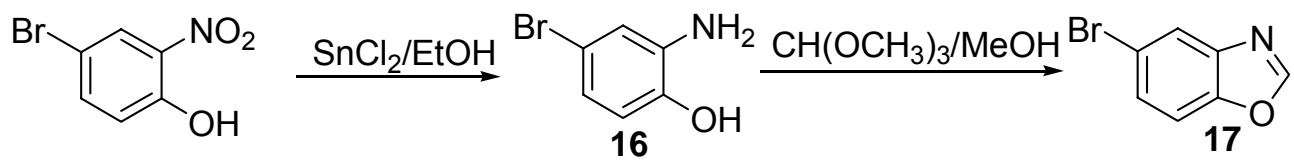

Figura 31. Procedimiento de obtención de 5-bromo-1,3-benzoxazol. 


\section{III.1.B.2. Síntesis de diarilmetanoles.}

Una vez preparados los bromoderivados de partida se han sintetizado los diarilmetanoles, empleando la misma metodología utilizada en la obtención de los diarilmetanoles con resto $N$-metilindolilo.

Obtención de (5-bromo-1-metil-1H-benzimidazol-2-il)(3,4,5-trimetoxifenil)metanol (69) y (6-bromo-1-metil-1H-benzimidazol-2-il)(3,4,5-trimetoxifenil)metanol (70).

A pesar de utilizar 2 equivalentes de $n$ BuLi por cada uno de bromobenzimidazol, no se evitó la aparición de derivados unidos a través de la posición 2 del benzimidazol. De este modo, partiendo de la mezcla de los isómeros 14 y 15, se obtienen los diarilmetanoles 69 y 70 que mantienen el bromo en la posición 5 y 6 , respectivamente. Mediante cromatografía sobre gel de sílice fue posible la separación de los isómeros que se obtienen con un rendimiento del $28 \%$ (69) y del $33 \%$ (70).

La identificación de cada uno de los alcoholes isómeros no se pudo realizar directamente, por lo que se ha deducido a partir de las cetonas a que dan lugar por oxidación. Éstas, a su vez, se identificaron mediante experimentos de diferencia de nOe. En el espectro de RMN ${ }^{1} \mathrm{H}$ se observa un mayor desapantallamiento de los hidrógenos que se encuentran en orto del nitrógeno no metilado $\left(\mathrm{H}_{4}\right.$ en 69 y $\mathrm{H}_{7}$ en 70), posiblemente debido al par de electrones.
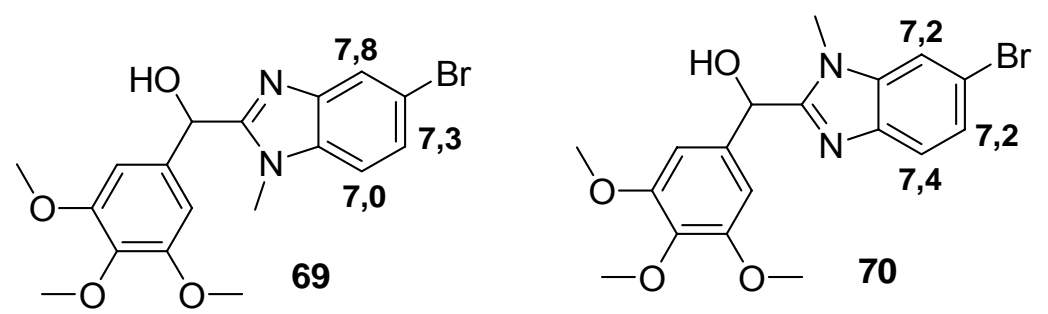

Figura 32. Señales espectroscópicas de ${ }^{1} \mathrm{H}$ RMN para los diarilmetanoles 69 y $\mathbf{7 0 .}$ 
Obtención de (1,3-benzoxazol-5-il)(3,4,5-trimetoxifenil)metanol (73):

Del mismo modo que en los derivados con resto indolilo y benzimidazolilo, el 5bromo-1,3-benzoxazol se trató con 2 equivalentes de $n$ BuLi para evitar la transmetalación y la formación de derivados unidos a través de la posición 2. La formación del compuesto 73 se observa en el espectro de $\mathrm{RMN}{ }^{1} \mathrm{H}$ por la aparición de la señal del hidrógeno del puente metabólico, que resuena a 5,9 ppm y la presencia de las señales de los hidrógenos $\mathrm{H}_{2}, \mathrm{H}_{4}, \mathrm{H}_{6}$ y $\mathrm{H}_{7}$ del resto benzoxazolilo.

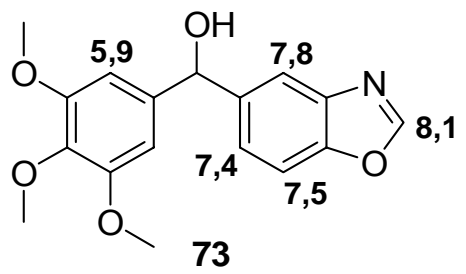

Figura 33. Señales espectroscópicas de $\mathrm{RMN}{ }^{1} \mathrm{H}$ del compuesto 73. 


\section{III.1.B.3. Síntesis de fenstatinas.}

La oxidación de estos derivados metanólicos se llevó a cabo usando permanganato potásico o dicromato de piridinio, oxidantes ya utilizados en este trabajo previamente. En la tabla se detalla el oxidante usado en cada caso y el rendimiento obtenido tras purificación mediante cromatografía en columna.

\begin{tabular}{|c|c|c|}
\hline Producto & Condiciones & $\begin{array}{c}\text { Rendimiento } \\
(\%)\end{array}$ \\
\hline $\mathbf{7 1}$ & $\mathrm{KMnO}_{4} 24 \mathrm{~h}$ & 41 \\
\hline $\mathbf{7 2}$ & $\mathrm{PDC} 24 \mathrm{~h}$ & 69 \\
\hline $\mathbf{7 4}$ & $\mathrm{PDC} 24 \mathrm{~h}$ & 26 \\
\hline
\end{tabular}

Tabla 4. Rendimiento y condiciones usadas en la obtención de los compuestos 71, 72 y 74.

En el espectro de RMN ${ }^{1} \mathrm{H}$ se puede destacar el despantallamiento que se observa tanto en las señales de los hidrógenos del trimetoxifenilo (de 6,6 ppm a 7,1 y 7,6 ppm) como en los hidrógenos del anillo $\mathrm{Ar}_{2}$, donde las diferencias oscilan entre 0,2 y 0,4 ppm.
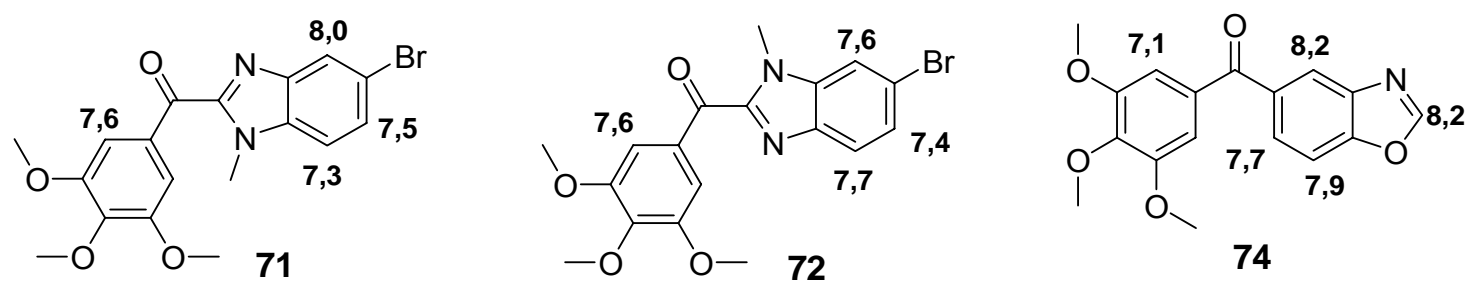

Figura 34. Señales espectroscópicas de $\mathrm{RMN}{ }^{1} \mathrm{H}$ de las fenstatinas 71, 72 y $\mathbf{7 4 .}$

La posición del bromo en 71 y 72 se ha establecido mediante experimentos de diferencia de nOe. Cuando se irradia el metilo unido a $\mathbf{N}$, en $\mathbf{7 1}$ se observa nOe con el doblete de $J \sim 8 \mathrm{~Hz}$ a 7,3 ppm, mientras que en 72, el nOe se produce con un doblete de $J \sim 2$ $\mathrm{Hz}$ que aparece a 7,6 ppm. La comparación de los valores de $\delta$ para 71 y 72 (figura 34) indica que los protones en orto del $\mathrm{N}$ no metilado están desapantallados. 



\section{III.1.C. Sintesis de derivados de combretastatinas.}

Una vez sintetizados los derivados de fenstatina del apartado anterior, el tercer objetivo de este trabajo se completa con la obtención de varias combretastatinas que posean la misma combinación de anillos aromáticos que algunas de las fenstatinas e isocombretastatinas sintetizadas, con el fin de establecer las comparaciones oportunas. Para ello, se seleccionó como anillo $\mathrm{Ar}_{1}$ el resto 3,4,5-trimetoxifenilo y como anillos $\mathrm{Ar}_{2}$ los restos $\mathrm{N}$-metilindol-3-carbaldehído, $\mathrm{N}$-etilindol-3-carbaldehído, $\mathrm{N}$-metilindol-3metanol y $N$-metilbenzimidazol.<smiles>COc1cc(/C=C\C2CCC2)cc(OC)c1OC</smiles><smiles>CCn1cc(C=O)c2cc(C(C)(C)C)ccc21</smiles>

Figura 35. Sistemas derivados de indol y benzimidazol seleccionados para ensayos de actividad de combretastatinas análogas.

La metodología más ampliamente descrita para la síntesis de análogos de combretastatina es la reacción de Wittig, que genera un doble enlace que puede tener estereoquímica $Z, E$ o resultar una mezcla de ambas. ${ }^{43}$

Esta metodología es la empleada habitualmente en bibliografía y ha sido aplicada satisfactoriamente en trabajos anteriores del grupo de investigación y en la síntesis de isocombretastatinas comentada anteriormente.

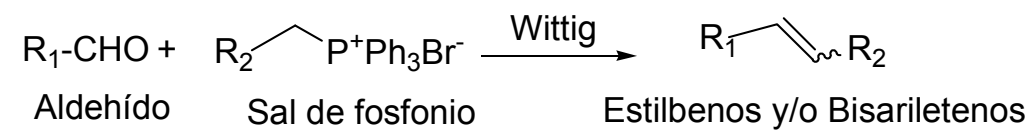

Esquema 4. Obtención de análogos de combretastatina.

\footnotetext{
43 a) March, J. Advanced Organic Chemistry. J. Willey \& Sons, Inc.; New York 1985. b) Smith, M. B. Organic Synthesis. McGrawHill; London 1994. c) Bestmann, H. J. Pure Appl. Chem. 1980, 52.
} 
En este caso se ha utilizado la sal de fosfonio derivada del bromuro de 3,4,5trimetoxibencilo y los aldehídos aromáticos correspondientes al anillo $\mathrm{Ar}_{2}$, como materiales de partida para la reacción de Wittig.

\section{III.1.C.1. Materiales de partida.}

Los aldehídos aromáticos $\mathrm{Ar}_{2}$ seleccionados son, en todos los casos, derivados de indol o de benzimidazol, por lo que fue necesaria la introducción de un metilo sobre el $\mathrm{N}$ en posición 1 por las razones que ya se han expuesto en los apartados anteriores.

\section{Obtención de 1-metil-1H-indol-5-carbaldehído (4).}

El derivado metilado se obtiene en un $93 \%$ por alquilación con ioduro de metilo en condiciones de transferencia de fase.

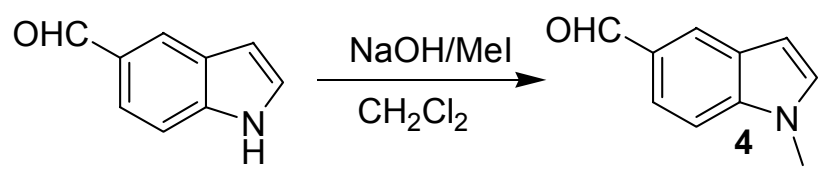

Figura 36. Metilación de 1H-indol-5-carbaldehído.

\section{Obtención de 1-etil-1H-indol-3,5-dicarbaldehído (3).}

En este caso se decidió realizar en primer lugar la formilación del indol en la posición 3, al contrario que en el resto de los compuestos (en los que se realiza la formilación una vez sintetizado el compuesto diarílico), para evitar una posible isomerización cis-trans de la combretastatina debido al medio ácido de reacción empleado en la reacción de Vilsmeier-Haack. La formilación se lleva a cabo en las mismas condiciones descritas en el apartado A.5.2. Sin embargo, el rendimiento obtenido es bastante menor (29\%) debido a que se producen reacciones de polimerización. Posteriormente se comprobó que la realización de la formilación una vez obtenida la combretastatinas, no provoca la isomerización del doble enlace (ver apartado C2), por lo que la ruta para la síntesis de estos análogos se ha modificado y, en el resto de los casos, se ha realizado la formilación en una etapa posterior a la reacción de Wittig. 
Una vez obtenido el dialdehído, se procede a la alquilación del NH usando como base carbonato potásico. La posterior adición de bromuro da como resultado el producto etilado con un rendimiento del $67 \%$.<smiles>CCn1cc(C=O)c2cc(C=O)ccc21</smiles>

Figura 37. Obtención de 1-etil-1H-indol-3,5-dicarbaldehído.

Obtención de 1-metil-1H-benzimidazol-5-carbaldehído (7) y 1-metil-1H-benzimidazol-6-carbaldehído (8).

Para la obtención de los derivados benzimidazólicos se hicieron diversas pruebas a partir del ácido $1 H$-benzimidazol-5-carboxílico y resultó necesaria la reducción del grupo ácido hasta alcohol y su posterior oxidación a aldehído, como pasos previos a la metilación. Cuando se realizaba la alquilación del ácido, su elevada solubilidad acuosa impedía la recuperación del producto metilado y la $N$-alquilación del derivado metanólico conllevaba la introducción de un metilo sobre el oxígeno.

Tras ensayar varias secuencias de pasos, se estableció la siguiente ruta: reducción del ácido $1 H$-benzimidazol-5-carboxílico con hidruro de aluminio y litio hasta el alcohol, que posteriormente se oxida con dióxido de manganeso a $1 \mathrm{H}$ benzimidazol-5-carbaldehído. La metilación con ioduro de metilo, mediante el tratamiento con hidróxido sódico en presencia de un catalizador de transferencia de fase, da lugar a la mezcla de los dos isómeros 7 y $\mathbf{8}$, al igual que en el caso del 5-bromo$1 H$-benzimidazol, y al compuesto 9 que se forma por la rotura del anillo imidazólico. Tras cromatografía en columna de gel de sílice se obtuvo la mezcla 1:1 de los isómeros 7 y 8 con un rendimiento del $44 \%$.

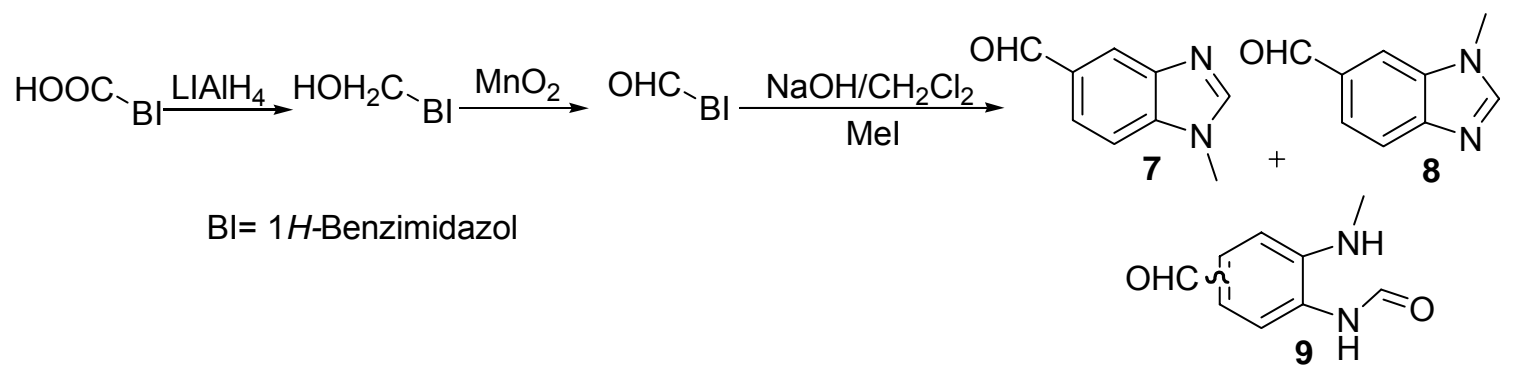

Figura 38. Procedimiento de obtención de los benzimidazoles metilados 7 y 8. 


\section{III.1.C.2. Síntesis de los análogos de combretastatinas.}

La formación del doble enlace se realiza, en nuestro caso, entre un aldehído y la sal de 3,4,5-trimetoxibencil(trifenil)fosfonio. Para la formación del iluro se emplean las siguientes condiciones: tratamiento de la sal de fosfonio con $n \mathrm{BuLi}$ en THF seco a baja temperatura, observándose que la disolución cambia a un color rojo oscuro, indicativo de la formación del iluro. Posteriormente, y a esta temperatura, se añade el aldehído correspondiente y se deja que alcance la temperatura ambiente. El producto de reacción se purifica por cromatografía de columna sobre gel de sílice.

La asignación de los dos posibles isómeros $(Z$ y $E)$ se realiza a partir de las diferencias observadas en los datos espectroscópicos:

1) el desplazamiento químico de los protones olefínicos, que aparece a campo más bajo en el trans ( 7,0 ppm) que en en el cis ( 6,7 ppm).

2) la constante de acoplamiento de los dobletes de los protones olefínicos (12 y $16 \mathrm{~Hz}$ para $Z$ y $E$ respectivamente).

3) el desplazamiento químico los 6 protones de los metoxilos equivalentes y los 2 protones aromáticos del resto trimetoxifenilo, que en los isómeros cis están apantallados con respecto a los isómeros trans. Éste apantallamiento se debe a la corriente del otro anillo aromático, que sólo se encuentra cerca en los isómeros cis. 
Obtención de (Z)- $N$-etil-5-[2-(3,4,5-trimetoxifenil)vinil]-1H-indol-3carbaldehído (75).

Para la obtención del compuesto 75 se adiciona el iluro sobre una disolución del dialdehído 3 en THF a $-78{ }^{\circ} \mathrm{C}$. Esta inversión en la adición tiene como fin favorecer la reacción del aldehído más reactivo con el iluro de fósforo y evitar la formación de compuestos triarílicos (reacción de los dos grupos aldehídos). El compuesto 75 se caracteriza espectroscópicamente por el desplazamiento químico y la constante de acoplamiento que presentan los hidrógenos olefínicos en el espectro de $\mathrm{RMN}{ }^{1} \mathrm{H}: 6,51 \mathrm{y}$ $6,73 \mathrm{ppm} ; J=12,3 \mathrm{~Hz}$, así como por el apantallamiento que se observa en los protones H-4 y H-6 del indol.

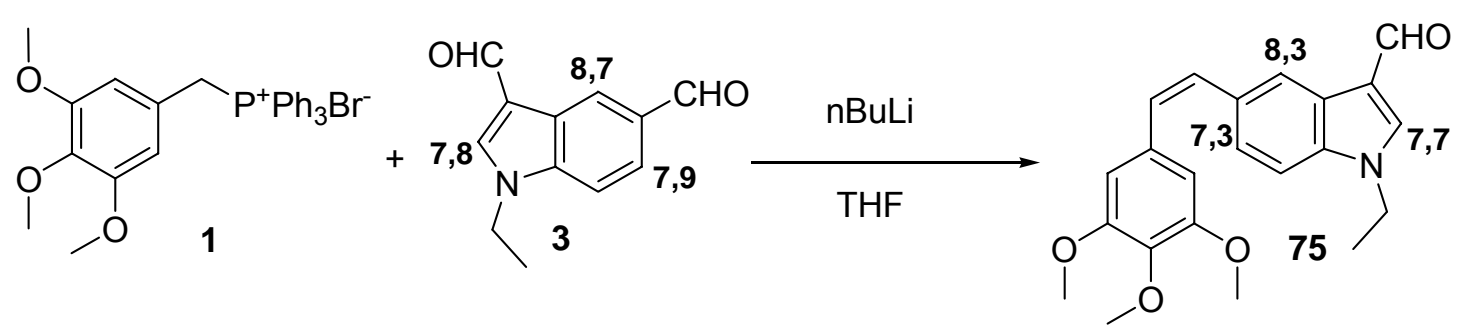

Figura 39. Obtención del compuesto 75.

Tras sucesivas cromatografías en columna se obtiene el compuesto con un rendimiento de tan sólo el 5\%, por lo que en las síntesis siguientes se ha preferido realizar la formilación sobre el compuesto diarílico en vez de hacerlo previamente sobre el material de partida. 
Obtención de ( $\boldsymbol{Z}$ y $\boldsymbol{E})$-1-metil-5-[2-(3,4,5-trimetoxifenil)vinil]-1H-benzimidazol $\left(\begin{array}{lll}79 Z & \text { y } & 79 E\end{array}\right)$ y de $\left(\begin{array}{lll}\boldsymbol{Z} & \text { y } & \boldsymbol{E}\end{array}\right)$-1-metil-6-[2-(3,4,5-trimetoxifenil)vinil]-1Hbenzimidazol ( $80 Z$ y $80 E)$.

La adición de la mezcla de los benzimidazoles 7 y 8 sobre el iluro de fósforo de 3,4,5-trimetoxifenilo genera los correspondientes isómeros $\boldsymbol{Z}$ y $\boldsymbol{E}$ de los compuestos 79 y 80, con un rendimiento del $69 \%$ tras cromatografía en columna de gel de sílice. En los espectros de RMN tan sólo se observa uno de los isómeros trans, que se separa por cristalización.
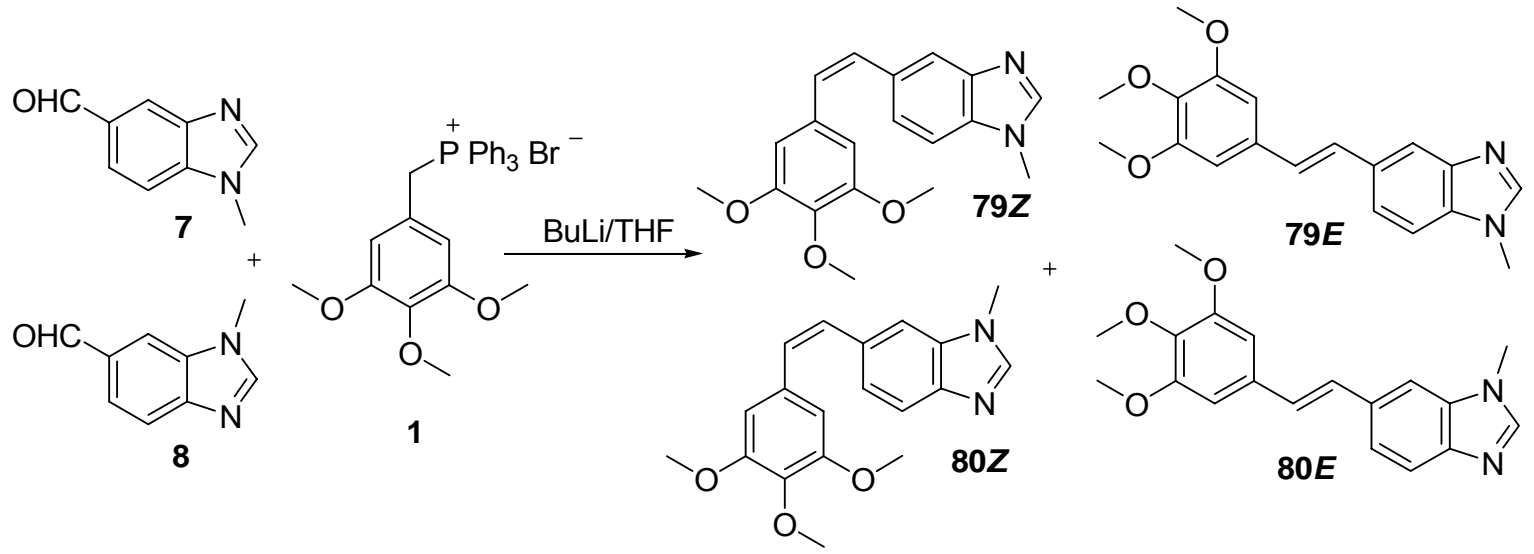

Figura 40. Obtención de los compuestos $79(Z$ y $E)$ y $80(Z$ y $E)$.

Obtención de ( $\boldsymbol{Z}$ y $\boldsymbol{E})$ - $N$-metil-5-[2-(3,4,5-trimetoxifenil)vinil]-1H-indol (76).

Como resultado de la reacción se obtuvo una mezcla 1:1 de los compuestos $76 Z$ y $\mathbf{7 6 E}$, que se separan por cromatografía.

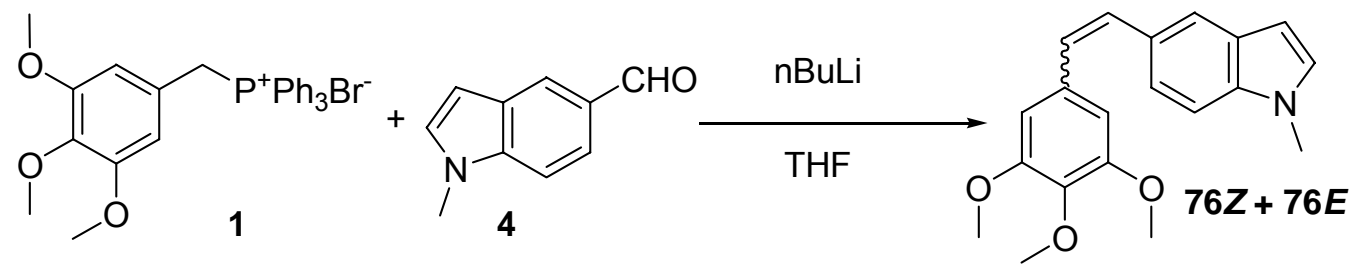

Figura 41. Obtención de los compuestos $76 Z$ y $76 E$. 
Obtención de (Z)- $N$-metil-5-[2-(3,4,5-trimetoxifenil)vinil]indol-3-carbaldehído (77) y obtención de (Z)-( $N$-metil-5-[2-(3,4,5-trimetoxifenil)vinil]indol-3il)metanol (78).

Una vez obtenido el análogo de combretastatina con el resto $N$-metilindolilo y disposición cis, se procedió a la introducción de un grupo formilo en posición 3 del indol y su posterior reducción al derivado hidroxilado, dos de las modificaciones realizadas en las isocombretastatinas.

La metodología empleada en ambas reacciones es la misma que la descrita para las isocombretastatinas y produce buenos rendimientos en las dos reacciones: Un 93\% en la formilación y un $89 \%$ en la reducción.

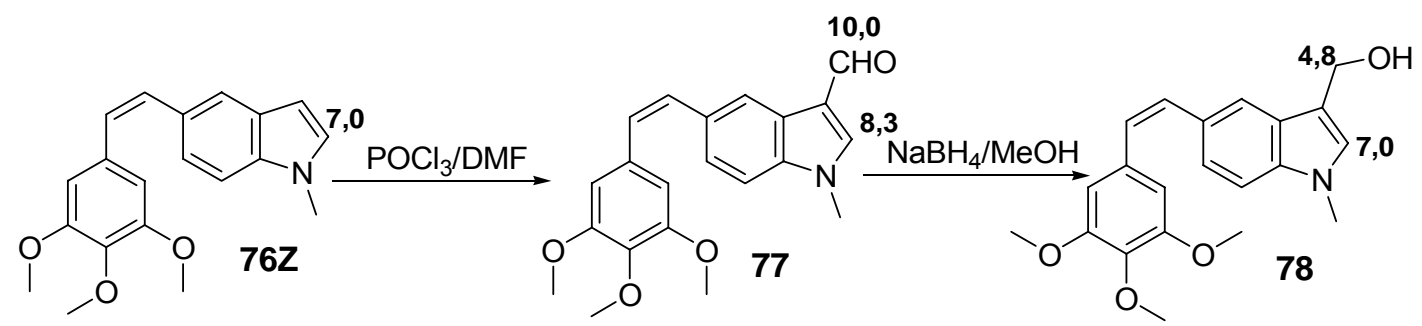

Figura 42. Preparación de los derivados formilado (77) y con hidroximetilo (78).

En el espectro de RMN ${ }^{1} \mathrm{H}$ podemos observar el desapantallamiento que sufre el hidrógeno de la posición 2 del indol cuando éste se formila y el consecuente apantallamiento cuando se reduce el grupo formilo. 



\section{III.2 SÍNTESIS DE COMPUESTOS MACROCÍCLICOS.}

La parte sintética de este trabajo se completa con la obtención de dos familias de compuestos macrocíclicos relacionados con combretastatinas. La introducción de un espaciador para unir los anillos aromáticos tiene como fin mantener la disposición cisoide del puente, independientemente de la presencia o ausencia de un doble enlace, y restringir las posibilidades conformacionales de las combretastatinas.

En trabajos anteriores de nuestro grupo de investigación se ha llevado a cabo la síntesis de varias familias de combretastatinas macrocíclicas que combinan fenilos metoxilados en diferentes posiciones con diferentes funciones en el puente de dos carbonos (olefina, diol, diacetato...) y espaciadores (3-oxapentametileno, hexametileno, tetrametileno) que unen los anillos aromáticos por las posiciones para-para o para-meta respecto al puente. ${ }^{44}$
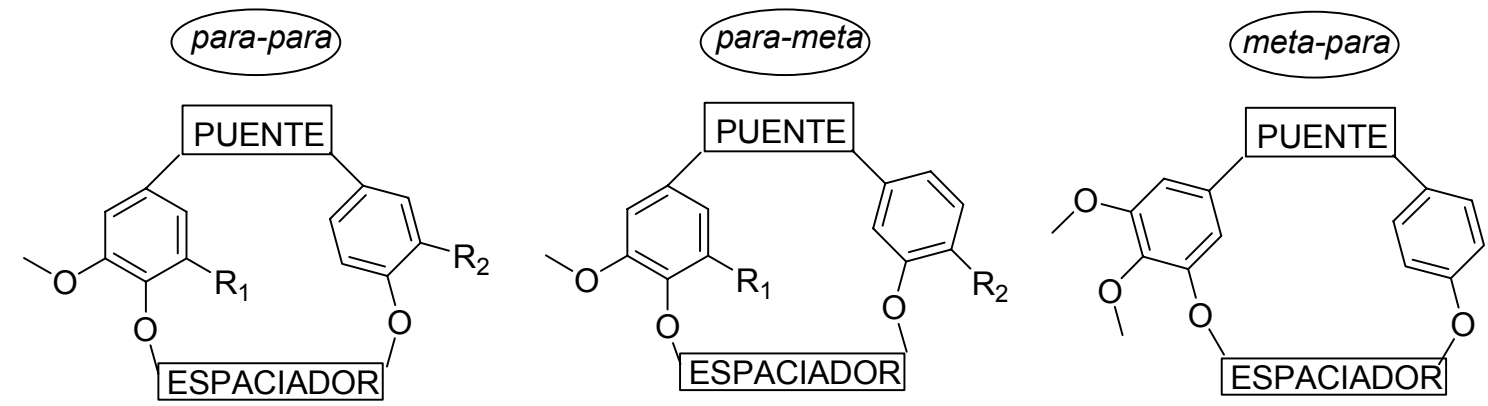

Figura 43. Esquema de combretastatinas macrocíclicas obtenidas previamente.

\footnotetext{
44 a) Mateo, C. Tesis Doctoral, Universidad de Salamanca, 2006. b) López, V. Tesis Doctoral, Universidad de Salamanca, 2007.
} 
En general, estos análogos macrocíclicos presentan una disminución en la actividad antimitótica, siendo los análogos más potentes aquellos que presentaban uniones para-para y el espaciador hexametileno. ${ }^{45}$

Tomando como base los resultados previos, se decidió ampliar el estudio de estos análogos mediante la obtención de dos familias, que presentaran mayor restricción conformacional, manteniendo la unión para-para y el espaciador hexametileno. Por ello, se seleccionó como anillo $\mathrm{Ar}_{2}$ un resto indolilo (buen sustituto del anillo de guayacol en combretastatinas $^{46}$ ) manteniendo como anillo $\mathrm{Ar}_{1}$ un resto equivalente a un di ó trimetoxifenilo. Aunque los compuestos macrocíclicos preparados con anterioridad no habían resultado activos, la presencia del sistema bicíclico de indol supone una notable alteración estructural y de la dinámica de estos compuestos. Estudios previos de modelado molecular sugieren que el hueco en la tubulina ocupado por uno de los metoxilos del anillo de trimetoxifenilo de la podofilotoxina puede ser ocupado por uno de los metilenos del espaciador, ${ }^{45}$ por lo que se decidió combinar el sistema indólico con restos fenilos que, además del espaciador, contuvieran uno o dos metoxilos (figura 44).

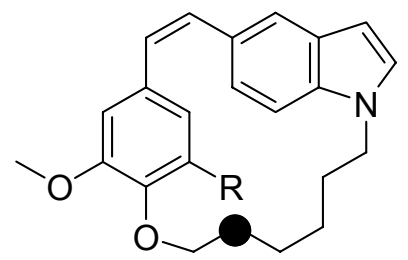<smiles>[R]c1cc([C@@H](O)[C@@H](O)c2ccc3c(ccn3CCCCCO)c2)cc(OC)c1OC</smiles><smiles>[R]c1cc([C@@H](OC(C)=O)[C@@H](OC(C)=O)c2ccc3c(ccn3CCCCCOc3ccco3)c2)cc(OC)c1OC</smiles>

$\mathrm{R}=\mathrm{H}, \mathrm{OCH}_{3}$

Figura 44. Análogos macrocíclicos obtenidos en este trabajo. En el espaciador se ha marcado la posición que puede ocupar el hueco cuando el metoxilo $\left(\mathrm{R}=\mathrm{OCH}_{3}\right)$ está ausente $(\mathrm{R}=\mathrm{H})$.

\footnotetext{
${ }^{45}$ Mateo, C.; Álvarez, R.; Pérez-Melero, C.; Peláez, R.; Medarde, M. Conformationally restricted macrocyclic analogues of combretastatins. Bioorg. Med. Chem. Lett. 2007, 17, 6316-6320.

${ }^{46}$ Maya, A. B.; Pérez-Melero, C.; Mateo, C.; Alonso, D.; Fernández, J. L.; Gajate, C.; Mollinedo, F.; Peláez, R.; Caballero, E.; Medarde, M. Further Naphthylcombretastatins. An Investigation on the Role of the Naphthalene Moiety. J. Med. Chem. 2005, 48, 556-568.
} 
El planteamiento general para la síntesis de estos compuestos se basa en la utilización de la reacción de McMurry para la obtención de las olefinas y dioles macrocíclicos. La selección de esta metodología, que implica el acoplamiento de carbonilos por titanio de baja valencia, ${ }^{47}$ se debe a que en trabajos anteriores ha resultado ser la metodología más adecuada para este tipo de macrociclación. Los intentos de acceder a las olefinas macrocíclicas mediante reacciones de cierre de anillo por metátesis, empleando diversos catalizadores de Grubbs, tiempo y condiciones de reacción, resultaron infructuosas, ${ }^{48}$ por lo que en este caso se optó por emplear directamente la reacción de McMurry.

La obtención de los dialdehídos se realiza mediante dos reacciones sucesivas de alquilación. En primer lugar se obtiene el intermedio monoarílico derivado del indol, común para las dos familias de compuestos a sintetizar $\mathrm{y}$, posteriormente, se hace reaccionar este intermedio con el aldehído fenólico correspondiente, dando lugar a los dialdehídos que se utilizarán en la reacción de macrociclación.

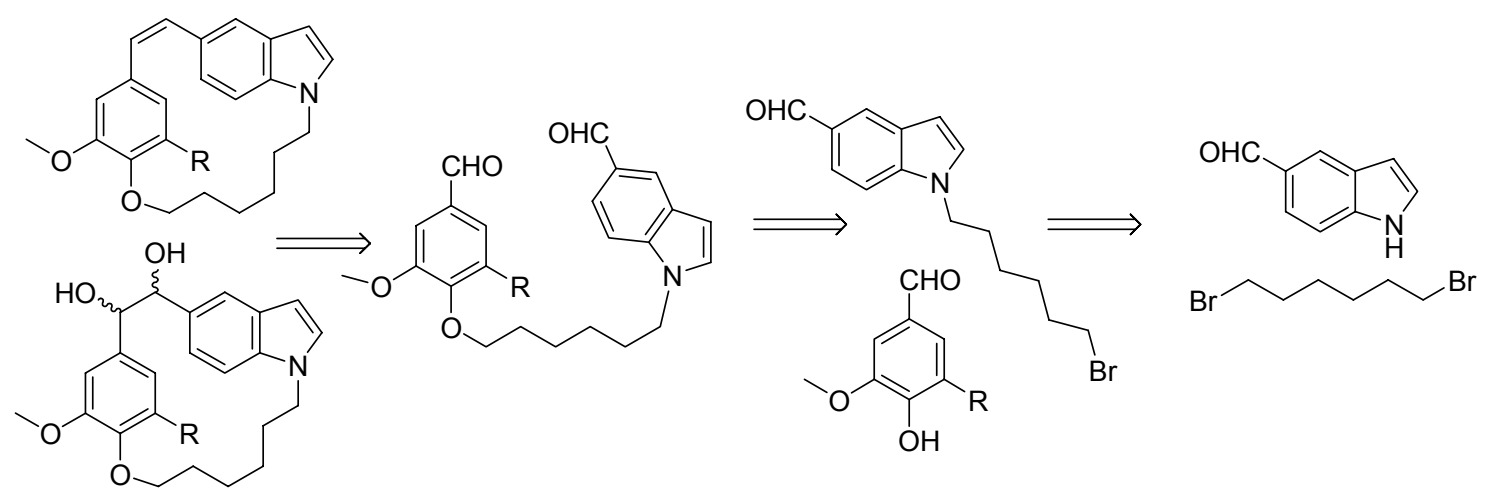

Figura 45. Análisis retrosintético de los análogos macrocíclicos.

\footnotetext{
${ }^{47}$ McMurry, J. E. Carbonyl-coupling reactions using low-valent titanium. Chem. Rev. 1989, 89, 1513-1524.

48 a) Mateo, C.; Pérez-Melero, C.; Peláez, R.; Medarde, M. Stilbenophane Analogues of Deoxycombretastatin A-4. J. Org. Chem. 2005, 70, 6544 - 6547; b) Mateo, C.; Pérez-Melero, C.; Peláez, R.; Medarde, M. Synthesis of a conformationally restricted polyoxygenated crownophane. Tetrahedron Lett. 2005, 46, 7055-7057. c) Mateo, C.; López, V.; Medarde, M.; Peláez, R. Synthesis and conformational analysis of macrocyclic hydroxystilbenes linked between the para-para positions. Chem. Eur. J. 2007, 13, 7246-7256.
} 



\section{III.2.A. Intermedios monoarílicos y diarílicos.}

Los materiales de partida utilizados para la obtención de los análogos macrocíclicos que constituyen el cuarto objetivo de este trabajo han sido indol-5-carbaldehído, vainillina y siringaldehído. Estos compuestos permiten la introducción de un espaciador mediante la alquilación del NH del indol y el grupo fenólico de los derivados de benzaldehído.<smiles>O=Cc1ccc2[nH]ccc2c1</smiles><smiles>COc1cc(C=O)ccc1O</smiles><smiles>COc1cc(C=O)cc(OC)c1O</smiles>

Figura 46. Materiales de partida empleados en la síntesis de análogos macrocíclicos.

La reacción de monoalquilación se produce, debido al carácter ácido del indol, mediante la formación del anión por tratamiento con bases en presencia de un catalizador de transferencia de fase (hidrogenosulfato de tetrabutilamonio), y la posterior adición de un exceso de 1,6-dibromohexano para evitar la formación de dímeros. ${ }^{49}$

De esta manera, se ha obtenido, con un rendimiento del $72 \%$, el compuesto 81 que se caracteriza por la aparición en el espectro de $\mathrm{RMN}{ }^{1} \mathrm{H}$ de las señales correspondientes a la cadena alquílica introducida (4,1 ppm metileno unido a $\mathrm{N}$ y 3,3 ppm metileno unido al bromo, que en el espectro de $\mathrm{RMN}{ }^{13} \mathrm{C}$ resuenan a 46,5 ppm y 33,8 ppm, respectivamente).

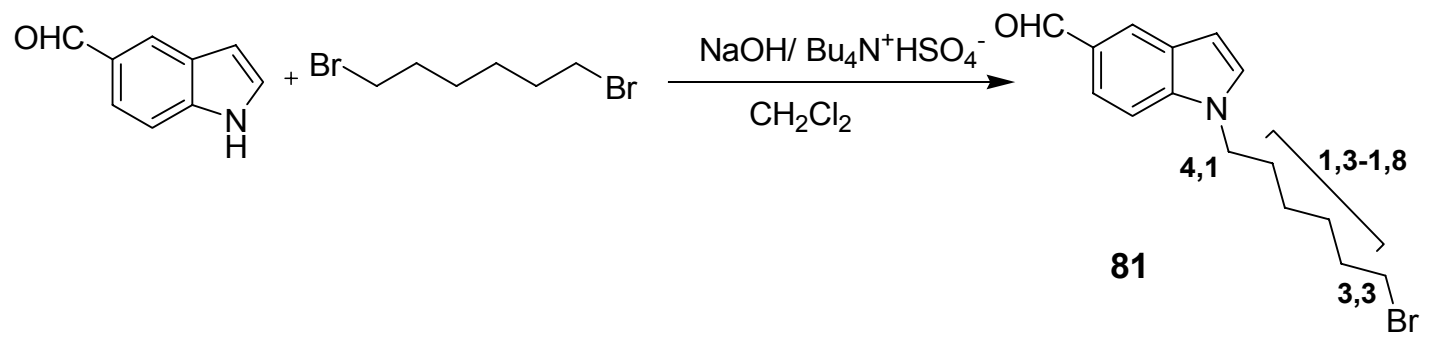

Figura 47. Obtención del compuesto 81.

\footnotetext{
49 McKillop, A.; Fiaud, J.-C.; Hug, R. P. The Use of Phase-Transfer Catalysis for the Synthesis of Phenol Ethers. Tetrahedron 1974, 30, 1379-1382.
} 
Una vez obtenido el intermedio de síntesis con el sistema indolilo unido al espaciador, se realiza la segunda reacción de alquilación en dimetilformamida en presencia de carbonato, ${ }^{50}$ debido a que la alquilación en las condiciones de transferencia de fase condujeron en todos los casos a la obtención del los materiales de partida inalterados.

La utilización de un exceso de carbonato potásico en dimetilformamida conduce a la obtención de los compuestos $\mathbf{8 2}$ y $\mathbf{8 3}$ de forma cuantitativa. En los espectros de RMN ${ }^{13} \mathrm{C}$ cabe destacar la aparición de la señal correspondiente a los metilenos unidos al oxígeno fenólico que resuenan a 69 y 73 ppm.

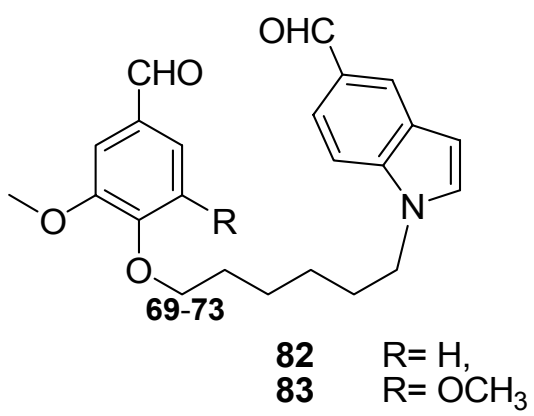

Figura 48. Señales de $\mathrm{RMN}{ }^{13} \mathrm{C}$ características de los compuestos 82 y 83.

50 Kao, C.-L.; Chern, J.-W. A convenient synthesis of naturally occurring benzofuran ailanthoidol. Tetrahedron Lett. 2001, 42, 1111-1113. 


\section{III.2.B. Compuestos macrocíclicos.}

La reacción de McMurry es un método eficiente para la preparación de olefinas estéricamente impedidas y pensionadas, ${ }^{51}$ por lo que se decidió emplear en la realización de las reacciones de macrociclación. Este método permite obtener olefinas y/o pinacoles variando las condiciones de temperatura y tiempo de reacción. Mientras que a bajas temperaturas sólo suelen obtenerse pinacoles, la realización de la reacción a reflujo permite la formación preferente de las olefinas. También se ha observado que tiempos prolongados de reacción conllevan la degradación de los productos. ${ }^{44,48}$

La reacción de McMurry, generalmente, se completa en dos pasos: primero se realiza la preparación del titanio de baja valencia a partir de $\operatorname{TiCl}_{n}(n=3,4)$ por tratamiento con un agente reductor y en segundo lugar se añade el compuesto dicarbonílico a la mezcla.

Para la síntesis de los análogos de combretastatina de este trabajo se han empleado 20 moles de $\mathrm{TiCl}_{4}$ y 10 moles de $\mathrm{Zn}$ por cada mol de dialdehído. El primer paso de la reacción ha tenido lugar a $0{ }^{\circ} \mathrm{C}$, mientras que, tras la adición del intermedio diarílico, la reacción se ha mantenido a reflujo durante 5 horas. Bajo estas condiciones de calentamiento durante tiempos de reacción no muy prolongados, es posible obtener tanto las olefinas como los pinacoles correspondientes en una sola reacción. Se utiliza una alta dilución en THF para lograr la ciclación intramolecular y evitar la polimerización intermolecular.

\footnotetext{
${ }^{51}$ Ephritikhine, M. A new look at the McMurry reaction. Chem. Commun. 1998, 2549-2554. b) Columbus, I.; Biali, S. E. Gear Effects in Polycyclohexyl Systems: Tetracyclohexylethene. J. Org. Chem. 1994, 59, 34023407.
} 


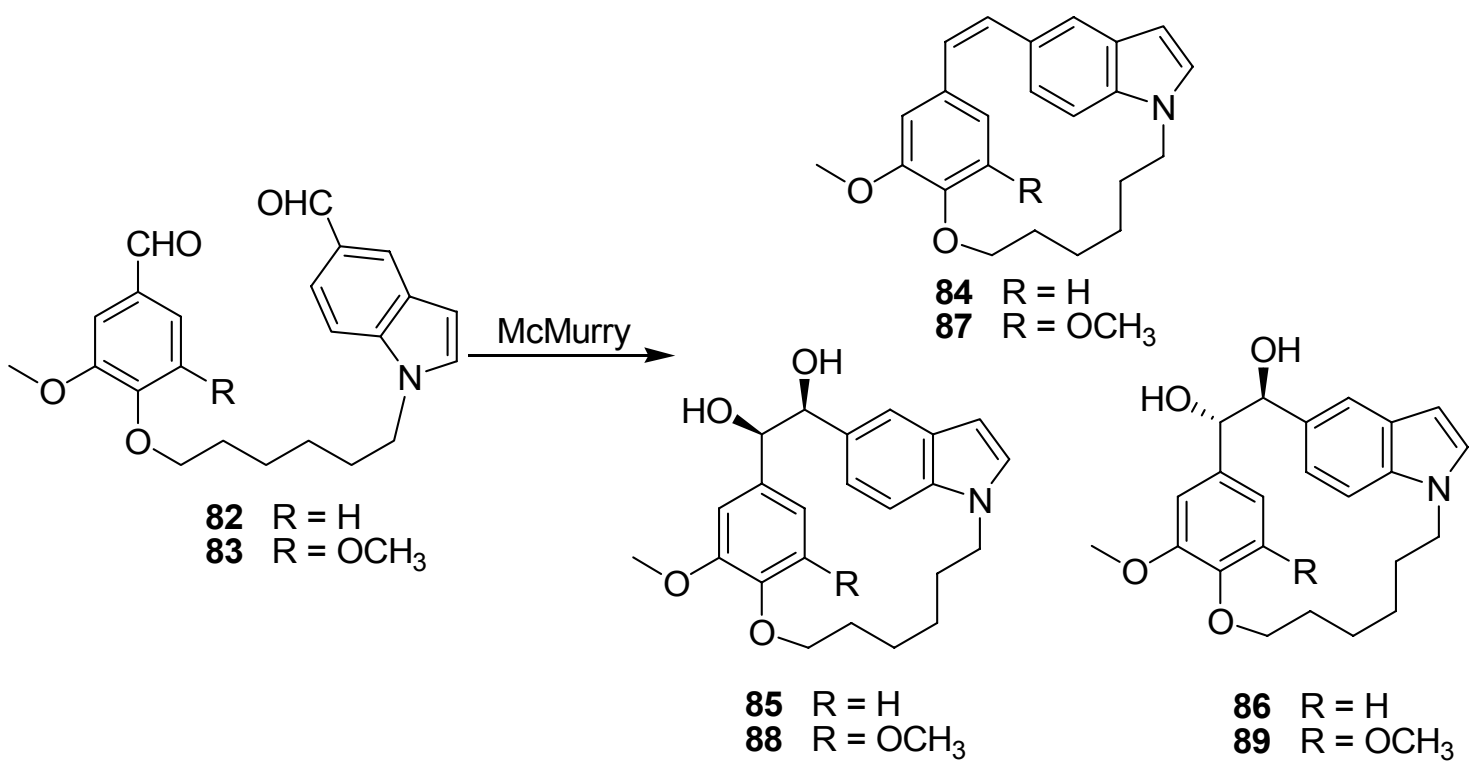

Figura 49. Compuestos obtenidos por el método de McMurry

Los resultados obtenidos se muestran en la siguiente tabla:

\begin{tabular}{|c|c|c|c|c|c|}
\hline $\begin{array}{c}\text { Material } \\
\text { de partida }\end{array}$ & $\begin{array}{c}\text { Concentración del } \\
\text { dialdehído }(\mathbf{m M})\end{array}$ & \% olefinas & \% diol cis & \%diol trans & $\begin{array}{c}\text { Rendimiento } \\
\text { total (\%) }\end{array}$ \\
\hline $\mathbf{8 2}$ & 15 & 10 & 21 & 27 & 58 \\
\hline $\mathbf{8 3}$ & 5 & 30 & 18 & 3 & 51 \\
\hline
\end{tabular}

Tabla 5. Rendimientos obtenidos en las reacciones de macrociclación (compuestos aislados mediante CC).

Una vez obtenidos los dioles cis y trans de ambas familias, se procedió a realizar las acetilaciones de los mismos. La introducción de un grupo atractor de electrones de mayor volumen puede modificar el carácter hidrofóbico, la solubilidad y la capacidad de establecer enlaces de hidrógeno sin afectar sustancialmente la disposición de los anillos. De esta manera, además de estudiar las modificaciones que estas variaciones suponen en la actividad antimitótica de los compuestos, el análisis espectroscópico de estos acetatos puede ayudar a la asignación de la estereoquímica de los dioles. Los rendimientos obtenidos en estas reacciones van desde el 32 al $73 \%$ y en sus espectros de RMN se observan las señales características de los grupos acetato (2,04-2,34 ppm en ${ }^{1} \mathrm{H}$ y 21,0-21,2 y $170,0-171,1 \mathrm{ppm}$ en ${ }^{13} \mathrm{C}$ ) como variación más apreciable. 

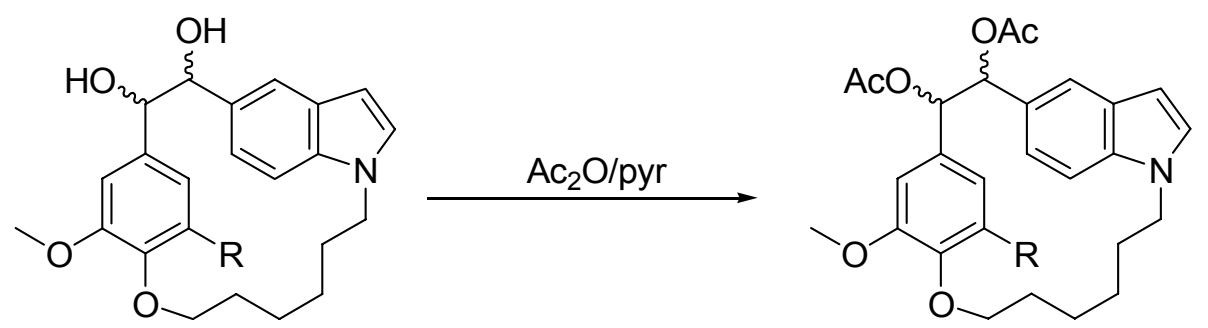

$\begin{array}{ll}85 & \mathrm{R}=\mathrm{H} \text {, cis } \\ 86 & \mathrm{R}=\mathrm{H} \text {, trans } \\ 88 & \mathrm{R}=\mathrm{OCH}_{3}, \text { cis } \\ 89 & \mathrm{R}=\mathrm{OCH}_{3} \text {, trans }\end{array}$

$90 \mathrm{R}=\mathrm{H}$, cis $\quad(73 \%)$

$91 \mathrm{R}=\mathrm{H}$, trans $(57 \%)$

$92 \mathrm{R}=\mathrm{OCH}_{3}$, cis $(32 \%)$

$93 \mathrm{R}=\mathrm{OCH}_{3}$, trans $(32 \%)$

Figura 50. Compuestos macrocíclicos acetilados obtenidos. 



\section{III.3. ANÁLISIS ESPECTROSCÓPICO DE LOS COMPUESTOS MACROCÍCLICOS.}

La determinación estructural de los compuestos se lleva a cabo mediante RMN ${ }^{1} \mathrm{H}$ $\mathrm{y}{ }^{13} \mathrm{C}$ y por difracción de Rayos X realizada sobre los cristales del compuesto 87 .

\section{III.3.A. Olefinas.}

Las olefinas sintetizadas presentan un juego único de señales, en el que los protones equivalentes presentan una señal común única.

Los protones olefínicos aparecen en ambos compuestos en el espectro de RMN ${ }^{1} \mathrm{H}$ con desplazamientos muy semejantes y presentan un valor de la constante de acoplamiento típico de doble enlace $c i s(J=10 \mathrm{~Hz})$.<smiles>[R]c1cc(/C=C\c2ccc3c(ccn3CCCCCP)c2)ccc1OC</smiles>

$84 \mathrm{R}=\mathrm{H}$

$87 \mathrm{R}=\mathrm{OCH}_{3}$

Tabla 6. Señales espectroscópicas características de las olefinas sintetizadas.

\begin{tabular}{|c|c|c|}
\hline $\mathbf{H}$ & $\mathbf{8 4}$ & $\mathbf{8 7}$ \\
\hline 2 & $6,92 d 10,2$ & $6,92 d 10,1$ \\
\hline 3 & $7,14 d 10,2$ & $7,16 d 10,1$ \\
\hline 5 & $6,38 d d 7,9 ; 1,8$ & $6,45 d d 8,2 ; 1,4$ \\
\hline 6 & $6,83 d 7,9$ & $6,87 d 8,2$ \\
\hline 21 & $6,44 s a$ & $6,05 s a$ \\
\hline 22 & $6,25 d d 8,1 ; 1,8$ & $6,05 s a$ \\
\hline 23 & $6,47 d 8,1$ & - \\
\hline 24 & $7,40 s$ & $7,40 s$ \\
\hline $\mathrm{OCH}_{3}-\mathrm{C}_{20}$ & $3,55 s$ & $3,45 s \mathrm{a}$ \\
\hline $\mathrm{OCH}_{3}-\mathrm{C}_{23}$ & - & $3,45 s \mathrm{a}$ \\
\hline
\end{tabular}


Como característica a destacar, en el caso del compuesto más sustituído (87), las señales del anillo simétrico tetrasustituído aparecen ensanchadas, indicando que se ha producido una alteración de la movilidad (intercambio conformacional) del sistema macrocíclico.

La olefina 87 es cristalina, por lo que su conformación en estado sólido ha sido determinada mediante difracción de rayos $\mathrm{X}$.

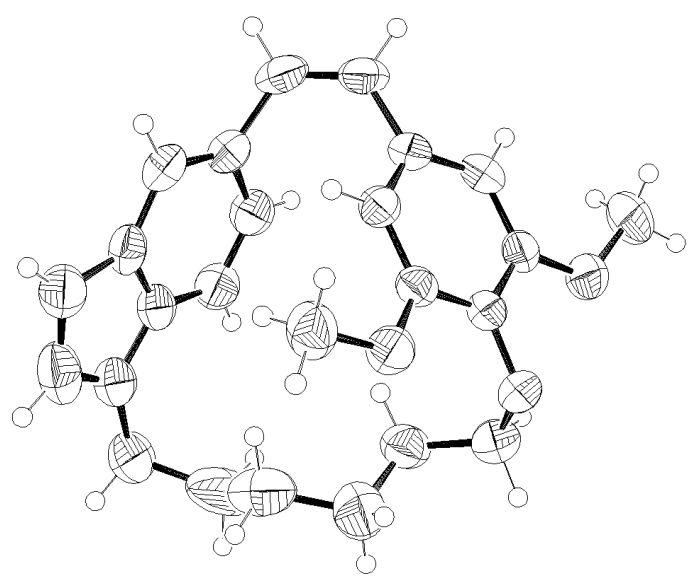

Figura 51. Estructura obtenida por difracción de Rayos X de la olefina 87.

\section{III.3.B. Dioles y acetatos.}

A partir del análisis espectroscópico de dioles sintetizados previamente en nuestro grupo de trabajo, ${ }^{44,48}$ se han determinado las diferencias existentes entre los isómeros cis y trans (tabla 7). Una diferencia fundamental es la constante de acoplamiento $(J)$ entre los dos metinos del puente, menor de $5,5 \mathrm{~Hz}$ para los compuestos con estereoquímica cis y mayor de 6,5 Hz para los que tienen estereoquímica trans. Además de las diferencias en la constante de acoplamiento, los glicoles con estereoquímica cis presentan un desplazamiento promedio de los dos protones del puente mayor de 4,70 ppm en $\mathrm{RMN}{ }^{1} \mathrm{H}$ y desplazamientos por debajo de 77,5 ppm en $\mathrm{RMN}{ }^{13} \mathrm{C}$ para los carbonos oxigenados del puente. Por el contrario, los glicoles con estereoquímica trans presentan un desplazamiento promedio de los protones del puente inferior a 4,70 ppm en $\mathrm{RMN}{ }^{1} \mathrm{H}$ y desplazamientos superiores a 79,5 ppm en $\mathrm{RMN}{ }^{13} \mathrm{C}$ para los carbonos oxigenados del puente. 


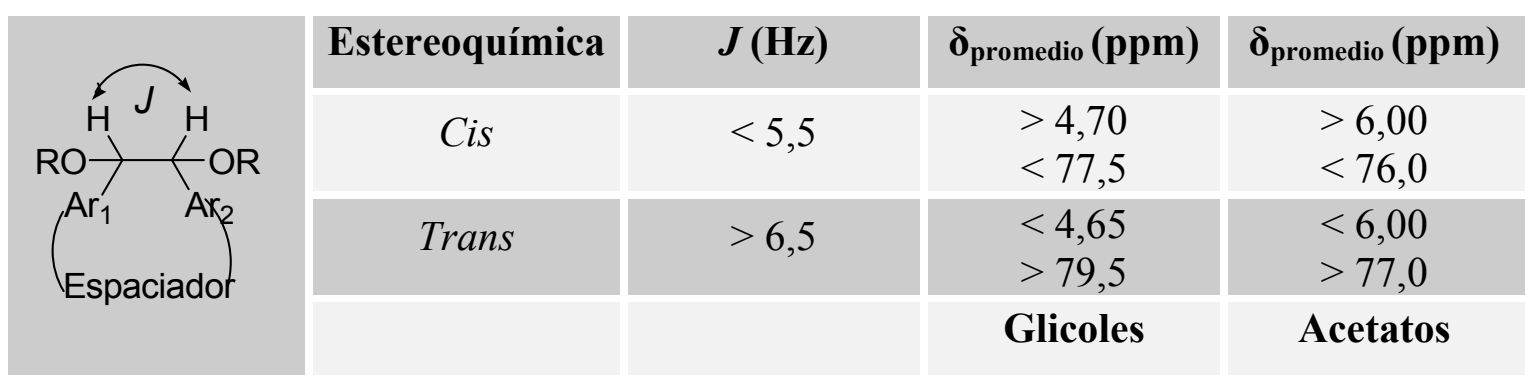

Tabla 7. Diferencias espectroscópicas entre los isómeros cis y trans de glicoles y diacetatos macrocíclicos.

Mediante tratamiento con anhídrido acético se obtienen, en todos los casos, los acetatos con las propiedades espectroscópicas características del grupo estereoquímico al que pertenece el glicol de partida. Las únicas diferencias apreciables son las debidas al desplazamiento producido por la presencia del grupo acetato, lo que indica que el cambio no tiene grandes efectos ni en la estructura ni en la dinámica de los compuestos y que la información obtenida en los glicoles puede trasladarse a los acetatos y viceversa.

Los datos espectroscópicos empleados para establecer la estereoquímica relativa de los dioles y acetatos obtenidos en este trabajo se muestran en la tabla 8. Los compuestos en los que aparecen datos duplicados se corresponden con aquellos en los que en los espectros de RMN se observan dos juegos de señales pertenecientes a dos conformaciones diferentes. 


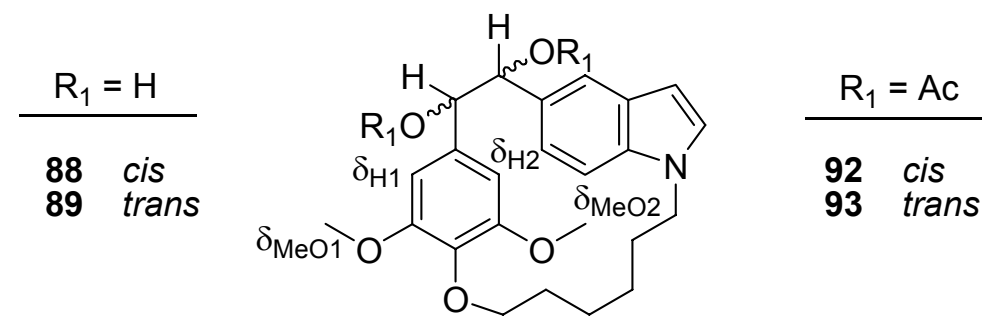

\begin{tabular}{|c|c|c|c|c|c|c|c|c|c|}
\hline \multirow{2}{*}{ Compuesto } & \multirow{2}{*}{$\begin{array}{c}\mathbf{J} \\
(\mathbf{H z})\end{array}$} & \multicolumn{3}{|c|}{$\delta^{1} \mathbf{H}(p p m)$} & \multicolumn{3}{|c|}{$\delta^{13} \mathrm{C}(\mathrm{ppm})$} & \multirow{2}{*}{ cis } & \multirow{2}{*}{ trans } \\
\hline & & $\mathrm{H}_{1}$ & $\mathrm{H}_{2}$ & Prom. & $\mathrm{C}_{1}$ & $\mathrm{C}_{2}$ & Prom. & & \\
\hline 85 & -- & $\begin{array}{l}5,25 \\
5,36\end{array}$ & $\begin{array}{l}4,91 \\
4,82\end{array}$ & $\begin{array}{l}5,08 \\
5,09\end{array}$ & -- & -- & -- & $\mathrm{X}$ & \\
\hline 86 & 7,8 & 4,73 & 4,66 & 4,70 & -- & -- & -- & & $X$ \\
\hline 88 & $\begin{array}{l}3,8 \\
3,8\end{array}$ & $\begin{array}{l}5,17 \\
5,32\end{array}$ & $\begin{array}{l}4,87 \\
4,76\end{array}$ & $\begin{array}{l}5,02 \\
5,04\end{array}$ & $\begin{array}{l}74,7 \\
75,3\end{array}$ & $\begin{array}{l}77,7 \\
77,7\end{array}$ & $\begin{array}{l}76,2 \\
76,5\end{array}$ & $\mathrm{X}$ & \\
\hline 89 & 8,1 & 4,64 & 4,71 & 4,69 & 82,6 & 82,0 & 82,3 & & $X$ \\
\hline 90 & $\begin{array}{l}4,5 \\
4,5\end{array}$ & $\begin{array}{l}5,99 \\
5,99\end{array}$ & $\begin{array}{l}6,60 \\
6,60\end{array}$ & $\begin{array}{l}6,30 \\
6,30\end{array}$ & $\begin{array}{l}73,7 \\
74,5\end{array}$ & $\begin{array}{l}77,4 \\
77,0\end{array}$ & $\begin{array}{l}75,6 \\
75,8\end{array}$ & $\mathrm{X}$ & \\
\hline 91 & $\begin{array}{l}7,9 \\
8,0\end{array}$ & $\begin{array}{l}6,08 \\
5,99\end{array}$ & $\begin{array}{l}6,27 \\
6,07\end{array}$ & $\begin{array}{l}6,18 \\
6,03\end{array}$ & $\begin{array}{l}79,5 \\
79,5\end{array}$ & $\begin{array}{l}79,2 \\
78,7\end{array}$ & $\begin{array}{l}79,4 \\
79,1\end{array}$ & & $X$ \\
\hline 92 & -- & $\begin{array}{l}6,40 \\
6,40\end{array}$ & $\begin{array}{l}6,00 \\
5,90\end{array}$ & $\begin{array}{l}6,20 \\
6,15\end{array}$ & -- & -- & -- & $\mathrm{X}$ & \\
\hline 93 & 8,8 & 5,93 & 6,02 & 5,98 & 79,5 & 79,1 & 79,3 & & $\mathrm{X}$ \\
\hline
\end{tabular}

Tabla 8. Datos de RMN que permiten el establecimiento de la estereoquímica relativa.

En general, los datos obtenidos coinciden con lo establecido en los trabajos anteriores. ${ }^{44,48}$ De esta manera, se observa que:

- La constante de acoplamiento entre los hidrógenos del puente permite diferenciar los compuestos con estereoquímica relativa trans $(J>7,5 \mathrm{~Hz})$ de los $\operatorname{cis}(J<5,0 \mathrm{~Hz})$.

- El desplazamiento químico promedio de los protones del puente para los derivados con estereoquímica cis es mayor de 5,00 ppm para los glicoles y de 6,20 ppm para los acetatos. En el caso de los derivados trans no se cumple exactamente lo visto anteriormente $(<4,65 \mathrm{ppm}$ en glicoles $\mathrm{y}<6,00 \mathrm{ppm}$ en acetatos); no obstante, el desplazamiento promedio es menor de 4,70 ppm en los dioles y menor de 6,2 ppm en los acetatos, por lo que la diferencia con los isómeros cis es apreciable. 
- El desplazamiento químico promedio de los metinos oxigenados (para los compuestos de los que se tienen los datos de $\mathrm{RMN}{ }^{13} \mathrm{C}$ ) coincide con lo establecido previamente. En los glicoles es menor de 77,5 ppm para los compuestos con estereoquímica cis y mayor de 79,5 ppm para los de estereoquímica trans y en los acetatos es menor de 76,0 ppm y mayor de 77,0 ppm respectivamente.

Adicionalmente, en los compuestos con un anillo aromático simétrico derivado de siringaldehído (tabla 9), se había observado que las diferencias de desplazamiento químico entre los hidrógenos de los dos grupos metoxilo eran menores a 0,20 ppm para los compuestos con estereoquímica cis y mayores a 0,20 ppm en el caso de los derivados trans. Igualmente se había observado que la diferencia de desplazamiento químico entre los dos hidrógenos del anillo aromático era menor de 0,70 ppm en los derivados cis, mientras que para los derivados trans era, en todos los casos, mayor de $0,75 \mathrm{ppm}$.
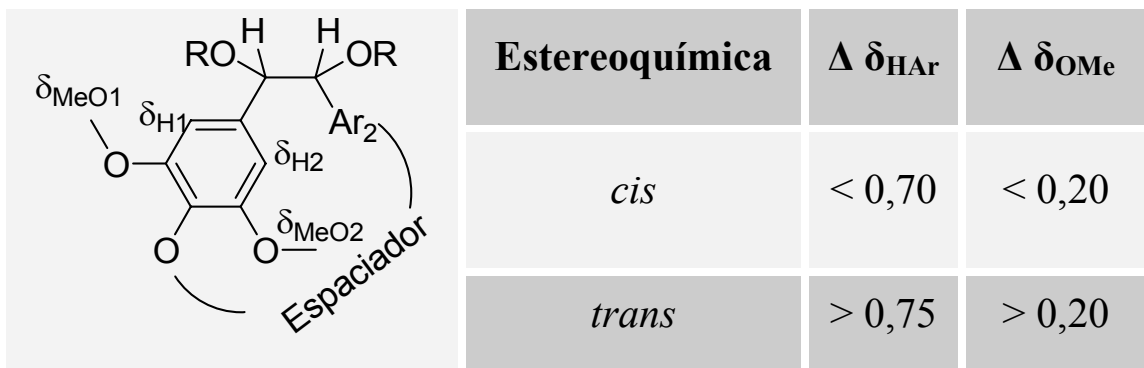

Tabla 9. Diferencias en el desplazamiento químico de protones químicamente equivalentes observadas en compuestos macrocíclicos obtenidos con anterioridad.

Sin embargo, en los compuestos sintetizados en este trabajo, se observa que las diferencias entre los protones químicamente equivalentes de los compuestos que combinan un anillo indólico con un anillo derivado de siringaldehído son siempre mayores a 0,70 ppm (tabla 10), no apreciándose diferencia entre las configuraciones cis y trans. Esto puede ser debido a una mayor restricción en los intercambios conformacionales, producida por la mayor rigidez que aporta el anillo indólico al sistema. 


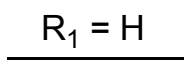

88 cis

89 trans

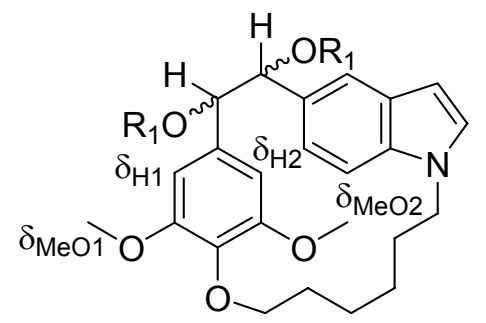

\begin{tabular}{c|c|c|c|c|c|c|c|} 
Compuesto & Estereoquímica & $\delta_{\mathrm{OMe} 1}$ & $\delta_{\mathrm{OMe} 2}$ & $\Delta \delta_{\mathrm{OMe}}$ & $\delta_{\mathrm{H} 1}$ & $\delta_{\mathrm{H} 2}$ & $\Delta \delta_{\mathrm{HAr}}$ \\
\hline \multirow{2}{*}{$\mathbf{8 8}$} & cis & 3,81 & 3,00 & 0,81 & 6,23 & 5,89 & 0,34 \\
\hline $\mathbf{8 9}$ & trans & 3,86 & 3,00 & 0,86 & 6,77 & 5,32 & 1,45 \\
\hline $\mathbf{9 2}$ & cis & 3,84 & 2,97 & 0,89 & 6,66 & 5,37 & 1,29 \\
\hline $\mathbf{9 3}$ & trans & 3,89 & 3,00 & 0,84 & 6,60 & 5,70 & 0,90 \\
\hline
\end{tabular}

Tabla 10. Diferencias en el desplazamiento químico de protones químicamente equivalentes. 


\section{III.4. ANÁLISIS CONFORMACIONAL DE LOS COMPUESTOS MACROCÍCLICOS.}

Como se ha indicado en el planteamiento, los compuestos macrocíclicos indólicos sintetizados en este trabajo son la última etapa de una serie de trabajos encaminados a estudiar la posibilidad de bloquear la disposición cisoide de los anillos aromáticos de las combretastatinas, que se considera la más adecuada para su actividad. ${ }^{44,45,48}$

Durante las distintas etapas de este proceso se ha observado que la macrociclación conduce a restricciones en la movilidad de los compuestos, que se traducen en notables diferencias en sus espectros de RMN. Con el fin de racionalizar estas diferencias, los compuestos han sido agrupados en función del patrón de sustitución en el puente de dos carbonos que une los anillos aromáticos en: olefinas, dioles cis y dioles trans. En cada apartado, se abordará:

1) El análisis de las posibles conformaciones que "a priori" pueden adoptar los macrociclos y las formas de pasar de unas a otras.

2) El estudio de las conformaciones energéticamente más accesibles según la mecánica molecular y las formas de interconversión de las mismas sugeridas por estudios de dinámica molecular.

3) La justificación de la apariencia de los espectros de RMN. 
Los primeros compuestos macrocíclicos sintetizados por nuestro grupo de investigación se ajustaban estrictamente a las relaciones estructura actividad descritas para las combretastatinas. Estos compuestos presentaban una unión para-para de los anillos aromáticos y dos anillos aromáticos simétricos, uno disustituido y uno tetrasustituido. ${ }^{4 a}$ La segunda generación consistió en compuestos con un anillo simétricamente y otro asimétricamente sustituidos. ${ }^{44 \mathrm{~b}}$ La tercera y última generación, en la que se incluyen los compuestos sintetizados en este trabajo, implica la sustitución del anillo asimétricamente sustituido por un anillo de indol. Se esperaba que esta sustitución, motivada por la interesente actividad inhibidora de la polimerización de tubulina y citotóxica mostrada por análogos de combretastatinas que incorporaban un resto de $N$-metil-5-indolilo en lugar del resto de 3-hidroxi-4-metoxifenilo de la combretastatina A-4, ${ }^{52}$ aumentara notablemente la rigidez del sistema y contribuyera a establecer la importancia de los distintos procesos en la apariencia de los espectros.

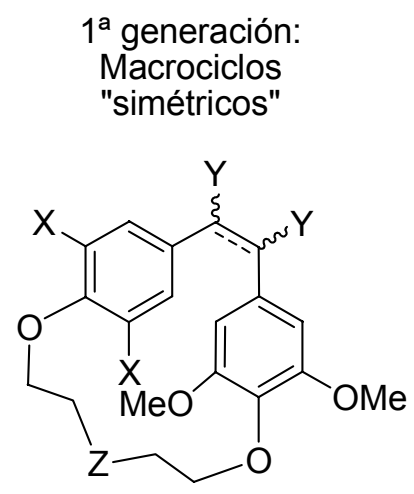

Puente glicólico $\mathrm{Y}=\mathrm{OH}$

OA $X=O M e, \quad Z=O$

Puente olefínico $\mathrm{Y}=\mathrm{H}$

OB $\mathrm{X}=\mathrm{H}, \quad \mathrm{Z}=\mathrm{O}$

OC $X=H, \quad Z=\left(\mathrm{CH}_{2}\right)_{2}$ $2^{a}$ generación:

Macrociclos

"asimétricos"<smiles>[Z]CCOc1ccc(C([Y])=C([Y])c2cc([R])c(OCC[Z])c(OC)c2)cc1[X]</smiles>

Puente olefínico $\mathrm{Y}=\mathrm{H}$

OD $\mathrm{R}=\mathrm{OMe}, \quad \mathrm{X}=\mathrm{OH}, \quad \mathrm{Z}=\left(\mathrm{CH}_{2}\right)_{2}$

OE $\mathrm{R}=\mathrm{H}, \quad \mathrm{X}=\mathrm{H}, \quad \mathrm{Z}=\mathrm{O}$

OF $\mathrm{R}=\mathrm{H}, \quad \mathrm{X}=\mathrm{H}, \quad \mathrm{Z}=\left(\mathrm{CH}_{2}\right)_{2}$

\section{$3^{\mathrm{a}}$ generación: \\ Macrociclos indólicos}<smiles>[Y]C([Y])=C(c1cc([R])c(OCCCCCCN2C=Cc3cccc2c3)c(OC)c1)c1ccc2cccn2c1</smiles>

Puente olefínico $\mathrm{Y}=\mathrm{H}$

$84 \mathrm{R}=\mathrm{H}$

$87 \mathrm{R}=\mathrm{OMe}$

Puente glicólico $\mathrm{Y}=\mathrm{OH}$

$85,86 \mathrm{R}=\mathrm{H}$

$88,89 \mathrm{R}=\mathrm{OMe}$

Figura 51. Estructura genérica de las distintas generaciones de compuestos macrocíclicos, con unión parapara de los anillos aromáticos, sintetizados en el grupo de trabajo y ejemplos representativos de cada uno de ellos. Los compuestos obtenidos en trabajos anteriores se han numerado de $\mathbf{0 A}$ a $\mathbf{0 F}$.

\footnotetext{
52 a) Mateo, C. Trabajo de Grado, Universidad de Salamanca, 2002. b) Maya, A. B.; Pérez-Melero, C.; Mateo, C.; Alonso, D.; Fernández, J. L.; Gajate, C.; Mollinedo, F.; Peláez, R.; Caballero, E.; Medarde, M. Further Naphthylcombretastatins. An Investigation on the Role of the Naphthalene Moiety J. Med. Chem. 2005, 48, 556-568.
} 


\section{III.4.A. Olefinas.}

\section{III.4.A.1. Análisis de conformaciones.}

Las olefinas macrocíclicas simétricas (0B-C) muestran espectros de RMN sencillos en los que sólo se observa un juego de señales y no existen diferencias entre las posiciones químicamente equivalentes en los espectros de $\mathrm{RMN}{ }^{1} \mathrm{H}$ y ${ }^{13} \mathrm{C} .{ }^{48}$ La naturaleza simétrica de los dos anillos aromáticos permite que un simple cambio en la helicidad, que puede ocurrir fácilmente sin que ninguno de los anillos aromáticos atraviese el plano del doble enlace (ver figura 52), promedie los entornos magnéticos en los que se encuentran los núcleos químicamente equivalentes.

Los compuestos con al menos un anillo aromático no simétrico (0D-F) también presentaban espectros con un único juego de señales y en la mayoría de los casos los núcleos químicamente equivalente resonaban como una única señal. En este caso, la mera interconversión de hélices no permitía explicar la simplicidad de los espectros, por lo que se procedió a analizar con más detalle las conformaciones accesibles a los compuestos y las posibles vías de transición entre ellas.

El cambio de la disposición helicoidal del esqueleto estilbénico debe ser tenido en cuenta para analizar los correspondientes equilibrios conformacionales (Figura 52). Ambas hélices (- en la parte superior y + en la parte inferior) pueden interconvertirse mediante la rotación de un anillo, que conlleva el giro flip del otro anillo (Figura 52, parte izquierda) o el doble flip de los anillos (Figura 52, parte derecha). Un giro flip se produce cuando el plano del anillo, al girar, atraviesa la perpendicular al plano del doble enlace. En cambio, se denomina rotación del anillo cuando el anillo atraviesa el plano del doble enlace al girar. $^{53}$

\footnotetext{
${ }^{53}$ a) Biali, S. E.; Rappoport, Z. Stable simple enols. 3. Static and dynamic NMR behavior of crowded triarylethenols and related compounds. Three-ring flip as the threshold mechanism for enantiomerization of crowded triarylvinyl propellers. J. Am. Chem. Soc. 1984, 106, 477-496. b) Rappoport, Z.; Biali, S. E. Threshold Rotational Mechanisms and Enantiomerization Barriers of Polyarylvinyl Propellers Acc. Chem. Res. 1997, 30, 307-314. c) Gur, E.; Kaftory, M.; Biali, S. E.; Rappoport, Z. Conformations and Threshold Rotational Mechanisms of the (Z)-1,2-Diarylethene Moiety: A Structural Correlation Study. J. Org. Chem. 1999, 64, 8144-8148. d) Gust, D.; Mislow, W.; Analysis of Isomerization in Compounds Displaying Restricted Rotation of Aryl Groups. J. Am. Chem. Soc. 1973, 95, 1535-1547.
} 
Cuando se produce una rotación del anillo $\mathrm{D}$, la orientación de la posición marcada $(\bullet)$ de dicho anillo cambia de arriba abajo, mientras que la posición marcada $\left(\bullet^{\bullet}\right.$ del anillo I permanece en la parte superior. Cuando tiene lugar un doble flip, ambas posiciones marcadas $\left({ }^{\bullet}\right)$ permanecen en la parte superior del plano después del cambio de helicidad. La rotación simultánea de ambos anillos (giros cero flip), que conlleva el cambio de la orientación de las posiciones marcadas en los dos anillos, requeriría una disposición coplanar improbable de los dos anillos.

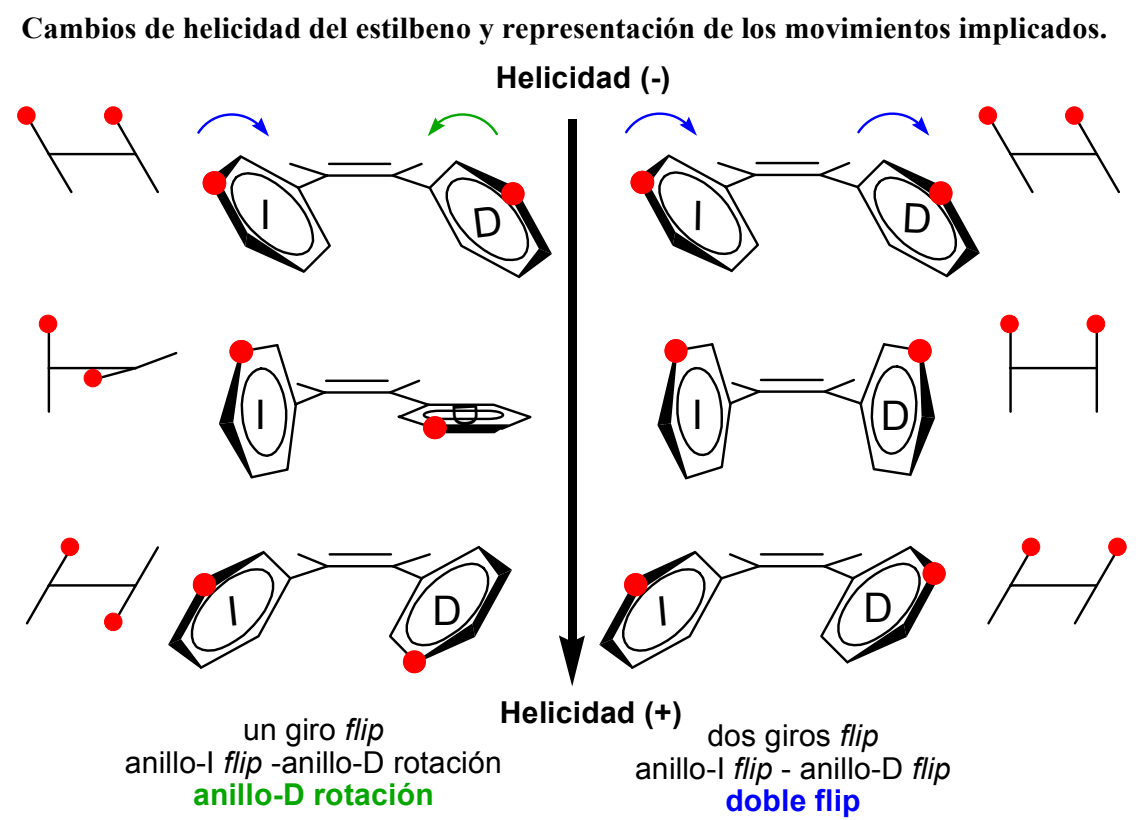

Figura 52. Se muestra el paso de helicidad negativa en la parte superior a helicidad positiva en la parte inferior, mediante rotación de un anillo (y flip del otro anillo) en la columna de la izquierda y el doble flip de los anillos en la derecha. Se incluye una representación esquemática en la que el plano del doble enlace se corresponde con la línea horizontal y los anillos aromáticos con las líneas verticales y oblicuas. Las posiciones marcadas (puntos rojos) facilitan la visualización de su localización por encima o debajo del plano del doble enlace. Anillo I: anillo representado a la izquierda; Anillo D: anillo representado a la derecha.

Del mismo modo, en los estilbenos macrocíclicos se producen cambios de helicidad por el paso de un anillo a través del espacio intra-anular (rotación de dicho anillo, flip del otro anillo) o por movimientos de doble flip (en los que ningún anillo pasa a través de ese espacio). 
La combinación de dos disposiciones helicoidales (positiva y negativa) con dos situaciones distintas (por encima y por debajo del plano del doble enlace) para cada posición marcada $(\bullet)$ de cada anillo da lugar a $2 * 2 * 2=8$ posibilidades conformacionales, a considerar en el análisi conformascional de las olefinas macrocíclicas, como se representa en las figuras 53 a 58. Cuatro de las ocho posibilidades son imágenes especulares de las otras cuatro, se diferencian solamente en su disposición helicoidal, y son indistinguibles mediante RMN. Por ello, se han numerado las ocho conformaciones de I a IV precedidas por su disposición helicoidal (+ o -), con el fin de simplificar la identificación de los pares de imágenes especulares. Además, I y III son indistinguibles, al igual que II y IV, cuando el anillo D es simétrico, aunque las posiciones marcadas (•) están situadas en diferente lugar en cada caso.

La interconversión conformacional entre estas 8 posibilidades se puede producir por uno de estos procesos:

a) rotación del anillo I (acompañado por el giro flip del anillo D).

b) rotación del anillo D (acompañado por el giro flip del anillo I).

c) doble flip (giro flip de los dos anillos).

En la figura siguiente, la rotación del anillo I (anillo $\mathrm{T}$, tri-sustituido) está representada en sentido horizontal; la rotación del anillo $\mathbb{D}$ (anillo $\mathrm{D}$, di-sustituido) está representada en sentido vertical y el doble flip está representado por las líneas oblicuas. Esta representación se mantendrá en las figuras de los equilibrios conformacionales, para cada uno de los compuestos analizados. 


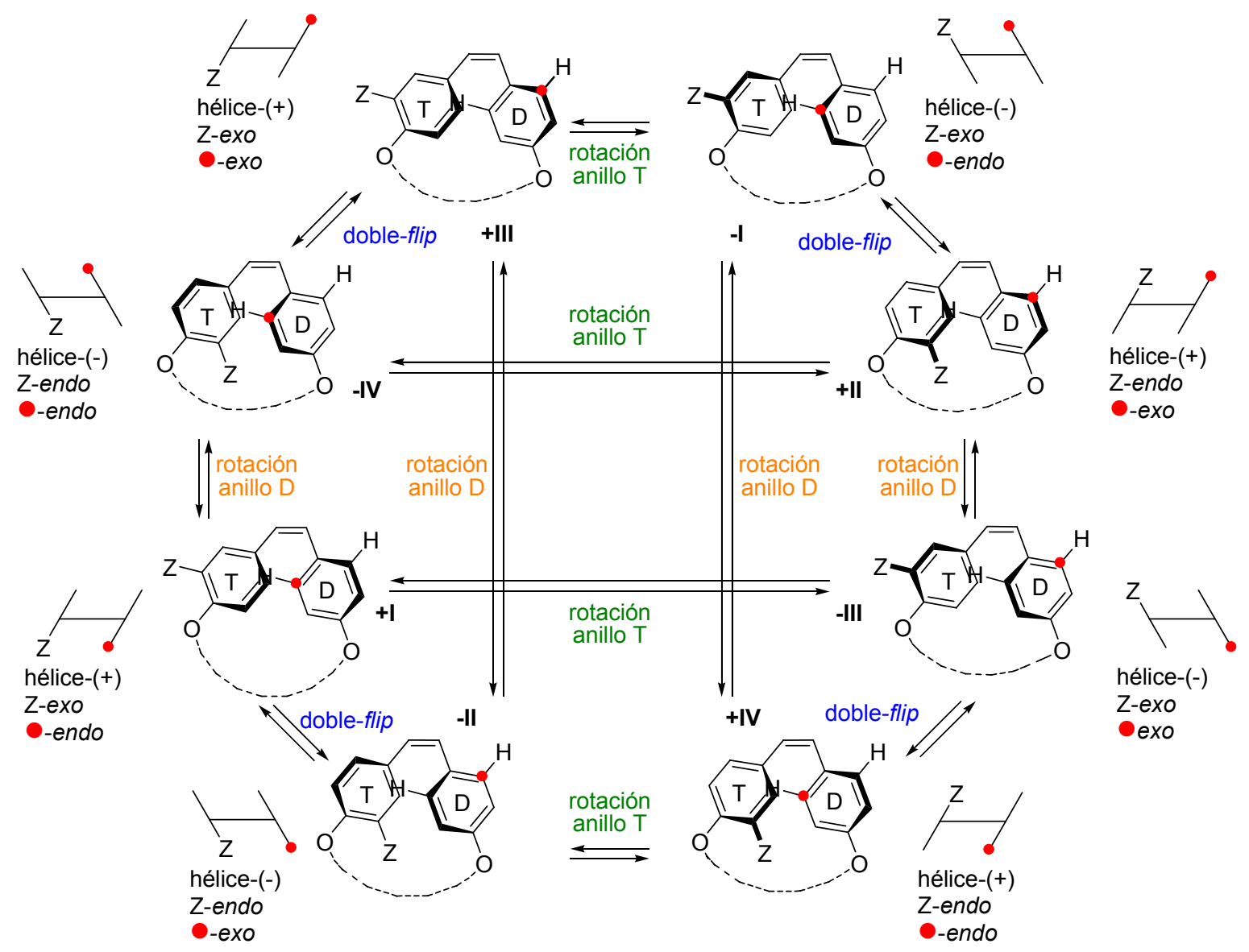

Figura 53. Equilibrio conformacional general de las olefinas con dos anillos fenilo. Se representa la rotación del anillo-T en sentido horizontal, la rotación del anillo-D en sentido vertical y el doble flip en sentido oblicuo. Anillos D y T: anillos Di-sustituidos y Tri-sustituidos.

Los espectros de RMN, de cada olefina macrocíclica obtenida, muestran un solo juego de señales, en todos los casos. Este hecho implica una interconversión rápida (en la escala de tiempo de la RMN) entre conformaciones (I-IV) que originen espectros diferentes. Además, en compuestos con un anillo simétrico los protones químicamente equivalentes dan lugar a señales únicas con un desplazamiento químico promedio. Esto requiere un intercambio rápido entre conformaciones que se diferencian sólo en el entorno magnético en el que se encuentran los núcleos magnéticamente equivalentes (como por ejemplo $\pm \mathrm{I}$ y $\pm \mathrm{II}$ ), por interconversión de las dos disposiciones helicoidales. Este hecho es interesante, ya que su análisis habría sido más complicado en sistemas con dos anillos no simétricos, puesto que en ellos el cambio de helicidad conduce a conformaciones que difieren en más elementos. 


\section{III.4.A.1.a. Olefinas macrocíclicas con dos restos fenilo. Equilibrio conformacional.}

El análisis conformacional previo de los macrociclos con dos restos fenilo (uno simétrico y otro asimétrico, 0D-F) facilitará el estudio de los macrociclos indólicos sintetizados en este trabajo, los cuales, debido a la presencia de un sistema bicíclico, presentan restricciones adicionales. De este modo, primero se analizará la relativa facilidad de estas interconversiones en el sistema con un anillo simétrico disustituido (0F, figura 54). Después, se considerará el efecto de un aumento en el grado de la dificultad para la rotación del anillo causada por:

a) La disminución del tamaño del macrociclo al pasar de hexametileno a 3oxapentametileno (0E, figura 55).

b) Un aumento del tamaño de los sustituyentes de los anillo simétricos al pasar de $\mathrm{H}$ a grupos $\mathrm{OMe}(\mathbf{0 D}$, figura 56).

Finalmente, se analizarán los compuestos sintetizados en este trabajo de tesis doctoral en los que el anillo trisustituido pasa a ser un anillo más rígido (resto indólico) y se combina con un anillo tetrasustituido (simétrico) (87, figura 57) o con un anillo trisustituído (situación en la que ninguno de los anillos es simétrico) (84, figura 58).

Independientemente de la naturaleza de los anillos aromáticos, si los tres tipos de movimientos de los anillos ocurren rápidamente en la escala de tiempo de la RMN, un promedio en el desplazamiento químico de las señales para las ocho conformaciones relevantes $( \pm \mathrm{I}- \pm \mathrm{IV})$ y los protones químicamente equivalentes (en los casos con anillos simétricos) explican los espectros de RMN sencillos que se obtienen.

Si tan sólo uno de los movimientos fuese rápido en la escala de tiempo de la RMN, deberían observarse dos juegos completos de señales espectroscópicas o dos señales diferentes para los pares químicamente equivalentes (tabla 11 y figura 53). 


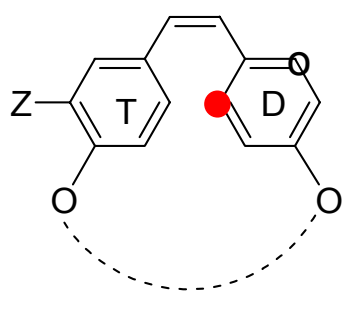

\begin{tabular}{|c|c|c|}
\hline $\begin{array}{c}\text { Rotación anillo-T } \\
\text { rápida. } \\
\text { Rotación anillo D y } \\
\text { Doble flip lentos }\end{array}$ & $\begin{array}{l}\text { Rotación anillo-D } \\
\text { rápida. } \\
\text { Rotación anillo-T y } \\
\text { Doble flip lentos }\end{array}$ & $\begin{array}{c}\text { Doble-flip rápido. } \\
\text { Rotación anillo-T y } \\
\text { Rotación anillo-D } \\
\text { lentos }\end{array}$ \\
\hline$( \pm) I \rightleftharpoons(\mp)$ III & $( \pm) \mathbf{I} \rightleftharpoons(\mp)$ IV & $( \pm) \mathbf{I} \rightleftharpoons(\mp)$ II \\
\hline $\begin{array}{ll}\text { Z-exo } & \text { Z-exo } \\
\text { O-endo } & \text { •exo } \\
\text { O-exo } & \text { O-endo }\end{array}$ & $\begin{array}{ll}\text { Z-exo } & \text { Z-endo } \\
\text { •-endo } & \text { ๑-endo } \\
\text { O-exo } & \text { O-exo }\end{array}$ & $\begin{array}{ll}\text { Z-exo } & \text { Z-endo } \\
\text {-endo } & \text { Oexo } \\
\text { O-exo } & \text { O-endo }\end{array}$ \\
\hline $\begin{array}{c}\text { yO promediadas } \\
\text { Z-exo }\end{array}$ & $\begin{array}{l}\text {-endo } \neq \text { O-exo } \\
\text { Z-promediado }\end{array}$ & $\begin{array}{l}\text { y O promediadas } \\
\text { Z- promediado }\end{array}$ \\
\hline$=(\mp) \mathbf{I V}$ & $( \pm)$ II $\rightleftharpoons(\mp)$ III & $( \pm) \mathbf{I I I} \rightleftharpoons(\mp)$ IV \\
\hline $\begin{array}{l}\text { Z-endo } \\
\text { O-exo } \\
\text { O-endo }\end{array}$ & $\begin{array}{ll}\text { Z-endo } & \text { Z-exo } \\
\text {-exo } & \text { O-exo } \\
\text { O-endo } & \text { O-endo }\end{array}$ & $\begin{array}{ll}\text { Z-exo } & \text { Z-endo } \\
\text {-exo } & \text {-endo } \\
\text { O-endo } & \text { O-exo }\end{array}$ \\
\hline $\begin{array}{c}\text { yO promediadas } \\
\mathrm{Z} \text { - endo }\end{array}$ & $\begin{array}{l}\text {-exo } \neq \text { O-endo } \\
\text { Z-promediado }\end{array}$ & $\begin{array}{c}\text { y O promediadas } \\
\text { Z-promediado }\end{array}$ \\
\hline Z-exo $\neq$ Z-endo & $\begin{array}{l}\text {-endo } \neq \text { ९-exo } \\
\text { O-exo } \neq \text { O-endo }\end{array}$ & $\begin{array}{c}\text { /O mismo lado que } Z \\
\neq \\
\text { /O distinto lado que } Z\end{array}$ \\
\hline $\begin{array}{c}\text { Dos juegos de señales } \\
\text { completos }\end{array}$ & $\begin{array}{c}\text { Señales diferentes en } \\
\text { el anillo D }\end{array}$ & $\begin{array}{c}\text { Señales diferentes en } \\
\text { el anillo D }\end{array}$ \\
\hline
\end{tabular}

Tabla 11. Equilibrios independientes resultantes si los movimientos (figura 53) indicados en cada columna son los únicos rápidos en la escala de tiempo de RMN. La disposición endo o exo del sustituyente $\mathrm{Z}$ del anillo trisustituido y de las posiciones químicamente equivalentes etiquetadas $(\bullet$ y $\mathrm{O})$, se indican debajo del número de la conformación (I-IV). En la fila inferior se indican las posiciones que no se promedian en cada caso, por corresponder a movimientos lentos entre conformaciones. Finalmente, en la última fila se indica el resultado que debería observarse en cuanto a la diferencia de las señales de RMN en cada uno de los supuestos. 
Si dos de los tres movimientos son rápidos en la escala de tiempo de la RMN (tabla 12), es posible explicar los datos observados experimentalmente (un solo juego de señales y átomos químicamente equivalentes como señal única) para determinados compuestos, debido a que las cuatro conformaciones representativas de todos los tipo (+I, -II, +III y -IV $\mathrm{y}-\mathrm{I},+\mathrm{II},-\mathrm{III}$ y $+\mathrm{IV})$ se interconvierten rápidamente.

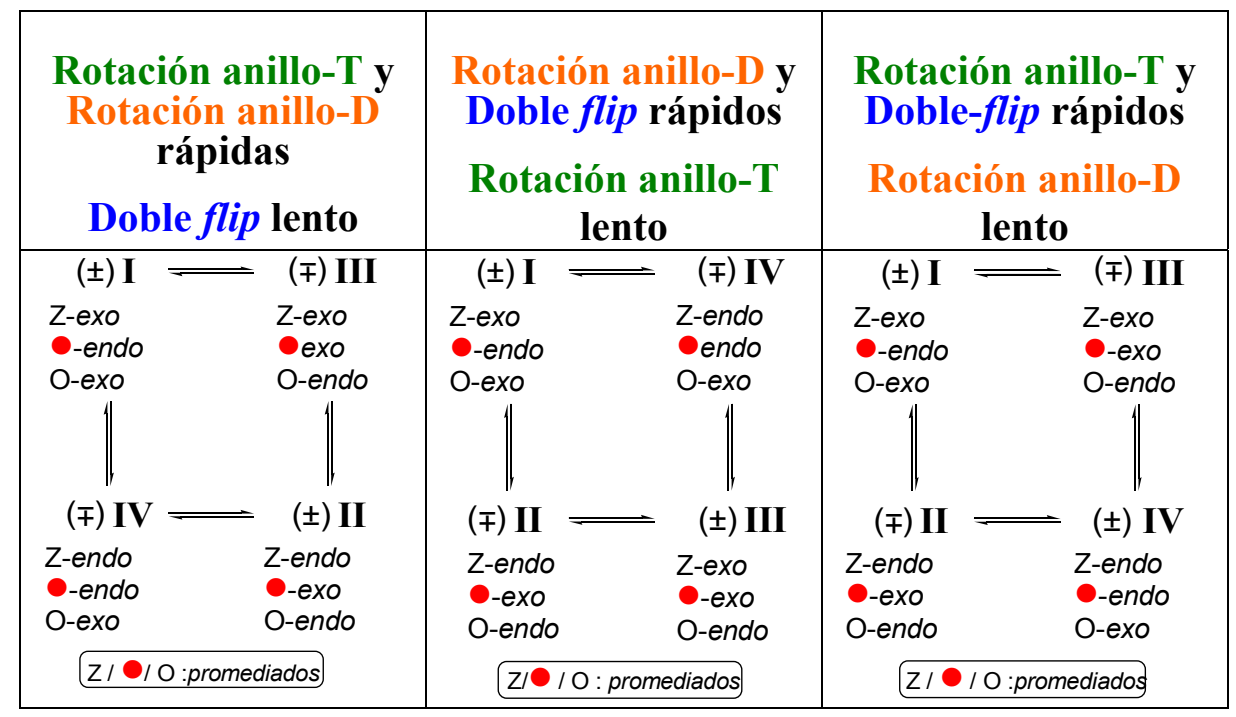

Tabla 12. Equilibrios independientes resultantes si los movimientos rápidos (figura 53) en la escala de tiempo RMN son los indicados en la fila superior. Las flechas de equilibrio horizontales indican las conversiones producidas por el primer movimiento rápido y las verticales indican las conversiones producidas por el segundo movimiento rápido. 
III.4.A.1.b. Olefinas macrocíclicas con un resto fenilo simétrico y otro asimétrico. Análisis conformacional de 0D, 0E y $\mathbf{0 F}$.

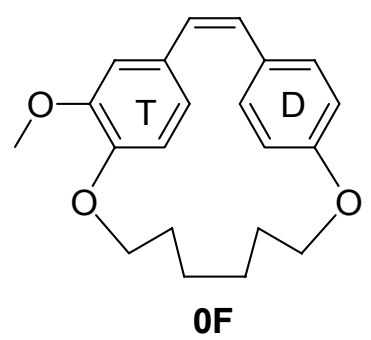

El equilibrio conformacional para el compuesto $\mathbf{0 F}$ se muestra en la figura 54. La mitad superior es idéntica a la inferior (-I=-III; +II=+IV; +I=+III; -II=-IV) y las conformaciones de la izquierda son imágenes especulares de las que se encuentran a la derecha.

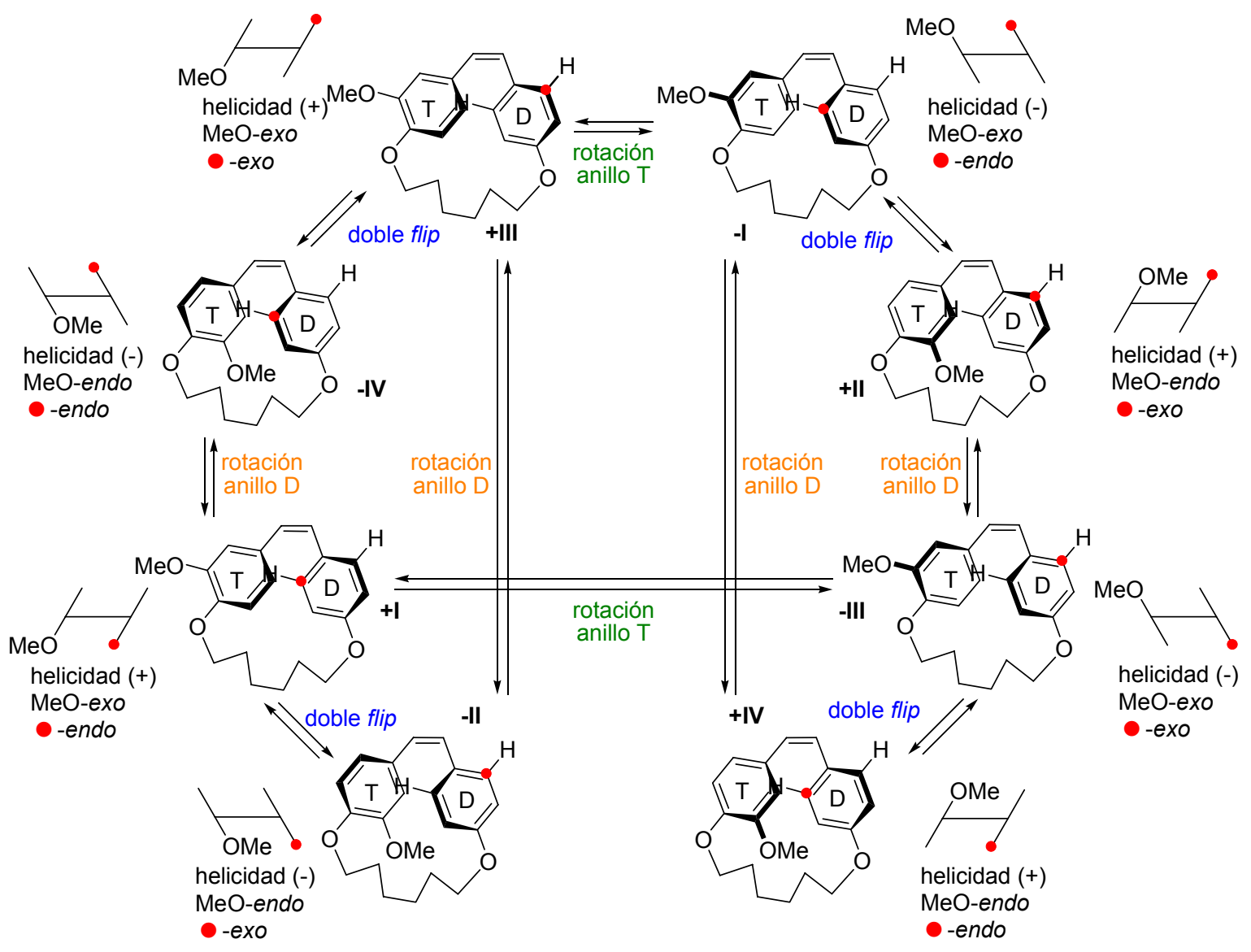

Figura 54. Equilibrio conformacional de la olefina $\mathbf{0 F}$ (un anillo simétrico). Se requiere la rotación rápida del anillo-D y/o del anillo-T a través del espacio del macrociclo de 18 átomos y/o rápido doble flip para que las posiciones químicamente equivalentes aparezcan como una única señal en RMN. 
Un equilibrio rápido entre las cuatro posibles conformaciones explica que las posiciones orto respecto al puente (marcadas $(\bullet)$ y no marcadas) y las posiciones orto respecto al espaciador en el anillo-D se observen como una sola señal de intensidad doble. Este intercambio rápido también explica que para el anillo-T se observe un promedio de las señales de ambas disposiciones (exo-OMe y endo-OMe, independientemente de su relativa contribución al equilibrio). Según lo explicado anteriormente, este equilibrio rápido requiere por lo menos dos movimientos conformacionales rápidos: doble-flip y una rotación o ambas rotaciones (tabla 12) de los anillo. Estos equilibrios se representan en la figura 54 a excepción de los cambios conformacionales menos probables, que requieren el paso del grupo OMe a través del espacio intra-anular (+II $\leftrightarrows-\mathrm{IV}$ y $-\mathrm{II} \leftrightarrows+\mathrm{IV})$.

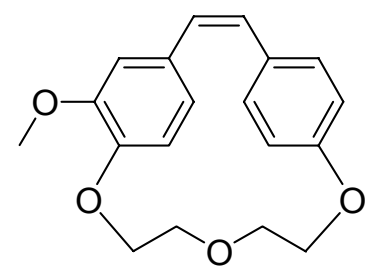

$\mathrm{OE}$

Cuando se cambia el espaciador hexametileno por el espaciador 3oxapentametileno, (olefina $\mathbf{0 E}$, figura 55) el tamaño del macrociclo se reduce de dieciocho átomos a diecisiete. En los espectros de RMN, esto se traduce en un ensanchamiento de las señales del anillo-D en el espectro de $\mathrm{RMN}{ }^{1} \mathrm{H}$. Esto indica que los movimientos rápidos (en la escala de tiempo de RMN) entre conformaciones se ven afectados por esta pequeña disminución del espacio intra-macrocíclico. El ensanchamiento de estas señales requiere al menos dos movimientos lentos (o más exactamente un movimiento lento y uno intermedio en la escala de tiempo de RMN) de los tres posibles: rotación dell anilllo-D, rotación del anillo-T y doble-flip. 
La rotación intermedia del anillo- $\mathrm{T}^{54}$ produciría un promedio de las señales químicamente equivalentes del anillo-D, pero las conformaciones exo-OMe y endo-OMe generarían dos juegos de señales. La razón de observar un solo juego puede deberse a que: solamente una de las dos posibilidades contribuye al espectro o un segundo movimiento es rápido en la escala de tiempo de RMN (bien la rotación del anillo-D, bien el doble-flip).

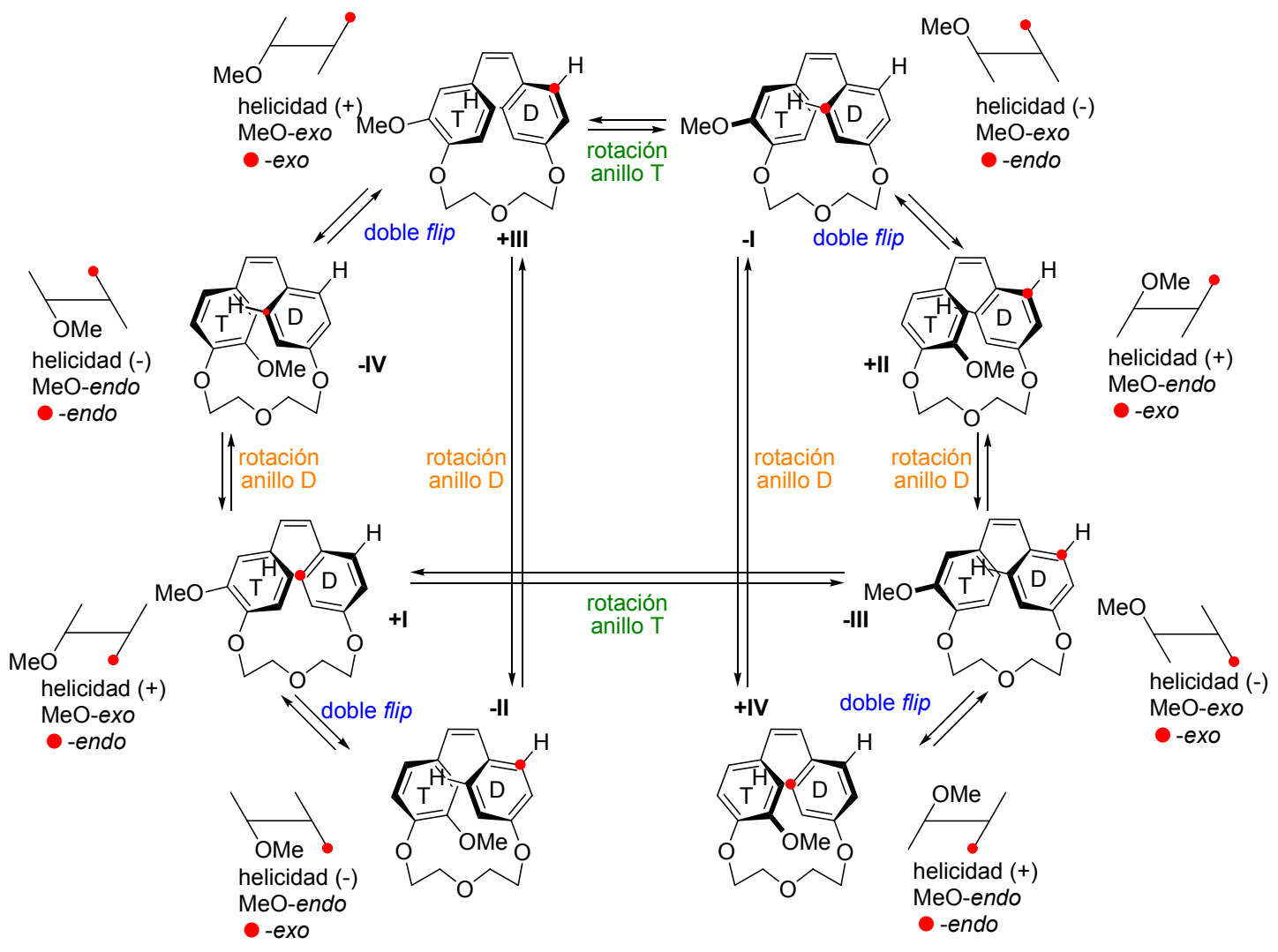

Figura 55. Equilibrio conformacional de la olefina $\mathbf{0 E}$ (un anillo simétrico y espaciador 3-oxapentametileno). Rotación lenta o intermedia de los anillos $\mathrm{D}$ y $\mathrm{T}$ a través del macrociclo de 17 átomos y rápido doble-flip explicarían los espectros de RMN.

Por consiguiente, la pequeña diferencia de espacio intramacrocíclico entre los compuestos $\mathbf{0 E}$ y $\mathbf{0 F}$ es suficiente para disminuir la velocidad del paso de átomos a través de dicho espacio en la escala de tiempo de RMN. Por tanto, el paso de otros sustituyentes de mayor tamaño (grupos metoxilo) debe ser también lento en cualquier caso. Este hecho puede ser comprobado si se analizan compuestos con un anillo simétrico más voluminoso (0D).

\footnotetext{
${ }^{54}$ La rotación del anillo T no debe ser rápida, ya que el anillo $\mathrm{D}$, menos restringido, también tendría rotación rápida, produciendo la interconversión rápida de las conformaciones $\pm \mathrm{I}- \pm \mathrm{IV}$.
} 


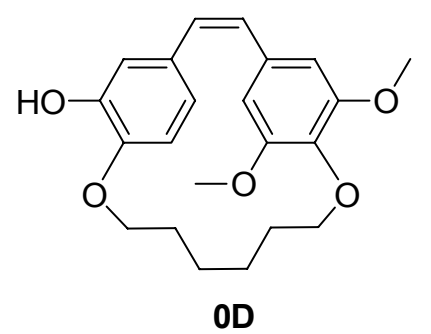

La figura 46 muestra la situación para el compuesto $\mathbf{0 D}$ (que difiere de $\mathbf{0 F}$ en la presencia de un anillo tetrasustituido, anillo-Q, en vez del anillo disustituido, anillo-D). Los espectros de RMN de OD muestran señales no ensanchadas y señales de doble intensidad para las posiciones químicamente equivalentes. Si aplicamos las equivalencias de \pm I a \pm III y \pm II a \pm IV vistas en la tabla 12 y consideramos improbables las rotaciones de los anillos que implican el paso de un grupo distinto de hidrógeno por el espacio intramacrocíclico, la rotación del anillo-T debe intercambiar las posiciones químicamente equivalentes del anillo-Q. La rotación del anillo-T no puede intercambiar por sí misma las disposiciones endo y exo, por lo que deberían ser observados dos juegos de señales, a menos que una de ellas sea minoritaria o el doble-flip sea también rápido. Igualmente, sólo un doble-flip rápido no explicaría los espectros, ya que siempre habría un metoxilo del lado del $\mathrm{OH}$ y otro del contrario.
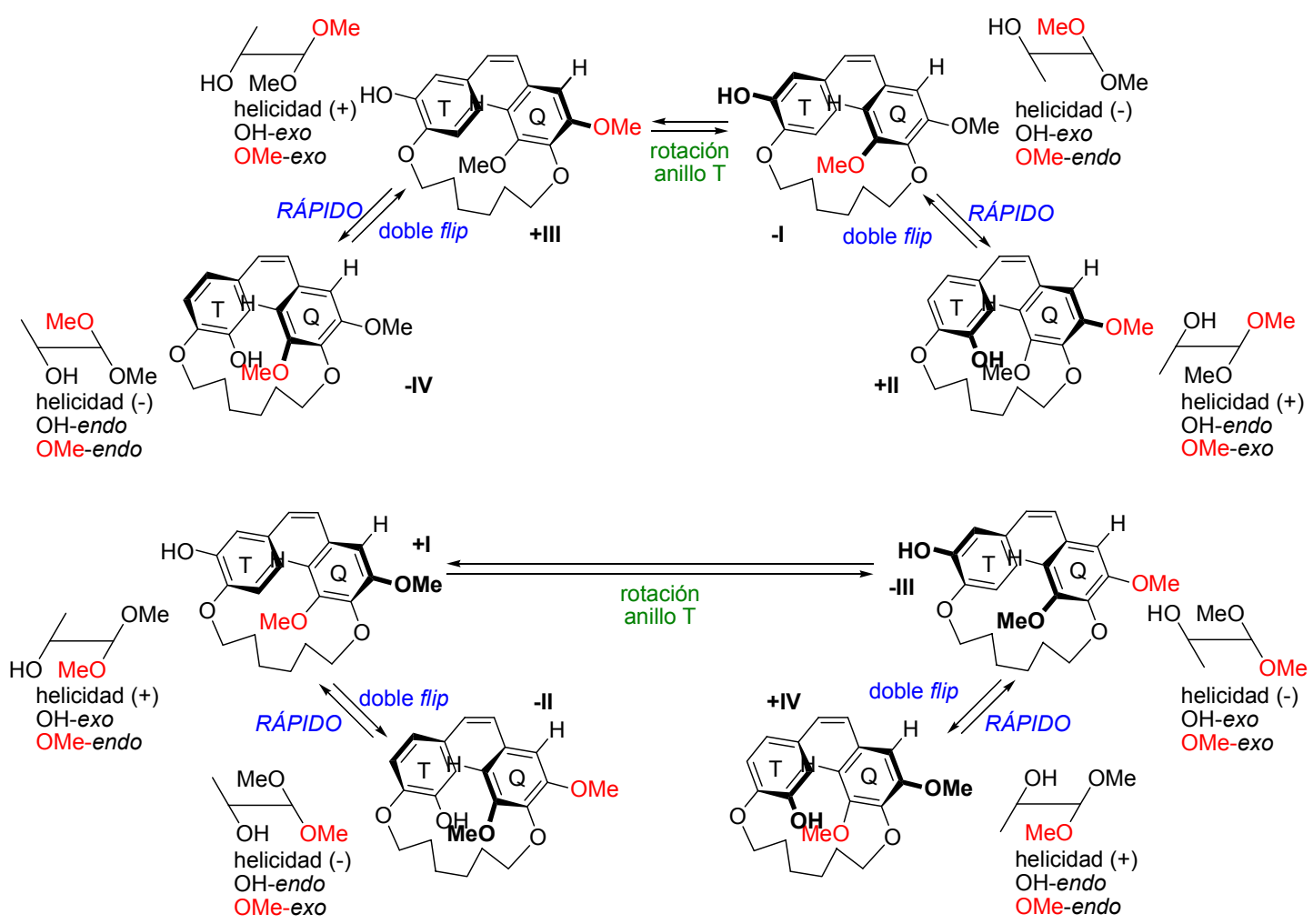

Figura 56. Equilibrio conformacional de la olefina 0D (un anillo simétrico tetrasustituido, un anillo asimétrico trisustituido y espaciador hexametilénico). Doble-flip y rotación del anillo-T rápidos, pasando los átomos de $\mathrm{H}$ a través del espacio intra-macrocíclico explican que las posiciones químicamente equivalentes aparezcan como un promedio en los espectros de RMN. 
En resumen, los espectros observados podrían explicarse mediante cambios doble flip rápidos y rotaciones rápidas de los anillos cuando los átomos de hidrógeno pasan a través de un macrociclo de 18 átomos, siendo lentos o intermedios los giros cuando el macrociclo es de 17 átomos. En cualquier caso, el paso de sustituyentes más voluminosos a través del macrociclo debe estar impedido.

III.4.A.1.c. Olefinas macrocíclicas con un resto indolilo. Análisis conformacional de 84 y 87.<smiles>COc1cccc(/C=C\c2ccc3c(ccn3CCCCCCOc3ccccc3)c2)c1</smiles>

84<smiles></smiles>

87

En el caso de las olefinas indólicas 84 y 87, la situación observada y el análisis presentan pocas variaciones. El compuesto 87 se puede considerar como análogo de 0D con un anillo de indol en vez del anillo trisustituido y el compuesto 84, en el que se ha eliminado un metoxilo del anillo tetrasustituido, es una versión aún menos simétrica, con dos anillos trisustituidos. Análogamente a 0D-F, en los compuestos 84 y 87 hay ocho posibles conformaciones $\pm \mathrm{I}$ - $\pm \mathrm{IV}$ (Figuras 57 y 58), que pueden interconvertirse mediante la rotación de los dos anillos y el doble-flip. Las rotaciones indicadas mediante flechas de menor intensiada corresponden a giros más improbables, debido a que requieren el paso de un grupo metoxilo a través del espacio intra-anular o una elongación inalcanzable del espaciador. 


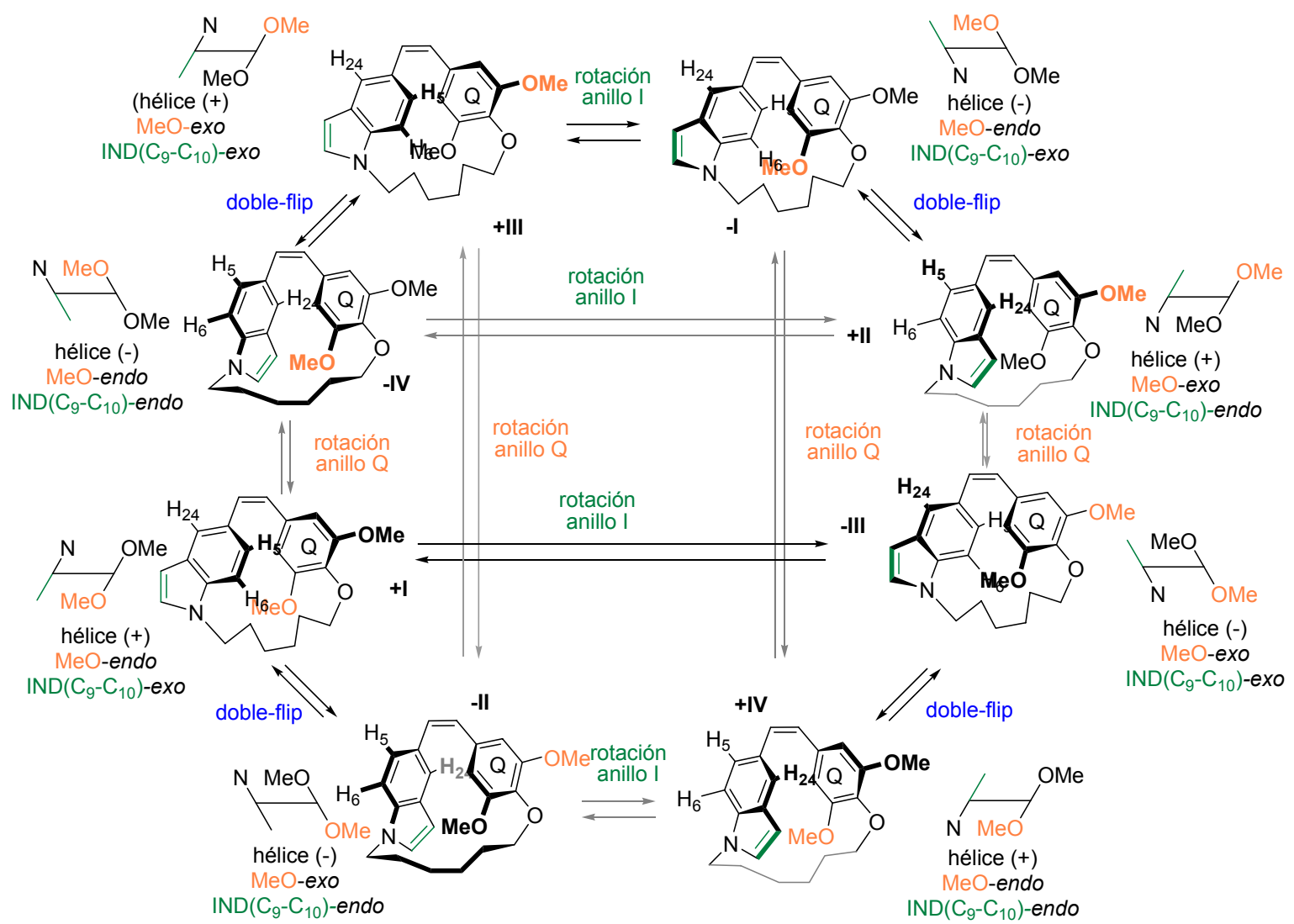

Figura 57. Equilibrio conformacional de la olefina 87. La rotación del indol requiere el paso de H-5 y H-6 a través del espacio interno del macrociclo. La rotación del fenilo es altamente improbable ya que requiere el paso de un grupo metoxilo por el espacio intra-anular.

El compuesto 87 (Figura 57) posee un resto fenilo simétrico que hace que las conformaciones $+\mathrm{I}$ y + III sean idénticas al igual que las de sus enantiómeros $-\mathrm{I}$ y - III. Del mismo modo +II y +IV son iguales y sus enantiómeros - II y -IV también. Sin embargo, en el compuesto 84, los dos anillos son asimétricos. 


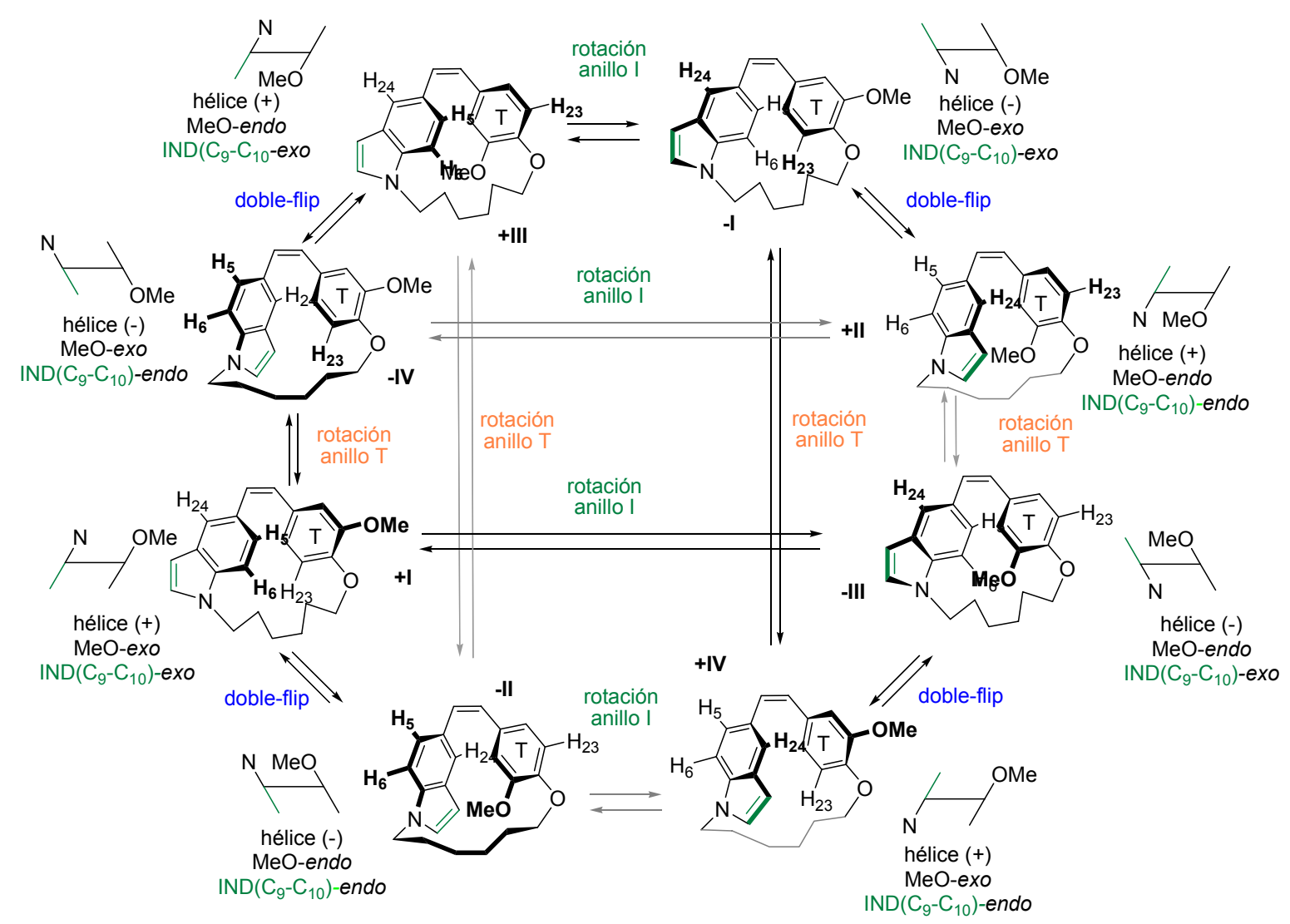

Figura 58. Equilibrio conformacional de la olefina 84. La rotación del indol requiere el paso de H-5 y H-6 a través del espacio interno del macrociclo. La rotación del fenilo requiere el paso de H-22 y H-23 por el espacio intra-anular (en los intercambios de -I $\leftrightarrows+\mathbf{I V}$ y $-\mathbf{I V} \leftrightarrows+\mathbf{I}$ ) o el paso del grupo metoxilo (en los intercambios de $+\mathbf{I I} \leftrightarrows-\mathbf{I I I}$ y $+\mathbf{I I I} \leftrightarrows-\mathbf{I I})$, siendo esta última rotación altamente improbable. 


\section{III.4.A.2 Estudios de mecánica molecular y dinámica molecular de las olefinas 84 y 87.}

\section{III.4.A.2.a Mecánica molecular}

La rigidez introducida en el sistema por el anillo de indol puede hacer que algunas de las conformaciones consideradas en el caso de los compuestos OD-F, no sean accesibles, por lo que no habría que tener en cuenta en la discusión conformacional algunas de las representadas en las figuras 57 y 58. En concreto, la inspección de los modelos moleculares planteaba dudas sobre la estabilidad de las conformaciones en las que el enlace $\mathrm{N}$-espaciador adopta una disposición exo $( \pm \mathrm{II}$ y $\pm \mathrm{IV})$. Con el fin de establecer las conformaciones accesibles a los compuestos 84 y 87 se llevó a cabo una búsqueda conformacional (Monte Carlo) ${ }^{55}$ utilizando mecánica molecular (campo de fuerzas MM3 con cloroformo como disolvente). ${ }^{56}$

En las conformaciones de mínima energía calculadas, se midieron varios ángulos diedros que permitían su asignación a los grupos conformacionales $\pm \mathrm{I}- \pm \mathrm{IV}$ anteriormente definidos (figuras 57 y 58). Los diedros utilizados para el compuesto 84 se definen en la siguiente figura. Para el compuesto 87 se emplearon diedros equivalentes.

\footnotetext{
${ }^{55}$ a) Howard, A. E.; Kollman, P. A. An analysis of current methodologies for conformational searching of complex molecules. J. Med. Chem. 1988, 31, 1669-1675. b) Saunders, M.; Houk, K. N.; Wu, Y-D.; Still, C. W.; Lipton, J. M.; Chang, G.; Guidal, W. C. Conformations of Cycloheptadecane. A Comparison of Methods for Conformational Searching. J. Am. Chem. Soc. 1990, 112, 1419-1427.

${ }^{56}$ a) Allinger, N. L.; Yuh, Y. H.; Lii, J. H. Molecular mechanics. The MM3 force field for hydrocarbons. 1. J. Am. Chem. Soc. 1989, 111, 8551-8566. b) Lii, J. H.; Allinger, N. L. Molecular mechanics. The MM3 force field for hydrocarbons. 2. Vibrational frequencies and thermodynamics. J. Am. Chem. Soc. 1989, 111, 85668576. c) Lii, J. H.; Allinger, N. L. Molecular mechanics. The MM3 force field for hydrocarbons. 3. The van der Waals' potentials and crystal data for aliphatic and aromatic hydrocarbons J. Am. Chem. Soc. 1989, 111, 8576-8582.
} 
a)

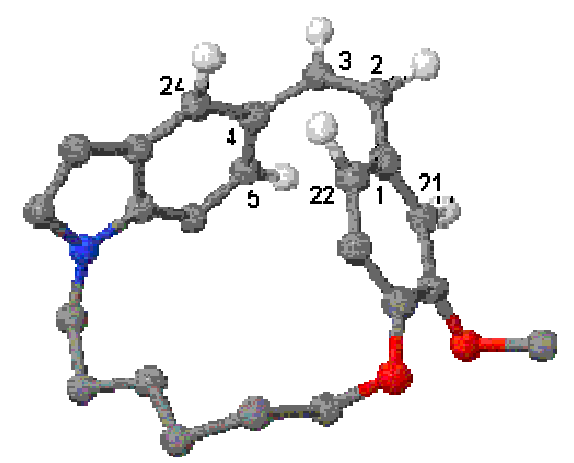

c)

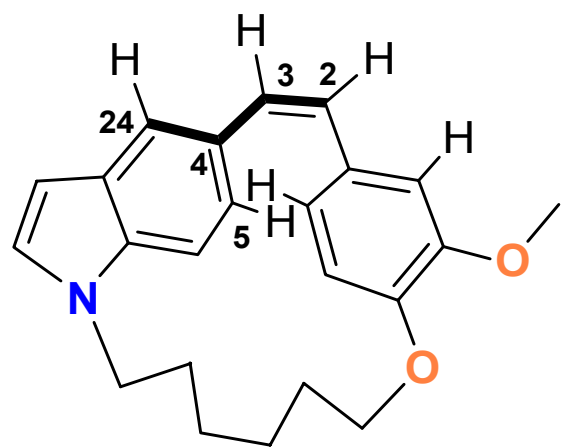

b)

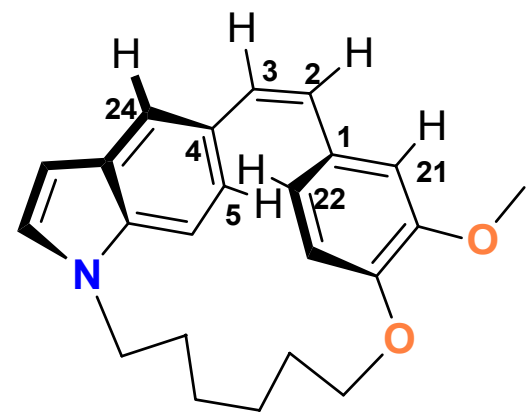

d)

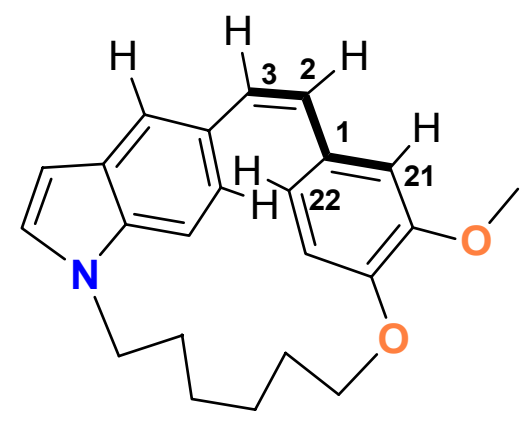

Figura 59. Visualización de los diedros empleados en la asignación de las conformaciones de mínima energía calculadas $\pm \mathrm{I}- \pm \mathrm{IV}$. Las figuras superiores se corresponden con la representación tridimensional (a) y bidimensional (b) de la conformación -I del compuesto 84. En las figuras inferiores se han marcado, sobre dicha conformación, los ángulos diedros utilizados. En $\mathbf{c}$ se indican los átomos empleados en la medición del ángulo diedro (DI) que forma el indol con el puente olefínico, mientras que en $\mathbf{d}$ se indican los átomos empleados para medir el ángulo formado entre el dicho puente y el anillo fenilo (DT).

En los estudios de dinámica molecular, ${ }^{57}$ que se describen más adelante, se observa cierta pérdida de la planaridad de los anillos aromáticos. Esto podría implicar que la consideración del diedro 24-4-3-2 (DI) o del diedro 5-4-3-2 llevara a resultados diferentes. Para evitarlo, se promedió el valor del diedro 24-4-3-2 (DI) con el del complementario a 54-3-2. Lo mismo se aplicó para 21-1-2-3 (DT) y 22-1-2-3. En ambos casos, el valor del diedro considerado para la asignación conformacional y la discusión que sigue, corresponde al valor del diedro indicado en primer lugar y resaltado en negrita en la figura.

\footnotetext{
${ }^{57}$ Hudson, B. D.; George, A. R.; Ford, M. G.; Livingstone D. J. Structure-activity relationships of pyrethroid insecticides. Part 2. The use of molecular dynamics for conformation searching and average parameter calculation. J. Comput.-Aided Mol. Des. 1992, 6, 191-201.
} 
Una vez medidos los diedros indicados, se determinó la helicidad correspondiente a cada conformación (ver figura 60). Para ello, se asignó una helicidad negativa (-) para los anillos con valores de los diedros DI o DT (flechas verdes) mayores de 90 o entre 0 y $-90^{\circ}$. Si la helicidad para ambos anillos era coincidente, se clasificaba la conformación con dicha helicidad. Si, por el contrario, era discordante, se marcaba la conformación como no correspondiente a los grupos considerados inicialmente.

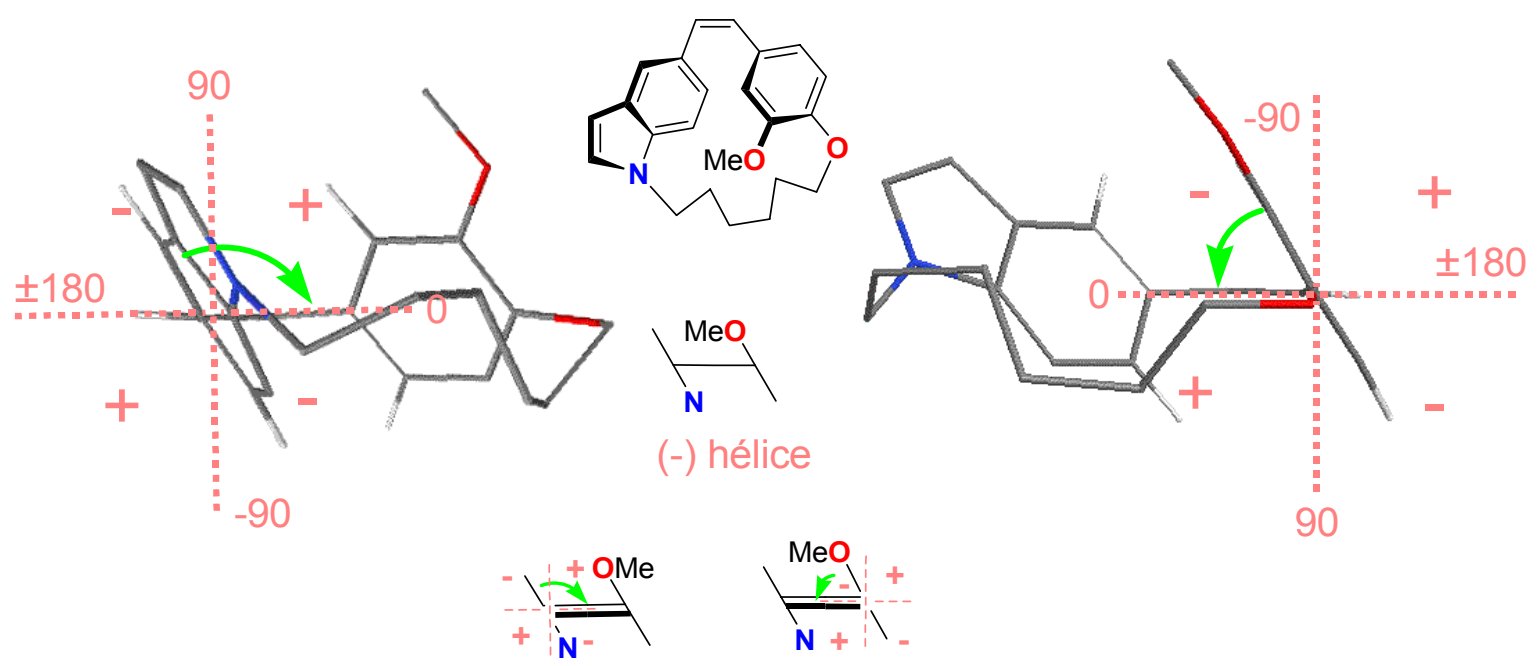

Figura 60. Representación del compuesto 84 en la conformación que se encuentra en el centro de la figura desde dos puntos de vista para que se visualicen los ángulos diedros medidos para cada anillo (IND a la izquierda, DM a la derecha). Los ángulos están marcados con las flechas verdes (desde el plano del anillo al plano del doble enlace). En la parte inferior de la figura se muestra la representación esquemática de esta conformación (la línea horizontal representa el doble enlace, las líneas oblicuas el plano de los anillos y las flechas verdes, nuevamente, los ángulos medidos). 
Las conformaciones de mínima energía se clasificaron en las categorías I-IV en función del valor de los ángulos diedro medidos y de acuerdo con los siguientes criterios:

\begin{tabular}{|c|c|c|c|c|}
\hline Conformación & Hélice + & Representación & Hélice - & Representación \\
\hline \multirow{2}{*}{ I } & $\mathrm{DI}<-90$ & $\mathbf{N}$ & $90<\mathrm{DI}$ & \\
\hline & DT $<-90$ & & $90<$ DT & $\mathrm{Me}$ \\
\hline \multirow{2}{*}{ II } & $0<\mathrm{DI}<90$ & 1 & $-90<\mathrm{DI}<0$ & $\mathbf{N}$ \\
\hline & $0<\mathrm{DT}<90$ & OMe & $-90<\mathrm{DT}<0$ & \\
\hline \multirow{2}{*}{ III } & $\mathrm{DI}<-90$ & $\mathbf{N}$ & $90<\mathrm{DI}$ & \\
\hline & $0<\mathrm{DT}<90$ & Me & $-90<\mathrm{DT}<0$ & $N$ \\
\hline \multirow{2}{*}{ IV } & $0<\mathrm{DI}<90$ & $\mathrm{OMe}$ & $-90<\mathrm{DI}<0$ & $\mathbf{N}$ \\
\hline & $\mathrm{DT}<-90$ & & $90<\mathrm{DT}$ & \\
\hline
\end{tabular}

Tabla 13. Rango de valores de los ángulos DI y DT para cada conformación I-IV y helicidad (aunque en la tabla se indiquen valores de $0,90^{\circ}$ y $180^{\circ}$ para que resulte más clara la asignación de los cuadrantes, en realidad se han empleado rangos de valores diez grados mayores y menores, como se explica más adelante, al considerar que las conformaciones con diedros muy cercanos a esos valores pueden representar situaciones intermedias entre categorías). Se incluye una representación gráfica de cada conformación en las columnas 3 y 5 . 
Las conformaciones con helicidad de los dos anillos aromáticos no coincidente o aquellas en las que uno o ambos anillos presentan un diedro cercano $\left( \pm 10^{\circ}\right)$ al cambio de categoría $\left(0^{\circ}, \pm 90^{\circ}, \pm 180^{\circ}\right)$, se han incluido en categorías adicionales:

\begin{tabular}{|c|c|c|c|}
\hline \begin{tabular}{c} 
Valores de los diedros \\
$-100<\mathrm{DI}<-80$ \\
\hline $80<\mathrm{DT}<100$ ó \\
$-100<\mathrm{DT}<-80$
\end{tabular} & Tipo de conformación \\
\hline $\begin{array}{l}80<\mathrm{DI}<100 \text { ó } \\
-100<\mathrm{DI}<-80\end{array}$ & Flip del indol \\
$80<\mathrm{DT}<100$ ó \\
$-100<\mathrm{DT}<-80$
\end{tabular}

Tabla 14. Valores de los ángulos diedros (columna de la izquierda) que definen cada uno de los estados intermedios considerados (columna de la derecha) y representación gráfica de alguna de las posibles conformaciones (columna central). 
La aplicación de estas reglas al resultado de las búsquedas conformacionales realizadas para los compuestos 84 y 87 permite obtener gráficas en las que asignar y analizar las conformaciones. Además, el mismo procedimiento se ha aplicado para $\mathbf{0 D}, \mathbf{0 E}$ y $\mathbf{0 F}$ con el fin de facilitar la comparación de las distintas series.

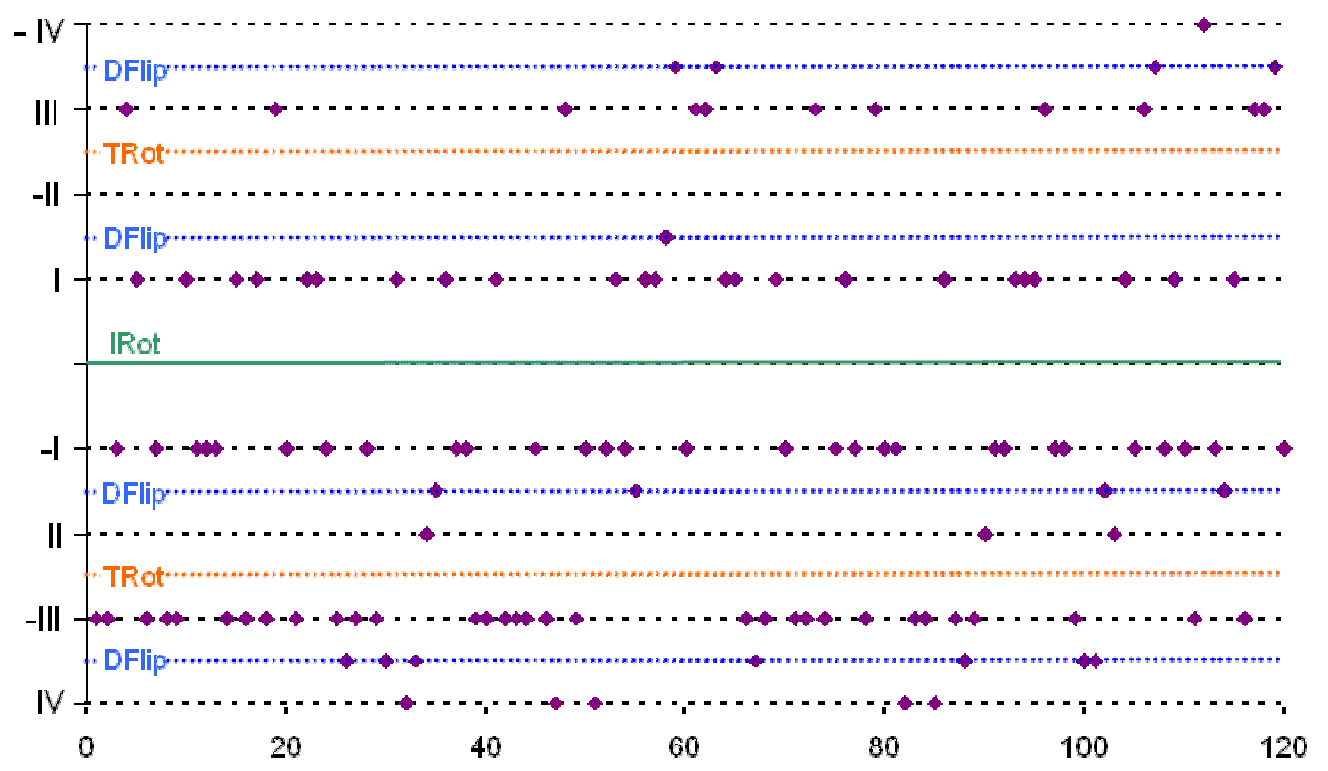

Figura 61.

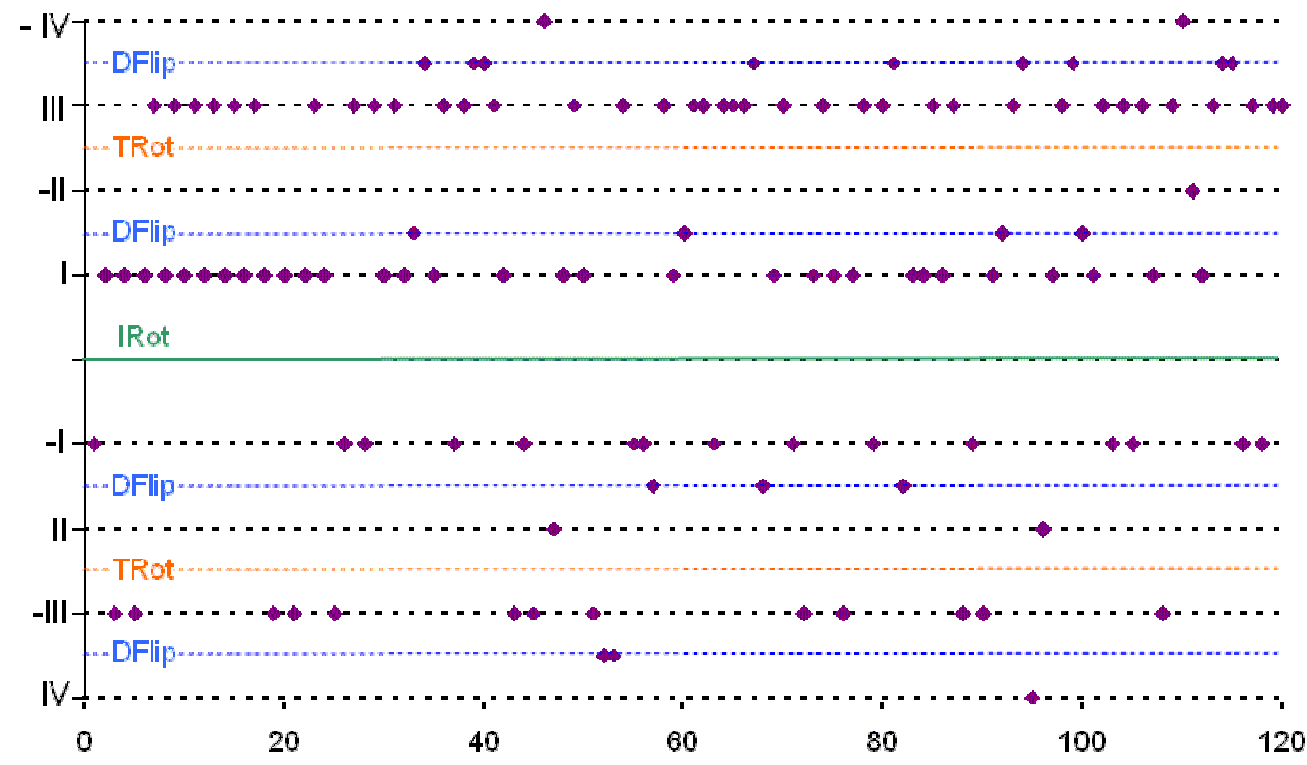

Figura 62.

Representaciones gráfica de las conformaciones de mínima energía calculadas para los compuestos 84 (figura 61, arriba) y 87 (figura 62, abajo). Cada punto indica una conformación, de menor a mayor energía (de izda. a dcha.). Las líneas horizontales indican los grupos conformacionales definidos (-IV, III, -II, I, -I, II, -III y IV, de arriba abajo) y los movimientos por los cuales se interconvierten entre ellos (Doble flip, Rotación del anillo T o Q, Doble flip, Rotación del anillo I, Doble flip, Rotación del anillo T o Q y Doble flip, de arriba abajo). 
Los resultados obtenidos al analizar las gráficas se resumen en la siguiente tabla, donde se indica a que grupo pertenecen las conformaciones de mínima energía encontradas para cada compuesto, la diferencia de energía de cada una de ellas respecto al mínimo global y el número de veces que se ha encontrado dicha conformación tras 1000 etapas y con una diferencia de energía inferior a $5 \mathrm{kcal} / \mathrm{mol}$ respecto al mínimo global.

\begin{tabular}{|c|c|c|c|c|c|c|c|c|c|}
\hline & I & -I & II & -II & III & -III & IV & -IV & Otras \\
\hline $\mathbf{8 4}$ & 0,6 & 0,3 & 2,1 & - & 0,4 & 0 & 2,3 & 4,5 & Doble \\
& $(8)$ & $(9)$ & $(5)$ & $(0)$ & $(15)$ & $(4)$ & $(7)$ & $(8)$ & flip \\
\hline $\mathbf{8 7}$ & 0,3 & 0 & 2,4 & 1,8 & 0,7 & 0,3 & 3,2 & 1,9 & Doble \\
& $(6)$ & $(5)$ & $(5)$ & $(7)$ & $(4)$ & $(4)$ & $(5)$ & $(2)$ & flip \\
\hline $\mathbf{0 D}$ & 0 & 0,7 & 2,7 & 1,7 & 0,6 & 0 & 2,7 & 1,7 & Doble \\
& $(12)$ & $(3)$ & $(6)$ & $(4)$ & $(2)$ & $(10)$ & $(3)$ & $(7)$ & flip \\
\hline $\mathbf{0 E}$ & 0,7 & 1,2 & - & - & - & - & 2,3 & 0 & Doble \\
& $(55)$ & $(20)$ & $(0)$ & $(0)$ & $(0)$ & $(0)$ & $(14)$ & $(46)$ & flip \\
\hline $\mathbf{0 F}$ & 0 & 0,9 & 0,5 & 1,0 & 0,9 & 2,6 & 3,3 & 2,9 & Doble \\
& $(22)$ & $(8)$ & $(23)$ & $(10)$ & $(5)$ & $(7)$ & $(2)$ & $(3)$ & flip \\
\hline
\end{tabular}

Tabla 15. Resultados del análisis conformacional para los compuestos 84, 87, 0D, 0E y 0F. En la parte superior de cada casilla se indica la mínima energía de cada grupo conformacional respecto al mínimo global (sombreado oscuro). Mientras que en la parte inferior se indica el numero de veces que se ha encontrado la conformación de mínima energía para cada grupo conformacional. En la columna de la derecha se indica si se han encontrado otras conformaciones intermedias a las definidas. Las conformaciones son iguales por parejas, $\pm \mathrm{I}= \pm \mathrm{III}$ y $\pm \mathrm{II}= \pm \mathrm{IV}$, para los compuestos 87 y $\mathbf{0 D}-\mathbf{F}$, mientras que para 84 I-IV son todas diferentes.

La diferencia de energía entre conformaciones idénticas o imágenes especulares nos informa del error intrínseco del método. Este error puede tener dos orígenes:

- El error asociado a los campos de fuerza utilizados. ${ }^{58}$

- La dificultad de encontrar el mínimo a partir de las conformaciones tensionadas generadas en la búsqueda conformacional, para sistemas en los que las rotaciones de los enlaces están muy interrelacionadas (como es el caso de macrociclos sustituidos). ${ }^{55}$

\footnotetext{
${ }^{58}$ Gundertofte, K.; Liljefors, T.; Norrby, P. O.; Pettersson, I. A Comparison of Conformational Energies Calculated by Several Molecular Mechanics Methods. J. Comput. Cheml. 1996, 4, 429-449.
} 
La segunda limitación puede superarse en cierta manera mediante el empleo de diferentes métodos de muestreo conformacional, ${ }^{55}$ como la dinámica molecular ${ }^{59}$ que se discutirá más adelante. En general, se observa que la diferencia de energía entre parejas de conformaciones enantiómeras es de hasta $2,3 \mathrm{kcal} / \mathrm{mol}$, aunque en la mayoría de los casos se mantienen por debajo de $1 \mathrm{kcal} / \mathrm{mol}$.

Para el compuesto 84, las conformaciones de mínima energía se corresponden con conformaciones de tipo I y III, mientras que las conformaciones de tipo II y IV parecen encontrarse menos pobladas. Para el compuesto 87, como se ha indicado anteriormente, las conformaciones tipo I y III son iguales entre sí e igualmente ocurre con las tipo II y IV, debido a la naturaleza simétrica del anillo tetrasustituido, por lo que deben considerarse conjuntamente, aunque se computen por separado. De cualquier modo, se observa que ambos tipos de conformaciones, I/III y II/IV, presentan diferencias en energía que hacen que todas deban ser tenidas en cuenta. La estructura obtenida por difracción de rayos $\mathrm{X}$ de cristales de la olefina 87 muestra una conformación en el estado sólido correspondiente a las conformaciones -I/-III, como se muestra en la figura 63. Para los compuestos 0D-F se observa una situación similar a la descrita para 84. Sin embargo, las conformaciones tipo II/IV presentan distintos grados de participación. En los compuestos 84 y 87, al igual que ocurre para 0D-F, se observa la presencia de conformaciones diferentes de las I-IV. En concreto, se observan conformaciones que corresponden a los doble flips.
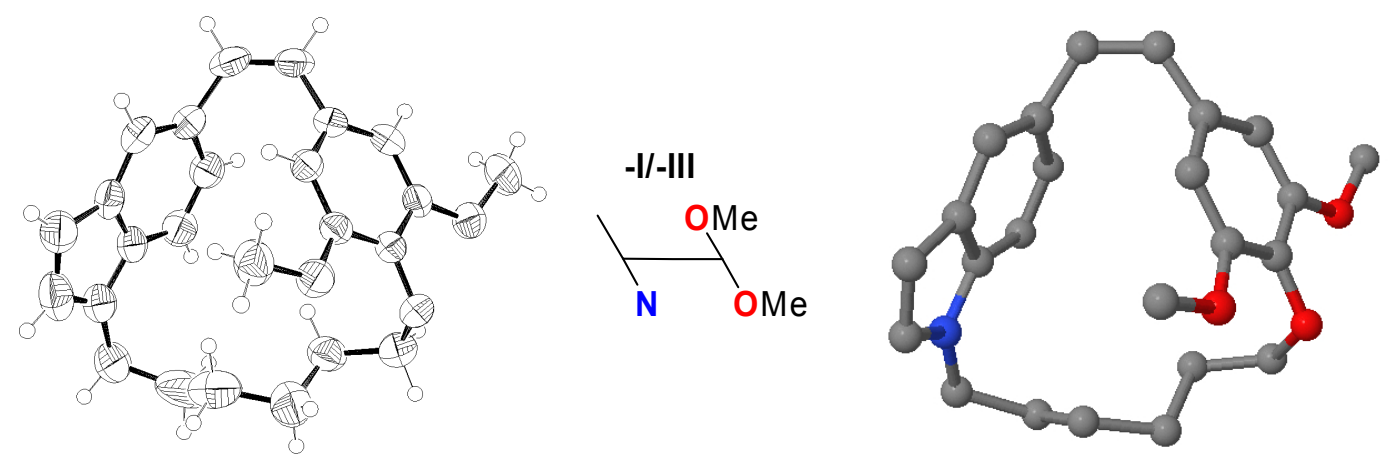

Figura 63. Estructura obtenida por difracción de rayos X de cristales de la olefina 87.

\footnotetext{
${ }^{59}$ Wilson, S. R.; Cui, W.; Moskowitz, J. W.; Schmidt, K. E. Conformational Analysis of Flexible Molecules: Location of the Global Minimum Energy Conformation by the Simulated Annealing Method. Tetrahedron Lett. 1988, 29, 4373-4376.
} 


\section{III.4.A.2.b. Dinámica molecular.}

Con el fin de estudiar las transiciones entre las conformaciones de los compuestos 84 y 87, se han llevado a cabo estudios de dinámica molecular. ${ }^{57}$ Esta metodología permite, además, llevar a cabo un muestreo conformacional complementario al realizado mediante el Monte Carlo. ${ }^{59}$ Las simulaciones se han llevado a cabo durante 3 ns a distintas temperaturas (típicamente 300, 600, 1200 y $1500 \mathrm{~K}$ ), empleando las mismas condiciones que las descritas para las búsquedas conformacionales utilizando Monte Carlo. Adicionalmente, y con el fin de facilitar el análisis de los resultados, se han llevado a cabo simulaciones análogas a las descritas para sistemas modelo (0G y $\mathbf{O H}$ ) que carecen del espaciador.
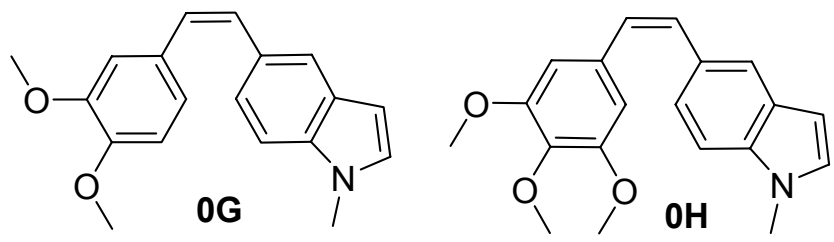

Los resultados de las dinámicas moleculares se han analizado de la misma forma que las búsquedas conformacionales, asignando las conformaciones a los tipos $\pm \mathrm{I}- \pm \mathrm{IV}$, más los que corresponden a situaciones de transición entre ellas (como se ha descrito anteriormente). Además, se ha analizado la trayectoria de forma secuencial, comparando cada conformación con la que le sigue en la simulación. El análisis de la forma en que ocurren las transiciones entre conformaciones permite la asignación de la ruta más simple posible (por ejemplo, un tránsito de +III a -I se considera producido por una rotación del anillo de indol -IRot-). Si con un único paso no es posible efectuar la interconversión, el mecanismo de transición no se indica. Cabe destacar que, a medida que aumenta la temperatura, la cantidad de conformaciones que corresponden a tipos distintos de $\pm \mathrm{I}- \pm \mathrm{IV}$ se incrementa considerablemente. 
Los procesos que determinan el aspecto de los espectros de RMN (tanto de protón como de carbono) son inaccesibles a simulaciones de dinámica molecular, ya que ocurren en una escala de tiempo de los microsegundos o superior. Pese a ello, las simulaciones de dinámica molecular permiten obtener una idea bastante fidedigna de la facilidad relativa con la que ocurren dichos procesos, facilitando notablemente la interpretación de los espectros. A bajas temperaturas los procesos ocurren demasiado lentamente como para que su frecuencia sea lo suficientemente alta como para observarlos durante simulaciones que duran 3 ns. Por ello, se ha procedido a incrementar progresivamente la temperatura de la simulación para facilitar la superación de barreras energéticas inaccesibles a menores temperaturas, puesto que procesos que ocurren con bajas frecuencias a temperatura ambiente pueden ser observables a $1500 \mathrm{~K}$.

La dinámica molecular a 300K de los análogos no macrocíclicos (0H y 0G) de 84 y 87 (figuras $64 \mathrm{a} \mathrm{y} \mathrm{b)} \mathrm{muestra} \mathrm{que} \mathrm{a} \mathrm{temperatura} \mathrm{ambiente} \mathrm{todas} \mathrm{las} \mathrm{conformaciones} \mathrm{son}$ accesibles durante la simulación. Además se observan tanto conformaciones con helicidad positiva como negativa. Para el compuesto con dos metoxilos (0G), el grupo conformacional más poblado es el \pm III, de acuerdo con lo descrito anteriormente para los análogos macrocíclicos no indólicos, aunque $\pm \mathrm{I}$ y $\pm \mathrm{IV}$ también están ampliamente representados. Las conformaciones tipo II son mucho menos frecuentes. De acuerdo con lo que se indica en la tabla 16, la distribución observada se corresponde con una situación dominada por la preferencia del metoxilo a adoptar una disposición endo, siendo menos importante la disposición del anillo de indol. Además, la disposición endo simultánea de los dos sustituyentes parece ser muy desfavorable. 


\begin{tabular}{|c|c|c|c|c|}
\hline $\begin{array}{c}\text { Preferencias } \\
\text { conformacionales }\end{array}$ & $\begin{array}{c}\text { Conformaciones } \\
\text { Preferidas }\end{array}$ & $\begin{array}{c}\text { Conformaciones } \\
\text { Intermedias }\end{array}$ & $\begin{array}{c}\text { Conformaciones } \\
\text { Desfavorecidas }\end{array}$ & $\begin{array}{c}\text { Conformaciones } \\
\text { Muy Desfavorecidas }\end{array}$ \\
\hline MeO endo & III $\sim$ II & & I $\sim$ IV & \\
\hline IND exo & III $\sim$ I & & II $\sim$ IV & \\
\hline $\begin{array}{c}\text { MeO endo } \\
\text { IND exo }\end{array}$ & III & I $\sim$ II & IV & \\
\hline Observado & III & & I $\sim$ IV & II \\
\hline
\end{tabular}

Tabla 16. Análisis de las posibles preferencias de los sustituyentes para adoptar disposiciones endo o exo y el efecto que dicha preferencia tendría sobre las conformaciones globales del análogo acíclico de la olefina 84 (0G). Se indican las conformaciones preferidas y desfavorecidas en los supuestos de que la preferencia conformacional sea la indicada en la columna de la izquierda.

En el compuesto con tres metoxilos (0H) los tipos I y III son el mismo, así como los tipos II y IV, observándose un predominio de la primera pareja sobre la segunda. Esta observación está de acuerdo con lo propuesto anteriormente, ya que siempre hay un metoxilo exo y uno endo presentes, lo que elimina el dominio que éste ejercía sobre la preferencia conformacional. La única diferencia posible es ahora la disposición del anillo de indol, que en este caso prefiere adoptar la disposición exo (que equivale a la exclusión de dos disposiciones endo simultáneas).

A $1200 \mathrm{~K}$ se observa un menor tiempo de residencia en cada tipo conformacional, como era de esperar. Este incremento en el número de transiciones facilita la ocupación de todos los tipos de conformaciones. A esta temperatura se observa un comportamiento muy similar de ambos compuestos.

En lo que respecta a las transiciones, en ambas simulaciones se observan rotaciones del anillo de indol, del anillo tri- o tetrasustituido y doble flips. Sin embargo, el compuesto con tres metoxilos $(\mathbf{0 H})$ aparentemente tiene una mayor dificultad para completar los giros del anillo de indol (cambios de la mitad superior a la inferior y viceversa del diagrama A, que perduran un tiempo). 


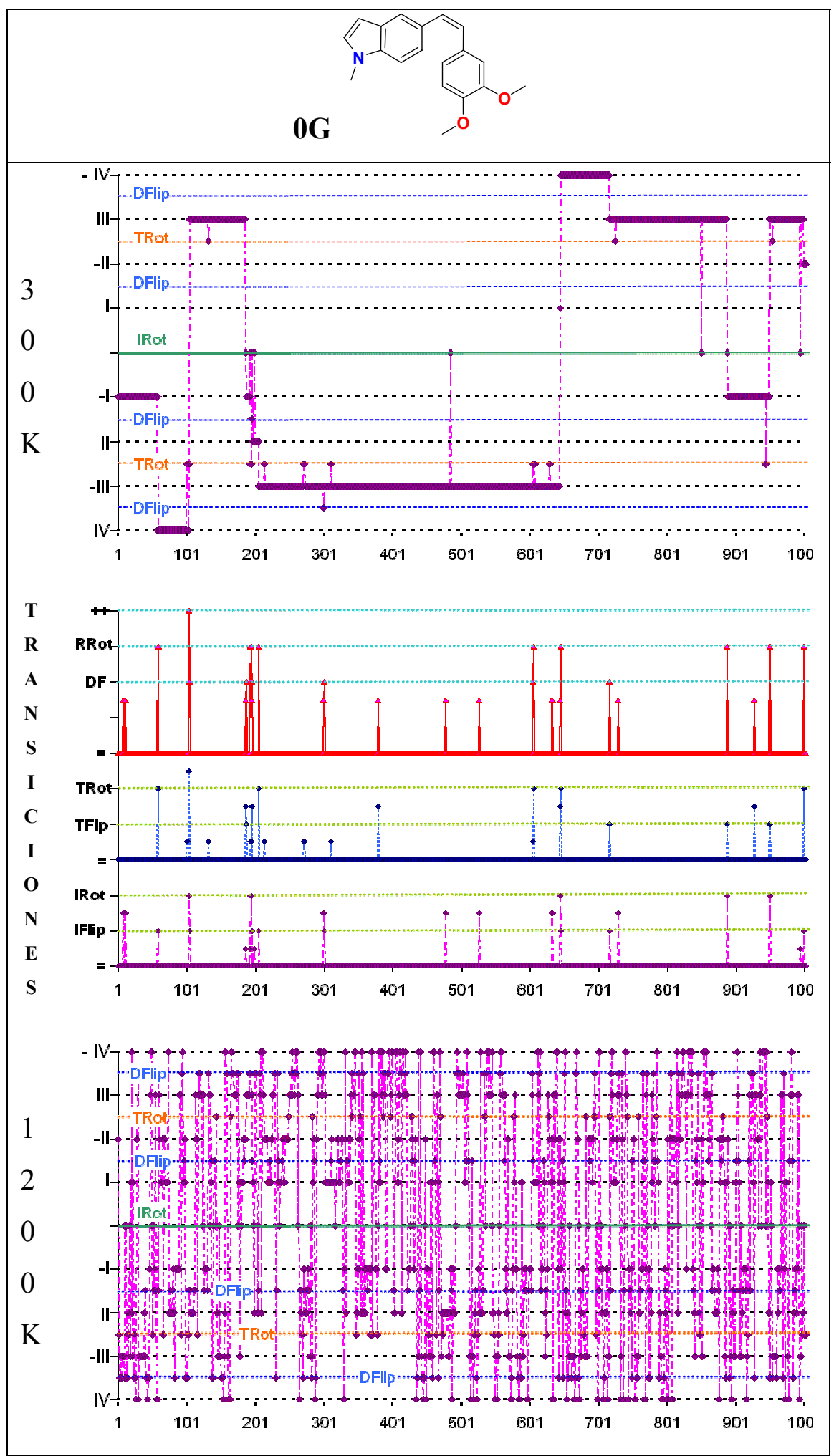

Figura 64a. Gráficas resumen de las dinámicas moleculares del análogo no macrocíclico de 84, 0G. La gráfica superior muestra los grupos conformacionales a los que pertenecen las conformaciones obtenidas de la dinámica molecular a $300 \mathrm{~K}$, mientras que la inferior los muestra para la dinámica a $1200 \mathrm{~K}$. En la gráfica central se indican las transiciones sencillas asignadas a las interconversiones en la dinámica molecular a 300: En rojo las de los dos anillos (sin cambios: =, rotación de alguno de los anillos: RRoT, doble flip: DF y transiciones complejas:++); en azul las del fenilo y en morado las del indol (sin cambios: $=$, rotación de 1 anillo: IRot o TRot, flip de anillo: IFlip o TFlip). Los puntos entre categorías indican estados de transición de la categoría superior y los puntos de las gráficas azul o morada por encima de TRot o IRot indican transiciones complejas de ese anillo. 


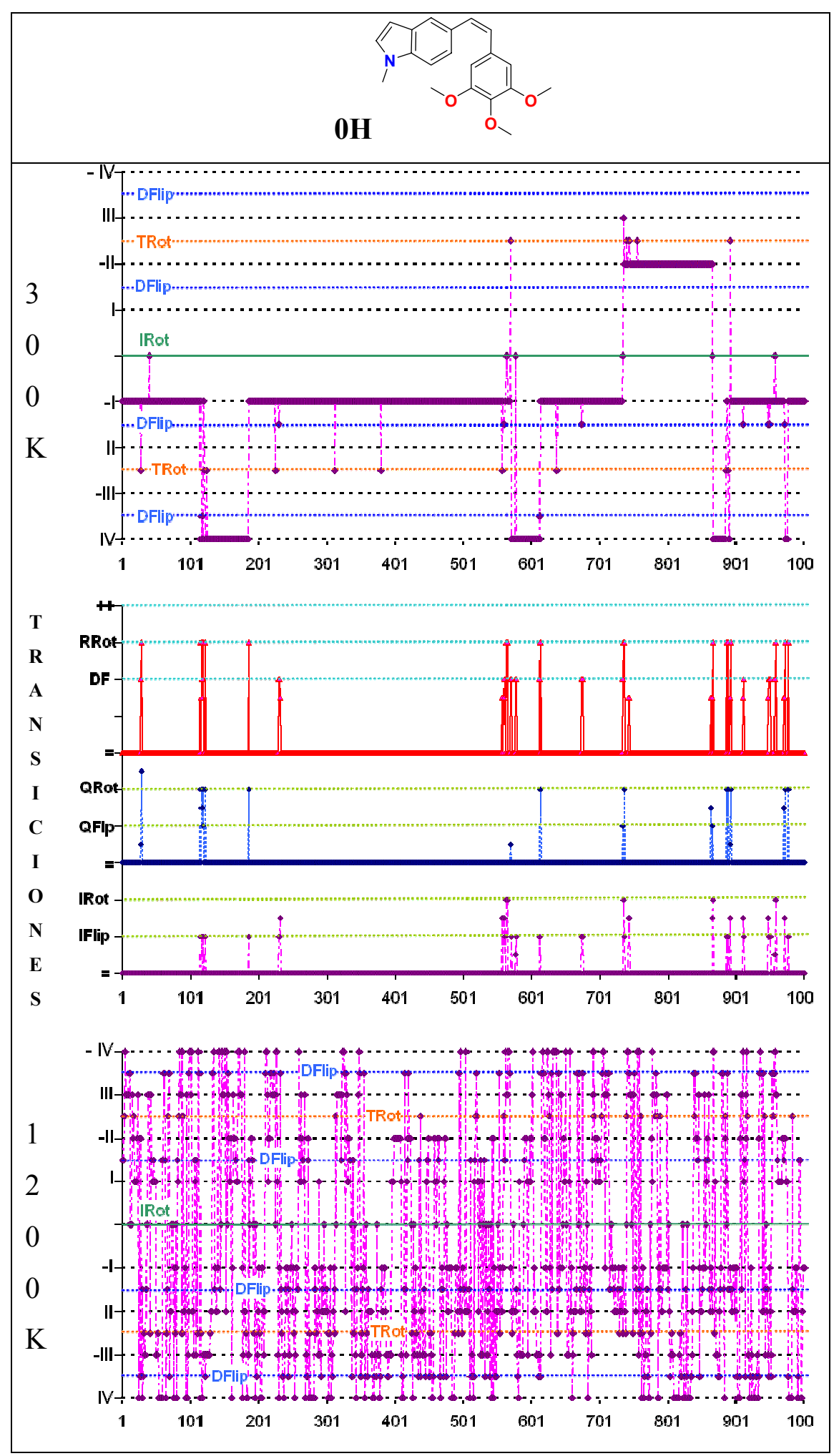

Figura 64b. Gráficas resumen de las dinámicas moleculares del análogo no macrocíclico de $\mathbf{8 7}, \mathbf{0 H}$. La gráfica superior muestra los grupos conformacionales a los que pertenecen las conformaciones obtenidas de la dinámica molecular a $300 \mathrm{~K}$, mientras que la inferior los muestra para la dinámica a $1200 \mathrm{~K}$. En la gráfica central se indican las transiciones sencillas asignadas a las interconversiones en la dinámica molecular a 300: En rojo las de los dos anillos (sin cambios: =, rotación de alguno de los anillos: RRoT, doble flip: DF y transiciones complejas:++); en azul las del fenilo y en morado las del indol (sin cambios: =, rotación de 1 anillo: IRot o TRot, flip de anillo: IFlip o TFlip). Los puntos entre categorías indican estados de transición de la categoría superior y los puntos de las gráficas azul o morada por encima de TRot o IRot indican transiciones complejas de ese anillo. 


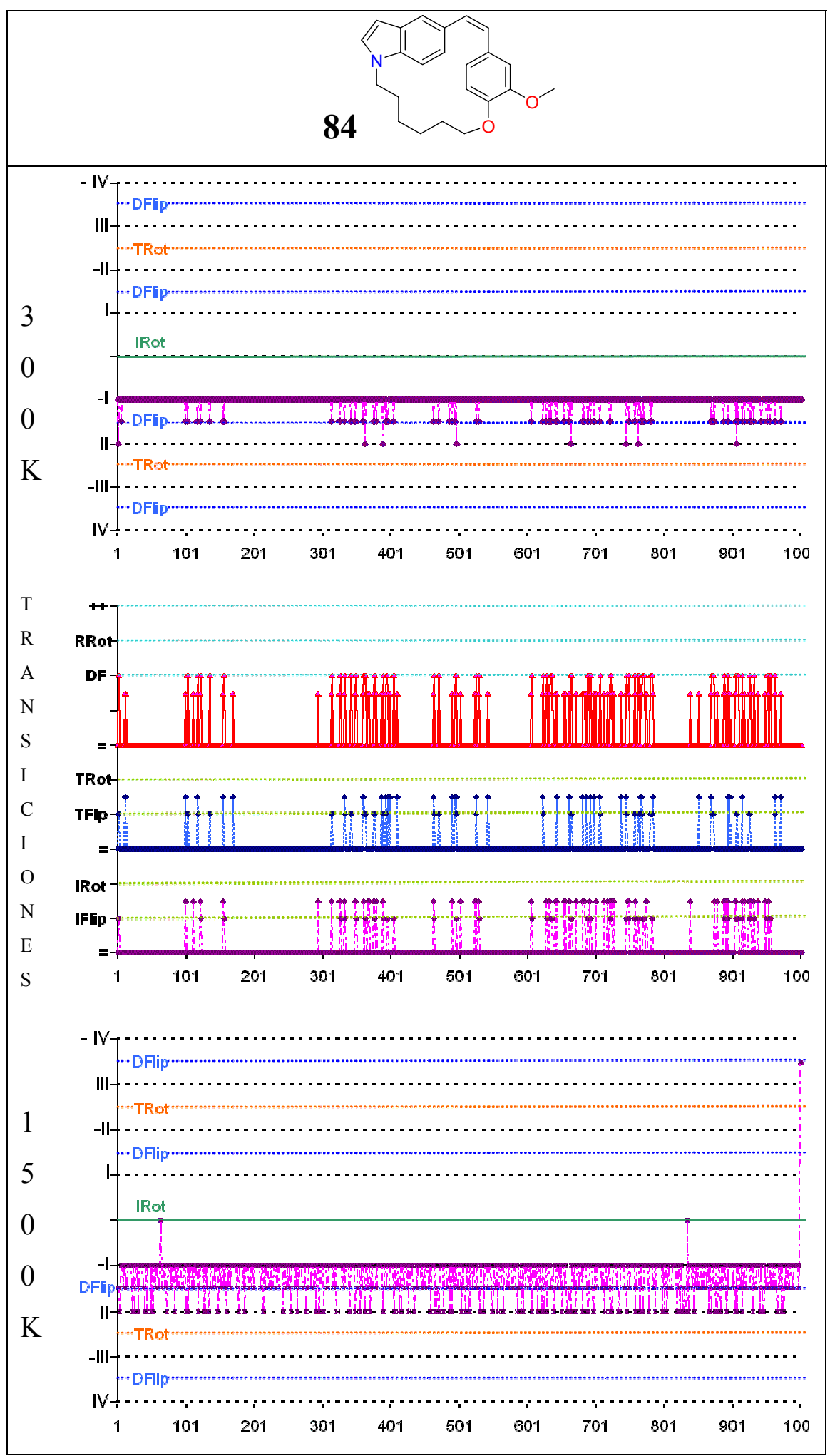

Figura 66a. Gráficas resumen de las dinámicas moleculares del compuestos 84. La gráfica superior muestra los grupos conformacionales a los que pertenecen las conformaciones obtenidas de la dinámica molecular a $300 \mathrm{~K}$, mientras que la inferior los muestra para la dinámica a $1500 \mathrm{~K}$. En la gráfica central se indican las transiciones sencillas asignadas a las interconversiones en la dinámica molecular a 300: En rojo las de los dos anillos (sin cambios: $=$, rotación de alguno de los anillos: RRoT, doble flip: DF y transiciones complejas:++); en azul las del fenilo y en morado las del indol (sin cambios: =, rotación de 1 anillo: IRot o TRot, flip de anillo: IFlip o TFlip). Los puntos entre categorías indican estados de transición de la categoría superior y los puntos de las gráficas azul o morada por encima de TRot o IRot indican transiciones complejas de ese anillo. 


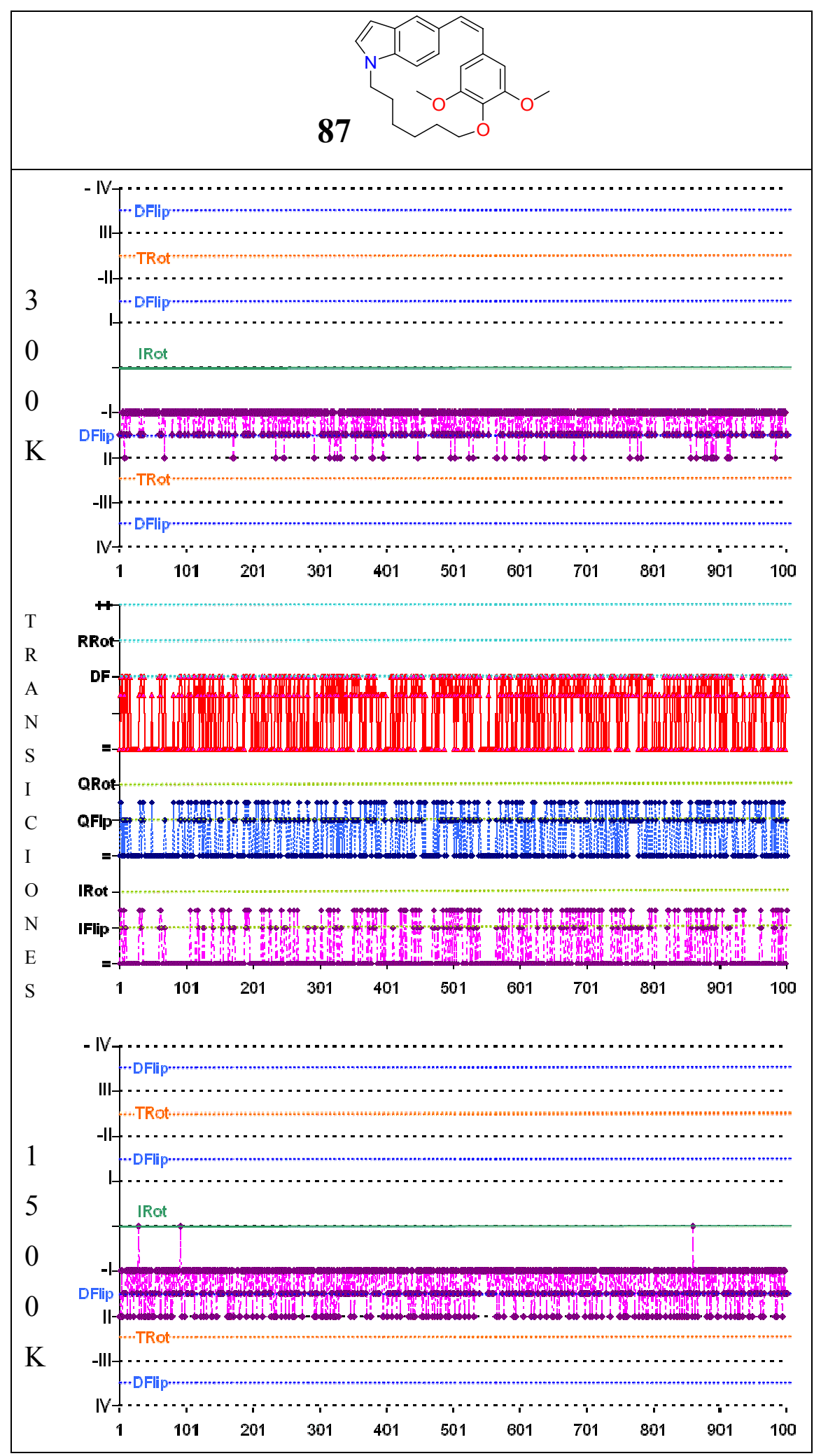

Figura 66b. Gráficas resumen de las dinámicas moleculares del compuestos 87 La gráfica superior muestra los grupos conformacionales a los que pertenecen las conformaciones obtenidas de la dinámica molecular a $300 \mathrm{~K}$, mientras que la inferior los muestra para la dinámica a $1500 \mathrm{~K}$. En la gráfica central se indican las transiciones sencillas asignadas a las interconversiones en la dinámica molecular a 300: En rojo las de los dos anillos (sin cambios: $=$, rotación de alguno de los anillos: RRoT, doble flip: DF y transiciones complejas: ++ ); en azul las del fenilo y en morado las del indol (sin cambios: =, rotación de 1 anillo: IRot o TRot, flip de anillo: IFlip o TFlip). Los puntos entre categorías indican estados de transición de la categoría superior y los puntos de las gráficas azul o morada por encima de TRot o IRot indican transiciones complejas de ese anillo. 
Las dinámicas moleculares a 300K, 1200K y 1500K (Figuras 66a y b) de 84 y 87 muestran sólo las conformaciones -I y + II, junto con numerosas conformaciones tipo doble flip (en las que los planos de los dos anillos están perpendiculares al del doble enlace), que representan estados intermedios entre ellas. Esto indica que el espaciador reduce notablemente la flexibilidad conformacional de estos compuestos, permitiendo sólo con facilidad el doble flip. Los resultados de las dinámicas moleculares no permiten analizar la estabilidad relativa de los tipos conformacionales para estos compuestos, al no alcanzarse una situación de equilibrio entre conformaciones.

Desde el punto de vista del análisis de las transiciones, al ser pequeñas las diferencias de energía entre conformaciones, el iniciar la simulación en una $u$ otra conformación no debe tener un gran efecto en los tipos y frecuencias de las transiciones observadas.

Cuando se comparan los resultados obtenidos a la misma temperatura para los dos macrociclos, el compuesto 87 muestra mayor movilidad (figura 66b) que el 84 (Figura 66a). Como estos movimientos se asocian a giros de tipo doble flip, éste parece verse facilitado en el compuesto con dos metoxilos. Una posible explicación es que el metoxilo adicional desestabilice las conformaciones -I de baja energía del compuesto 87 (al forzar siempre a situar un metoxilo hacia el interior del macrociclo) respecto al estado de transición, con los metoxilos dirigidos perpendicularmente al plano del doble enlace (y por tanto interaccionando más débilmente). En comparación, el compuesto 84 tiene menos interacción entre el metoxilo y el espaciador en -I, y este efecto desestabilizador disminuye menos entre la conformación -I y el estado de transición.

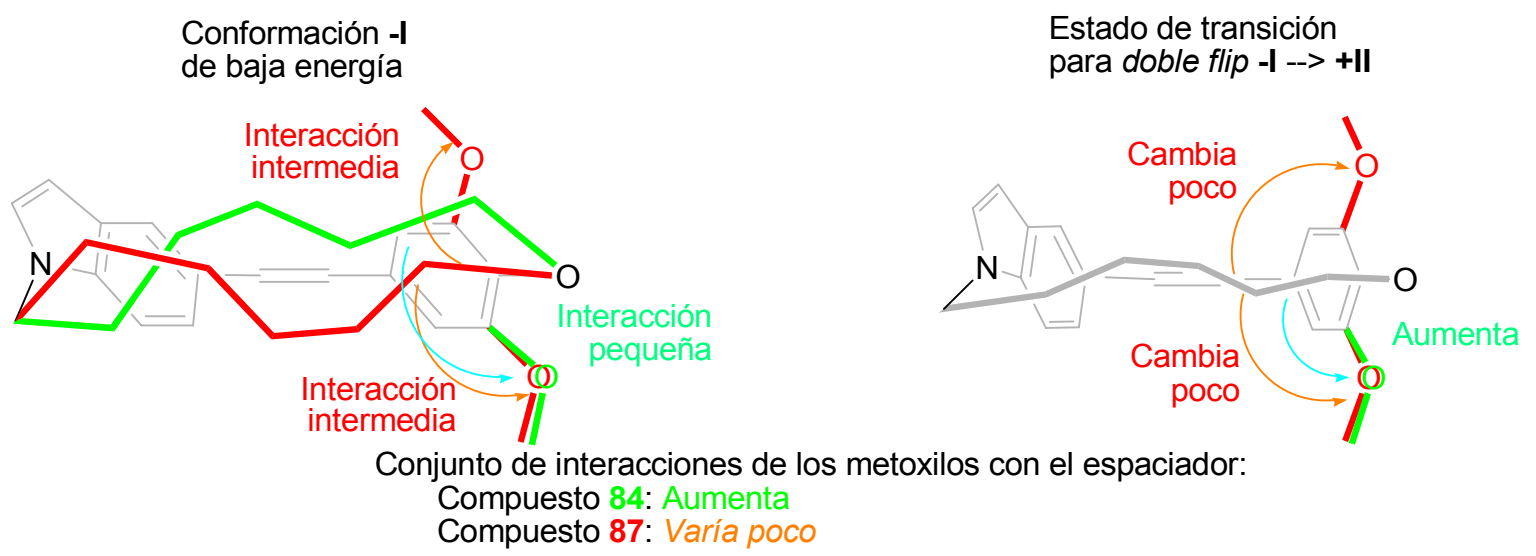

Figura 65. Representación de la interacción de los metoxilos con el espaciador para la conformación -I y el estado de transición -I $\rightarrow$ II para los compuestos 84 y 87 . 
Con el fin de discriminar entre los efectos del espaciador y los debidos a la rigidez introducida en el sistema por el anillo de indol, hemos llevado a cabo dinámicas moleculares iguales a las descritas para 84 y 87 sobre 0D, 0E y 0F. Los resultados para 0D y $\mathbf{0 F}$ (ambos con espaciador hexametileno) son muy similares, por lo que sólo se muestran los de éste último y $\mathbf{0 E}$ (espaciador 3-oxapentametileno). Al igual que en el caso anterior, a $300 \mathrm{~K}$ sólo se aprecia una conformación muy mayoritaria (en este caso -III, la conformación inicial) y una minoritaria (IV), además de la conformación de tipo doble flip intermedia entre ambas.

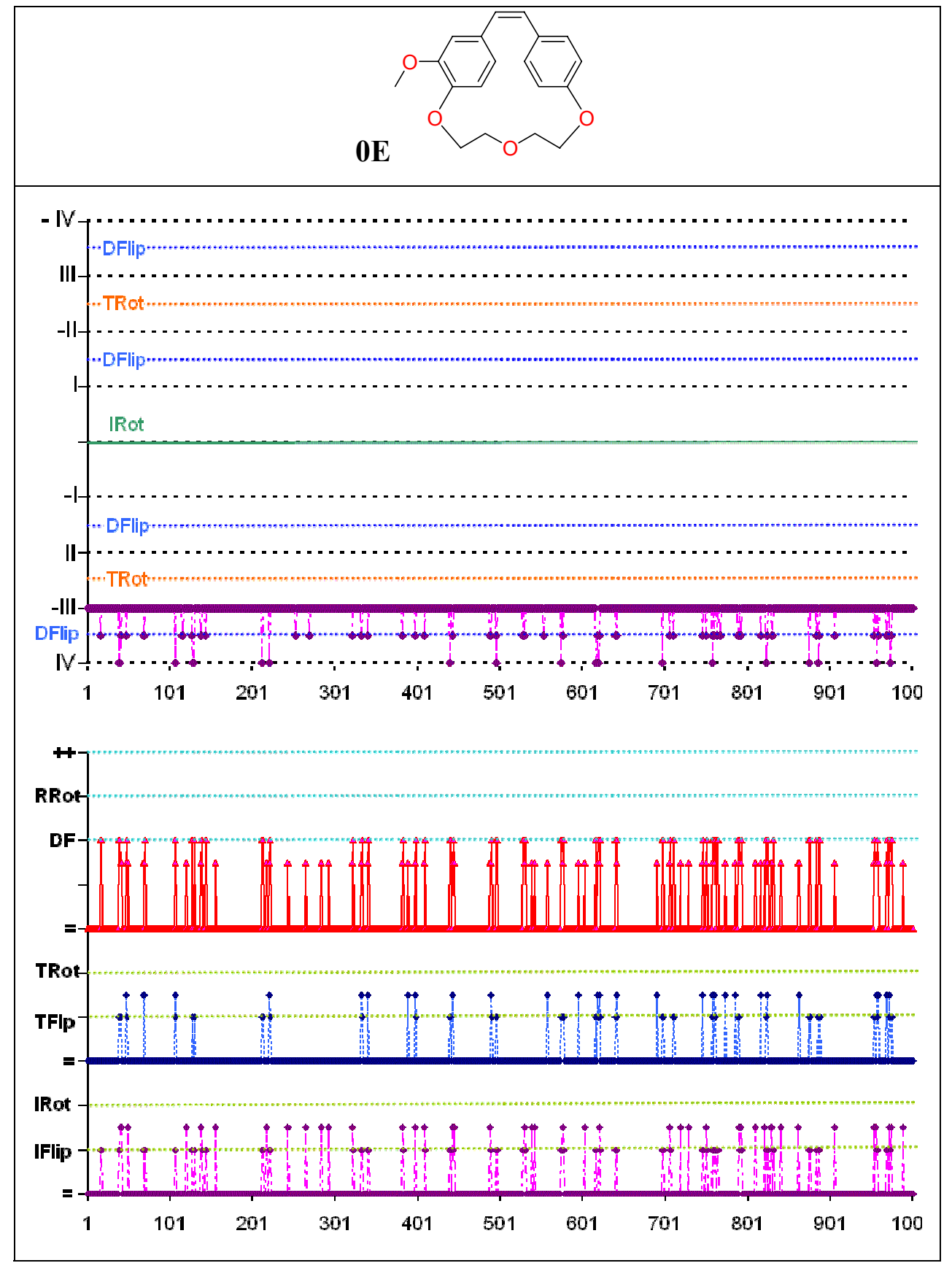

Figura 67a. Conformaciones (gráfica superior) y transiciones observadas (gráfica inferior) en la dinámica molecular a $300 \mathrm{~K}$ del compuesto $\mathbf{0 E}$. 


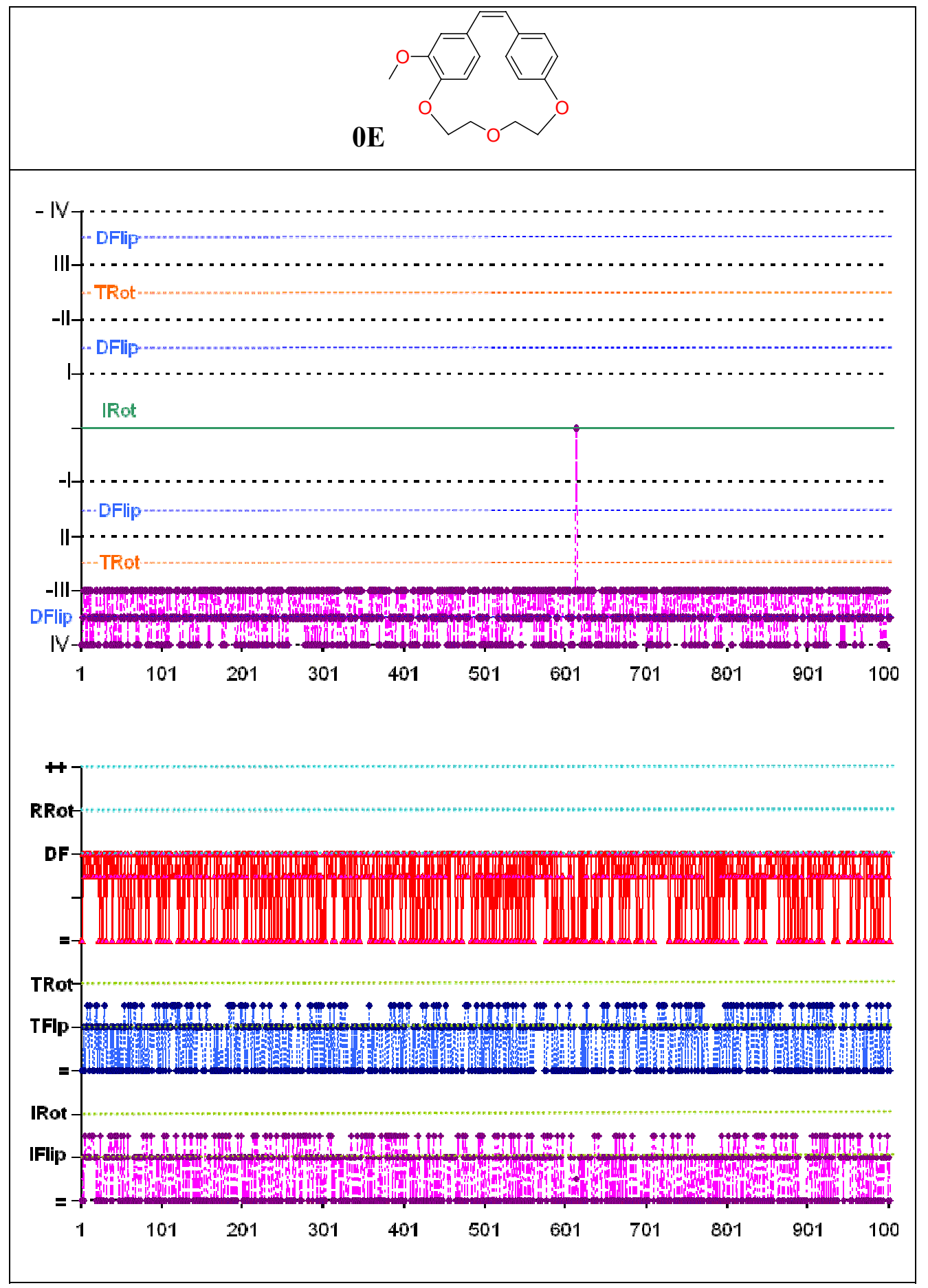

Figura 67b. Conformaciones (gráfica superior) y transiciones observadas (gráfica inferior) en la dinámica molecular a $1200 \mathrm{~K}$ del compuesto $\mathbf{0 E}$.

Tanto en la figura 67a como en la 67b se muestra en la gráfica inferior: En rojo las de los dos anillos (sin cambios: =, rotación de alguno de los anillos: RRoT, doble flip: DF y transiciones complejas:++); en azul las del fenilo y en morado las del indol (sin cambios: =, rotación de 1 anillo: IRot o TRot, flip de anillo: IFlip o TFlip). Los puntos entre categorías indican estados de transición de la categoría superior y los puntos de las gráficas azul o morada por encima de TRot o IRot indican transiciones complejas de ese anillo. 


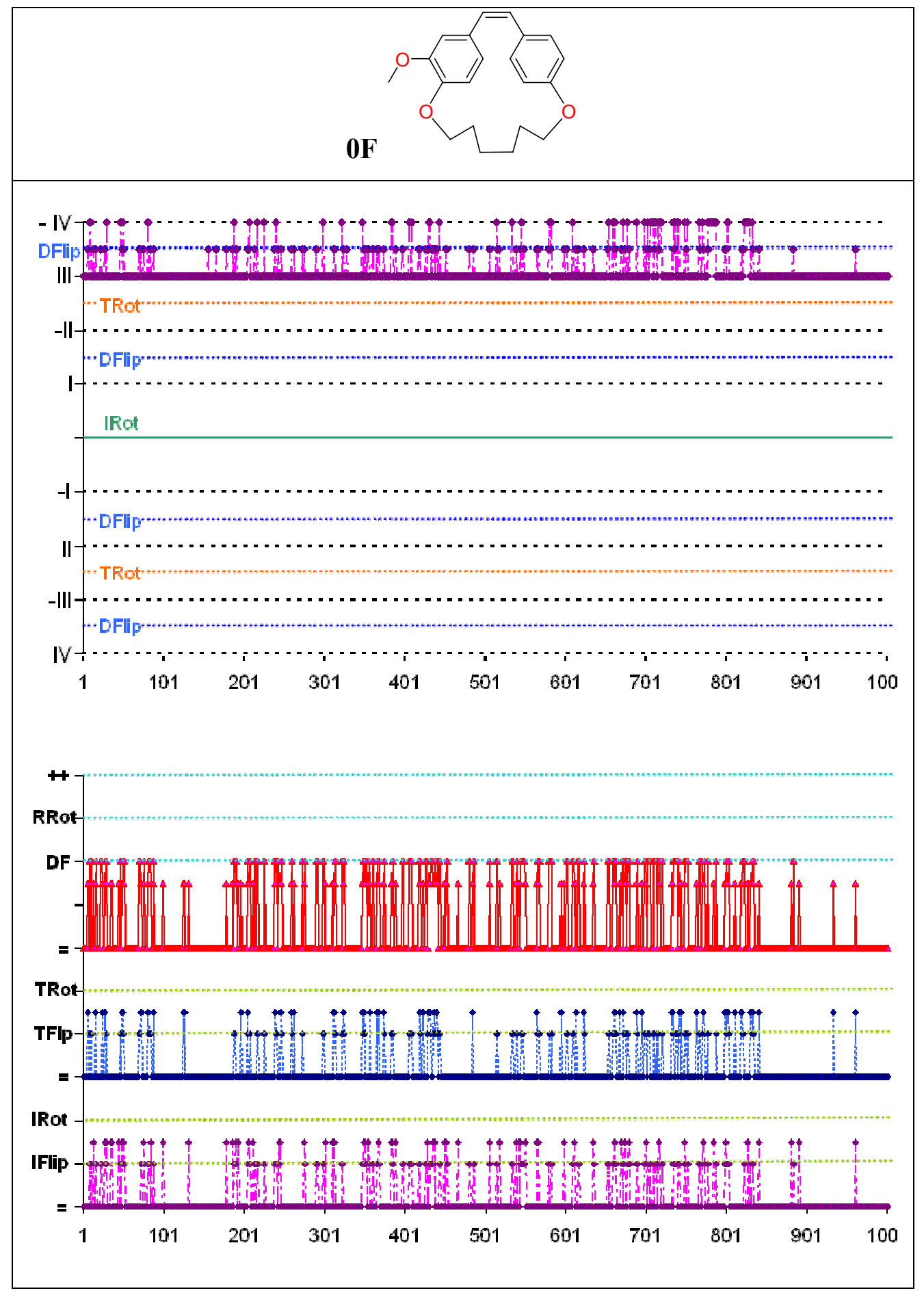

Figura 67c. Conformaciones (gráfica superior) y transiciones observadas (gráfica inferior) en la dinámica molecular a $300 \mathrm{~K}$ del compuesto $\mathbf{0 F}$.

Tanto en la figura 67c como en la figura 67d se muestra en la gráfica inferior: En rojo las de los dos anillos (sin cambios: $=$, rotación de alguno de los anillos: RRoT, doble flip: DF y transiciones complejas: ++ ); en azul las del fenilo y en morado las del indol (sin cambios: =, rotación de 1 anillo: IRot o TRot, flip de anillo: IFlip o TFlip). Los puntos entre categorías indican estados de transición de la categoría superior y los puntos de las gráficas azul o morada por encima de TRot o IRot indican transiciones complejas de ese anillo. 


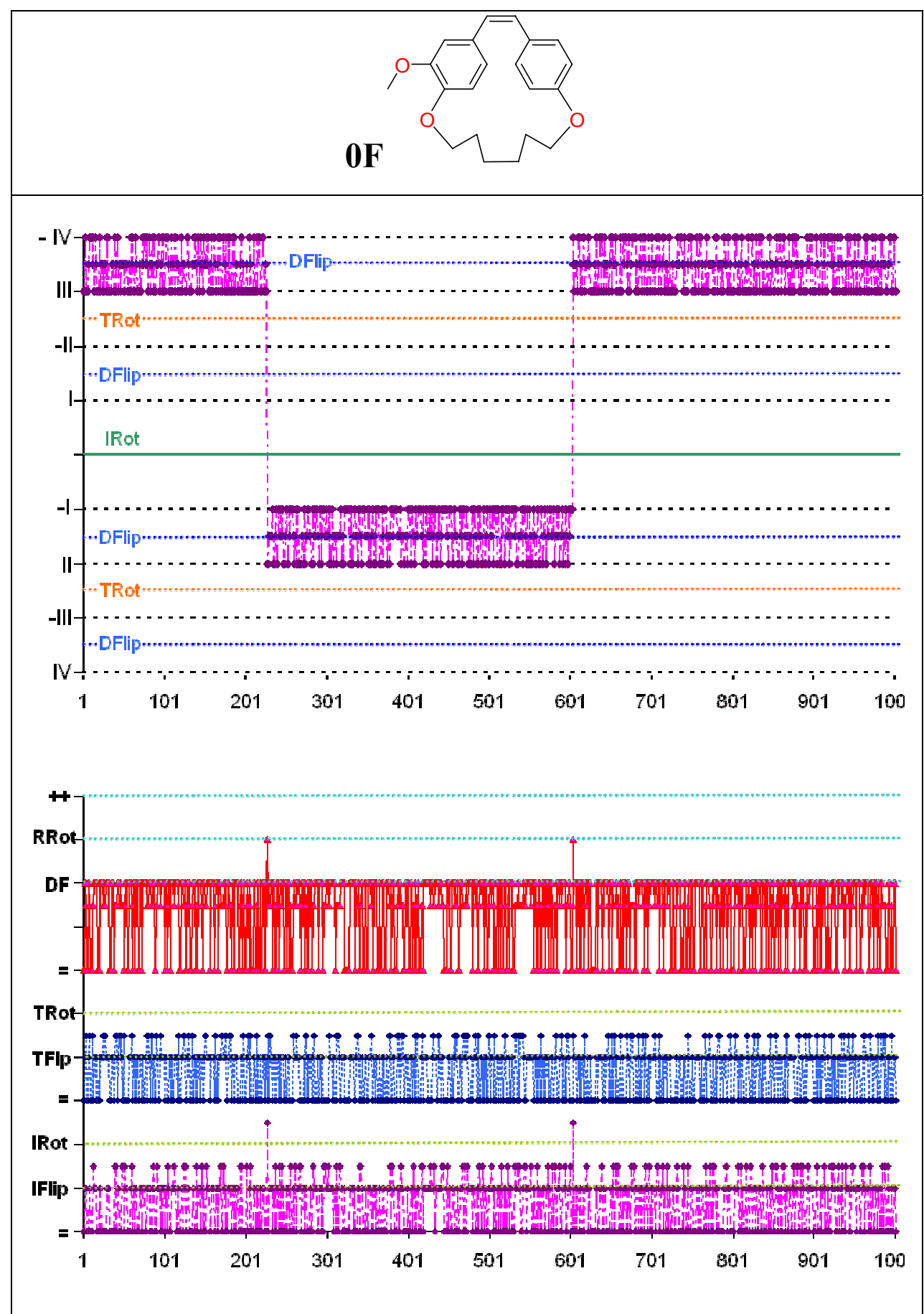

Figura 67d. Conformaciones (gráfica superior) y transiciones observadas (gráfica inferior) en la dinámica molecular a $1200 \mathrm{~K}$ del compuesto $\mathbf{0 F}$.

Para el compuesto con espaciador más corto, el aumento de temperatura a $1200 \mathrm{~K}$ sólo modifica la frecuencia con la que se producen estas transiciones (figura $67 \mathrm{~b}$ ). Sin embargo, para el compuesto con el espaciador más largo (0F, figura 67d), se observa que al aumentar la temperatura a $1200 \mathrm{~K}$, se alcanzan, además, las conformaciones -I y +II, debido a que se produce la rotación del anillo trisustituido. 
Anteriormente, en el análisis conformacional de dioles trans relacionados con $\mathbf{0 E}$ y $\mathbf{0 F}$, en los que existe un anillo disustituido y otro tetrasustituido (0J y $\mathbf{0 K}$ ) habíamos descrito una situación similar: a $1200 \mathrm{~K}$ el anillo disustituido de $\mathbf{0 K}$ efectuaba rotaciones, (a través del macrociclo de mayor tamaño con espaciador hexametileno) mientras que el de 0J no lo hacía (debido al menor tamaño del macrociclo). ${ }^{44,48}$ Sin embargo, en el caso de $\mathbf{0 F}$, el anillo que rota es el anillo trisustituido, mientras que en $\mathbf{0 K}$ es el anillo disustituido elque lo hace.

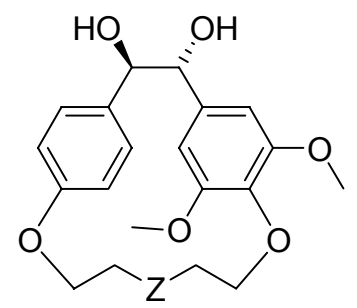

OJ $Z=O$

OK $Z=\left(\mathrm{CH}_{2}\right)_{2}$

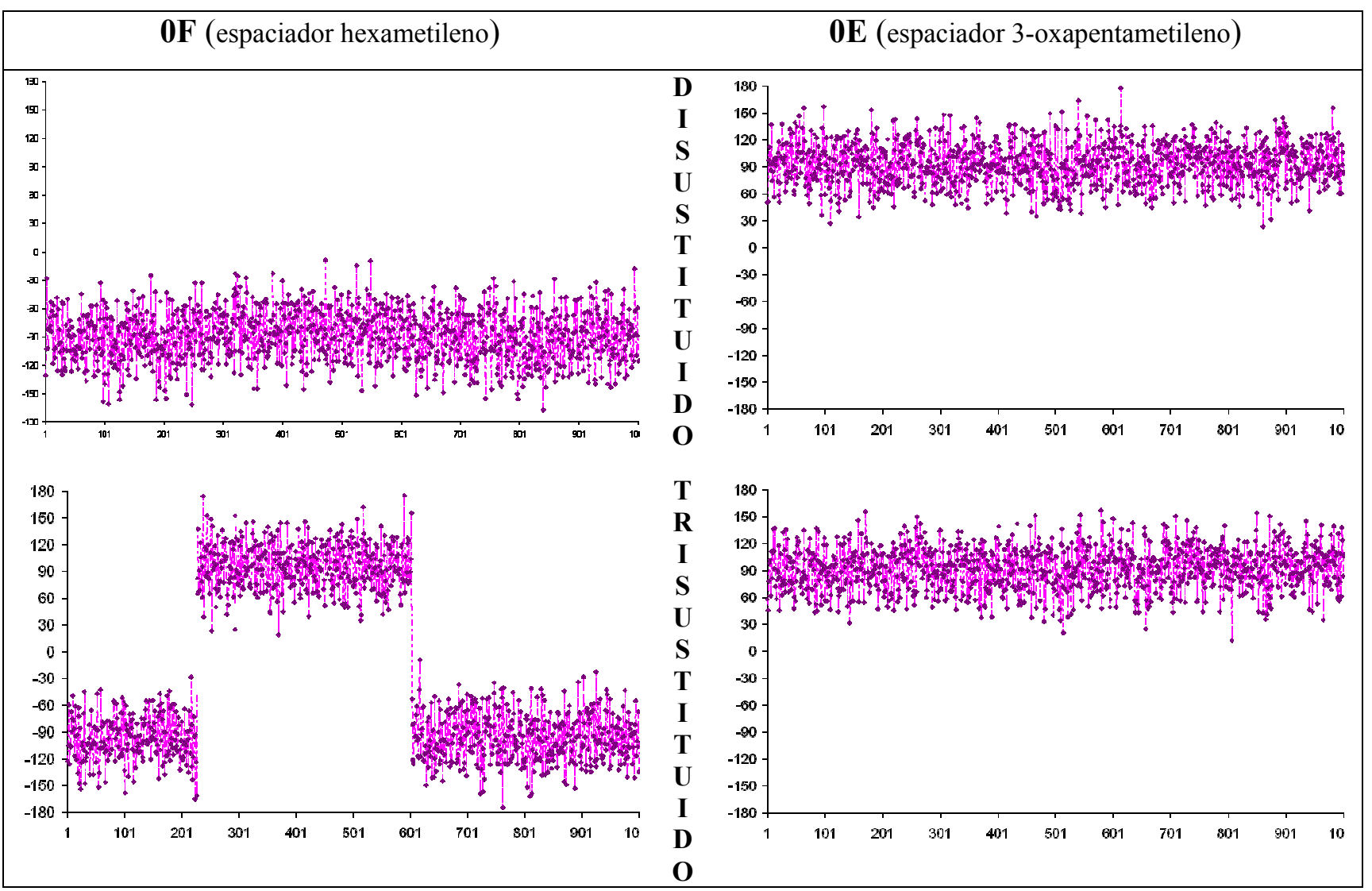

Figura 68. Representación gráfica de los valores de los ángulos diedros DI y DT (definidos anteriormente y que nos indican la disposición de los anillos aromáticos respecto al puente olefínico) de las conformaciones obtenidas en los estudios de dinámica molecular a $1200 \mathrm{~K}$ de $\mathbf{0 F}$ (a la izquierda) y $\mathbf{0 E}$ (a la derecha). Las gráficas superiores se corresponden con los valores de los ángulos diedros del anillo disustituido y las inferiores con los del anillo trisustituido. Así, se observa que sólo se produce un cambio (giro del anillo) en el anillo trisustituido de $\mathbf{0 F}$. 
Una posible explicación para dicha discrepancia es que el anillo tetrasustituido de 0G no puede efectuar la rotación, ya que esto requeriría el paso de un metoxilo a través del espacio intraanular. En el caso de $\mathbf{0 F}$, tanto el anillo disustituido como el trisustituido podrían efectuar la rotación pasando un hidrógeno por el espacio intraanular. Si el anillo que rota es el anillo trisustituido su sustituyente se dirige hacia el exterior, no interfiriendo con la rotación. Por el contrario, cuando se produce la rotación del anillo disustituido, el anillo trisustituido debe situarse perpendicular al plano del doble enlace, con el fin de permitir el paso del otro anillo por el espacio intraanular. El metoxilo se dirige entonces hacia el interior, viéndose dificultada la rotación por las interacciones entre el metoxilo, el espaciador y el anillo en rotación.
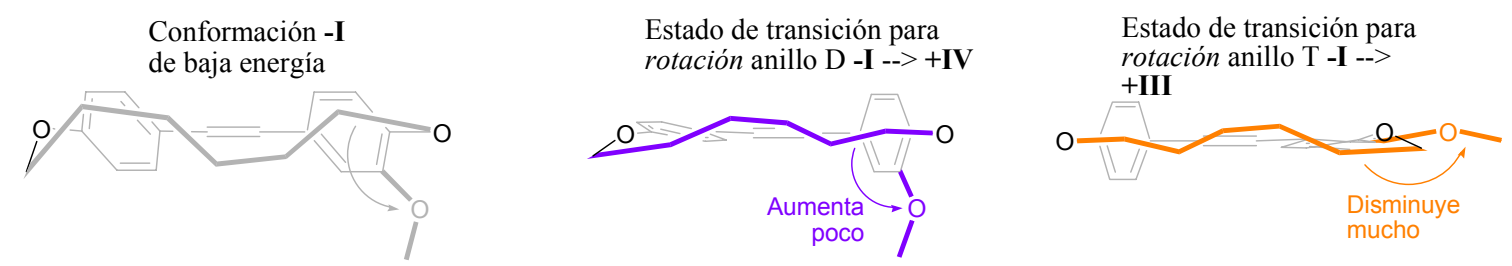

Figura 69. Esquema de la interacción entre el espaciador y el metoxilo del anillo trisustituido del compuesto 0F cuando se produce la rotación de dicho anillo que interconvierte las conformaciones -I y +III (en naranja a la derecha) y cuando se produce la rotación del anillo disustituido (en morado, en el centro).

En el caso de 0E (en que el hueco intra-anular es más pequeño) y en los de 84 y 87 no se observan los giros de los anillos en la simulación, ni siquiera a temperaturas superiores (1500K). En el caso de 84 y 87, no se observa en las simulaciones transiciones causadas por la rotación del anillo de indol, como por ejemplo I-III ó II-IV y viceversa, aunque si se observan conformaciones en las que el anillo de indol es coplanar con el doble enlace (conformaciones cercanas al estado de transición de la rotación del anillo de indol). Al igual que se ha mencionado para $\mathbf{0 F}$, el metoxilo del anillo trisustituido dificulta el giro del otro anillo. En el caso de los derivados indólicos, puede esperarse que este efecto sea incluso más pronunciado, ya que el enlace indol N-C hace al espaciador menos flexible. 


\section{III.4.A.3 Justificación de la apariencia de los espectros de RMN de las olefinas 84 y 87.}

Todas las olefinas macrocíclicas presentan unos espectros de RMN con un único juego de señales y en los que los núcleos que se intercambian mutuamente resuenan isocronos, excepto 0E y 87, en los que están ensanchadas. Como se ha indicado anteriormente y teniendo en cuenta la facilidad para la rotación de los anillos encontrada en los experimentos de dinámica molecular, la situación puede explicarse considerando una interconversión rápida entre las especies I-IV, independientemente de su helicidad. Esta rápida interconversión requiere que al menos dos de los movimientos considerados (giro de cada uno de los anillos o doble flip) sean rápidas en la escala de tiempo de la RMN (teniendo en cuenta la diferencia de entorno magnético que tiene que ser promediada). El doble flip parece ocurrir con facilidad, por lo que sólo se requiere que el giro de uno de los dos anillos también sea rápido. El análisis de las dinámicas moleculares permite deducir la facilidad relativa de giro de los anillos, que en todos los casos es sustancialmente más lenta que el doble flip.

El compuesto 87, con un anillo tetrasustituido, muestra en sus espectros de RMN ${ }^{1} \mathrm{H}$ y ${ }^{13} \mathrm{C}$ un único juego de señales, donde las correspondientes a los átomos mutuamente intercambiables del anillo tetrasustituido (20-OMe/23-OMe y H-21/H-22) están ensanchadas de manera significativa. La rotación más lenta del anillo indólico, que requiere el paso de los hidrógenos $\mathrm{H}-5 / \mathrm{H}-6$ a través del espacio intra-anular (intercambio de las conformaciones enantioméricas -I/+III y +I/-III), puede explicar este ensanchamiento (el entorno de 20-OMe/23-OMe y H-21/H-22, químicamente equivalentes, es diferente en dichas conformaciones intercambiables). Otra posibilidad para explicar este ensanchamiento, consiste en una rotación intermedia del anillo- $Q$ en la que un grupo metoxilo pasa a través del espacio intra-macrocíclico, aunque es menos probable. En ambas posibilidades, debe producirse un rápido doble-flip. En caso contrario, observaríamos dos juegos completos de señales, o un solo juego que se correspondería con la disposición más estable (por ejemplo, $\mathrm{N}$-espaciador endo -I/+III predominaría sobre Nespaciador exo $+\mathrm{II} /-\mathrm{IV})$. 
Considerando los resultados de la dinámica molecular, la rotación del anillo tetrasustituido no debe ser rápida. Además, para 84, con un anillo trisustituido, la dinámica molecular sugiere que el anillo de indol tampoco le permite rotar con facilidad. Esto parece apuntar a la rotación del anillo de indol como el origen de la diferencia. Sin embargo, el anillo de indol tampoco gira con facilidad, ni en la olefina 84 ni en la 87. Estas consideraciones estarían de acuerdo con las características espectroscópicas descritas para 87, considerando que el ensanchamiento de los metoxilos y los protones aromáticos es causado por el giro del indol. Sin embargo, esto conduciría a un espectro para 84 en el que el anillo trisustituido y el del indol darían lugar a dos juegos de señales (uno correspondiente a I-II y el otro a III-IV), salvo que la rotación del indol se viera acelerada por la supresión de un metoxilo (hecho que no se observa en las dinámicas moleculares). Una segunda posibilidad, acorde con los resultados de la mecánica molecular, es que una de las parejas de conformaciones (I/II ó III/IV) contribuyera menos al equilibrio.

Como ya se ha indicado, para explicar los espectros de las olefinas no indólicas, se ha propuesto una situación diferente: dos giros rápidos. ${ }^{48}$ Esto implicaría que el cambio de un anillo fenólico por el de indol acarrea una gran diferencia en la movilidad del anillo. Por otra parte, el anillo de indol es, magnéticamente, mucho más anisotrópico que los equivalentes fenólicos considerados, por lo que la diferencia de desplazamiento químico en presencia de estos se reduciría, y con ella la velocidad del proceso que intercambia los sitios mutuamente intercambiables.

De todo ello parece desprenderse que los intercambios entre conformaciones son suficientemente rápidos cuando el espaciador es mayor (hexametileno), reduciéndose la movilidad cuando se reduce el tamaño (0E, espaciador 3-oxapentametileno) o aumenta la rigidez debido a la presencia del sistema indol (84 y 87). En estos casos el doble flip debe seguir siendo rápido y el giro del indol intermedio, produciéndose con mayor dificultad para 84, en el que además debe predominar una de las conformaciones mayoritariamente. 


\begin{tabular}{|c|c|c|c|c|c|c|c|}
\hline & $\begin{array}{l}\text { Doble } \\
\text { flip }\end{array}$ & $\begin{array}{c}\text { Giro } \\
\text { D }\end{array}$ & $\begin{array}{c}\text { Giro } \\
\text { T }\end{array}$ & $\begin{array}{c}\text { Giro } \\
\text { Q }\end{array}$ & $\begin{array}{c}\text { Giro } \\
\text { I }\end{array}$ & RMN & Explicación \\
\hline OD & +++ & - & + & No & - & 1 juego & $\begin{array}{c}\text { Intercambio rápido } \\
\text { Promedio }\end{array}$ \\
\hline OE & +++ & $\bullet$ & $+/ \bullet$ & - & - & $\begin{array}{c}1 \text { juego } \\
\text { ensanchado }\end{array}$ & $\begin{array}{l}\text { Intercambio } \\
\text { intermedio }\end{array}$ \\
\hline $\mathbf{0 F}$ & +++ & + & + & - & - & 1 juego & $\begin{array}{c}\text { Intercambio rápido } \\
\text { Promedio }\end{array}$ \\
\hline 84 & +++ & - & $+/ \bullet$ & - & $+/ \bullet$ & 1 juego & $\begin{array}{l}\text { Intercambio lento } \\
\text { Predominio de } 1 \\
\text { conformación }\end{array}$ \\
\hline 87 & +++ & - & - & No & $+/ \bullet$ & $\begin{array}{c}1 \text { juego } \\
\text { ensanchado }\end{array}$ & $\begin{array}{l}\text { Intercambio } \\
\text { intermedio }\end{array}$ \\
\hline
\end{tabular}

Tabla 17. Resumen del análisis conformacional de las olefinas, donde +++ indica un giro rápido, + giro menos rápido, $\bullet$ indica giro lento y No que el giro está impedido. Las letras D, T, Q e I se refieren a los anillos aromáticos disustituidos, trisustituidos, tetrasustituidos y $\mathrm{N}$-metilindol, respectivamente. 



\section{III.4. B Dioles y diacetatos.}

\section{III.4.B.1 Análisis de conformaciones.}

\section{III.4.B.1.a. Análisis de conformaciones de dioles con dos restos fenilo.}

El análisis conformacional de los dioles se complica por la existencia de una mayor libertad conformacional producida por la posibilidad de giro del puente, que no tenía lugar en el caso del puente olefínico. ${ }^{44,48,60}$ Para este análisis conformacional se pueden tomar en consideración las posibilidades representadas en la figura 70: a) rotación de un anillo (A), b) rotación del otro anillo (B), c) rotación del puente, que conlleva el cambio entre las dos disposiciones sinclinales para los dos restos fenilo, y d) cambio de la helicidad de los anillos (signos de los ángulos diedros definidos por los planos de los anillos con el enlace central del puente). El giro de los anillos sin completar su rotación puede dar lugar a múltiples conformaciones en intercambio rápido, ya que no existe una restricción severa de la misma por no requerir del paso de los sustituyentes a través del espacio intraanular. El cambio entre una conformación sinclinal y la otra, producida por giro del puente, tampoco presenta este tipo de limitación.

\footnotetext{
${ }^{60}$ a) Pennigton, W.; Chakraborty, S.; Paul, I. C.; Curtin, D. Y. Crystal Structures of D-(+)- and mesoHydrobenzoin. Absolute Direction of the Dipole Moment of D- and L-Hydrobenzoin in the Crystal and Correlation with Crystal Crystal Morphology, Pyroelectric Effect, and Absolute Configuration. J. Am. Chem. Soc. 1998, 110, 6498-6504. b) Momchilova, T. G.; Ivanov, P. M. MM2 Conformational-Analysis of Diastereoisomers with Phenyl Groups on Neighboring Carbon-Atoms and Intramolecular HydrogenBonding. Theochem. Mol. Struct. 1993, 288, 133-149.
} 


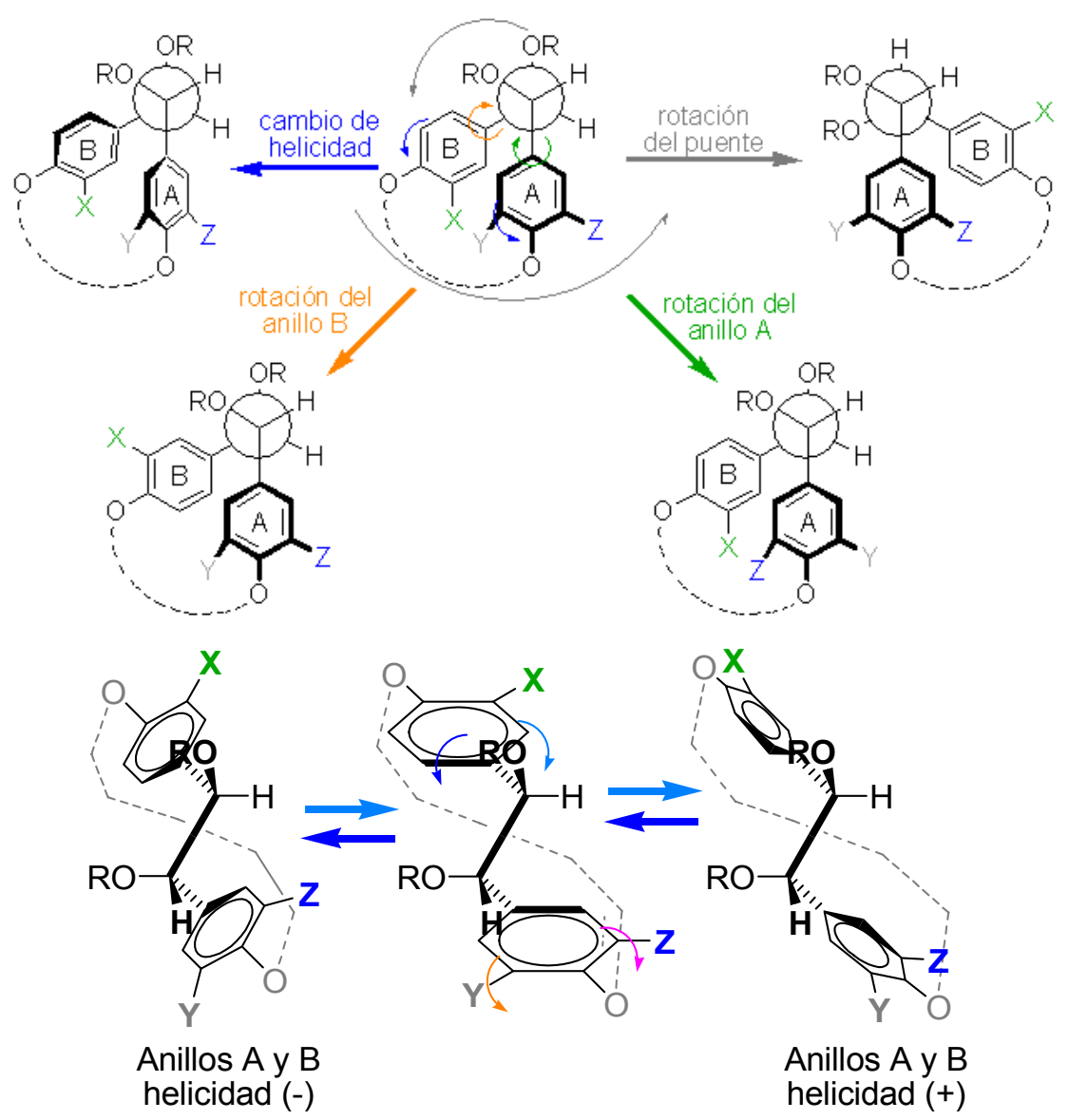

Figura 70. Posibilidades de cambio conformacional para los dioles: giro del anillo A (flechas verdes), giro del anillo B (flechas naranjas), giro del puente (que cambia de una disposición (+)-sinclinal a otra (-)-sinclinal de los grupos fenilo, flechas grises) y cambio de helicidad de los anillos (flechas azules). Esta última posibilidad, se detalla en la representación de la parte inferior de la figura.

Las cuatro posibilidades de cambio conformacional descritas en la figura 70 pueden producir dieciséis conformaciones de referencia, que se representan en las figuras 71 y 72 . En la primera de ellas se presentan las conformaciones indicando la disposición de distintos elementos que las caracterizan: el puente (Sinclinal + ó -; OH,OH- gauche o anti), la helicidad de los anillos y la situación de la rotación de cada uno de los anillos, representada por la situación de uno de los sustituyentes. 


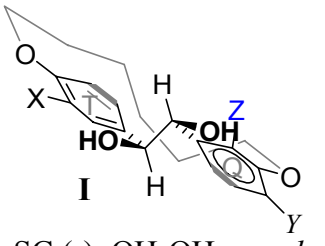

SC:(-); OH-OH: gauche helicidad : (-)

$\mathrm{X}-\quad:$ endo

Z-

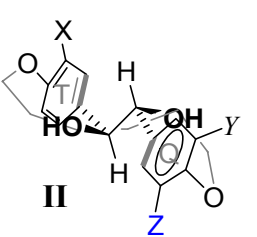

$\mathrm{SC}:(-)$; OH-OH: gauche

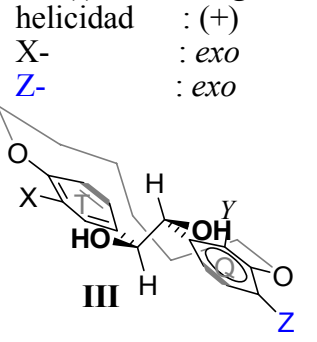

$\mathrm{SC}:(-)$; $\mathrm{OH}-\mathrm{OH}:$ gauche helicidad : (-)

$\mathrm{X}-\quad:$ endo

Z- $\quad$ exo

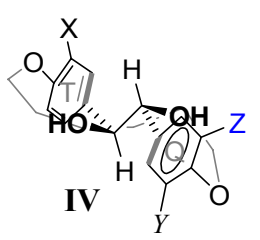

$\mathrm{SC}:(-)$; $\mathrm{OH}-\mathrm{OH}$ : gauche helicidad : $(+)$ $\mathrm{X}$ -

Z-

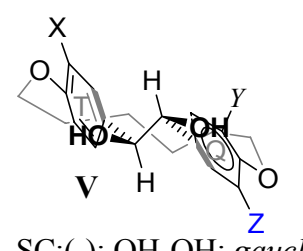

$\mathrm{SC}:(-)$; OH-OH: gauche helicidad : $(-)$

$\mathrm{X}$ -

Z-

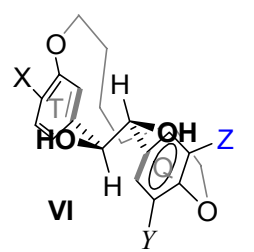

$\mathrm{SC}:(-)$; $\mathrm{OH}-\mathrm{OH}$ : gauche helicidad : $(+)$ $\mathrm{X}-$

Z-

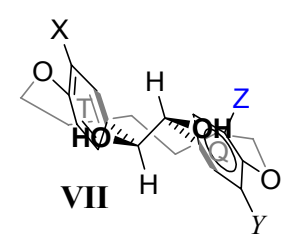

SC:(-); OH-OH: gauche helicidad : (-)

$\mathrm{X}-\quad:$ exo

Z- $\quad$ endo

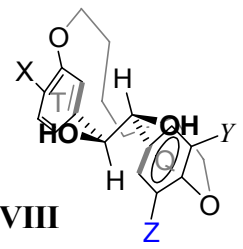

SC:(-); $\mathrm{OH}-\mathrm{OH}$ : gauche

helicidad $:(+)$ $\mathrm{X}$

Z-

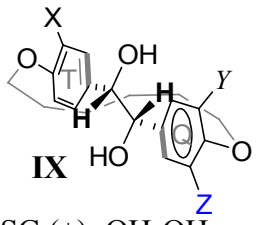

$\mathrm{SC}:(+)$; OH-OH: anti helicidad : (-) $\mathrm{X}-\quad$ : endo Z- : endo

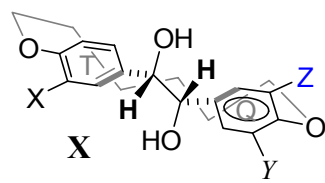

$\mathrm{SC}:(+)$; OH-OH: anti helicidad : $(+)$ $\mathrm{X}$

: exo

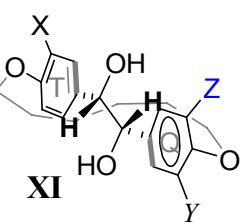

$\mathrm{SC}:(+)$; OH-OH: anti helicidad : (-) $\mathrm{X}-\quad$ : endo Z-

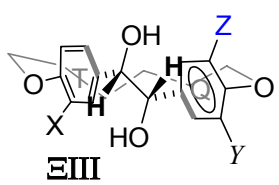

SC:(+); OH-OH: anti helicidad : (-)

$\mathrm{X}-\quad$ : exo

$\mathrm{Z}-\quad$ : exo

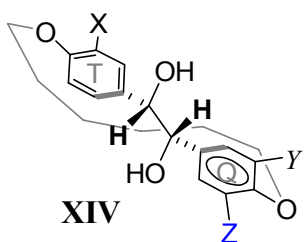

SC:(+); OH-OH: anti

helicidad $:(+)$

$\mathrm{X}-\quad$ : endo

Z- : endo

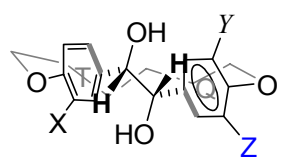

XV

$\mathrm{SC}:(+)$; OH-OH: anti

helicidad : $(-)$

$\mathrm{X}-\quad$ : exo

$\mathrm{Z}-\quad$ : endo

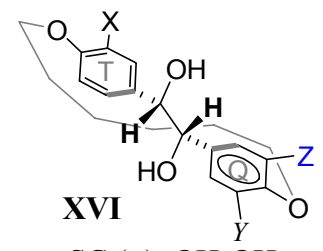

$\mathrm{SC}:(+)$; OH-OH: ant helicidad : $(+)$

$\mathrm{X}-\quad$ : endo

$\mathrm{Z}-\quad$ : exo

Figura 71. Conformaciones de referencia I-XVI para los dioles macrocíclicos, producidas por giro del puente, los restos fenilo A y B y el cambio de helicidad. En la figura se han representado de forma general para un diol de configuración trans, que puede adoptar ocho conformaciones con disposición gauche de los grupos hidroxilo del puente (I-VIII) y otras ocho conformaciones con disposición anti de dichos grupos hidroxilo (IX-XVI). Los dioles de configuración cis (no representados) pueden adoptar conformaciones análogas, todas ellas con disposición gauche de los grupos hidroxilo, ocho con signo + y otras ocho con signo - para el ángulo diedro entre ambos. Sólo se ha representado el enantiómero $S, S$.

En la siguiente figura, se representan las conformaciones relacionándolas mediante el cambio conformacional que ha tenido lugar para pasar de unas a otras. El giro del puente se puede producir sin cambio de helicidad (flechas sólidas) o con cambio simultáneo de la helicidad (flechas de puntos). 


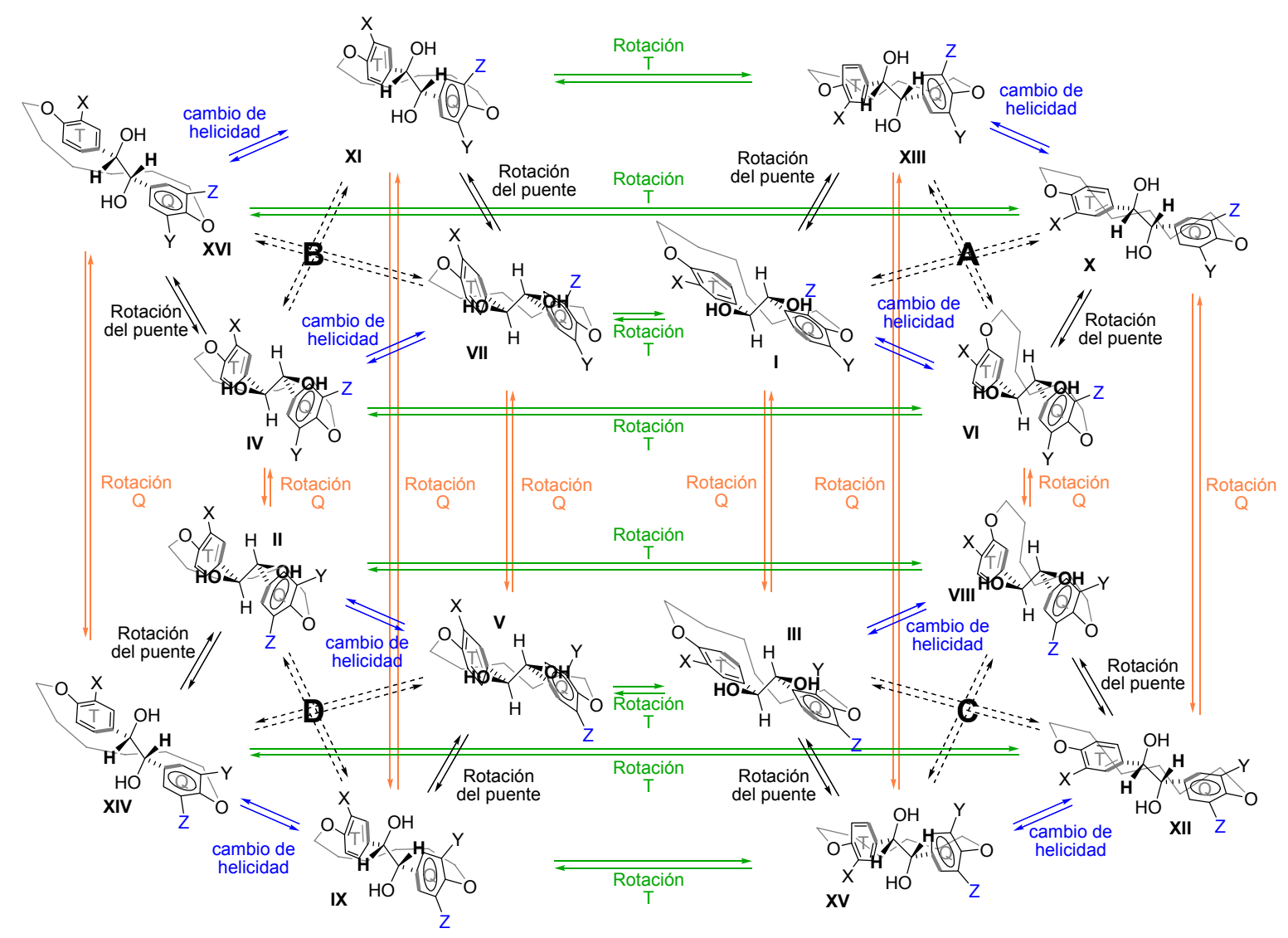

Figura 72. Equilibrio conformacional general de dioles macrocíclicos (se ha representado para un diol de configuración trans). Se representa la rotación del anillo-T en sentido horizontal, la rotación del anillo-Q en sentido vertical y el cambio de helicidad y la rotación del puente en las conexiones de las conformaciones de cada grupo (A, B, C y D) formado por cuatro conformaciones. Las flechas discontinuas indican cambios simultáneos en la helicidad y en el puente.

De acuerdo con lo observado en trabajos anteriores, las conformaciones preferidas para los dioles con configuración trans son aquellas en que los dos grupos hidroxilo están en disposición gauche (I-VIII en la figuras 71 y 72), mientras que en el caso de los dioles cis las dieciséis conformaciones tienen los grupos hidroxilo en disposición gauche. ${ }^{44,48,60}$ En la figura 73, se esquematizan de forma simplificada los equilibrios por rotación del puente, ya que no se consideran otros cambios conformacionales y sólo se representa un enantiómero para cada uno de los dioles. Como se ha comentado más arriba, este cambio conformacional puede ser rápido, ya que no supone el paso de ningún sustituyente a través del macrociclo. 

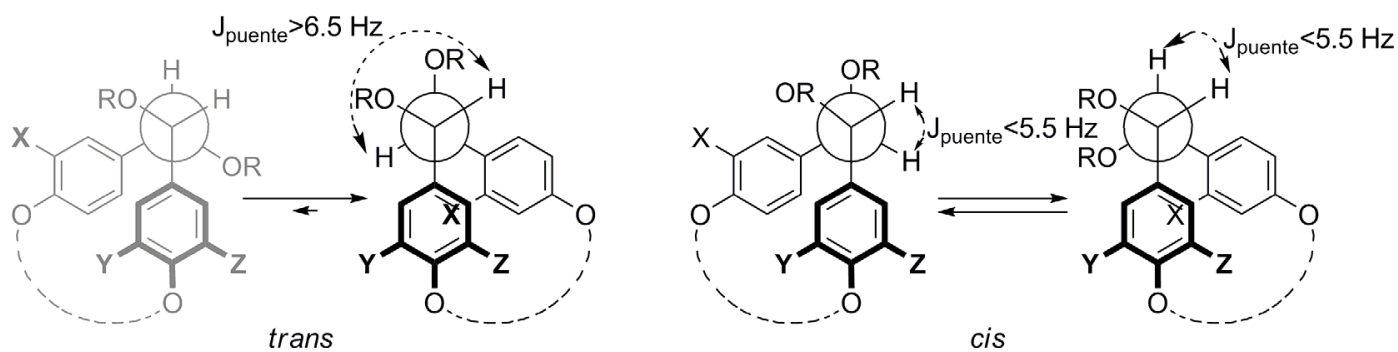

Figura 73. Representación simplificada de las posibilidades conformacionales, para los dioles trans y cis, generadas por rotación del enlace central del puente. Sólo se ha representado un enantiómero (una configuración del puente) en esta figura y en las figuras siguientes.

Debido a su mayor complejidad y a que ya se ha realizado previamente una aproximación al análisis conformacional de los dioles con dos restos fenilo, únicamente se comentarán más adelante las situaciones particulares de los derivados indólicos (tanto los de configuración trans, 86 y 89, sus diacetatos, 91 y 93, como los de configuración cis, 85 y $\mathbf{8 8}$, como los diacetatos, 90 y $\mathbf{9 2}$ ) obtenidos en este trabajo.

Como resumen de lo observado en los dioles macrocíclicos con dos restos fenilo, cabe destacar que, dependiendo de los sustituyentes en los anillos y de que se trate de los alcoholes o de sus acetatos, en RMN se puede observar uno o dos juegos completos de señales. En cada uno de ellos aparecen diferenciados los protones y los carbonos químicamente equivalentes.

La existencia de dos juegos de señales indica, claramente, que hay conformaciones de estabilidades no muy diferentes y que se interconvierten lentamente en la escala de tiempo de RMN. Sin embargo, cuando sólo aparece un juego de señales puede deberse a la presencia de una sola conformación o a varias conformaciones en intercambio rápido. El ensanchamiento de las señales en algún caso indica un intercambio lento-intermedio en dicha escala de tiempo. 
III.4.B.1.b. Análisis de conformaciones de dioles con un resto indolilo.

De forma similar a lo planteado para los compuestos generales, según se ha representado en las figuras 71 y 72, puede hacerse una consideración previa de las conformaciones de los dioles indólicos trans y cis. Los resultados de los cálculos de las conformaciones más estables y de las dinámicas moleculares que se comentan en el apartado siguiente se analizarán en base a estos grupos y cambios conformacionales.

Las dieciséis conformaciones representativas de los dioles trans se recogen en las figuras $74 \mathrm{a}$ y $74 \mathrm{~b}$ y sus posibles interconversiones en las figuras $75 \mathrm{a}$ y $75 \mathrm{~b}$, mientras que las correspondientes a los dioles cis se han recogido en las figuras 76 y 77.

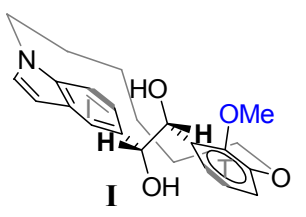

SC:(-); OH-OH: anti helicidad : (-) Indol(C9-C10): endo $\mathrm{OMe}-\quad$ : endo

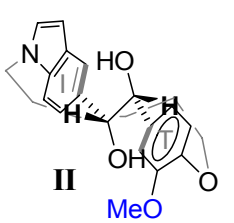

$\mathrm{SC}:(-)$; OH-OH: anti helicidad $:(+)$ Indol(C9-C10): exo $\mathrm{OMe}-\quad$ : exo

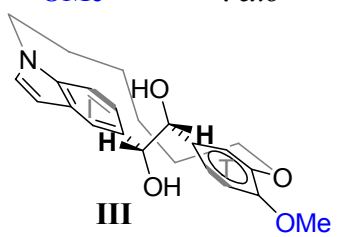

SC:(-); OH-OH: anti helicidad : (-) Indol(C9-C10): endo $\mathrm{OMe}-\quad$ exo

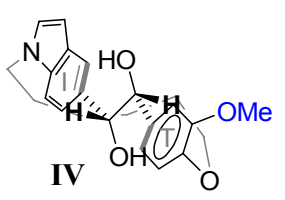

SC:(-); OH-OH: anti helicidad $:(+)$ Indol(C9-C10): exo OMe- : endo

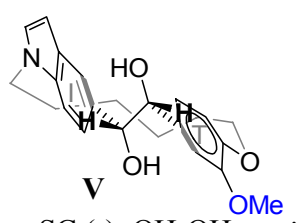

SC:(-); OH-OH: anti helicidad : (-) Indol(C9-C10): exo OMe- : exo

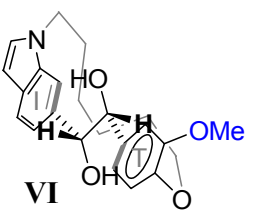

$\mathrm{SC}:(-)$; OH-OH: anti helicidad $:(+)$ Indol(C9-C10): endo $\mathrm{OMe}-\quad$ : endo

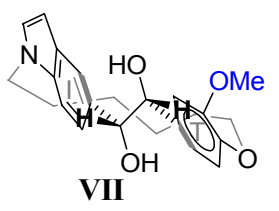

SC:(-); OH-OH: anti helicidad : (-) Indol(C9-C10): exo $\mathrm{OMe}-$

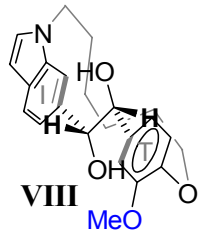

SC:(-); OH-OH: anti helicidad $:(+)$ Indol(C9-C10): endo $\mathrm{OMe}-$

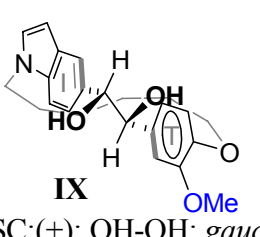

$\mathrm{SC}:(+)$; OH-OH: gauche helicidad : (-)

Indol(C9-C10): endo

$\mathrm{OMe}-\quad$ endo

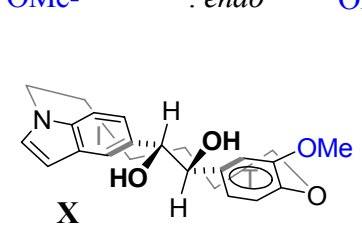

$\mathrm{SC}:(+)$; OH-OH: gauche helicidad : $(+)$ Indol(C9-C10): exo

$\mathrm{OMe}-\quad$ : exo

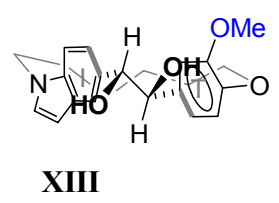

$\mathrm{SC}:(+)$; OH-OH: gauche helicidad : (-) Indol(C9-C10): exo OMe- : exo

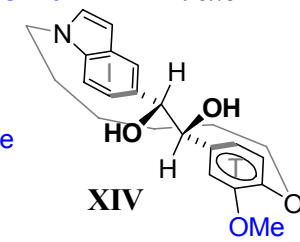

$\mathrm{SC}:(+)$; OH-OH: gauche helicidad $:(+)$ Indol(C9-C10): endo $\mathrm{OMe}-\quad$ : endo

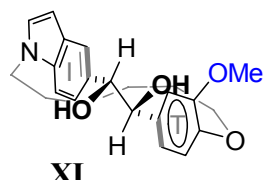

$\mathrm{SC}:(+)$; OH-OH: gauche helicidad : $(-)$

Indol(C9-C10): endo

$\mathrm{OMe}-\quad$ : exo

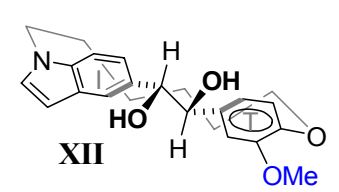

SC:(+); OH-OH: gauche helicidad : $(+)$ Indol(C9-C10): exo $\mathrm{OMe}-$

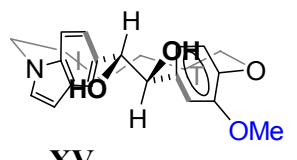

XV

SC:(+); OH-OH: gauche helicidad : (-) Indol(C9-C10): exo $\mathrm{OMe}-\quad$ endo

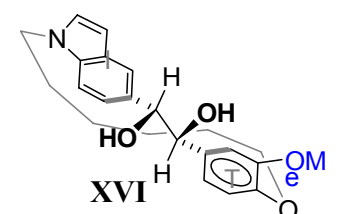

$\mathrm{SC}:(+)$; OH-OH: gauche helicidad : $(+)$ Indol(C9-C10): endo $\mathrm{OMe}-\quad$ exo

Figura 74a. Conformaciones representativas del diol trans 86 (diacetato 91) coincidentes con las representadas en la figura $75 \mathrm{a}$ y las gráficas de las figuras $82 \mathrm{c}$ y $85 \mathrm{~b}$ (izquierda). 


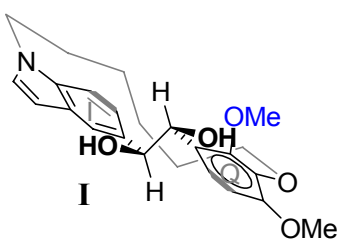

$\mathrm{SC}:(-)$; $\mathrm{OH}-\mathrm{OH}$ : gauche helicidad :(-) Indol(C9-C10): endo $\mathrm{OMe}-$ : endo

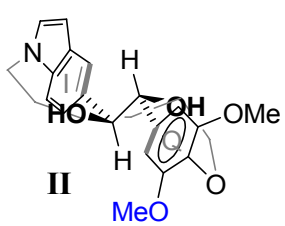

$\mathrm{SC}:(-)$; OH-OH: gauche helicidad : $(+)$ Indol(C9-C10): exo OMe- : exo

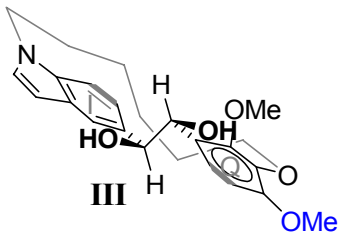

SC:(-); OH-OH: gauche helicidad : (-) Indol(C9-C10): endo

OMe- : exo

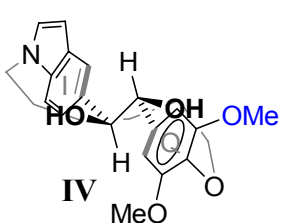

SC:(-); $\mathrm{OH}-\mathrm{OH}$ : gauche helicidad $:(+)$ Indol(C9-C10): exo $\mathrm{OMe}-$ : endo

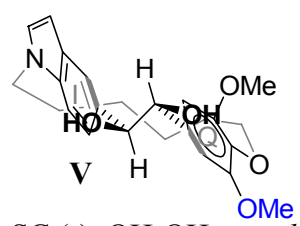

$\mathrm{SC}:(-)$; $\mathrm{OH}-\mathrm{OH}$ : gauche helicidad : (-) Indol(C9-C10): exo

OMe- : exo

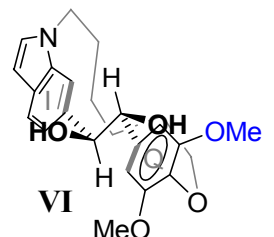

SC:(-); OH-OH: gauche helicidad : $(+)$ Indol(C9-C10): endo

$\mathrm{OMe}-\quad$ endo

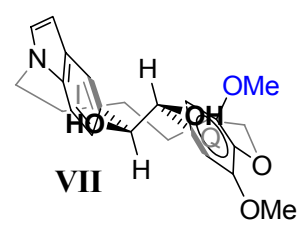

$\mathrm{SC}:(-)$; OH-OH: gauche helicidad : (-) Indol(C9-C10): exo

$\mathrm{OMe}-$ : endo

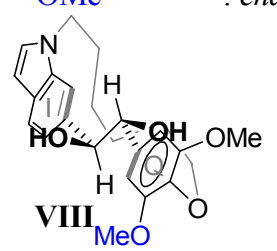

$\mathrm{SC}:(-)$; $\mathrm{OH}-\mathrm{OH}:$ gauche helicidad $:(+)$ Indol(C9-C10): endo $\mathrm{OMe}-$

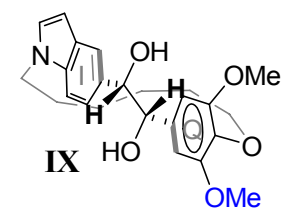

$\mathrm{SC}:(+)$; OH-OH: anti helicidad : (-) Indol(C9-C10): endo $\mathrm{OMe}-\quad$ : endo

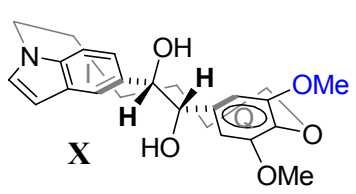

SC:(+); OH-OH: anti helicidad : $(+)$ Indol(C9-C10): exo $\mathrm{OMe}-$ : exo

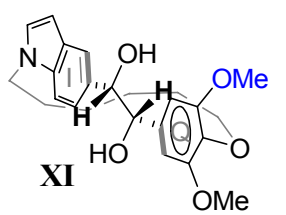

$\mathrm{SC}:(+)$; OH-OH: anti helicidad : (-) Indol(C9-C10): endo

OMe- : exo

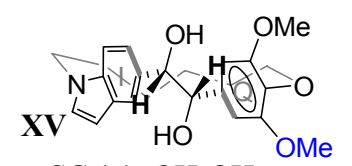

$\mathrm{SC}:(+)$; OH-OH: anti

helicidad : (-)

Indol(C9-C10): exo

$\mathrm{OMe}-\quad$ : endo

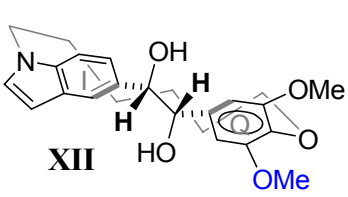

$\mathrm{SC}:(+)$; OH-OH: anti helicidad : $(+)$

Indol(C9-C10): exo

$\mathrm{OMe-} \quad$ endo

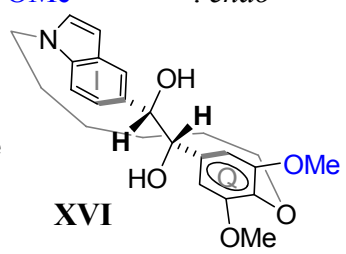

$\mathrm{SC}:(+)$; OH-OH: anti helicidad : $(+)$ Indol(C9-C10): endo $\mathrm{OMe}-\quad$ : exo

Figura 74b. Conformaciones representativas del diol trans 89 (diacetato 93), coincidentes con las representadas en la figura $75 \mathrm{~b}$ y las gráficas de las figuras $82 \mathrm{~d}$ y $85 \mathrm{~b}$ (derecha). 


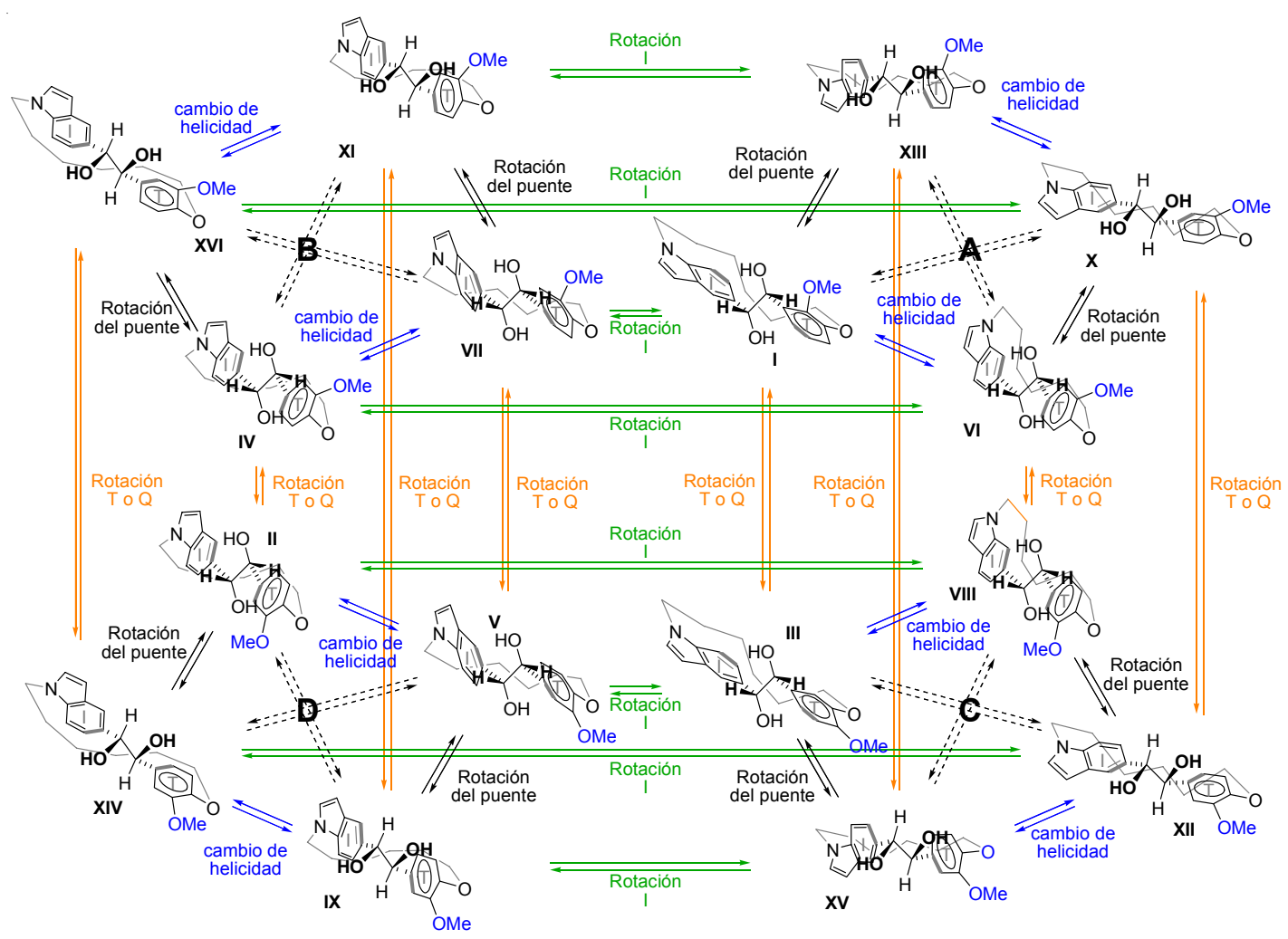

Figura 75a. Equilibrios conformacionales del diol trans $\mathbf{8 6}$.

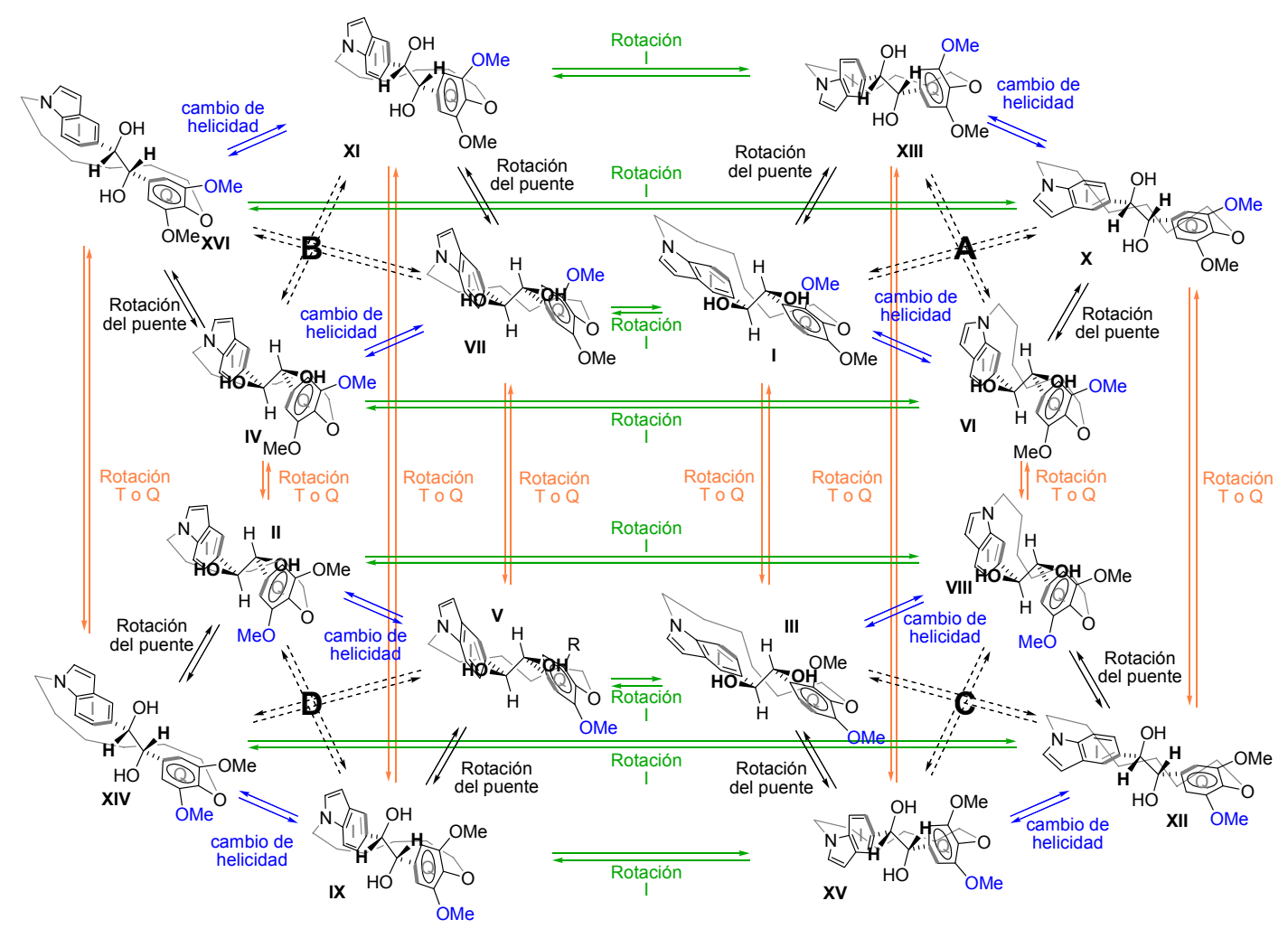

Figura 75b. Equilibrios conformacionales del lo diol trans 89. Tanto en las figuras 75 a y 77 como en ésta, se representa la rotación del anillo-T en sentido horizontal, la rotación del anillo-Q (o anillo T) en sentido vertical y el cambio de helicidad y la rotación del puente en las conexiones de las conformaciones de cada grupo formado por cuatro conformaciones $(\mathbf{A}, \mathbf{B}, \mathbf{C} \mathbf{y} \mathbf{D})$. Las flechas discontinuas indican cambios simultáneos en la helicidad y en el puente. 


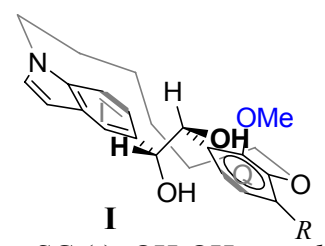

$\mathrm{SC}:(-)$; OH-OH: gauche helicidad :(-) Indol(C9-C10): endo $\mathrm{OMe}-\quad$ endo

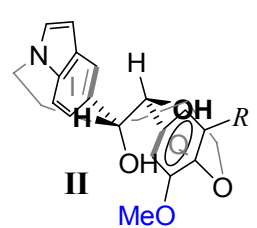

$\mathrm{SC}:(-)$; OH-OH: gauche helicidad $:(+)$ Indol(C9-C10): exo $\mathrm{OMe}-$

: exo

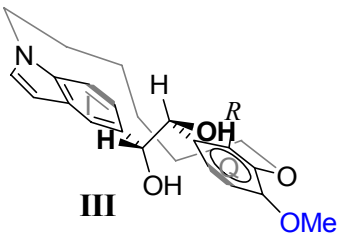

$\mathrm{SC}:(-)$; OH-OH: gauche helicidad : (-) Indol(C9-C10): endo $\mathrm{OMe}-$ : exo

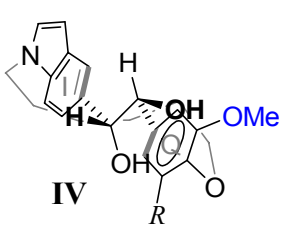

$\mathrm{SC}:(-)$; $\mathrm{OH}-\mathrm{OH}$ : gauche helicidad : $(+)$

Indol(C9-C10): exo

$\mathrm{OMe}-\quad$ : endo

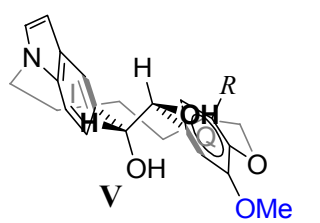

$\mathrm{SC}:(-)$; $\mathrm{OH}-\mathrm{OH}$ : gauche $\mathrm{SC}:(+)$; $\mathrm{OH}-\mathrm{OH}$ : gauche

Indol(C9-C10): exo

OMe- : exo

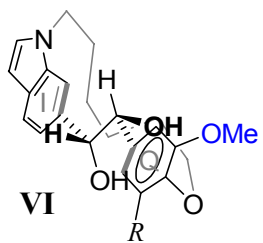

$\mathrm{SC}:(-) ; \mathrm{OH}-\mathrm{OH}$ : gauche

helicidad $:(+)$

Indo(C9-C10): endo

$\mathrm{OMe}-\quad$ : endo

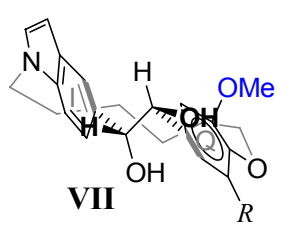

SC:(-); $\mathrm{OH}-\mathrm{OH}$ : gauche helicidad : (-)

Indol(C9-C10): exo

$\mathrm{OMe}-$ : endo

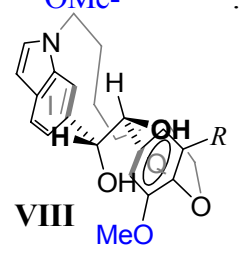

$\mathrm{SC}:(-)$; $\mathrm{OH}-\mathrm{OH}$ : gauche helicidad : $(+)$

Indol (C9-C10): endo

OMe-

: exo

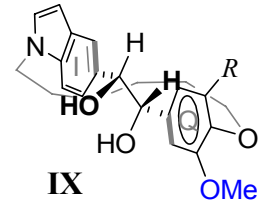

helicidad : (-)

Indol(C9-C10): endo

$\mathrm{OMe}-$

: endo

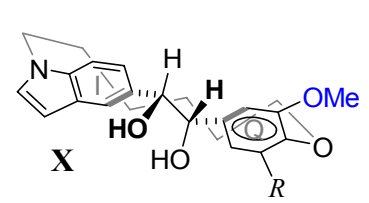

$\mathrm{SC}:(+)$; OH-OH: gauche helicidad : $(+)$

Indol(C9-C10): exo

$\mathrm{OMe}-\quad$ : exo

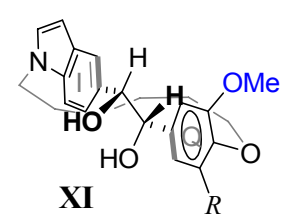

$\mathrm{SC}:(+)$; $\mathrm{OH}-\mathrm{OH}$ : gauche helicidad : (-)

Indol(C9-C10): endo

OMe- : exo

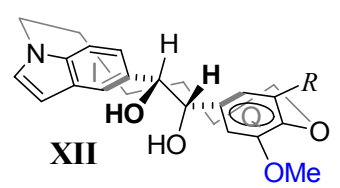

$\mathrm{SC}:(+)$; $\mathrm{OH}-\mathrm{OH}$ : gauche helicidad : $(+)$

Indol(C9-C10): exo

$\mathrm{OMe}-\quad$ endo

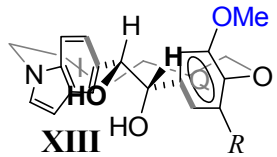

$\mathrm{SC}:(+)$; OH-OH: gauche helicidad : $(-)$ Indol(C9-C10): exo

OMe- : exo

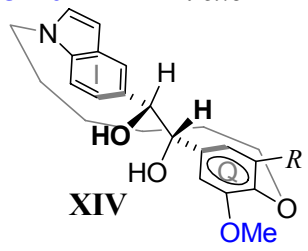

$\mathrm{SC}:(+)$; $\mathrm{OH}-\mathrm{OH}$ : gauche helicidad : $(+)$ Indol(C9-C10): endo $\mathrm{OMe}-\quad$ : endo

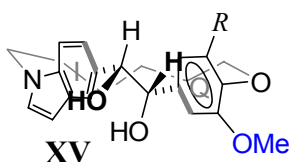

$\mathrm{SC}:(+)$; OH-OH: gauche helicidad : (-)

Indol(C9-C10): exo

$\mathrm{OMe}$ : endo

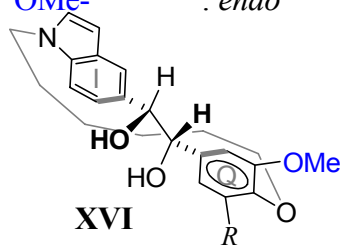

$\mathrm{SC}:(+)$; OH-OH: gauche

helicidad : $(+)$

Indol(C9-C10): endo

$\mathrm{OMe}-\quad$ exo

Figura 76. Conformaciones representativas de los dioles cis $\mathbf{8 5}(\mathrm{R}=\mathrm{H})$ y $\mathbf{8 8}(\mathrm{R}=\mathrm{OMe})$ (diacetatos 90 y 92$)$. 


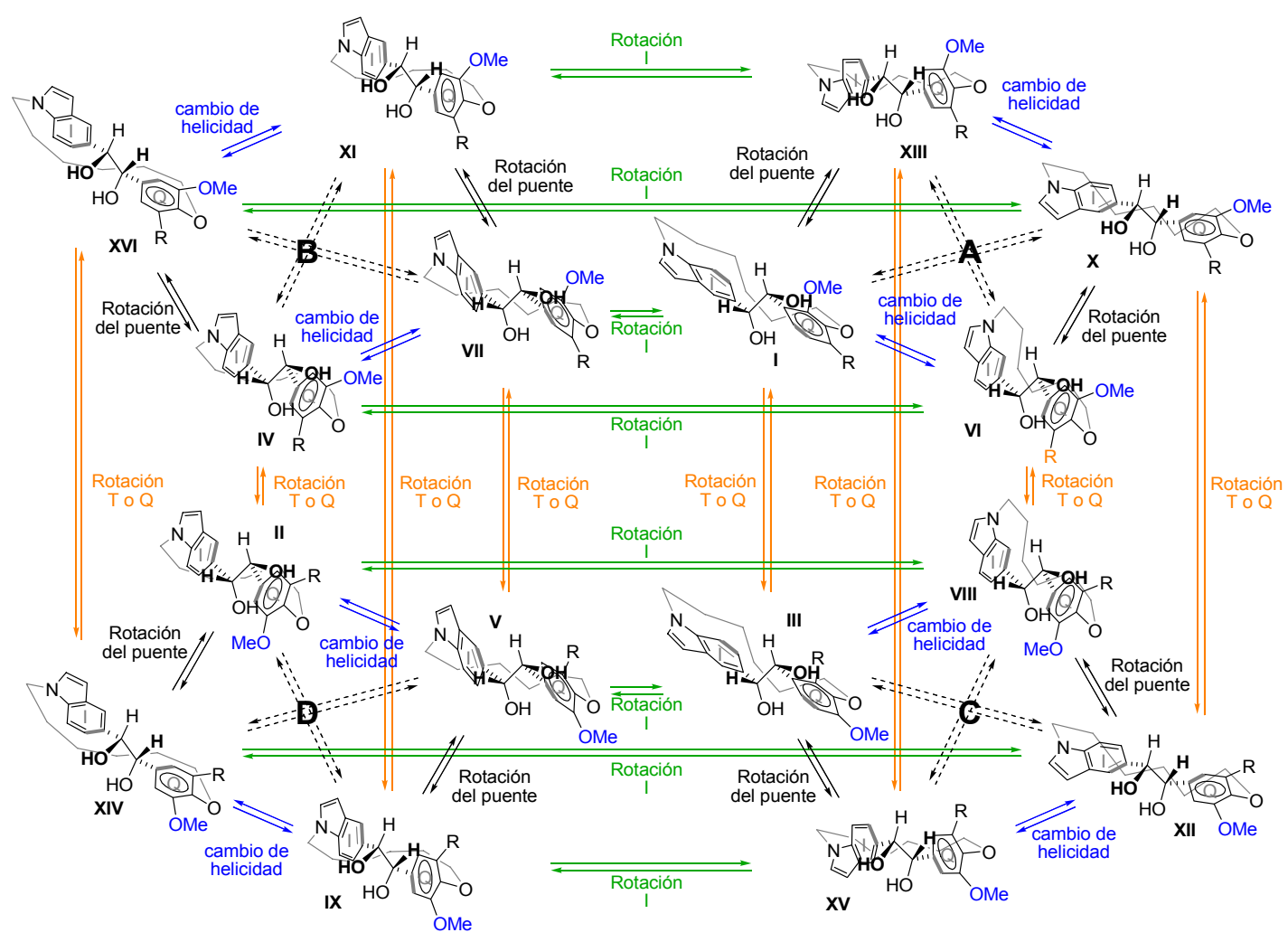

Figura 77. Equilibrios conformacionales de los dioles cis $\mathbf{8 5}$ y $\mathbf{8 8}$. Para los dioles $\mathbf{8 8}$ cis y $\mathbf{8 9}$ trans, con anillo $\mathrm{Q}$ simétrico, las conformaciones de los grupos en la parte superior son idénticas a las de la parte inferior $(\mathrm{A}=\mathrm{C}$ y $\mathrm{B}=\mathrm{D})$. 


\section{III.4.B.2 Estudios de mecánica molecular y dinámica molecular de dioles y acetatos.}

Al igual que en las olefinas macrocíclicas, es posible que no todos los grupos conformacionales (representados genéricamente por I-XVI) sean accesibles, por lo que no habría que tenerlos en cuenta en la discusión conformacional. Para intentar estudiar las conformaciones de menor energía de los dioles cis 85 y 88 y trans 86 y 89 se llevaron a cabo búsquedas conformacionales (Monte Carlo) ${ }^{55}$ utilizando mecánica molecular (campo de fuerzas MM3 con cloroformo como disolvente), ${ }^{56}$ que se complementaron con estudios de dinámica molecular a distintas temperaturas (típicamente $300 \mathrm{~K}$ y $1200 \mathrm{~K}$ ). ${ }^{58}$

Como se ha indicado con anterioridad, las conformaciones (o más propiamente los grupos conformacionales) propuestos para los dioles se generan por la rotación de los tres enlaces sencillos que conectan los dos anillos aromáticos. Así, para facilitar el análisis de las conformaciones encontradas, se midieron varios ángulos diedros (indicados por círculos de color naranja en la figura 78) que permitían determinar el estado de cada uno de los enlaces rotables y asignar las conformaciones a los grupos I-XVI anteriormente definidos.

El enlace central del puente (en gris en la figura 78) genera las disposiciones $+\mathrm{y}-$ sinclinales, y puede medirse utilizando el diedro formado por los dos átomos de carbono del puente y los átomos de los anillos aromáticos unidos a ellos. Esta selección de átomos conduce a resultados independientes de la estereoquímica relativa y/o absoluta de los dioles, por lo que se ha preferido a otras posibilidades, como por ejemplo los carbonos del puente y los oxígenos de los dioles. 
Para cada uno de los enlaces entre los anillos aromáticos y los carbonos del puente (indicados en verde y azul en la figura 78) se han elegido los dos carbonos del puente, el carbono del anillo aromático que es cabeza de puente del macrociclo y el carbono directamente unido a éste que conduzca por la ruta más corta a un carbono aromático sustituido. Al igual que para el enlace central del puente, esta elección es independiente de la estereoquímica relativa y absoluta del diol analizado, a diferencia de diedros que incorporan el oxígeno del hidroxilo o el hidrógeno geminal a éstos.

Como ocurría con las olefinas (para evitar que desviaciones de la posición de los átomos de los anillos aromáticos del plano del anillo condujeran a resultados dispares cuando se seleccionaba el carbono adyacente al puente de un lado o de otro del anillo aromático) se han medido ambos diedros y se ha promediado el valor del diedro indicado por los cuatro círculos naranjas de mayor tamaño (y descrito en el texto) con el complementario del diedro indicado por tres círculos naranjas de mayor tamaño y el cuarto reemplazado por el círculo naranja pequeño. Los valores de estos diedros permiten definir para cada anillo una sentido helicoidal positivo o negativo y determinar la disposición endo o exo de los sustituyentes (OMe, $\mathrm{R},-\mathrm{CH}=\mathrm{CH}-$ ) de los anillos aromáticos. El cambio de la disposición de los sustituyentes se asocia a una rotación del anillo (paso del plano del anillo por el plano definido por los carbonos del puente, el carbono del anillo unido al puente y el carbono en para respecto a éste último). 


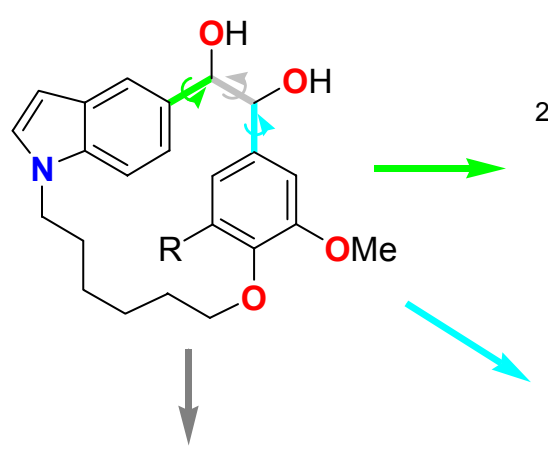<smiles>[R]c1cc(C(O)=S)cc(OC)c1OCCCCCCn1ccc2cc(C(O)O)ccc21</smiles>

Diedro del puente DP Rotación del puente $+y-S C$<smiles></smiles>

Diedro del indol DI

Rotación del indol

Helicidad del indol

$-\mathrm{CH}(2)=\mathrm{CH}(3)$ - endo o exo<smiles>[R]c1cc(C(O)=C(O)c2ccc3c(ccn3CCCCCCO)c2)cc(OC)c1OCC</smiles>

Diedro del otro anillo DT ó DQ

Rotación del otro anillo

Helicidad del otro anillo $\mathrm{MeO}$ endo o exo

Figura 78. Ángulos diedros empleados en la asignación de las conformaciones de menor energía calculadas IXVI y posibilidades conformacionales relacionadas con el mismo.

Una vez medidos los diedros indicados, se asignó una disposición $+\mathrm{o}-\operatorname{sinclinal}(+$ ó $-S C$ ) a las conformaciones en función del signo del diedro del puente (DP). Está clasificación distingue las conformaciones tipo I-VIII $(-S C)$, de las conformaciones tipo IX-XVI $(+S C)$. De acuerdo con este criterio de signos, las conformaciones I-VIII se han representado en las gráficas, que se mostrarán más adelante, en la parte negativa del eje de ordenadas y las IX-XVI en la positiva. Los valores de los diedros del indol y del otro anillo permiten definir las disposiciones endo y exo y el sentido helicoidal de cada anillo, cuyas combinaciones delimitan los grupos conformacionales (tabla18).

\begin{tabular}{|l|c|c|c|}
\hline & & IND endo & IND exo \\
\hline \multirow{2}{*}{ T o Q endo } & $(-S C)$ & I (-) y VI (+) & IV (+) y VII (-) \\
\hline & $(+S C)$ & IX (-) y XIV (+) & XII (+) y XV (-) \\
\hline \multirow{2}{*}{ T o Q exo } & $(-S C)$ & III (-) y VIII (+) & II (+) y V (-) \\
\hline \multirow{2}{*}{$(+S C)$} & XI (-) y XVI (+) & X (+) y XIII (-) \\
\hline
\end{tabular}

Tabla 18. Clasificación de las conformaciones en función de la disposición sinclinal, endo/exo de los sustituyentes y de la helicidad (entre paréntesis) que presentan. 
Las disposiciones endo y exo para los sustituyentes en meta del puente de los anillos bencénicos (tanto del indol como del otro anillo) se han designado como endo si el sustituyente se sitúa entre los dos anillos cuando se observa el compuesto con el enlace central del puente dirigido perpendicular al plano del papel (ver figura 79). Esta definición implica que el cambio de una disposición $-S C$ a $+S C$, sin que simultáneamente se produzcan otras, conduce a un cambio de las disposiciones endo a exo y viceversa.
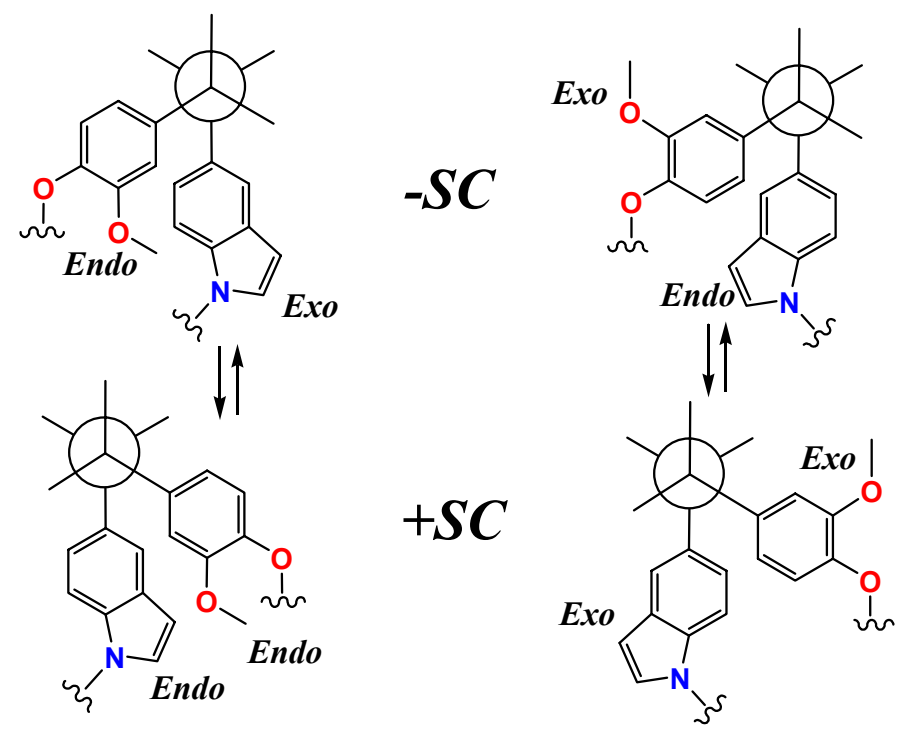

Figura 79. Representación de la asignación de la disposición de los sustituyentes del fenilo (OMe) y del indol $(\mathrm{C} 9=\mathrm{C} 10)$. Las conformaciones inferiores se producen por la rotación del puente de las superiores (paso de $S C$ a $+S C$ sin ningún otro cambio simultáneo y viceversa).

El sentido helicoidal adoptado por los anillos se asignó en función del ángulo que forma el plano del anillo aromático con el plano definido por los carbonos del puente y el carbono del anillo unido a ellos. Así, a los anillos con valores de los diedros DI o DT/DQ mayores de 90 o entre 0 y $-90^{\circ}$ se les asignó un sentido helicoidal negativo (-). Si dicho sentido helicoidal coincidía para ambos anillos, se asignaba a la conformación completa. $\mathrm{Si}$, por el contrario, era discordante, se marcaba la conformación como no correspondiente a los grupos considerados inicialmente. En las gráficas (figura 84 y siguientes), la disposición discordante se indica por los puntos de color marrón en la parte inferior que se sitúan a la altura de $\mathrm{Hel} \neq$. 

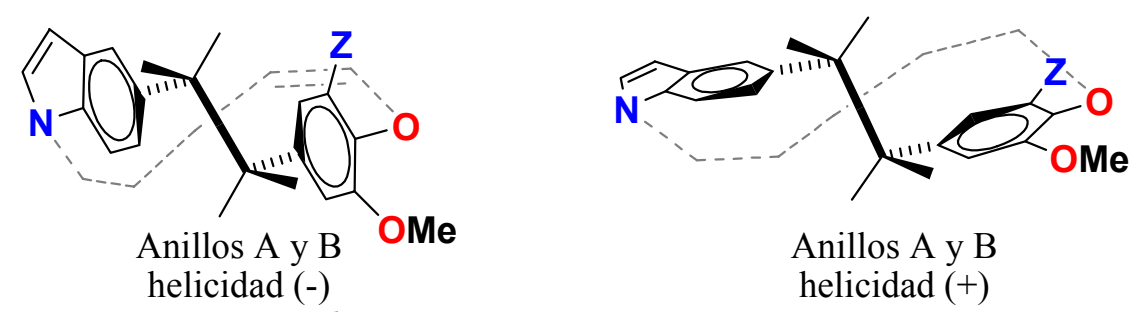

Anillos A y B helicidad $(+)$
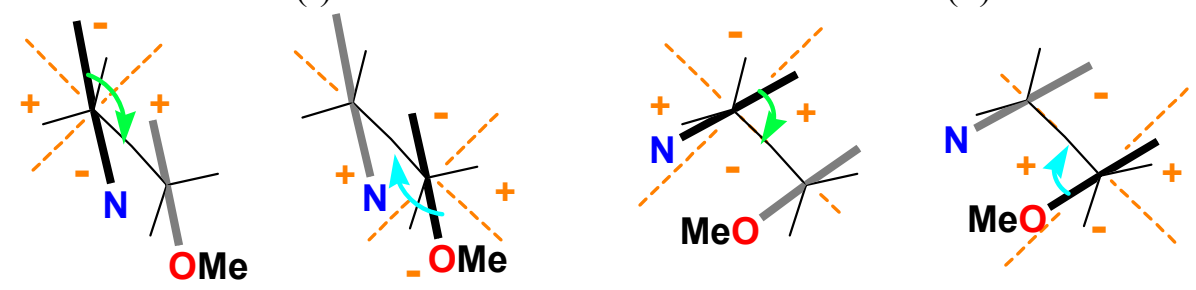

Figura 80. Representación de dos conformaciones en las que los dos anillos presentan la misma helicidad, negativa a la izquierda y positiva a la derecha. Los esquemas de la parte inferior muestran con flechas los ángulos diedros medidos (DI y DT); las líneas gruesas simbolizan el plano de los anillos aromáticos y en naranja se indican los cuadrantes que determinan cada helicidad.

El sentido helicoidal diferencia las parejas de conformaciones indicadas en la tabla 18, con lo que todas las conformaciones que poseen dos anillos con el mismo sentido pueden asignarse a los dieciséis grupos I-XVI.

Además, con el fin de analizar con más detalle la disposición de los anillos aromáticos, se ha analizado la posición de los mismos con respecto a los sustituyentes del carbono bencílico. Así, los sustituyentes dividen la circunferencia en tres tercios, que se han denominado C-H, C-OH y H-OH en función de los sustituyentes que los delimitan. En el diagrama (figura 81) se indica la situación del enlace C-C del anillo aromático que está más cercano al primer sustituyente (C9-C10 del indol, indicado por un círculo negro), de acuerdo con los criterios indicados en la figura.
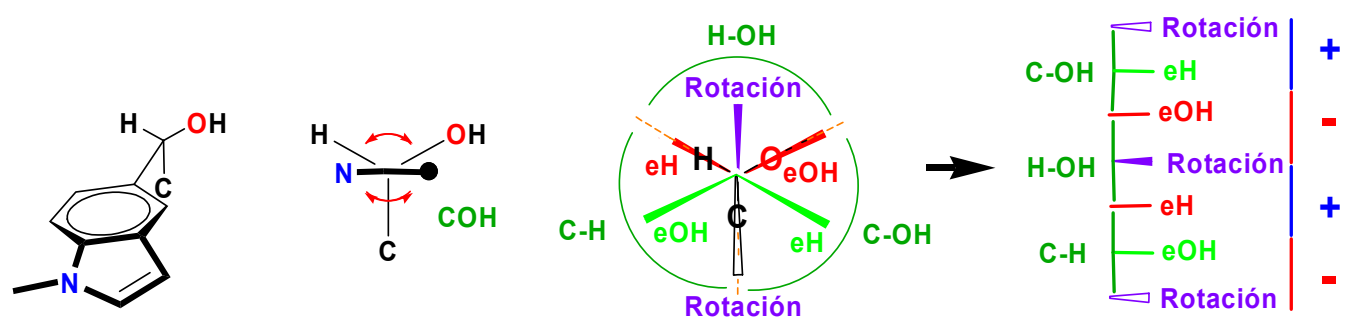

Figura 81. Representación de la disposición del indol respecto a los sustituyentes del carbono del puente al que se encuentra unido. En verde oscuro se indican los tercios delimitados por los sustituyentes; en morado, la alineación del anillo con el enlace; en rojo, la alineación de un sustituyente con el lado C9=C10 del anillo y en verde claro, la alineación de un sustituyente con el lado opuesto del anillo. A la derecha se muestra la helicidad (+ ó -) que presenta el anillo cuando se encuentras en las disposiciones establecidas. 
Cuando el plano del anillo aromático está alineado con alguno de estos sustituyentes, con un margen de $\pm 10^{\circ}$, también se ha hecho notar, destacando el lado del anillo que se alinea con el sustituyente (en rojo para el lado más cercano al primer sustituyente y en verde si es el opuesto a este). Cuando el plano del anillo aromático se alinea con el enlace C-C se produce una rotación del anillo, que se ha indicado en color morado. Cuando el lado del anillo que se eclipsa con el enlace C-C es el que está más cercano al primer sustituyente (C9-C10 del indol), esta rotación ocurre entre los tercios C$\mathrm{OH}$ y C-H (cuña morada hueca) y cuando es el lado opuesto tiene lugar en el centro del tercio H-OH (cuña morada sólida). En este caso, las definiciones de zonas dependen de la estereoquímica absoluta de cada carbono del puente, ya que si se cambian el $\mathrm{OH}$ y el $\mathrm{H}$, la zona $\mathrm{C}-\mathrm{H}$ debe pasar a $\mathrm{C}-\mathrm{OH}$ y viceversa.

También se han representado las transiciones que han tenido lugar entre una conformación y la siguiente. En el caso de los Monte Carlo estas transiciones no tienen significado, pero en las dinámicas moleculares indican qué procesos han tenido que ocurrir para pasar de una situación a la siguiente. Esto permite deducir la facilidad relativa con la que ocurren los procesos indicados, ayudando a la interpretación en términos moleculares de la apariencia de los espectros de RMN. Las transiciones consideradas han sido:

- El cambio de signo de la disposición sinclinal por rotación del enlace central del puente.

- La rotación de los anillos aromáticos (pasando el plano de los mismos por el plano definido por los carbonos del puente y el enlace que los une al anillo considerado: átomos $\left.\mathrm{C}_{\text {puente }}-\mathrm{C}_{\text {puente }}-\mathrm{C}_{\mathrm{Ar}}\right)$.

- El cambio de sector (al pasar el plano del anillo aromático por el plano que definen el enlace que une el anillo al puente y cada uno de los enlaces del carbono bencílico con sus sustituyentes). 
III.4.B.2.a. Mecánica molecular. Análisis de resultados.

La aplicación de estas reglas al resultado de las búsquedas conformacionales realizadas para los compuestos $\mathbf{8 5}, \mathbf{8 6}, \mathbf{8 8}$ y $\mathbf{8 9}$ permite obtener gráficas en las que asignar y analizar las conformaciones.
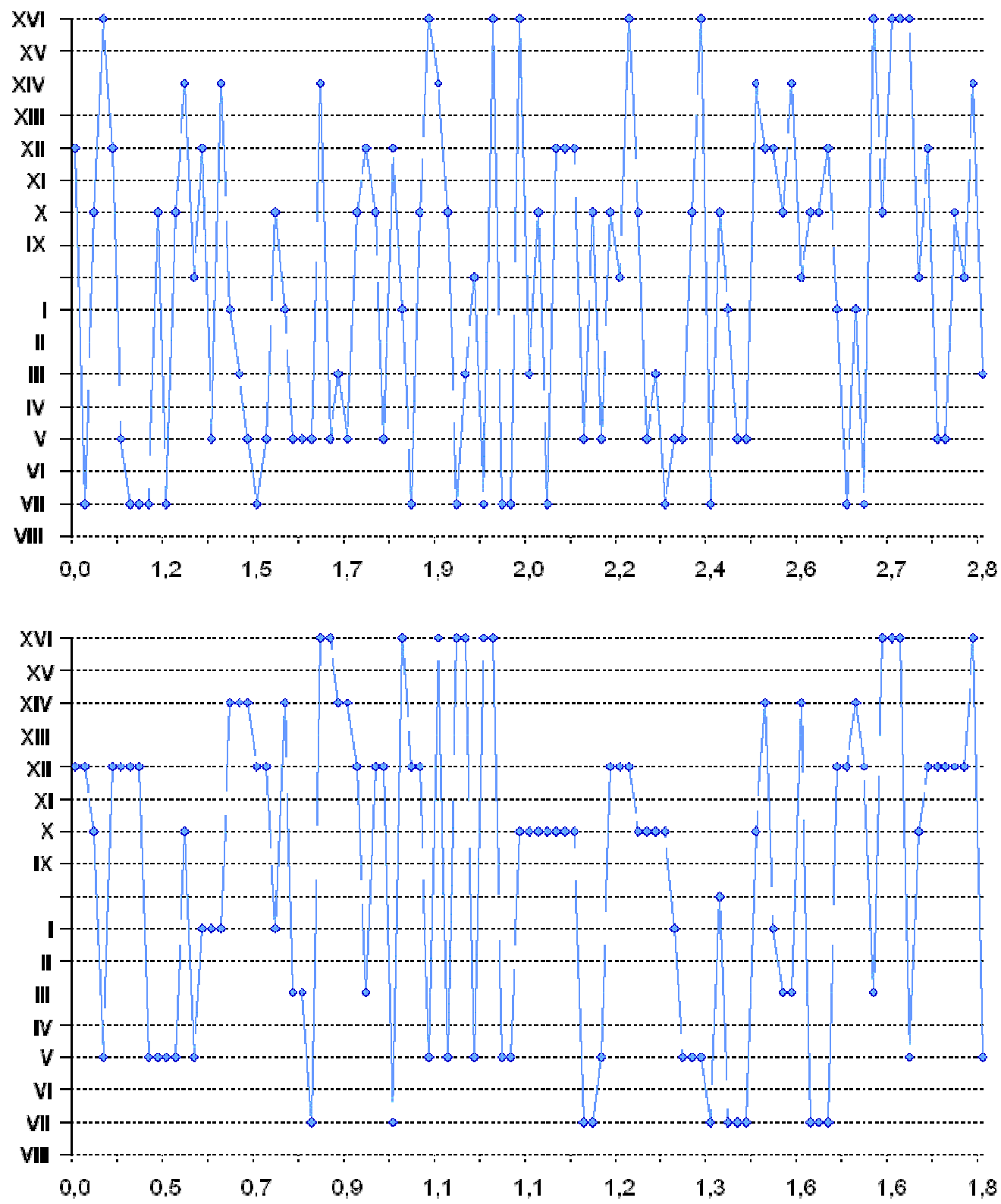

Figuras 82a (arriba) y 82b (abajo). Asignación de las conformaciones más estables, obtenidas mediante Monte Carlo, del diol cis 85 (arriba) y del diol cis 88 (abajo), a los grupos conformacionales (I-XVI) establecidos previamente. Los grupos descritos están colocados de IX a XVI en la parte positiva del eje de ordenadas y de I a VIII en la parte negativa. El valor 0 se asigna a conformaciones que no corresponden a IXVI. 

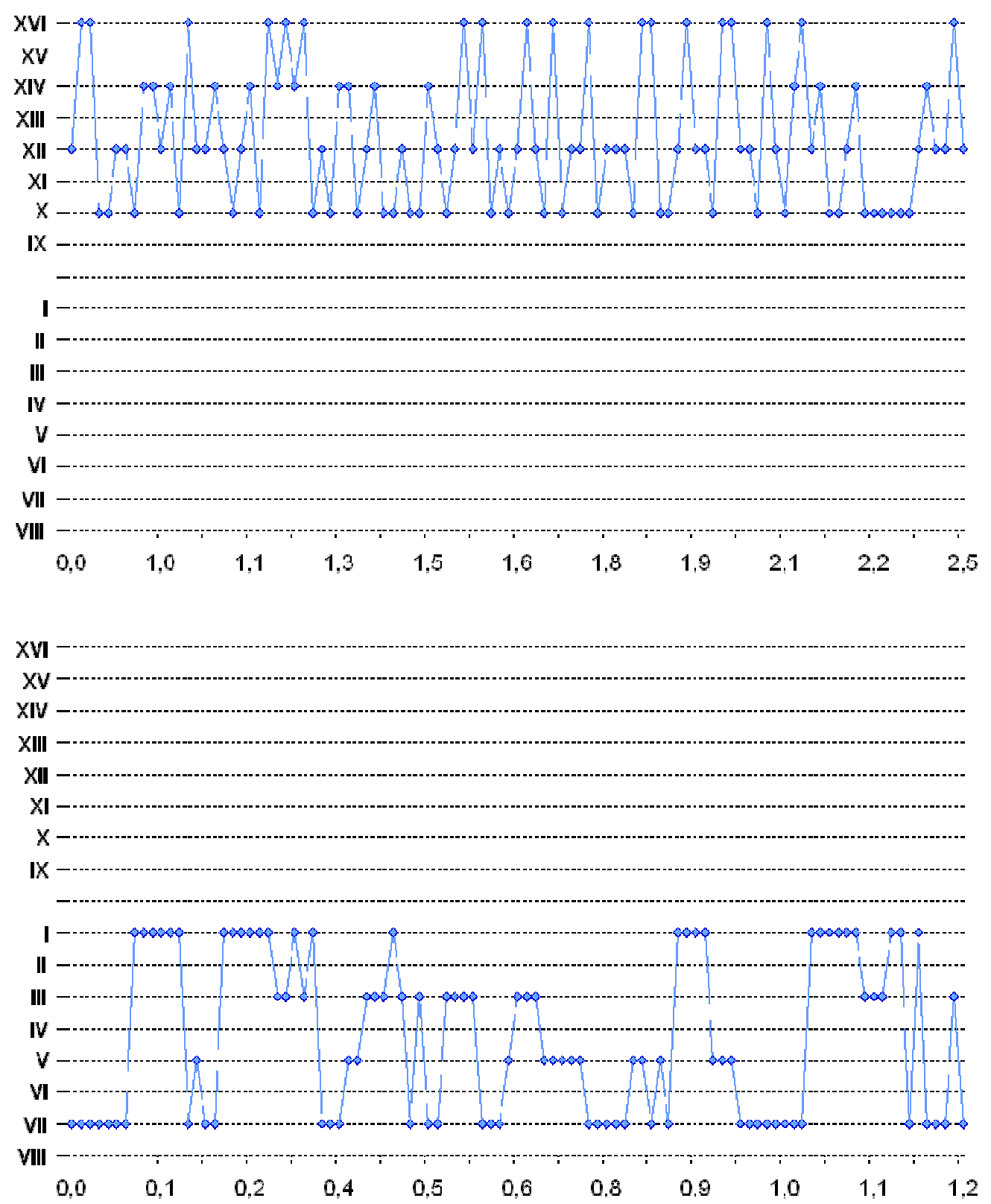

Figuras 82c (arriba) y 82d (abajo). Asignación de las conformaciones más estables, obtenidas mediante Monte Carlo, del diol trans 86 (arriba) y del diol trans 89 (abajo), a los grupos conformacionales (I-XVI) establecidos previamente. Los grupos descritos están colocados de IX a XVI en la parte positiva del eje de ordenadas y de I a VIII en la parte negativa. El valor 0 se asigna a conformaciones que no corresponden a IXVI.

Los resultados obtenidos al analizar las gráficas se resumen en la siguiente tabla, donde se indica a qué grupo pertenecen las conformaciones de mínima energía encontradas para cada compuesto, la diferencia de energía de cada una de ellas respecto al mínimo global y el número de veces que se ha encontrado dicha conformación tras 1000 etapas y con una diferencia de energía inferior a $5 \mathrm{kcal} / \mathrm{mol}$ respecto al mínimo global. 


\begin{tabular}{|c|c|c|c|c|c|c|c|c|c|c|c|c|c|c|c|c|c|}
\hline & I & II & III & IV & $\mathbf{V}$ & VI & VII & VIII & IX & $\mathbf{X}$ & XI & XII & XIII & XIV & $\mathbf{X V}$ & XVI & Otras \\
\hline 85 & $\begin{array}{l}1,5 \\
(1)\end{array}$ & - & $\begin{array}{l}1,5 \\
(1)\end{array}$ & - & $\begin{array}{l}0,8 \\
\text { (1) }\end{array}$ & - & $\begin{array}{l}0,2 \\
(1)\end{array}$ & - & - & $\begin{array}{l}0,5 \\
(3)\end{array}$ & - & $\begin{array}{c}0 \\
(2)\end{array}$ & - & $\begin{array}{l}1,3 \\
(4)\end{array}$ & - & $\begin{array}{l}0,7 \\
(1)\end{array}$ & - \\
\hline 88 & $\begin{array}{l}0,6 \\
(1)\end{array}$ & & $\begin{array}{l}0,8 \\
\text { (1) }\end{array}$ & - & $\begin{array}{l}0,1 \\
\text { (1) }\end{array}$ & - & $\begin{array}{l}0,8 \\
(1)\end{array}$ & - & - & $\begin{array}{l}0,1 \\
\text { (1) }\end{array}$ & - & $\begin{array}{c}0 \\
(1)\end{array}$ & - & $\begin{array}{l}0,7 \\
(1)\end{array}$ & - & $\begin{array}{l}0,9 \\
(1)\end{array}$ & - \\
\hline 86 & - & - & - & - & - & - & - & - & - & $\begin{array}{l}0,2 \\
\text { (1) }\end{array}$ & - & $\begin{array}{c}0 \\
(1)\end{array}$ & - & $\begin{array}{l}0,9 \\
(5)\end{array}$ & - & $\begin{array}{l}0,1 \\
(3)\end{array}$ & - \\
\hline 89 & $\begin{array}{l}0,1 \\
(2)\end{array}$ & & $\begin{array}{l}0,3 \\
\text { (3) }\end{array}$ & & $\begin{array}{l}0,1 \\
(2)\end{array}$ & & $\begin{array}{c}0 \\
(1)\end{array}$ & & - & - & - & - & - & - & - & - & - \\
\hline
\end{tabular}

Tabla 19. Resumen de los resultados del análisis conformacional para los compuestos 85, 86, 88 y 89. En la parte superior de cada casilla se indica la mínima energía en $\mathrm{kcal} / \mathrm{mol}$ de cada grupo conformacional respecto al mínimo global (sombreado oscuro), mientras que en la parte inferior se indica el número de veces que se ha encontrado dicha conformación de menor energía para cada grupo conformacional. En la columna de la derecha se indica si se han encontrado otras conformaciones intermedias a las definidas.

Tanto la tabla 19 como las figuras muestran que los compuestos con la misma estereoquímica relativa se comportan de manera muy similar. La principal diferencia observada es que en los dioles trans, 86 sólo adopta la disposición $+S C$ y 89 la $-S C$. Esto se debe a que la estereoquímica absoluta de los modelos moleculares de 86 y 89 es la opuesta, de modo que las disposiciones $+S C$ de 86 y $-S C$ de 89 se corresponden con una disposición gauche de los hidroxilos del puente. Así pues, ambos resultados son coincidentes.

Los dioles trans se diferencian de los cis en que sólo una de las disposiciones sinclinales está presente en los primeros, mientras que en los segundos se observan las dos. Esto se debe a que en los dioles trans las dos conformaciones sinclinales son muy diferentes, una con los hidroxilos gauche y la otra con los hidroxilos anti. La preferencia por conformaciones con hidroxilos en disposición gauche observada en este trabajo está de acuerdo con trabajos anteriores y con la bibliografía. ${ }^{60}$ En los dioles cis, las conformaciones sinclinales son más similares, lo cual está de acuerdo con que ambas estén igualmente pobladas. 
Otro aspecto a destacar es que todas las conformaciones encontradas presentan una diferencia de energía pequeña con respecto a la del mínimo global, por lo que todas deben ser tenidas en cuenta en la interpretación de los espectros de RMN. Aunque el número de veces que la búsqueda conformacional ha encontrado la conformación de mínima energía de cada tipo conformacional es pequeño (como indica el número entre paréntesis en la tabla), el número de veces que el proceso encuentra conformaciones de ese tipo es elevado, como se aprecia en las gráficas. Esto sugiere que cada tipo conformacional está a su vez representado por conformaciones que difieren más entre sí que lo que diferían las conformaciones en las olefinas. Además, las pequeñas diferencias en energía sugieren que dichas conformaciones no difieren mucho en energía unas de otras. El hecho de que, en todos los casos en que están presentes, las conformaciones tipo XII sean las de menor energía es anecdótico, debido a las pequeñas diferencias en energía encontradas.

Si se considera que para los dioles con un anillo simétrico (86 y 89) las conformaciones I y III, V y VII, X y XII y XVI y XVI son estructuralmente idénticas, la diferencia de energía entre ellas nos informa del error intrínseco de la metodología empleada, al igual que se indicó en las olefinas. ${ }^{55 b}$ En este caso las diferencias de energía observadas son menores que para las olefinas (aunque también el número de comparaciones efectuadas es menor), con diferencias inferiores a $0,7 \mathrm{kcal} / \mathrm{mol}$ en todos los casos. Posiblemente esto se debe a que la mayor flexibilidad de los dioles, comentada en el párrafo anterior, facilita la relajación de las estructuras intermedias generadas por la búsqueda conformacional y permite encontrar con más facilidad los mínimos locales.

También llama la atención en la tabla que de las conformaciones -SC (I-VIII) sólo se observan aquellas con sentido helicoidal negativo (I, III, V y VII), mientras que para las +SC (IX-XVI) sólo se observan las que tienen sentido helicoidal positivo (X, XII, XIV y $\mathrm{XVI}$ ), tanto en los dioles cis como en los trans. A la vista de esta observación se han analizado los resultados de las búsquedas conformacionales en dioles no indólicos, habiéndose encontrado la misma situación. Así pues, la preferencia de los compuestos por conformaciones con igual signo de la disposición sinclinal y del sentido de giro de la hélice no es debida a la presencia del anillo de indol. 
Para explicar esta preferencia resulta conveniente representar las moléculas con el enlace central del puente en el plano del papel, dirigido en dirección vertical y con el resto de la molécula situada por encima del papel. En esta disposición se observa que en las conformaciones en que el signo de la disposición sinclinal y el sentido de giro de la hélice difieren, los lados endo de los anillos aromáticos se dirigen hacia el hueco entre los anillos (representado, en la figura 83, por el elipsoide rosa situado entre la posición orto-endo de un anillo y la del otro). Esto reduce el hueco para el espaciador, en comparación con las combinaciones en que los signos coinciden, como se aprecia por el tamaño relativo de los elipsoides rosas. Además, como se aprecia en la figura 83, en la que se han omitido los grupos hidroxilo y los hidrógenos del puente para hacer un planteamiento general, independiente de la estereoquímica, este efecto es común para todas las configuraciones, de acuerdo con lo observado en las búsquedas conformacionales.

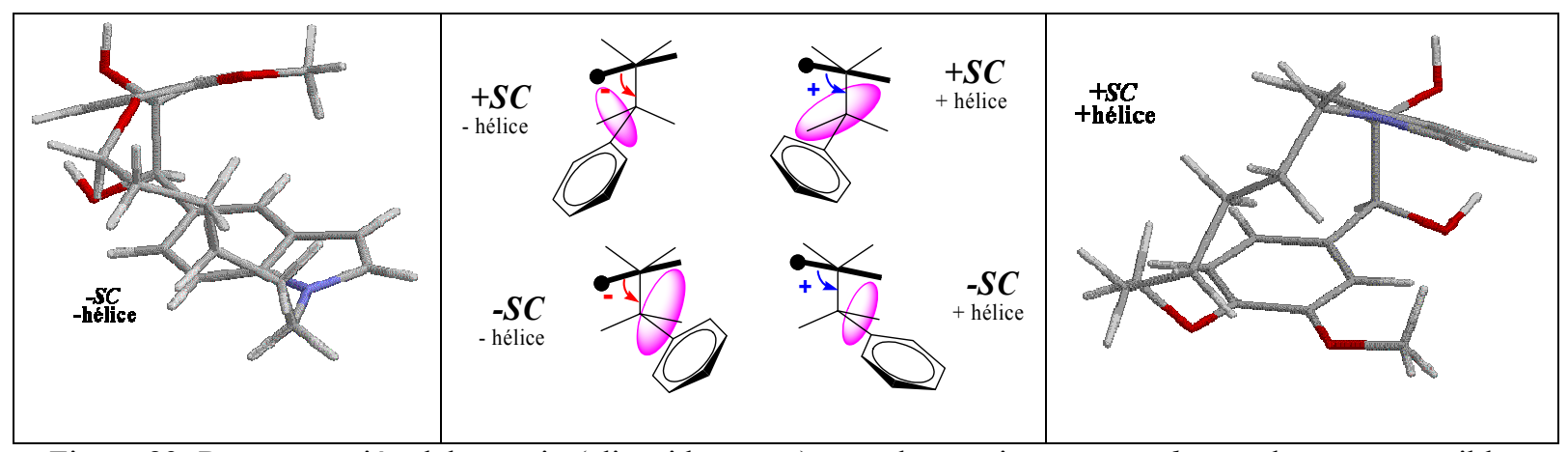

Figura 83. Representación del espacio (elipsoides rosas) entre los sustituyentes endo para las cuatro posibles combinaciones diferentes de sinclinal y helicidad. En los laterales se muestran dos conformaciones reales en los signos del sinclinal y la helicidad son coincidentes (- a la derecha, + a la izquierda). 
Una vez analizados en conjunto los tipos conformacionales presentes, es posible analizar más detalladamente los resultados de la búsqueda conformacional, utilizando las gráficas en que se muestran con detalle las características de cada conformación.
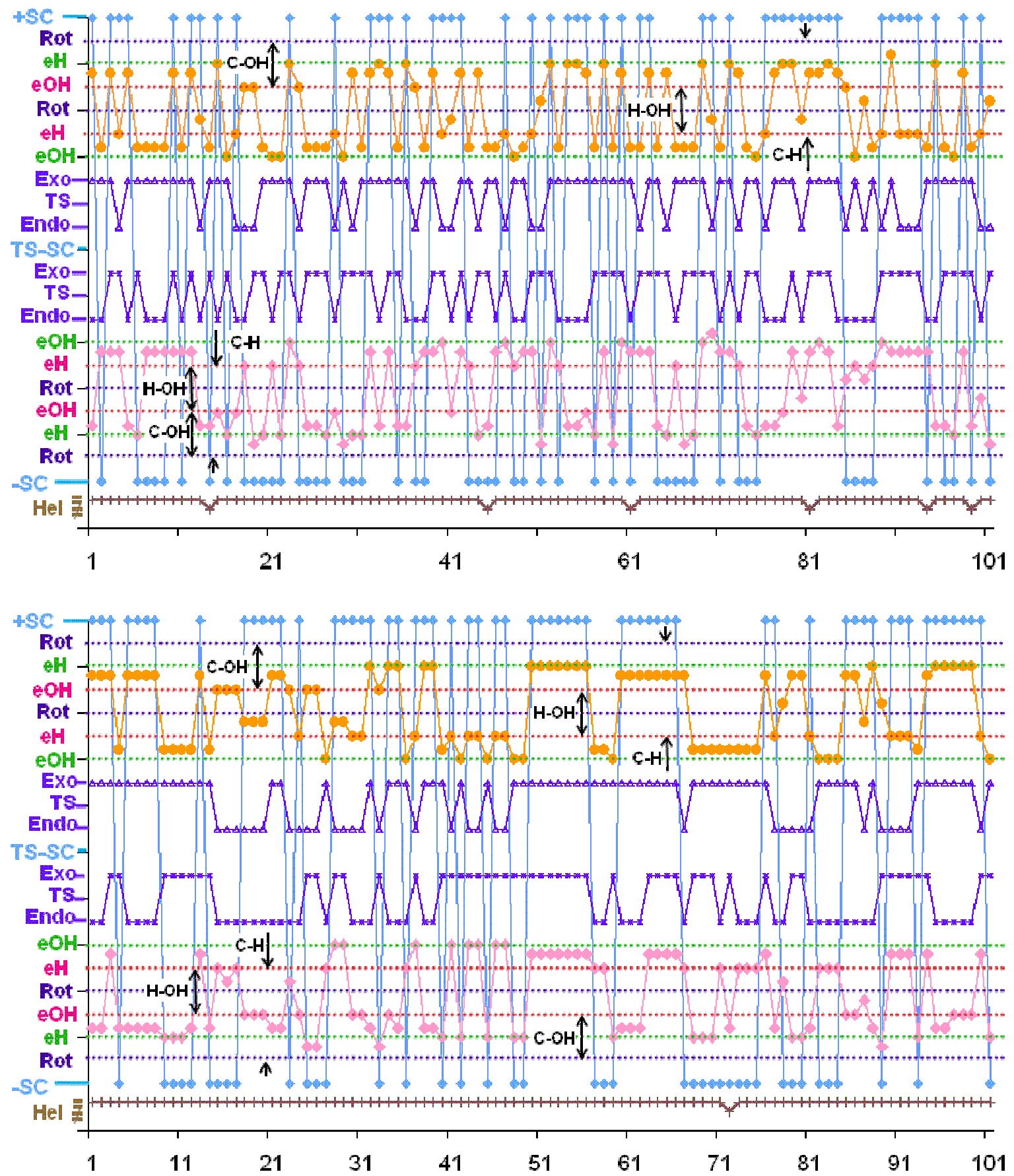

Figura 84a. Gráficas correspondientes a los dioles cis (85 arriba, 88 abajo) donde se representa, para cada conformación resultante del Monte Carlo, la disposición sinclinal (línea azul clara), la helicidad coincidente o discordante de los anillos (línea marrón), la orientación de los sustituyentes de cada anillo (líneas moradas, arriba indol y abajo fenilo) y la disposición de cada anillo en relación a los sustiyuyentes del carbono bencílico (líneas naranjas y arriba, indol; líneas rosas y abajo, fenilo). 

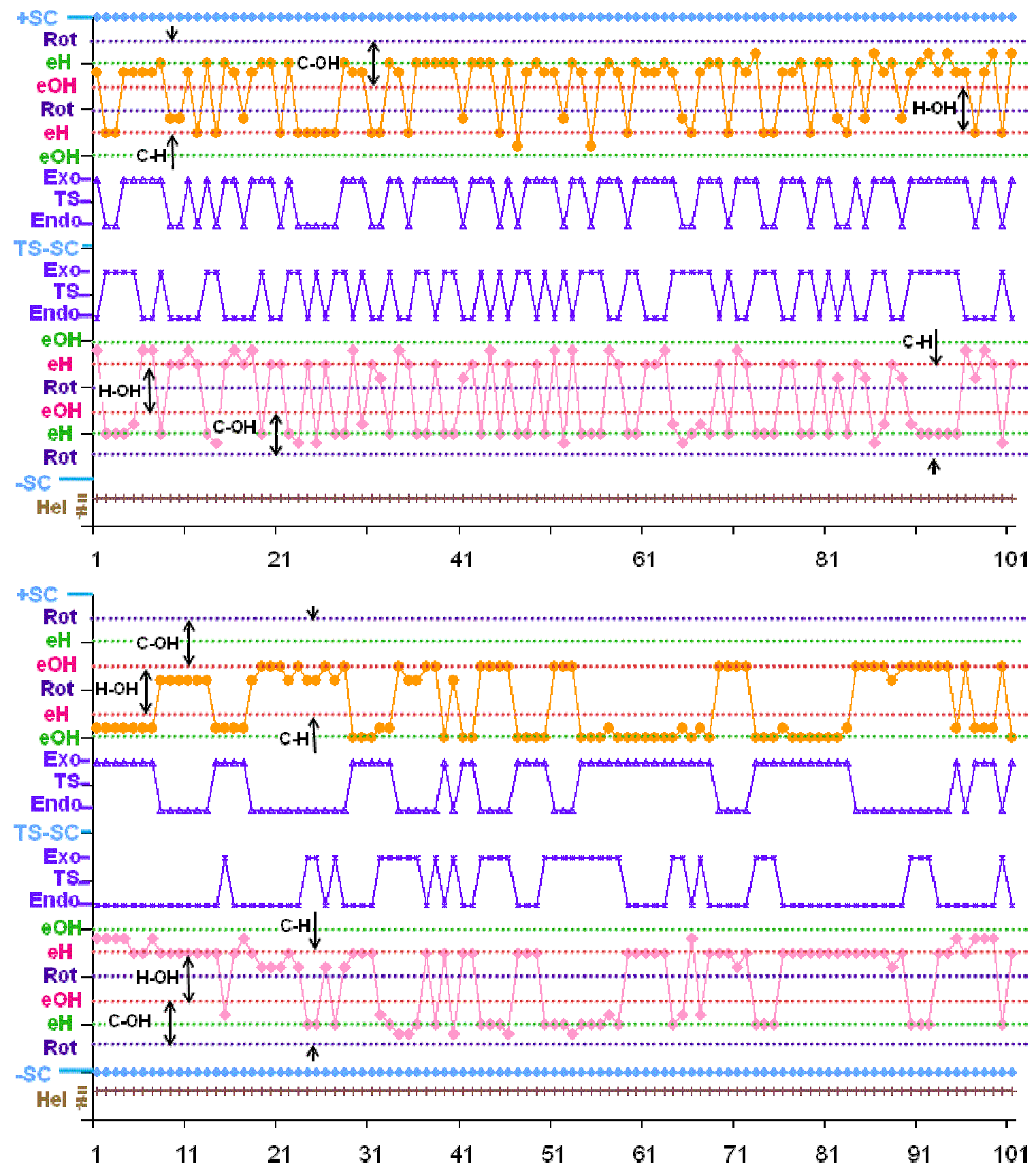

Figura 84b. Gráficas correspondientes a los dioles trans (86 arriba, 89 abajo) donde se representa, para cada conformación resultante del Monte Carlo, la disposición sinclinal (línea azul clara), la helicidad coincidente o discordante de los anillos (línea marrón), la orientación de los sustituyentes de cada anillo (líneas moradas, arriba indol y abajo fenilo) y la disposición de cada anillo en relación a los sustiyuyentes del carbono bencílico (líneas naranjas y arriba, indol; líneas rosas y abajo fenilo).

En concordancia con lo indicado anteriormente, los dioles cis (figura 84a) muestran conformaciones $+S C$ y $-S C$ (línea de color azul claro), mientras que en los dioles trans (figura 84b) sólo se observa una de las dos (la que se corresponde con disposición gauche de los hidroxilos). Tanto en los dioles cis como en los trans se observan disposiciones endo de los dos anillos, como muestran las líneas de color morado. 
En los compuestos que presentan un anillo tetrasustituido, la disposición endo del indol se observa en menor número de conformaciones que el exo. Esto sugiere que la presencia constante del sustituyente endo en los anillos tetrasustituidos dificulta la disposición endo del indol, probablemente por interacción del metoxilo en disposición endo con el espaciador. Esto está de acuerdo con el hecho de que las conformaciones endo del indol en los compuestos con anillos trisustituidos presentan menor energía cuando el metoxilo del otro anillo adopta una disposición exo, y con lo comentado en el apartado de las olefinas indólicas.

Tanto en los dioles cis como en los trans se aprecia que, en las conformaciones de baja energía, los dos anillos aromáticos tienen un sentido de giro de la hélice que coincide en signo. En principio, la mayor distancia entre los anillos aromáticos debida a las disposiciones sinclinales preferentes en los dioles podría permitir que los anillos no se colocaran en planos casi paralelos, pero esto parece ser una observación general.

El análisis de las líneas de color verde (correspondientes a la rotación de los planos de los anillos respecto a los sustituyentes del carbono bencílico) muestra que las conformaciones preferidas sitúan los planos de los anillos en los tercios C-OH y C-H, y dentro de ellos en los segmentos entre las conformaciones eclipsadas eH y eOH. En estas zonas se produce la transición de hélices + a hélices -, por lo que esta representación no es tan ilustrativa como el análisis de los grupos conformacionales antes comentada. Por otro lado, las preferencias observadas sugieren que las disposiciones más favorables alejan los planos de los anillos aromáticos del plano que forma el enlace central del puente y el enlace que une el puente con el anillo. Las disposiciones desfavorables dirigirían el anillo hacia el espacio intraanular, de modo que chocarían con el espaciador. 


\section{III.4.B.2.b. Dinámica molecular.}

Con el fin de explorar las interconversiones entre las conformaciones se han llevado a cabo estudios de dinámica molecular a 300 y 1200K, empleando las mismas condiciones que las descritas para las búsquedas conformacionales utilizando Monte Carlo.

Los resultados de las dinámicas moleculares se han analizado de la misma forma que las búsquedas conformacionales y, además, se ha analizado la trayectoria de forma secuencial, comparando cada conformación con la que le sigue en la simulación para analizar si se han producido cambios en la disposición del puente ( $+S C$ a $-S C$ y viceversa), rotaciones de los anillos (entendiendo por tales el paso del plano del anillo por el plano formado por los átomos $\mathrm{C}_{\text {arom }}-\mathrm{C}_{\text {puente }}-\mathrm{C}_{\text {puente }}$ ) y cambios de segmento de los anillos (correspondientes a rotaciones de los anillos que atraviesan el plano $\mathrm{C}_{\text {arom }}-\mathrm{C}_{\text {puente-Sustit }}$ H/OH. Figura 81). A medida que aumenta la temperatura de la simulación, se espera un aumento del número de transiciones y de la cantidad de conformaciones que no corresponden a los tipos conformacionales I-XVI. Para facilitar la comparación de experimentos a distintas temperaturas, en todos los casos las dinámicas moleculares para un mismo compuesto se han iniciado partiendo de la misma conformación. 


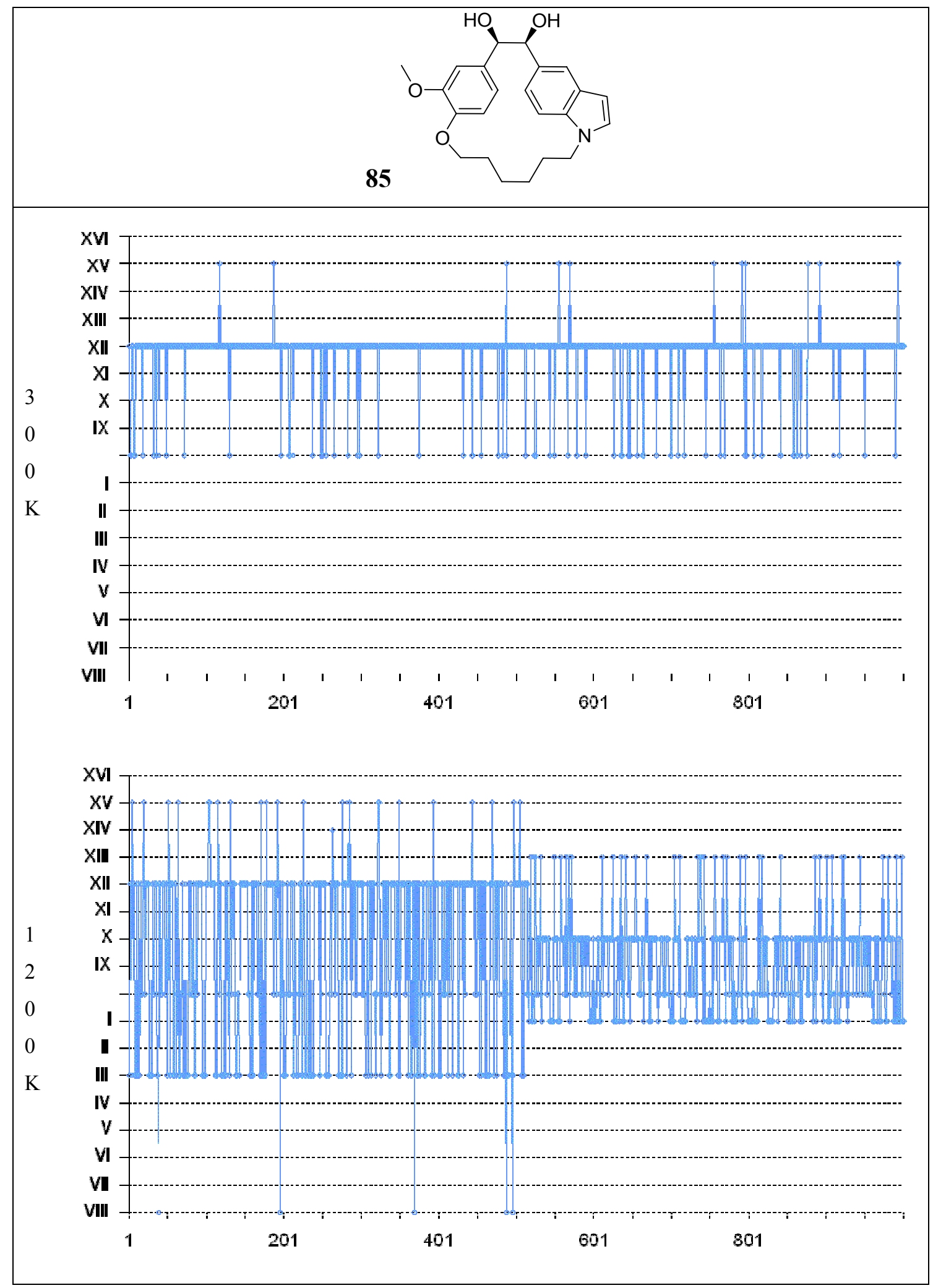




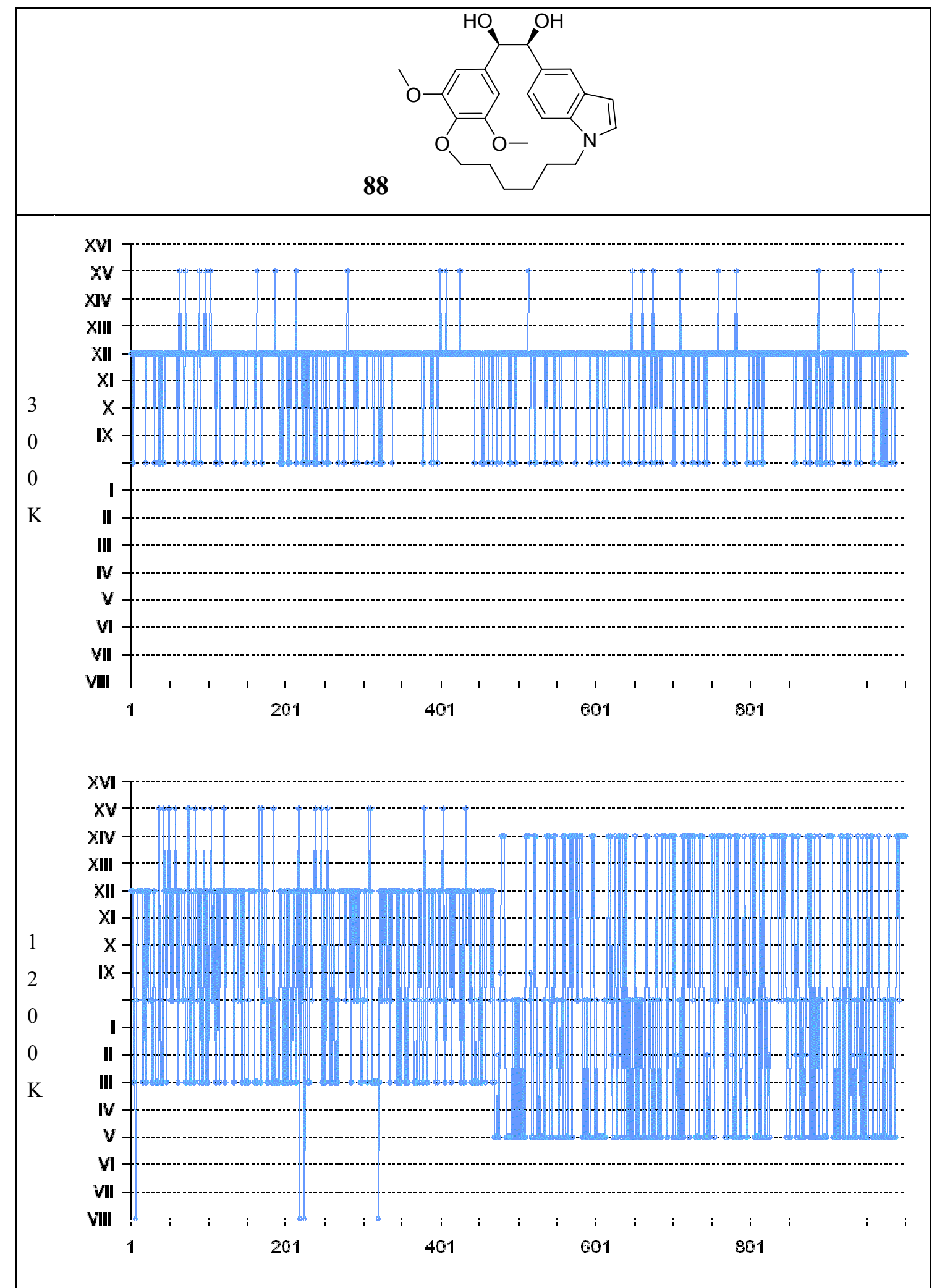

Figura 85a. Asignación de las conformaciones de los dioles cis, obtenidas mediante dinámica molecular, a los grupos conformacionales (I-XVI) establecidos previamente. La parte positiva del eje de ordenadas se corresponde con conformaciones $+S C$ y la de abajo con las $-S C$. En el centro se sitúan las conformaciones que no corresponden a las clases I-XVI. 


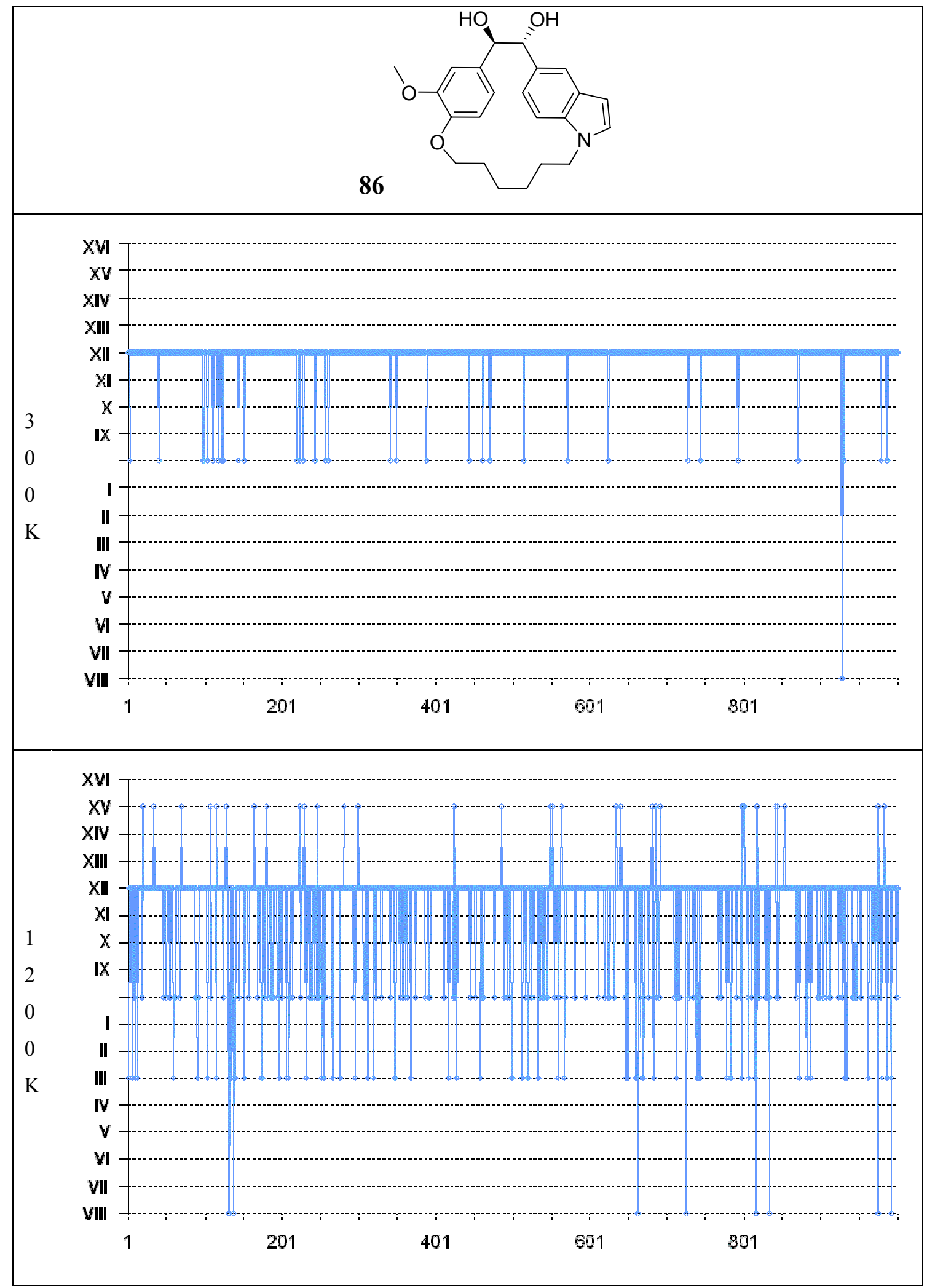




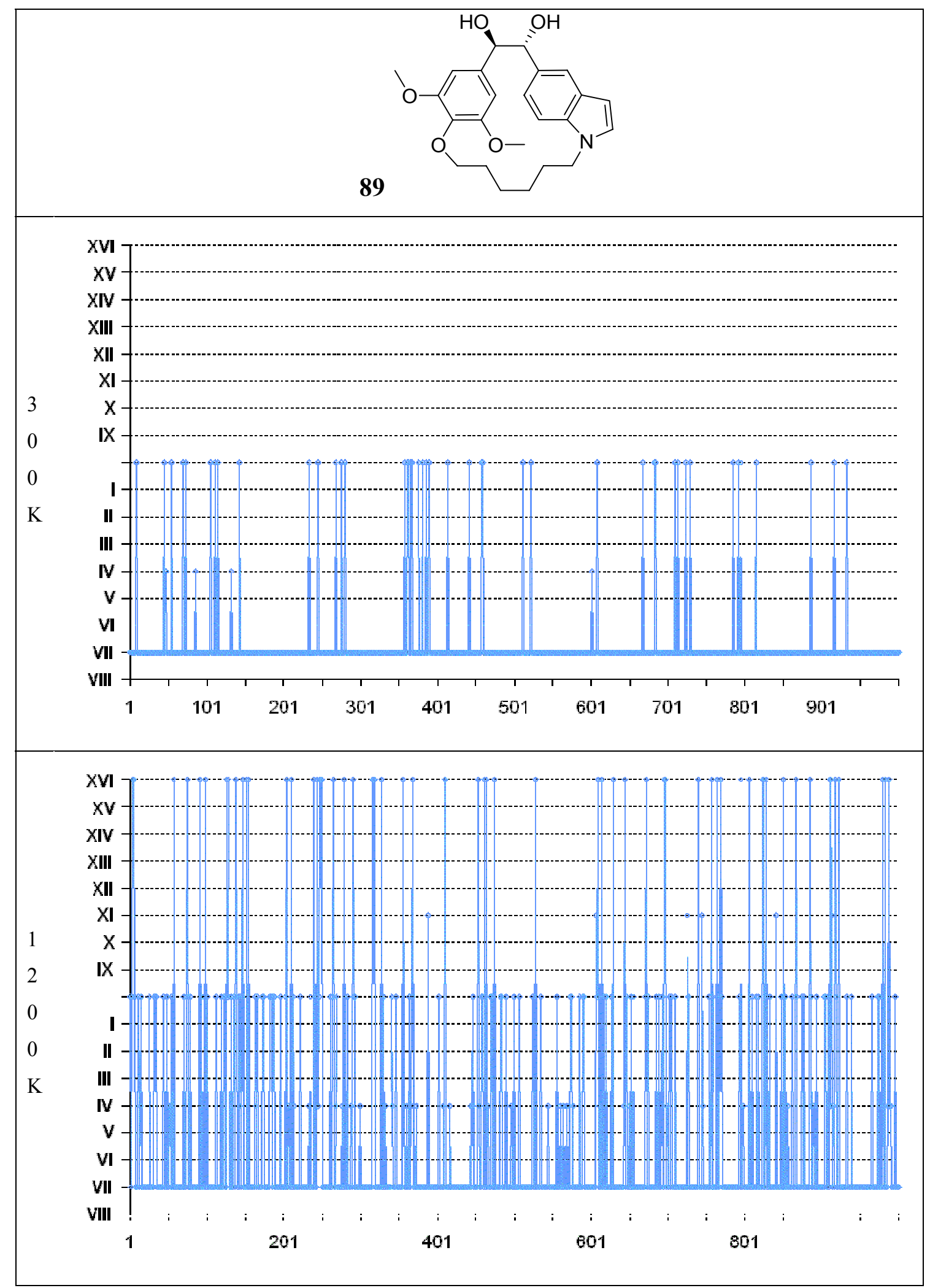

Figura 85b. Asignación de las conformaciones de los dioles trans, obtenidas mediante dinámica molecular, a los grupos conformacionales (I-XVI) establecidos previamente. Los grupos descritos están colocados de IX a XVI en la parte positiva del eje de ordenadas y de I a VIII en la parte negativa. En el centro se sitúan las conformaciones que no corresponden a las clases I-XVI. 
El incremento de temperatura va asociado, en todos los casos, a un incremento en el número de estructuras que no corresponden con los tipos I-XVI, como era de esperar. La comparación de las dinámicas a $300 \mathrm{~K}$ y $1200 \mathrm{~K}$ para el mismo compuesto muestra que al aumentar la temperatura se incrementa el número de conformaciones accesibles. Las dinámicas moleculares para los compuestos con anillo trisustituido son muy similares a las de los que tienen anillo tetrasustituido. El análisis de las conformaciones accedidas a 300K y $1200 \mathrm{~K}$ muestra conformaciones que no estaban presentes en la búsqueda conformacional, fundamentalmente conformaciones en que el signo de la disposición sinclinal y el del sentido de avance de la hélice para los anillos aromáticos difiere. De acuerdo con lo comentado en la búsqueda conformacional, estas conformaciones se encuentran ocupadas con menor frecuencia, lo que indica su mayor inestabilidad. Por otra parte, la facilidad (representada por la alta frecuencia) con que se produce el paso (incluso a $300 \mathrm{~K}$ ) sugiere que la barrera energética entre ambas es pequeña.

\begin{tabular}{|c|c|c|c|c|c|c|c|c|c|c|c|c|c|c|c|c|c|c|}
\hline & & I & II & III & IV & $\mathbf{V}$ & VI & VII & VIII & IX & $\mathbf{X}$ & XI & XII & XIII & XIV & $\overline{X V}$ & $\overline{X V I}$ & Alt \\
\hline \multirow{3}{*}{85} & $\mathrm{MC}$ & $\mathbf{X}$ & - & $\mathbf{X}$ & - & $\mathbf{X X}$ & - & $\mathbf{X X}$ & - & - & $\mathbf{X X}$ & - & $\mathbf{X X}$ & - & $\mathbf{X}$ & - & $\mathbf{X}$ & - \\
\hline & $300 \mathrm{~K}$ & & & & & & & & & & & & $\mathbf{X X}$ & & & $\mathbf{x}$ & & 0 \\
\hline & $1200 \mathrm{~K}$ & $\mathbf{X}$ & & $X$ & & & & & $\mathrm{x}$ & & $\mathbf{X X}$ & & $\mathbf{X X}$ & $\mathbf{x}$ & & $\mathbf{x}$ & & 0 \\
\hline \multirow{3}{*}{88} & $\mathrm{MC}$ & $\mathbf{X X}$ & & XX & - & $\mathbf{X X}$ & - & $\mathrm{XX}$ & - & - & XX & - & $\mathbf{X X}$ & - & $\mathbf{X X}$ & - & XX & - \\
\hline & $300 \mathrm{~K}$ & & & & & & & & & & & & $\mathbf{X X}$ & & & $\mathbf{x}$ & & 0 \\
\hline & $1200 \mathrm{~K}$ & $\mathbf{X}$ & & $\mathbf{X}$ & & & & & $\mathrm{X}$ & & $\mathbf{X X}$ & & $\mathbf{X X}$ & $\mathbf{x}$ & & $\mathbf{x}$ & & 0 \\
\hline \multirow{3}{*}{86} & $\mathrm{MC}$ & - & - & - & - & - & - & - & - & - & $\mathrm{XX}$ & - & $\mathbf{X X}$ & - & $\mathbf{X X}$ & - & $\mathbf{X X}$ & - \\
\hline & $300 \mathrm{~K}$ & & & & & & & & $\mathbf{x}$ & & & & $\mathbf{X X}$ & & & & & 0 \\
\hline & $1200 \mathrm{~K}$ & & & $\mathbf{X}$ & & & & & $\mathbf{x}$ & & & & $\mathbf{X X}$ & & & $\mathbf{x}$ & & 0 \\
\hline \multirow{3}{*}{89} & $\mathrm{MC}$ & XX & & $\mathbf{X X}$ & & $\mathbf{X X}$ & & $\mathrm{XX}$ & & - & - & - & - & - & - & - & - & - \\
\hline & $300 \mathrm{~K}$ & & & & $\mathbf{x}$ & & & $\mathrm{XX}$ & & & & & & & & & & 0 \\
\hline & $1200 \mathrm{~K}$ & & & & $\mathbf{x}$ & & & $\mathbf{X X}$ & & & & $\mathbf{x}$ & & & & & $\mathbf{X}$ & 0 \\
\hline
\end{tabular}

Tabla 20. Resumen de las conformaciones obtenidas a partir del Monte Carlo y de las dinámicas moleculares para los compuestos $85,86,88$ y 89. En la columna de la derecha se indica si se han encontrado otras conformaciones intermedias a las definidas. 
A $300 \mathrm{~K}$ las únicas transiciones observadas son las asociadas al cambio de sentido de la hélice de los anillos aromáticos, que interconvierten XII y XV (en los dioles cis y en 86) y VII y IV (en 89). A temperaturas superiores aparecen nuevas transiciones (que se analizarán posteriormente) y que permiten observar otras transiciones de este tipo, como son las que intercambian III y VIII (89) y X y XIII (dioles cis y 86). Para facilitar la inspección detallada de los cambios entre tipos conformacionales se ha ampliado la gráfica correspondiente a la dinámica molecular de 85 a 1200K (figura 86).

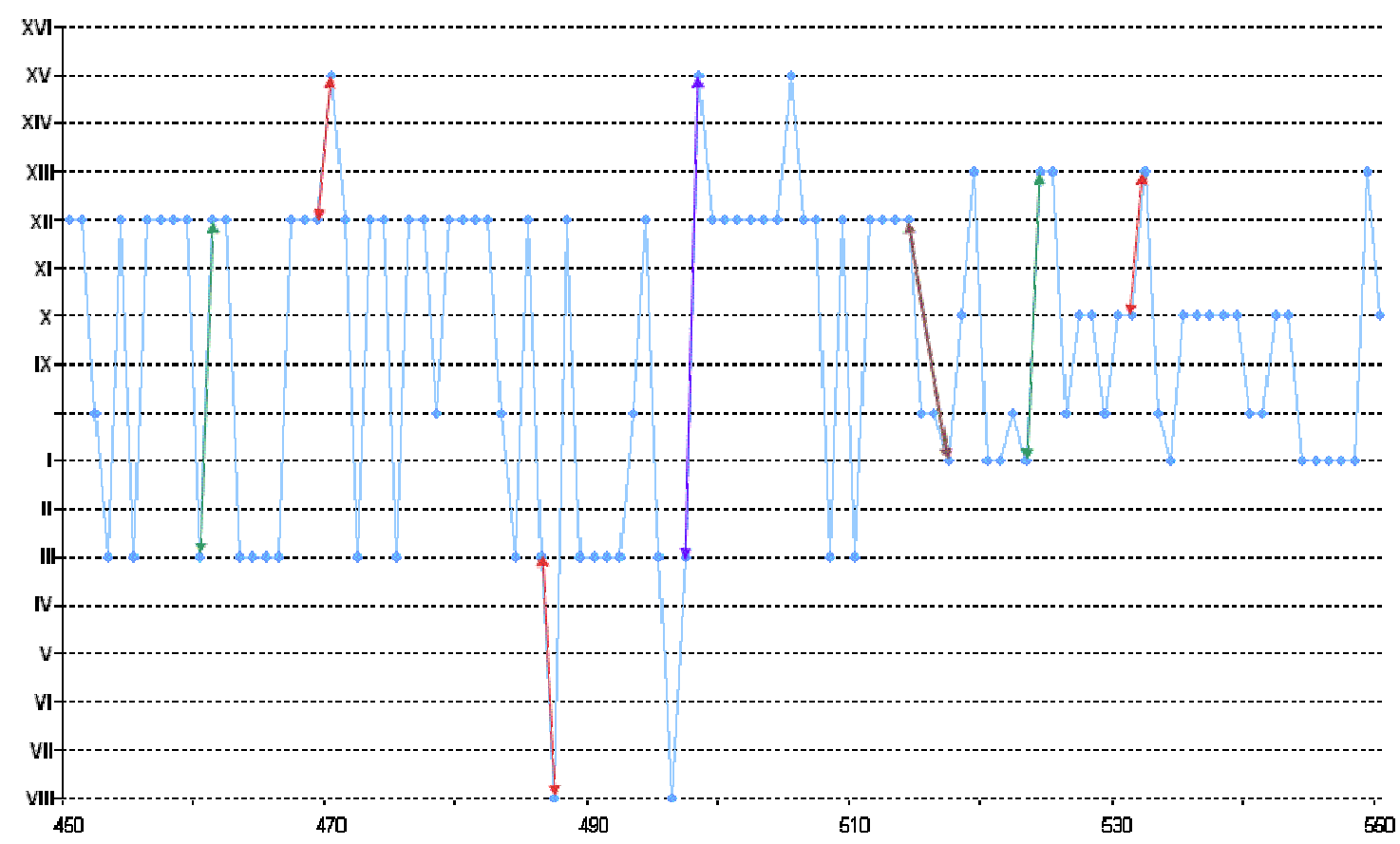

Figura 86. Ampliación de la dinámica molecular a $1200 \mathrm{~K}$ del compuesto 85. En morado se indican cambios de la disposición sinclinal (giro del puente), en rojo cambios de helicidad, en verde cambios simultáneos en la disposición sinclinal y en la helicidad y en marrón el cambio infrecuente de la conformación XII a la I, que implica el cambio de disposición sinclinal, de helicidad y la rotación del anillo trisustituido.

En ella se observa, que las transiciones más frecuentes a $1200 \mathrm{~K}$ son cambios en la disposición sinclinal del puente acompañadas de cambio de helicidad (indicadas en color verde), como son las transiciones entre XII y III o entre X y I. Estos cambios se traducen en la gráfica en pasos de la mitad inferior a la superior y viceversa. 
El cambio de disposición sinclinal convierte las posiciones endo en exo y viceversa, sin que se produzca la rotación de los anillos. Como se ha indicado, las transiciones observadas mayoritariamente implican no sólo la rotación del puente, sino también el cambio de sentido de giro de la hélice de los anillos aromáticos hacia la conformación más estable ( $+S C$ y hélice+ ó $-S C$ y hélice-) que se produce por giro parcial de los anillos, por lo que este cambio de helicidad debe ser más rápido que el giro del puente, como se ha discutido anteriormente. Así, en ocasiones, ambos procesos no ocurren simultáneamente y se observa el cambio de conformación por giro del puente (cambio de $S C$ ) y antes de que cambie el sentido helicoidal (indicado por las flechas de color morado), como por ejemplo en el paso de III a XV.

En las dinámicas moleculares de los dioles cis a 1200K, además de las transiciones de alta frecuencia ya mencionadas se producen transiciones que ocurren con baja frecuencia (una vez en 3 ns de simulación) y que permiten acceder a nuevos tipos conformacionales. Estas transiciones son apreciables en la gráfica completa de la simulación porque se produce un claro cambio en el patrón de las mismas.

La baja frecuencia de dichas transiciones hace que no sea posible comparar las poblaciones de ambos tipos conformacionales para deducir su estabilidad relativa, ya que el proceso de retorno a las conformaciones iniciales es también infrecuente y no se produce durante el resto del tiempo de la simulación, por lo que no puede compararse con los resultados del Monte Carlo. En el caso de 85, esta transición se produce al pasar de la conformación XII a la conformación I (indicado por una flecha marrón en la ampliación). En realidad, esta transición implica un paso del grupo de conformaciones $\mathbf{C}$ (XII-XV-IIIVIII) al grupo A (I-VI-X-XIII). La conformación VI, aunque no observada, se ha incluido en el grupo puesto que se generaría por el mismo tipo de transiciones que convierten XII en XV, III en VIII y X en XIII. Puesto que I es menos estable que X, como muestra su menor número de apariciones, la existencia de VI debe ser demasiado efímera para ser recogida, pero la facilidad propuesta para los cambios de helicidad nos hace suponer que debe estar presente. 
La transición de XII a I implica un cambio de disposición sinclinal y helicidad ya mencionados como procesos frecuentes, pero además implica una rotación del anillo trisustituido, como confirma el hecho de que un nuevo cambio en la disposición sinclinal (más el giro sin rotación de los anillos) genere X, que sólo se diferencia de XII en la disposición del metoxilo (exo para X y endo para XII).

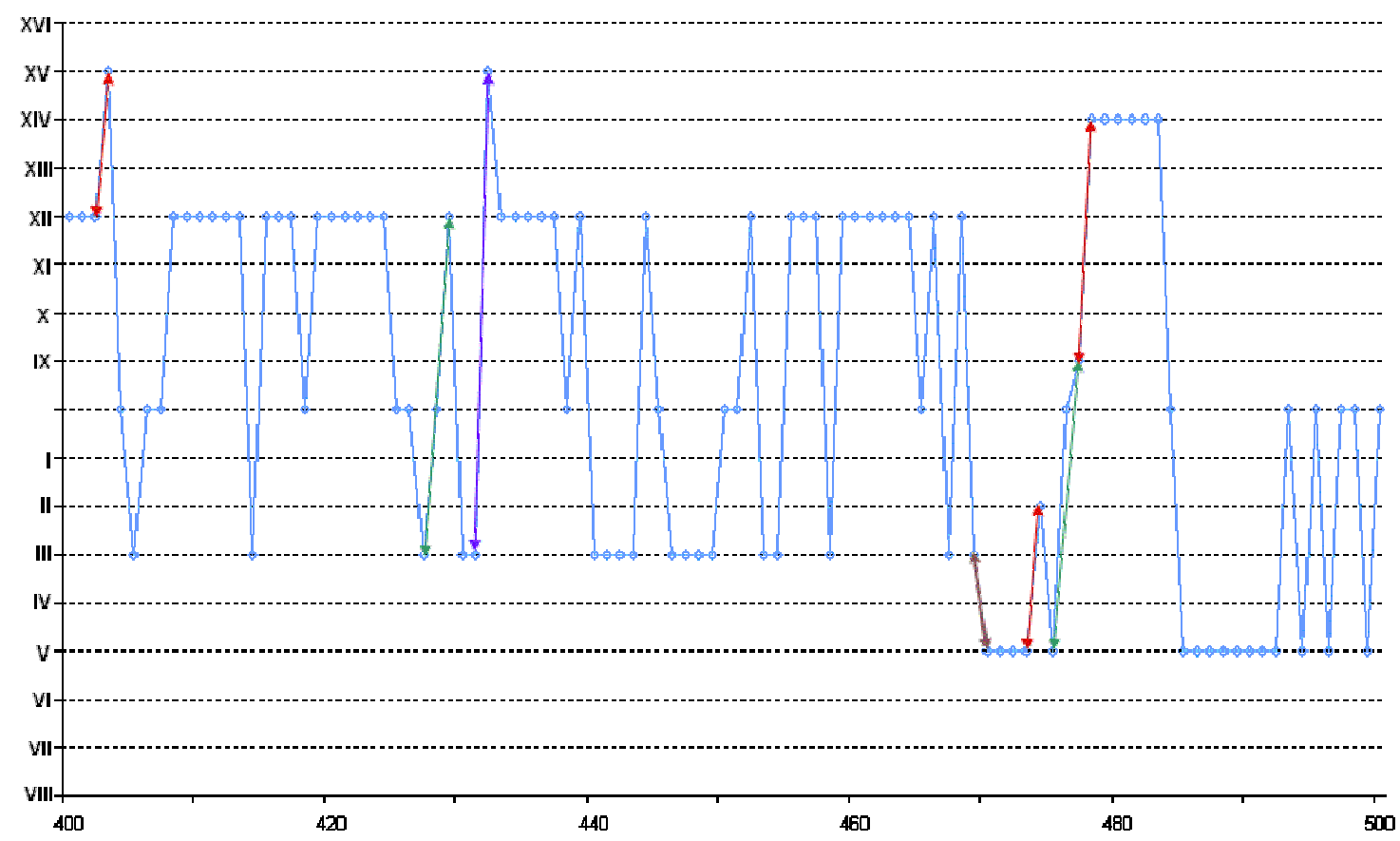

Figura 87. Ampliación de la dinámica molecular a $1200 \mathrm{~K}$ del compuesto 88. En morado se indican cambios de la disposición sinclinal (giro del puente), en rojo cambios de helicidad, en verde cambios simultáneos en la diposición sinclinal y en la helicidad y en marrón el cambio infrecuente de la conformación III a la V, que implica solamente la rotación del anillo de indol.

En el caso del diol cis con un anillo tetrasustituido, 88, se observa el paso del conjunto C (XII-XV-III-VIII) al conjunto D (XIV-IX-V-II), mediante la transición de III a V (figuras 77 y 87). En este caso, la transición implica solamente la rotación del anillo de indol. El carácter simétrico del anillo tetrasustituido hace que los conjuntos de conformaciones C (XII-XV-III-VIII) y A (X-XIII-I-VI) y los conjuntos D (XIV-IX-V-II) y B (XVI-XI-VII-IV) sean estructuralmente iguales, por lo que se puede considerar que la dinámica muestrea todas las conformaciones propuestas para él. 
La baja frecuencia de las rotaciones de los anillos no permite establecer la facilidad relativa con que tienen lugar. Sin embargo, su mera ocurrencia sugiere que las rotaciones del indol y del anillo trisustituido pueden ocurrir con relativa facilidad. Estructuralmente, parece razonable, ya que ambos pueden rotar dirigiendo hacia el espacio intraanular átomos de hidrógeno. Por el contrario, estructuralmente parece más difícil que rote el anillo tetrasustituido, puesto que requeriría pasar un grupo metoxilo por el espacio intraanular. En los dioles trans no se observan rotaciones de los anillos aromáticos.

Las conclusiones extraídas del análisis de los estudios de dinámica molecular están de acuerdo con las consideraciones propuestas inicialmente para analizar los equilibrios conformacionales de los dioles, basadas en desglosar la movilidad de las moléculas en cuatro posibilidades (figura 70, pág. 140): a) rotación del anillo de indol (A), b) rotación del otro anillo (B), c) rotación del puente, que conlleva el cambio entre las dos conformaciones sinclinales entre los dos restos fenilo, y d) cambio del sentido helicoidal de los anillos. Además, es posible establecer un orden relativo de facilidad de los cuatro elementos: $\mathrm{d}>\mathrm{c}>\mathrm{a} \sim \mathrm{b}(\mathrm{TR})>\mathrm{b}(\mathrm{QR})$. Este orden también está de acuerdo con los planteamientos iniciales. 


\title{
III.4.B.3. Justificación de la apariencia de los espectros de RMN de dioles y sus diacetatos.
}

\author{
III.4.B.3.a. Giro rápido del puente-Interconversión conformaciones \\ $\underline{\text { sinclinales. }}$
}

Si las transiciones tipo d y c son rápidas en la escala de tiempo de la resonancia, los equilibrios conformacionales propuestos para los dioles cis y trans se pueden considerar como equilibrios entre 4 conjuntos de conformaciones. A su vez, estos conjuntos de conformaciones pueden considerarse integrados por una conformación prioritaria en el caso de los dioles trans (la conformación sinclinal con los hidroxilos gauche con su sentido de hélice preferido) y por dos en los dioles cis (correspondientes a las dos conformaciones sinclinales con su sentido helicoidal preferido). El aspecto de los espectros vendrá, pues, condicionado por las rotaciones de los anillos de indol y bencénicos.

DIOLES CIS

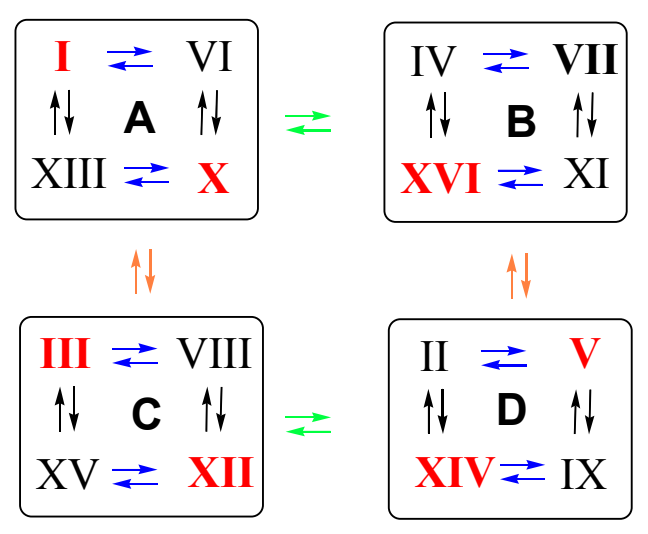

DIOLES TRANS

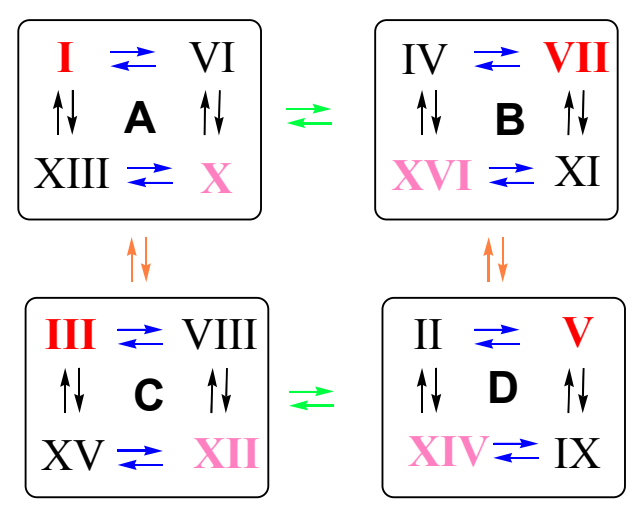

Figura 88. Conjuntos de conformaciones para los dioles cis y trans que se interconvierten entre ellos por rotaciones del anillo indólico (flechas verdes) o del anillo bencénico (flechas naranjas). Cada conjunto está formado por cuatro conformaciones que se interconvierten por transiciones rápidas en la escala de tiempo de RMN: rotación del puente (flechas negras) y cambio de helicidad (flechas azules). Las conformaciones prioritarias de cada conjunto se indican en rojo (rosa para el diol trans 86): una en los dioles trans (conformación en la que los hidroxilos están en gauche y la disposición sinclinal coincide con su helicidad preferida) y dos conformaciones en los dioles cis (correspondientes a las dos conformaciones en las que el signo de la disposición sinclinal y la helicidad coinciden).

En cada conjunto de conformaciones, la situación de los sustituyentes en los anillos aromáticos (el metoxilo y los metinos aromáticos del anillo bencénico y los metinos del anillo de pirrol -P- y bencénicos del indol) se puede describir como un promedio (intercambio rápido) entre las situaciones que más contribuyen al equilibrio (marcadas en rojo/rosa). 
Así, se observa que en los dioles cis los metinos del anillo de indol (P, en las figuras 89-96, que es equivalente a Indol C9-10 de las figuras 74-77) y los metoxilos se encuentran promediados entre una situación endo y una exo en cada uno de los conjuntos de conformaciones (en intercambio rápido). Por el contrario, los dioles trans, con una sola conformación como principal contribuyente al equilibrio, los presentan en una única situación en cada equilibrio. En consecuencia, es de esperar que, para cada conjunto de conformaciones, las señales correspondientes a los elementos indicados en los espectros de RMN de los dioles cis correspondan a situaciones promediadas, mientras que en los dioles trans correspondan a situaciones más extremas. En otras palabras, es de esperar que las situaciones que pueden interconvertirse por rotación de los anillos aromáticos en los dioles cis sean más similares (en desplazamiento químico) que las correspondientes a los dioles trans.

DIOLES CIS

\begin{tabular}{ccccc}
\hline $\begin{array}{c}\text { P-endo } \\
\text { MeO-endo }\end{array}$ & & \\
$\mathbf{I}$ & $\rightleftarrows$ & VI \\
$\uparrow \downarrow$ & $\mathbf{A}$ & $\uparrow \downarrow$ \\
XIII & $\rightleftarrows$ & $\mathbf{X}$ \\
& & $\begin{array}{c}\text { P-exo } \\
\text { MeO-exo }\end{array}$ \\
& & &
\end{tabular}

P: Promediado exo-endo $\mathrm{MeO}$ : Promediado exo-endo

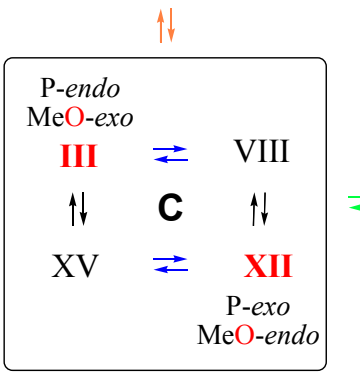

P: Promediado exo-endo $\mathrm{MeO}$ : Promediado exo-endo

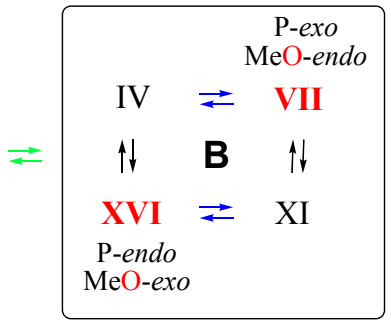

P: Promediado exo-endo $\mathrm{MeO}$ : Promediado exo-endo

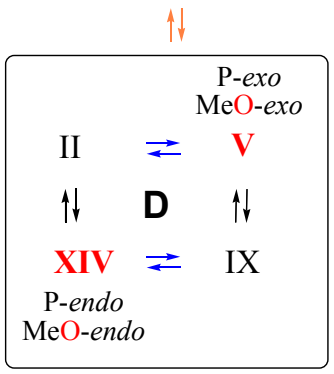

P: Promediado exo-endo $\mathrm{MeO}$ : Promediado exo-endo
DIOLES TRANS

\begin{tabular}{|c|c|c|}
\hline \multicolumn{3}{|c|}{$\begin{array}{c}\mathrm{P}-\text { endo } \\
\mathrm{MeO}-\text { endo }\end{array}$} \\
\hline $\mathbf{I}$ & $\rightleftarrows$ & VI \\
\hline$\uparrow \downarrow$ & $\mathbf{A}$ & $\uparrow \downarrow$ \\
\hline XIII & $\rightleftarrows$ & $\mathbf{X}$ \\
\hline
\end{tabular}
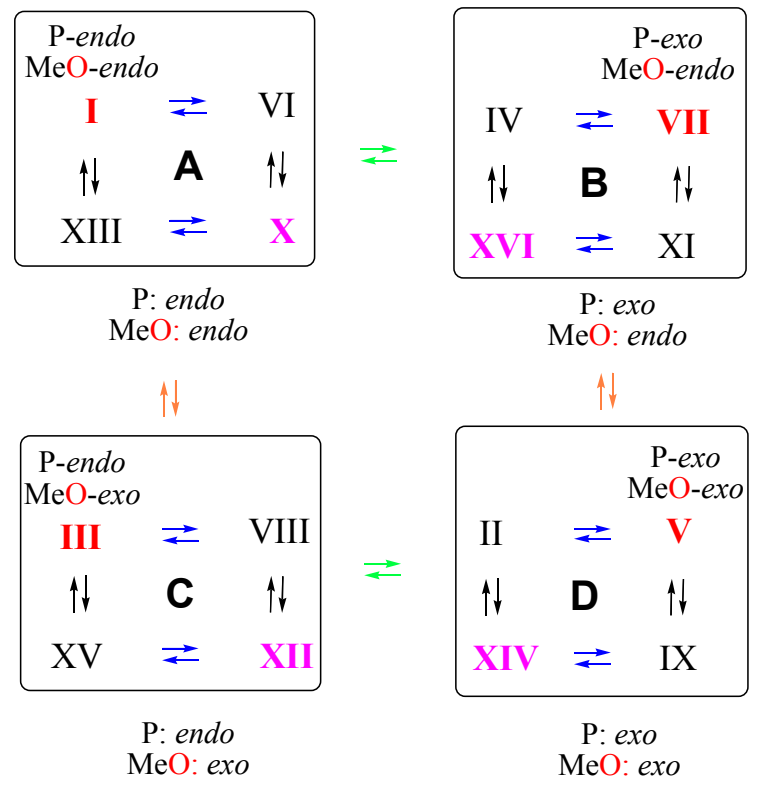

Figura 89. Conjuntos de conformaciones para los dioles cis y trans que se interconvierten entre ellos por rotaciones del anillo indólico (flechas verdes) o del anillo bencénico (flechas naranjas). En cada conjunto se ha indicado la disposición endo o exo del metoxilo $(\mathrm{MeO})$ y de los hidrógenos del anillo pirrólico del indol ( $\mathrm{P}$, equivalente a Indol C9-C10 de las figuras 74-77) para las conformaciones prioritarias. Las disposiciones indicadas en el diol trans son las correspondientes al diol 89. 
Además, en los dioles simétricos los conjuntos de conformaciones A y $\mathbf{C}$ у $\mathbf{B}$ у $\mathbf{D}$ son estructuralmente indistinguibles, por lo que el número de conformaciones a considerar en el equilibrio se reduce aún más, dependiendo el aspecto de los espectros únicamente de la rotación de los anillos de indol. Al ser el anillo tetrasustituido simétrico, el anillo de indol se encuentra en entornos similares, se encuentre a un lado u otro del mismo, por lo que el efecto de la rotación del indol es menos apreciable y se requiere una menor frecuencia para promediar las señales del mismo. Sin embargo, los dos lados del anillo simétrico sí que se encuentran en entornos muy diferentes dependiendo de su disposición, lo que justifica la presencia de señales diferentes para núcleos químicamente equivalentes. Así, las principales diferencias (excluyendo las originadas por la existencia de diferentes sistemas de spines) entre los espectros de los compuestos tri- y tetrasustituidos se deberán a que el efecto de la rotación del indol es más fácilmente apreciable en los primeros.

DIOL CIS 88

$$
\begin{array}{ccccc}
\hline \begin{array}{ccc}
\text { P-endo } \\
\text { MeO-endo }
\end{array} & & \\
\text { I } & \rightleftarrows & \text { VI } \\
\uparrow \downarrow & \text { A } & \uparrow \downarrow \\
\text { XIII } & \rightleftarrows & \mathbf{X} \\
& & \text { P-exo } \\
& & \text { MeO-exo } \\
& & \\
\text { P: Promediado exo-endo }
\end{array}
$$
$\mathrm{MeO}$ : Promediado exo-endo

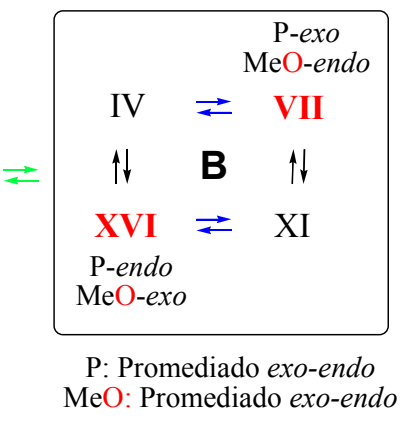

DIOL TRANS 89

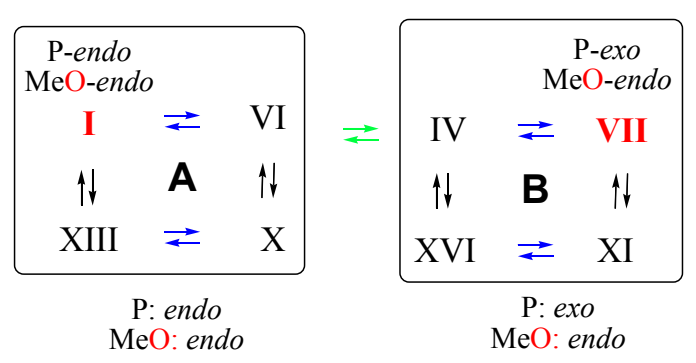

Figura 90. Conjuntos de conformaciones a considerar en los compuestos en los que el anillo bencénico es simétrico $(\mathbf{8 8}$ y 89$)$, ya que $\mathrm{A}=\mathrm{C}$ y $\mathrm{B}=\mathrm{D}$.

Por tanto, para intentar explicar la apariencia de los espectros de RMN de los dioles, habrá que considerar cuatro conjuntos de conformaciones $(\mathbf{A}, \mathbf{B}, \mathbf{C}$ y $\mathbf{D})$ para los que presentan un anillo trisustituido y dos (A y $\mathbf{B}$, por ejemplo) para los que presentan un anillo bencénico tetrasustuido simétrico.

Las situaciones susceptibles de ser intercambiadas por rotación de los anillos son más similares en los dioles cis que en los trans. Las dinámicas moleculares indican que las rotaciones de anillos son más fáciles en los dioles cis que en los isómeros trans. Además, los experimentos de dinámica molecular sugieren que las rotaciones de los dos anillos para los que presentan un anillo trisustituido son factibles, mientras que en los que presentan un anillo bencénico tetrasustuido simétrico la rotación del anillo tetrasustituido debe ser más infrecuente. 
Teniendo todo lo anterior en cuenta, el sistema más simple debe ser el diol 89. Sus espectros de RMN muestran un único juego de señales, resonando los núcleos químicamente equivalentes del anillo tetrasustituido a frecuencias distintas. En principio, considerando lo expuesto hasta el momento, para el diol 89 cabría esperar la existencia de dos juegos de señales con los núcleos químicamente equivalentes del anillo tetrasustituido resonando a frecuencias distintas. La presencia de un único juego de señales puede ser el resultado de al menos una de las dos siguientes posibilidades (figura 91): una rotación rápida del indol, que promediaría las poblaciones $\mathbf{A}$ y $\mathbf{B}$, o una contribución diferente de las poblaciones A y $\mathbf{B}$ al espectro, que se produciría si uno de los dos conjuntos de conformaciones estuviese menos poblado que el otro.

La rotación rápida del indol (no observada en las dinámicas moleculares) daría lugar a que todas las conformaciones formaran un único conjunto conformacional en intercambio rápido. Sin embargo, el hecho de que la naturaleza simétrica del anillo tetrasustituido haga que los subconjuntos A y $\mathbf{C}$ y $\mathbf{B}$ y $\mathbf{D}$ sean indistinguibles no implica que sus metoxilos ni los metinos estén en el mismo entorno magnético, explicando la existencia de dos señales para las parejas de núcleos químicamente equivalentes. Por otra parte, los resultados del Monte Carlo sugieren que las conformaciones de menor energía de ambos conjuntos de conformaciones (I y VII y sus idénticas III y V) son muy próximas en energía, lo cual no estaría de acuerdo con el predominio de una de ellas.

ROTACIÓN RÁPIDA DEL INDOL

\begin{tabular}{|c|c|c|c|c|}
\hline $\begin{array}{c}\text { P-endo } \\
\text { MeO-endo }\end{array}$ & RÁPIDA & & & $\begin{array}{l}\text { P-exo } \\
\text { leO-exo }\end{array}$ \\
\hline $\mathrm{I} / \mathrm{III} \quad \rightleftarrows \mathrm{VI} / \mathrm{VIII}$ & $\rightleftarrows$ & $\mathrm{II} / \mathrm{IV}$ & $\rightleftarrows$ & V/VII \\
\hline$\uparrow \downarrow \quad \mathbf{A} / \mathbf{C} \quad \uparrow \downarrow$ & & $\uparrow \downarrow$ & $B / D$ & $\uparrow \downarrow$ \\
\hline $\mathrm{XIII} / \mathrm{XV} \rightleftarrows \mathrm{X} / \mathrm{XII}$ & & XIV/XVI & $\rightleftarrows$ & $\mathrm{IX} / \mathrm{XI}$ \\
\hline
\end{tabular}

PREDOMINIO DE A O B

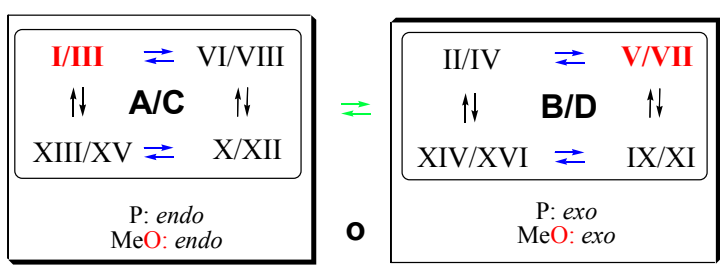

Figura 91. Posibilidades que justificarían la presencia de un solo juego de señales en los espectros de RMN del diol trans 89. 
Los espectros de RMN del diol trans 86 son muy similares a los de 89, lo que sugiere un comportamiento similar. Sin embargo, la consideración de los equilibrios para $\mathbf{8 6}$ sugiere que, para alcanzar una situación equivalente a la de $\mathbf{8 9}$, las rotaciones de los dos anillos deben ser lo suficientemente rápidas en la escala de tiempo de la resonancia como para promediar las señales correspondientes a los grupos A, B, C y D. Si esto no fuera así, habría dos juegos de señales por cada anillo cuya rotación fuera lenta. El desplazamiento químico del grupo metoxilo, intermedio entre los metoxilos endo y exo del compuesto 89, está de acuerdo con esta situación.

Los espectros de RMN del diol cis $\mathbf{8 8}$ presentan dos juegos diferenciados de señales, en proporción aproximada 2:1. Esta diferencia en energía, y más si intervienen cuatro posibles conformaciones, no puede ser discriminada por la mecánica molecular. En la dinámica molecular, además, la naturaleza infrecuente de la transición entre los dos conjuntos de poblaciones no permite establecer comparaciones de ocupación de los estados. Si se considera la naturaleza simétrica del anillo no indólico y que la rotación del indol es rápida y la del anillo tetrasustituido no, todas las conformaciones están en equilibrio rápido, lo que no justificaría la existencia de dos juegos de señales en el espectro (figura 92). La consideración de que la rotación del anillo de indol sea lenta en prncipio solucionaría el problema, ya que el equilibrio a considerar es el que se establece entre I/III-VI/VIII-X/XII-XIII/XV y II/IV-V/VII-IX/XI-XIV/XVI, siendo los tipos conformacionales en rojo los más representativos.

DIOL CIS 88

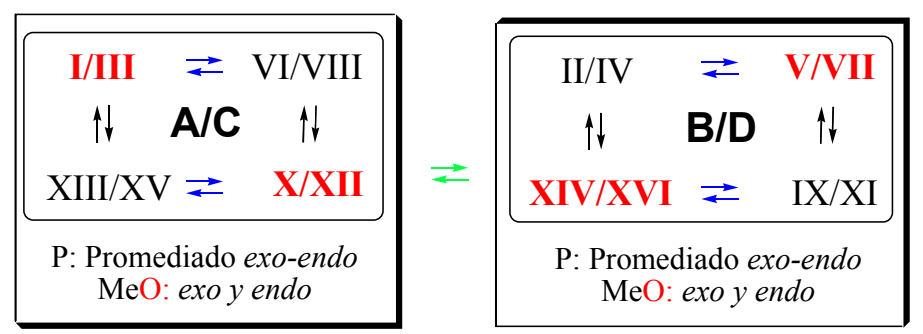

Figura 92. Grupos conformacionales a considerar en el diol cis $\mathbf{8 8}$ y disposición de los sustituyentes de los anillos en cada grupo si se considera que la rotación del puente y el cambio de helicidad son rápidos en la escala de tiempo de RMN.

Sin embargo, el análisis detallado de los desplazamientos químicos del diol $\mathbf{8 8}$ muestra que, en contra de lo esperado para un intercambio rápido entre conformaciones $+\mathrm{y}$ - sinclinales, los núcleos químicamente equivalentes se encuentran en entornos magnéticos muy diferentes, como se muestra en la tabla 21. 

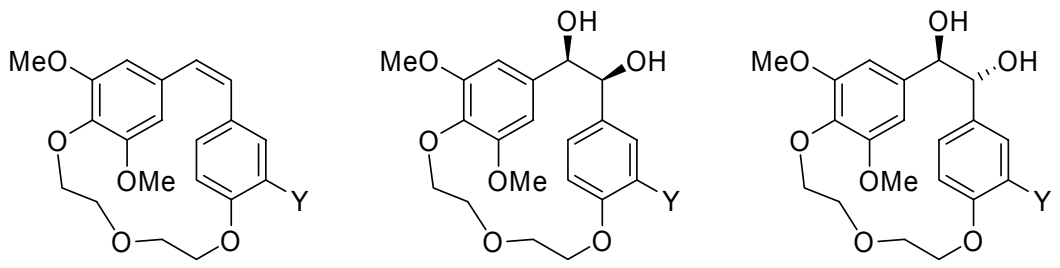

\begin{tabular}{|c|c|c|c|c|c|}
\hline Compuesto & Tipo de puente & MeO & CH & $\Delta_{\text {OMe }}$ & $\Delta_{\mathrm{CH}}$ \\
\hline \multirow{3}{*}{$\mathbf{Y}=\mathbf{H}$} & Olef & $3,62 / 3,62$ & $5,93 / 5,93$ & 0 & 0 \\
\hline & Diol-cis & $3,63 / 3,62$ & $6,19 / 5,67$ & 0,01 & 0,51 \\
\hline & Diol-trans & $3,70 / 3,39$ & 6,47 / 5,39 & 0,31 & 1,08 \\
\hline \multirow{5}{*}{$\mathbf{Y}=\mathbf{O H}$} & Olef & $3,65 / 3,65$ & $6,13 / 6,13$ & 0 & 0 \\
\hline & \multirow{2}{*}{ Diol-cis } & $3,68 / 3,64$ & $6,25 / 5,87$ & 0,04 & 0,37 \\
\hline & & $3,71 / 3,60$ & $6,39 / 5,70$ & 0,09 & 0,69 \\
\hline & \multirow{2}{*}{ Diol-trans } & $3,83 / 3,49$ & $6,54 / 5,49$ & 0,34 & 1,05 \\
\hline & & $3,85 / 3,55$ & $6,55 / 5,64$ & 0,30 & 0,91 \\
\hline 87 & Olef & $3,45 / 3,45$ & $6,05 / 6,05$ & 0 & 0 \\
\hline \multirow{2}{*}{88} & \multirow{2}{*}{ Diol-cis } & $3,86 / 3,00$ & $6,23 / 5,89$ & 0,86 & 0,34 \\
\hline & & $3,81 / 3,00$ & $6,77 / 5,32$ & 0,81 & 1,45 \\
\hline 89 & Diol-trans & 3,86 / 2,97 & $6,66 / 5,87$ & 0,89 & 0,79 \\
\hline
\end{tabular}

Tabla 21. Desplazamientos químicos de los metoxilos y metinos (y las diferencias entre cada pareja químicamente equivalente) del anillo simétrico de los compuestos 87, 88 y 89 y de los compuestos que se muestran encima de la tabla.

Así, la diferencia de desplazamiento químico de los dos metoxilos del anillo tetrasustituido es muy similar en los dos dioles. La diferencia de desplazamiento químico de los metinos aromáticos del anillo tetrasustituido en la población mayoritaria del diol cis es menor que en el trans, lo que estaría de acuerdo con un equilibrio conformacional, pero en la minoritaria esta diferencia es incluso superior a la observada en el diol trans. Estos datos sugieren una interpretación diferente de la anteriormente expuesta, según se discute en el apartado siguiente. 
III.4.B.3.a. Giro lento del puente. Interconversiones lentas de conformaciones sinclinales.

Manteniendo el cambio de helicidad como transición más favorable (rápida) y de acuerdo con los cálculos de las dinámicas moleculares a $300 \mathrm{~K}$, se puede proponer la existencia de un giro rápido del anillo de indol y una interconversión lenta entre las conformaciones sinclinales, con lo que el equilibrio conformacional podría resumirse como se muestra en la figura siguiente (Figura 96 para el compuesto 89).

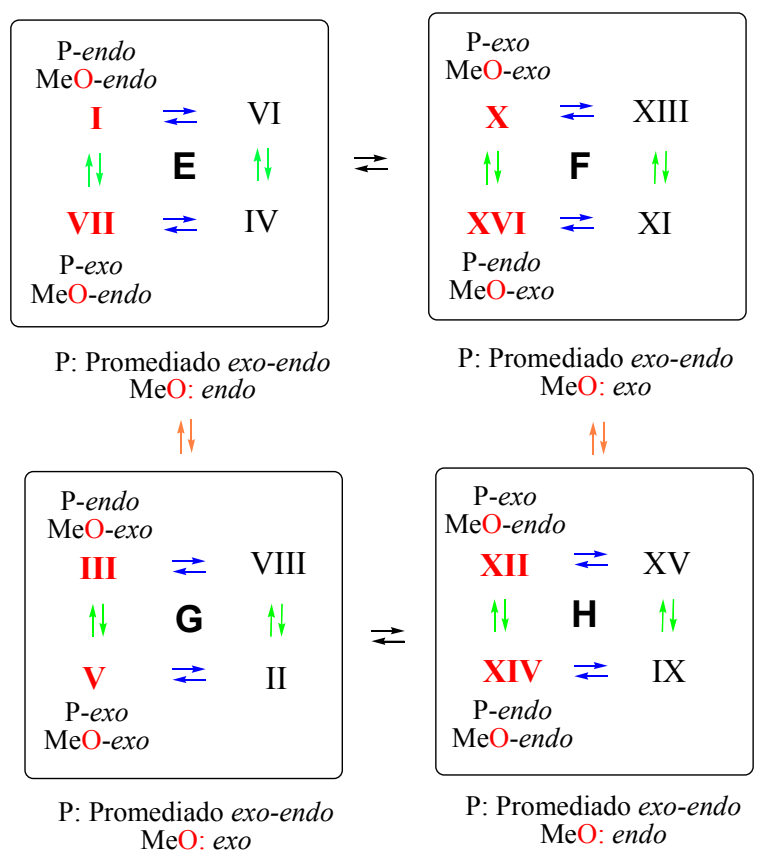

Figura 93. Conjuntos confomacionales para los dioles cis que resultan de considerar rápidas las transiciones debidas al cambio de helicidad (flechas azules) y la rotación del indol (flechas verdes). Los cambios entre estos grupos se producirían mediante las transiciones (más lentas) debidas a la rotación del anillo tetrasustituido (flechas naranjas) y a la rotación del puente (flechas negras).

Si reconsideramos la situación con un anillo simétrico $(\mathbf{E}=\mathbf{G}$ y $\mathbf{F}=\mathbf{H}$, figura 94), para el diol cis quedan dos equilibrios, uno correspondiente a disposiciones + sinclinales y el otro - sinclinales. Para el diol trans, las mismas consideraciones llevarían a tomar en consideración un único equilibrio (aquel con los alcoholes del puente gauche), ya que el otro sería menos estable. Además, en ambas situaciones la rotación del anillo tetrasustituido sería lenta, por lo que sus núcleos químicamente equivalente darían señales diferentes. Tal y como se muestra en el esquema, los núcleos químicamente equivalentes estarían en entornos muy distintos en el conjunto de conformaciones en equilibrio, por lo que sus desplazamientos químicos serían bastante extremos tanto en el diol cis como en el trans, de acuerdo con lo observado. 
DIOL CIS

\begin{tabular}{|ccc|}
\hline $\mathrm{P}-$ endo & & \\
$\mathrm{MeO}$ endo & & \\
$\mathrm{I} / \mathrm{III}$ & $\rightarrow$ & $\mathrm{VI} / \mathrm{VIII}$ \\
$\uparrow \downarrow$ & $\mathbf{E}$ & $\uparrow$ \\
$\mathrm{VII} / \mathrm{V}$ & $\rightleftarrows$ & $\mathrm{IV} / \mathrm{II}$ \\
$\mathrm{P}-$ exo & & \\
$\mathrm{MeO}-$ endo & &
\end{tabular}

P: Promediado exo-endo $\mathrm{MeO}$ : endo

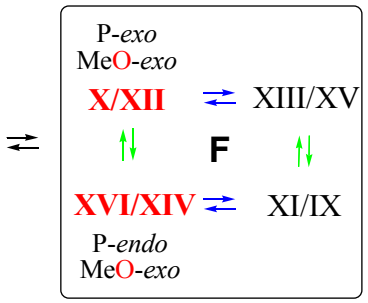

P: Promediado exo-endo MeO: exo

Figura 94 Conjuntos confomacionales para los dioles $\mathbf{8 8}$ y $\mathbf{8 9}$ que resultan de considerar rápidas las transiciones debidas al cambio de helicidad (flechas azules) y la rotación del indol (flechas verdes). Los cambios entre estos grupos se producirían mediante las transiciones (más lentas) debidas a la rotación del anillo tetrasustituido (flechas naranjas, no mostradas, ver figura 93) y a la rotación del puente (flechas negras).Los conjuntos $\mathrm{G}$ y $\mathrm{H}$ no se consideran ya que $\mathrm{E}=\mathrm{G}$ y $\mathrm{F}=\mathrm{H}$. En rojo se han resaltado las conformaciones preferidas, para las que los signos de la disposición sinclinal y la helicidad son coincidentes. $\mathrm{MeO}-$ endo o MeO-exo hacen referencia a la situación dekl grupo $\mathrm{MeO}$ - señalado en azul para la primera conformación indicas (I, VII, etc) o en color negro para la segunda (II, V, etc).

Como se ha indicado antes, la consideración de los equilibrios para $\mathbf{8 6}$ sugiere que, para alcanzar una situación equivalente a la de $\mathbf{8 9}$, la rotación del otro anillo debe ser lo suficientemente rápida como para promediar las señales correspondientes a los grupos $\mathbf{F}$ y H (figura 95, izquierda) o debe existir el predominio de una frente a otra (figura 95, derecha). En el primer caso cabría esperar un promediado de las señales que alternan entre disposiciones endo y exo, mientras que en el segundo predominaría una disposición (endo o exo) del anillo trisustituido. El desplazamiento químico del metoxilo es intermedio entre las disposiciones exo y endo, aunque parece predominar la primera, lo que sugiere un equilibrado rápido de los conjuntos de conformaciones $\mathbf{F}$ y $\mathbf{H}$. Esta explicación es indistinguible de la propuesta anterior de tres giros rápidos, pero permite una explicación unificada de los dioles indólicos trans. 


\section{ROTACIÓN RÁPIDA DEL TRISUSTITUIDO}

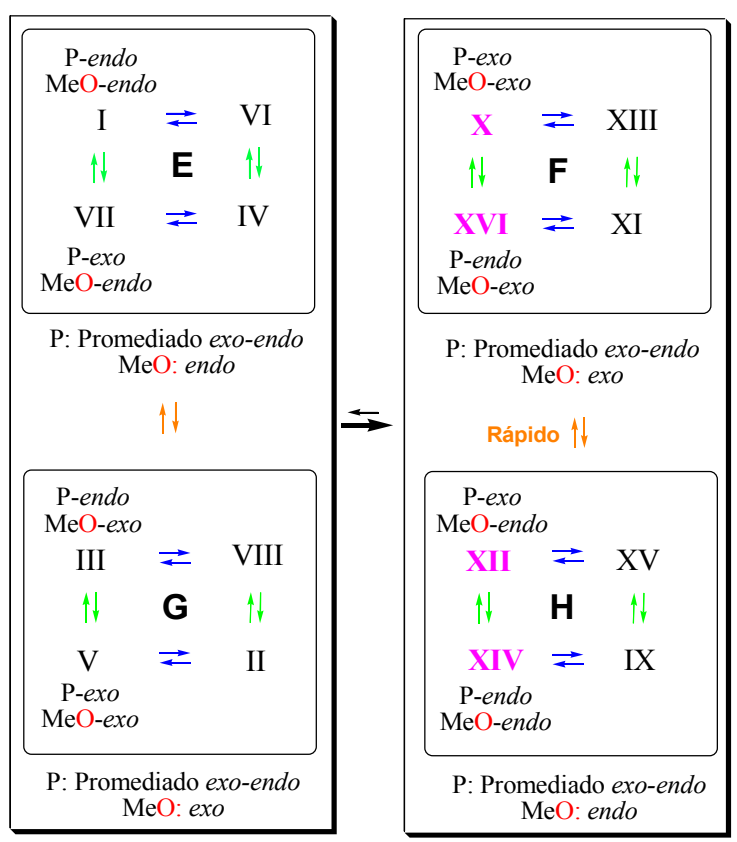

PREDOMINIO DE E O G

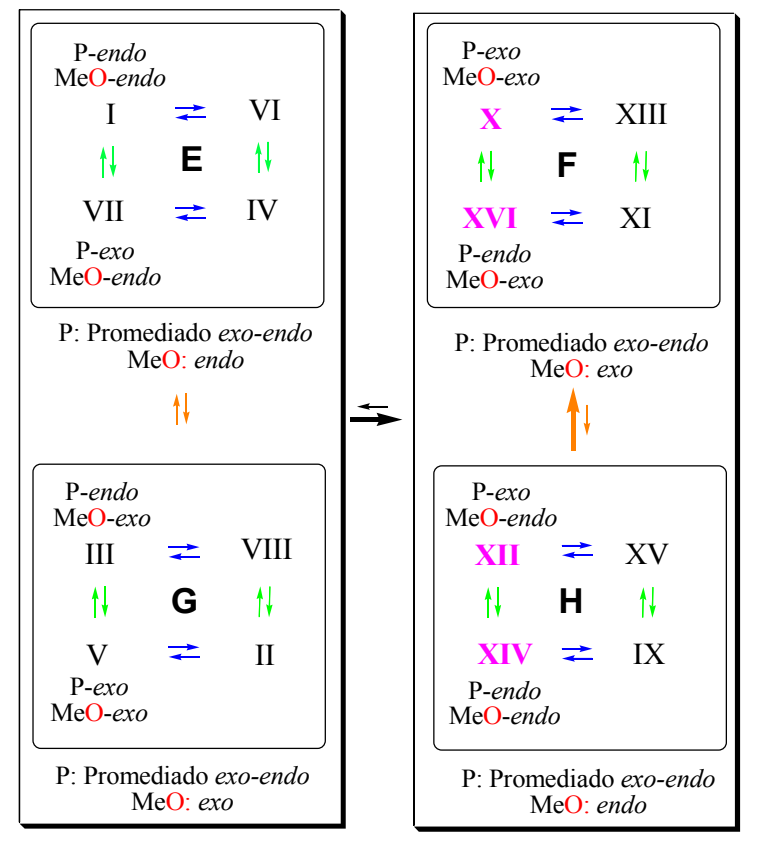

Figura 95. Posibilidades de grupos conformacionales para el diol trans 86, dependiendo de si la rotación del anillo trisustituida es rápida (a la izquierda) o de si es más lenta y predomina una de las posiciones del metoxilo (a la derecha).

La acetilación de los dioles trans conduce a los diacetatos 91 y 93. El segundo presenta un espectro de RMN muy similar al de su alcohol de origen, por lo que es de esperar un comportamiento similar. Por el contrario, el acetato de 86 (91) muestra dos juegos de señales. Esto puede explicarse por una ralentización (respecto al diol de partida) de la rotación del anillo trisustituido y del giro del puente si consideramos la hipótesis inicial de los tres giros rápidos (apareciendo las señales de los conjuntos $\mathbf{F}$ y $\mathbf{H}$ independientes). Estas explicaciones están de acuerdo con la apariencia del diol de partida, que muestra algunas señales ensanchadas.

El diol cis con anillo trisustituido 85 y su acetato 90 muestran espectros complejos que pueden asignarse a dos conjuntos de señales y podrían explicarse con los modelos conformacionales propuestos (rotación del indol rápida y rotación del anillo trisustituido y del puente lentas), aunque no es posible analizarlos con detalle debido al ensanchamiento de las señales en los mismos.

Esta explicación unificada de los compuestos 85-93 se muestra en la tabla 22. 


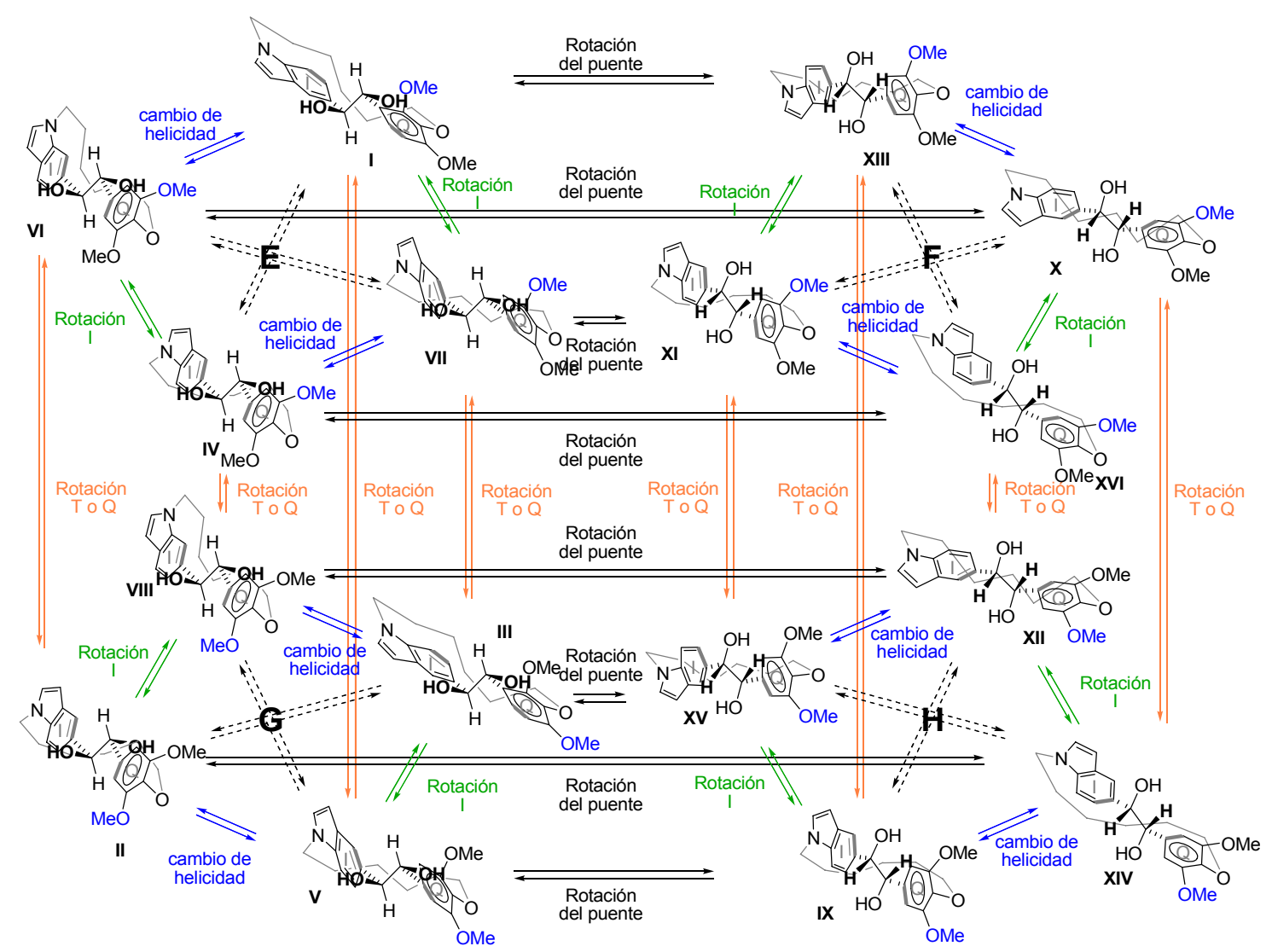

Figura 96. Equilibrios conformacionales del diol trans 89, en el que se aprecia la formación de los conjuntos E, F, G y $\mathbf{H}$ al considerar la rotación del indol y el cambio de helicidad como rápidos en la escala de tiempo de RMN y lentos la rotación del puente y del anillo tetrasustituido. Esta figura puede aplicarse de igual modo a los demás dioles y acetatos. 


\begin{tabular}{|c|c|c|c|c|c|c|c|}
\hline Comp. & Puente & Rot. I & Rot. T & Rot. Q & Rot. puente & RMN & Explicación \\
\hline 85 & $\mathrm{OH}$ cis & +++ & $\ell$ & - & $\ell$ & Complejo & E-F-G-H \\
\hline 90 & $\begin{array}{l}\text { OAc } \\
\text { cis }\end{array}$ & +++ & $\ell$ & - & $\ell$ & Complejo & E-F-G-H \\
\hline 86 & $\begin{array}{l}\mathrm{OH} \\
\text { trans }\end{array}$ & +++ & $\begin{array}{c}+++ \\
o ́ \\
\ell\end{array}$ & - & $\ell$ & $\begin{array}{l}1 \text { juego } \\
(\mathrm{QE} \neq)\end{array}$ & $\begin{array}{l}\text { Promedio de F } \\
\text { y H ó } \\
\text { predominio de } \\
\text { F o H }\end{array}$ \\
\hline 91 & $\begin{array}{l}\text { OAc } \\
\operatorname{tran} s\end{array}$ & +++ & $\ell$ & - & $\ell$ & $\begin{array}{c}2 \text { juegos } \\
(\mathrm{QE} \neq)\end{array}$ & $\begin{array}{c}\text { Conjuntos F y } \\
\text { H. }\end{array}$ \\
\hline 88 & $\mathrm{OH} c i s$ & +++ & - & No & $\ell$ & $\begin{array}{c}2 \text { juegos } \\
(Q E \neq)\end{array}$ & $\begin{array}{c}\text { Conjuntos E y } \\
\text { F }\end{array}$ \\
\hline 92 & $\begin{array}{l}\text { OAc } \\
\text { cis }\end{array}$ & +++ & - & No & $\ell$ & $\begin{array}{c}2 \text { juegos } \\
(\mathrm{QE} \neq)\end{array}$ & $\begin{array}{c}\text { Conjuntos E y } \\
\text { F }\end{array}$ \\
\hline 89 & $\begin{array}{l}\mathrm{OH} \\
\text { trans }\end{array}$ & +++ & - & No & $\ell$ & $\begin{array}{l}1 \text { juego } \\
(\mathrm{QE} \neq)\end{array}$ & Conjunto E \\
\hline 93 & $\begin{array}{l}\text { OAc } \\
\operatorname{trans}\end{array}$ & +++ & - & No & $\ell$ & $\begin{array}{l}1 \text { juego } \\
(\mathrm{QE} \neq)\end{array}$ & Conjunto E \\
\hline
\end{tabular}

Tabla 22. Resumen del análisis conformacional de los dioles y sus acetatos, donde +++ indica un giro rápido, $\ell$ indica giro lento y No que el giro está impedido. Las letras T, Q e I se refieren a los anillos aromáticos trisustituidos, tetrasustituidos y $N$-metilindol, respectivamente. $\mathrm{QE} \neq$ significa que los átomos químicamente equivalentes presentan señales espectroscópicas diferentes. 



\section{III.5. ACTIVIDAD BIOLÓGICA.}

\section{III.5.A. Actividad inhibidora de la polimerización de tubulina.}

La inhibición de polimerización de tubulina es un método "in vitro" para evaluar la actividad de los compuestos sintetizados. Se lleva a cabo sobre proteína microtubular (MTP) y se determina la potencia inhibitoria estableciéndose la $\mathrm{IC}_{50}$ de los compuestos más potentes.

El proceso consta de tres etapas bien diferenciadas:

- Aislamiento de proteína microtubular.

- Medida de la actividad inhibitoria de los compuestos.

- Determinación de la $\mathrm{IC}_{50}$. 


\section{III.5.A.1. Aislamiento de la proteína.}

La proteína microtubular (MTP) fue purificada de cerebros de terneros mediante dos ciclos de polimerización/despolimerización dependientes de temperatura, de acuerdo con el método de Shelanski ${ }^{61}$ con modificaciones.

En cada ciclo se lleva a cabo una polimerización inducida por la alta temperatura $\left(37^{\circ} \mathrm{C}\right)$ y el GTP, que permite recoger la proteína microtubular en el precipitado resultante por centrifugación. La proteína precipitada se despolimeriza por enfriamiento a $0{ }^{\circ} \mathrm{C}$ y se vuelve a centrifugar, desechando en esta ocasión el precipitado. Tras 2 ciclos, se obtiene la MTP de una composición adecuada para llevar a cabo los ensayos de inhibición de polimerización de tubulina. En esta proteína microtubular hay una mezcla de isotipos de tubulina (70\%) y MAPs (30\%) (proteínas asociadas a los microtúbulos).

En el siguiente esquema se representa el proceso de aislamiento desde los cerebros hasta la proteína preparada para realizar los ensayos.

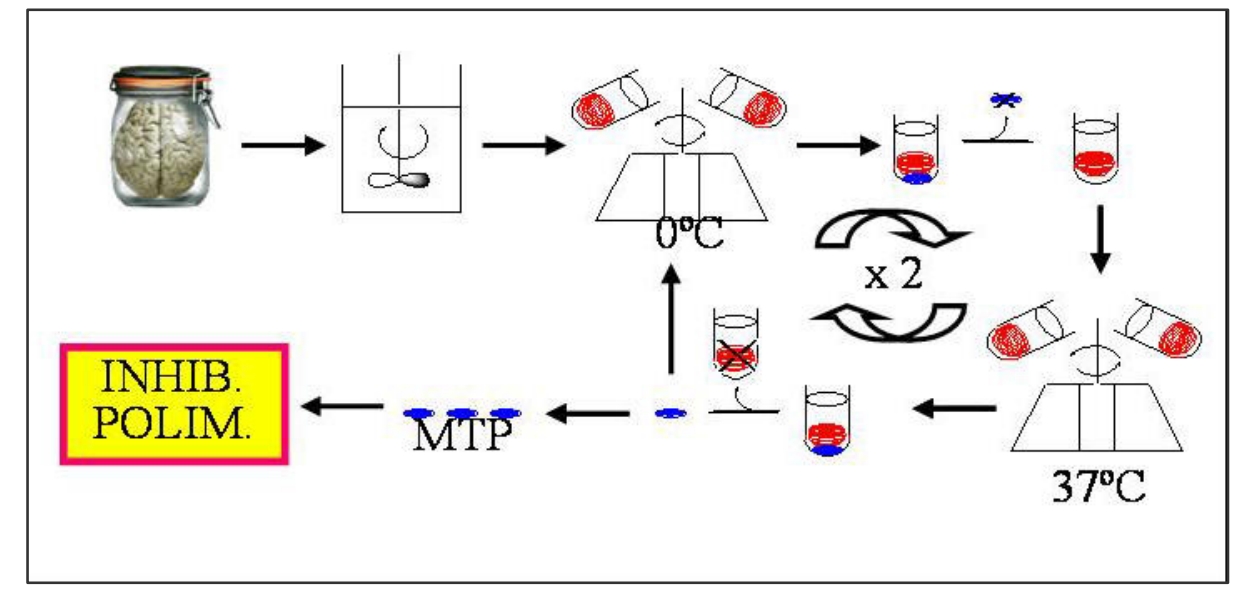

Figura 97. Proceso de aislamiento de tubulina.

\footnotetext{
61 Shelanski, M. L.; Gaskin, F.; Cantor, C. R. Microtubule assembly in the absence of added nucleotides. Proc. Nat. Acad. Sci. 1973, 70, 765-768.
} 


\section{III.5.A.2. Ensayos de la actividad inhibitoria de polimerización de tubulina de los compuestos.}

El ensamblaje in vitro de tubulina se monitoriza a través de la medida a $450 \mathrm{~nm}$ (en lugar de $350 \mathrm{~nm}$ para evitar la absorción por los ligandos) de la turbidez generada por la formación de microtúbulos. ${ }^{62}$ Cada ensayo incluye siempre un control, sin ligando. Las muestras contienen $1,0 \mathrm{mg} / \mathrm{mL}$ de MTP y el ligando a una concentración $20 \mu \mathrm{M}$ en el caso de que sólo haya un compuesto.

Todos los compuestos utilizados están disueltos en DMSO para evitar problemas de solubilidad. La concentración máxima de DMSO en los experimentos es del 4\%, concentración que no afecta a la polimerización de la tubulina. ${ }^{63}$

Los ensayos se realizan a una concentración relativamente alta $(20 \mu \mathrm{M})$ con el fin de seleccionar los compuestos que presentan una $\mathrm{IC}_{50}$ igual o inferior a esta concentración. La determinación de la $\mathrm{IC}_{50}$ se desarrolla en el siguiente apartado.

El grado de inhibición de la polimerización presentada por los ligandos se establece por comparación de la amplitud de la curva de polimerización de cada muestra con ligando con la de la muestra control, considerada como el 100\% de polimerización. La relación entre ambas amplitudes (\%) es la capacidad de polimerización de la preparación de tubulina en presencia de ese ligando.

De esta manera, se realizó un primer screening de todos los compuestos sintetizados y se seleccionaron para medir las $\mathrm{IC}_{50}$ aquellos cuya inhibición era superior al $50 \%$. En la tabla siguiente se recogen los resultados de los compuestos que no fueron seleccionados:

\footnotetext{
${ }^{62}$ Gaskin, F.; Cantor, C. R.; Shelanski, M. L. Turbidimetric Studies of the in Vitro Assembly and Disassembly of Porcine Neurotubules. J. Mol. Biol. 1974, 89, 737-758.

${ }^{63}$ Dumortier, C.; Gorbunoff, M.; Andreu, J. M.; Engelborghs, Y. Different kinetic pathways of the binding of two biphenyl analogues of colchicine to tubulin. Biochemistry 1996, 35, 4387-4395.
} 


\begin{tabular}{|c|c|c|c|c|c|}
\hline COMPUESTO & $\begin{array}{c}\text { CONC } \\
(\boldsymbol{\mu} \boldsymbol{M})\end{array}$ & $\begin{array}{c}\text { INHIBICIÓN } \\
(\mathbf{\%})\end{array}$ & COMPUESTO & $\begin{array}{c}\text { CONC } \\
(\boldsymbol{\mu M})\end{array}$ & $\begin{array}{c}\text { INHIBICIÓN } \\
(\mathbf{\%})\end{array}$ \\
\hline $\mathbf{1 9}$ & 20 & 12 & $\mathbf{7 0}$ & 20 & 22 \\
\hline $\mathbf{2 2}$ & 20 & 20 & $\mathbf{7 1}$ & 20 & 37 \\
\hline $\mathbf{2 6}$ & 20 & 0 & $\mathbf{7 2}$ & 20 & 37 \\
\hline $\mathbf{2 7}$ & 20 & 5 & $\mathbf{7 3}$ & 20 & 0 \\
\hline $\mathbf{3 4}$ & 20 & 7 & $\mathbf{7 4}$ & 20 & 0 \\
\hline $\mathbf{3 5}$ & 20 & 16 & $\mathbf{7 9 E} \mathbf{8 0 E}$ & 20 & 49 \\
\hline $\mathbf{3 8}$ & 20 & 12 & $\mathbf{8 4}$ & 20 & 19 \\
\hline $\mathbf{3 9}$ & 20 & 32 & $\mathbf{8 5}$ & 40 & 0 \\
\hline $\mathbf{5 1}$ & 20 & 32 & $\mathbf{8 6}$ & 40 & 0 \\
\hline $\mathbf{5 6}$ & 20 & 12 & $\mathbf{8 7}$ & 20 & 44 \\
\hline $\mathbf{5 7}$ & 20 & 9 & $\mathbf{8 8}$ & 40 & 0 \\
\hline $\mathbf{6 2}$ & 20 & 32 & $\mathbf{8 9}$ & 40 & 0 \\
\hline $\mathbf{6 6}$ & 20 & 40 & $\mathbf{9 0}$ & 40 & 18 \\
\hline $\mathbf{6 7}$ & 20 & - & $\mathbf{9 1}$ & 40 & 0 \\
\hline $\mathbf{6 8}$ & 20 & 0 & $\mathbf{9 2}$ & 40 & 0 \\
\hline $\mathbf{6 9}$ & 20 & 2 & $\mathbf{9 3}$ & 40 & 0 \\
\hline
\end{tabular}

Los compuestos seleccionados para calcular la $\mathrm{IC}_{50}$, se muestran en la tabla siguiente:

\begin{tabular}{|c|c|c|c|c|c|}
\hline COMPUESTO & $\begin{array}{c}\text { CONC } \\
(\boldsymbol{\mu M})\end{array}$ & $\begin{array}{c}\text { INHIBICIÓN } \\
(\mathbf{\%})\end{array}$ & COMPUESTO & $\begin{array}{c}\text { CONC } \\
(\boldsymbol{\mu M})\end{array}$ & $\begin{array}{c}\text { INHIBICIÓN } \\
(\mathbf{\%})\end{array}$ \\
\hline $\mathbf{2 0}$ & 20 & 52 & $\mathbf{5 2}$ & 20 & 90 \\
\hline $\mathbf{2 3}$ & 5 & 81 & $\mathbf{5 3}$ & 20 & 93 \\
\hline $\mathbf{2 4}$ & 20 & 61 & $\mathbf{5 4}$ & 5 & 93 \\
\hline $\mathbf{2 5}$ & 20 & 86 & $\mathbf{5 5}$ & 20 & 96 \\
\hline $\mathbf{3 0}$ & 20 & 94 & $\mathbf{5 9}$ & 20 & 97 \\
\hline $\mathbf{3 2}$ & 20 & 86 & $\mathbf{6 0}$ & 20 & 98 \\
\hline $\mathbf{4 3}$ & 20 & 86 & $\mathbf{6 1}$ & 20 & 98 \\
\hline $\mathbf{4 4}$ & 20 & 68 & $\mathbf{6 3}$ & 20 & 87 \\
\hline $\mathbf{4 5}$ & 20 & 98 & $\mathbf{6 4}$ & 20 & 95 \\
\hline $\mathbf{4 6}$ & 20 & 61 & $\mathbf{6 5}$ & 5 & 89 \\
\hline $\mathbf{4 7}$ & 20 & 96 & $\mathbf{7 5}$ & 20 & 95 \\
\hline $\mathbf{4 8}$ & 5 & 85 & $\mathbf{7 7}$ & 20 & 98 \\
\hline $\mathbf{4 9}$ & 20 & 100 & $\mathbf{7 8}$ & 20 & 91 \\
\hline $\mathbf{5 0 Z}$ & 20 & 96 & $\mathbf{7 9 Z} \mathbf{8 0 Z}$ & 20 & 93 \\
\hline $\mathbf{5 0}$ & 20 & 88 & & & \\
\hline
\end{tabular}




\section{III.5.A.3. Determinación de la $\mathrm{IC}_{50}$ de los compuestos seleccionados.}

Una vez seleccionados los compuestos, se ensayan a diferentes concentraciones (generalmente $0,5,1,2,5,7$ y $10 \mu \mathrm{M}$ ) con el fin de calcular su $\mathrm{IC}_{50}$, definida como la concentración de compuesto que causa el $50 \%$ de la inhibición de polimerización. La determinación se realiza después de 20 minutos de incubación de las muestras (ligando + MTP). La IC $_{50}$ para los diferentes ligandos inhibidores de polimerización de tubulina se establece ajustando a una ecuación monoexponencial el porcentaje de polimerización encontrado en función de la concentración de ligando. ${ }^{64}$ En la siguiente tabla se recogen los valores de $\mathrm{IC}_{50}$ calculados para los compuestos seleccionados:

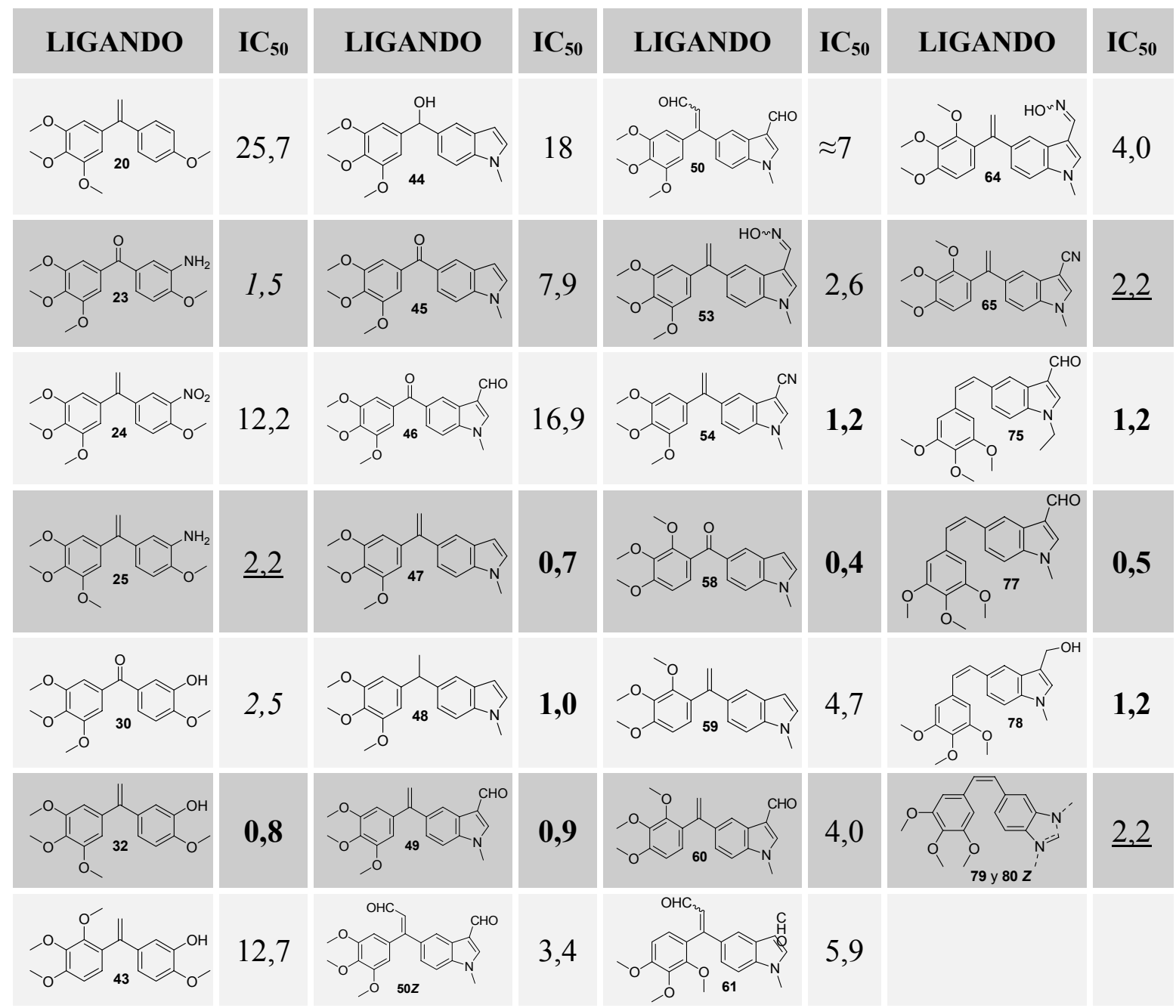

Tabla 25. $\mathrm{IC}_{50}$ de los compuestos seleccionados. En cursiva las $\mathrm{Ic}_{50}$ de la fenstatina y la aminofenstatina. Se ha subrayado la $\mathrm{IC}_{50}$ de los compuestos más potentes que la fenstatina (aunque menos que la aminofenstatina) y en negrita se han señalado las $\mathrm{IC}_{50}$ que están por debajo de la presentada por la aminofenstatina.

${ }^{64}$ Origin ${ }^{\circledR}$ 6.0: http://www.originlab.com/ 



\section{III.5.B. Citotoxicidad.}

La toxicidad frente a líneas de células cancerosas representativas de los compuestos sintetizados en este trabajo ha sido evaluada por el Dr. Mollinedo (Instituto del Cáncer de Salamanca). Los compuestos se han ensayado frente a distintas líneas celulares para determinar la citotoxicidad. ${ }^{65}$ Con este fin se han utilizado los siguientes tipos de células.

$>$ HL-60: Leucemia mieloide humana.

> A-549: Cáncer de pulmón humano.

$>$ HeLa: Carcinoma cervical humano.

> HT-29: Carcinoma de colon humano.

Los resultados obtenidos se recogen en la tabla siguiente y expresan la concentración que produce un $50 \%$ de inhibición de la proliferación celular $\left(\mathrm{IC}_{50}\right)$.

\begin{tabular}{|c|c|c|c|c|}
\hline Compuesto & $\begin{array}{c}\text { HL-60 } \\
\left(10^{-6} \mathrm{M}\right)\end{array}$ & $\begin{array}{c}\text { A-549 } \\
\left(10^{-6} \mathrm{M}\right)\end{array}$ & $\begin{array}{c}\text { HeLa } \\
\left(10^{-6} \mathrm{M}\right)\end{array}$ & $\begin{array}{c}\text { НT-29 } \\
\left(10^{-6} \mathrm{M}\right)\end{array}$ \\
\hline 19 & 0,27 & 3,10 & 0,037 & $\underline{0,29}$ \\
\hline 20 & 0,30 & 2,00 & 0,29 & $\underline{0,31}$ \\
\hline 22 & 1,80 & $>10$ & 2,50 & 2,90 \\
\hline 23 & 0,03 & 0,057 & 0,03 & 0,032 \\
\hline 24 & 0,032 & 0,026 & 0,30 & $\underline{0,06}$ \\
\hline 25 & 0,029 & 0,031 & 0,0032 & 0,041 \\
\hline 26 & 0,31 & 2,30 & 0,27 & $\underline{0,36}$ \\
\hline 27 & 0,27 & 0,52 & 0,034 & $\underline{0,25}$ \\
\hline 30 & 0,031 & 0,29 & 0,03 & 1,80 \\
\hline 32 & 0,0028 & 0,028 & 0,0029 & $\underline{0,44}$ \\
\hline 34 & 2,00 & $>10$ & 1,80 & 3,10 \\
\hline 35 & 0,48 & $>10$ & 0,30 & 3,20 \\
\hline 38 & 2,60 & $>10$ & 0,032 & 2,90 \\
\hline
\end{tabular}

${ }^{65}$ Skehan, P.; Storeng, R.; Scudiero, D.; Monks, A.; McMahon, J.; Vistica, D.; Warren, J. T.; Bokesch, H.; Kenney, S.; Boyd, M. R. New colorimetric cytotoxicity assay for anticancer-drug screening. J. Natl. Cancer Inst. 1990, 82, 1107-1112. 


\begin{tabular}{|c|c|c|c|c|}
\hline Compuesto & $\begin{array}{c}\text { HL-60 } \\
\left(10^{-6} \mathrm{M}\right)\end{array}$ & $\begin{array}{c}\text { A-549 } \\
\left(10^{-6} \mathrm{M}\right)\end{array}$ & $\begin{array}{c}\text { HeLa } \\
\left(10^{-6} \mathrm{M}\right)\end{array}$ & $\begin{array}{c}\text { HT-29 } \\
\left(10^{-6} \mathrm{M}\right)\end{array}$ \\
\hline 39 & 0,23 & 2,70 & 0,06 & $\underline{0,33}$ \\
\hline 43 & 0,24 & $\underline{0,27}$ & 0,035 & $\underline{0,31}$ \\
\hline 45 & $\mathbf{0 , 0 2 7}$ & $\underline{0,19}$ & 0,025 & 0,027 \\
\hline 46 & 0,31 & $>10$ & 0,32 & 3,00 \\
\hline 47 & 0,0028 & 0,028 & 0,0027 & 0,0031 \\
\hline 48 & 0,032 & 0,053 & 0,012 & 0,028 \\
\hline 49 & 0,028 & 3,00 & 0,0032 & $\underline{0,28}$ \\
\hline 50 & 0,029 & 0,32 & 0,03 & $\underline{0,17}$ \\
\hline $50 Z$ & 0,033 & 0,34 & 0,031 & $\underline{0,22}$ \\
\hline 51 & 0,25 & 3,20 & 0,31 & 2,00 \\
\hline 52 & 0,28 & 0,32 & 0,31 & 0,31 \\
\hline 54 & 0,0056 & 0,029 & 0,0032 & 0,0037 \\
\hline 56 & 0,18 & 3,2 & 0,038 & $\underline{0,30}$ \\
\hline 58 & 0,24 & 0,38 & 0,03 & $\underline{0,24}$ \\
\hline 59 & 0,28 & 0,73 & 0,032 & $\underline{0,31}$ \\
\hline 60 & 0,032 & 1,80 & 0,032 & $\underline{0,29}$ \\
\hline 61 & 0,32 & 0,35 & 0,30 & $\underline{0,34}$ \\
\hline 62 & 0,22 & 0,44 & 0,30 & $\underline{0,32}$ \\
\hline 63 & 0,37 & 0,47 & 0,31 & 2,40 \\
\hline 64 & 0,27 & $\underline{0,29}$ & 0,034 & $\underline{0,32}$ \\
\hline 65 & 0,027 & 0,36 & 0,032 & 0,032 \\
\hline 66 & 0,29 & 2,00 & 0,27 & 0,31 \\
\hline 67 & 0,30 & 2,30 & 0,3 & 0,31 \\
\hline 68 & 1,80 & $>10$ & 0,43 & 3,20 \\
\hline 75 & 0,03 & $>10$ & 0,029 & 3,10 \\
\hline 77 & 0,0031 & 2,70 & 0,0032 & $\underline{0,28}$ \\
\hline 78 & 0,028 & 0,045 & 0,032 & $\underline{0,033}$ \\
\hline $79 Z$ y $80 Z$ & 0,032 & 0,034 & 0,031 & $\mathbf{0 , 0 3 2}$ \\
\hline
\end{tabular}

Tabla 26. $\mathrm{IC}_{50}$ de los compuestos ensayados frente a cada una de las líneas celulares. Al igual que en la tabla anterior se han marcado en negrita los valores de los compuestos que presentan mayor potencia que la fenstatina y la amino fenstatina (en cursiva) y se han subrayado los que son más potentes que la fenstatina aunque menos que la aminofenstatina. 


\section{III.5.C. Discusión de los resultados de actividad.}

\section{III.5.C.1. Aspectos generales.}

Los resultados de inhibición de polimerización de tubulina y los de citotoxicidad frente a distintas líneas celulares muestran que los análogos macrocíclicos de combretastatinas son inactivos o presentan una potencia muy reducida. ${ }^{66}$ Por el contrario, los resultados obtenidos para los análogos no macrocíclicos muestran que, como conjunto, los compuestos sintetizados en este trabajo constituyen una familia con gran capacidad para inhibir la proliferación celular, probablemente a través de la inhibición de la polimerización de la tubulina.

La comparación de la actividad de los compuestos sintetizados previamente en el grupo de investigación ${ }^{67}$ con la de los compuestos obtenidos en este trabajo, sugiere que estos últimos poseen una combinación de elementos estructurales que confieren alta potencia inhibitoria de la polimerización de tubulina. Así, en numerosos compuestos de esta familia, la presencia conjunta de un anillo de trimetoxifenilo y de un resto $\mathrm{N}$-metil-5indolilo, conectados por distintos puentes que sitúan los anillos en planos diferentes, parece ser un esqueleto muy favorable, como se deduce de la alta potencia observada.

\footnotetext{
${ }^{66}$ a) Mateo, C.; Álvarez, R.; Pérez-Melero, C.; Peláez, R.; Medarde, M. Conformationally restricted macrocyclic analogues of combretastatins Bioorg. Med. Chem. Lett., 2007, 17, 6316-6320. b) Mateo, C.; Pérez-Melero, C.; Peláez, R.; Medarde, M. Stilbenophane Analogues of Deoxycombretastatin A-4. J. Org. Chem. 2005, 70, $6544-6547$.

${ }^{67}$ a) Sánchez Maya, A. B. Tesis Doctoral, Universidad de Salamanca, 2004. b) Mateo, C. Tesis Doctoral, Universidad de Salamanca, 2006. c) Álvarez, C. Tesis Doctoral, Universidad de Salamanca, 2006. d) López, V. Tesis Doctoral, Universidad de Salamanca, 2007. d) Mateo, C.; López, V.;.Medarde, M.; Peláez, R. Synthesis and conformational analysis of macrocyclic hydroxystilbenes linked between the para-para positions. Chem. Eur. J. 2007, 13, 7246-7256.
} 
Este trabajo

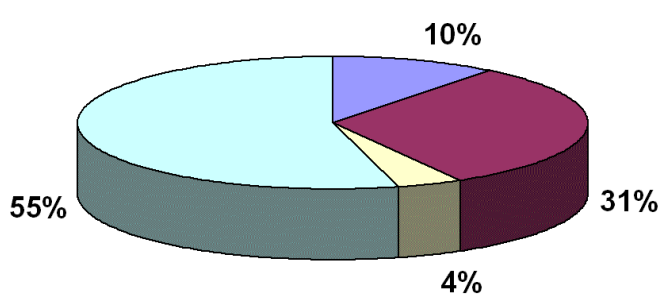

IPT

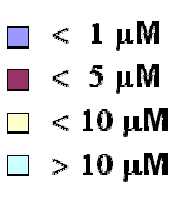

Resultados históricos $^{68}$

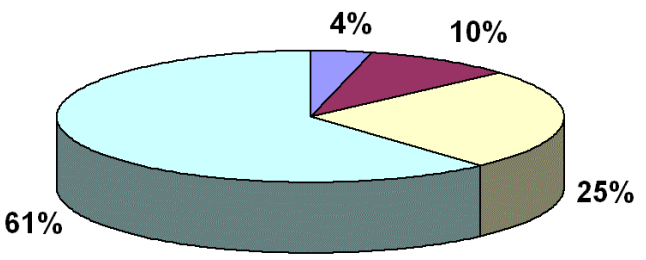

Figura 98. Clasificación de los compuestos obtenidos en este trabajo (a la izquierda) y de los compuestos obtenidos por el grupo de investigación anteriormente (a la derecha) en función de la IPT que presentan: menor de $1 \mu \mathrm{M}$ en morado, entre 1 y $5 \mu \mathrm{M}$ en granate, entre 5 y $10 \mu \mathrm{M}$ en amarillo y por encima de $10 \mu \mathrm{M}$ en verde.

La correlación de los resultados de citotoxicidad con los resultados de inhibición de polimerización de tubulina es, en general, buena. Esta correlación es mejor para valores de citotoxicidad promedio y máximos, dominados por los valores correspondientes a líneas celulares sensibles, en los que el efecto del compuesto depende principalmente de la potencia de éste. Sin embargo, la correlación disminuye en los valores mínimos de citotoxicidad, que se corresponden con los de líneas celulares más resistentes. Esta disminución puede ser debida a que el efecto citotóxico esté influenciado, además de por la potencia del compuesto, por otros mecanismos de resistencia celulares. De cualquier modo, la tendencia observada en los tres casos en la figura 99 sugiere que la interferencia con la polimerización de la tubulina es el mecanismo por el que estos compuestos ejercen su actividad frente a los cultivos celulares. En investigaciones anteriores se ha observado que, compuestos relacionados con los descritos en este trabajo, y a las dosis en que ejercen su acción sobre las células, producen efectos observables sobre el sistema microtubular, lo cual apoya dicha hipótesis. ${ }^{69}$

\footnotetext{
${ }^{68}$ Sólo se han evaluado los valores de IPT de aquellos compuestos que presentaban citotoxicidades inferiores a $1 \mu \mathrm{M}$.

${ }^{69}$ Maya, A. B.; Pérez-Melero, C.; Mateo, C.; Alonso, D.; Fernández, J. L.; Gajate, C.; Mollinedo, F.; Peláez, R.; Caballero, E.; Medarde, M. Further Naphthylcombretastatins. An Investigation on the Role of the Naphthalene Moiety J. Med. Chem. 2005, 48, 556-568.
} 


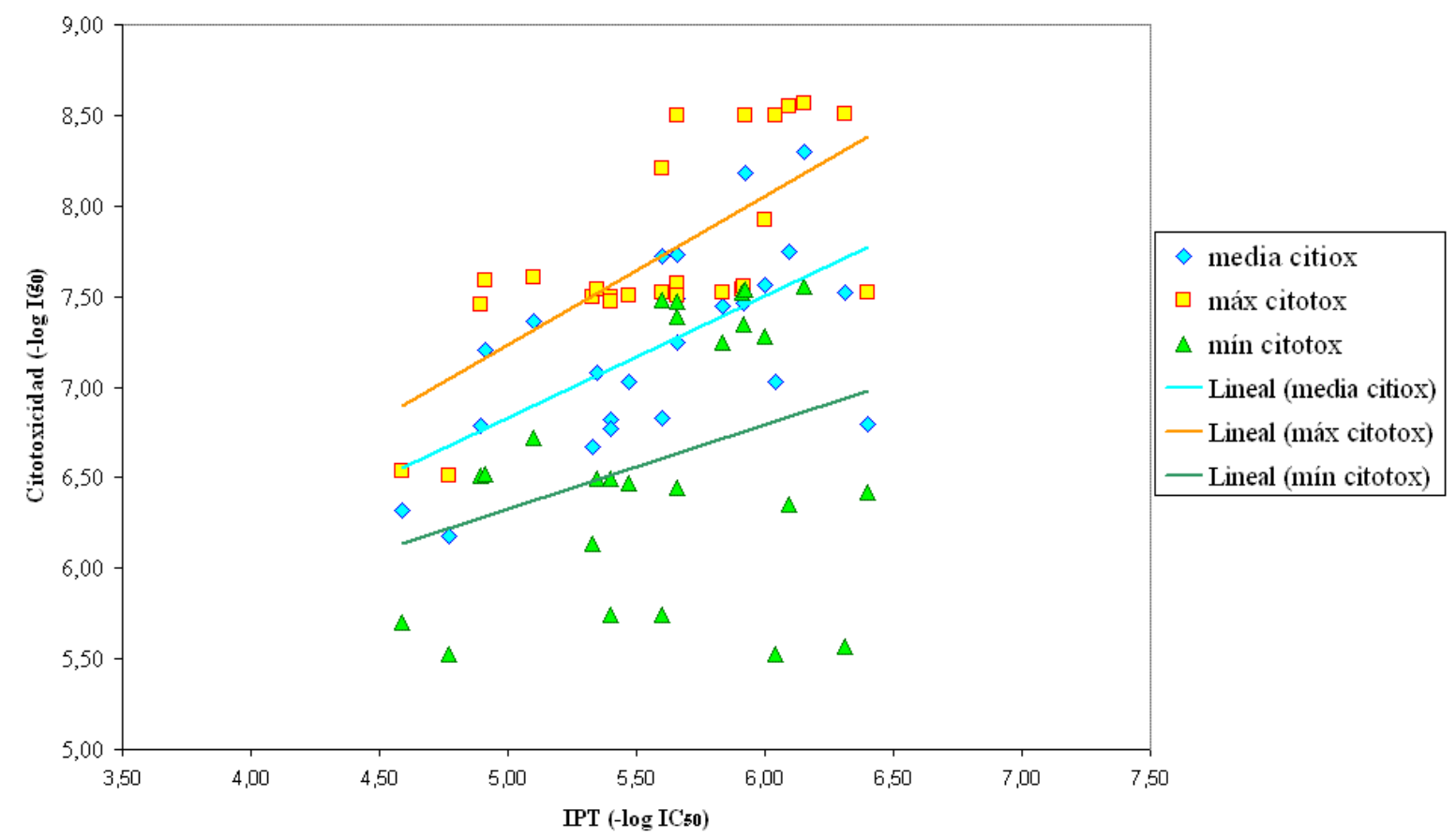

Figura 99. Correlación de las $\mathrm{IC}_{50}$ de inhibición de polimerización de tubulina con las $\mathrm{IC}_{50}$ promedio (azul claro), máximos (naranja) y mínimos (verde) de citotoxicidad frente a las cuatro líneas celulares.

El ensayo de la actividad inhibitoria de la polimerización de tubulina de los compuestos a una única concentración elevada permite discriminar los compuestos más potentes de los menos, lo cual permite una rápida detección de combinaciones poco favorables. La detección precoz de zonas del espacio químico más desfavorecidas (como en nuestro caso las combretastatinas macrocíclicas) permite ahorrar esfuerzos sintéticos y concentrarlos en zonas más favorables.

Las $\mathrm{IC}_{50}$ confirman las tendencias observadas en los ensayos iniciales, pero su determinación es importante para matizar las relaciones estructura-actividad y facilitar el diseño de nuevos compuestos. En la mayoría de los casos, los valores de inhibición de polimerización de tubulina obtenidos para un mismo compuesto a distintas concentraciones se ajustan bien a comportamientos monoexponenciales (figura 100), de acuerdo con lo esperado. ${ }^{63}$ Los valores de $\mathrm{IC}_{50}$ obtenidos en este trabajo se encuentran entre los más potentes descritos para inhibidores de la polimerización de tubulina. 


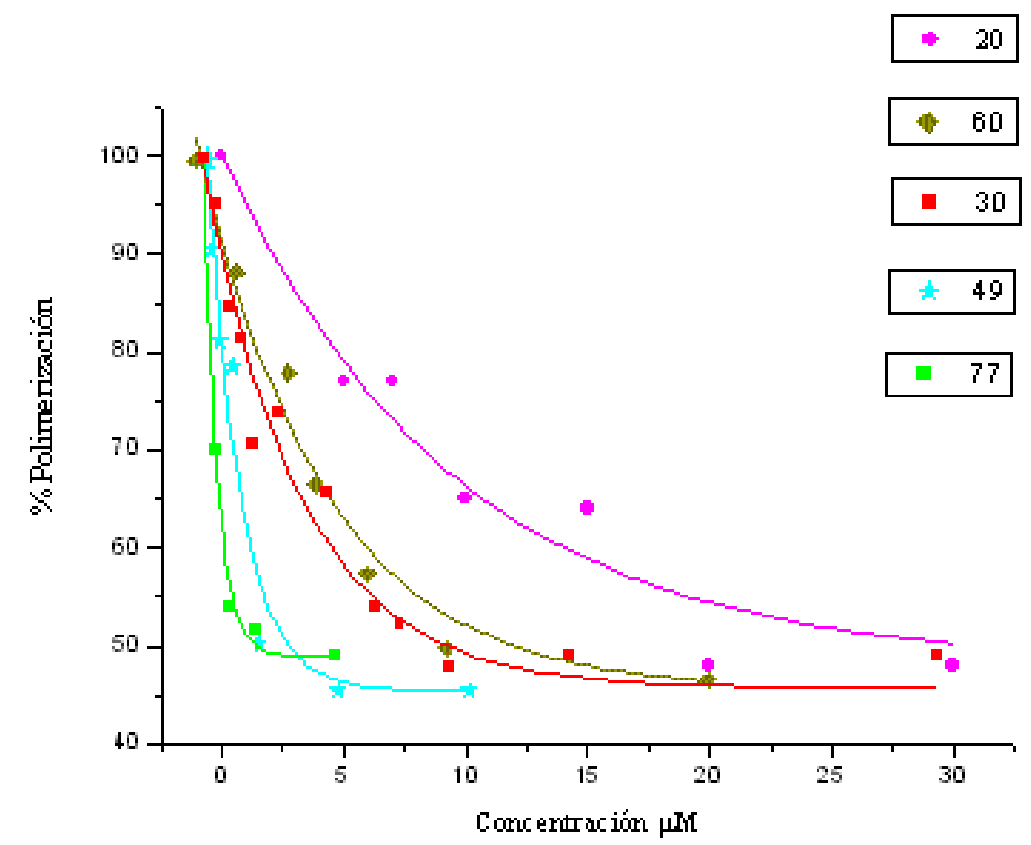

Figura 100. Representación gráfica de la polimerización de tubulina a diferentes concentraciones, a partir de la cual se ha calculado la $\mathrm{IC}_{50}$ en IPT, para cinco de los compuestos sintetizados en este trabajo.

La comparación de las potencias citotóxicas frente a las diferentes líneas celulares (representadas frente a la inhibición de polimerización de tubulina en la figura 101) muestra que HeLa (línea rosa) y HL-60 (línea naranja) son más sensibles, mientras que A549 (línea azul) y HT-29 (línea verde) son más resistentes. Las líneas convergen hacia la izquierda ya que los compuestos poco potentes frente a la polimerización de tubulina son poco citotóxicos. El origen de estas diferencias puede deberse a una sensibilidad diferente de la tubulina en cada línea celular (atribuible a la expresión de distintos isotipos) o a factores ajenos a la tubulina (captación, eliminación...). 


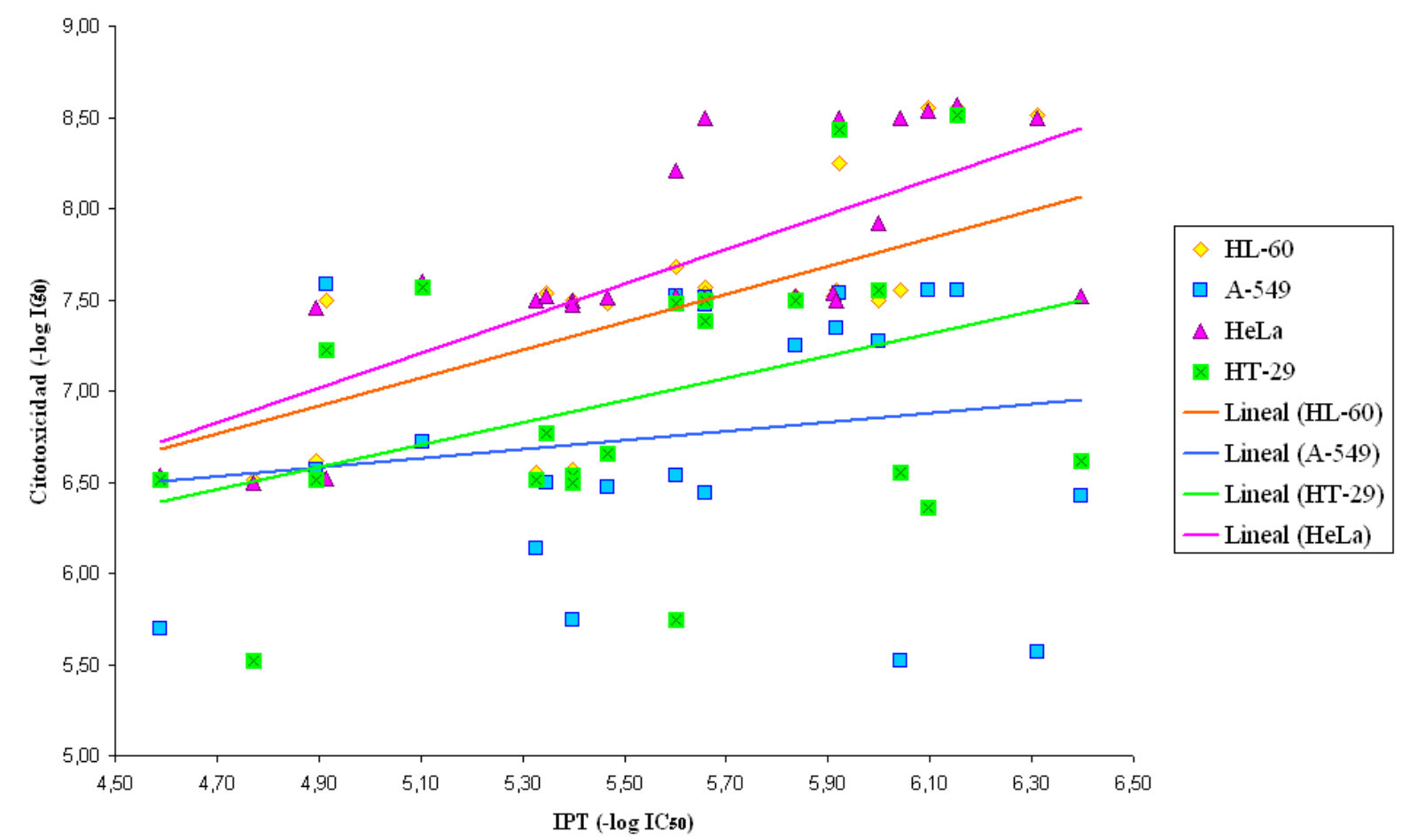

Figura 101. Representación de los valores de cada línea celular frente a los valores de inhibición de polimerización de tubulina. HeLa (en rosa), HL-60 (en naranja), A-549 (en azul) y HT-29 (en verde). 


\section{III.5.C.2. Consideraciones estructurales generales.}

A lo largo de este trabajo se han sintetizado compuestos que pueden ser clasificados estructuralmente en diversas categorías, dependiendo de los elementos estructurales que incorporan. La comparación de conjuntos de compuestos que sólo difieren por parejas en un elemento estructural permite, al menos de forma cualitativa, establecer qué elementos son más o menos favorables. En nuestro caso, hemos comparado compuestos que difieren en el anillo de trimetoxifenilo (2,3,4- frente a 3,4,5-), en la naturaleza del segundo anillo (indoles frente a fenilos sustituidos) o en el puente entre los anillos (combretastatinas frente a fenstatinas frente a isocombretastatinas). Además, es posible comparar la potencia de cada uno de los grupos en los diferentes ensayos.

Para comparar los grupos que se diferencian en el anillo de trimetoxifenilo se han representado los valores de uno frente a los del otro para cada pareja. Si ambos elementos estructurales conducen a compuestos equipotentes, los puntos se sitúan en la diagonal. Si un elemento estructural confiere una mayor potencia, los puntos se concentran en la mitad del gráfico delimitada por el eje correspondiente a dicho elemento estructural. Así, en la figura 102, los puntos se concentran en la mitad inferior del gráfico, indicando una preferencia por el anillo 3,4,5-trimetoxifenilo frente al 2,3,4-trimetoxifenilo, tanto para la inhibición de polimerización de tubulina (puntos marrones) como para las cuatro líneas celulares HL-60 (rombos naranjas), A-549 (cuadrados azules), HeLa (triángulos rosas) y HT-29 (cuadrados verdes). 


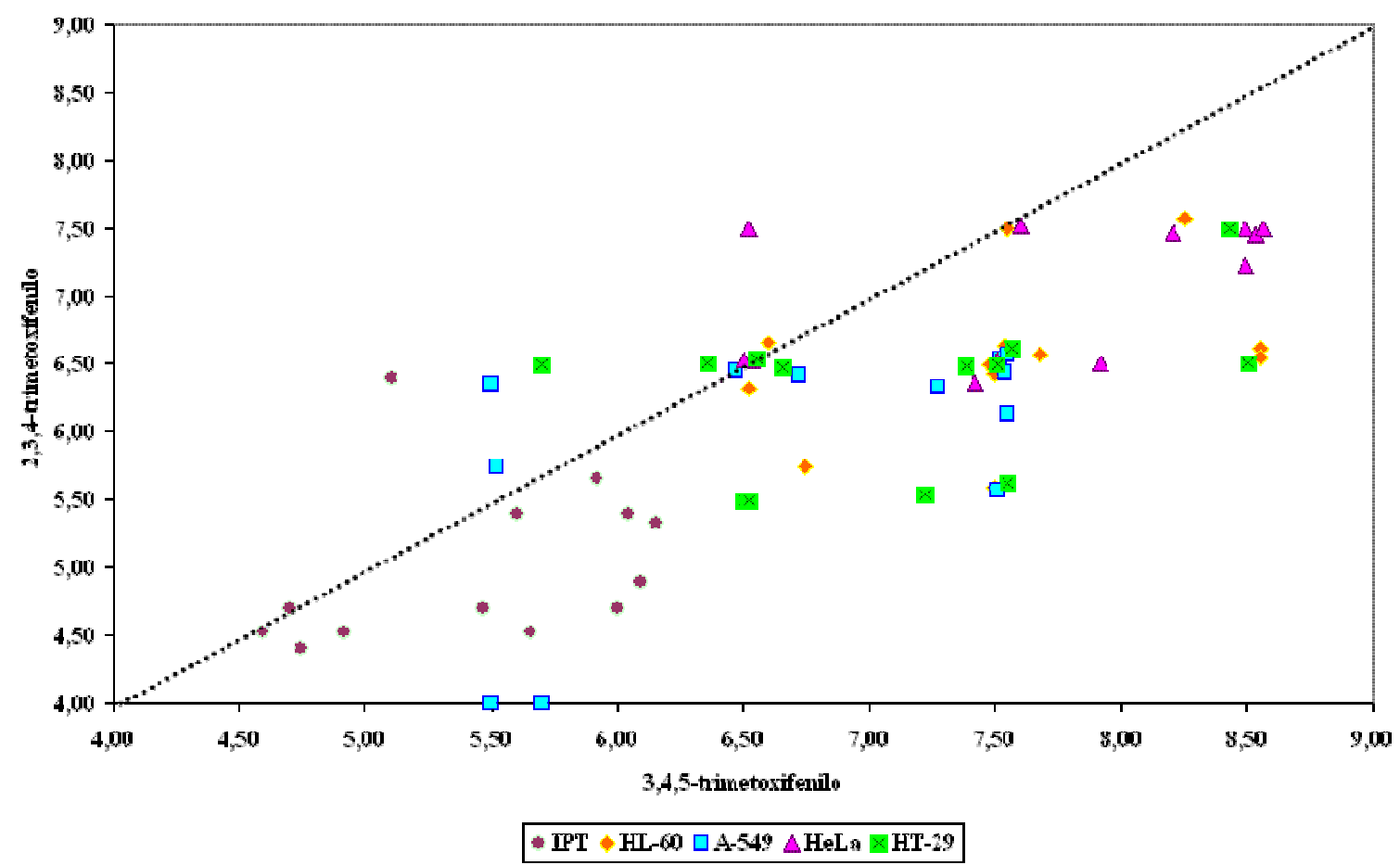

Figura 102. Representación de los valores de citotoxicidad e inhibición de polimerización de tubulina por parejas de valores que sólo difieren en la disposición del trimetoxifenilo. IPT (en marrón), HeLa (en rosa), HL-60 (en naranja), A-549 (en azul) y HT-29 (en verde). Los valores representados corresponden al -log de las $\mathrm{IC}_{50}$.

La representación gráfica (figura 103) de la citotoxicidad promedio frente a la IPT en compuestos con el resto 2,3,4-trimetoxifenilo, combinado bien con indoles (puntos rosas) o con fenilos sustituidos (rombos azules), muestra una gran diferencia entre ambos tipos estructurales: los derivados bencénicos (en verde) son muy poco activos, mientras que los derivados indólicos presentan potencias elevadas, tal y como se observa en los diagramas de barras para la IPT (arriba a la izquierda) y para la citotoxicidad promedio (abajo a la derecha). En este caso no parecen cumplirse las reglas habituales que permiten clasificar combretastatinas, fenstatinas e isocombretastatinas en activos o inactivos en función de los anillos aromáticos. ${ }^{70}$ Una posible explicación es que el resto 2,3,4trimetoxifenilo fuerce al resto de la molécula a adoptar una disposición algo diferente, lo que permite discriminar entre ambos tipos estructurales (fenilos e indoles) al cambiar el entorno donde se localizan.

\footnotetext{
${ }^{70}$ a) Gaukroger, K.; Had.eld, J. A.; Lawrence, N. J.; Nolan S.; McGown, A. T. Structural requirements for the interaction of combretastatins with tubulin: how important is the trimethoxy unit? Org. Biomol. Chem. 2003, 1, 3033-3037. b) Nam, N. H. Combretastatin A-4 analogues as antimitotic antitumor agents. Curr. Med. Chem. 2003, 10, 1697-1722. c) Tron, G. C.; Pirali, T.; Sorba, G.; Pagliai, F.; Busacca, S.; Genazzani, A. A. Medicinal chemistry of combretastatin A4: present and future directions. J. Med. Chem. 2006, 49, 3033-3044.
} 


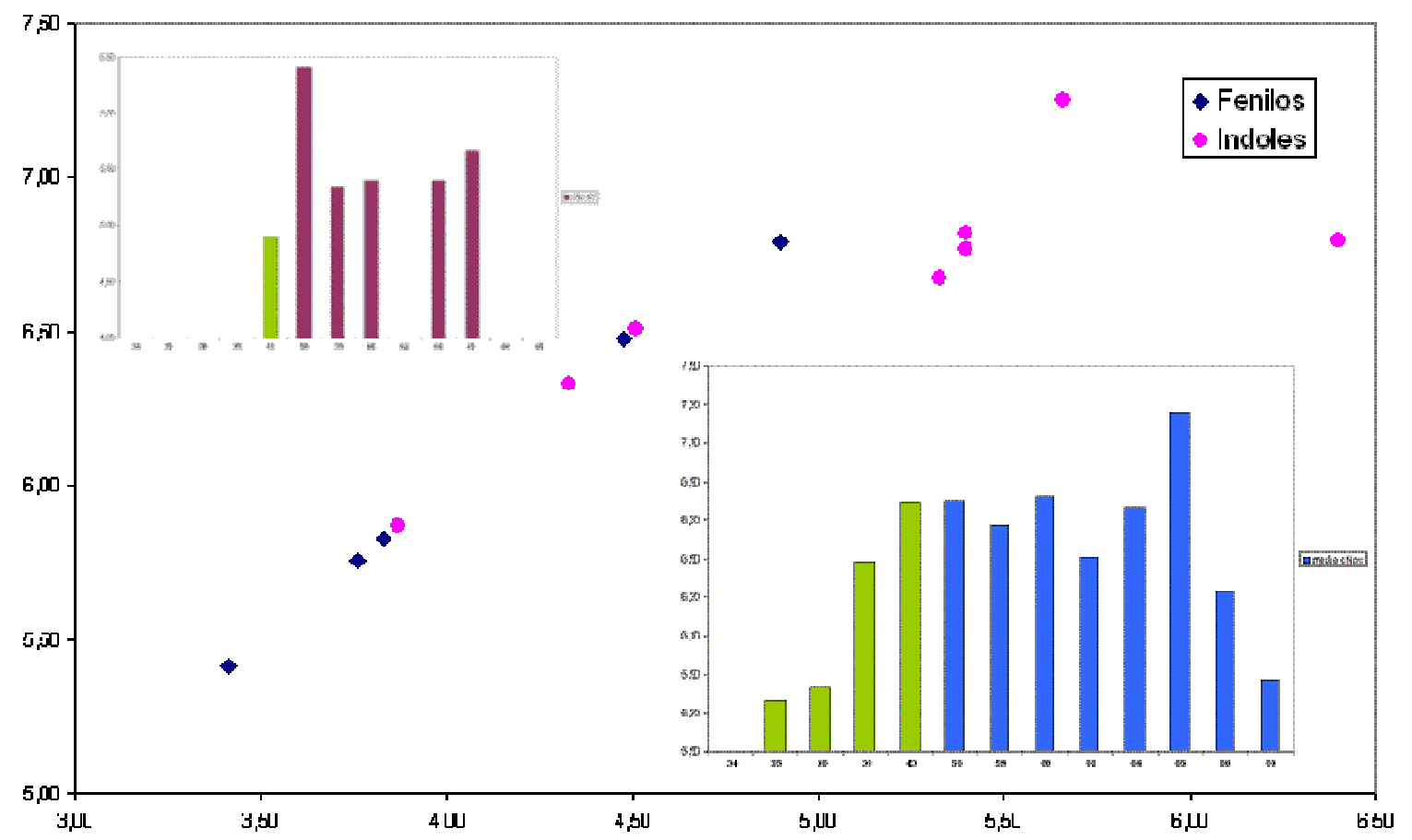

Figura 103. Representación gráfica de $\operatorname{los}-\log \mathrm{IC}_{50}$ de citotoxicidad media frente a los de IPT de los compuestos con 2,3,4-trimetoxifenilo, diferenciando entre los que el otro anillo aromático está formado por otro resto fenilo (rombos azules) de los que poseen un indol (puntos rosas). También se muestran los diagramas de barras en los que se representa la IPT $\left(\mathrm{IC}_{50} \mu \mathrm{M}\right)$ para cada compuesto representado en la gráfica de puntos (arriba a la izquierda) y la citotoxicidad media $\left(\mathrm{IC}_{50} \mu \mathrm{M}\right)$ para los mismos compuestos (abajo a la derecha). En ambos diagramas las barras verdes se corresponden con los compuestos que no poseen grupo indol.

La comparación entre los compuestos que difieren en el anillo B (resto fenilo o resto indolilo) también se ha realizado mediante la representación de los valores de citotoxicidad media frente a los de inhibición de polimerización de tubulina para cada uno de los grupos. La figura 104 muestra que ambos grupos son muy similares, de acuerdo con los resultados obtenido en trabajos anteriores, que sugerían que el resto $N$-metil-5-indolilo es un buen reemplazo del grupo 4-metoxi-3-hidroxifenilo presente en la combretastatina A-4 y la fenstatina, que son los más representativos entre los inhibidores más potentes de polimerización de tubulina que se unen al sitio de la colchicina. ${ }^{69,71}$

71 Álvarez, C.; Álvarez, R.; Corchete, P.; López, J. L.; Pérez-Melero, C.; Peláez, R.; Medarde, M. Diarylmethoxime and hydrazone derivatives with 5-indolyl moieties as potent inhibitors of tubulin polymerization. Bioorg. Med. Chem. 2008, 16, 5952-5961. 
Además, se observa una mayor dispersión de los datos correspondientes al indol. Parte de esta dispersión puede ser debida al mayor número de compuestos representados. Sin embargo, son interesantes los compuestos que se desvían de la tendencia general en las regiones de alta potencia. Estos compuestos, que presentan citotoxicidades (elipsoide verde) o inhibiciones de la polimerización de tubulina (elipsoide azul) por encima de los demás, se discutirán más adelante cuando se haga referencia a patrones de sustitución concretos.

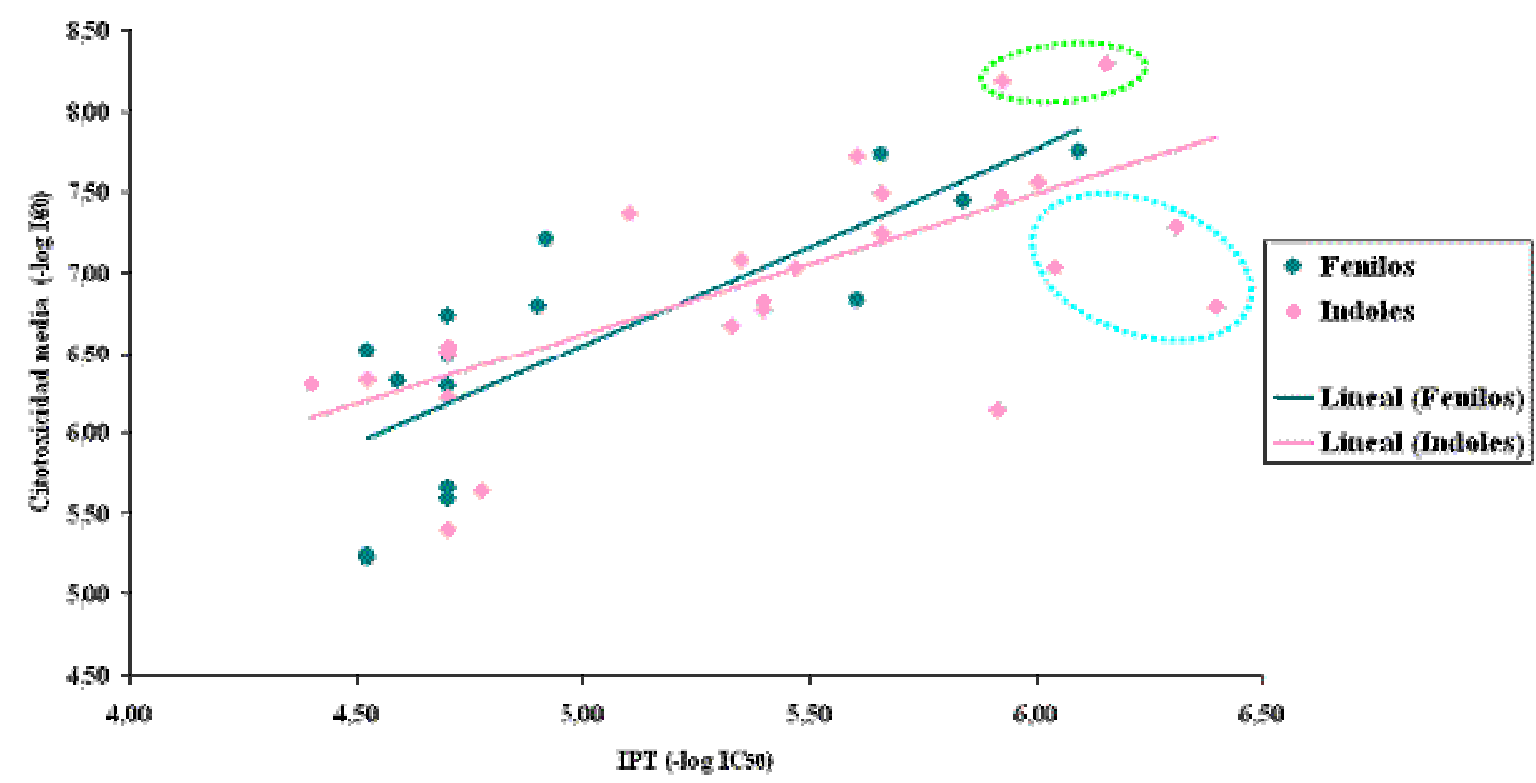

Figura 104. Representación de los valores de citotoxicidad frente a los de inhibición de polimerización de tubulina en la que se diferencian los compuestos en los que el anillo B es un resto fenilo (puntos azules) o un resto indolilo (rombos rosas).

La representación de los valores de citotoxicidad medios, frente a los valores de inhibición de polimerización de tubulina, también es útil para establecer comparaciones entre compuestos con diferente puente entre los anillos aromáticos (figura 105). Las isocombretastatinas son más citotóxicas que las fenstatinas a similar potencia inhibidora de la polimerización de tubulina. Las combretastatinas presentan una mayor variabilidad, como muestran los compuestos cuya toxicidad no correlaciona con la IPT (marcados por círculos naranjas). Si se excluyen estos compuestos, se observa que las combretastatinas presentan una mayor potencia citotóxica que fenstatinas con similar IPT. 
Sin embargo, las combretastatinas y las isocombretastatinas presentan relaciones citotoxicidad - IPT comparables. Los compuestos hidrogenados presentan bajas potencias, salvo el derivado indólico señalado con una flecha en la gráfica. Otros análogos con hibridación $\mathrm{sp}^{3}$ en el puente son también menos potentes, como ocurre con los alcoholes, de acuerdo con lo descrito anteriormente. ${ }^{69,71,72}$

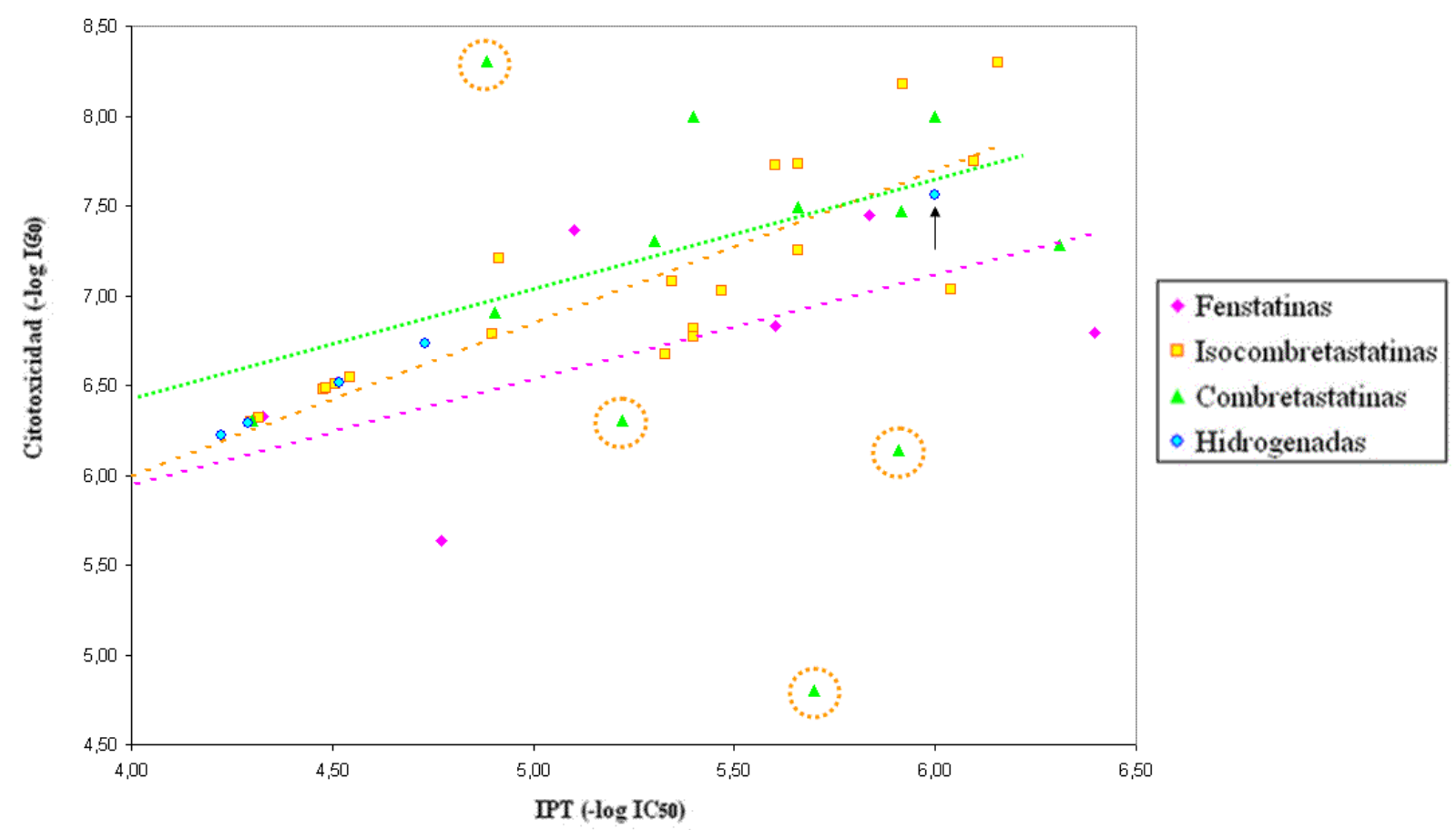

Figura 105. Representación de los valores de citotoxicidad frente a los de inhibición de polimerización de tubulina en la que se diferencian los compuestos por el tipo de puente entre los anillos aromáticos: fenstatinas (rombos rosas), isocombretastatinas (cuadrados amarillos), combretastatinas (triángulos verdes) y derivados hidrogenados (puntos azules).

\footnotetext{
72 a) Álvarez, C.; Álvarez, R.; Corchete, P.; Pérez-Melero, C.; Peláez, R.; Medarde, M. Synthesis and biological activity of naphthalene analogues of phenstatins: naphthylphenstatins. Bioorg. Med. Chem. Lett. 2007, 17, 3417-3420. b) Álvarez, C.; Álvarez, R.; Corchete, P.; Pérez-Melero, C.; Peláez, R.; Medarde, M. Naphthylphenstatins as tubulin ligands: synthesis and biological evaluation. Bioorg. Med. Chem. 2008, 16, 8999-9008.
} 


\section{III.5.C.3. Análisis de la contribución de elementos estructurales individuales.}

Para el diseño de nuevos compuestos es interesante disponer de reglas sencillas que permitan valorar cualitativamente la importancia o la contribución a la actividad de distintos sustituyentes. Así, en combretastatinas el anillo de trimetoxifenilo es considerado esencial, el metoxilo en para del otro anillo es importante y el sustituyente en orto de éste es reemplazable e incluso prescindible. Estas reglas resumen la estructura de la mayor parte de las combretastatinas con potencias interesantes descritas en bibliografía. ${ }^{70}$ La comparación de parejas de estructuras con o sin determinados sustituyentes permite valorar la importancia de dichos sustituyentes. Además, la consideración de varios sustituyentes en una misma posición puede servir para establecer reglas de carácter más general (sustituyentes voluminosos no son tolerados, dadores de enlace de hidrógeno son buenos, etc...). Con este fin, se han llevado a cabo comparaciones de sustituyentes (o reemplazos de átomos) en la posición tres del anillo de indol, tanto en fenstatinas como en combretastatinas o en isocombretastatinas.

Los primeros compuestos sintetizados con modificaciones en la posición 3 del indol fueron los aldehídos (figura 106). La comparación de sus resultados de actividad con los de los compuestos no sustituidos revela que la introducción del grupo formilo es muy favorable en combretastatinas, menos en isocombretastatinas y desfavorable en las fenstatinas.
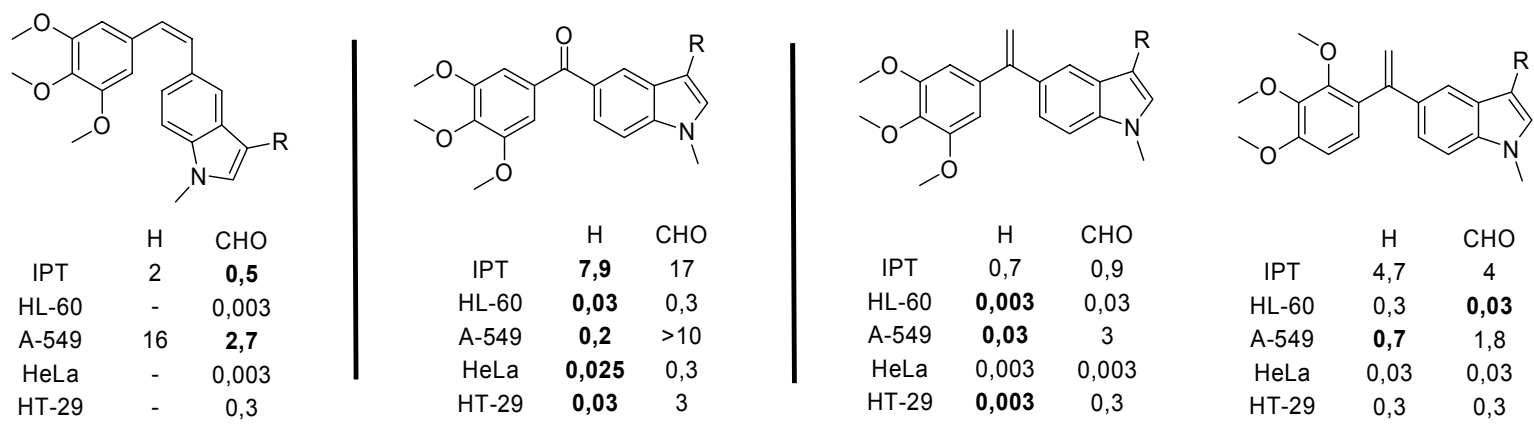

Figura 106. Comparación de las $\mathrm{IC}_{50}(\mu \mathrm{M})$ de los derivados con grupo formilo en posición tres del indol en combretastatinas (izquierda), ${ }^{69}$ fenstatinas ${ }^{71}$ (centro) e isocombretastatinas (derecha). Los valores que implican una clara mejora están resaltados en negrita. 
La reducción del grupo aldehído a hidroximetilo (figura 107) conduce, en general, a compuestos menos potentes. En las combretastatinas el derivado hidroximetílico es más potente que el compuesto no sustituido. Además, las dos líneas celulares habitualmente más resistentes (A-549 y HT-29) parecen ser más sensibles a estos compuestos con un grupo alcohólico, superando incluso al derivado formilado.
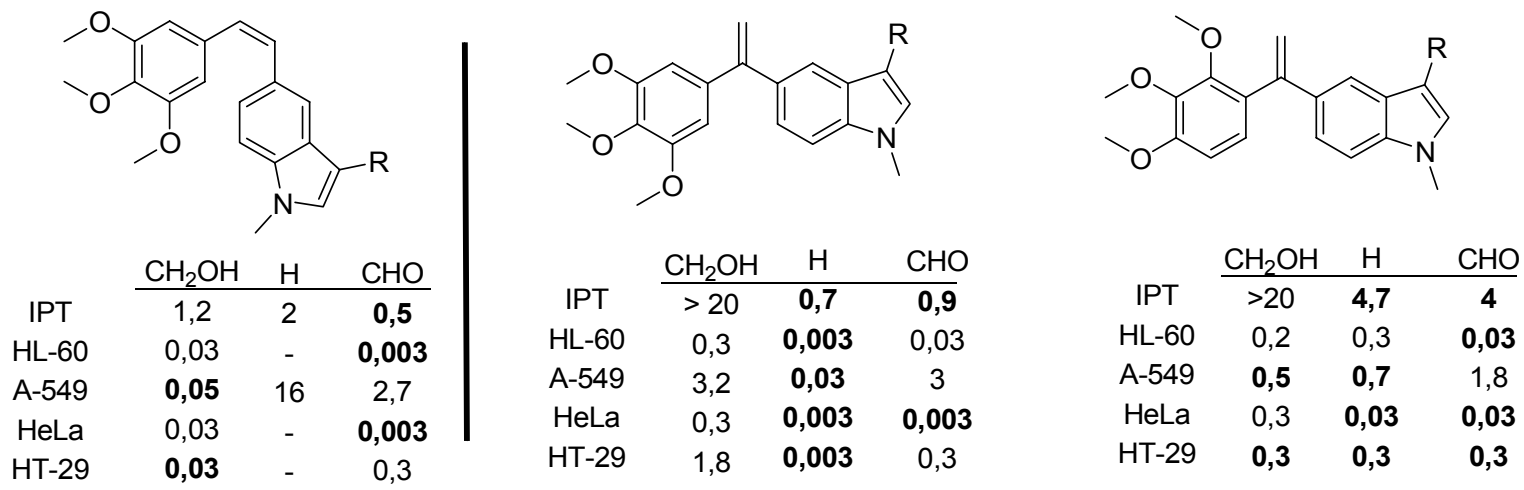

Figura 107. Comparación de las $\mathrm{IC}_{50}(\mu \mathrm{M})$ de los derivados con grupo hidroximetilo en posición tres del indol en combretastatinas (izquierda) e isocombretastatinas (derecha). Los valores que implican una clara mejora están resaltados en negrita.

A partir del derivado formilado se introdujeron diferentes modificaciones en la posición tres del indol de las isocombretastatinas. Estas modificaciones incluían variaciones en el tamaño, la geometría, el patrón de dadores y aceptores de enlaces de hidrógeno. Así, se prepararon las oximas y sus acetatos, las hidrazonas y los nitrilos a partir de los acetatos de oxima. En la siguiente gráfica (figura 108) puede compararse el efecto en la actividad de dichas modificaciones. 

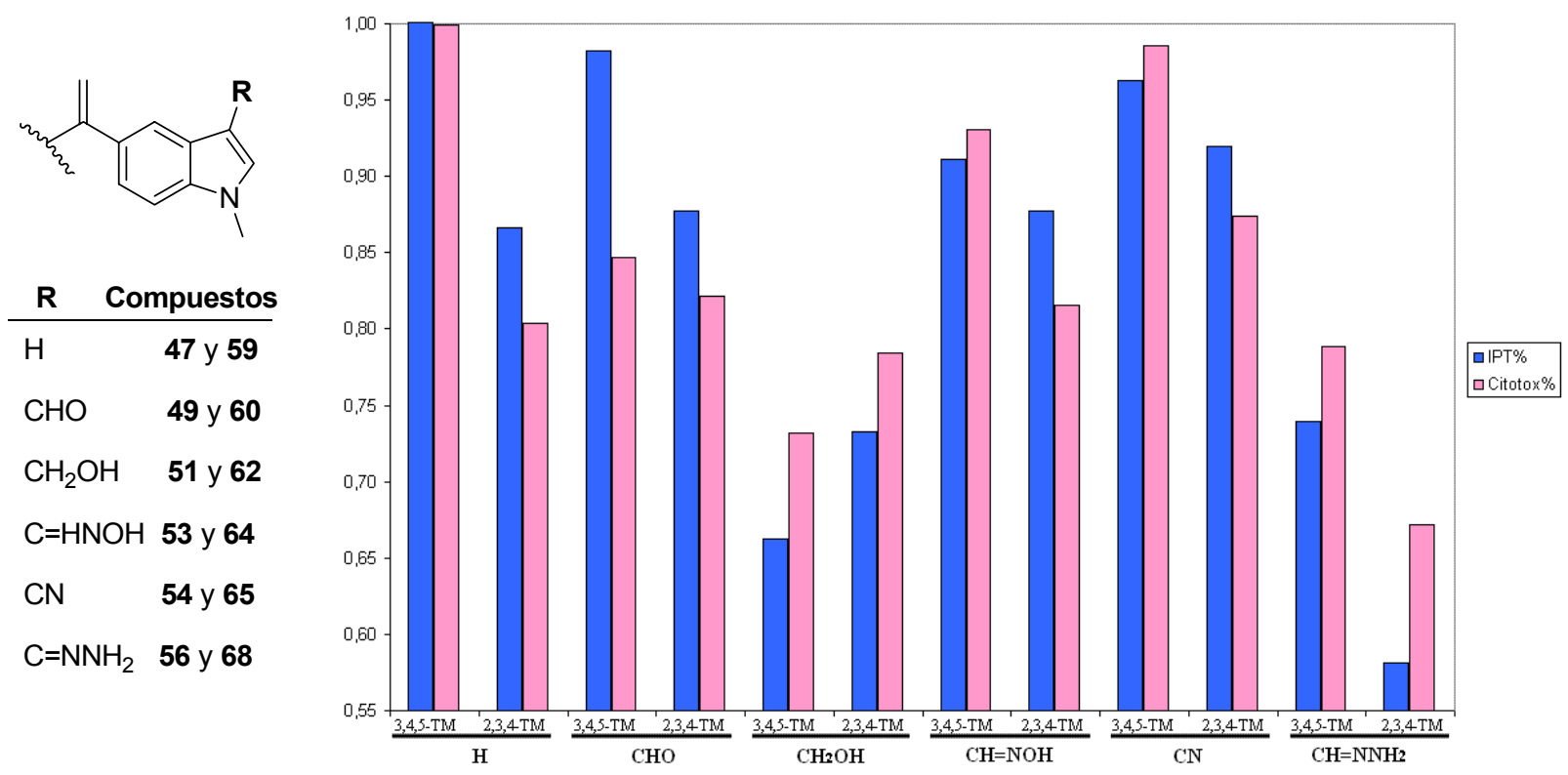

Figura 108. Representación de la potencia en IPT (azul) y citotoxicidad (rosa) de los compuestos con diferentes sustituyentes en la posición tres del indol respecto al compuesto de referencia (45).

De la figura 108 se deduce que ninguna de las sustituciones mejora la potencia presentada por la isocombretastatina con el indol sin sustituir, tanto en IPT como en citotoxicidad. La sustitución más favorable de las ensayadas es el grupo nitrilo, que presenta una actividad comparable con la del modelo. A diferencia de otros sustituyentes, la combinación del nitrilo con un resto 2,3,4-trimetoxifenilo no es muy desfavorable. Estos resultados sugieren que el volumen del sustituyente es un factor importante en la actividad. De acuerdo con esta afirmación, intentos de llevar a cabo experimentos de docking de estos ligandos sobre el complejo de tubulina con colchicina o podofilotoxina produjeron, en todos los casos, complejos en los que el ligando se encontraba desplazado fuera del sitio de la colchicina o rotado respecto a la disposición que adopta el ligando sin sustituyentes. ${ }^{73}$ Las oximas mostraron valores próximos a los de los nitrilos, tanto en citotoxicidad como en IPT, mientras que las hidrazonas resultaron ser mucho menos potentes.

\footnotetext{
73 a) Peláez, R.; Therón, R.; García, C. A.; López, J. L.; Medarde, M. Design of New Chemoinformatic Tools for the Analysis of Virtual Screening Studies: Application to Tubulin Inhibitors Adv. Soft. Comp. 2009 49, 189. b) Peláez, R.; Therón, R.; García, C. A.; López, J. L.; Medarde, M. Application of Chemoinformatic Tools for the Analysis of Virtual Screening Studies of Tubulin Inhibitors. Adv. Soft. Comp. 2007 44, 411.
} 
Para analizar en mayor detalle los efectos de las sustituciones más potentes (oximas y nitrilos) sobre cada línea celular ensayada, se han representado sus potencias respecto a la de los compuestos sin sustituir (figura 109). De acuerdo con lo expuesto en la discusión de los aspectos estructurales generales, los compuestos con 3,4,5-trimetoxifenilo son más potentes, presentando una citotoxicidad cercana a la del compuesto más potente en IPT, con el indol sin sustituir. Además, se observa una disminución de la citotoxicidad en relación a la IPT para HL-60 y HT-29. Por el contrario HeLa y A-549, que es una de las líneas habitualmente más resistentes, mantienen la sensibilidad en proporción a la potencia inhibidora de la polimerización de tubulina. Esta selectividad, que puede ser una característica interesante de los compuestos con anillo 2,3,4-trimetoxifenilo, no se observa en el análogo con un grupo nitrilo. Los compuestos con anillo de 3,4,5-trimetoxifenilo presentan una notable actividad frente a A-549 y, en particular, la oxima muestra una gran citotoxicidad frente a esta línea celular en relación a su actividad inhibidora de polimerización de tubulina.

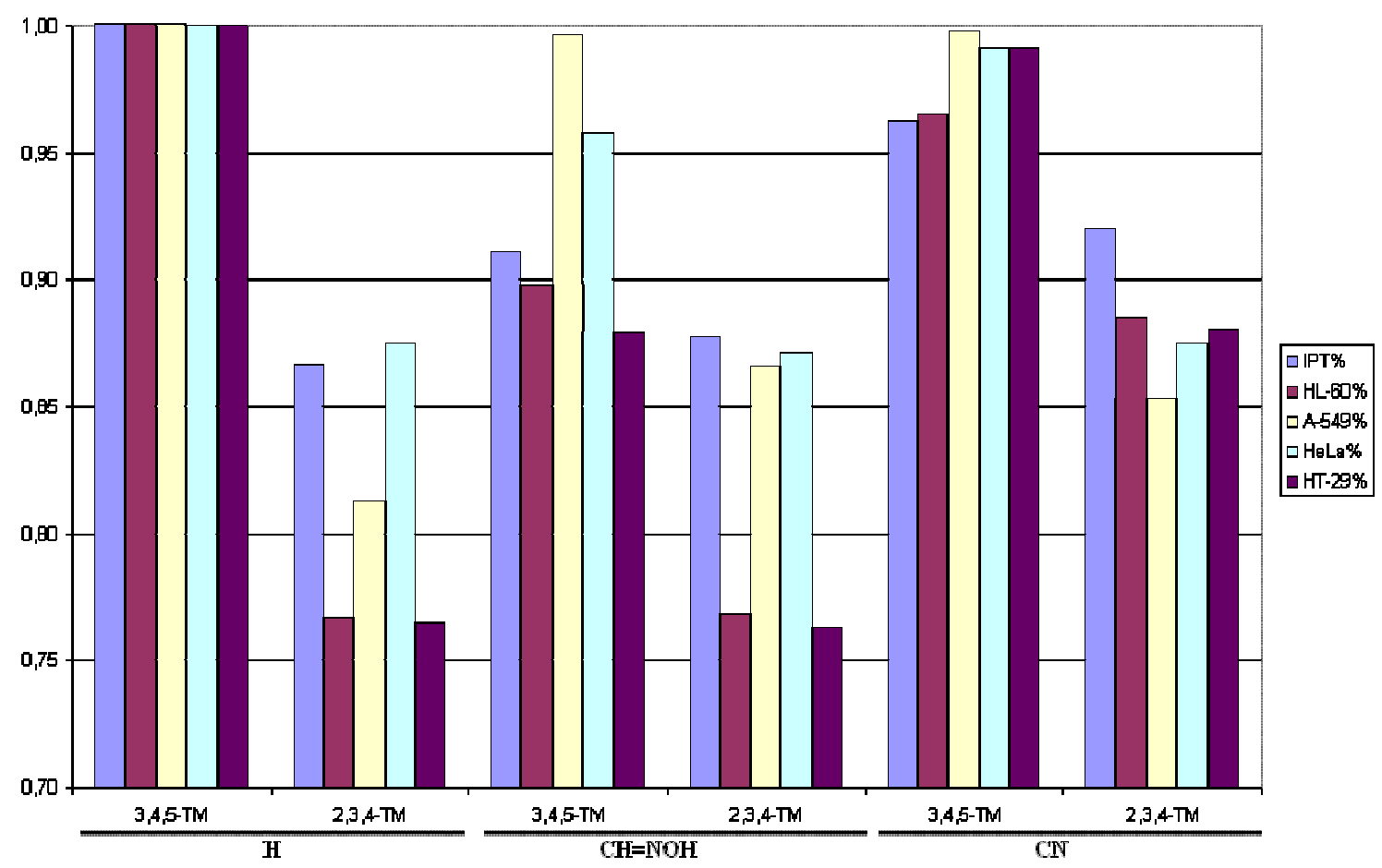

Figura 109. Representación de la potencia en IPT (azul) y citotoxicidad frente a las diferentes líneas celulares de los compuestos con grupos oxima y nitrilo respecto al compuesto de referencia (que posee el anillo indólico sin sustituir, 45). 
Durante la síntesis de los derivados aldehídicos, se han obtenido las formil isocombretastatinas que incluyen un grupo formilo adicional en el puente (figura 110). Estos derivados, análogos estructurales de los alquenilidendiarilmetanos (ADAMs) y CC$5079,{ }^{74}$ han resultado ser menos potentes que las isocombretastatinas con un solo formilo sobre el anillo indólico. En general, parece que la combinación de un puente apolar (olefina) con un sustituyente polar $(\mathrm{CHO}, \mathrm{CN}, \mathrm{C}=\mathrm{NOH})$ en la posición 3 del indol es favorable, mientras que la combinación de dos elementos polares está menos favorecida $(\mathrm{C}=\mathrm{O}, \mathrm{C}=\mathrm{CH}-\mathrm{CHO}$ en el puente con $\mathrm{CHO}, \mathrm{CN}$ en tres del indol).<smiles></smiles>
$\mathrm{X}=\mathrm{H} Y=\mathrm{OMe} \quad 61$<smiles>COc1noc2c(C)cc(/C(=C\CCc3nnc(C)o3)c3ccc(C#N)cc3)cc12</smiles>

ADAMs<smiles>COc1cc(OC)cc(C(=CC#N)c2ccc(OC)c(OC)c2)c1</smiles>

CC-5079

Figura 110. Formil isocombretastatinas sintetizadas en este trabajo y alquenilidendiarilmetanos, análogos estructurales de las mismas.

\footnotetext{
${ }^{74}$ a) Cullen, M. D.; Sarkar, T.; Hamel, E.; Hartman, T. L.; Watson, K. M.; Buckheit, R. W.; Pannecouque, C.; De Clercq, E.; Cushman, M. Inhibition of tubulin polymerization by select alkenyldiarylmethanes. Bioorg Med. Chem. Lett. 2008, 18, 469-473. b) Cullen, M. D.; Cheung, Y. F.; Houslay, M. D.; Hartman, T. L.; Watson, K. M.; Buckheit, R. W.; Pannecouque, C.; De Clercq, E.; Cushman, M. Investigation of the alkenyldiarylmethane non-nucleoside reverse transcriptase inhibitors as potential cAMP phosphodiesterase4B2 inhibitors. Bioorg. Med. Chem. Lett. 2008, 18, 1530-1533. c) Deng, B. L.; Hartman, T. L.; Buckheit, R. W.; Pannecouque, C.; De Clercq, E.; Cushman, M. Replacement of the metabolically labile methyl esters in the alkenyldiarylmethane series of non-nucleoside reverse transcriptase inhibitors with isoxazolone, isoxazole, oxazolone, or cyano substituents. J. Med. Chem. 2006, 49, 5316-5323. d) Deng, B. L.; Hartman, T. L.; Buckheit, R. W.; Pannecouque, C.; De Clercq, E.; Fanwick, P. E.; Cushman, M. Synthesis, anti-HIV activity, and metabolic stability of new alkenyldiarylmethane HIV-1 non-nucleoside reverse transcriptase inhibitors. J. Med. Chem. 2005, 48, 6140-6155. e) Wu, L.; Zhang, L. H.; Pedemonte, M.; Nazriuddin, S.; Lai, Y.; Lu, L.; Schafer, P.; Muller, G.; Stirling, D.; Payvandi, F. CC-5079 causes NF-kB-independent apoptosis in hematopoietic cancer cell lines and in taxol and doxorubicin drug-resistant cells. Blood 2003, 102, 209B210B. f) Zhang, L. H.; Lu, L.; Wit, L.; Robarge, M.; Liu, W.; Chen, R. S.; Muller, G. W.; Stirling, D.; Payvandi, F. CC-5079, a novel microtubule and TNF-a inhibitor with antiangiogenic and antimetastasis activity. Clin. Cancer Res. 2003, 9, 6142S-6142S. g) Zhang, L. H.; Wu, L.; Raymon, H. K.; Chen, R. S.; Corral, L.; Shirley, M. A.; Narla, R. K.; Gamez, J.; Muller, G. W.; Stirling, D. I.; Bartlett, J. B.; Schafer, P. H.; Payvandi, F. The synthetic compound CC-5079 is a potent inhibitor of tubulin polymerization and tumor necrosis factor-alpha production with antitumor activity. Cancer Res. 2006, 66, 951-959.
} 
Además de la introducción de sustituyentes en la posición C-3 del indol, se ha explorado el efecto de reemplazar dicho carbono por un heteroátomo. Así, se han sintetizado análogos $N$-metilbenzimidazólicos y 1,3-benzoxazólicos de combretastatinas (79 y 80) y fenstatinas (69-74), unidos por distintas posiciones. La sustitución del metino del indol por un $\mathrm{N}$ en las combretastatinas conduce a compuestos potentes tanto en IPT como en citotoxicidad. Por el contrario, el reemplazo del metino del indol por un nitrógeno y del resto $N$-metilo por un oxígeno conduce a la pérdida de la potencia en fenstatinas. Durante la síntesis de los análogos $N$-metilbenzimidazólicos de las fenstatinas se obtuvieron los derivados unidos al puente por la posición dos, que resultaron ser poco potentes. Ésto concuerda con estudios anteriores en los que se había observado que la sustitución de uno de los anillo bencénicos de combretastatinas por anillos aromáticos de cinco miembros (benzofusionados o no) reducía notablemente la potencia. ${ }^{67,69}$

Respecto a los análogos macrocíclicos, ninguno de ellos presentó actividad inhibitoria de la polimerización de tubulina. ${ }^{66}$ Puesto que análogos que sólo difieren en la ausencia del espaciador presentan potencias elevadas, ${ }^{69,75}$ es razonable proponer que la pérdida de actividad se debe al espaciador. El estudio de las conformaciones accesibles a los análogos macrocíclicos con un anillo tetrasustituido sugerían que alguno de los metilenos del espaciador podían ocupar el espacio que ocupan los metoxilos de colchicina y podofilotoxina cuando se unen a la tubulina. Esto podría desplazar los metoxilos laterales del anillo aromático tetrasustituido a zonas ocupadas por la proteína, dificultando así su unión. Por ello, se sintetizaron los análogos trisustituidos, en los que la ausencia de un metoxilo podría facilitar que adoptasen una disposición más parecida a la que adoptan los análogos no macrocíclicos más potentes. ${ }^{66}$ Sin embargo, los resultados de actividad muestran que dichos compuestos tampoco inhiben la polimerización de tubulina. Esto sugiere que la causa de que los análogos macrocíclicos no sean activos es la interacción desfavorable del espaciador con la proteína. Estudios de docking realizados con los análogos no macrocíclicos sugieren que la zona ocupada por el espaciador corresponde a la parte superior de una lámina $\beta$ que forman los residuos de Val313 a Val316 y de Asn348 a Ala352. ${ }^{71-73}$

\footnotetext{
${ }^{75}$ Mateo, C. Trabajo de grado, Universidad de Salamanca, 2002.
} 


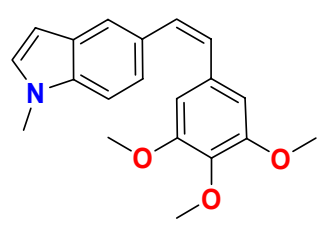

IPT $2 \mu \mathrm{M}$
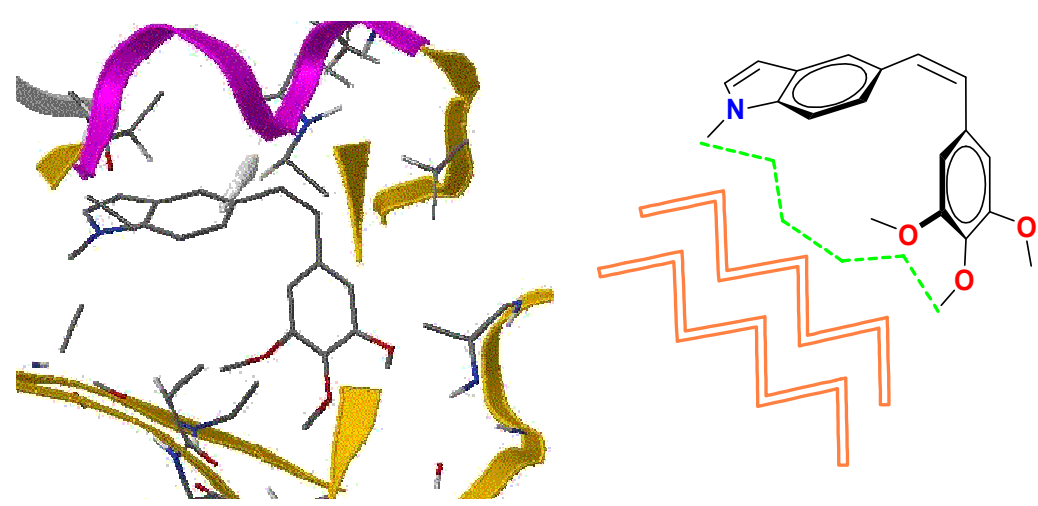

Figura 111. Representación de la combretastatina indólica no macrocíclica en el sitio de unión de la colchicina (izquierda y centro) y representación esquemática de la interacción del espaciador (en verde) de la combretastatina indólica macrocíclica con la lámina $\beta$ (zig-zag naranja) del sitio de unión (a la derecha). ${ }^{76}$

Los elementos estructurales introducidos pueden analizarse teniendo en cuenta los modelos de farmacóforo propuestos para los ligandos del sitio de la colchicina (figura 112). ${ }^{77}$ Así, se considera que en las fenstatinas el carbonilo incrementa la potencia de IPT al comportarse como aceptor de enlace de hidrógeno frente a un dador de la proteína (indicado por una esfera de puntos azul claro). Sin embargo, isocombretastatinas que carecen de esta interacción favorable son más potentes. El anillo de pirrol del indol ocupa tres sitios del farmacóforo: una zona hidrofóbica (esfera negra), un aceptor de enlace de hidrógeno (esfera verde) y un dador de enlace de hidrógeno (esfera rosa) algo más alejado. En principio, el $N$-metilo debería ocupar la zona hidrofóbica, quedando desocupada la zona del aceptor en los indoles, pero podrían actuar como tales los nitrógenos en el caso de los benzimidazoles.

\footnotetext{
${ }^{76} \mathrm{http}: / /$ web.usal.es/ pelaez/Pelaez/TESIS.htm\#RAKE

77 a) Bhattacharyya, B.; Panda, D.; Gupta, S.; Banerjee, M. Anti-mitotic activity of colchicine and the structural basis for its interaction with tubulin. Med. Res. Rev. 2008, 28, 155-183. b) Zefirova, O. N.; Diikov, A. G.; Zyk, N. V.; Zefirov, N. S. Ligands of the colchicine site of tubulin: A common pharmacophore and new structural classes. Russ. Chem. Bull. 2007, 56, 680-688. c) Nguyen, T. L.; McGrath, C.; Hermone, A. R.; Burnett, J. C.; Zaharevitz, D. W.; Day, B. W.; Wipf, P.; Hamel, E.; Gussio, R. A common pharmacophore for a diverse set of colchicine site inhibitors using a structure-based approach. J. Med. Chem. 2005, 48, 61076116. d) Ducki, S.; Mackenzie, G.; Lawrence, N. J.; Snyder, J. P. Quantitative structure-activity relationship (5D-QSAR) study of combretastatin-like analogues as inhibitors of tubulin assembly. J. Med. Chem. 2005, 48, 457-465. e) Brown, M. L.; Rieger, J. M.; Macdonald, T. L. Comparative molecular field analysis of colchicine inhibition and tubulin polymerization for combretastatins binding to the colchicine binding site on beta-tubulin. Bioorg. Med. Chem. 2000, 8, 1433-1441. f) terHaar, E.; Rosenkranz, H. S.; Hamel, E.; Day, B. W. Computational and molecular modeling evaluation of the structural basis for tubulin polymerization inhibition by colchicine site agents. Bioorg. Med. Chem. 1996, 4, 1659-1671.
} 
Los sustituyentes en posición tres del indol podrían en principio interaccionar con la lisina $350 \beta$, cuyo grupo amino (mostrado en cpk) se podría situar cerca de los mismos, favoreciendo la interacción con grupos más polares (como por ejemplo $\mathrm{CHO}, \mathrm{CN}$ ). Otro sitio hidrofóbico (no mostrado) estaría ocupado por el anillo de trimetoxifenilo, que también aportaría un aceptor de enlace de hidrógeno (no mostrado) y el segundo anillo aromático ocuparía la llamada zona plana hidrofóbica

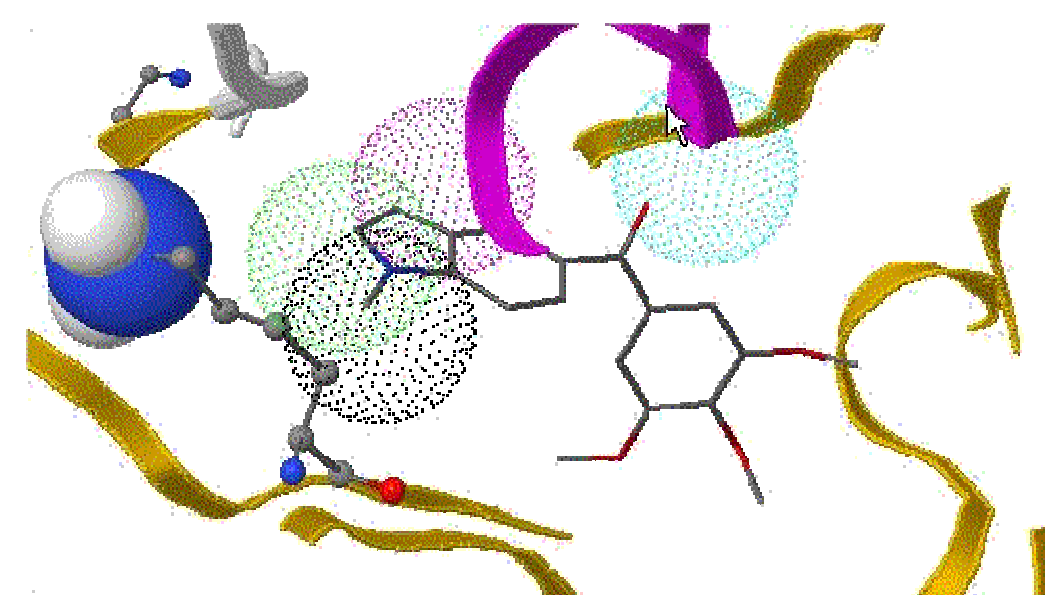

Figura 112. Representación de cuatro de los puntos del farmacóforo de los ligandos que se unen a la tubulina en el sitio de la colchicina y de la Lys $350 \beta\left(\mathrm{NH}_{2}\right.$ terminal en modelo $\left.\mathrm{CPK}\right){ }^{76}$

A modo de resumen de los resultados obtenidos en este trabajo, cabe destacar que:

- La potencia citotóxica que presentan las isocombretastatinas es mayor que la mostrada por las fenstatinas y comparable con la de combretastatinas con potencias similares de inhibición de polimerización de tubulina.

- La presencia del resto 3,4,5-trimetoxifenilo conduce a compuestos más potentes que la presencia del resto 2,3,4-trimetoxifenilo. Sin embargo, la potencia de los compuestos con un resto 2,3,4-trimetoxifenilo se ve incrementada cuando se combina con un anillo indólico (en vez de un segundo resto fenilo).

- El resto $N$-metil-5-indolilo es un buen reemplazo del anillo aromático $\mathrm{Ar}_{2}$ en isocombretastatinas, al igual que se había descrito en combretastatinas y fenstatinas.

- La sustitución del anillo indólico por otros heterociclos benzofusionados conduce a la pérdida de la actividad.

- La introducción de sustituyentes en la posición C-3 del $N$-metilindol conduce a compuestos de actividad variable en función del sustituyente, siendo los derivados más potentes aquellos que contienen un grupo nitrilo o una oxima. 



\section{IV.1. TÉCNICAS GENERALES.}

\section{IV.1.A. Instrumentación.}

La instrumentación utilizada en cada caso es la que se cita a continuación:

- Puntos de fusión: BUCHI 510, en baño de silicona y no fueron corregidos.

- Espectros IR: Espectrofotómetro FT-IR o Nicolet Impact 410, en película, salvo indicación contraria. Los valores de la frecuencia de absorción se expresan en $\mathrm{cm}^{-1}$.

- Espectros de RMN ${ }^{1} \mathbf{H}$ y de $\mathbf{R M N}{ }^{13} \mathbf{C}$ : Espectrómetros BRUKER AC 200 (200 MHz), y BRUKER DRX 400 (400 MHz), utilizando $\mathrm{CDCl}_{3}$ como disolvente, salvo indicación contraria. Los valores de desplazamiento químico $(\delta)$ se expresan en ppm y los de las constantes de acoplamiento $(J)$ en $\mathrm{Hz}$.

- Espectros de gases-masas: Se determinaron en un sistema de cromatográfo de gases acoplado con un espectrómetro de masas que dispone de un detector de masas Hewlett-Packard 5890 series II, dotado de una columna SPB-1 de dimetilsilicona de 12 metros de longitud, 0,2 mm de diámetro interno, con un espesor de pared de 0,33 $\mu \mathrm{m}$. Las condiciones de experimentación utilizadas son las siguientes: una vez inyectada la muestra, el detector se mantiene a 100 ${ }^{\circ} \mathrm{C}$ durante 5 minutos y después se programa un gradiente de $10{ }^{\circ} \mathrm{C} /$ minuto hasta alcanzar la temperatura máxima de $300{ }^{\circ} \mathrm{C}$, temperatura a la cual se mantiene durante 5 minutos. 


\section{IV.1.B Técnicas cromatográficas.}

- Cromatografía flash. Se utilizó gel de sílice MERCK 60 (0,040-0,063 mm) en proporción 30-40 g de sílice por gramo de sustancia.

- Cromatografía de capa fina. Se utilizaron láminas de poliéster prefabricadas POLYCHROM de 0,25 mm de espesor, con recubrimiento de gel de sílice con indicador fluorescente UV-254. Para el revelado se pulveriza con una disolución de ácido sulfúrico al 10\% en etanol, o ácido fosfomolíbdico al 10\% en etanol, calentando a continuación a $110{ }^{\circ} \mathrm{C}$ durante unos minutos.

- HPLC. Se utilizó un cromatógrafo de líquidos Agilent HP Series 1100, equipado con columnas Waters X-Terra ${ }^{\circledR} \mathrm{MS} \mathrm{C}_{8}(5 \mu \mathrm{m}, 4,6 \mathrm{x} 150 \mathrm{~mm})$, Waters XTerra ${ }^{\circledR}$ MS $\mathrm{C}_{18}(5 \mu \mathrm{m}, 4,6 \mathrm{x} 150 \mathrm{~mm})$ o Waters X-Terra ${ }^{\circledR} \mathrm{MS}(5 \mu \mathrm{M}, 4,6 \mathrm{x} 150$ $\mathrm{mm}) \mathrm{C}_{\text {fenílica }}$.

\section{IV.1.C. Tratamiento de disolventes y reactivos.}

- Tolueno. El tolueno comercial se seca sobre láminas de Na.

- Cloruro de metileno. El $\mathrm{CH}_{2} \mathrm{Cl}_{2}$ comercial se seca sobre tamiz molecular.

- Hexano. El hexano comercial se destila en columna de rectificación y se recoge sobre $\mathrm{CaCl}_{2}$.

- Tetrahidrofurano. El THF comercial se destila, inmediatamente antes de su uso, sobre láminas de sodio, bajo atmósfera de argón, usando benzofenona como indicador. 


\section{IV.1.D. Modelado molecular.}

Los cálculos de Modelado Molecular fueron llevados a cabo en una estación de trabajo Indy 5500 Silicon Graphics. Los compuestos fueron construidos utilizando el módulo de construcción del paquete Macromodel 5,5 ${ }^{78}$ y minimizados usando los campos de fuerzas MM3 y MMFF.

El análisis conformacional para cada compuesto se realizó mediante un protocolo de búsqueda conformacional de tipo Monte Carlo, ${ }^{79}$ generando 1000 conformaciones para cada compuesto. Algunas de estas confomaciones se encuentran disponibles en la dirección http://web.usal.es/ ppelaez/Pelaez/TESIS.htm

Las dinámicas moleculares a distintas temperaturas (típicamente a 300, 600, 1200 y $1500 \mathrm{~K}$ ) se han llevado a cabo con el campo de fuerzas MM3, utilizando cloroformo como disolvente. ${ }^{80}$ Tras un periodo de equilibrado de 200 ps, para estabilizar la simulación a la temperatura deseada, sigue una fase de producción de 3 ns, en la que se generan 1000 conformaciones. ${ }^{81}$

\footnotetext{
${ }^{78}$ Mohamadi, F.; Richards, N. G.; Guida, W. C.; Liskamp, R.; Lipton, M.; Caueld, C.; Chang, G.; Hendrickson, T.; Still, W. C. MacroModel an integrated software system for modeling organic and bioorganic molecules using molecular mechanics. J. Comp. Chem. 1990, 11, 440-467.

${ }^{79}$ a) Hallberg, A.; Isaksson, R. Martin, A. R.: Sndström, J. Chromatographic resolution, circular dichroism spectra, and absolute configurations of dimers of $5 \mathrm{H}$-indolo[1,7-ab][1]benzazepine and coumarin with $C_{2}$ symmetry. J. Am. Chem. Soc., 1989, 111, 4387-4392. b) Saunders, M.; Houk, K. N.; Wu, Y-D.; Still, W. C.; Lipton, M.; Chang, G.; Guida, W. C. Conformations of cicloheptadecane. A comparison of methods for conformational searching. J. Am. Chem. Soc., 1990, 112, 1429-1427.

${ }^{80}$ a) Allinger, N. L.; Yuh, Y. H.; Lii, J. H. Molecular mechanics. The MM3 force field for hydrocarbons. 1. J. Am. Chem. Soc. 1989, 111, 8551-8566. b) Lii, J. H.; Allinger, N. L. Molecular mechanics. The MM3 force field for hydrocarbons. 2. Vibrational frequencies and thermodynamics. J. Am. Chem. Soc. 1989, 111, 85668576. c) Lii, J. H.; Allinger, N. L. Molecular mechanics. The MM3 force field for hydrocarbons. 3. The van der Waals' potentials and crystal data for aliphatic and aromatic hydrocarbons J. Am. Chem. Soc. 1989, 111, 8576-8582.

${ }^{81}$ Hudson, B. D.; George, A. R.; Ford, M. G.; Livingstone D. J. Structure-activity relationships of pyrethroid insecticides. Part 2. The use of molecular dynamics for conformation searching and average parameter calculation. J. Comput.-Aided Mol. Des. 1992, 6, 191-201.
} 



\section{IV.2. MÉTODOS GENERALES.}

\section{IV.2.A. MÉTODO A. N-Alquilación de 1 H-indoles.}

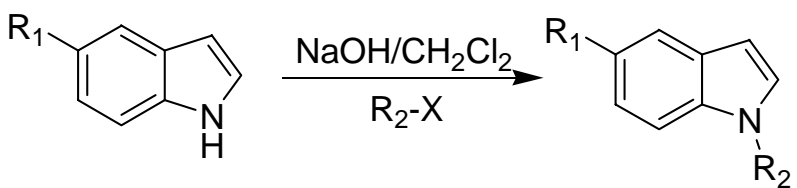

A una disolución 0,25-0,26 M del derivado de indol en $\mathrm{CH}_{2} \mathrm{Cl}_{2}$ seco, se añaden 2 equivalentes de $\mathrm{NaOH}$ perfectamente triturada y $\sim 1 \%$ en peso respecto del indol de $n \mathrm{Bu}_{4} \mathrm{~N}^{+} \mathrm{HSO}_{4}{ }^{-}$. Tras una hora en agitación en atmósfera de argón y t.a., se añaden entre 2 y 3 equivalentes del derivado halogenado (MeI o EtBr). La reacción se deja en estas condiciones durante $48 \mathrm{~h}$. La mezcla de reacción se trata extrayendo con $\mathrm{H}_{2} \mathrm{O}$ varias veces. Las fases orgánicas se secan con $\mathrm{Na}_{2} \mathrm{SO}_{4}$ anhidro, se filtran y evaporan, obteniéndose el indol alquilado. 


\section{IV.2.B. MÉTODO B. Reacción de Wittig.}<smiles>[R]C=C([R])[Al]C</smiles>

A una suspensión 0,08 $\mathrm{M}$ de sal de fosfonio en THF seco a $-40^{\circ} \mathrm{C}$ y en atmósfera de argón, se le añaden de 0,75 a 1,1 equivalentes de $n \operatorname{BuLi}$ (1,6 M en hexano). La suspensión resultante se agita durante 1 hora. En estas condiciones, se añaden desde 0,25 a 0,90 equivalentes del compuesto carbonílico y se permite que alcance progresivamente la temperatura ambiente. Transcurridas 12-24 horas, se vierte la reacción sobre hielo y se extrae con $\mathrm{CH}_{2} \mathrm{Cl}_{2}$. El conjunto de las fases orgánicas se lava hasta neutralidad con una disolución saturada de $\mathrm{NaCl}$, se seca con $\mathrm{Na}_{2} \mathrm{SO}_{4}$ anhidro, se filtra y se evapora hasta sequedad. El producto obtenido se purifica mediante cromatografía en columna.

\section{IV.2.C. MÉTODO C. Formación de diarilmetanoles.}

\section{C1. A parir de derivados organolíticos.}

$$
\mathrm{Ar}_{1}-\mathrm{X}+\mathrm{Ar}_{2}-\mathrm{CHO} \stackrel{\mathrm{nBuLi} / \mathrm{THF}}{\longrightarrow} \mathrm{Ar}_{1} \overbrace{\mathrm{Ar}_{2}}^{\mathrm{OH}}
$$

Una suspensión 2,4-45,2 mmol del derivado halogenado en THF (20-60 mL) se pone en agitación y atmósfera de argón a $-78^{\circ} \mathrm{C}$. Se añaden 3,0-34 mL de $n \operatorname{BuLi}(1,6 \mathrm{M})$ y tras 1-2 horas se adicionan lentamente 2,9-54,2 $\mathrm{mmol}$ (1,2 mmoles/mmol de derivado halogenado) del aldehído correspondiente y se deja subir la temperatura espontáneamente. Tras 12-24 horas, se vierte la mezcla sobre hielo y posteriormente se extrae con $\mathrm{CH}_{2} \mathrm{Cl}_{2}$. Las fases orgánicas se juntan y se secan con $\mathrm{Na}_{2} \mathrm{SO}_{4}$, se filtran y evaporan. 


\section{C2. Con magnesianos.}<smiles>[R]c1cc(C(O)c2cc(OC)c(OC)c(OCC)c2)ccc1OCCOc1ccc(C=O)cc1OCC</smiles>

Sobre una suspensión 6 M de Mg en THF se añade, en frío, unos cristales de $\mathrm{I}_{2}$ y la cuarta parte del derivado bromado. Se agita hasta decoloración de la solución y a continuación se añade lentamente el resto del derivado bromado disuelto en THF y se deja en agitación una hora. Tras este tiempo, la solución obtenida se vierte sobre una disolución 3,25 M del aldehído correspondiente en THF a $0{ }^{\circ} \mathrm{C}$ y se deja en agitación hasta alcanzar temperatura ambiente. La reacción se para mediante la adición de $10 \mathrm{~mL}$ de una solución acuosa saturada de $\mathrm{NH}_{4} \mathrm{Cl}$ y el bruto de reacción se obtiene tras extraer 3 veces con AcOEt, secar con $\mathrm{Na}_{2} \mathrm{SO}_{4}$, filtrar y evaporar.

\section{C3. Con organolíticos a partir de 1,2,3-trimetoxibenceno.}<smiles>[R1]c1cc(C(O)c2ccc(OCC)c(OCC)c2OC)ccc1OCCOc1ccc(C=O)cc1OC</smiles>

Sobre una suspensión 1,2 $\mathrm{M}$ de 1,2,3-trimetoxibenceno en THF a $0{ }^{\circ} \mathrm{C}$, se añaden 0,9 equivalentes de $n \mathrm{BuLi}$ (1,6 M en hexano). La solución amarilla resultante se agita hasta decoloración entre 1 y 2 horas en atmósfera de argón. Posteriormente se añade lentamente entre 0,3 y 0,8 equivalentes del aldehído correspondiente disuelto en THF y se deja en agitación un tiempo variable entre 12 y 24 horas. Tras este tiempo, la mezcla de reacción se trata con agua y hielo y se extrae con $\mathrm{CH}_{2} \mathrm{Cl}_{2}$ tres veces. El conjunto de las fases orgánicas se lava con disolución saturada de $\mathrm{NaCl}$ hasta $\mathrm{pH}$ neutro de las aguas de lavado, se seca con $\mathrm{Na}_{2} \mathrm{SO}_{4}$ anhidro, se filtra y se evapora a sequedad. El producto obtenido se purifica por cromatografía en columna. 


\section{IV.2.D. MÉTODO D. Oxidación de diarilmetanoles.}

\section{D1. Con PDC.}

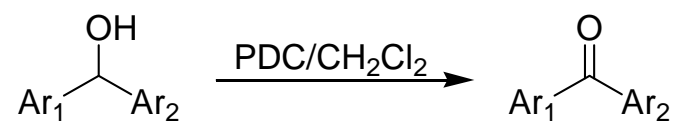

Sobre una disolución a $0{ }^{\circ} \mathrm{C}$ del diarilmetanol en cloruro de metileno seco, se añade 1,5 equivalentes de PDC, se deja alcanzar temperatura ambiente y tras 4-24 h se filtra a través de celita y se evapora para obtener el bruto de reacción.

\section{D2. Con $\mathrm{KMnO}_{4}$}

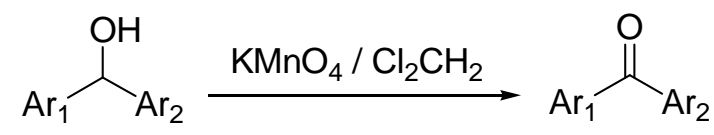

A una disolución del diarilmetanol en cloruro de metileno se añaden entre 2,5 y 5 equivalentes de permanganato potásico, $20 \mathrm{mg}$ del catalizador de transferencia de fase (hidrogenosulfato de tetrabutil amonio) y $1 \mathrm{~mL}$ de agua y se mantiene con agitación a temperatura ambiente durante 24 horas. Se filtra por alúmina usando como eluyente cloruro de metileno, se evapora y el producto obtenido se purifica mediante cromatografía de columna.

\section{IV.2.E. MÉTODO E. Formilación.}<smiles>[R]c1ccc2c(c1)cc(CC)n2C</smiles>

Sobre 1-5 mL de DMF seca a $0{ }^{\circ} \mathrm{C}\left(\mathrm{CaCl}_{2}\right)$ se añade 1 equivalente de $\mathrm{POCl}_{3}$ y se mantiene en agitación durante media hora, tras la cual, se adiciona el derivado indólico y se calienta a $60{ }^{\circ} \mathrm{C}$. Después de 2 horas, la solución resultante se vierte sobre hielo con acetato sódico, se añade agua y se deja en la nevera durante 24 horas. El precipitado obtenido se redisuelve en $\mathrm{CH}_{2} \mathrm{Cl}_{2}$, se seca con $\mathrm{NaSO}_{4}$ anhidro, se filtra y se evapora. 


\section{IV.2.F. MÉTODO F. Hidrogenaciones de dobles enlaces.}

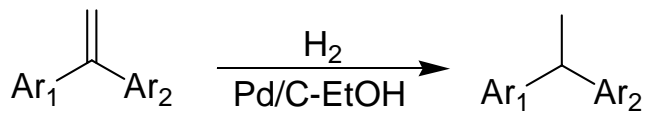

A una disolución 0,01-0,02 M de la olefina en EtOH se le añaden cantidades catalíticas de $\mathrm{Pd} / \mathrm{C}$ y se deja en agitación, a temperatura ambiente y bajo atmósfera de $\mathrm{H}_{2}$ durante 16-24 horas. Transcurrido este tiempo, se filtra a través de sílice y se evapora el disolvente.

\section{IV.2.G. MÉTODO G. Reducción con $\mathrm{NaBH}_{4}$.}

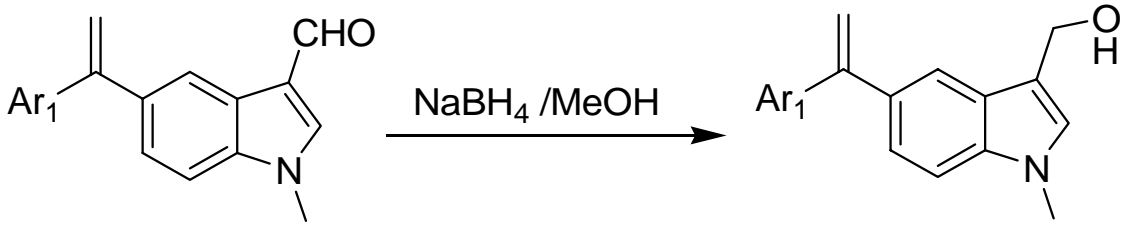

A una disolución 0,01-0,02 M de aldehído en 10-15 mL de $\mathrm{MeOH}$, se añade un exceso de $\mathrm{NaBH}_{4}$ y se mantiene en agitación. Transcurrida media hora, se evapora el $\mathrm{MeOH}$ y el residuo resultante se redisuelve en $\mathrm{CH}_{2} \mathrm{Cl}_{2}$ y se lava con agua hasta $\mathrm{pH}$ neutro. Las fases orgánicas se secan con $\mathrm{Na}_{2} \mathrm{SO}_{4}$, se filtran y se evaporan.

\section{IV.2.H. MÉTODO H. Formación de oximas.}<smiles>C=C([Al])c1ccc2c(c1)c(C=O)cn2C</smiles><smiles>C=C([Al])c1ccc2c(c1)c(/C=N\O)cn2C</smiles>

A una disolución 0,02-0,06 M de aldehído en 10-25 mL de $\mathrm{MeOH}$, se añade 1,215,5 mmol de $\mathrm{NH}_{2} \mathrm{OH} \cdot \mathrm{HCl}$ (10 $\mathrm{mmol} / \mathrm{mmol}$ de aldehído) y 2-4 gotas de piridina. La reacción se mantiene a reflujo durante 12-24 horas. Tras este tiempo, se evapora el disolvente y el producto bruto se redisuelve en $\mathrm{CH}_{2} \mathrm{Cl}_{2}$ y se extrae con agua. Las fases orgánicas se secan con $\mathrm{Na}_{2} \mathrm{SO}_{4}$ anhidro, se filtran y evaporan. 


\section{IV.2.I. MÉTODO I. Formación de hidrazonas.}<smiles>C=C([Al])c1ccc2c(c1)c(C=O)c(N)n2C</smiles>

A una disolución 0,02-0,06 M de aldehído en 10-25 mL de $\mathrm{MeOH}$, se añade 2,415,5 mmol de $\mathrm{NH}_{2}-\mathrm{NH}_{2} \cdot \mathrm{H}_{2} \mathrm{O}$ (10 mmol/mmol de cetona) y 2-4 gotas de ácido acético glacial. La reacción se mantiene a reflujo 12-48 horas. Tras este tiempo, se evapora el disolvente y el producto bruto se redisuelve en $\mathrm{CH}_{2} \mathrm{Cl}_{2}$ y se extrae con agua. Las fases orgánicas se secan con $\mathrm{Na}_{2} \mathrm{SO}_{4}$ anhidro, se filtran y evaporan.

\section{IV.2.J. MÉTODO J. Acetilaciones.}<smiles>[R]c1cc([C@@H](O)[C@H](O)c2ccc3c(ccn3CCCCCCCOc3ccccc3)c2)cc(OC)c1OC</smiles><smiles>[R]c1cccc([C@@H](OC(C)=O)[C@@H](OC(C)=O)c2ccc3c(ccn3CCCCCCOc3cc(OC)c(OC)cc3[R])c2)c1</smiles>

El material de partida se disuelve en piridina y posteriormente se añade anhídrido acético y se somete a agitación durante 20-24 horas. Después de ese tiempo, la reacción se recoge sobre $\mathrm{HCl} 2 \mathrm{~N}$ y AcOEt, se lava con $\mathrm{NaOH} 4 \%$ y con una disolución acuosa saturada de $\mathrm{NaCl}$ hasta neutralización de las aguas de lavado. El conjunto de las fases orgánicas se seca con $\mathrm{Na}_{2} \mathrm{SO}_{4}$ anhidro y se evapora. Los productos de reacción se aíslan por cromatografía en columna de gel de sílice. 


\section{IV.3. SÍNTESIS DE COMPUESTOS NO MACROCÍCLICOS.}

\section{IV.3.A. Materiales de partida.}

Obtención de Bromuro de 3,4,5-trimetoxibenciltrifenilfosfonio (1).<smiles>COc1cc(CBr)cc(OCc2ccccc2)c1OC</smiles>

Sobre una disolución de 4,12 g (15,8 mmol) de bromuro de 3,4,5-trimetoxibencilo en tolueno seco $(20 \mathrm{~mL})$ y en agitación, se añaden 5,63 g (21,5 mmol) de trifenilfosfina disuelta en tolueno seco $(15 \mathrm{~mL})$. Se continúa la agitación durante 23 h a temperatura ambiente, observándose la formación de un sólido. Después de filtrar y secar se obtienen 6,26 g (76,0\%) de un sólido blanco, que corresponde al bromuro 1.

\section{Bromuro de 3,4,5-trimetoxibenciltrifenilfosfonio (1):}

$\mathbf{R M N}^{1} \mathbf{H}: 3,48$ (6H, s, $\left.\mathrm{OCH}_{3}\right) ; 3,75$ (3H, s, $\left.\mathrm{OCH}_{3}\right) ; 5,36$ (2H, d, J=14,2; $\left.\mathrm{CH}_{2} \mathrm{P}\right)$; 6,46 (2H, s, Ar); 7,1-7,9 (15H, m, Ar). 


\section{Obtención de $1 H$-indol-3,5-dicarbaldehído(2).}<smiles>O=Cc1ccc2[nH]ccc2c1</smiles><smiles>O=Cc1ccc2[nH]cc(C=O)c2c1</smiles>

Siguiendo el método E, la adición de 1,5 g (10,34 mmol) de $1 H$-indol-5carbaldehído sobre una disolución de $960 \mathrm{~mL}(10,34 \mathrm{mmol})$ de $\mathrm{POCl}_{3}$ en $3 \mathrm{~mL}$ de DMF generan 515 mg (29\%) de 2.

\section{$\underline{1 H \text {-indol-3,5-dicarbaldehído (2): }}$}

IR (pastilla de KBr): 1665, 1611, 1440, 1183, $790 \mathrm{~cm}^{-1}$.

P.f.: $175-185^{\circ} \mathrm{C} .\left(\mathrm{CH}_{2} \mathrm{Cl}_{2} / \mathrm{Hex}\right)$.

RMN ${ }^{1} \mathbf{H}: 7,37\left(1 \mathrm{H}, \mathrm{d} ; J=8,4, \mathrm{H}_{7}\right) ; 7,62\left(1 \mathrm{H}, \mathrm{dd} ; J=8,4 ; 1,4, \mathrm{H}_{6}\right) ; 7,89(1 \mathrm{H}, \mathrm{d} ; J=1,4$, $\left.\mathrm{H}_{4}\right) ; 8,54$ (1H, sa, $\left.\mathrm{H}_{2}\right) ; 9,80$ (1H, s, CHO ); 9,83 (1H, s, CHO).

\section{Obtención del $\mathrm{N}$-etil-1H-indol-3,5-dicarbaldehído (3).}<smiles>O=Cc1ccc2[nH]cc(C=O)c2c1</smiles><smiles>CCn1cc(C=O)c2cc(C=O)ccc21</smiles>

A una disolución de 230 mg (1,33 mmol) de dialdehído en DMF seca se le añade un exceso de carbonato de potasio ( 3 g) y se mantiene en agitación durante 1 hora a temperatura ambiente y atmósfera inerte. A continuación se añaden 0,2 mL (2,66 mmol) de bromuro de etilo y se aumenta la temperatura hasta $70{ }^{\circ} \mathrm{C}$. Transcurridas 48 horas la mezcla de reacción se vierte sobre hexano y se filtra para eliminar las sales. A continuación se evapora el filtrado, se redisuelve en $\mathrm{CH}_{2} \mathrm{Cl}_{2}$, se lava con $\mathrm{NaOH}$ al $4 \%$ y con agua saturada de $\mathrm{NaCl}$ hasta $\mathrm{pH}$ neutro de las aguas de lavado. El conjunto de las fases orgánicas se seca con $\mathrm{Na}_{2} \mathrm{SO}_{4}$ anhidro, se filtra y se evapora hasta sequedad para obtener $180 \mathrm{mg}(67 \%)$ de 3. 


\section{$\underline{N \text {-etil-1H-indol-3,5-carbaldehído (3): }}$}

IR (película): 1687, 1662, $1191 \mathrm{~cm}^{-1}$.

RMN ${ }^{1} \mathbf{H}: 1,54$ (3H, t; $\left.J=7,2, \mathrm{CH}_{3}\right) ; 4,25$ (2H, c, $\left.J=7,2, \mathrm{CH}_{2}\right) ; 7,44(1 \mathrm{H}, \mathrm{d} ; J=8,6$, $\left.\mathrm{H}_{7}\right) ; 7,84\left(1 \mathrm{H}, \mathrm{s}, \mathrm{H}_{2}\right) ; 7,85\left(1 \mathrm{H}, \mathrm{dd} ; J=8,6 ; 1,6, \mathrm{H}_{6}\right) ; 8,73\left(1 \mathrm{H}, \mathrm{d} ; J=1,6, \mathrm{H}_{4}\right) ; 9,99$ $(1 \mathrm{H}, \mathrm{s}, \mathrm{CHO}) ; 10,04(1 \mathrm{H}, \mathrm{s}, \mathrm{CHO})$.

RMN ${ }^{13} \mathrm{C}: 15,0\left(\mathrm{CH}_{3}\right) ; 42,1\left(\mathrm{CH}_{2}\right) ; 110,8(\mathrm{CH}) ; 118,8(\mathrm{C}) ; 123,4(\mathrm{CH}) ; 125,0(\mathrm{C})$; 126,8 (CH); 131,7 (C); 139,7 (CH); 140,1 (C); 184,5 (CH); 192,1 (CH).

\section{Obtención del $N$-metil-1H-indol-5-carbaldehído(4).}<smiles>O=Cc1ccc2[nH]ccc2c1</smiles><smiles></smiles>

Siguiendo el método A, la adición sobre una disolución de 1,56 g (10,8 mmol) de $1 H$-indol-5-carbaldehído en $40 \mathrm{~mL}$ de $\mathrm{CH}_{2} \mathrm{Cl}_{2}$ seco, de $2 \mathrm{~mL}$ (32,3 mmol) de ioduro de metilo, 0,86 g (21,6 mmol) de $\mathrm{NaOH}$ y $20 \mathrm{mg}$ de $n-\mathrm{Bu}_{4} \mathrm{~N}^{+} \mathrm{HSO}_{4}{ }^{-}$, produce $1,60 \mathrm{~g}(93,0 \%)$ del compuesto 4 .

\section{N-metil-1H-indol-5-carbaldehído(4):}

P.f. $=85^{\circ} \mathrm{C}$ (metil tercbutil éter).

RMN ${ }^{1} \mathbf{H}: 3,76$ (3H, s, $\left.\mathrm{CH}_{3}\right) ; 6,55$ (1H, d; $\left.J=3,3, \mathrm{H}_{3}\right) ; 7,10\left(1 \mathrm{H}, \mathrm{d} ; J=3,3, \mathrm{H}_{2}\right) ; 7,41$ $\left(1 \mathrm{H}, \mathrm{d} ; J=8,8, \mathrm{H}_{7}\right) ; 7,80\left(1 \mathrm{H}, \mathrm{dd} ; J=8,8 ; 1,9, \mathrm{H}_{6}\right) ; 8,05$ (1H, d; $\left.J=1,9, \mathrm{H}_{4}\right) ; 9.92(1 \mathrm{H}$, $\mathrm{s}, \mathrm{CHO})$.

RMN ${ }^{13}$ C: $32.6\left(\mathrm{CH}_{3}\right) ; 103,1(\mathrm{CH}) ; 109,8(\mathrm{CH}) ; 121,4(\mathrm{CH}) ; 126,1(\mathrm{CH}) ; 128,2$ (C); 129,1 (C); 130,9 (CH); 139,8 (C); 192,3 (CH). 


\section{Obtención de $1 H$-benzimidazol-5-ilmetanol (5).}<smiles>O=C(O)c1ccc2[nH]c(CC(F)F)nc2c1</smiles>

A una suspensión de 2,00 g (12,35 mmol) de ácido $1 H$-benzimidazol-5-carboxílico en 50 mL de THF seco, en atmósfera de argón, se añaden 938 mg (24,7 mmol) de $\mathrm{LiAlH}_{4}$ y se calienta a $65^{\circ} \mathrm{C}$. Transcurridas 48 horas la mezcla de reacción se vierte sobre AcOEt, se añade $\mathrm{EtOH}$, se filtra para retirar las sales de litio generadas y se evapora, obteniéndose 1,4 g (75\%) de $1 H$-benzimidazol-5-ilmetanol que se utilizarán en la siguiente reacción sin más purificación.

\section{H-Benzimidazol-5-ilmetanol (5):}

RMN ${ }^{1} \mathbf{H}: 4,60$ (2H, s, CH 2$) ; 7,08$ (1H, dd; $\left.J=8,4 ; 1,6, \mathrm{H}_{6}\right) ; 7,45$ (1H, d; $\left.J=8,4, \mathrm{H}_{7}\right)$; 7,49 (1H, sa, $\left.\mathrm{H}_{4}\right) ; 7,94\left(1 \mathrm{H}, \mathrm{s}, \mathrm{H}_{2}\right)$.

$\mathbf{R M N}{ }^{13} \mathrm{C}:$ 65,9 ( $\left(\mathrm{CH}_{2}\right) ; 115,2(\mathrm{CH}) ; 116,3(\mathrm{CH}) ; 121,3(\mathrm{CH}) ; 136,1(\mathrm{C}) ; 140,6(\mathrm{C})$; $141,0(\mathrm{C}) ; 146,0(\mathrm{CH})$.

\section{Obtención de $1 H$-benzimidazol-5-carbaldehído (6).}<smiles>OCc1ccc2[nH]cnc2c1</smiles><smiles>COCCOC</smiles><smiles>O=Cc1ccc2[nH]cnc2c1</smiles>

4,94 g (56,75 mmol) de $\mathrm{MnO}_{2}$ se añaden sobre una disolución de 1,40 g (9,46 mmol) de 5 en $50 \mathrm{~mL}$ de $\mathrm{MeOH}$. Tras 48 horas en agitación y a temperatura ambiente, se filtra la mezcla de reacción, el filtrado se pasa a través de sílice y se evapora obteniendo 1,24 g (90\%) de 1H-benzimidazol-5-carbaldehído.

\section{H-Benzimidazol-5-carbaldehído (6):}

RMN ${ }^{1} \mathbf{H}: 7,55$ (1H, d; $\left.J=8,4, \mathrm{H}_{7}\right) ; 7,65$ (1H, dd; $\left.J=8,4 ; 1,4, \mathrm{H}_{6}\right) ; 8,01$ (1H, sa, $\left.\mathrm{H}_{4}\right)$; 8,24 (1H, s, $\left.\mathrm{H}_{2}\right)$; 9,85 (1H, s, CHO).

RMN ${ }^{13}$ C: 116,3 (CH); 120,5 (CH); 124,5 (CH); 133,1 (C); 139,7 (C); 142,8 (C); $145,9(\mathrm{CH}) ; 194,0(\mathrm{CH})$. 


\section{Obtención de 1-metil-1H-benzimidazol-5-carbaldehído (7) y de 1-metil-} $1 H$-benzimidazol-6-carbaldehído (8).<smiles>O=Cc1ccc2[nH]cnc2c1</smiles><smiles>CNc1cc(C=O)ccc1N(C)C(=O)Cn1cc2c(c[cH+]1)ncn2C</smiles>

A una disolución de 1,24 g (8,49 mmol) de 1H-benzimidazol-5-carbaldehído en 50 $\mathrm{mL}$ de una mezcla $\mathrm{CH}_{2} \mathrm{Cl}_{2}: \mathrm{H}_{2} \mathrm{O}$ (3:2), se añaden $700 \mathrm{mg}$ (17,5 mmol) de $\mathrm{NaOH}$ triturado y $40 \mathrm{mg}$ del catalizador $\mathrm{Bu}_{4} \mathrm{~N}^{+} \mathrm{HSO}_{4}{ }^{-}$. Después de 1 hora en agitación, se añaden 1,33 mL (21,2 mmol) de MeI. Transcurridas 24 horas, la mezcla de reacción se extrae con $\mathrm{CH}_{2} \mathrm{Cl}_{2}$, se lava con una solución acuosa saturada de $\mathrm{NaCl}$, se seca con $\mathrm{Na}_{2} \mathrm{SO}_{4}$ anhidro, se filtra y se evapora, obteniéndose $900 \mathrm{mg}$ de crudo de reacción. Mediante purificación por cromatografía en columna, usando como eluyente $\mathrm{CH}_{2} \mathrm{Cl}_{2} / \mathrm{AcOEt} 1 / 1$, se obtienen $70 \mathrm{mg}$ (4,3\%) del subproducto 9 y 600 mg (44\%) de una mezcla 1:1 de 7 y 8.

\section{N-metilbenzimidazol-5-carbaldehído (7) / N-metilbenzimidazol-6-carbaldehído}

(8):

RMN ${ }^{1} \mathbf{H}: 3,60$ (3H, s); 3,63 (3H, s); 7,17 (1H, d; $\left.J=8,4, \mathrm{H}_{7}\right) ; 7,56$ (1H, dd; $J=8,4$; $\left.J=1,6, \mathrm{H}_{6}\right) ; 7,56\left(1 \mathrm{H}, \mathrm{dd} ; J=8,4 ; 1,6, \mathrm{H}_{6}\right) ; 7,59\left(1 \mathrm{H}, \mathrm{d} ; J=8,4, \mathrm{H}_{7}\right) ; 7,61\left(1 \mathrm{H}, \mathrm{s}, \mathrm{H}_{2}\right)$; 7,77 (1H, s, $\left.\mathrm{H}_{2}\right) ; 7,82\left(1 \mathrm{H}, \mathrm{d} ; J=1,6, \mathrm{H}_{4}\right) ; 7,98\left(1 \mathrm{H}, \mathrm{d} ; J=1,6, \mathrm{H}_{4}\right) ; 9,78(1 \mathrm{H}, \mathrm{s}$, $\mathrm{CHO}) ; 9,79$ (1H, s, CHO).

RMN ${ }^{13} \mathbf{C}: 31,2(2)\left(\mathrm{CH}_{3}\right) ; 110,1(\mathrm{CH}) ; 111,8(\mathrm{CH}) ; 120,2(\mathrm{CH}) ; 123,2(\mathrm{CH}) ; 123,5$ (CH); 123,8 (CH); 131,3 (C); 131,5 (C); 134,5 (C); 138,7 (C); 143,4 (C); 145,9 (CH); 147,0 (CH); 148,1 (C); 191,7 (CH); 191,9 (CH).

\section{$\mathrm{N}$-(4/5-formil-2-metilamino)fenil)- $\mathrm{N}$-metilformamida (9):}

RMN ${ }^{1} \mathbf{H}: 2,89$ (3H, d; $\left.J=5, \mathrm{CH}_{3}\right)$; 3,07 (3H, s, CH $)$; 6,66 (1H, d; $\left.J=8,4\right) ; 7,47$ (1H, d; $J=1,4) ; 7,70$ (1H, dd; $J=8,4 ; 1,6) ; 8,00$ (1H, s); 9,64 (1H, s, CHO).

RMN ${ }^{13} \mathrm{C}: 29,8\left(\mathrm{CH}_{3}\right)$; 32,2 $\left(\mathrm{CH}_{3}\right) ; 109,9(\mathrm{CH}) ; 125,3(\mathrm{C}) ; 126,6(\mathrm{C}) ; 129,9(\mathrm{CH})$; 133,4 (CH); 151,2 (C); 163,7 (CH); 189,7 (CH). 


\section{Obtención de ioduro de metiltrifenilfosfonio.}

$$
\mathrm{H}_{3} \mathrm{C}-\mathrm{I} \underset{\text { tolueno }}{\stackrel{\mathrm{PPh}_{3}}{\longrightarrow}} \mathrm{H}_{3} \mathrm{C}-\mathrm{PPh}_{3}{ }^{+} \mathrm{I}^{-}
$$

Sobre una disolución de $5 \mathrm{~g}$ de ioduro de metilo en tolueno seco (20 mL) y en agitación, se añaden 5 g de trifenilfosfina. La reacción se deja en agitación y atmósfera de argón durante 24 horas, observándose la aparición de un sólido blanco. Se filtra, se seca, y se obtiene el ioduro de metiltrifenilfosfonio de forma cuantitativa.

\section{Obtención de 1-metil-5-bromo-1H-indol (10).}

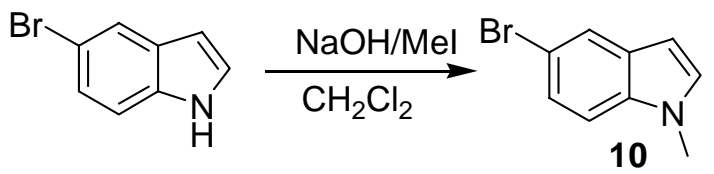

Según el método A, 2,5 g (12,7 mmol) de 5-bromo- $1 H$-indol, 1,12 g (28,1 mmol) de $\mathrm{NaOH}, 25 \mathrm{mg}$ de hidrogenosulfato de tetrabutilamonio y 2,3 $\mathrm{mL}$ (37 mmol) de yoduro de metilo, reaccionan para dar 2,3 g del compuesto metilado 10 (86\%).

\section{1-metil-5-bromo-1H-indol (10):}

IR (película): 1051, 793, $775 \mathrm{~cm}^{-1}$.

RMN ${ }^{1} \mathbf{H}: 3,77$ (3H, s, $\left.\mathrm{CH}_{3}\right)$; 6,42 (1H, d; $\left.J=3,1, \mathrm{H}_{3}\right) ; 7,05$ (1H, d; $\left.J=3,1, \mathrm{H}_{2}\right) ; 7,19$ (1H, d; $\left.J=8,5, \mathrm{H}_{7}\right) ; 7,29$ (1H, dd; $\left.J=8,5 ; 1,9, \mathrm{H}_{6}\right) ; 7,75$ (1H, d; J=1,9, $\mathrm{H}_{4}$ ).

RMN ${ }^{13} \mathbf{C}: 32,8\left(\mathrm{CH}_{3}\right) ; 100,8(\mathrm{CH}) ; 111,2(\mathrm{CH}) ; 112,9(\mathrm{C}) ; 123,4(\mathrm{CH}) ; 124,3$ (CH); 130,5 (CH); 130,5 (C); 135,6 (C). 


\section{Obtención de 4-metoxi-3-tercbutildifenilsiloxibenzaldehído (11).}

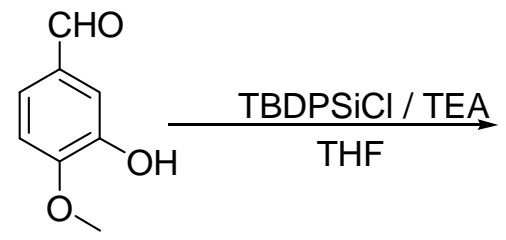<smiles>COc1ccc(C=O)cc1OCCS</smiles>

11

A una disolución de 2,00 g (13,16 mmol) de 3-hidroxi-4-metoxibenzaldehído en 75 mL de THF seco, se añaden 4,52 g (16,45 mmol) de TBDPSiCl. Se enfría a $0{ }^{\circ} \mathrm{C}$ y se añaden lentamente 2,29 mL (16,45 mmol) de trietilamina. Después de 24 horas, se filtra, se evapora, se redisuelve en éter, se filtra a través de una capa de alúmina neutra y una capa de carbón activo y se evapora a vacío, obteniéndose 5,54 g de bruto de reacción, que se purifican mediante cromatografía de columna sobre gel de sílice para obtener 2,05 g (5,25 mmol 40\%) del producto 11.

\section{4-Metoxi-3-tercbutildifenilsiloxibenzaldehído (11):}

RMN ${ }^{1} \mathbf{H}: 1,12$ (9H, s, tBu); 3,56 (3H, s, $\left.\mathrm{OCH}_{3}\right) ; 6,80\left(1 \mathrm{H}, \mathrm{d} ; J=8,6, \mathrm{H}_{5}\right) ; 7,29-7,43$ (8H, m); 7,66-7,70 (4H, m); 9,66 (1H, s, CHO).

RMN ${ }^{13} \mathrm{C}: 20,0(\mathrm{C}) ; 26,9(3)\left(\mathrm{CH}_{3}\right) ; 55,3\left(\mathrm{CH}_{3}\right) ; 111,5(\mathrm{CH}) ; 120,0(\mathrm{CH}) ; 126,2$ $(\mathrm{CH}) ; 127,8$ (4) (CH); 130,0 (2) (CH); 133,2 (2) (C); 135,4 (4) (CH); 135,9 (C); 145,6 (C); 156,3 (C); 191,0 (CH).

\section{Obtención de 4-metoxi-3-tercbutildimetilsiloxibenzaldehído (12).}<smiles>COc1ccc(C=O)cc1O</smiles><smiles>CCOc1cc(C=O)ccc1OC</smiles>

12

A una disolución de 2,05 g (13,48 mmol) de 3-hidroxi-4-metoxibenzaldehído en 75 mL de THF seco, se añaden 2,50 g (16,67 mmol) de TBDMSiCl. Se enfría a $0{ }^{\circ} \mathrm{C}$ y se añaden lentamente 2,32 mL (16,67 mmol) de trietilamina. Después de 24 horas, se filtra, se evapora, se redisuelve en éter, se filtra a través de una capa de alúmina neutra y una capa de carbón activo y se evapora a vacío, obteniéndose 2,88 g (10,82 mmol, $80 \%)$ de bruto de reacción, que se utilizan sin purificar en el siguiente paso. 


\section{4-Metoxi-3-tercbutildimetilsiloxibenzaldehído (12):}

RMN ${ }^{1} \mathbf{H}: 0,17$ (6H, s, $\left.\mathrm{SiCH}_{3}\right) ; 1,00(9 \mathrm{H}, \mathrm{s}, \mathrm{tBu}) ; 3,90\left(3 \mathrm{H}, \mathrm{s}, \mathrm{OCH}_{3}\right) ; 6,96(1 \mathrm{H}, \mathrm{d}$; $\left.J=8,2, \mathrm{H}_{5}\right) ; 7,37\left(1 \mathrm{H}, \mathrm{d} ; J=2,2, \mathrm{H}_{2}\right) ; 7,48\left(1 \mathrm{H}, \mathrm{dd} ; J=8,2,2,2, \mathrm{H}_{6}\right) ; 9,82(1 \mathrm{H}, \mathrm{s}$, $\mathrm{CHO})$.

RMN ${ }^{13} \mathrm{C}:-4,6(2)\left(\mathrm{CH}_{3}\right) ; 18,4(\mathrm{C}) ; 25,6(3)\left(\mathrm{CH}_{3}\right) ; 55,6\left(\mathrm{CH}_{3}\right) ; 111,2(\mathrm{CH}) ; 119,9$ (CH); 126,4 (CH); 130,2 (C); 145,6 (C); 156,6 (C); 190,9 (CH).

\section{Obtención de 5-bromo-1H-benzimidazol (13).}

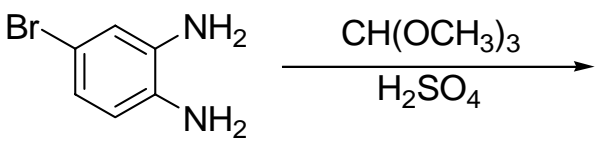<smiles>Brc1ccc2[nH]cnc2c1</smiles>

A una disolución de 2,00 g (10,7 mmol) de 4-bromo-1,2-diaminobenceno en $30 \mathrm{~mL}$ de tolueno, se añaden 1,17 mL (10,7 mmol) de ortoformiato de trimetilo. A continuación se dejan caer, gota a gota, desde un embudo de adición compensada, 0,3 $\mathrm{mL}$ de $\mathrm{H}_{2} \mathrm{SO}_{4}$ disueltos en $5 \mathrm{~mL}$ de tolueno y se calienta a $120{ }^{\circ} \mathrm{C}$. Transcurridos 4 días, la mezcla de reacción se vierte sobre $\mathrm{Na}_{2} \mathrm{CO}_{3}$ anhidro, se añade AcOEt, se filtra, lavando el precipitado con $\mathrm{MeOH}$ y se evapora para obtener de forma cuantitativa el 5-bromobenzimidazol.

\section{5-bromo-1H-benzimidazol (13):}

RMN ${ }^{1} \mathbf{H}: 7,12\left(1 \mathrm{H}, \mathrm{dd} ; J=8,8 ; 1,8, \mathrm{H}_{6}\right) ; 7,28\left(1 \mathrm{H}, \mathrm{d} ; J=8,8, \mathrm{H}_{7}\right) ; 7,58(1 \mathrm{H}, \mathrm{d} ; J=1,8$, $\left.\mathrm{H}_{4}\right) ; 7,99\left(1 \mathrm{H}, \mathrm{s}, \mathrm{H}_{2}\right)$.

RMN ${ }^{13}$ C: 117,1 (CH); 118,4 (CH); 120,5 (C); 130,8 (CH); 131,0 (C); 132,9 (C); $142,2(\mathrm{CH})$. 


\section{Obtención de 1-metil-5-bromo-1H-benzimidazol (14) y 1-metil-6-bromo- 1H-benzimidazol (15).}
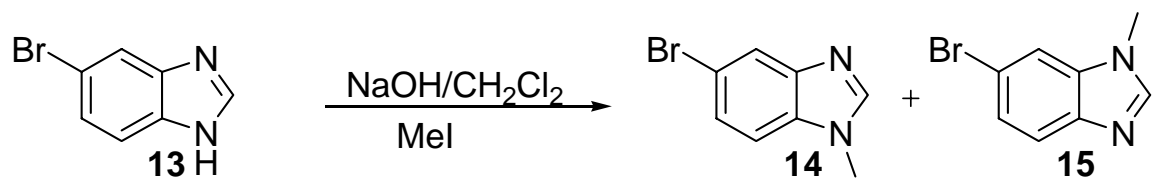

Siguiendo el método A, la adición de 1,44 mL (23 mmol) de MeI a una disolución de 2,00 g (10,2 mmol) de 5-bromobenzimidazol, $850 \mathrm{mg}$ (21,2 mmol) de $\mathrm{NaOH}$ y $30 \mathrm{mg}$ de $\mathrm{Bu}_{4} \mathrm{~N}^{+} \mathrm{HSO}_{4}{ }^{-}$en $50 \mathrm{~mL}$ de una mezcla $\mathrm{CH}_{2} \mathrm{Cl}_{2} / \mathrm{H}_{2} \mathrm{O}$ (4/1), producen 1,65 g de producto bruto. Después de cromatografiar en columna de gel de sílice, usando como eluyente $\mathrm{CH}_{2} \mathrm{Cl}_{2} / \mathrm{AcOEt}$ 1/1, se obtienen 1,13 g (53\%) de una mezcla de 14 y 15.

\section{1-metil-5-bromo-1H-benzimidazol (14) y 1-metil-6-bromo-1H-benzimidazol} (15):

RMN ${ }^{1} \mathbf{H}: 3,60$ (6H, s, $\left.\mathrm{NCH}_{3}\right) ; 7,04$ (1H, d; $\left.J=8,4, \mathrm{H}_{7}\right) ; 7,23$ (2H, dd; $\left.J=8,8 ; 1,8\right)$; 7,34 (1H, d; $J=1,8) ; 7,52$ (1H, d; $J=8,4) ; 7,68$ (2H, s, $\left.\mathrm{H}_{2}\right) ; 7,81$ (1H, d; $J=1,8$ ).

RMN ${ }^{13} \mathrm{C}: 31,1$ (2) $\left(\mathrm{CH}_{3}\right) ; 110,7(\mathrm{CH}) ; 112,5(\mathrm{CH}) ; 115,1(\mathrm{C}) ; 116,1(\mathrm{C}) ; 121,4$ (CH); 122,8 (CH); 125,3 (CH); 125,8 (CH); 133,4 (C); 135,5 (C); 142,5 (C); 144,2 (CH); 144,5 (CH); 144,8 (C).

\section{Obtención de 2-amino-4-bromofenol (16).}<smiles>Nc1cc(Br)ccc1OCc1ccc(Br)cc1</smiles>

Una disolución de 1,50 g (6,9 mmol) de 4-bromo-2-nitrofenol y 6,3 g (34,5 mmol) de $\mathrm{SnCl}_{2}$ en $10 \mathrm{ml}$ de etanol absoluto se calienta a $70^{\circ} \mathrm{C}$ bajo atmósfera de nitrógeno. Después de 30 minutos, la solución se deja enfriar y se vierte sobre hielo. A continuación, se adiciona, lentamente, solución acuosa de bicarbonato sódico al 5\% hasta conseguir un pH ligeramente básico. La solución obtenida se extrae con AcOEt, el conjunto de las fases orgánicas se lava con una solución acuosa saturada de $\mathrm{NaCl}$, se seca con $\mathrm{MgSO}_{4}$ anhidro, se filtra y se evapora para obtener 0,95 g (5,1 mmol, 73\%) de 16. 


\section{Obtención de 5-bromo-1,3-benzoxazol (17).}

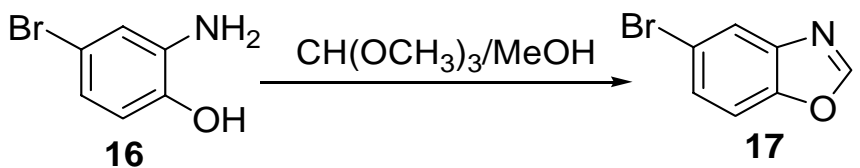

A una disolución de $850 \mathrm{mg}$ (4,5 mmol) de 4-bromo-2-aminofenol y 0,75 mL (6,9 mmol) de ortoformiato de trimetilo en $1,5 \mathrm{~mL}$ de metanol, a temperatura ambiente, se añaden $20 \mu \mathrm{L}$ de $\mathrm{HCl}$ concentrado. La mezcla se calienta lentamente en un aparato de destilación simple hasta alcanzar $90-95{ }^{\circ} \mathrm{C}$, temperatura que se mantiene hasta la destilación completa del metanol. A continuación, se extrae el residuo con éter y el conjunto de las fases orgánicas se lava con $\mathrm{NaOH}$ al 5\% y agua, se seca con $\mathrm{MgSO}_{4}$ anhidro, se filtra y se evapora para obtener 512 mg de crudo de reacción, que se cromatografían en columna de sílice usando como eluyente éter de petroleo y AcOEt en una proporción 9/1. Finalmente se obtienen 384 mg (1,94 mmol, 43\%) de 5-bromo-1,3benzoxazol.

\section{5-bromo-1,3-benzoxazol (17):}

$\mathbf{R M N}{ }^{1} \mathbf{H}\left(500 \mathrm{MHz} ; \mathrm{CDCl}_{3}\right): 7,33\left(1 \mathrm{H}, \mathrm{d} ; J=8,5, \mathrm{H}_{6}\right), 7.37(1 \mathrm{H}, \mathrm{dd} ; J=8,5 ; 2,0$; $\left.\mathrm{H}_{6}\right), 7,83\left(1 \mathrm{H}, \mathrm{d} ; J=2,0 ; \mathrm{H}_{4}\right), 8,05\left(1 \mathrm{H}, \mathrm{s}, \mathrm{H}_{2}\right)$.

RMN ${ }^{13}$ C (125 MHz; $\left.\mathrm{CDCl}_{3}\right): 112,1(\mathrm{CH}) ; 117,3(\mathrm{C}) ; 123,5(\mathrm{CH}) ; 128,6(\mathrm{CH})$; 141,6 (C); 148,8 (C); 153,5 (CH). 


\section{IV.3.B. Sintesis de fenstatinas $e$ isocombretastatinas difenílicas.}

\section{Obtención de (4-metoxifenil)(3,4,5-trimetoxifenil)metanol (18).}

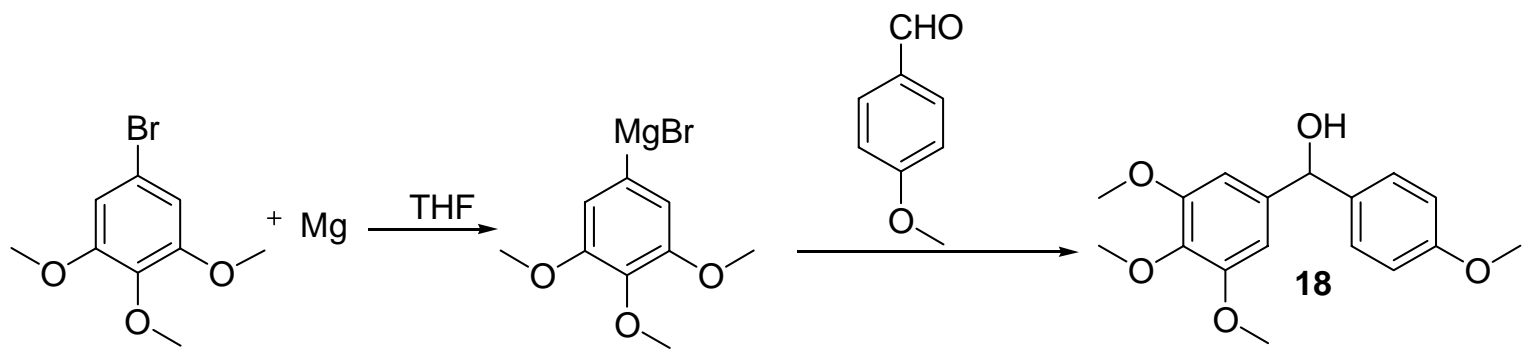

Siguiendo el método C2, a una suspensión de 304 mg (12,15 mmol) de magnesio en 2,5 mL de THF seco se añaden 2,00 g (8,1 mmol) de 5-bromo-1,2,3-trimetoxibenceno y $5 \mathrm{mg}$ de yodo. A continuación, la suspensión blanquecina se añade sobre $1,10 \mathrm{~g}$ (8,1 mmol) de $p$-anisaldehído disueltos en $3 \mathrm{~mL}$ de THF a $0{ }^{\circ} \mathrm{C}$. Después de 1 hora, se obtienen 3,04 g de bruto de reacción, que se purifican por cristalización en $\mathrm{CH}_{2} \mathrm{Cl}_{2}$ / Hex.

\section{(4-metoxifenil)(3,4,5-trimetoxifenil)metanol (18):}

RMN ${ }^{1} \mathbf{H}$ : (Fig. Ia) 3,80 (3H, s, $\left.\mathrm{OCH}_{3}\right)$; 3,83 (9H, s, $\left.\mathrm{OCH}_{3}\right)$; 5,74 (1H, sa, $\left.\mathrm{CHOH}\right)$;

6,60 (2H, s, $\mathrm{H}_{2}$, $\mathrm{H}_{6}$ ); 6,87 (2H, d; $J=8,6, \mathrm{H}_{3}, \mathrm{H}_{5}$ ); 7,29 (2H, d; $J=8,6 ; \mathrm{H}_{2}, \mathrm{H}_{6}$ ).

RMN ${ }^{13}$ C: (Fig. Ib) 55,3 (CH $)$; 56,1 (2) $\left(\mathrm{CH}_{3}\right) ; 60,9\left(\mathrm{CH}_{3}\right) ; 75,9(\mathrm{CH}) ; 103,4$ (2)

$(\mathrm{CH}) ; 114,0$ (2) (CH); 128,0 (2) (CH); 131,4 (C); 136,4 (C); 139,7 (C); 153,3 (2)

(C); 159,2 (C). 


\section{Obtención de (4-metoxifenil)(3,4,5-trimetoxifenil)metanona (19).}<smiles>COc1ccc(C(=O)c2cc(OC)c(OCC(=O)OCC(C)(C)C)c(OC)c2)cc1</smiles>

Siguiendo el método D1, a una solución de 668 mg (2,2 mmol) de 18 en 25 mL de $\mathrm{CH}_{2} \mathrm{Cl}_{2}$ seco a $0{ }^{\circ} \mathrm{C}$ se añaden $1,24 \mathrm{~g}$ (3,30 mmol) de PDC. Después de 24 horas, se obtienen 646 mg (97\%) del producto de oxidación 19.

\section{(4-metoxifenil)(3,4,5-trimetoxifenil)metanona (19):}

RMN ${ }^{1} \mathbf{H}$ : (Fig. IIa) 3,88 (6H, s, $\left.\mathrm{OCH}_{3}\right) ; 3,90\left(3 \mathrm{H}, \mathrm{s}, \mathrm{OCH}_{3}\right) ; 3,93\left(3 \mathrm{H}, \mathrm{s}, \mathrm{OCH}_{3}\right)$; 6,97 (2H, d; J=9, $\mathrm{H}_{3}, \mathrm{H}_{5}$ ); 7,02 (2H, s, $\mathrm{H}_{2}$, $\mathrm{H}_{6}$ ); 7,83 (2H, d; $J=9, \mathrm{H}_{2}, \mathrm{H}_{6}$ ).

RMN ${ }^{13}$ C: (Fig. IIb) 55,6 ( $\left(\mathrm{CH}_{3}\right) ; 56,3$ (2) $\left(\mathrm{CH}_{3}\right) ; 61,0\left(\mathrm{CH}_{3}\right) ; 107,4$ (2) (CH); 113,6 (2) (CH); 130,3 (C); 132,4 (2) (CH); 133,4 (C); 141,6 (C); 152,8 (2) (C); 163,2 (C); 194,7 (C).

EM: $302\left(\mathbf{M}^{+}\right)$.

\begin{tabular}{|c|c|}
\hline HPLC: Columna $\mathrm{C}_{18}$ & $\mathrm{t}_{\mathrm{R}}: 13,93 \mathrm{~min}$. \\
\hline Columna $\mathrm{C}_{8}$ & $\mathrm{t}_{\mathrm{R}}: 13,06 \mathrm{~min}$. \\
\hline Columna fenílica & $t_{R}: 13,00$ \\
\hline
\end{tabular}

\section{Obtención de 5-[1-(4-metoxifenil)vinil]-1,2,3-trimetoxibenceno (20).}<smiles>C=C(c1ccc(OC)cc1)c1cc(OC)c(OC)c(OC)c1</smiles>

Siguiendo el método B, a una suspensión de $250 \mathrm{mg}(0,62 \mathrm{mmol})$ de ioduro de metiltrifenilfosfonio en $5 \mathrm{~mL}$ de THF seco, se añaden $0,32 \mathrm{~mL}(0,51 \mathrm{mmol})$ de $n$-Buli $(1,6$ M en hexano) y $102 \mathrm{mg}$ (0,34 mmol) de (4-metoxifenil)(3,4,5-trimetoxifenil)metanona. Después de 20 horas, el crudo de reacción, 299 mg, se purifica por cromatografía de columna en gel de silice (Hex/AcOEt 4/1) y se obtienen $25 \mathrm{mg}$ (25\%) del producto metilénico (20). 


\section{5-[1-(4-metoxifenil)vinil]-1,2,3-trimetoxibenceno (20):}

IR (película): 1580, 1507, 1242, 1126, 1031, 895, $839 \mathrm{~cm}^{-1}$.

RMN ${ }^{1} \mathbf{H}$ : (Fig. IIIa) 3,81 (6H, s, $\left.\mathrm{OCH}_{3}\right) ; 3,83$ (3H, s, $\left.\mathrm{OCH}_{3}\right) ; 3,88\left(3 \mathrm{H}, \mathrm{s}, \mathrm{OCH}_{3}\right)$; 5,32 $\left(1 \mathrm{H}\right.$, sa, $\left.\mathrm{C}=\mathrm{CH}_{2}\right) ; 5,37\left(1 \mathrm{H}\right.$, sa, $\left.\mathrm{C}=\mathrm{CH}_{2}\right) ; 6,56\left(2 \mathrm{H}, \mathrm{s}, \mathrm{H}_{2}, \mathrm{H}_{6}\right)$; 6,87 (2H, d; $\left.J=8,2, \mathrm{H}_{2}, \mathrm{H}_{6}\right) ; 7,30$ (2H, d; $\left.J=8,2, \mathrm{H}_{3}, \mathrm{H}_{5}\right)$.

RMN ${ }^{13} \mathrm{C}$ : (Fig. IIIb) 55,3 $\left(\mathrm{CH}_{3}\right) ; 56,1$ (2) $\left(\mathrm{CH}_{3}\right) ; 61,0\left(\mathrm{CH}_{3}\right) ; 105,6$ (2) (CH); 112,6 ( $\left.\mathrm{CH}_{2}\right) ; 113,5$ (2) (CH); 129,5 (2) (CH); 133,7 (2) (C); 137,6 (C); 149,6 (C); 152,9 (2) (C); 159,4 (C).

EM: $300\left(\mathrm{M}^{+}\right)$.

$\begin{array}{cc}\text { HPLC: Columna } \mathrm{C}_{18} & \mathrm{t}_{\mathrm{R}}: 14,18 \mathrm{~min} . \\ \text { Columna } \mathrm{C}_{8} & \mathrm{t}_{\mathrm{R}}: 12,89 \mathrm{~min} . \\ \text { Columna fenílica } & \mathrm{t}_{\mathrm{R}}: 13,73 \mathrm{~min} .\end{array}$

\section{Obtención de (4-metoxi-3-nitrofenil)(3,4,5-trimetoxifenil)metanol (21).}

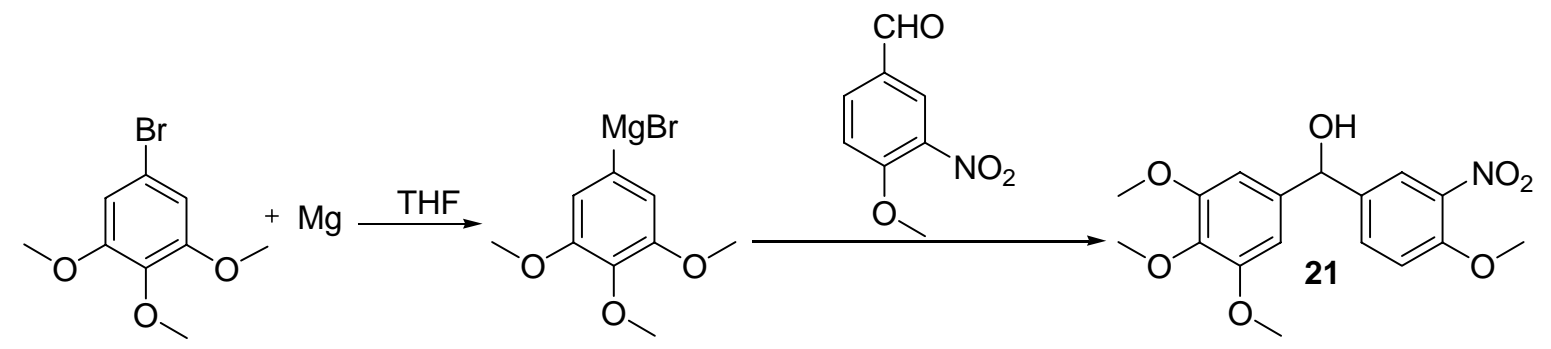

Siguiendo el método C2, a una suspensión de $304 \mathrm{mg}$ (12,15 mmol) de magnesio en 2,5 mL de THF seco, se añaden 2,00 g (8,1 mmol) de 5-bromo-1,2,3-trimetoxibenceno y $5 \mathrm{mg}$ de yodo. A continuación, la suspensión blanquecina se añade sobre 1,46 g (8,1 mmol) de 4-metoxi-3-nitrobenzaldehído disueltos en $3 \mathrm{~mL}$ de THF a $0{ }^{\circ} \mathrm{C}$. Después de 1 hora, se obtienen 3,90 g de bruto de reacción que se utilizan en el siguiente paso sin purificar.

\section{(4-metoxi-3-nitrofenil)(3,4,5-trimetoxifenil)metanol (21):}

RMN ${ }^{1} \mathbf{H}$ crudo de reacción: (Fig. IV, señales asignadas a 21) 3,83 (6H, s, $\left.\mathrm{OCH}_{3}\right)$; 3,85 (3H, s, $\left.\mathrm{OCH}_{3}\right) ; 3,94\left(3 \mathrm{H}, \mathrm{s}, \mathrm{OCH}_{3}\right) ; 5,74(1 \mathrm{H}, \mathrm{s}, \mathrm{CHOH}) ; 6,55\left(2 \mathrm{H}, \mathrm{s}, \mathrm{H}_{2}\right.$, $\mathrm{H}_{6}$ ); 7,04 (1H, d; $\left.J=8,6, \mathrm{H}_{5}\right) ; 7,55$ (1H, dd; $\left.J=8,6 ; 2,3, \mathrm{H}_{6}\right) ; 7,90\left(1 \mathrm{H}, \mathrm{d} ; J=2,3, \mathrm{H}_{2}\right)$. 


\section{Obtención de (4-metoxi-3-nitrofenil)(3,4,5-trimetoxifenil)metanona (22).}<smiles>[Z20]c1ccc(OCC(=O)c2ccc(OC)c([N+](=O)[O-])c2)c([N+](=O)[O-])c1</smiles>

Siguiendo el método D1, a una solución de 3,90 g (11,19 mmol) de (4-metoxi-3nitrofenil)(3,4,5-trimetoxifenil)metanol en $125 \mathrm{~mL}$ de $\mathrm{CH}_{2} \mathrm{Cl}_{2}$ seco a $0{ }^{\circ} \mathrm{C}$, se añaden 6,31 g (16,78 mmol) de PDC. Después de 24 horas, se obtienen 4,01 g de bruto de reacción que se purifican por cristalización en $\mathrm{CH}_{2} \mathrm{Cl}_{2} / \mathrm{Hex}$, obteniéndose 1,01 g (26\%) del producto de oxidación 22.

\section{(4-metoxi-3-nitrofenil)(3,4,5-trimetoxifenil)metanona (22):}

RMN ${ }^{1} \mathbf{H}$ : (Fig. Va) 3,89 (6H, s, $\left.\mathrm{OCH}_{3}\right) ; 3,95\left(3 \mathrm{H}, \mathrm{s}, \mathrm{OCH}_{3}\right) ; 4,07$ (3H, s, $\left.\mathrm{OCH}_{3}\right)$; 7,01 (2H, s, $\left.\mathrm{H}_{2}, \mathrm{H}_{6}{ }^{\prime}\right) ; 7,21\left(1 \mathrm{H}, \mathrm{d} ; J=8,8, \mathrm{H}_{5}\right) ; 8,08$ (1H, dd; $\left.J=8,8 ; 2,4, \mathrm{H}_{6}\right) ; 8,34$ $\left(1 \mathrm{H}, \mathrm{d} ; J=2,4, \mathrm{H}_{2}\right)$.

RMN ${ }^{13}$ C: (Fig. Vb) 56,4 (2) $\left(\mathrm{CH}_{3}\right) ; 57,0\left(\mathrm{CH}_{3}\right) ; 61,1\left(\mathrm{CH}_{3}\right) ; 107,5$ (2) (CH); 113,3 (CH); 127,9 (CH); 129,9 (C); 131,8 (C); 135,8 (CH); 139,1 (C); 153,1 (2) (C);153,4 (C); 155,8 (C); 192,5 (C).
HPLC: Columna $\mathrm{C}_{18}$ $t_{\mathrm{R}}: 14,19 \mathrm{~min}$.
Columna $\mathrm{C}_{8}$ $\mathrm{t}_{\mathrm{R}}: 13,07 \mathrm{~min}$.
Columna fenílica $\mathrm{t}_{\mathrm{R}}: 13,73 \mathrm{~min}$.

\section{Obtención de (3-amino-4-metoxifenil)(3,4,5-trimetoxifenil)metanona (23).}<smiles>COc1ccc(C(=O)c2cc(OC)c(OC)c(OC)c2)cc1OCC(=O)Oc1ccc(C(=O)c2cc(OC)c(OC)c(OC)c2)cc1[N+](=O)[O-]</smiles>

Sobre una mezcla de etanol, ácido acético y agua (2:2:1) se añade una gota de $\mathrm{HCl}$ concentrado, $347 \mathrm{mg}$ (1,00 mmol) de 22 y $431 \mathrm{mg}(7,72 \mathrm{mmol})$ de Fe y se calienta a 100 ${ }^{\circ} \mathrm{C}$. Transcurrida media hora, se deja enfriar la mezcla y se pasa a través de celita. A continuación, se lava con agua, se extrae con $\mathrm{CHCl}_{3}$, se lava con una solución acuosa de $\mathrm{NaHCO}_{3}$ al $5 \%$ y con agua saturada de $\mathrm{NaCl}$, se seca con $\mathrm{Na}_{2} \mathrm{SO}_{4}$ anhdro, se filtra y se evapora. El crudo de reacción se purifica mediante cromatografía en columna de gel de sílice (eluyente Hex/AcOEt 1/1) y se obtienen 95 mg (30\%) de la aminofenstatina 23. 


\section{(3-amino-4-metoxifenil)(3,4,5-trimetoxifenil)metanona (23):}

RMN ${ }^{1} \mathbf{H}$ : (Fig. VIa) 3,88 (6H, s, $\mathrm{OCH}_{3}$ ); 3,92 (3H, s, $\left.\mathrm{OCH}_{3}\right)$; 3,95 (3H, s, $\mathrm{OCH}_{3}$ ); $6,87\left(1 \mathrm{H}, \mathrm{d} ; J=8,6, \mathrm{H}_{3}\right) ; 7,03\left(2 \mathrm{H}, \mathrm{s}, \mathrm{H}_{2}, \mathrm{H}_{6}\right)$ ); 7,33 (1H, da; $\left.J=8,6, \mathrm{H}_{4}\right) ; 7,42(1 \mathrm{H}$, sa, $\left.\mathrm{H}_{6}\right)$.

RMN ${ }^{13}$ C: (Fig. VIb) 55,7 ( $\left.\mathrm{CH}_{3}\right)$; 56,3 (2) $\left(\mathrm{CH}_{3}\right) ; 61,0\left(\mathrm{CH}_{3}\right) ; 107,5$ (2) (CH); 109,0 (CH); 115,9 (CH); 122,4 (CH); 130,6 (C); 133,7 (C); 136,3 (C); 141,4 (C); 150,9 (C); 152,8 (2) (C); 195,3 (C).

HPLC: Columna $\mathrm{C}_{18} \quad \mathrm{t}_{\mathrm{R}}: 11,64 \mathrm{~min}$.

Columna $\mathrm{C}_{8} \quad \mathrm{t}_{\mathrm{R}}: 10,18 \mathrm{~min}$.

Columna fenílica $\quad t_{\mathrm{R}}: 11,30 \mathrm{~min}$.

\section{Obtención de 1-metoxi-2-nitro-4-[1-(3,4,5-trimetoxifenil)vinil]benceno} (24).

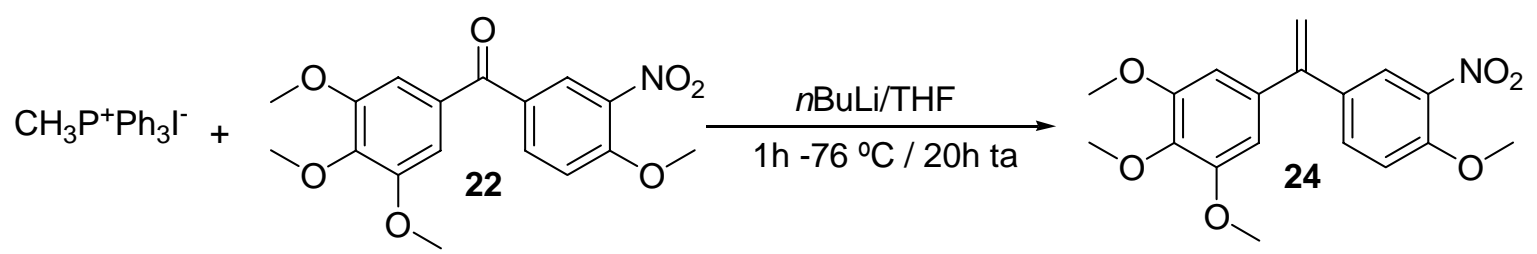

Siguiendo el método B, a una suspensión de $465 \mathrm{mg}$ (1,15 mmol) de ioduro de metiltrifenilfosfonio en $7 \mathrm{~mL}$ de THF seco, se añaden $0,58 \mathrm{~mL}(0,92 \mathrm{mmol})$ de $n$ Buli $(1,6$ M en hexano) y $200 \mathrm{mg}$ (0,58 mmol) de 22. Después de 6 horas, el crudo de reacción, 599 mg, se purifican por cromatografía de columna en gel de sílice (Hex/AcOEt 75/25) y se obtienen 116 mg (58\%) del producto 24. 


\section{1-metoxi-2-nitro-4-[1-(3,4,5-trimetoxifenil)vinil]benceno (24):}

IR (película): 1531, 1277, 1127, 1012, 903, $838 \mathrm{~cm}^{-1}$.

RMN ${ }^{1} \mathbf{H}$ : (Fig. VIIa) 3,79 (6H, s, $\left.\mathrm{OCH}_{3}\right)$; 3,85 (3H, s, $\left.\mathrm{OCH}_{3}\right)$; 3,95 (3H, s, $\mathrm{OCH}_{3}$ ); 5,41 (2H, s, C=CH $)$; 6,48 (2H, s, $\mathrm{H}_{2}, \mathrm{H}_{6}$ ); 7,04 (1H, d; J=8,6, $\left.\mathrm{H}_{5}\right) ; 7,50$ (1H, dd; $\left.J=8,6 ; 2,4, \mathrm{H}_{6}\right) ; 7,83\left(1 \mathrm{H} \mathrm{d} ; J=2,4, \mathrm{H}_{2}\right)$.

RMN ${ }^{13}$ C: (Fig. VIIb) 56,2 (2) $\left(\mathrm{CH}_{3}\right) ; 56,6\left(\mathrm{CH}_{3}\right) ; 60,9\left(\mathrm{CH}_{3}\right) ; 105,5$ (2) (CH); 113,3 (CH); 114,7 ( $\left.\mathrm{CH}_{2}\right) ; 125,1(\mathrm{CH}) ; 133,8(\mathrm{CH}) ; 133,8$ (C); 136,2 (C); 139,3 (C); 147,1 (C); 147,6 (C); 152,5 (C); 153,1 (2) (C).

EM: $345\left(\mathrm{M}^{+}\right)$.

$\begin{array}{cc}\text { HPLC: Columna } \mathrm{C}_{18} & \mathrm{t}_{\mathrm{R}}: 15,67 \mathrm{~min} . \\ \text { Columna } \mathrm{C}_{8} & \mathrm{t}_{\mathrm{R}}: 14,38 \mathrm{~min} . \\ \text { Columna fenílica } & \mathrm{t}_{\mathrm{R}}: 15,11 \mathrm{~min} .\end{array}$

\section{Obtención de 2-metoxi-5-[1-(3,4,5-trimetoxifenil)vinil]anilina (25).}<smiles>[Z4]Oc1ccc(C(=C)c2cc(OC)c(OC)c(OC)c2)cc1[N+](=O)[O-]</smiles><smiles>C=C(c1ccc(OC)c(N)c1)c1cc(OC)c(OC)c(OC)c1</smiles>

A una disolución de $85 \mathrm{mg}(0,25 \mathrm{mmol})$ de 24 en $2 \mathrm{~mL}$ de $\mathrm{CH}_{2} \mathrm{Cl}_{2}$, bajo atmósfera de argón, se añaden 10 mL de ácido acético glacial y 129 mg (1,97 mmol) de Zn. Después de 14 horas, se filtra a través de celita, se evapora el disolvente y se obtienen 76 mg (96\%) del producto reducido 25.

\section{2-metoxi-5-[1-(3,4,5-trimetoxifenil)vinil]anilina (25):}

IR (película): 3370, 1581, 1232, 1125, 1023, $846 \mathrm{~cm}^{-1}$.

RMN ${ }^{1} \mathbf{H}$ : (Fig. VIIIa) 3,82 (6H, s, $\left.\mathrm{OCH}_{3}\right) ; 3,87$ (6H, s, OCH $)$; 5,27 (1H, d; $J=1,2$, $\left.\mathrm{C}=\mathrm{CH}_{2}\right) ; 5,34\left(1 \mathrm{H}, \mathrm{d} ; J=1,2, \mathrm{C}=\mathrm{CH}_{2}\right) ; 6,56\left(2 \mathrm{H}, \mathrm{s}, \mathrm{H}_{2}, \mathrm{H}_{6}{ }^{\prime}\right) ; 6,74\left(3 \mathrm{H}, \mathrm{s}, \mathrm{H}_{2}, \mathrm{H}_{5}\right.$, $\mathrm{H}_{6}$ ).

RMN ${ }^{13}$ C: (Fig. VIIIb) 55,6 $\left(\mathrm{CH}_{3}\right) ; 56,2$ (2) $\left(\mathrm{CH}_{3}\right) ; 61,0\left(\mathrm{CH}_{3}\right) ; 105,7$ (2) (CH); 109,9 (CH); 112,4 ( $\left(\mathrm{CH}_{2}\right) ; 115,3(\mathrm{CH}) ; 119,0(\mathrm{CH}) ; 134,1(\mathrm{C}) ; 135,4(\mathrm{C}) ; 137,6(\mathrm{C})$; 137,8 (C); 147,5 (C); 150,0 (C); 152,8 (2) (C).

EM: $315\left(\mathbf{M}^{+}\right)$.

$\begin{array}{cc}\text { HPLC: } \text { Columna } \mathrm{C}_{18} & \mathrm{t}_{\mathrm{R}}: 13,71 \mathrm{~min} . \\ \text { Columna } \mathrm{C}_{8} & \mathrm{t}_{\mathrm{R}}: 12,48 \mathrm{~min} . \\ \text { Columna fenílica } & \mathrm{t}_{\mathrm{R}}: 13,65 \mathrm{~min} .\end{array}$




\section{Obtención de $N$-etil-2-metoxi-5-[1-(3,4,5-trimetoxifenil)etil]anilina (26).}<smiles>[Z4]Oc1ccc(C(=C)c2cc(OC)c(OC)c([N+](=O)[O-])c2)cc1C(C)c1cc(OC)c(OC)c(OC)c1</smiles>

Siguiendo el método F, $11 \mathrm{mg}$ (0,03 mmol) de 24, $5 \mathrm{mg}$ de Paladio sobre Carbono y 10 mL de $\mathrm{EtOH}$, en atmósfera de $\mathrm{H}_{2}$, reaccionan para dar 8 mg (73\%) de 26 .

\section{N-etil-2-metoxi-5-[1-(3,4,5-trimetoxifenil)etil]anilina (26):}

IR (película): 3414, 1591, 1513, 1228, $1126 \mathrm{~cm}^{-1}$.

RMN ${ }^{1} \mathbf{H}$ : (Fig. IXa) 1,26 (3H, t; $J=7,2, \mathrm{CH}_{2} \mathrm{CH}_{3}$ ); 1,59 (3H, d; $J=7,2, \mathrm{CHCH}_{3}$ ); 3,12 (2H, c; J=7,2, $\left.\mathrm{CH}_{2} \mathrm{CH}_{3}\right) ; 3,83\left(12 \mathrm{H}, \mathrm{s}, \mathrm{OCH}_{3}\right) ; 3,99\left(1 \mathrm{H}, \mathrm{q}, J=7,2, \mathrm{CHCH}_{3}\right)$; $6,45\left(1 \mathrm{H}, \mathrm{d}, J=8,2, \mathrm{H}_{4}\right) ; 6,46\left(2 \mathrm{H}, \mathrm{s}, \mathrm{H}_{2}, \mathrm{H}_{6}\right) ; 6,53\left(1 \mathrm{H}, \mathrm{d} ; J=2, \mathrm{H}_{6}\right) ; 6,68(1 \mathrm{H}, \mathrm{d}$; $\left.J=8,2, \mathrm{H}_{3}\right)$.

RMN ${ }^{13}$ C: (Fig. IXb) 14,8 ( $\left.\mathrm{CH}_{3}\right)$; 22,4 $\left(\mathrm{CH}_{3}\right)$; 38,2 $\left(\mathrm{CH}_{2}\right)$; 44,9 (CH); 55,5 $\left(\mathrm{CH}_{3}\right)$; 56,1 (2) $\left(\mathrm{CH}_{3}\right) ; 60,9\left(\mathrm{CH}_{3}\right) ; 104,6(2)(\mathrm{CH}) ; 109,1(\mathrm{CH}) ; 109,6(\mathrm{CH}) ; 114,5(\mathrm{C}) ;$ 114,8 (CH); 117,2 (C); 138,2 (C); 139,1 (C); 142,8 (C); 153,0 (2) (C).

EM: $345\left(\mathrm{M}^{+}\right)$.

\section{Obtención de 2-metoxi-5-[1-(3,4,5-trimetoxifenil)etil]anilina (27).}<smiles>C=C(c1ccc(OC)c(N)c1)c1cc(OC)c(OC)c(OC)c1</smiles>

Siguiendo el método F, a una disolución de 29 mg (0,09 mmol) de 25 en $20 \mathrm{~mL}$ de EtOH, bajo atmósfera de $\mathrm{H}_{2}$, se añaden $8 \mathrm{mg}$ de $\mathrm{Pd} / \mathrm{C}$. Veinticuatro horas después, se obtienen 23 mg (79\%) del producto hidrogenado 27. 


\section{2-metoxi-5-[1-(3,4,5-trimetoxifenil)etil]anilina (27):}

IR (película): 3370, 1588, $1125 \mathrm{~cm}^{-1}$.

RMN ${ }^{1} \mathbf{H}$ : (Fig. Xa) 1,56 (3H, d; J=7,2, $\left.\mathrm{CHCH}_{3}\right) ; 3,81\left(12 \mathrm{H}, \mathrm{s}, \mathrm{OCH}_{3}\right) ; 3,83(1 \mathrm{H}$, m, $\left.\mathrm{CHCH}_{3}\right) ; 6,43\left(2 \mathrm{H}, \mathrm{s}, \mathrm{H}_{2}, \mathrm{H}_{6}{ }^{\prime}\right) ; 6,56\left(1 \mathrm{H} \mathrm{d} ; J=2,2, \mathrm{H}_{6}\right) ; 6,62$ (1H, dd, $J=8,2 ; 2,2$ $\left.\mathrm{H}_{4}\right) ; 6,71\left(1 \mathrm{H}, \mathrm{d} ; J=8,2, \mathrm{H}_{3}\right)$.

RMN ${ }^{13}$ C: (Fig. Xb) 22,2 $\left(\mathrm{CH}_{3}\right) ; 44,4(\mathrm{CH}) ; 55,6\left(\mathrm{CH}_{3}\right) ; 56,1$ (2) $\left(\mathrm{CH}_{3}\right) ; 60,9$ $\left(\mathrm{CH}_{3}\right) ; 104,6(2)(\mathrm{CH}) ; 110,3(\mathrm{CH}) ; 114,6(\mathrm{CH}) ; 117,2$ (CH); 135,2 (C); 135,9 (C) 139,1 (C); 142,6 (C); 149,3 (C); 153,0 (2) (C).

EM: $317\left(\mathbf{M}^{+}\right)$.

\section{Obtención de (3-tercbutildifenilsiloxi-4-metoxifenil)(3,4,5-trimetoxifenil) metanol (28).}

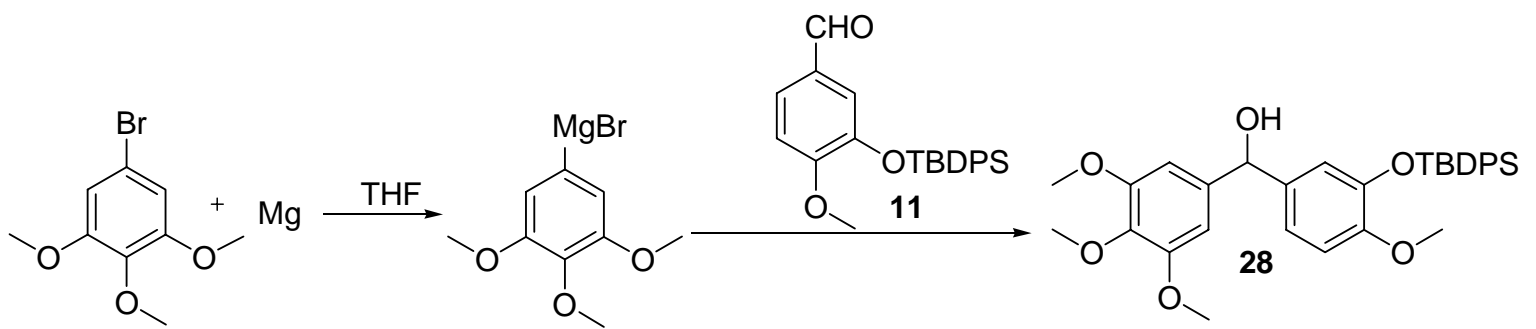

Siguiendo el método C2, a una suspensión de $304 \mathrm{mg}$ (12,15 mmol) de magnesio en 2,5 mL de THF seco, se añaden 2,00 g (8,1 mmol) de 5-bromo-1,2,3-trimetoxibenceno y $5 \mathrm{mg}$ de yodo. A continuación, la suspensión blanquecina se añade sobre 1,00 g (2,56 mmol) de 11 disuelto en $3 \mathrm{~mL}$ de THF a $0{ }^{\circ} \mathrm{C}$. Después de 1 hora, se obtienen 2,93 g de bruto de reacción que se purifican por percolación en columna de sílice (Hex-AcOEt 1:1) y se obtienen 1,34 g (94\%) del producto 28. 


\section{(3-tercbutildifenilsilioxi-4-metoxifenil)(3,4,5-trimetoxifenil)metanol (28):}

RMN ${ }^{1} \mathbf{H}$ : (Fig. XIa) 1,09 (9H, s, C( $\left.\left.\mathrm{CH}_{3}\right)_{3}\right) ; 3,60\left(3 \mathrm{H}, \mathrm{s}, \mathrm{OCH}_{3}\right) ; 3,74(6 \mathrm{H}, \mathrm{s}$, $\left.\mathrm{OCH}_{3}\right) ; 3,82\left(3 \mathrm{H}, \mathrm{s}, \mathrm{OCH}_{3}\right) ; 5,49(1 \mathrm{H}, \mathrm{d}, \mathrm{J}=3,6, \mathrm{CHOH}) ; 6,41\left(2 \mathrm{H}, \mathrm{s}, \mathrm{H}_{2}, \mathrm{H}_{6}\right.$ ) $)$ 6,66 $\left(1 \mathrm{H} \mathrm{d}, J=2,2, \mathrm{H}_{2}\right) ; 6,74\left(1 \mathrm{H}, \mathrm{d} ; J=8,2 \mathrm{H}_{5}\right) ; 6,85\left(1 \mathrm{H}, \mathrm{d} ; J=8,6 ; 2,2, \mathrm{H}_{6}\right) ; 7,30(6 \mathrm{H}$, $\mathrm{m}) ; 7,66(4 \mathrm{H}, \mathrm{m})$.

RMN ${ }^{13}$ C: (Fig. XIb) 14,2 (C); 26,7 (3) $\left(\mathrm{CH}_{3}\right) ; 55,4\left(\mathrm{CH}_{3}\right) ; 55,8$ (2) $\left(\mathrm{CH}_{3}\right) 60,8$ $\left(\mathrm{CH}_{3}\right) ; 75,5(\mathrm{CH}) ; 103,2(2)(\mathrm{CH}) ; 118,8(\mathrm{CH}) ; 119,8(\mathrm{CH}) ; 122,1(\mathrm{CH}) ; 127,5$ (4) (CH); 129,7 (2) (CH); 133,5 (2) (C); 135,4 (4) (CH); 136,6 (C); 140,0 (C); 144,9 (C); 150,0 (C); 152,9 (2) (C); 153,4 (C).

\section{Obtención de (3-tercbutildifenilsiloxi-4-metoxifenil)(3,4,5-trimetoxifenil) metanona (29).}

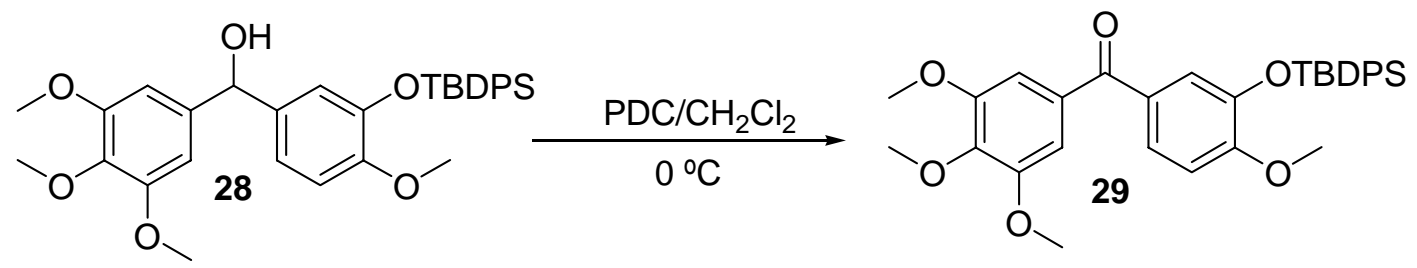

Siguiendo el método D2, a una solución de 1,34 g (2,39 mmol) de 28 en 40 mL de $\mathrm{CH}_{2} \mathrm{Cl}_{2}$ seco a $0{ }^{\circ} \mathrm{C}$, se añaden $1,20 \mathrm{~g}(3,11 \mathrm{mmol})$ de PDC. Después de 24 horas, se obtienen 1,12 g (85\%) de bruto de reacción, que se utilizan en el siguiente paso sin purificación previa.

\section{(3-tercbutildifenilsilioxi-4-metoxifenil)(3,4,5-trimetoxifenil)metanona (29):}

RMN ${ }^{1} \mathbf{H}$ : (Fig. XIIa) 1,12 (9H, s, C(CH3) $)$; 3,60 (3H, s, $\left.\mathrm{OCH}_{3}\right) ; 3,77(6 \mathrm{H}, \mathrm{s}$, $\left.\mathrm{OCH}_{3}\right) ; 3,92\left(3 \mathrm{H}, \mathrm{s}, \mathrm{OCH}_{3}\right) ; 6,79\left(1 \mathrm{H}, \mathrm{d} ; J=8,2, \mathrm{H}_{5}\right) ; 6,85\left(2 \mathrm{H}, \mathrm{s}, \mathrm{H}_{2}, \mathrm{H}_{6}{ }^{\prime}\right) ; 7,23(1 \mathrm{H}$ d; $\left.\left.J=2,2, \mathrm{H}_{2}\right) ; 7,28-7,36(6 \mathrm{H}, \mathrm{m}) ; 7,40 \mathrm{~J}=8,6 ; 2,2, \mathrm{H}_{6}\right) ; 7,66$ (4H, m).

RMN ${ }^{13}$ C: (Fig. XIIb) 19,8 (C); 26,7 (3) $\left(\mathrm{CH}_{3}\right) ; 55,2\left(\mathrm{CH}_{3}\right) ; 56,0$ (2) $\left(\mathrm{CH}_{3}\right)$ 60,9 $\left(\mathrm{CH}_{3}\right) ; 107,1(2)(\mathrm{CH}) ; 111,1(\mathrm{CH}) ; 121,9(\mathrm{CH}) ; 125,0(\mathrm{CH}) ; 127,6(4)(\mathrm{CH}) ; 129,8$ (2) (CH); 129,9 (C); 133,1 (2) (C); 135,3 (4) (CH); 137,6 (C); 141,3 (C); 144,5 (C); 152,7 (2) (C); 154,5 (C); 194,4 (C). 


\section{Síntesis de (3-hidroxi-4-metoxifenil)(3,4,5-trimetoxifenil)metanona (30).}

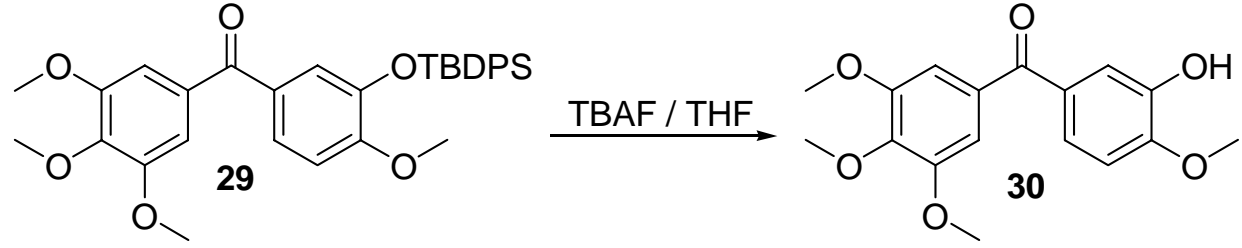

A una disolución de $354 \mathrm{mg}$ (0,64 mmol) de 29 en $10 \mathrm{~mL}$ de THF, se añaden 1,00 mL (1,00 mmol) de TBAF (1,0 M en THF). Después de 24 horas en agitación bajo atmósfera de argón, se vierte sobre agua y se extrae con éter 3 veces. El conjunto de las fases orgánicas se lava con disolución acuosa saturada de $\mathrm{NaCl}$, se seca con $\mathrm{Na}_{2} \mathrm{SO}_{4}$ anhidro, se filtra y se evapora a sequedad. El crudo de reacción obtenido (356 mg) se purifica por cromatografía en columna de gel de sílice (Hex-AcOEt 8:2) para dar 85 mg (42\%) del producto 30.

\section{(3-hidroxi-4-metoxifenil)(3,4,5-trimetoxifenil)metanona (30):}

IR (película): 3409, 1645, 1454, 1278, 1009, $763 \mathrm{~cm}^{-1}$.

RMN ${ }^{1} \mathbf{H}$ : (Fig. XIIIa) 3,84 (6H, s, $\left.\mathrm{OCH}_{3}\right) ; 3,90\left(3 \mathrm{H}, \mathrm{s}, \mathrm{OCH}_{3}\right) ; 3,93(3 \mathrm{H}, \mathrm{s}$, $\left.\mathrm{OCH}_{3}\right) ; 6,89\left(1 \mathrm{H}, \mathrm{d} ; J=8,2, \mathrm{H}_{5}\right) ; 7,00\left(2 \mathrm{H}, \mathrm{s}, \mathrm{H}_{2}, \mathrm{H}_{6}\right.$ ); 7,35 (1H, dd; $\left.J=8,2 ; 2,2, \mathrm{H}_{6}\right)$; 7,41 (1H d; $J=2,2, \mathrm{H}_{2}$ ).

RMN ${ }^{13}$ C: (Fig. XIIIb) 56,1 ( $\left.\mathrm{CH}_{3}\right)$; 56,3 (2) $\left(\mathrm{CH}_{3}\right) 61,0\left(\mathrm{CH}_{3}\right) ; 107,5$ (2) (CH); 109,8 (CH); 116,3 (CH); 123,7 (CH); 130,9 (C); 133,2 (C); 141,6 (C); 145,5 (2) (C); 150,4 (C); 152,8 (C); 194,8 (C).

EM: $318\left(\mathrm{M}^{+}\right)$.

$\begin{array}{cc}\text { HPLC: Columna } \mathrm{C}_{18} & \mathrm{t}_{\mathrm{R}}: 10,88 \mathrm{~min} . \\ \text { Columna } \mathrm{C}_{8} & \mathrm{t}_{\mathrm{R}}: 10,04 \mathrm{~min} . \\ \text { Columna fenílica } & \mathrm{t}_{\mathrm{R}}: 10,83 \mathrm{~min} .\end{array}$




\section{Obtención de tercbutil-\{2-metoxi-5-[1-(3,4,5-trimetoxifenil)vinil]fenoxi\} difenilsilano (31).}<smiles>C=C(c1ccc(OC)c(OCC(C)(C)C)c1)c1cc(OC)c(OC)c(OCC)c1</smiles>

Siguiendo el método B, a una suspensión de $653 \mathrm{mg}$ (1,62 mmol) de ioduro de metiltrifenilfosfonio en $7 \mathrm{~mL}$ de THF seco, se añaden $0,84 \mathrm{~mL}(1,35 \mathrm{mmol})$ de $n$ Buli $(1,6$ M en hexano) y $310 \mathrm{mg}$ (0,56 mmol) de 29. Después de 6 horas, el crudo de reacción obtenido, 864 mg se purifica por cromatografía de columna en geñ de sílice (Hex-AcOEt 9:1) para dar $177 \mathrm{mg}$ (57\%) del producto 31.

\section{tercbutil-\{2-metoxi-5-[1-(3,4,5-trimetoxifenil)vinil]fenoxi\}difenilsilano (31):}

RMN ${ }^{1} \mathbf{H}$ : (Fig. XIVa) 1,14 (9H, s, tBu); 3,62 (3H, s, $\left.\mathrm{OCH}_{3}\right) ; 3,74\left(6 \mathrm{H}, \mathrm{s}, \mathrm{OCH}_{3}\right)$; 3,89 (3H, s, $\left.\mathrm{OCH}_{3}\right) ; 5,10\left(1 \mathrm{H}, \mathrm{d} ; J=1,4, \mathrm{CH}_{2}\right) ; 5,15\left(1 \mathrm{H}, \mathrm{d} ; J=1,4, \mathrm{CH}_{2}\right) ; 6,42(2 \mathrm{H}$, s, $\left.\mathrm{H}_{2}, \mathrm{H}_{6}\right)$ ); 6,72 (1H, d; $\left.J=1,8, \mathrm{H}_{6}\right) ; 6,73\left(1 \mathrm{H}, \mathrm{d} ; J=8,2, \mathrm{H}_{3}\right) ; 6,85(1 \mathrm{H}$ dd; $J=8,2$; 1,8, $\left.\mathrm{H}_{4}\right) ; 7,35$ (6H, m); 7,70 (4H, m).

RMN ${ }^{13}$ C: (Fig. XIVb) 19,8 (C); 26,8 (3) $\left(\mathrm{CH}_{3}\right) ; 55,5\left(\mathrm{CH}_{3}\right) ; 56,0$ (2) $\left(\mathrm{CH}_{3}\right) ; 61,0$ $\left(\mathrm{CH}_{3}\right) ; 105,5$ (2) $(\mathrm{CH}) ; 111,7(\mathrm{CH}) ; 112,4\left(\mathrm{CH}_{2}\right) ; 120,2(\mathrm{CH}) ; 121,4(\mathrm{CH}) ; 127,5$ (4) $(\mathrm{CH}) ; 129,7$ (2) (CH); 133,5 (2) (C); 133,7 (2) (C); 135,6 (4) (CH); 137,5 (C); 144,7 (C); 149,5 (C); 150,5 (C); 152,7 (2) (C).

\section{Obtención de 2-metoxi-5-[1-(3,4,5-trimetoxifenil)vinil]fenol (32).}

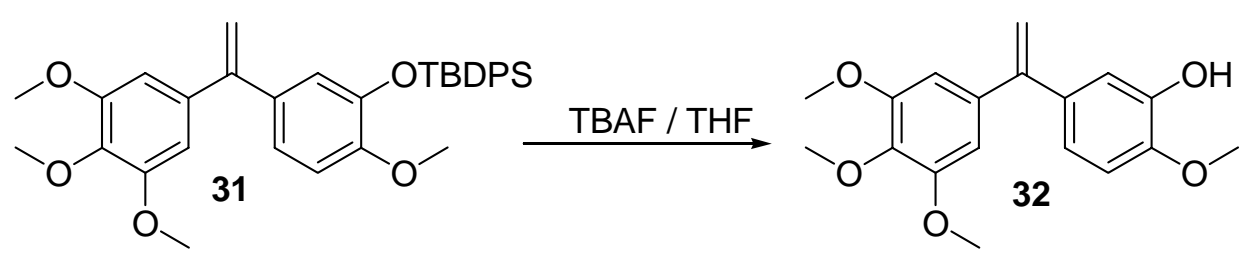

A una disolución de $86 \mathrm{mg}(0,16 \mathrm{mmol})$ de 31 en $4 \mathrm{~mL}$ de THF, se añaden 0,50 mL (0,50 mmol) de TBAF (1,0 M en THF). Después de 8 horas, en agitación bajo atmósfera de argón se vierte sobre agua y se extrae con éter 3 veces. El conjunto de las fases orgánicas se lava con disolución acuosa saturada de $\mathrm{NaCl}$, se seca con $\mathrm{Na}_{2} \mathrm{SO}_{4}$ anhidro, se filtra y se evapora hasta sequedad para obtener $66 \mathrm{mg}$ de crudo de reacción. Tras cromatografía en columna sobre gel de sílice, usando como eluyente Hex/AcOEt 8/2, se obtienen 25 mg (50\%) del producto desprotegido 32 y $20 \mathrm{mg}$ de la cetona 30 (39\%). 


\section{2-metoxi-5-[1-(3,4,5-trimetoxifenil)vinil]fenol (32):}

IR (película): 3415, 1580, 1252, 1125, $1024 \mathrm{~cm}^{-1}$.

RMN ${ }^{1} \mathbf{H}$ : (Fig. XVa) 3,81 (6H, s, $\mathrm{OCH}_{3}$ ); 3,87 (3H, s, $\left.\mathrm{OCH}_{3}\right)$; 3,90 (3H, s, $\mathrm{OCH}_{3}$ ); 5,30 (1H, d; $\left.J=1,4, \mathrm{CH}_{2}\right) ; 5,37$ (1H, d; $\left.J=1,4, \mathrm{CH}_{2}\right) ; 6,55\left(2 \mathrm{H}, \mathrm{s}, \mathrm{H}_{2}, \mathrm{H}_{6}\right.$ ) $) 6,80(1 \mathrm{H}$, d; $\left.J=8,2, \mathrm{H}_{3}\right) ; 6,85\left(1 \mathrm{H}\right.$, dd; $\left.J=8,2 ; 1,8, \mathrm{H}_{4}\right) ; 6,97\left(1 \mathrm{H} \mathrm{d} ; J=1,8, \mathrm{H}_{6}\right)$.

RMN ${ }^{13}$ C: (Fig. XVb) 56,0 (3) $\left(\mathrm{CH}_{3}\right) ; 61,0\left(\mathrm{CH}_{3}\right) ; 105,7$ (2) $(\mathrm{CH}) ; 110,2(\mathrm{CH})$; 113,0 ( $\left.\mathrm{CH}_{2}\right) ; 114,5(\mathrm{CH}) ; 120,0(\mathrm{CH}) ; 127,7$ (C); 134,7 (C); 137,5 (C); 145,2 (C); 146,5 (C); 149,6 (C); 152,8 (2) (C).

EM: $316\left(\mathrm{M}^{+}\right)$.

HPLC: Columna $\mathrm{C}_{18} \quad \mathrm{t}_{\mathrm{R}}: 14,17 \mathrm{~min}$.

Columna $\mathrm{C}_{8} \quad \mathrm{t}_{\mathrm{R}}: 12,94 \mathrm{~min}$.

Columna fenílica $\quad t_{R}: 13,24$ min.

\section{Obtención de (4-metoxifenil)(2,3,4-trimetoxifenil)metanol (33).}<smiles>COc1ccc(C(O)c2ccc(OC)c(OC)c2OCCOc2ccc(C=O)cc2)cc1</smiles>

Siguiendo el método C3, a una solución de 2,00 g (11,9 mmol) de trimetoxibenceno en $10 \mathrm{~mL}$ de THF seco a $0{ }^{\circ} \mathrm{C}$, se añaden $7,44 \mathrm{~mL}(11,9 \mathrm{mmol})$ de $n$ Buli $(1,6 \mathrm{M}$ en hexano). Se mantiene en agitación 1 hora y se añaden 1,62 g (11,9 mmol) de panisaldehído. Después de 13 horas, se obtienen 3,62 g de crudo de reacción que se utilizan en el siguiente paso sin purificación previa. 


\section{(4-metoxifenil)(2,3,4-trimetoxifenil)metanol (33):}

IR (película): 3472, 1602, 1248, 1096, $807 \mathrm{~cm}^{-1}$.

RMN ${ }^{1} \mathbf{H}$ : (Fig. XVIa) 3,67 (3H, s, $\left.\mathrm{OCH}_{3}\right) ; 3,80\left(3 \mathrm{H}, \mathrm{s}, \mathrm{OCH}_{3}\right) ; 3,85(6 \mathrm{H}, \mathrm{s}$, $\left.\mathrm{OCH}_{3}\right) ; 5,89(1 \mathrm{H}, \mathrm{d} ; J=5, \mathrm{CHOH}) ; 6,64\left(1 \mathrm{H}, \mathrm{d} ; J=8,6, \mathrm{H}_{5},{ }^{*}\right) ; 6,86\left(2 \mathrm{H}, \mathrm{d} ; J=8,6, \mathrm{H}_{3}\right.$, $\left.\mathrm{H}_{5}\right) ; 6,97\left(1 \mathrm{H}, \mathrm{d} ; J=8,6, \mathrm{H}_{6}{ }^{*}\right) ; 7,28\left(2 \mathrm{H}, \mathrm{d} ; J=8,6, \mathrm{H}_{2}, \mathrm{H}_{6}\right)$.

* Asignación intercambiable.

RMN ${ }^{13}$ C: (Fig. XVIb) 55,2 (CH $)$; 56,0 $\left(\mathrm{CH}_{3}\right) ; 60,4\left(\mathrm{CH}_{3}\right) ; 60,7\left(\mathrm{CH}_{3}\right) ; 71,6(\mathrm{CH})$; 107,0 (CH); 113,6 (2) (CH); 122,0 (CH); 127,7 (2) (CH); 130,2 (C); 136,4 (C); 142,1 (C); 151,1 (C); 153,2 (C); 158,7 (C).

EM: $304\left(\mathrm{M}^{+}\right)$.

\section{Obtención de (4-metoxifenil)(2,3,4-trimetoxifenil)metanona (34).}<smiles>COc1ccc(C(=O)c2ccc(OC)c(OC)c2OC)cc1</smiles>

Siguiendo el método D2, a una solución de 3,62 g (11,9 mmol) de 33 en $50 \mathrm{~mL}$ de $\mathrm{CH}_{2} \mathrm{Cl}_{2}$ se añaden 3,76 g (24,0 mmol) de $\mathrm{KMnO}_{4}, 20 \mathrm{mg}$ de $\mathrm{Bu}_{4} \mathrm{~N}^{+} \mathrm{H}_{4} \mathrm{SO}_{4}{ }^{-}$y $1 \mathrm{~mL}$ de $\mathrm{H}_{2} \mathrm{O}$. Después de 24 horas, se obtienen 3,00 g que se purifican por cromatografía de columna (Hex/AcOEt 8/2) para obtener $604 \mathrm{mg}$ (2,00 mmol, 17\%) de 34 y 1,38 g (38\%) del material de partida 33 sin reaccionar. 


\section{(4-metoxifenil)(2,3,4-trimetoxifenil)metanona (34).}

IR (película): 1651, 1596, 1025, 850, $806 \mathrm{~cm}^{-1}$.

RMN ${ }^{1} \mathbf{H}$ : (Fig. XVIIa) 3,65 (3H, s, $\left.\mathrm{OCH}_{3}\right) ; 3,71\left(3 \mathrm{H}, \mathrm{s}, \mathrm{OCH}_{3}\right) ; 3,77(6 \mathrm{H}, \mathrm{s}$, $\left.\mathrm{OCH}_{3}\right) ; 6,60\left(1 \mathrm{H}, \mathrm{d} ; J=8,6, \mathrm{H}_{5}{ }^{*}\right) ; 6,79\left(2 \mathrm{H}, \mathrm{d} ; J=9, \mathrm{H}_{3}, \mathrm{H}_{5}\right) ; 6,94(1 \mathrm{H}, \mathrm{d} ; J=8,6$, $\left.\mathrm{H}_{6},{ }^{*}\right) ; 7,67\left(2 \mathrm{H}, \mathrm{d} ; J=9, \mathrm{H}_{2}, \mathrm{H}_{6}\right)$;

* Asignación intercambiable

RMN ${ }^{13}$ C: (Fig. XVIIb) 55,4 ( $\left(\mathrm{CH}_{3}\right) ; 56,0\left(\mathrm{CH}_{3}\right) ; 60,8\left(\mathrm{CH}_{3}\right) ; 61,7\left(\mathrm{CH}_{3}\right) ; 106,8$ (CH); 113,4 (2) (CH); 124,5 (CH); 126,7 (C); 130,9 (C); 132,2 (2) (CH) 142,0 (C); 152,2 (C); 155,7 (C); 163,4 (C); 193,9 (C).

EM: $302\left(\mathrm{M}^{+}\right)$.

\begin{tabular}{|c|c|}
\hline HPLC: Columna $\mathrm{C}_{18}$ & $\mathrm{t}_{\mathrm{R}}: 13,63 \mathrm{~min}$. \\
\hline Columna $\mathrm{C}_{8}$ & $t_{R}: 12,80$ \\
\hline Columna fenílica & $t_{R}: 13,29$ \\
\hline
\end{tabular}

\section{Obtención de 1,2,3-trimetoxi-4-[1-(4-metoxifenil)vinil]benceno (35).}

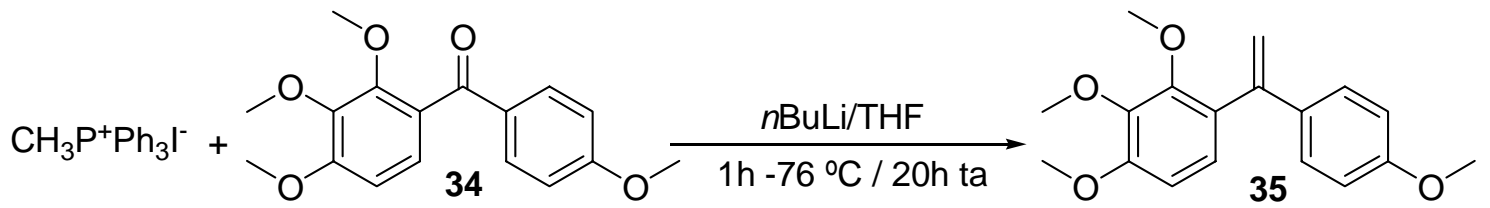

Siguiendo el método $B$, a una suspensión de $731 \mathrm{mg}(1,80 \mathrm{mmol})$ de ioduro de metiltrifenilfosfonio en $7 \mathrm{~mL}$ de THF seco, se añaden 0,85 mL (1,36 mmol) de $n$-Buli (1,6 M en hexano) y $137 \mathrm{mg}(0,45 \mathrm{mmol})$ de 34. Después de 20 horas, se obtienen $834 \mathrm{mg}$ que se purifican por cromatografía de columna de gel de sílice (Hex-AcOEt 9:1) para dar 27 mg (20\%) del producto metilénico 35. 


\section{1,2,3-trimetoxi-4-[1-(4-metoxifenil)vinil]benceno (35):}

IR (película): 1602, 1500, 1288, 1098, 1026, 895, $838 \mathrm{~cm}^{-1}$.

RMN ${ }^{1} \mathbf{H}$ : (Fig. XVIIIa) 3,55 (3H, s, $\left.\mathrm{OCH}_{3}\right) ; 3,80\left(3 \mathrm{H}, \mathrm{s}, \mathrm{OCH}_{3}\right) ; 3,86(3 \mathrm{H}, \mathrm{s}$, $\left.\mathrm{OCH}_{3}\right) ; 3,89\left(3 \mathrm{H}, \mathrm{s}, \mathrm{OCH}_{3}\right) ; 5,18\left(1 \mathrm{H}, \mathrm{d} ; J=1,4, \mathrm{CH}_{2}\right) ; 5,54\left(1 \mathrm{H}, \mathrm{d} ; J=1,4, \mathrm{CH}_{2}\right)$; $6,67\left(1 \mathrm{H}, \mathrm{d} ; J=8,6, \mathrm{H}_{5}{ }^{*}\right)$; $6,83\left(2 \mathrm{H}, \mathrm{d} ; J=9, \mathrm{H}_{3}, \mathrm{H}_{5}\right) ; 6,95\left(1 \mathrm{H}, \mathrm{d} ; J=8,6, \mathrm{H}_{6}{ }^{*}{ }^{*}\right) ; 7,25$ (2H, d; $\left.J=8,6, \mathrm{H}_{2}, \mathrm{H}_{6}\right)$.

* Asignación intercambiable.

RMN ${ }^{13}$ C: (Fig. XVIIIb) 55,3 $\left(\mathrm{CH}_{3}\right) ; 56,0\left(\mathrm{CH}_{3}\right) ; 60,7\left(\mathrm{CH}_{3}\right) ; 60,9\left(\mathrm{CH}_{3}\right) ; 106,9$ $(\mathrm{CH}) ; 113,5$ (2) (CH); 113,7 ( $\left.\mathrm{CH}_{2}\right) ; 125,2(\mathrm{CH}) ; 127,8$ (2) (CH); 129,4 (C); 134,5 (C); 142,1 (C); 146,3 (C); 151,7 (C); 153,5 (C); 159,2 (C).

EM: $300\left(\mathrm{M}^{+}\right)$.

$\begin{array}{cc}\text { HPLC: Columna } \mathrm{C}_{18} & \mathrm{t}_{\mathrm{R}}: 17,21 \mathrm{~min} . \\ \text { Columna } \mathrm{C}_{8} & \mathrm{t}_{\mathrm{R}}: 15,48 \mathrm{~min} . \\ \text { Columna fenílica } & \mathrm{t}_{\mathrm{R}}: 15,55 \mathrm{~min} .\end{array}$

\section{Obtención de (4-metoxi-3-nitrofenil)(2,3,4-trimetoxifenil)metanol (36).}

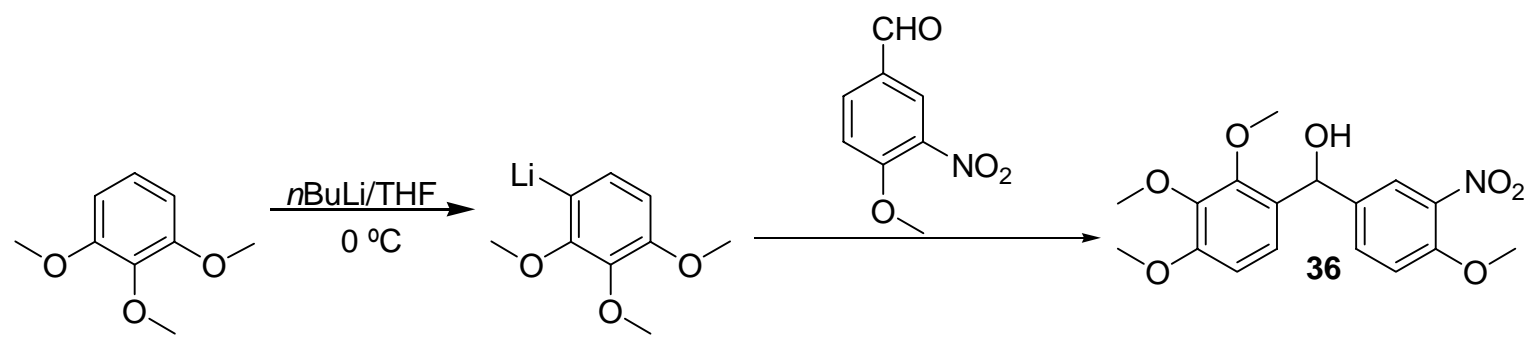

Siguiendo el método C3, a una solución de 2,00 g (11,9 mmol) de trimetoxibenceno en $10 \mathrm{~mL}$ de THF seco a $0{ }^{\circ} \mathrm{C}$, se añaden 7,2 mL (11,5 mmol) de $n$-Buli (1,6 M en hexano). Se mantiene en agitación 1 hora y se añaden 2,08 g (11,5 mmol) de 4-metoxi-3nitrobenzaldehído. Después de 12 horas, se obtienen 2,53 g que se purifican por percolación en columna de gel de sílice (Hex/AcOEt 9/1) para dar 1,27 g (32\%) del alcohol 36. 


\section{(4-metoxi-3-nitrofenil)(2,3,4-trimetoxifenil)metanol (36):}

RMN ${ }^{1} \mathbf{H}$ : (Fig. XIXa) 3,73 (3H, s, $\left.\mathrm{OCH}_{3}\right) ; 3,85\left(3 \mathrm{H}, \mathrm{s}, \mathrm{OCH}_{3}\right) ; 3,86(3 \mathrm{H}, \mathrm{s}$, $\left.\mathrm{OCH}_{3}\right) ; 3,95\left(3 \mathrm{H}, \mathrm{s}, \mathrm{OCH}_{3}\right) ; 5,88(1 \mathrm{H}, \mathrm{d}, J=6,2, \mathrm{CHOH}) ; 6,65\left(1 \mathrm{H}, \mathrm{d} ; J=8,4, \mathrm{H}_{5},{ }^{*}\right)$; $6,93\left(1 \mathrm{H}, \mathrm{d} ; J=8,4, \mathrm{H}_{6}{ }^{*}\right)$; 7,04 (1H, d; $\left.J=8,2, \mathrm{H}_{5}\right) ; 7,55\left(1 \mathrm{H}, \mathrm{dd} ; J=8,6 ; 2,2, \mathrm{H}_{6}\right)$; $7,87\left(1 \mathrm{H} \mathrm{d} ; J=2,2, \mathrm{H}_{2}\right)$.

* Asignación intercambiable.

RMN ${ }^{13}$ C: (Fig. XIXb) 56,1 $\left(\mathrm{CH}_{3}\right)$; 56,6 $\left(\mathrm{CH}_{3}\right) ; 60,7\left(\mathrm{CH}_{3}\right) ; 60,8\left(\mathrm{CH}_{3}\right) ; 70,4$ $(\mathrm{CHOH}) ; 107,2(\mathrm{CH}) ; 113,2(\mathrm{CH}) ; 121,8(\mathrm{CH}) ; 123,9(\mathrm{CH}) ; 129,0(\mathrm{C}) ; 132,3(\mathrm{CH})$; 137,0 (C); 139,1 (C); 142,0 (C); 150,9 (C); 151,8 (C); 153,6 (C).

\section{Obtención de (4-metoxi-3-nitrofenil)(2,3,4-trimetoxifenil)metanona (37).}<smiles>COc1ccc(C(=O)c2ccc(OCC(C)(C)C)c(OC)c2OCCOc2ccc(C(O)c3ccc(OC)c(OC)c3OC)cc2[N+](=O)[O-])cc1[N+](=O)[O-]</smiles>

Siguiendo el método D2, a una solución de $567 \mathrm{mg}$ (1,62 mmol) de 36 en $30 \mathrm{~mL}$ de $\mathrm{CH}_{2} \mathrm{Cl}_{2}$, se añaden 1 ,28 g (8,12 mmol) de $\mathrm{KMnO}_{4}, 20 \mathrm{mg}$ de $\mathrm{Bu}_{4} \mathrm{~N}^{+} \mathrm{H}_{4} \mathrm{SO}_{4}{ }^{-}$y $1 \mathrm{~mL}$ de $\mathrm{H}_{2} \mathrm{O}$. Después de 24 horas, se obtienen 220 mg (39\%) que se utilizan sin purificación previa en el siguiente paso.

\section{(4-metoxi-3-nitrofenil)(2,3,4-trimetoxifenil)metanona (37):}

RMN ${ }^{1} \mathbf{H}$ : (Fig. XXa) 3,71 (3H, s, $\left.\mathrm{OCH}_{3}\right) ; 3,84\left(3 \mathrm{H}, \mathrm{s}, \mathrm{OCH}_{3}\right) ; 3,90$ (3H, s, $\left.\mathrm{OCH}_{3}\right)$; 4,00 (3H, s, $\left.\mathrm{OCH}_{3}\right) ; 6,72\left(1 \mathrm{H}, \mathrm{d} ; J=8,6, \mathrm{H}_{5}{ }^{*}\right) ; 7,10\left(1 \mathrm{H}, \mathrm{d} ; J=8,6, \mathrm{H}_{6}{ }^{*}\right) ; 7,12(1 \mathrm{H}$, d; $\left.J=8,6, \mathrm{H}_{5}\right) ; 8,00\left(1 \mathrm{H}, \mathrm{dd} ; J=8,6 ; 2,2, \mathrm{H}_{6}\right) ; 8,21\left(1 \mathrm{H} \mathrm{d} ; J=2,2, \mathrm{H}_{2}\right)$.

* Asignación intercambiable.

RMN ${ }^{13}$ C: (Fig. XXb) 56,2 ( $\left(\mathrm{CH}_{3}\right)$; 56,9 $\left(\mathrm{CH}_{3}\right) ; 61,1\left(\mathrm{CH}_{3}\right) ; 61,9\left(\mathrm{CH}_{3}\right) ; 107,2$ $(\mathrm{CH}) ; 113,1(\mathrm{CH}) ; 125,2(\mathrm{CH}) ; 127,6(\mathrm{CH}) ; 130,6$ (C); 135,6 (CH); 139,0 (C); 142,0 (C); 151,0 (C); 152,5 (C); 156,0 (C); 156,8 (C); 192,2 (C). 


\section{Obtención de 1-metoxi-2-nitro-4-[1-(2,3,4-trimetoxifenil)vinil]benceno} (38).

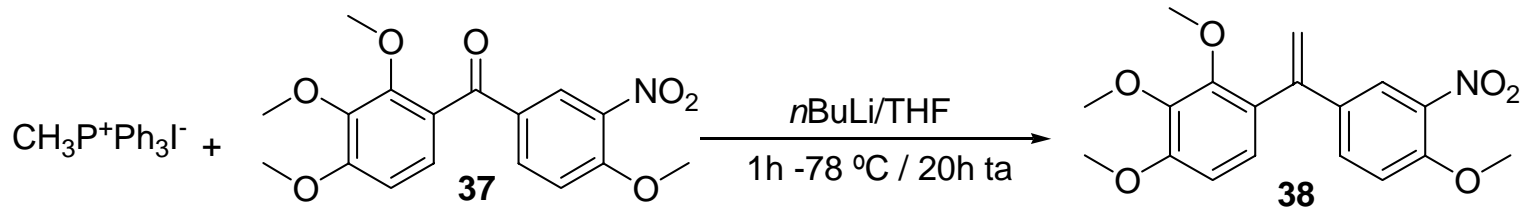

Siguiendo el método B, a una suspensión de 1,02 g (2,54 mmol) de ioduro de metiltrifenilfosfonio en $10 \mathrm{~mL}$ de THF seco, se añaden 1,38 mL (2,22 mmol) de $n$ Buli (1,6 M en hexano) y $220 \mathrm{mg}$ (0,63 mmol) de 37. Después de 6 horas, el crudo de reacción obtenido, 1,31 g, se purifica por cromatografía de columna de gel de sílice (Hex/AcOEt 9/1) para dar $58 \mathrm{mg}$ (27\%) del producto 38.

\section{1-metoxi-2-nitro-4-[1-(2,3,4-trimetoxifenil)vinil]benceno (38):}

IR (película): 1598, 1531, 1279, 1095, 1091, 897, $813 \mathrm{~cm}^{-1}$.

RMN ${ }^{1} \mathbf{H}$ : (Fig. XXIa) 3,55 (3H, s, $\left.\mathrm{OCH}_{3}\right) ; 3,84\left(3 \mathrm{H}, \mathrm{s}, \mathrm{OCH}_{3}\right) ; 3,89(3 \mathrm{H}, \mathrm{s}$, $\left.\mathrm{OCH}_{3}\right) ; 3,94\left(3 \mathrm{H}, \mathrm{s}, \mathrm{OCH}_{3}\right) ; 5,30\left(1 \mathrm{H}, \mathrm{s}, \mathrm{CH}_{2}\right) ; 5,58\left(1 \mathrm{H}, \mathrm{s}, \mathrm{CH}_{2}\right) ; 6,68(1 \mathrm{H}, \mathrm{d}$; $\left.J=8,4, \mathrm{H}_{5}{ }^{*}\right)$; 6,94 (1H, d; $\left.J=8,4, \mathrm{H}_{6}{ }^{*}\right) ; 7,00\left(1 \mathrm{H}, \mathrm{d} ; J=8,8, \mathrm{H}_{6}\right) ; 7,47$ (1H, dd; $J=8,8$; 2,2, $\left.\mathrm{H}_{5}\right) ; 7,78\left(1 \mathrm{H} \mathrm{d} ; J=2,2, \mathrm{H}_{3}\right)$.

* Asignación intercambiable

RMN ${ }^{13}$ C: (Fig. XXIb) 56,1 ( $\left(\mathrm{CH}_{3}\right)$; 56,6 $\left(\mathrm{CH}_{3}\right) ; 60,7\left(\mathrm{CH}_{3}\right) ; 61,0\left(\mathrm{CH}_{3}\right) ; 107,2$ (CH); 113,1 (CH); 115,9 ( $\left.\mathrm{CH}_{2}\right) ; 123,5(\mathrm{CH}) ; 125,2(\mathrm{CH}) ; 127,7(\mathrm{C}) ; 132,1(\mathrm{CH})$; 134,6 (C); 139,3 (C); 142,4 (C); 144,6 (C); 151,5 (C); 152,2 (C); 154,1 (C).

EM: $345\left(\mathrm{M}^{+}\right)$.

$\begin{array}{cc}\text { HPLC: Columna } \mathrm{C}_{18} & \mathrm{t}_{\mathrm{R}}: 15,80 \mathrm{~min} . \\ \text { Columna } \mathrm{C}_{8} & \mathrm{t}_{\mathrm{R}}: 14,59 \mathrm{~min} . \\ \text { Columna fenílica } & \mathrm{t}_{\mathrm{R}}: 15,14 \mathrm{~min} .\end{array}$




\section{Obtención de 2-metoxi-5-[1-(2,3,4-trimetoxifenil)vinil]anilina (39).}<smiles>C=C(c1ccc(OC)c([N+](=O)[O-])c1)c1ccc(OC)c(OC)c1OC</smiles><smiles>C=C(c1ccc(OC)c(N)c1)c1ccc(OC)c(OC)c1OC</smiles>

A una disolución de $57 \mathrm{mg}(0,17 \mathrm{mmol})$ de 38 en $2 \mathrm{~mL}$ de $\mathrm{CH}_{2} \mathrm{Cl}_{2}$ se añaden $10 \mathrm{~mL}$ de ácido acético glacial y $100 \mathrm{mg}(1,54 \mathrm{mmol})$ de Zn. Después de 18 horas, se filtra a través de celita, se evapora el disolvente y se obtienen $52 \mathrm{mg}$ (97\%) del producto de reducción 39.

\section{2-metoxi-5-[1-(2,3,4-trimetoxifenil)vinil]anilina (39):}

IR (película): 3367, 1596, 1227, 892, $807 \mathrm{~cm}^{-1}$.

RMN ${ }^{1} \mathbf{H}$ : (Fig. XXIIa) 3,56 (3H, s, $\left.\mathrm{OCH}_{3}\right)$ 3,82 (3H, s, $\left.\mathrm{OCH}_{3}\right) ; 3,85(3 \mathrm{H}, \mathrm{s}$, $\left.\mathrm{OCH}_{3}\right) ; 3,87\left(3 \mathrm{H}, \mathrm{s}, \mathrm{OCH}_{3}\right) ; 5,15\left(1 \mathrm{H}, \mathrm{s}, \mathrm{CH}_{2}\right) ; 5,51\left(1 \mathrm{H}, \mathrm{s}, \mathrm{CH}_{2}\right) ; 6,66(4 \mathrm{H}, \mathrm{m})$; $6,92(1 \mathrm{H}, \mathrm{d} ; J=8,2)$.

RMN ${ }^{13}$ C: (Fig. XXIIb) 55,6 $\left(\mathrm{CH}_{3}\right)$; 56,0 $\left(\mathrm{CH}_{3}\right) ; 60,8\left(\mathrm{CH}_{3}\right) ; 60,9\left(\mathrm{CH}_{3}\right) ; 106,8$ $(\mathrm{CH}) ; 109,9(\mathrm{CH}) ; 113,7\left(\mathrm{CH}_{2}\right) ; 114,2(\mathrm{CH}) ; 118,0(\mathrm{CH}) ; 125,3(\mathrm{CH}) ; 129,5(\mathrm{C}) ;$ 134,8 (C); 142,3 (C); 146,5 (2) (C); 147,5 (C); 151,7 (C); 153,4 (C).

EM: $315\left(\mathbf{M}^{+}\right)$.

$\begin{array}{cc}\text { HPLC: Columna } \mathrm{C}_{18} & \mathrm{t}_{\mathrm{R}}: 14,17 \mathrm{~min} . \\ \text { Columna } \mathrm{C}_{8} & \mathrm{t}_{\mathrm{R}}: 12,83 \mathrm{~min} . \\ \text { Columna fenílica } & \mathrm{t}_{\mathrm{R}}: 13,41 \mathrm{~min} .\end{array}$




\section{Obtención de (3-tercbutildimeltilsiloxi-4-metoxifenil)(2,3,4-trimetoxifenil)} metanol (40).<smiles>COc1ccc(C(O)c2ccc(OC)c(OC)c2OC)cc1OCCOc1ccc(C=O)cc1OCCOc1ccc(Cl)c(OCC(F)(F)C(F)(F)C(F)(F)F)c1OC</smiles>

Siguiendo el método C3, a una solución de 5,50 g (32,7 mmol) de trimetoxibenceno en $20 \mathrm{~mL}$ de THF seco a $0{ }^{\circ} \mathrm{C}$, se añaden 18,75 mL (30,00 mmol) de $n$ Buli $(1,6 \mathrm{M}$ en hexano). Se mantiene en agitación 1 hora y se añaden 2,88 g (10,1 mmol) de 12. Después de 12 horas, se obtienen 7,54 g que se purifican por percolación en columna de sílice (Hex/AcOEt 9/1), aislándose 3,22 g (69\%) de alcohol 40.

\section{(3-tercbutildimeltilsiloxi-4-metoxifenil)(2,3,4-trimetoxifenil)metanol (40):}

RMN ${ }^{1} \mathbf{H}$ : (Fig. XXIIIa) 0,12 (6H, s, $\left.\mathrm{SiCH}_{3}\right)$; 0,97 (9H, s, $\left.t \mathrm{Bu}\right) ; 3,65$ (3H, s, $\mathrm{OCH}_{3}$ ); 3,78 (3H, s, $\left.\mathrm{OCH}_{3}\right) ; 3,85\left(3 \mathrm{H}, \mathrm{s}, \mathrm{OCH}_{3}\right) ; 3,87\left(3 \mathrm{H}, \mathrm{s}, \mathrm{OCH}_{3}\right) ; 5,82(1 \mathrm{H}, \mathrm{d} ; J=6,2$, $\mathrm{CHOH}) ; 6,64\left(1 \mathrm{H}, \mathrm{d} ; J=8,6, \mathrm{H}_{5}{ }^{*}\right) ; 6,79\left(1 \mathrm{H} \mathrm{d} ; J=8,6, \mathrm{H}_{5}\right) ; 6,86$ (1H, dd; $J=8,6 ; 2,2$, $\left.\mathrm{H}_{6}\right) ; 6,88\left(1 \mathrm{H}, \mathrm{d} ; J=2,2, \mathrm{H}_{2}\right) ; 6,94\left(1 \mathrm{H}, \mathrm{d} ; J=8,6, \mathrm{H}_{6}{ }^{*}\right)$.

*Asignación intercambiable.

RMN ${ }^{13}$ C: (Fig. XXIIIb) -4,6 (2) $\left(\mathrm{CH}_{3}\right) ; 18,5$ (C); 25,8 (3) $\left(\mathrm{CH}_{3}\right) ; 55,5\left(\mathrm{CH}_{3}\right) ; 56,0$ $\left(\mathrm{CH}_{3}\right) ; 60,7$ (2) $\left(\mathrm{CH}_{3}\right) ; 106,9(\mathrm{CH}) ; 111,7(\mathrm{CH}) ; 119,5(\mathrm{CH}) ; 119,7(\mathrm{CH}) ; 122,1$ (CH); 129,2 (C); 130,3 (C); 137,0 (C); 144,7 (C); 150,1 (C); 151,5 (C); 153,2 (C).

\section{Obtención de (3-tercbutildimeltilsiloxi-4-metoxifenil)(2,3,4-trimetoxifenil)} metanona (41).

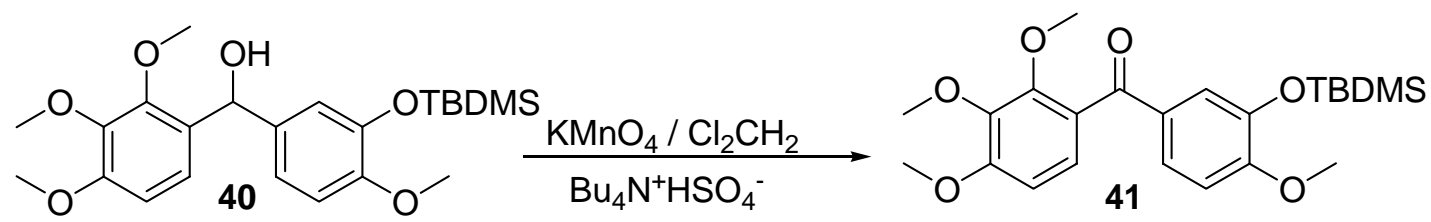

Siguiendo el método D2, a una solución de 2,02 g (4,65 mmol) de 40 en $100 \mathrm{~mL}$ de $\mathrm{CH}_{2} \mathrm{Cl}_{2}$, se añaden 3,50 g (22,15 mmol) de $\mathrm{KMnO}_{4}, 100 \mathrm{mg}$ de $\mathrm{Bu}_{4} \mathrm{~N}^{+} \mathrm{H}_{4} \mathrm{SO}_{4}{ }^{-}$y $2 \mathrm{~mL}$ de $\mathrm{H}_{2} \mathrm{O}$. Después de 24 horas, se obtienen 1,85 g (4,28 mmol, 92\%) de una mezcla de producto de oxidación 41 y de material de partida 39, que se utilizan sin purificación previa en el siguiente paso. $\mathrm{RMN}{ }^{1} \mathrm{H}$ del crudo de reacción: Figura XXIVa. 
Obtención de tercbutil\{2-metoxi-5-[1-(2,3,4-trimetoxifenil)vinil]fenoxi\} dimetilsilano (42).

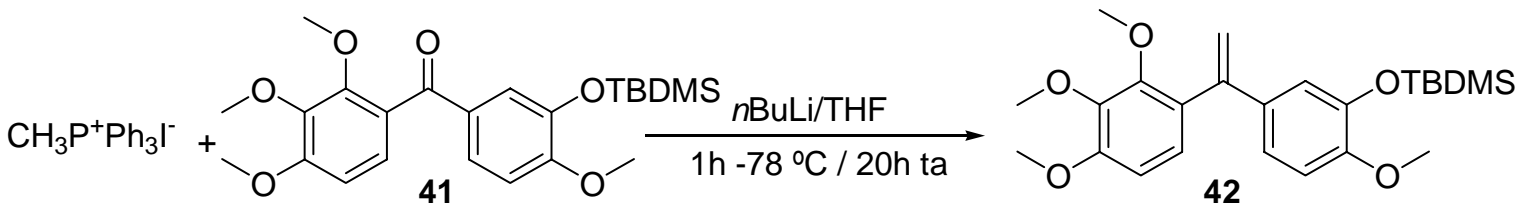

Siguiendo el método B, a una suspensión de 3,70 g (9,20 mmol) de ioduro de metiltrifenilfosfonio en $40 \mathrm{~mL}$ de THF seco, se añaden 4,31 mL (6,90 mmol) de $n$-Buli (1,6 M en hexano) y 1,00 g (2,31 mmol) de 41. Después de 16 horas, se obtienen 4,41 g que se purifican por cromatografía de columna (Hex-AcOEt 9:1) para dar $80 \mathrm{mg}$ (8\%) de 42 y $370 \mathrm{mg}$ (37\%) de 40, sin reaccionar.

\section{tercbutil\{2-metoxi-5-[1-(2,3,4-trimetoxifenil)vinil]fenoxi\}dimetilsilano (42):}

RMN ${ }^{1}$ H: (Fig. XXVa) 0,13 (6H, s, $\left.\mathrm{SiCH}_{3}\right) ; 0,98$ (9H, s, $\left.t \mathrm{Bu}\right) ; 3,54$ (3H, s, $\mathrm{OCH}_{3}$ ); 3,79 (3H, s, $\left.\mathrm{OCH}_{3}\right) ; 3,85\left(3 \mathrm{H}, \mathrm{s}, \mathrm{OCH}_{3}\right) ; 3,89\left(3 \mathrm{H}, \mathrm{s}, \mathrm{OCH}_{3}\right) ; 5,17(1 \mathrm{H}, \mathrm{d} ; J=1,4$, $\left.\mathrm{CH}_{2}\right)$; 5,51 (1H, d; $\left.J=1,4, \mathrm{CH}_{2}\right) ; 6,67\left(1 \mathrm{H}, \mathrm{d} ; J=8,6, \mathrm{H}_{5}{ }^{*}\right)$; $6,73\left(1 \mathrm{H}, \mathrm{d} ; J=8,6, \mathrm{H}_{6}{ }^{*}{ }^{*}\right.$ ); 6,80 (1H, dd; $\left.J=8,6 ; 2,2, \mathrm{H}_{4}\right) ; 6,89\left(1 \mathrm{H}, \mathrm{d} ; J=2,2, \mathrm{H}_{6}\right) ; 6,93\left(1 \mathrm{H}, \mathrm{d} ; J=8,6, \mathrm{H}_{3}\right)$.

* Asignación intercambiable

RMN ${ }^{13}$ C: (Fig. XXVb) -4,52 (2) $\left(\mathrm{CH}_{3}\right) ; 18,5(\mathrm{C}) ; 25,8$ (3) $\left(\mathrm{CH}_{3}\right) ; 55,5\left(\mathrm{CH}_{3}\right) ; 56,0$ $\left(\mathrm{CH}_{3}\right)$; 60,7 ( $\left(\mathrm{CH}_{3}\right) ; 60,8\left(\mathrm{CH}_{3}\right) ; 106,9(\mathrm{CH}) ; 111,4(\mathrm{CH}) ; 113,7\left(\mathrm{CH}_{2}\right) ; 119,4(\mathrm{CH})$; 120,3 (CH); 125,2 (CH); 132,2 (C); 134,9 (C); 142,3 (C); 144,6 (C); 146,4 (C); 150,6 (C); 151,6 (C); 153,5 (C).

\section{Obtención de 2-metoxi-5-[1-(2,3,4-trimetoxifenil)vinil]fenol (43).}

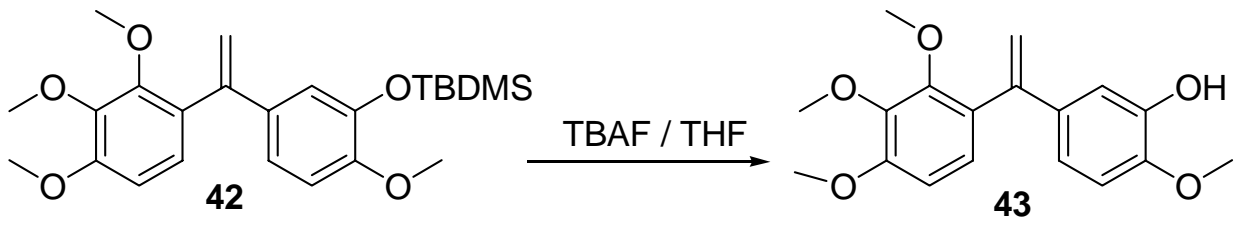

A una disolución de $80 \mathrm{mg}$ (0,19 mmol) de 42 en $2 \mathrm{~mL}$ de THF, se añaden 0,56 mL (0,56 mmol) de TBAF (1,0 M en THF). Después de 1 hora en agitación bajo atmósfera de argón, se vierte sobre agua y se extrae con éter 3 veces. El conjunto de las fases orgánicas se lava con disolución acuosa saturada de $\mathrm{NaCl}$, se seca con $\mathrm{Na}_{2} \mathrm{SO}_{4}$ anhidro, se filtra y se evapora hasta sequedad para obtener 57 mg (95\%) del producto desprotegido 43. 


\section{2-metoxi-5-[1-(2,3,4-trimetoxifenil)vinil]fenol (43):}

IR (película): 3415, 1593, 1266, 1095, $1024 \mathrm{~cm}^{-1}$.

RMN ${ }^{1} \mathbf{H}$ : (Fig. XXVIa) 3,57 (3H, s, $\left.\mathrm{OCH}_{3}\right) ; 3,85\left(3 \mathrm{H}, \mathrm{s}, \mathrm{OCH}_{3}\right) ; 3,86(3 \mathrm{H}, \mathrm{s}$, $\left.\mathrm{OCH}_{3}\right) ; 3,88\left(3 \mathrm{H}, \mathrm{s}, \mathrm{OCH}_{3}\right) ; 5,18\left(1 \mathrm{H}, \mathrm{d} ; J=1,6, \mathrm{CH}_{2}\right) ; 5,55\left(1 \mathrm{H}, \mathrm{d} ; J=1,6, \mathrm{CH}_{2}\right)$; 6,66 (1H, d; $J=8,6) ; 6,76$ (2H, d; $J=1,4) ; 6,92$ (2H, d; $J=8,2)$.

RMN ${ }^{13}$ C: (Fig. XXVIb) 56,0 (CH $)$; 56,1 $\left(\mathrm{CH}_{3}\right) ; 60,8\left(\mathrm{CH}_{3}\right) ; 60,9\left(\mathrm{CH}_{3}\right) ; 107,0$ $(\mathrm{CH}) ; 110,1(\mathrm{CH}) ; 113,0(\mathrm{CH}) ; 114,1\left(\mathrm{CH}_{2}\right) ; 118,7(\mathrm{CH}) ; 125,2(\mathrm{CH}) ; 129,2(\mathrm{C}) ;$ 135,4 (C); 142,3 (C); 145,2 (2) (C); 146,2 (2) (C); 153,5 (C).

EM: $316\left(\mathrm{M}^{+}\right)$.

HPLC: Columna $\mathrm{C}_{18} \quad \mathrm{t}_{\mathrm{R}}: 14,22 \mathrm{~min}$.

Columna $\mathrm{C}_{8} \quad \mathrm{t}_{\mathrm{R}}: 12,80 \mathrm{~min}$.

Columna fenílica $\quad t_{\mathrm{R}}: 13,04 \mathrm{~min}$. 



\section{IV.3.C. Sintesis de fenstatinas e isocombretastatinas con un resto indolilo.}

\section{Obtención de (1-metil-1H-indol-5-il)(3,4,5-trimetoxifenil)metanol (44).}<smiles>[CH2+]Oc1cc(C=O)cc(OC)c1OC</smiles>

Según el método C1, a una disolución de 5,30 g (25,2 mmol) de 5-bromo-N-metil$1 H$-indol en $40 \mathrm{~mL}$ de THF seco, se añaden 34,7 mL (55,2 mmol) de $n \operatorname{BuLi}$ (1,6 M en hexano) y 6,50 g (33,5 mmol) de 3,4,5-trimetoxibenzaldehído. Tras 24 horas de reacción, se obtienen 6,50 g (79\%) de producto bruto, el cual se purifica por cromatografía en columna sobre gel de sílice (eluyente: AcOEt) para dar 4 g (50\%) del compuesto 44.

\section{(1-metil-1H-indol-5-il)(3,4,5-trimetoxifenil)metanol (44):}

P. f.: $125-127^{\circ} \mathrm{C} .\left(\mathrm{Cl}_{2} \mathrm{CH}_{2} / \mathrm{Hex}\right)$.

IR (pastilla de $\mathrm{KBr}$ ): 3386, 1591, 1125, $734 \mathrm{~cm}^{-1}$.

RMN ${ }^{1} \mathbf{H}$ : (Fig. XXVIIa) 3,77 (3H, s, $\left.\mathrm{NCH}_{3}\right) ; 3,81\left(6 \mathrm{H}, \mathrm{s}, \mathrm{OCH}_{3}\right) ; 3,83(3 \mathrm{H}, \mathrm{s}$, $\left.\mathrm{OCH}_{3}\right) ; 5,88(1 \mathrm{H}, \mathrm{s}, \mathrm{CHOH}) ; 6,47\left(1 \mathrm{H}, \mathrm{d}, J=3,3, \mathrm{H}_{3}\right) ; 6,67\left(2 \mathrm{H}, \mathrm{s}, \mathrm{H}_{2}, \mathrm{H}_{6}\right.$ ); 7,06 $\left(1 \mathrm{H}, \mathrm{d}, J=3,3, \mathrm{H}_{2}\right) ; 7,22\left(1 \mathrm{H}, \mathrm{dd}, J=8,6 ; 1,8, \mathrm{H}_{6}\right) ; 7,29\left(1 \mathrm{H}, \mathrm{d}, J=8,6, \mathrm{H}_{7}\right) ; 7,62(1 \mathrm{H}$, d, $\left.J=1,8, \mathrm{H}_{4}\right)$.

RMN ${ }^{13}$ C: (Fig. XXVIIb) 32,9 ( $\left.\mathrm{NCH}_{3}\right) ; 56,1$ (2) $\left(\mathrm{OCH}_{3}\right) ; 60,9\left(\mathrm{OCH}_{3}\right) ; 76,9$ (CHOH); 101,2 (CH); 103,4 (2) (CH); 109,5 (CH); 119,2 (CH); 120,7 (CH); 128,4 (C); 129,5 (CH); 135,1 (C); 136,4 (C); 136,9 (C); 140,4 (C); 153,2 (2) (C).

EM: $311\left(\mathbf{M}^{+}\right)$. 


\section{Obtención de (1-metil-1H-indol-5-il)(3,4,5-trimetoxifenil)metanona (45):}<smiles>COc1cc(C(O)c2ccc3c(c2)cc(-c2ccccc2)n3C)cc(OC)c1OC</smiles>

Según el método D1, a una disolución de 2,97 g (9,1 mmol) de 44 en $50 \mathrm{~mL}$ de $\mathrm{CH}_{2} \mathrm{Cl}_{2}$, se añaden 5,12 g (13,6 mmol) de PDC. Tras 24 horas a temperatura ambiente, se obtienen 3,3 g de crudo de reacción, que se purifican mediante cromatografía de columna usando como eluyente Hex/AcOEt 7/3 para dar 1,92 g (65\%) del compuesto 45.

\section{(1-metil-1H-indol-5-il)(3,4,5-trimetoxifenil)metanona (45):}

IR (película): 1649, 1582, 820, $761 \mathrm{~cm}^{-1}$.

RMN ${ }^{1} \mathbf{H}$ : (Fig. XXVIIIa) 3,75 (3H, s, N-CH $)$; 3,81 (6H, s, $\left.\mathrm{OCH}_{3}\right) ; 3,90$ (3H, s, $\left.\mathrm{OCH}_{3}\right) ; 6,53\left(1 \mathrm{H}, \mathrm{d}, J=3,3, \mathrm{H}_{3}\right) ; 7,04\left(2 \mathrm{H}, \mathrm{s}, \mathrm{H}_{2}, \mathrm{H}_{6}\right.$ ) $)$ 7,08 (1H, d, $\left.J=3,3, \mathrm{H}_{2}\right) ; 7,32$ (1H, d, $\left.J=8,8, \mathrm{H}_{7}\right) ; 7,74$ (1H, dd, $\left.J=8,8 ; 1,8, \mathrm{H}_{6}\right) ; 8,09$ (1H, d, $\left.J=1,8, \mathrm{H}_{4}\right)$.

RMN ${ }^{13}$ C: (Fig. XXVIIIb) 33,1 ( $\left.\mathrm{NCH}_{3}\right) ; 56,4$ (2) $\left(\mathrm{OCH}_{3}\right) ; 61,0\left(\mathrm{OCH}_{3}\right) ; 103,0$ $(\mathrm{CH}) ; 107,8$ (2) (CH); 109,1 (CH); 123,8 (CH); 125,2 (CH); 127,7 (C); 129,3 (C); 130,5 (CH); 134,3 (C); 138,9 (C); 141,3 (C); 152,8 (2) (C); 196,4 (C).

EM: $325\left(\mathrm{M}^{+}\right)$.

\section{Obtención de 1-metil-5-[1-(3,4,5-trimetoxibenzoil)]-1H-indol-3-} carbaldehído (46).

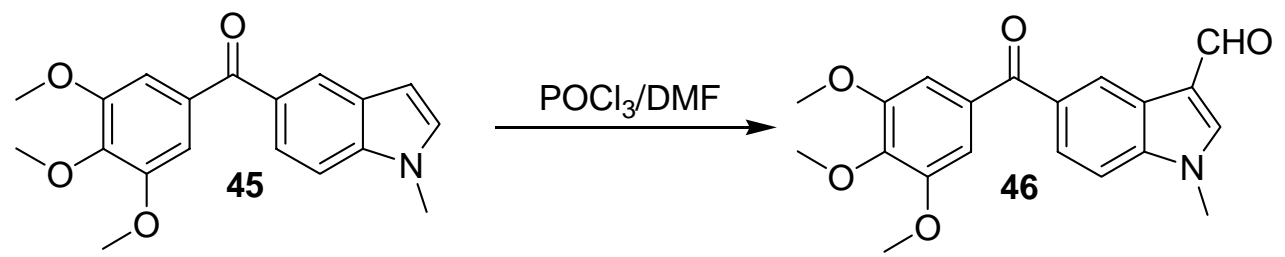

Siguiendo el método E, $160 \mathrm{mg}(0,49 \mathrm{mmol})$ de 45, $46 \mu \mathrm{L}(0,49 \mathrm{mmol})$ de $\mathrm{POCl}_{3} \mathrm{y}$ 0,60 mL de DMF reaccionan para dar 117 mg (68\%) del carbaldehído 46. 


\section{1-metil-5-[1-(3,4,5-trimetoxibenzoil)]-1H-indol-3-carbaldehído (46):}

RMN ${ }^{1} \mathbf{H}$ : (Fig. XXIXa) 3,79 (6H, s, $\left.\mathrm{OCH}_{3}\right) ; 3,85$ (3H, s, $\left.\mathrm{NCH}_{3}\right) ; 3,88$ (3H, s, $\left.\mathrm{OCH}_{3}\right) ; 7,03$ (2H, s, $\mathrm{H}_{2}$, $\mathrm{H}_{6}$ ); 7,37 (1H, d, $\left.J=8,4, \mathrm{H}_{7}\right) ; 7,74\left(1 \mathrm{H}, \mathrm{s}, \mathrm{H}_{2}\right) ; 7,79(1 \mathrm{H}$, dd; $\left.J=8,8 ; 1,4, \mathrm{H}_{6}\right) ; 8,67$ (1H, d, J=1,4, $\left.\mathrm{H}_{4}\right) ; 9$,88 (1H, s, CHO).

RMN ${ }^{13}$ C: (Fig. XXIXb) 33,9 ( $\left.\mathrm{NCH}_{3}\right) ; 56,3$ (2) $\left(\mathrm{OCH}_{3}\right) ; 61,0\left(\mathrm{OCH}_{3}\right) ; 107,9$ (2)

(CH); 110,1 (CH); 118,8 (C); 124,4 (C); 125,3 (CH); 125,9 (CH); 132,4 (C); 133,2 (C); 139,9 (C); 140,9 (CH); 141,7 (C); 152,8 (2) (C); 184,4 (CH); 195,7 (C).

$\begin{array}{cc}\text { HPLC: Columna } \mathrm{C}_{18} & \mathrm{t}_{\mathrm{R}}: 11,64 \mathrm{~min} . \\ \text { Columna } \mathrm{C}_{8} & \mathrm{t}_{\mathrm{R}}: 11,23 \mathrm{~min} . \\ \text { Columna fenílica } & \mathrm{t}_{\mathrm{R}}: 12,33 \mathrm{~min} .\end{array}$

Obtención de 1-metil-5-[1-(3,4,5-trimetoxifenil)vinil]-1H-indol (47).<smiles>C=C(c1cc(OC)c(OC)c(OC)c1)c1cc(OC)c(OC)c(C(=O)c2ccc3c(ccn3C)c2)c1</smiles>

Según el método B, a una suspensión de 6,72 g (16,6 mmol) de $\mathrm{CH}_{3} \mathrm{P}^{+} \mathrm{Ph}_{3}{ }^{-}$en 50 mL de THF seco, se añaden 19,9 mL (12,5 mmol) de $n B$ BuLi (1,6 M en hexano) y 1,92 g (5,9 mmol) de 45. Tras 24 horas y purificación por cromatografía en columna sobre gel de sílice, eluyendo con Hexano/AcOEt (7/3), se obtuvieron 1,60 g (84\%) del compuesto 47. 


\section{1-metil-5-[1-(3,4,5-trimetoxifenil)vinil]-1H-indol (47):}

IR: $1582 \mathrm{~cm}^{-1}$.

RMN ${ }^{1} \mathbf{H}$ : (Fig. XXXa) 3,80 (6H, s, $\left.\mathrm{OCH}_{3}\right) ; 3,82\left(3 \mathrm{H}, \mathrm{s}, \mathrm{NCH}_{3}\right) ; 3,88(3 \mathrm{H}, \mathrm{s}$, $\left.\mathrm{OCH}_{3}\right)$; 5,36 (1H, d; $\left.J=1,4, \mathrm{CH}_{2}\right) ; 5,43\left(1 \mathrm{H}, \mathrm{d} ; J=1,4, \mathrm{CH}_{2}\right) ; 6,48\left(1 \mathrm{H}, \mathrm{d}, J=2,8, \mathrm{H}_{3}\right)$; 6,61 (2H, s, $\left.\mathrm{H}_{2}, \mathrm{H}_{6}\right)$ ); 7,07 (1H, d, J=2,8, $\left.\mathrm{H}_{2}\right) ; 7,26\left(2 \mathrm{H}, \mathrm{sa}, \mathrm{H}_{6}, \mathrm{H}_{7}\right) ; 7,62(1 \mathrm{H}, \mathrm{d}$, $J=1,4, \mathrm{H}_{4}$ ).

RMN ${ }^{13}$ C: (Fig. XXXb) 33,0 (N-CH $)$; 56,2 (2) $\left(\mathrm{OCH}_{3}\right) ; 60,1\left(\mathrm{OCH}_{3}\right) ; 101,4(\mathrm{CH})$; 106,0 (2) (CH); 108,9 (CH); 112,5 ( $\left.\mathrm{CH}_{2}\right) ; 120,9(\mathrm{CH}) ; 122,5(\mathrm{CH}) ; 128,4(\mathrm{C}) ;$ 129,4 (CH); 132,8 (C); 136,6 (C); 137,8 (C); 138,5 (C); 151,2 (C); 152,9 (2) (C).

EM: $323\left(\mathrm{M}^{+}\right)$.

$\begin{array}{cc}\text { HPLC: Columna } \mathrm{C}_{18} & \mathrm{t}_{\mathrm{R}}: 13,05 \mathrm{~min} . \\ \text { Columna } \mathrm{C}_{8} & \mathrm{t}_{\mathrm{R}}: 12,10 \mathrm{~min} . \\ \text { Columna fenílica } & \mathrm{t}_{\mathrm{R}}: 11,51 \mathrm{~min} .\end{array}$

\section{Obtención de 1-metil-5-[1-(3,4,5-trimetoxifenil)etil]-1H-indol (48):}<smiles>C=C(c1cc(OC)c(OC)c(OC)c1)c1ccc2c(ccn2C)c1</smiles><smiles>O=C(O)CCCCCCO</smiles><smiles>COc1cc(C(C)c2ccc3c(ccn3C)c2)cc(OC)c1OC</smiles>

Según el método F, 26 mg (0,08 mmol) de 47 y 8 mg de $\mathrm{Pd} / \mathrm{C}$ en $8 \mathrm{~mL}$ de EtOH, bajo atmósfera de $\mathrm{H}_{2}$, reaccionan para dar $20 \mathrm{mg}$ (78\%) del compuesto 48.

\section{1-metil-5-[1-(3,4,5-trimetoxifenil)etil]-1H-indol (48):}

RMN ${ }^{1} \mathbf{H}$ : (Fig. XXXIa) 1,68 (3H, d; J=7,2, $\mathrm{CHCH}_{3}$ ); 3,74 (3H, s, $\left.\mathrm{CH}_{3}\right)$; 3,81 (6H, s, $\left.\mathrm{OCH}_{3}\right) ; 3,82\left(3 \mathrm{H}, \mathrm{s}, \mathrm{CH}_{3}\right) ; 4,20\left(1 \mathrm{H}, \mathrm{c} ; J=7,2, \mathrm{CHCH}_{3}\right) ; 6,44\left(1 \mathrm{H}, \mathrm{d} ; J=3,0, \mathrm{H}_{3}\right)$; 6,50 (2H, s, $\left.\mathrm{H}_{2}, \mathrm{H}_{6}\right)$ ); 7,02 (1H, d, $\left.J=3,0, \mathrm{H}_{2}\right) ; 7,09\left(1 \mathrm{H}, \mathrm{dd} ; J=8,4 ; 1,6, \mathrm{H}_{6}\right) ; 7,24$ (1H, d; $\left.J=8,4, \mathrm{H}_{7}\right) ; 7,49\left(1 \mathrm{H}, \mathrm{d}, J=1,6, \mathrm{H}_{4}\right)$.

RMN ${ }^{13}$ C: (Fig. XXXIb) 22,6 ( $\left(\mathrm{CH}_{3}\right) ; 32,9\left(\mathrm{NCH}_{3}\right) ; 45,1(\mathrm{CH}) ; 56,1$ (2) $\left(\mathrm{OCH}_{3}\right)$; $60,9\left(\mathrm{OCH}_{3}\right) ; 100,8(\mathrm{CH}) ; 104,7$ (2) $(\mathrm{CH}) ; 109,1(\mathrm{CH}) ; 119,0(\mathrm{CH}) ; 121,9(\mathrm{CH})$; 128,7 (CH); 132,1 (C); 135,5 (C); 136,0 (C); 137,3 (C); 143,2 (C); 153,0 (2) (C).
HPLC: Columna $\mathrm{C}_{18}$ $\mathrm{t}_{\mathrm{R}}: 17,31$ y $19,80 \mathrm{~min} .(2: 1)$.
Columna $\mathrm{C}_{8}$ $\mathrm{t}_{\mathrm{R}}: 15,76$ y 18,06 min. (2:1).
Columna fenílica $\mathrm{t}_{\mathrm{R}}: 16,02$ y $17,94 \min .(2: 1)$. 


\section{Obtención de 1-metil $\quad$-5-[1-(3,4,5-trimetoxifenil)vinil]-1H-indol-3-} carbaldehído (49).<smiles>C=C(c1cc(OC)c(OC)c(OC)c1)c1cc(OC)c(OC)c(C(=C)c2ccc3c(c2)c(CO)c(C(C)C)n3C)c1</smiles>

Siguiendo el método E, 1,6 g (4,94 mmol) de 47, 0,48 mL (5,2 mmol) de $\mathrm{POCl}_{3}$ y 5,5 mL de DMF generan 1,80 g de crudo de reacción. Tras sucesivas cristalizaciones y cromatografías en columna (eluyente Hex/AcOEt 4/6), se obtienen $230 \mathrm{mg}$ (13\%) de monoaldehído 49, 306 mg (16\%) de la mezcla de dialdehídos 50, 87 mg (4,6\%) del dialdehídos 50Z y 851 mg (47\%) de una mezcla de monoaldehído 49 y dialdehídos 50.

\section{1-metil -5-[1-(3,4,5-trimetoxifenil)vinil]-1H-indol-3-carbaldehído (49):}

P.f.: $156-158^{\circ} \mathrm{C}$. $\left(\mathrm{CH}_{2} \mathrm{Cl}_{2} / \mathrm{Hex}\right)$.

IR (película): 1656, 1457, 1124, $785 \mathrm{~cm}^{-1}$.

RMN ${ }^{1} \mathbf{H}$ : (Fig. XXXIIa) 3,75 (6H, s, $\left.\mathrm{OCH}_{3}\right) ; 3,82\left(3 \mathrm{H}, \mathrm{s}, \mathrm{NCH}_{3}\right)$; 3,86 (3H, s, $\left.\mathrm{OCH}_{3}\right) ; 5,42(1 \mathrm{H}, \mathrm{s}) ; 5,45(1 \mathrm{H}, \mathrm{s}) ; 6,54\left(2 \mathrm{H}, \mathrm{s} \mathrm{H}_{2}, \mathrm{H}_{6}\right.$ ); 7,26 (2H, s); 7,66 (1H, s); 8,34 (1H, s); 9,91 (1H, s, CHO).

RMN ${ }^{13}$ C: (Fig. XXXIIb) 33,8 ( $\left.\mathrm{NCH}_{3}\right) ; 56,1$ (2) $\left(\mathrm{OCH}_{3}\right) ; 60,9\left(\mathrm{OCH}_{3}\right) ; 105,6$ (2) (CH); 109,6 (CH); 114,1 ( $\left.\mathrm{CH}_{2}\right) ; 118,3(\mathrm{C}) ; 121,7(\mathrm{CH}) ; 125,1(\mathrm{CH}) ; 125,3(\mathrm{C}) ;$ 136,7 (C); 137,7 (C); 137,8 (C); 140,1 (CH); 150,4 (C); 152,9 (2) (C) 184,5 (CH).
HPLC: Columna $\mathrm{C}_{18}$ $t_{\mathrm{R}}: 14,25 \mathrm{~min}$.
Columna $\mathrm{C}_{8}$ $\mathrm{t}_{\mathrm{R}}: 13,61 \mathrm{~min}$.
Columna fenílica $t_{R}: 14,16 \min$. 


\section{(Z)1-metil-5-(3-oxo-1-(3,4,5-trimetoxifenil)prop-1-enil)-1H-indol-3- carbaldehído (50Z):}

P.f.: $196-198{ }^{\circ} \mathrm{C} .(\mathrm{MeOH})$.

RMN ${ }^{1} \mathbf{H}$ : (Fig. XXXIIIa) 3,81 (6H, s, $\left.\mathrm{OCH}_{3}\right) ; 3,90$ (3H, s, $\mathrm{NCH}_{3}$ ); 3,94 (3H, s, $\left.\mathrm{OCH}_{3}\right) ; 6,54\left(2 \mathrm{H}, \mathrm{s} \mathrm{H}{ }^{\prime}, \mathrm{H}_{6}{ }^{\prime}\right) ; 6,63(1 \mathrm{H}, \mathrm{d} ; J=8) ; 7,33(1 \mathrm{H}, \mathrm{m}) ; 7,34(1 \mathrm{H}, \mathrm{m}) ; 7,74$ $(1 \mathrm{H}, \mathrm{s}) ; 8,42(1 \mathrm{H}, \mathrm{sa}) ; 9,58(1 \mathrm{H}, \mathrm{d} ; J=8) ; 10,00$ (1H, s, CHO).

RMN ${ }^{13}$ C: (Fig. XXXIIIb) 33,9 (NCH $)$; 56,1 (2) $\left(\mathrm{OCH}_{3}\right) ; 61,0\left(\mathrm{OCH}_{3}\right) ; 108,3$ (2) (CH); 110,2 (CH); 118,5 (C); 122,8 (CH); 125,2 (CH); 125,4 (C); 127,2 (CH); 132,8 (2) (C); 134,7 (C); 139,1 (C); 140,5 (CH); 153,0 (2) (C); 163,2 (C); 184,5 (CH); 193,4 (CH).

$$
\begin{array}{cc}
\text { HPLC: Columna } \mathrm{C}_{18} & \mathrm{t}_{\mathrm{R}}: 11,96 \text { y 13,28 min. (4:1). } \\
\text { Columna } \mathrm{C}_{8} & \mathrm{t}_{\mathrm{R}}: 11,59 \text { y 12,69 min. (4:1). } \\
\text { Columna fenílica } & \mathrm{t}_{\mathrm{R}}: 12,79 \text { y 13,65 min. (4:1). }
\end{array}
$$

\section{(Z y $E) 1-m e t i l-5-(3-0 x 0-1-(3,4,5-t r i m e t o x i f e n i l) p r o p-1-e n i l)-1 H$-indol-3-}

\section{carbaldehído (50):}

RMN ${ }^{1} \mathbf{H}$ : (Fig. XXXIIIc) 3,64 (6H, s, $\left.\mathrm{OCH}_{3}\right)$; 3,71 (6H, s, $\left.\mathrm{OCH}_{3}\right) ; 3,79$ (3H, s, $\left.\mathrm{NCH}_{3}\right) ; 3,83\left(3 \mathrm{H}, \mathrm{s}, \mathrm{OCH}_{3}\right) ; 3,85\left(3 \mathrm{H}, \mathrm{s}, \mathrm{NCH}_{3}\right) ; 3,86\left(3 \mathrm{H}, \mathrm{s}, \mathrm{OCH}_{3}\right) ; 6,46(2 \mathrm{H}, \mathrm{s}$ $\mathrm{H}_{2}, \mathrm{H}_{6}$ ); 6,47 (1H, d; J=8); 6,48 (2H, s H $\mathrm{H}^{\prime}, \mathrm{H}_{6}$ ); 6,99 (1H, d, J=1,8); 7,17 (1H, m); 7,37 (1H, m); 7,70 (1H, m); 7,76 (1H, m); 8,22 (1H, sa); 8,32 (1H, sa); 9,35 (1H, da; $J=8) ; 9$,48 (1H, da; $J=8) ; 9,80$ (1H, s, CHO); 9,82 (1H, s, CHO).

RMN ${ }^{13}$ C: (Fig. XXXIIId) 33,9 (2) $\left(\mathrm{NCH}_{3}\right) ; 56,1$ (4) $\left(\mathrm{OCH}_{3}\right) ; 60,3\left(\mathrm{OCH}_{3}\right) ; 60,8$ $\left(\mathrm{OCH}_{3}\right) ; 106,4$ (2) (CH); 108,3 (2) (CH); 110,0 (CH); 110,3 (CH); 118,2 (C); 118,4 (C); 122,6 (CH); 124,8 (CH); 125,1 (CH); 125,3 (C); 126,8 (CH); 126,9 (CH); 128,4 (CH); 131,2 (C); 131,9 (C); 132,1 (C); 132,7 (2) (C); 134,5 (C); 135,9 (C); 138,9 (C); 139,1 (C); 140,1 (CH); 140,9 (CH); 152,8 (2) (C); 153,0 (2) (C); 163,0 (C); 163,2 (C) 184,4 (2) (CH); 193,2 (CH); 193,6 (CH).
HPLC: Columna $\mathrm{C}_{18}$ $t_{R}: 11,96$ y 13,85 min. (7:3).
Columna $\mathrm{C}_{8}$ $t_{\mathrm{R}}: 11,50$ y $12,89 \min .(7: 3)$.
Columna fenílica $t_{\mathrm{R}}: 12,82$ y $13,41 \min .(7: 3)$. 
Obtención de 1-metil -5-[1-(3,4,5-trimetoxifenil)vinil]-1H-indol-3ilmetanol (51).<smiles>C=C(c1cc(OC)c(OC)c(OC)c1)c1ccc2c(c1)c(C=O)cn2C</smiles>

Según el método G, $51 \mathrm{mg}(0,15 \mathrm{mmol})$ de 49 y $38 \mathrm{mg}$ (1 mmol) de $\mathrm{NaBH}_{4}$ en 10 $\mathrm{mL}$ de $\mathrm{MeOH}$ producen $39 \mathrm{mg}$ (74\%) del producto 51.

\section{1-metil -5-[1-(3,4,5-trimetoxifenil)vinil]-1H-indol-3-ilmetanol (51):}

IR (película): 3396, 1579, $1126 \mathrm{~cm}^{-1}$.

RMN ${ }^{1} \mathbf{H}$ : (Fig. XXXIVa) 3,77 (3H, s, $\left.\mathrm{NCH}_{3}\right) ; 3,79\left(6 \mathrm{H}, \mathrm{s}, \mathrm{OCH}_{3}\right) ; 3,89$ (3H, s, $\left.\mathrm{OCH}_{3}\right) ; 4,84$ (2H, s, $\left.\mathrm{CH}_{2} \mathrm{OH}\right) ; 5,39(1 \mathrm{H}, \mathrm{d} ; J=1,4) ; 5,45$ (1H, d; $\left.J=1,4\right) ; 6,62$ (2H, s, $\mathrm{H}_{2}, \mathrm{H}_{6}$ ); 7,07 (1H, s); 7,25 (2H, sa); 7,27 (1H, s).

RMN ${ }^{13}$ C: (Fig. XXXIVb) 32,9 (N-CH $) ; 56,2$ (2) $\left(\mathrm{OCH}_{3}\right) ; 57,0\left(\mathrm{CH}_{2}\right) ; 61,0$ $\left(\mathrm{OCH}_{3}\right) ; 105,8(2)(\mathrm{CH}) ; 109,0(\mathrm{CH}) ; 112,9\left(\mathrm{CH}_{2}\right) ; 115,1(\mathrm{C}) ; 119,0(\mathrm{CH}) ; 123,1$ (CH); 126,9 (C); 128,4 (CH); 133,0 (C); 137,1 (C); 137,6 (C); 138,3 (C); 151,0 (C); $152,8(2)(\mathrm{C})$.

$\begin{array}{cc}\text { HPLC: Columna } \mathrm{C}_{18} & \mathrm{t}_{\mathrm{R}}: 14,95 \mathrm{~min} . \\ \text { Columna } \mathrm{C}_{8} & \mathrm{t}_{\mathrm{R}}: 13,56 \mathrm{~min} . \\ \text { Columna fenílica } & \mathrm{t}_{\mathrm{R}}: 14,09 \mathrm{~min} .\end{array}$

Obtención de 1,3-dimetil-5-[1-(3,4,5-trimetoxifenil)etil]-1H-indol (52).<smiles>C=C(c1cc(OC)c(OC)c(OC)c1)c1ccc2c(c1)c(C=O)cn2C</smiles><smiles>O=CCO</smiles><smiles>[R6]Oc1cc(C(C)c2ccc3c(c2)c(C)cn3C)cc(OC)c1OC</smiles>

Según el método F, 20 mg (0,06 mmol) de 49 y 5 mg de Pd/C en 8 mL de EtOH, bajo atmósfera de $\mathrm{H}_{2}$, reaccionan para dar 16 mg (83\%) del compuesto 52. 


\section{1-3-dimetil-5-[1-(3,4,5-trimetoxifenil)etil]-1H-indol (52):}

RMN ${ }^{1} \mathbf{H}$ : (Fig. XXXVa) 1,70 (3H, d; J=7,2, $\left.\mathrm{CHCH}_{3}\right) ; 2,32\left(3 \mathrm{H}, \mathrm{s}, \mathrm{CH}_{3}\right) ; 3,70(3 \mathrm{H}$, s, $\left.\mathrm{NCH}_{3}\right) ; 3,82\left(9 \mathrm{H}, \mathrm{s}, \mathrm{OCH}_{3}\right) ; 4,22(1 \mathrm{H}, \mathrm{q} ; J=7,2) ; 6,51\left(2 \mathrm{H}, \mathrm{s}, \mathrm{H}_{2}, \mathrm{H}_{6}\right.$ ) $)$ 6,81 (1H, s); 7,07 (1H, dd; $\left.J=8,2 ; 1,8, \mathrm{H}_{6}\right) ; 7,19\left(1 \mathrm{H}, \mathrm{d} ; J=8,2, \mathrm{H}_{7}\right) ; 7,43\left(1 \mathrm{H}, \mathrm{sa}, \mathrm{H}_{4}\right)$.

RMN ${ }^{13}$ C: (Fig. XXXVb) 9,69 $\left(\mathrm{CH}_{3}\right) ; 22,8\left(\mathrm{CH}_{3}\right) ; 32,6\left(\mathrm{~N}-\mathrm{CH}_{3}\right) ; 45,2(\mathrm{CH}) ; 56,1$ (2) $\left(\mathrm{OCH}_{3}\right) ; 60,9\left(\mathrm{OCH}_{3}\right) ; 104,8(2)(\mathrm{CH}) ; 109,0(\mathrm{CH}) ; 110,0(\mathrm{C}) ; 117,1(\mathrm{CH})$; 121,7 (CH); 126,8 (CH); 128,6 (C); 135,7 (C); 136,0 (C); 136,5 (C); 143,4 (C); $153,0(2)(\mathrm{C})$.

$\begin{array}{cc}\text { HPLC: Columna } \mathrm{C}_{18} & \mathrm{t}_{\mathrm{R}}: 17,23 \text { y 18,52 min. (4:1) } \\ \text { Columna } \mathrm{C}_{8} & \mathrm{t}_{\mathrm{R}}: 15,79 \text { y 16,75 min. (4:1) } \\ \text { Columna fenílica } & \mathrm{t}_{\mathrm{R}}: 16,00 \text { y 16,73 min. (4:1) }\end{array}$

\section{Obtención de las oximas del 1-metil -5-[1-(3,4,5-trimetoxifenil)vinil]-1H- indol-3-carbaldehído (53).}<smiles>C=C(c1cc(OC)c(OC)c(OC)c1)c1ccc2c(c1)c(C=O)cn2C</smiles><smiles>C=C(c1cc(OC)c(OC)c(OC)c1)c1ccc2c(c1)c(/C=N\O)cn2C</smiles>

Según el método H, a una disolución de 157 mg (0,45 mmol) de 49 en 10 mL de $\mathrm{MeOH}$, se añaden $311 \mathrm{mg}$ (4,5 mmol) de clorhidrato de hidroxilamina y dos gotas de piridina. Tras 23 horas de reacción, se obtienen $145 \mathrm{mg}$ (88\%) de una mezcla 1:1 de las oximas $53 Z$ y $\mathbf{5 3 E}$, que se separan mediante CC, para dar $34 \mathrm{mg}$ (21\%) de uno de los isómeros y $53 \mathrm{mg}$ (32\%) del otro isómero. Cuando estas oximas se mantienen en disolución, se isomerizan para dar la mezcla obtenida inicialmente. 


\section{Oxima de 1-metil -5-[1-(3,4,5-trimetoxifenil)vinil]-1H-indol-3-carbaldehído}

\section{(53Z ó E).}

P.f.: $162-164{ }^{\circ} \mathrm{C} .\left(\mathrm{CH}_{2} \mathrm{Cl}_{2} / \mathrm{Hex}\right)$.

IR (película): 3450, 1579, $1093 \mathrm{~cm}^{-1}$.

RMN ${ }^{1} \mathbf{H}$ : (Fig. XXXVIa) 3,80 (9H, s, $\left.\mathrm{CH}_{3}\right)$; 3,89 (3H, s, $\left.\mathrm{CH}_{3}\right) ; 5,41$ (1H, s); 5,48 (1H, s); 6,60 (2H, s H${ }_{2}, H_{6}$ ); 7,25 (2H, s); 7,27 (1H, s); 8,15 (1H, s); 8,32 (1H, s).

RMN ${ }^{13}$ C: (Fig. XXXVIb) 33,3 ( $\left.\mathrm{NCH}_{3}\right) ; 56,2$ (2) $\left(\mathrm{OCH}_{3}\right) ; 61,0\left(\mathrm{OCH}_{3}\right) ; 105,8$ (2) $(\mathrm{CH}) ; 109,1(\mathrm{CH}) ; 113,4\left(\mathrm{CH}_{2}\right) ; 118,2(\mathrm{C}) ; 121,8(\mathrm{CH}) ; 124,0(\mathrm{CH}) ; 125,2$ (2) (C); 131,8 (CH); 134,6 (C); 137,5 (C); 138,1 (C); 145,5 (CH); 150,8 (C); 152,8 (2) (C).

HPLC: Columna $\mathrm{C}_{18} \quad \mathrm{t}_{\mathrm{R}}$ : 14,92 y 15,50 min. (1:1). Columna $\mathrm{C}_{8} \quad \mathrm{t}_{\mathrm{R}}: 13,67$ y $13,97 \mathrm{~min} .(1: 1)$. Columna fenílica $\quad t_{R}: 14,41$ y 14,69 min. (1:1).

\section{Oxima de 1-metil -5-[1-(3,4,5-trimetoxifenil)vinil]-1H-indol-3-carbaldehído} (53Z ó E).

P.f.: $162-164{ }^{\circ} \mathrm{C} .\left(\mathrm{CH}_{2} \mathrm{Cl}_{2} / \mathrm{Hex}\right)$.

IR (película): 3450, 1579, $1093 \mathrm{~cm}^{-1}$.

RMN ${ }^{1} \mathbf{H}$ : (Fig. XXXVIa) 3,80 (6H, s, $\left.\mathrm{OCH}_{3}\right) ; 3,85\left(3 \mathrm{H}, \mathrm{s}, \mathrm{NCH}_{3}\right) ; 3,90(3 \mathrm{H}, \mathrm{s}$, $\left.\mathrm{OCH}_{3}\right) ; 5,44(1 \mathrm{H}, \mathrm{s}) ; 5,46(1 \mathrm{H}, \mathrm{s}) ; 6,60\left(2 \mathrm{H}, \mathrm{s} \mathrm{H}_{2}, \mathrm{H}_{6}\right.$ ); 7,31 (2H, s); 7,77 (1H s); 7,80 (1H, s); 8,27 (1H, s).

RMN ${ }^{13}$ C: (Fig. XXXVIb) 33,4 (N-CH $) ; 56,2$ (2) $\left(\mathrm{OCH}_{3}\right) ; 61,0\left(\mathrm{OCH}_{3}\right) ; 105,7$ (2) $(\mathrm{CH}) ; 109,4(\mathrm{CH}) ; 113,3\left(\mathrm{CH}_{2}\right) ; 118,2(\mathrm{CH}) ; 123,5(\mathrm{CH}) ; 127,2$ (2) (C); 134,4 (C); 135,7 (CH); 135,7 (C); 137,7 (C); 138,0 (CH); 139,5 (C); 150,8 (C); 152,9 (2) (C). HPLC: Columna $\mathrm{C}_{18} \quad \mathrm{t}_{\mathrm{R}}$ : 14,92 y $15,50 \mathrm{~min}$. (1:1). Columna $\mathrm{C}_{8} \quad \mathrm{t}_{\mathrm{R}}: 13,67$ y $13,97 \mathrm{~min} .(1: 1)$. Columna fenílica $\quad t_{R}: 14,41$ y 14,69 min. (1:1). 


\section{Obtención de 1-metil -5-[1-(3,4,5-trimetoxifenil)vinil]-1H-indol-3- carbonitrilo (54).}<smiles>C=C(c1cc(OC)c(OC)c(OC)c1)c1cc(OC)c(OC)c(C(=C)c2cc(OC)c(OC)c(OC)c2)c1</smiles>

$85 \mathrm{mg}(0,23 \mathrm{mmol})$ de la mezcla de oximas $\mathbf{5 3 Z}+\mathbf{5 3 \boldsymbol { E }}$ se disuelven en $0,4 \mathrm{~mL}$ de piridina y posteriormente se añaden $0,4 \mathrm{~mL}$ de anhídrido acético. Tras 4 horas en agitación, la mezcla de reacción se recoge sobre $\mathrm{HCl} 2 \mathrm{~N}$ y AcOEt, se lava con $\mathrm{NaOH} 4 \%$ hasta neutralización de las aguas de lavado y por último se lava con una disolución acuosa saturada de $\mathrm{NaCl}$. Se seca con $\mathrm{Na}_{2} \mathrm{SO}_{4}$ anhidro y se evapora. El crudo de reacción se purifica por cromatografía en columna de gel de sílice (eluyente $\mathrm{CH}_{2} \mathrm{Cl}_{2} / \mathrm{AcOEt}$ 95/5) y se obtienen 27 mg (34\%) del carbonitrilo 54 y 20 mg (21\%) de la mezcla de acetatos 55Z + $\mathbf{5 5 E}$. Los acetatos obtenidos se degradan en disolución.

\section{1-metil -5-[1-(3,4,5-trimetoxifenil)vinil]-1H-indol-3-carbonitrilo (54):}

IR (película): 2216, 1580, $1125 \mathrm{~cm}^{-1}$.

RMN ${ }^{1} \mathbf{H}$ : (Fig. XXXVIIa) 3,80 (6H, s, $\left.\mathrm{CH}_{3}\right)$; 3,87 (3H, s, $\left.\mathrm{CH}_{3}\right)$; 3,89 (3H, s, $\mathrm{CH}_{3}$ ); 5,46 (2H, s); 6,55 (2H, s, $\mathrm{H}_{2}, \mathrm{H}_{6}$ ); 7,34 (2H, s); 7,54 (1H, s); 7,77 (1H, s).

RMN ${ }^{13}$ C: (Fig. XXXVIIb) 33,8 ( $\left.\mathrm{NCH}_{3}\right) ; 56,1$ (2) $\left(\mathrm{OCH}_{3}\right) ; 61,0\left(\mathrm{OCH}_{3}\right) ; 85,8(\mathrm{C})$; 105,8 (2) (CH); 110,0 (CH); 114,2 ( $\left.\mathrm{CH}_{2}\right) ; 115,9(\mathrm{C}) ; 119,6(\mathrm{CH}) ; 124,9(\mathrm{CH})$; 127,9 (C); 135,8 (C); 135,9 (CH); 136,1 (C); 137,6 (C); 138,2 (C); 150,2 (C); 153,0 (2) (C).

Acetil oxima de 1-metil -5-[1-(3,4,5-trimetoxifenil)vinil]-1H-indol-3carbaldehído (55Z ó E).

RMN ${ }^{1} \mathbf{H}$ : (Fig. XXXVIIIa) 2,21 (3H, s, $\left.\mathrm{CH}_{3}\right) ; 3,78\left(6 \mathrm{H}, \mathrm{s}, \mathrm{CH}_{3}\right) ; 3,84(3 \mathrm{H}, \mathrm{s}$, $\left.\mathrm{CH}_{3}\right) ; 3,87\left(3 \mathrm{H}, \mathrm{s}, \mathrm{CH}_{3}\right) ; 5,42(1 \mathrm{H}, \mathrm{s}) ; 5,49(1 \mathrm{H}, \mathrm{s}) ; 6,57\left(2 \mathrm{H}, \mathrm{s} \mathrm{H}_{2^{\prime}}, \mathrm{H}_{6}{ }^{\prime}\right) ; 7,06(1 \mathrm{H}$, s); 7,27 (1H, s); 7,46 (1H, s); 8,17 (1H, s); 8,50 (1H, s). 


\section{Obtención de 1-metil-5-[1-(3,4,5-trimetoxifenil)vinil]-1H-indol-3-ilmetilen hidrazona (56).}<smiles>C=C(c1cc(OC)c(OC)c(OC)c1)c1ccc2c(c1)c(C=O)cn2C</smiles>

Según el método I, a una disolución de 154 mg (0,44 mmol) de 49 en 10 mL de $\mathrm{MeOH}$ se añade hidrato de hidrazina en exceso y dos gotas de ácido acético. Tras 24 horas de reacción, después de estraer y lavar el crudo de reacción y tratada la mezcla, se obtienen $138 \mathrm{mg}(86 \%)$ de la mezcla de las hidrazonas $\mathbf{5 6 Z}$ y $\mathbf{5 6 E}$.

\section{1-metil-5-[1-(3,4,5-trimetoxifenil)vinil]-1H-indol-3-ilmetilen hidrazona}

\section{$(56 Z+E):$}

RMN ${ }^{1} \mathbf{H}$ : (Fig. XXXIXa) 3,81 (9H, s, $\left.\mathrm{OCH}_{3}\right) ; 3,83\left(6 \mathrm{H}, \mathrm{s}, \mathrm{OCH}_{3}\right) ; 3,85(6 \mathrm{H}, \mathrm{s}$, $\mathrm{NCH}_{3}$ ); 3,90 (3H, s, $\left.\mathrm{OCH}_{3}\right) ; 5,47$ (2H, s, $\left.\mathrm{CH}_{2}\right) ; 5,54\left(2 \mathrm{H}, \mathrm{s}, \mathrm{CH}_{2}\right) ; 6,56\left(2 \mathrm{H}, \mathrm{s}, \mathrm{H}_{2}\right.$, $\mathrm{H}_{6}$ ); 6,66 (2H, s, $\mathrm{H}_{2}, \mathrm{H}_{6}$ ); 7,01-7,50 (6H, m, $\left.\mathrm{H}_{4}, \mathrm{H}_{6}, \mathrm{H}_{7}\right) ; 8,40\left(1 \mathrm{H}, \mathrm{s}, \mathrm{H}_{2}\right) ; 8,57$ $\left(1 \mathrm{H}, \mathrm{s}, \mathrm{H}_{2}\right)$; 8,71 (1H, s, $\left.\mathrm{CH}=\mathrm{NH}_{2}\right) ; 8,93\left(1 \mathrm{H}, \mathrm{s}, \mathrm{CH}=\mathrm{NH}_{2}\right)$.

RMN ${ }^{13}$ C: (Fig. XXXIXb) 33,4 (2) $\left(\mathrm{NCH}_{3}\right) ; 56,2$ (4) $\left(\mathrm{OCH}_{3}\right) ; 61,0$ (2) $\left(\mathrm{OCH}_{3}\right)$; 104,9 (2) (CH); 105,8 (2) (CH); 109,1 (CH); 109,6 (CH); 112,0 (C); 112,5 (C); 113,3 $\left(\mathrm{CH}_{2}\right) ; 120,9(\mathrm{CH}) ; 122,5(\mathrm{CH}) ; 123,3(\mathrm{CH}) ; 124,0(\mathrm{CH}) ; 126,0$ (2) (C); 134,0 (C); 134,6 (CH); 134,7 (CH); 136,1 (C); 136,6 (C); 137,7 (2) (C); 138,2 (C); 139,5 (C); 142,9 (C); 150,9 (C); 152,8 (2) (C); 153,1 (2) (CH); 155,0 (C). 


\section{Obtención de (1-metil-1H-indol-5-il)(2,3,4-trimetoxifenil)metanol (57).}<smiles>COc1ccc(C=O)c(OC)c1OC</smiles>

Según el método C3, $500 \mathrm{mg}(2,14 \mathrm{mmol})$ de 10,3,3 mL (5,2 mmol) de $n$ BuLi y $564 \mathrm{mg}$ (2,9 mmol) de 2,3,4-trimetoxibenzaldehído reaccionan durante 24 horas. El crudo de reacción se purifica mediante cromatografía en columna sobre gel de sílice con Hex/AcOEt (7/3) y se obtienen 550 mg (71\%) del compuesto 57.

\section{(1-metil-1H-indol-5-il)(2,3,4-trimetoxifenil)metanol (57):}

IR(película): 3445, 1600, $1513 \mathrm{~cm}^{-1}$.

RMN ${ }^{1} \mathbf{H}$ : (Fig. XLa) 3,65 (3H, s, N-CH $)$; 3,76 (3H, s, $\left.\mathrm{OCH}_{3}\right)$; 3,85 (3H, s, $\left.\mathrm{OCH}_{3}\right)$; 3,87 (3H, s, $\left.\mathrm{OCH}_{3}\right) ; 6,11(1 \mathrm{H}, \mathrm{s}, \mathrm{CHOH}) ; 6,46\left(1 \mathrm{H}, \mathrm{d}, J=3,1, \mathrm{H}_{3}\right) ; 6,65(1 \mathrm{H}, \mathrm{d}$, $\left.J=8,4 \mathrm{H}_{5}{ }^{*}\right) ; 7,04\left(1 \mathrm{H}, \mathrm{d}, J=3,1, \mathrm{H}_{2}\right) ; 7,07\left(1 \mathrm{H}, \mathrm{d}, J=8,4, \mathrm{H}_{6}{ }^{*}\right) ; 7,27\left(2 \mathrm{H}, \mathrm{sa}, \mathrm{H}_{6}\right.$, $\left.\mathrm{H}_{7}\right) ;$ 7,64 (1H, sa, $\left.\mathrm{H}_{4}\right)$.

*Asignación intercambiable.

RMN ${ }^{13}$ C: (Fig. XLb) 32,9 (N-CH $)$; 56,1 $\left(\mathrm{OCH}_{3}\right) ; 60,9$ (2) $\left(\mathrm{OCH}_{3}\right) ; 72,5(\mathrm{CHOH})$; 101,2 (CH); 107,1 (CH); 109,1 (CH); 118,9 (CH); 120,9 (CH); 122,2 (CH); 128,4 (C); 129,3 (CH); 131,0 (C); 135,3 (C); 136,2 (C); 142,2 (C); 151,3 (C); 153,1 (C).
HPLC: Columna $\mathrm{C}_{18}$ $t_{R}: 9,71$ min.
Columna $\mathrm{C}_{8}$ $t_{R}: 9,29$ min.
Columna fenílica $t_{\mathrm{R}}: 9,05 \min$.

\section{Obtención de (1-metil-1H-indol-5-il)(2,3,4-trimetoxifenil)metanona (58).}<smiles>COc1ccc(C(O)c2ccc3c(c2)cc(-c2c(Cl)c4ccccc4n2C)n3C)c(OC)c1OC</smiles>

Según el método D1, a una disolución de 1,60 g (4,9 mmol) de 57 en $50 \mathrm{~mL}$ de $\mathrm{CH}_{2} \mathrm{Cl}_{2}$, se añaden 2,76 g $(7,35 \mathrm{mmol})$ de PDC. Tras 4 horas a temperatura ambiente, se obtienen 1,4 g de producto bruto que se cromatografía en columna sobre gel de sílice, usando como eluyente Hex/AcOEt 7/3, para obtener 747 mg (47\%) de 58. 


\section{(1-metil-1H-indol-5-il)(2,3,4-trimetoxifenil)metanona (58):}

P.f.: $104-106^{\circ} \mathrm{C} .\left(\mathrm{CH}_{2} \mathrm{Cl}_{2} / \mathrm{Hex}\right)$.

IR (película): 1651, 1579, $820 \mathrm{~cm}^{-1}$.

RMN ${ }^{1} \mathbf{H}$ : (Fig. XLIa) 3,77 (3H, s, $\left.\mathrm{NCH}_{3}\right)$; 3,83 (3H, s, $\left.\mathrm{OCH}_{3}\right)$; 3,92 (3H, s, $\left.\mathrm{OCH}_{3}\right)$; 3,93 (3H, s, $\left.\mathrm{OCH}_{3}\right) ; 6,55\left(1 \mathrm{H}, \mathrm{d}, J=3,2, \mathrm{H}_{3}\right) ; 6,73\left(1 \mathrm{H}, \mathrm{d}, J=8,6, \mathrm{H}_{5},{ }^{*}\right) ; 7,10(1 \mathrm{H}, \mathrm{d}$, $\left.J=3,2, \mathrm{H}_{2}\right) ; 7,11\left(1 \mathrm{H}, \mathrm{d}, J=8,6, \mathrm{H}_{6}{ }^{*}\right)$; 7,35 (1H, d, $\left.J=8,6, \mathrm{H}_{7}\right) ; 7,85$ (1H, dd; $J=8,6$;

$\left.1,6, \mathrm{H}_{6}\right) ; 8,10\left(1 \mathrm{H}, \mathrm{d}, J=1,6, \mathrm{H}_{4}\right)$.

*Asignación intercambiable.

RMN ${ }^{13}$ C: (Fig. XLIb) 33,0 (N-CH $)$; 56,1 $\left(\mathrm{OCH}_{3}\right) ; 61,0\left(\mathrm{OCH}_{3}\right) ; 61,8\left(\mathrm{OCH}_{3}\right)$; 103,1 (CH); 106,8 (CH); 108,9 (CH); 123,4 (CH); 124,4 (CH); 125,4 (CH); 127,8 (2) (C); 130,4 (CH); 139,3 (C); 139,9 (C); 142,2 (C); 152,4 (C); 155,5 (C); 195,7 (C).

$\begin{array}{cc}\text { HPLC: Columna } \mathrm{C}_{18} & \mathrm{t}_{\mathrm{R}}: 10,79 \mathrm{~min} . \\ \text { Columna } \mathrm{C}_{8} & \mathrm{t}_{\mathrm{R}}: 10,22 \mathrm{~min} . \\ \text { Columna fenílica } & \mathrm{t}_{\mathrm{R}}: 9,99 \mathrm{~min} .\end{array}$

\section{Obtención de 1-metil-5-[1-(2,3,4-trimetoxifenil)vinil]-1H-indol (59).}

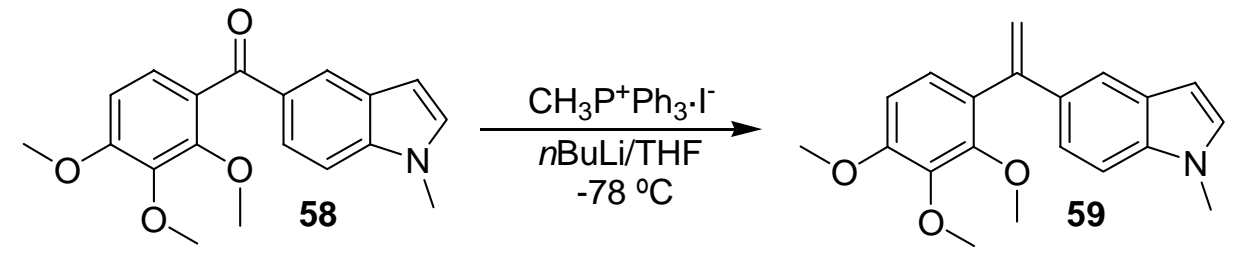

Según el método B, a una suspensión de 3,24 g (8,05 mmol) de yoduro de metiltrifenilfosfonio en $40 \mathrm{~mL}$ de THF seco, se añaden 4,30 mL (6,90 mmol) de $n$ BuLi (1,6 M en hexano) y $747 \mathrm{mg}(2,30 \mathrm{mmol})$ de 58. Tras 24 horas y purificación por cromatografía en columna sobre gel de sílice, eluyendo con Hexano/AcOEt (8:2), se obtienen 493 mg (66\%) del compuesto 59. 


\section{1-metil-5-[1-(2,3,4-trimetoxifenil)vinil]-1H-indol (59):}

IR (película): 1595, 1493, $888 \mathrm{~cm}^{-1}$.

RMN ${ }^{1} \mathbf{H}$ : (Fig. XLIIa) 3,55 (3H, s, $\left.\mathrm{NCH}_{3}\right)$; 3,78 (3H, s, $\left.\mathrm{OCH}_{3}\right) ; 3,90$ (3H, s, $\left.\mathrm{OCH}_{3}\right) ; 3,92\left(3 \mathrm{H}, \mathrm{s}, \mathrm{OCH}_{3}\right) ; 5,27\left(1 \mathrm{H}, \mathrm{d}, J=1,8, \mathrm{CH}_{2}\right) ; 5,66\left(1 \mathrm{H}, \mathrm{d}, J=1,8, \mathrm{CH}_{2}\right)$; $6,45\left(1 \mathrm{H}, \mathrm{d}, J=3,1, \mathrm{H}_{3}\right) ; 6,71\left(1 \mathrm{H}, \mathrm{d}, J=8,6 \mathrm{H}_{5}{ }^{*}\right) ; 7,02\left(1 \mathrm{H}, \mathrm{d}, J=8,6, \mathrm{H}_{6},{ }^{*}\right) ; 7,03$ (1H, d, $\left.J=3,1, \mathrm{H}_{2}\right) ; 7,23-7,31\left(2 \mathrm{H}, \mathrm{m}, \mathrm{H}_{6}, \mathrm{H}_{7}\right) ; 7,55$ (1H, sa, $\left.\mathrm{H}_{4}\right)$.

* Asignación intercambiable.

RMN ${ }^{13}$ C: (Fig. XLIIb) 32,9 (N-CH 3$) ; 56,1\left(\mathrm{OCH}_{3}\right) ; 60,7\left(\mathrm{OCH}_{3}\right) ; 60,9\left(\mathrm{OCH}_{3}\right)$; 101,9 (CH); 107,3 (CH); 109,3 (CH); 113,6 ( $\left.\mathrm{CH}_{2}\right) ; 120,4(\mathrm{CH}) ; 120,9(\mathrm{CH}) ; 123,3$ (CH); 125,4 (C); 127,6 (C); 128,2 (C); 129,5 (CH); 137,4 (C); 142,4 (C); 151,4 (C); 154,2 (C); 156,7 (C).
HPLC: Columna $\mathrm{C}_{18}$ $t_{R}: 13,24$ min.
Columna $\mathrm{C}_{8}$ $t_{\mathrm{R}}: 12,32 \mathrm{~min}$.
Columna fenílica $\mathrm{t}_{\mathrm{R}}: 11,63 \mathrm{~min}$.

\section{Obtención de 1-metil-5-[1-(2,3,4-trimetoxifenil)vinil]-1H-indol-3- carbaldehído (60).}

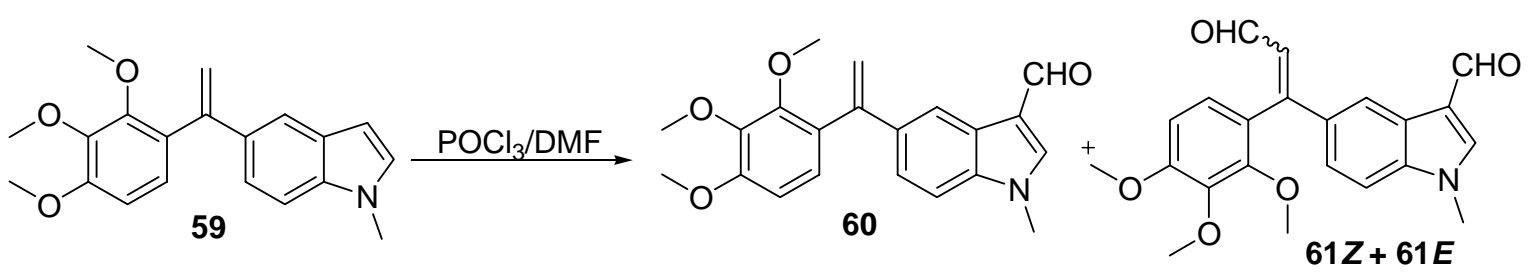

Siguiendo el método F, $318 \mathrm{mg}(0,98 \mathrm{mmol})$ de 59, 0,093 mL (0,99 mmol) de $\mathrm{POCl}_{3}$ y $1 \mathrm{~mL}$ de DMF, generan $214 \mathrm{mg}$ de crudo de reacción, que se purifican mediante cromatografía en columna (eluyente Hex/AcOEt 4/6) para dar 36 mg (10\%) de monoaldehído 60 y 62 mg (16\%) de una mezcla de dialdehídos $61 Z+61 E$. 


\section{1-metil-5-[1-(2,3,4-trimetoxifenil)vinil]-1H-indol-3-carbaldehído(60):}

IR (película): 1657, $1095 \mathrm{~cm}^{-1}$.

RMN ${ }^{1} \mathbf{H}$ : (Fig. XLIIIa) 3,51 (3H, s, $\left.\mathrm{OCH}_{3}\right) ; 3,81$ (3H, s, $\left.\mathrm{NCH}_{3}\right) ; 3,85$ (3H, s, $\left.\mathrm{OCH}_{3}\right) ; 3,89\left(3 \mathrm{H}, \mathrm{s}, \mathrm{OCH}_{3}\right) ; 5,31(1 \mathrm{H}, \mathrm{s}) ; 5,66(1 \mathrm{H}, \mathrm{s}) ; 6,69\left(1 \mathrm{H}, \mathrm{d}, J=8,6, \mathrm{H}_{5}\right.$ ); 6,99 (1H, d, J=8,6, H $\left.6^{\prime}\right) ; 7,24(2 \mathrm{H}, \mathrm{s}) ; 7,61(1 \mathrm{H}, \mathrm{m}) ; 8,29(1 \mathrm{H}, \mathrm{s}) ; 9,92(1 \mathrm{H}, \mathrm{s}$, $\mathrm{CHO})$.

RMN ${ }^{13}$ C: (Fig. XLIIIb) 33,8 $\left(\mathrm{NCH}_{3}\right) ; 56,1\left(\mathrm{OCH}_{3}\right) ; 60,7\left(\mathrm{OCH}_{3}\right) ; 61,0\left(\mathrm{OCH}_{3}\right)$; $107,1(\mathrm{CH}) ; 109,4(\mathrm{CH}) ; 115,4\left(\mathrm{CH}_{2}\right) ; 118,3(\mathrm{C}) ; 119,8(\mathrm{CH}) ; 123,6(\mathrm{CH}) ; 125,4$ (CH); 125,4 (C); 129,5 (C); 137,4 (C); 137,5 (C); 139,7 (CH); 142,4 (C); 147,3 (C); 151,7 (C); 153,5 (C) 184,3 (CH).
HPLC: Columna $\mathrm{C}_{18}$ $\mathrm{t}_{\mathrm{R}}: 14,56 \mathrm{~min}$.
Columna $\mathrm{C}_{8}$ $\mathrm{t}_{\mathrm{R}}: 13,52 \mathrm{~min}$.
Columna fenílica $t_{R}: 14,14$ min.

\section{(Z y E)1-metil-5-(3-oxo-1-(2,3,4-trimetoxifenil)prop-1-enil)-1H-indol-3- carbaldehído $(61 Z$ y $E)$ :}

RMN ${ }^{1} \mathbf{H}$ : (Fig. LIVa) 3,44 (3H, s, $\mathrm{CH}_{3}$ ); 3,50 (3H, s, $\mathrm{CH}_{3}$ ); 3,80 (3H, s, $\mathrm{CH}_{3}$ ); 3,84 $\left(3 \mathrm{H}, \mathrm{s}, \mathrm{CH}_{3}\right) ; 3,86\left(3 \mathrm{H}, \mathrm{s}, \mathrm{CH}_{3}\right) ; 3,88\left(3 \mathrm{H}, \mathrm{s}, \mathrm{CH}_{3}\right) ; 3,89\left(3 \mathrm{H}, \mathrm{s}, \mathrm{CH}_{3}\right) ; 3,91(3 \mathrm{H}, \mathrm{s}$, $\left.\mathrm{CH}_{3}\right) ; 6,49(1 \mathrm{H}, \mathrm{d} ; J=8) ; 6,65(1 \mathrm{H}, \mathrm{d} ; J=8) ; 6,73(1 \mathrm{H}, \mathrm{d} ; J=8,6) ; 6,87(1 \mathrm{H}, \mathrm{d} ; J=8,6)$; 6,92 (1H, d, $J=8,6) ; 7,23-7,42(4 \mathrm{H}, \mathrm{m}) ; 7,68(1 \mathrm{H}, \mathrm{s}) ; 7,73(1 \mathrm{H}, \mathrm{s}) ; 8,21(1 \mathrm{H}, \mathrm{sa})$; 8,32 (1H, sa); 9,47 (1H, da; J=8); 9,51 (1H, da; $J=8) ; 9,89$ (1H, s, CHO); 9,90 (1H, $\mathrm{s}, \mathrm{CHO})$.

RMN ${ }^{13}$ C: (Fig. LIVb) 33,9 (2) $\left(\mathrm{NCH}_{3}\right) ; 56,1$ (2) $\left(\mathrm{OCH}_{3}\right) ; 60,9$ (4) $\left(\mathrm{OCH}_{3}\right) ; 107,0$ $(\mathrm{CH}) ; 109,6(\mathrm{CH}) ; 110,1(\mathrm{CH}) ; 118,3(\mathrm{C}) ; 118,6(\mathrm{C}) ; 121,9(\mathrm{CH}) ; 123,6(\mathrm{CH})$; 123,9 (CH); 125,4 (C); 125,7 (C); 126,0 (CH); 126,8 (CH); 127,6 (CH); 128,1 (C); 128,7 (CH); 129,3 (C); 132,0 (CH); 132,2 (CH); 133,3 (C); 135,1 (C); 138,2 (C); 138,9 (C); 140,3 (2) (CH); 142,6 (C); 152,1 (C); 152,6 (C); 155,0 (C); 155,4 (C); 159,8 (C); 160,9 (2) (C); 184,3 (2) (CH); 193,5 (CH); 194,0 (CH).

HPLC: Columna $\mathrm{C}_{18} \quad \mathrm{t}_{\mathrm{R}}$ : 11,08 y $12,22 \mathrm{~min}$. (3:7).

Columna $\mathrm{C}_{8} \quad \mathrm{t}_{\mathrm{R}}: 10,55$ y $11,72 \mathrm{~min}$. (3:7).

Columna fenílica $\quad t_{R}: 11,71$ y 12,79 min. (3:7). 


\section{Obtención de \{1-metil-5-[1-(2,3,4-trimetoxifenil)vinil]-1H-indol-3-il\} metanol (62).}<smiles>C=C(c1ccc2c(c1)c(CO)cn2C)c1ccc2c(c1)c(CO)cn2C</smiles>

Según el método G, 19 mg (0,05 mmol) de 60 y 20 mg (0,5 mmol) de $\mathrm{NaBH}_{4}$ en 10 mL de MeOH producen 15 mg (85\%) del alcohol 62.

\section{\{1-metil-5-[1-(2,3,4-trimetoxifenil)vinil]-1H-indol-3-il\}metanol (62):}

IR (película): 3385, 1569, 1096, $1024 \mathrm{~cm}^{-1}$.

RMN ${ }^{1} \mathbf{H}$ : (Fig. XLVa) 3,51 (3H, s, $\left.\mathrm{NCH}_{3}\right) ; 3,75\left(3 \mathrm{H}, \mathrm{s}, \mathrm{OCH}_{3}\right) ; 3,86(3 \mathrm{H}, \mathrm{s}$, $\left.\mathrm{OCH}_{3}\right) ; 3,91$ (3H, s, $\left.\mathrm{OCH}_{3}\right) ; 4,80\left(2 \mathrm{H}, \mathrm{s}, \mathrm{CH}_{2} \mathrm{OH}\right) ; 5,27(1 \mathrm{H}, \mathrm{s}) ; 5,64(1 \mathrm{H}, \mathrm{s}) ; 6,69$ $\left(1 \mathrm{H}, \mathrm{d}, J=8,6, \mathrm{H}_{5}{ }^{*}\right) ; 7,00\left(1 \mathrm{H}, \mathrm{d}, J=8,6, \mathrm{H}_{6}{ }^{*}\right) ; 7,03(1 \mathrm{H}, \mathrm{s}) ; 7,23(2 \mathrm{H}, \mathrm{s}) ; 7,64(1 \mathrm{H}$, s).

*Asignación intercambiable.

RMN ${ }^{13}$ C: (Fig. XLVb) 32,9 (N-CH $)$; 56,0 $\left(\mathrm{OCH}_{3}\right) ; 57,0\left(\mathrm{CH}_{2}\right) ; 60,7\left(\mathrm{OCH}_{3}\right)$; 60,9 $\left(\mathrm{OCH}_{3}\right) ; 106,9(\mathrm{CH}) ; 109,0(\mathrm{CH}) ; 114,0\left(\mathrm{CH}_{2}\right) ; 115,2(\mathrm{C}) ; 117,2(\mathrm{CH}) ; 121,6$ (CH); 125,4 (CH); 126,9 (C); 128,2 (CH); 129,9 (C); 133,8 (C); 137,0 (C); 142,4 (C); 147,7 (C); 152,2 (C); 153,4 (C).

$\begin{array}{cc}\text { HPLC: Columna } \mathrm{C}_{18} & \mathrm{t}_{\mathrm{R}}: 14,97 \mathrm{~min} . \\ \text { Columna } \mathrm{C}_{8} & \mathrm{t}_{\mathrm{R}}: 13,52 \mathrm{~min} . \\ \text { Columna fenílica } & \mathrm{t}_{\mathrm{R}}: 13,76 \mathrm{~min} .\end{array}$

\section{Obtención de 1-metil-5-[1-(2,3,4-trimetoxifenil)etil]-1H-indol (63).}<smiles>C=C(c1ccc2c(ccn2C)c1)c1ccc2c(ccn2C)c1C(=O)O</smiles>

Según el método F, 26 mg (0,08 mmol) de 59 y 8 mg de Pd/C en $10 \mathrm{~mL}$ de EtOH, bajo atmósfera de $\mathrm{H}_{2}$, reaccionan para dar 25 mg (96\%) del producto reducido 63. 


\section{1-metil-5-[1-(2,3,4-trimetoxifenil)etil]-1H-indol (63):}

RMN ${ }^{1} \mathbf{H}$ : (Fig. XLVIa) 1,63 (3H, d; $\left.J=7,2\right) ; 3,65$ (3H, s, $\left.\mathrm{NCH}_{3}\right) ; 3,75$ (3H, s, $\left.\mathrm{OCH}_{3}\right) ; 3,80(1 \mathrm{H}, \mathrm{m}) ; 3,84\left(3 \mathrm{H}, \mathrm{s}, \mathrm{OCH}_{3}\right) ; 3,87\left(3 \mathrm{H}, \mathrm{s}, \mathrm{OCH}_{3}\right) ; 4,60(1 \mathrm{H}, \mathrm{c}, J=7,2$, $\left.\mathrm{CHCH}_{3}\right) ; 6,42\left(1 \mathrm{H}, \mathrm{d}, J=3,1, \mathrm{H}_{3}\right) ; 6,63\left(1 \mathrm{H}, \mathrm{d}, J=8,6 \mathrm{H}_{5}{ }^{\prime}\right) ; 6,93\left(1 \mathrm{H}, \mathrm{d}, J=8,6, \mathrm{H}_{6^{\prime}}\right)$; 7,01 (1H, d, $\left.J=3,1, \mathrm{H}_{2}\right) ; 7,10\left(1 \mathrm{H}, \mathrm{dd} ; J=8,6 ; 1,4, \mathrm{H}_{6}\right) ; 7,22\left(1 \mathrm{H}, \mathrm{d}, J=8,6 \mathrm{H}_{7}\right) ; 7,49$ $\left(1 \mathrm{H}, \mathrm{sa}, \mathrm{H}_{4}\right)$.

RMN ${ }^{13}$ C: (Fig. XLVIb) 22,5 $\left(\mathrm{CH}_{3}\right)$; 32,9 (N-CH$)$; 37,7 (CH); 56,0 $\left(\mathrm{OCH}_{3}\right) ;$ 60,7 $\left(\mathrm{OCH}_{3}\right) ; 60,9\left(\mathrm{OCH}_{3}\right) ; 100,7(\mathrm{CH}) ; 107,1(\mathrm{CH}) ; 108,9(\mathrm{CH}) ; 119,0(\mathrm{CH}) ; 122,0$ (CH); 122,2 (CH); 128,5 (C); 128,9 (CH); 133,7 (C); 135,3 (C); 137,9 (C); 142,3 (C); 151,6 (C); 151,9 (C).

$\begin{array}{cc}\text { HPLC: Columna } \mathrm{C}_{18} & \mathrm{t}_{\mathrm{R}}: 18,22 \mathrm{~min} . \\ \text { Columna } \mathrm{C}_{8} & \mathrm{t}_{\mathrm{R}}: 16,49 \mathrm{~min} . \\ \text { Columna fenílica } & \mathrm{t}_{\mathrm{R}}: 16,45 \mathrm{~min} .\end{array}$

\section{Obtención de las oximas del 1-metil-5-[1-(2,3,4-trimetoxifenil)vinil]-1H- indol-3-carbaldehído (64).}<smiles>C=C(c1ccc2c(c1)c(C=O)cn2C)c1ccc(OC)c(OC)c1OC</smiles>

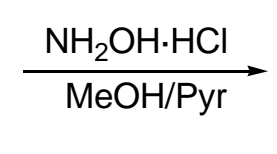<smiles>C=C(c1ccc2c(c1)c(/C=N\O)cn2C)c1ccc(OC)c(OC)c1OC</smiles>

Según el método $\mathrm{H}$, a una disolución de $155 \mathrm{mg}$ (0,44 mmol) de $\mathbf{6 0}$ en $10 \mathrm{~mL}$ de $\mathrm{MeOH}$, se añaden $307 \mathrm{mg}$ (4,4 mmol) de clorhidrato de hidroxilamina y dos gotas de piridina. Tras 24 horas de reacción, se obtienen $166 \mathrm{mg}$ de una mezcla de las oximas 64Z y $\mathbf{6 4 E}$, que se separan mediante CC para dar $83 \mathrm{mg}$ (52\%) de uno de los isómeros y $15 \mathrm{mg}$ (9\%) del otro isómero. Ambas oximas en disolución se isomerizan para regenerar la mezcla inicial. 


\section{Oximas del 1-metil -5-[1-(2,3,4-trimetoxifenil)vinil]-1H-indol-3-carbaldehído}

\section{(64Z y 64E):}

P.f.: $97-99^{\circ} \mathrm{C} .\left(\mathrm{CH}_{2} \mathrm{Cl}_{2} / \mathrm{Hex}\right)$.

IR (película): 3391, 1595, $1090 \mathrm{~cm}^{-1}$.

RMN ${ }^{1} \mathbf{H}$ : (Fig. XLVIIa) 3,49 (3H, s, $\left.\mathrm{OCH}_{3}\right) ; 3,53\left(3 \mathrm{H}, \mathrm{s}, \mathrm{OCH}_{3}\right) ; 3,77$ (3H, s, $\left.\mathrm{OCH}_{3}\right) ; 3,83\left(3 \mathrm{H}, \mathrm{s}, \mathrm{OCH}_{3}\right) ; 3,86\left(6 \mathrm{H}, \mathrm{s}, \mathrm{OCH}_{3}\right) ; 3,89\left(3 \mathrm{H}, \mathrm{s}, \mathrm{OCH}_{3}\right) ; 3,91(3 \mathrm{H}, \mathrm{s}$, $\left.\mathrm{OCH}_{3}\right) ; 5,28(1 \mathrm{H}, \mathrm{s}) ; 5,30(1 \mathrm{H}, \mathrm{s}) ; 5,64(1 \mathrm{H}, \mathrm{s}) ; 5,67(1 \mathrm{H}, \mathrm{s}) ; 6,68(1 \mathrm{H}, \mathrm{d}, J=8,2)$; 6,71 (1H, d, $J=8,4) ; 7,00$ (1H, d, $J=8,4) ; 7,02$ (1H, d, $J=8,2) ; 7,22-7,38$ (4H, m); 7,68 (1H, s); 7,80 (2H, m); 8,07 (1H, s); 8,24 (1H, s); 8,30 (1H, s). RMN ${ }^{13}$ C: (Fig. XLVIIb) 33,2 ( $\left.\mathrm{NCH}_{3}\right) ; 33,3\left(\mathrm{NCH}_{3}\right) ; 56,1$ (2) $\left(\mathrm{OCH}_{3}\right) ; 60,7$ (2) $\left(\mathrm{OCH}_{3}\right) ; 61,0$ (2) $\left(\mathrm{OCH}_{3}\right) ; 105,7$ (2) (C); 106,9 (2) (CH); 109,0 (CH); 109,3 (CH); 114,5 (2) ( $\left.\mathrm{CH}_{2}\right) ; 116,4(\mathrm{CH}) ; 119,8(\mathrm{CH}) ; 122,0(\mathrm{CH}) ; 122,6(\mathrm{CH}) ; 125,4$ (2) (CH); 127,3 (2) (C); 129,7 (CH); 131,5 (2) (C); 135,2 (CH); 135,6 (2) (C); 137,3 (2) (C); 139,5 (CH); 142,4 (2) (C); 145,5 (CH); 147,6 (2) (C); 151,8 (2) (C); 153,4 (C); 153,5 (C).

$\begin{array}{cc}\text { HPLC: Columna } \mathrm{C}_{18} & \mathrm{t}_{\mathrm{R}}: 14,85 \text { y 15,54 min. (1:1). } \\ \text { Columna } \mathrm{C}_{8} & \mathrm{t}_{\mathrm{R}}: 13,54 \text { y 14,08 min. (1:1). } \\ \text { Columna fenílica } & \mathrm{t}_{\mathrm{R}}: 14,14 \text { y 14,55 min. (1:1). }\end{array}$




\section{Obtención de 1-metil -5-[1-(2,3,4-trimetoxifenil)vinil]-1H-indol-3- carbonitrilo (65).}

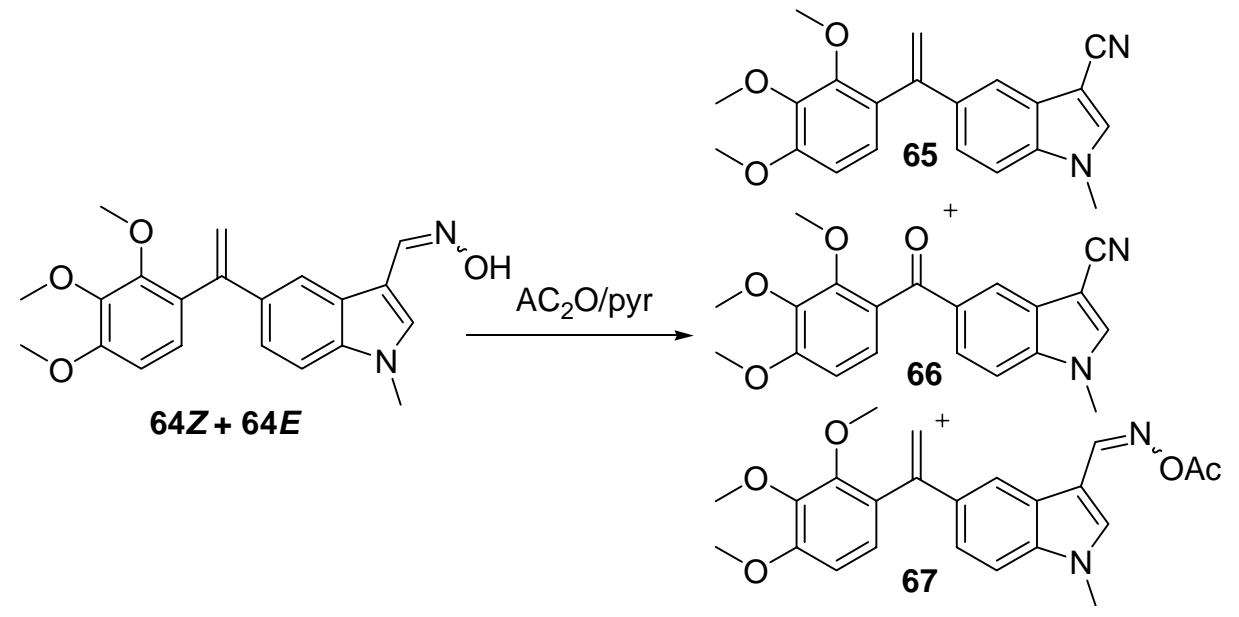

$90 \mathrm{mg}(0,25 \mathrm{mmol})$ de la mezcla de oximas $64 \mathrm{Z}$ y $\mathbf{6 4 E}$ se disuelven en $0,4 \mathrm{~mL}$ de piridina y posteriormente se añaden 0,4 mL de anhídrido acético. Tras 4 horas en agitación, la mezcla de reacción se recoge sobre $\mathrm{HCl} 2 \mathrm{~N}$ y AcOEt, se lava con $\mathrm{NaOH} 4 \%$ con una disolución acuosa saturada de $\mathrm{NaCl}$. Por último, se seca con $\mathrm{Na}_{2} \mathrm{SO}_{4}$ anhidro y se evapora. El crudo de reacción (83 mg) se purifica por cromatografía en columna de gel de sílice (eluyente: $\mathrm{CH}_{2} \mathrm{Cl}_{2} / \mathrm{AcOEt}$ 95/5) y se obtienen $27 \mathrm{mg}$ (31\%) del carbonitrilo 65, 6 mg (7\%) de la cetona-carbonitrilo 66 y 19 mg (19\%) de la mezcla en que es mayoritario uno de los acetatos $67 Z$ o $67 \boldsymbol{E}$. Los acetatos obtenidos se degradan en disolución.

\section{1-metil -5-[1-(2,3,4-trimetoxifenil)vinil]-1H-indol-3-carbonitrilo (65):}

IR (película): 2215, 1569, 1025, $808 \mathrm{~cm}^{-1}$.

RMN ${ }^{1} \mathbf{H}$ : (Fig. XLVIIIa) 3,50 (3H, s, $\left.\mathrm{CH}_{3}\right)$; 3,83 (3H, s, $\left.\mathrm{CH}_{3}\right)$; 3,85 (3H, s, $\left.\mathrm{CH}_{3}\right)$; 3,91 (3H, s, $\left.\mathrm{CH}_{3}\right) ; 5,32\left(1 \mathrm{H}, \mathrm{s}, \mathrm{CH}_{2}\right) ; 5,63\left(1 \mathrm{H}, \mathrm{s}, \mathrm{CH}_{2}\right) ; 6,71\left(1 \mathrm{H}, \mathrm{d} ; J=8,2, \mathrm{H}_{5},{ }^{*}\right)$; $6,99\left(1 \mathrm{H}, \mathrm{d} ; J=8,2, \mathrm{H}_{6}{ }^{*}\right)$; 7,31 (1H, d, $\left.J=8,4, \mathrm{H}_{7}\right) ; 7,33\left(1 \mathrm{H}, \mathrm{da} ; J=8,4, \mathrm{H}_{6}\right) ; 7,52$ $\left(1 \mathrm{H}, \mathrm{s}, \mathrm{H}_{2}\right) ; 7,66\left(1 \mathrm{H}, \mathrm{sa}, \mathrm{H}_{4}\right)$.

*Asignación intercambiable.

RMN ${ }^{13}$ C: (Fig. XLVIIIb) 33,8 (N-CH $)$; 56,1 $\left(\mathrm{OCH}_{3}\right) ; 60,7\left(\mathrm{OCH}_{3}\right) ; 61,0\left(\mathrm{OCH}_{3}\right)$; 85,7 (C); 107,1 (CH); 110,0 (CH); 115,4 $\left(\mathrm{CH}_{2}\right) ; 116,1(\mathrm{C}) ; 117,8(\mathrm{CH}) ; 123,3$ (CH); 125,2 (CH); 127,8 (C); 129,2 (C); 135,7 (C); 135,9 (CH); 136,7 (C); 142,4 (C); 147,0 (C); 151,2 (C); 153,0 (C).

$\begin{array}{cc}\text { HPLC: Columna } \mathrm{C}_{18} & \mathrm{t}_{\mathrm{R}}: 15,73 \mathrm{~min} . \\ \text { Columna } \mathrm{C}_{8} & \mathrm{t}_{\mathrm{R}}: 14,03 \mathrm{~min} . \\ \text { Columna fenílica } & \mathrm{t}_{\mathrm{R}}: 15,05 \mathrm{~min} .\end{array}$




\section{1-metil -5-(2,3,4-trimetoxibenzoil)-1H-indol-3-carbonitrilo (66):}

IR (película): 2219, 1653,1593, $1097 \mathrm{~cm}^{-1}$.

RMN ${ }^{1} \mathbf{H}$ : (Fig. ILa) 3,76 (3H, s, $\left.\mathrm{CH}_{3}\right) ; 3,91$ (3H, s, $\left.\mathrm{CH}_{3}\right) ; 3,92\left(3 \mathrm{H}, \mathrm{s}, \mathrm{CH}_{3}\right) ; 3,95$ $\left(3 \mathrm{H}, \mathrm{s}, \mathrm{CH}_{3}\right) ; 6,75\left(1 \mathrm{H}, \mathrm{d} ; J=8,6, \mathrm{H}_{5}{ }^{*}\right) ; 7,13\left(1 \mathrm{H}, \mathrm{d} ; J=8,6, \mathrm{H}_{6}{ }^{*}\right) ; 7,46(1 \mathrm{H}, \mathrm{d}$; $\left.J=8,6, \mathrm{H}_{7}\right) ; 7,65$ (1H, s, H2); 7,98 (1H, dd; $\left.J=8,6 ; 1,8, \mathrm{H}_{6}\right) ; 8,12\left(1 \mathrm{H}, \mathrm{d} ; J=1,8, \mathrm{H}_{4}\right)$.

*Asignación intercambiable.

RMN ${ }^{13}$ C: (Fig. ILb) 34,0 (N-CH $)$; 56,1 $\left(\mathrm{OCH}_{3}\right) ;$ 61,0 $\left(\mathrm{OCH}_{3}\right) ;$ 61,9 $\left(\mathrm{OCH}_{3}\right) ; 87,5$ (C); 106,9 (CH); 110,4 (CH); 123,7 (CH); 124,9 (CH); 125,2 (CH); 137,0 (CH). Los carbonos cuaternarios no se observan.
HPLC: Columna $\mathrm{C}_{18}$ $t_{R}: 12,43$ y $15,76 \min .(9: 1)$.
Columna $\mathrm{C}_{8}$ $\mathrm{t}_{\mathrm{R}}: 11,95$ y 14,71 min. (9:1).
Columna fenílica $t_{R}: 12,88$ y 15,16 min. $(9: 1)$.

Acetil oxima de 1-metil-5-[1-(2,3,4-trimetoxifenil)vinil]-1H-indol-3carbaldehído (67):

RMN ${ }^{1} \mathbf{H}$ : (Fig. La) 2,19 (3H, s, $\left.\mathrm{CH}_{3}\right)$; 3,53 (3H, s, $\left.\mathrm{OCH}_{3}\right) ; 3,81\left(3 \mathrm{H}, \mathrm{s}, \mathrm{OCH}_{3}\right)$; 3,85 (3H, s, $\left.\mathrm{OCH}_{3}\right) ; 3,90\left(3 \mathrm{H}, \mathrm{s}, \mathrm{OCH}_{3}\right) ; 5,29(1 \mathrm{H}, \mathrm{s}) ; 5,70(1 \mathrm{H}, \mathrm{s}) ; 6,69(1 \mathrm{H}, \mathrm{d}$; $J=8,2, \mathrm{H}_{5}$ ); 7,00 (1H, d; $\left.J=8,2, \mathrm{H}_{6}{ }^{\prime}\right) ; 7,26\left(1 \mathrm{H}, \mathrm{d}, J=8,8, \mathrm{H}_{7}\right) ; 7,34(1 \mathrm{H}, \mathrm{da} ; J=8,8$, $\left.\mathrm{H}_{6}\right) ;$ 7,43 (1H, s, $\left.\mathrm{H}_{2}\right) ; 8,01\left(1 \mathrm{H}, \mathrm{sa}, \mathrm{H}_{4}\right) ; 8,46(1 \mathrm{H}, \mathrm{s}, \mathrm{CH}=\mathrm{NOH})$.

*Asignación intercambiable.

RMN ${ }^{13}$ C: 20,0 $\left(\mathrm{CH}_{3}\right)$; 33,5 $\left(\mathrm{NCH}_{3}\right)$; 56,1 $\left(\mathrm{OCH}_{3}\right) ; 60,8\left(\mathrm{OCH}_{3}\right) ; 60,9\left(\mathrm{OCH}_{3}\right)$; 107,1 (CH); 109,3 (CH); 114,7 ( $\left.\mathrm{CH}_{2}\right) ; 120,0(\mathrm{CH}) ; 122,7(\mathrm{CH}) ; 125,0(\mathrm{CH}) ; 125,4$ (CH); 133,6 (C); 135,9 (C); 150,1 (CH). Algunos carbonos cuaternarios no se observan. 


\section{Obtención de las hidrazonas de 1-\{(1-metil-5-[1-(2,3,4-trimetoxifenil)etil]-} $1 H$-indol-3-il\}carbaldehído (68).<smiles>C=C(c1ccc2c(c1)c(C=O)cn2C)c1ccc(OC)c(OC)c1OC</smiles><smiles>COc1ccc(C(C)c2ccc3c(c2)c(/C=N\N)cn3C)c(OC)c1OC</smiles>

Según el método I, a una disolución de 154 mg (0,44 mmol) de 60 en $10 \mathrm{~mL}$ de $\mathrm{MeOH}$ se añade hidrato de hidracina en exceso y dos gotas de ácido acético. Tras 24 horas de reacción y tratada la mezcla, se obtienen $141 \mathrm{mg}$ (88\%) de la mezcla de hidrazonas 68 en proporción aproximada 1:1.

\section{1-((1-metil-5-(1-(2,3,4-trimetoxifenil)etil)-1H-indol-3-il)metilen)hidrazona} $(68 Z$ y $E):$

RMN ${ }^{1} \mathbf{H}$ : (Fig. LIa) 1,71 (6H, d; $\left.J=3,2, \mathrm{CHCH}_{3}\right) ; 3,67$ (3H, s, $\left.\mathrm{CH}_{3}\right) ; 3,72$ (3H, s, $\left.\mathrm{CH}_{3}\right)$; 3,77 (3H, s, $\left.\mathrm{CH}_{3}\right) ; 3,80\left(3 \mathrm{H}, \mathrm{s}, \mathrm{CH}_{3}\right) ; 3,84\left(6 \mathrm{H}, \mathrm{s}, \mathrm{OCH}_{3}\right) ; 3,86\left(3 \mathrm{H}, \mathrm{s}, \mathrm{CH}_{3}\right)$; 3,88 (3H, s, $\left.\mathrm{CH}_{3}\right) ; 4,66\left(2 \mathrm{H}, \mathrm{m}, \mathrm{CHCH}_{3}\right) ; 6,62\left(2 \mathrm{H}, \mathrm{d} ; J=8,6, \mathrm{H}_{5}\right) ; 6,65(2 \mathrm{H}, \mathrm{d}$; $\left.J=8,2, \mathrm{H}_{5}{ }^{\prime}\right) ; 6,95$ (2H, d; $\left.J=8,6, \mathrm{H}_{6}{ }^{\prime}\right) ; 6,96\left(2 \mathrm{H}, \mathrm{d} ; J=8,2, \mathrm{H}_{6}{ }^{\prime}\right) ; 7,00-7,30$ (4H, m); 7,33 (1H, s); 7,46 (1H, s); 8,25 (1H, s); 8,36 (1H, s); 8,59 (1H, s, CH=NH $)$; 8,92 $\left(1 \mathrm{H}, \mathrm{s}, \mathrm{CH}=\mathrm{NH}_{2}\right)$.

RMN ${ }^{13}$ C: (Fig. LIb) 22,4 (2) $\left(\mathrm{CH}_{3}\right) ; 33,4$ (2) $\left(\mathrm{NCH}_{3}\right) ; 37,8$ (2) (CH); 56,0 (2) $\left(\mathrm{OCH}_{3}\right) ; 60,8$ (2) $\left(\mathrm{OCH}_{3}\right) ; 61,0$ (2) $\left(\mathrm{OCH}_{3}\right) ; 107,1$ (2) $(\mathrm{CH}) ; 109,4(2)(\mathrm{CH}) ; 111,9$ (2) (C); 120,7 (CH); 120,9 (CH); 122,1 (2) (CH); 123,5 (CH); 123,8 (CH); 126,2 (2) (C); 132,0 (C); 133,5 (2) (CH); 134,1 (C); 136,5 (2) (C); 139,9 (C); 140,2 (C); 142,3 (2) (C); 151,5 (2) (C); 151,9 (2) (C); 154,0 (CH); 154,8 (CH). 



\section{IV.3.D. Sintesis de fenstatinas con un heterociclo distinto de indol.}

Obtención de (5-bromo-1-metil-1H-benzimidazol-2-il)(3,4,5trimetoxifenil)metanol (69) y (6-bromo-1-metil-1H-benzimidazol-2-il) (3,4,5-trimetoxifenil)metanol (70).<smiles>Brc1ccc2c(c1)ncn2Cn1cnc2ccc(Br)cc21</smiles>

15<smiles>COc1cc(C=O)cc(OC)c1OC</smiles><smiles>CCCCC[13CH]C</smiles><smiles>COc1cc(C(O)c2nc3ccc(Br)cc3n2C)cc(OC)c1OC</smiles>

Siguiendo el método C1, 1,00 g (4,74 mmol) de la mezcla de 14 y 15, 5,94 mL (9,5 mmol) de $n \operatorname{BuLi}$ (1,6 M en hexano) y 1,12 g (5,69 mmol) de 3,4,5-trimetoxibenzaldehído en $40 \mathrm{~mL}$ de THF, producen 1,80 g de crudo de reacción. Después de cromatografiar en columa sobre gel de sílice, usando como eluyente Hex/AcOEt 1/1, se obtienen $429 \mathrm{mg}$ (28\%) de 69 y 508 mg (33\%) de una mezcla del alcohol 70 y una impureza no identificada.

\section{(5-bromo-1-metil-1H-benzimidazol-2-il)(3,4,5-trimetoxifenil)metanol (69):}

P.f.: $89-91{ }^{\circ} \mathrm{C} .\left(\mathrm{CH}_{2} \mathrm{Cl}_{2} / \mathrm{Hex}\right)$.

RMN ${ }^{1} \mathbf{H}$ : (Fig. LIIa) 3,51 (3H, s, $\left.\mathrm{NCH}_{3}\right) ; 3,78\left(6 \mathrm{H}, \mathrm{s}, \mathrm{OCH}_{3}\right) ; 3,82\left(3 \mathrm{H}, \mathrm{s}, \mathrm{OCH}_{3}\right)$; 6,04 (1H, sa, CHOH); 6,60 (2H, s, $\mathrm{H}_{2}, \mathrm{H}_{6}$ ); 7,00 (1H, d; J=8,4, $\left.\mathrm{H}_{7}\right) ; 7,30(1 \mathrm{H}, \mathrm{d}$; $\left.J=8,4 ; 1,8, \mathrm{H}_{6}\right) ; 7,78\left(1 \mathrm{H}, \mathrm{d} ; J=1,8, \mathrm{H}_{4}\right)$.

RMN ${ }^{13}$ C: (Fig. LIIb) 30,6 $\left(\mathrm{NCH}_{3}\right) ; 56,2$ (2) $\left(\mathrm{OCH}_{3}\right) ; 60,9\left(\mathrm{OCH}_{3}\right) ; 69,6(\mathrm{CH})$; 103,2 (2) (CH); 110,6 (CH); 115,1 (C); 121,6 (CH); 126,0 (CH); 135,0 (C); 135,2 (C); 137,5 (C); 142,0 (C); 153,4 (2) (C); 156,3 (C). 
(6-bromo-1-metil-1H-benzimidazol-2-il)(3,4,5-trimetoxifenil)metanol (70):

RMN ${ }^{1} \mathbf{H}$ : (Fig. LIIIa) 3,45 (3H, s, $\left.\mathrm{NCH}_{3}\right)$; 3,72 (6H, s, $\left.\mathrm{OCH}_{3}\right) ; 3,79$ (3H, s, $\left.\mathrm{OCH}_{3}\right)$; 6,08 (1H, d; J=2,8, CHOH); 6,58 (2H, s, $\left.\mathrm{H}_{2}, \mathrm{H}_{6^{\prime}}\right) ; 7,21\left(1 \mathrm{H}, \mathrm{sa}, \mathrm{H}_{7}\right) .7,23(1 \mathrm{H}, \mathrm{d}$; $\left.J=8,8 ; 1,8, \mathrm{H}_{5}\right) ; 7,40\left(1 \mathrm{H}, \mathrm{d} ; J=8,8, \mathrm{H}_{4}\right)$.

RMN ${ }^{13}$ C: (Fig. LIIIb) 30,6 ( $\left.\mathrm{NCH}_{3}\right) ; 56,2$ (2) $\left(\mathrm{OCH}_{3}\right) ; 60,9\left(\mathrm{OCH}_{3}\right) ; 69,6(\mathrm{CH})$; 103,2 (2) (CH); 112,6 (CH); 116,3 (C); 120,1 (CH); 125,5 (CH); 135,1 (C); 137,2 (C); 139,8 (C); 141,9 (C); 153,3 (2) (C); 156,0 (C).

EM: $405\left(\mathrm{M}^{+}\right)$.

Obtención de (5-bromo-1-metil-1H-benzimidazol-2-il)(3,4,5trimetoxifenil)metanona (71).<smiles>[Y1]Cn1c(C(=O)c2cc(OC)c(OC)c(OC)c2)nc2cc(Br)ccc21</smiles>

Siguiendo el método D1, a una disolución de $67 \mathrm{mg}(0,17 \mathrm{mmol})$ del alcohol 69 en $30 \mathrm{~mL}$ de $\mathrm{CH}_{2} \mathrm{Cl}_{2}$ seco, se añaden $93 \mathrm{mg}$ (0,25 mmol) de PDC. Tras 24 horas de reacción se obtienen 46 mg (69\%) de la cetona 71.

(5-bromo-1-metil-1H-benzimidazol-2-il)(3,4,5-trimetoxifenil)metanona (71):

IR: $1645,1455,1321 \mathrm{~cm}^{-1}$.

RMN ${ }^{1} \mathbf{H}$ : (Fig. LIVa) 3.91 (6H, s, $\mathrm{CH}_{3}$ ); 3.94 (3H, s, $\mathrm{CH}_{3}$ ); 4,08 (3H, s, $\mathrm{CH}_{3}$ ); 7,34 $\left(1 \mathrm{H}, \mathrm{d} ; J=9, \mathrm{H}_{7}\right) ; 7,52\left(1 \mathrm{H}, \mathrm{dd} ; J=9 ; \mathrm{J}=1,8, \mathrm{H}_{6}\right) ; 7,66\left(2 \mathrm{H}, \mathrm{s}, \mathrm{H}_{2}, \mathrm{H}_{6}\right.$ ) $)$ 8,02 (1H, d; $\left.\mathrm{J}=1,8, \mathrm{H}_{4}\right)$.

RMN ${ }^{13}$ C: (Fig. LIVb) 32,4 $\left(\mathrm{NCH}_{3}\right) ; 56,3$ (2) $\left(\mathrm{OCH}_{3}\right) ; 61,0\left(\mathrm{OCH}_{3}\right) ; 108,9$ (2) (CH); 111,8 (CH); 116,6 (C); 124,5 (CH); 128,7 (CH); 131,3 (C); 135,4 (C); 142,9 (C); 143,4 (C); 147,5 (C); 152,9 (2) (C); 184,5 (C).

EM: $407\left(\mathrm{M}^{+}\right)$. 
Obtención de (6-bromo-1-metil-1H-benzimidazol-2-il)(3,4,5trimetoxifenil)metanona (72).

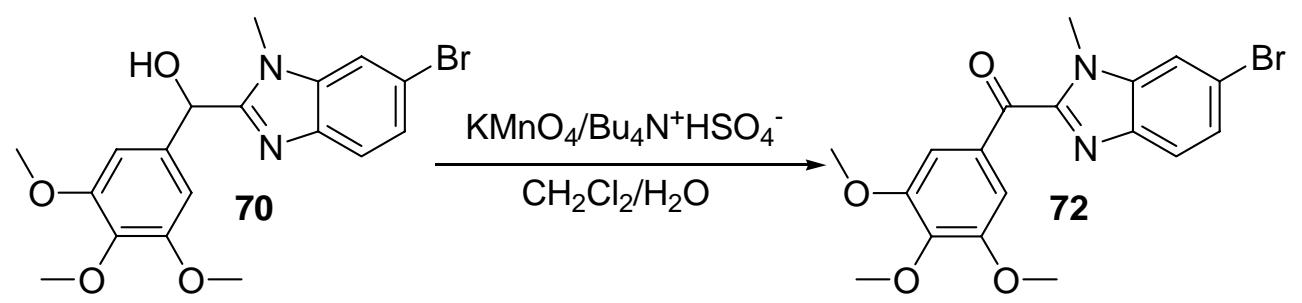

Siguiendo el método D2, a una disolución de $508 \mathrm{mg}$ (1,55 mmol) de la mezcla del alcohol 70 y una impureza no identificada en $30 \mathrm{~mL}$ de $\mathrm{CH}_{2} \mathrm{Cl}_{2}$, se añaden $245 \mathrm{mg}(1,55$ mmol) de $\mathrm{KMnO}_{4}, 40 \mathrm{mg}$ de $\mathrm{Bu}_{4} \mathrm{~N}^{+} \mathrm{HSO}_{4}{ }^{-}$y $1 \mathrm{~mL}$ de $\mathrm{H}_{2} \mathrm{O}$. Tras 24 horas de reacción, se obtienen $206 \mathrm{mg}$ (41\%) de la cetona 72 y $200 \mathrm{mg}$ (40\%) de una mezcla de 72 y una impureza no identificada.

(6-bromo-1-metil-1H-benzimidazol-2-il)(3,4,5-trimetoxifenil)metanona (72):

IR: $1645,1445,1125 \mathrm{~cm}^{-1}$.

RMN ${ }^{1} \mathbf{H}$ : (Fig. LVa) 3,87 (6H, s, $\mathrm{CH}_{3}$ ); 3,90 (3H, s, $\mathrm{CH}_{3}$ ); 4,01 (3H, s, $\mathrm{CH}_{3}$ ); 7,39 $\left(1 \mathrm{H}, \mathrm{dd} ; J=8,8 ; \mathrm{J}=1,8, \mathrm{H}_{6}\right) ; 7,57\left(1 \mathrm{H}, \mathrm{d} ; \mathrm{J}=1,8, \mathrm{H}_{4}\right) ; 7,63\left(2 \mathrm{H}, \mathrm{s}, \mathrm{H}_{2}, \mathrm{H}_{6}\right.$ ); 7,69 (1H, d; $\left.J=8,8 ; \mathrm{H}_{7}\right)$.

RMN ${ }^{13}$ C: (Fig. LVb) 32,3 ( $\left.\mathrm{NCH}_{3}\right) ; 56,2$ (2) $\left(\mathrm{OCH}_{3}\right) ; 60,9\left(\mathrm{OCH}_{3}\right) ; 108,9$ (2) (CH); 113,5 (CH); 119,0 (C); 123,1 (CH); 127,0 (CH); 131,3 (C); 137,3 (C); 140,5 (C); 143,3 (C); 147,2 (C); 152,7 (2) (C); 184,2 (C).

EM: $406\left(\mathrm{M}^{+}\right)$.

\section{Obtención de (1,3-benzoxazol-5-il)(3,4,5-trimetoxifenil)metanol (73).}<smiles>Brc1ccc2ocnc2c1</smiles>

17<smiles>COc1cc(C=O)cc(OC)c1OC</smiles>

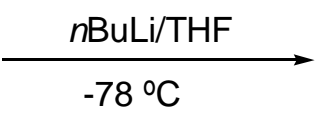<smiles>COc1cc(C(O)c2ccc3ocnc3c2)cc(OC)c1OC</smiles>

Siguiendo el método C1, 1,7 mL (2,73 mmol) de BuLi (1,6 M en hexano), $246 \mathrm{mg}$ (1,24 mmol) de 17 y $291 \mathrm{mg}$ (1,49 mmol) de 3,4,5-trimetoxibenzaldehído en $5 \mathrm{~mL}$ THF seco a $-78{ }^{\circ} \mathrm{C}$ reaccionan para dar, tras 24 horas, $267 \mathrm{mg}$ de crudo de reacción, que fueron usados en el siguiente paso sin más purificación. 


\section{(1,3-benzoxazol-5-il)(3,4,5-trimetoxifenil)metanol (73):}

RMN ${ }^{1} \mathbf{H}$ : (500MHz; $\mathrm{CDCl}_{3}$ ) (Fig. LVIa) 3,83 (6H, s, $\mathrm{OCH}_{3}$ ); 3,84 (3H, s, $\mathrm{OCH}_{3}$ ); 5,91 (1H, s, $\mathrm{CHOH}) ; 6,63\left(2 \mathrm{H}, \mathrm{s}, \mathrm{H}_{2}, \mathrm{H}_{6^{\prime}}\right), 7,44\left(1 \mathrm{H}, \mathrm{dd}, J=8,5,1,5, \mathrm{H}_{6}\right) ; 7,55(1 \mathrm{H}$, d, $\left.J=8,5, \mathrm{H}_{7}\right) ; 7,82\left(1 \mathrm{H}, \mathrm{d}, J=1,5, \mathrm{H}_{4}\right) ; 8.10\left(1 \mathrm{H}, \mathrm{s}, \mathrm{H}_{4}\right)$.

RMN ${ }^{13}$ C: (125 MHz; $\left.\mathrm{CDCl}_{3}\right)$ (Fig. LVIb) 56,1 (2) $\left(\mathrm{CH}_{3}\right) ; 60,8\left(\mathrm{CH}_{3}\right) ; 76,1(\mathrm{CH})$; 103,5 (2) (CH); 110,9 (CH); 118,5 (CH); 124,5 (CH); 137,4 (C); 139,5 (C); 140,1 (C); 140,9 (C); 149,4 (C); 153,1 (CH); 153,3 (2) (C).

\section{Obtención de (1,3-benzoxazol-5-il)(3,4,5-trimetoxifenil)metanona (74).}<smiles>COc1cc(C(O)c2ccc3oc(CCC(=O)O)nc3c2)cc(OC)c1OC</smiles><smiles>[Z4]Oc1cc(C(=O)c2ccc3ocnc3c2)cc(OC)c1OC</smiles>

Según el método D1, la adición de 478 mg (1,27 mmol) de PDC sobre 267 mg (0,85 mmol) de 73 en $20 \mathrm{~mL}$ de $\mathrm{CH}_{2} \mathrm{Cl}_{2}$ a $0{ }^{\circ} \mathrm{C}$ producen, tras 4 horas, $219 \mathrm{mg}$ de crudo de reacción. Por purificación mediante cromatografía de columna de gel de sílice (eluyente: éter de petróleo/AcOEt 8/2) se obtienen 68 mg (26\%) del producto de oxidación 74.

\section{(1,3-benzoxazol-5-il)(3,4,5-trimetoxi-fenil)metanona (74):}

RMN ${ }^{1} \mathbf{H}$ : (500MHz; $\mathrm{CDCl}_{3}$ ) (Fig. LVIIa) 3,87 (6H, s, $\left.\mathrm{OCH}_{3}\right)$; 3,95 (3H, s, $\mathrm{OCH}_{3}$ ); 7,07 (2H, s, $\mathrm{H}_{2}, \mathrm{H}_{6}$ ) ; 7,70 (1H, d, $\left.J=8,3, \mathrm{H}_{6}\right) ; 7,94\left(1 \mathrm{H}, \mathrm{d}, J=8,3, \mathrm{H}_{7}\right), 8,22(1 \mathrm{H}, \mathrm{s}$, $\left.\mathrm{H}_{4}\right) ; 8,24\left(1 \mathrm{H}, \mathrm{s}, \mathrm{H}_{2}\right)$.

RMN ${ }^{13}$ C: (125 MHz; $\left.\mathrm{CDCl}_{3}\right)$ (Fig. LVIIb) 56,4 (2) $\left(\mathrm{CH}_{3}\right) ; 61,0\left(\mathrm{CH}_{3}\right) ; 107,8$ (2) (CH); 111,0 (CH); 123,0 (CH); 127,9 (CH); 132,6 (C); 134,9 (C); 139,9 (C); 142,2 (C); 152,4 (C); 152,9 (CH); 153,8 (2) (C); 194,8 (C). 


\section{IV.3.E. Sintesis de combretastatinas.}

\section{Obtención de (Z)-N-etil-5-[2-(3,4,5-trimetoxifenil)vinil]-1H-indol-3- carbaldehído (75).}<smiles>CCn1cc(C=O)c2cc(/C=C\c3cc(OC)c(OC)c(OC)c3)ccc21</smiles>

A $466 \mathrm{mg}(0,89 \mathrm{mmol})$ de $\mathbf{1}$ en THF seco $(20 \mathrm{~mL})$, a $-40^{\circ} \mathrm{C}$ y en atmósfera de argón, se añaden $0,56 \mathrm{~mL}$ de $n \operatorname{BuLi}(0,89 \mathrm{mmol})$ y se mantiene 1 hora en agitación. A continuación, el iluro de fósforo formado se añade, lentamente, sobre una disolución de $189 \mathrm{mg}(0,89 \mathrm{mmol})$ de 3 en $10 \mathrm{~mL}$ de THF seco, a $-40{ }^{\circ} \mathrm{C}$ y en atmósfera de argón y se daja que alcance progresivamente la temperatura ambiente. Transcurridas 24 horas, se vierte la reacción sobre cloruro de amonio y se extrae con $\mathrm{CH}_{2} \mathrm{Cl}_{2}$. El conjunto de las fases orgánicas se lava hasta neutralidad con una disolución saturada de $\mathrm{NaCl}$, se seca con $\mathrm{Na}_{2} \mathrm{SO}_{4}$ anhidro, se filtra y se evapora hasta sequedad. Tras sucesivas cromatografías de columna usando como eluyentes Hex/AcOEt 7/3 y $\mathrm{CH}_{2} \mathrm{Cl}_{2} / \mathrm{AcOEt}$ 96/4, se obtienen: 27 mg (5,1\%) del compuesto 75.

\section{(Z)- $N$-etil-5-[2-(3,4,5-trimetoxifenil)vinil]-1H-indol-3-carbaldehído (75):}

IR (película): 1655, 1459, 1397, 1124, $784 \mathrm{~cm}^{-1}$.

RMN ${ }^{1} \mathbf{H}$ : (Fig. LVIIIa) 1,51 (3H, t, $\left.J=7,2, \mathrm{CH}_{2} \mathrm{CH}_{3}\right) ; 3,61\left(6 \mathrm{H}, \mathrm{s}, \mathrm{OCH}_{3}\right) ; 3,82$ (3H, s, $\left.\mathrm{CH}_{3}\right) ; 4,19$ (2H, c, J=7,2, $\left.\mathrm{CH}_{2} \mathrm{CH}_{3}\right) ; 6,51\left(1 \mathrm{H}, \mathrm{d} ; J=12,2, \mathrm{H}_{1 \mathrm{a}}{ }^{*}\right) ; 6,50(2 \mathrm{H}, \mathrm{s}$, $\mathrm{H}_{2}, \mathrm{H}_{6}$ ); 6,73 (1H, d; $\left.J=12,2, \mathrm{H}_{2 \mathrm{a}}{ }^{*}\right) ; 7,19\left(1 \mathrm{H}, \mathrm{d} ; J=8,8, \mathrm{H}_{7}\right) ; 7,30$ (1H, dd; $J=8,8$, 2,0, $\left.\mathrm{H}_{6}\right) ; 7,72\left(1 \mathrm{H}, \mathrm{s}, \mathrm{H}_{2}\right) ; 8,26\left(1 \mathrm{H}, \mathrm{sa}, \mathrm{H}_{4}\right) ; 9,96(1 \mathrm{H}, \mathrm{s}, \mathrm{CHO})$.

* Asignación intercambiable.

RMN ${ }^{13}$ C: (Fig. LVIIIb) 15,1 $\left(\mathrm{CH}_{3}\right) ; 42,0\left(\mathrm{CH}_{2}\right) ; 55,9$ (2) $\left(\mathrm{CH}_{3}\right) ; 61,0\left(\mathrm{CH}_{3}\right) ; 106,2$ (2) (CH); 109,4 (CH); 118,2 (C); 122,8 (CH); 125,2 (CH); 125,6 (C); 129,4 (CH); 130,4 (CH); 132,3 (C); 132,9 (C); 136,0 (C); 137,2 (C); 137,6 (CH); 152,8 (2) (C); $184,4(\mathrm{CH})$.

EM: $365\left(\mathbf{M}^{+}\right)$. 


\section{Obtención de (Z)- $N$-metil-5-[2-(3,4,5-trimetoxifenil)vinil]-1H-indol (76).}<smiles>COc1cc(C[Pb]Br)cc(OC)c1OC</smiles>

1<smiles>Cn1ccc2cc(C=O)ccc21</smiles>

Siguiendo el método B, a una suspensión de 1,81 g (3,46 mmol) de 1 se añaden 2,2 $\mathrm{mL}$ de $n \operatorname{BuLi}$ (3,46 mmol). Después de 1 hora, se adicionan $500 \mathrm{mg}$ (3,14 mmol) de 4. Transcurridas 16 horas, el crudo de reacción se purifica mediante cromatografía de columna sobre sílice, utilizando como eluyente Hexano/AcOEt 85:15 y se obtienen 208 mg (21\%) de $\mathbf{7 6 Z}$ y 388 mg (38\%) de $\mathbf{7 6 E}$.

\section{(Z)-N-metil-5-[2-(3,4,5-trimetoxifenil)vinil]-1H-indol (76Z):}

IR (película): 1614, 1574, 1503, 1126, $971 \mathrm{~cm}^{-1}$,

RMN ${ }^{1} \mathbf{H}$ : (Fig. LIXa) 3,63 (6H, s, $\left.\mathrm{OCH}_{3}\right) ; 3,76\left(3 \mathrm{H}, \mathrm{s}, \mathrm{CH}_{3}\right) ; 3,84\left(3 \mathrm{H}, \mathrm{s}, \mathrm{OCH}_{3}\right)$; 6,40 (1H, d; $\left.J=2,6, \mathrm{H}_{3}\right) ; 6,43\left(1 \mathrm{H}, \mathrm{d} ; J=12,0, \mathrm{H}_{1 \mathrm{a}}{ }^{*}\right) ; 6,58\left(2 \mathrm{H}, \mathrm{s}, \mathrm{H}_{2}, \mathrm{H}_{6}\right.$ ) $) 6,70(1 \mathrm{H}$, d; $\left.J=12,0, \mathrm{H}_{2 \mathrm{a}}{ }^{*}\right) ; 7,00\left(1 \mathrm{H}, \mathrm{d} ; J=2,6, \mathrm{H}_{2}\right) ; 7,17\left(1 \mathrm{H}, \mathrm{da}, J=8,6, \mathrm{H}_{7}\right) ; 7,22(1 \mathrm{H}$, dd, $\left.J=8,6 ; 1,4, \mathrm{H}_{6}\right) ; 7,60\left(1 \mathrm{H}, \mathrm{sa}, \mathrm{H}_{4}\right)$.

* Asignación intercambiable

RMN ${ }^{13}$ C: (Fig. LIXb) 32,8 $\left(\mathrm{CH}_{3}\right)$; 55,9 (2) $\left(\mathrm{CH}_{3}\right) ; 61,0\left(\mathrm{CH}_{3}\right) ; 101,3(\mathrm{CH}) ; 106,2$ (2) $(\mathrm{CH}) ; 108,9(\mathrm{CH}) ; 121,6(\mathrm{CH}) ; 123,0(\mathrm{CH}) ; 127,9(\mathrm{CH}) ; 128,3(\mathrm{C}) ; 128,6(\mathrm{C}) ;$ 128,9 (CH); 131,4 (CH); 133,5 (C); 136,1 (C); 137,1 (C); 153,0 (2) (C).

\section{(E)-N-metil-5-[2-(3,4,5-trimetoxifenil)vinil]-1H-indol (76E):}

P.f.: $110^{\circ} \mathrm{C}$ (Éter).

IR (película): 1579, 1506, 1126, $1006 \mathrm{~cm}^{-1}$.

RMN ${ }^{1} \mathbf{H}$ : (Fig. LIXc) 3,81 (3H, s, $\left.\mathrm{OCH}_{3}\right) ; 3,87$ (3H, s, $\left.\mathrm{CH}_{3}\right)$; 3,93 (6H, s, $\mathrm{OCH}_{3}$ ); 6,49 (1H, d; $\left.J=3,3, \mathrm{H}_{3}\right) ; 6,77\left(2 \mathrm{H}, \mathrm{s}, \mathrm{H}_{2}, \mathrm{H}_{6}\right.$ ); 7,00 (1H, d, J=16,4, $\left.\mathrm{H}_{1}{ }^{\prime}{ }^{*}\right) ; 7,06$ $\left(1 \mathrm{H}, \mathrm{d} ; J=3,3, \mathrm{H}_{2}\right) ; 7,16\left(1 \mathrm{H}, \mathrm{d} ; J=16,4, \mathrm{H}_{1 \mathrm{a}}{ }^{*}\right) ; 7,31\left(1 \mathrm{H}, \mathrm{d} ; J=8,8, \mathrm{H}_{7}\right) ; 7,47(1 \mathrm{H}$, dd, $\left.\mathrm{H}_{7} ; J_{1}=8,8, J_{2}=1,6, \mathrm{H}_{6}\right) ; 7,74\left(1 \mathrm{H}, \mathrm{d} ; J=1,6, \mathrm{H}_{4}\right)$.

\footnotetext{
* Asignación intercambiable
}

RMN ${ }^{13}$ C: (Fig. LIXd) 32,9 ( $\left.\mathrm{CH}_{3}\right) ; 56,2$ (2) $\left(\mathrm{CH}_{3}\right) ; 61,0\left(\mathrm{CH}_{3}\right) ; 101,4(\mathrm{CH}) ; 103,4$ (2) $(\mathrm{CH}) ; 109,7(\mathrm{CH}) ; 119,7(\mathrm{CH}) ; 120,2$ (CH); 125,9 (CH); 129,0 (2) (C); 129,7 (CH); 129,8 (CH); 134,1 (C); 136,7 (C); 137,5 (C); 153,5 (2) (C). 
Obtención de (Z)- $N$-metil-5-[2-(3,4,5-trimetoxifenil)vinil]indol-3carbaldehído (77).<smiles>COc1cc(/C=C\c2ccc3c(ccn3C)c2)cc(OC)c1OC</smiles><smiles>COc1cc(/C=C\c2ccc3c(c2)c(C=O)cn3C)cc(OC)c1OC</smiles>

Según el método E, 0,125 mL (1,35 mmol) de $\mathrm{POCl}_{3}$ se añaden sobre $1 \mathrm{~mL}$ de DMF seca. Media hora después se añaden 395 mg (1,23 mmol) de 76Z. Después de 2 horas se obtienen $400 \mathrm{mg}$ (93\%) de 77.

\section{(Z)- $N$-metil-5-[2-(3,4,5-trimetoxifenil)vinil]indol-3-carbaldehído (77):}

\section{P.f.: $144-146{ }^{\circ} \mathrm{C} .\left(\mathrm{CH}_{2} \mathrm{Cl}_{2} / \mathrm{Hex}\right)$.}

RMN ${ }^{1} \mathbf{H}$ : (Fig. LXa) 3,62 (6H, s, $\left.\mathrm{OCH}_{3}\right) ; 3,84$ (3H, s, NCH $)$; 3,86 (3H, s, $\left.\mathrm{OCH}_{3}\right)$; $6,52\left(2 \mathrm{H}, \mathrm{s}, \mathrm{H}_{2}, \mathrm{H}_{6}\right)$; $6,52\left(1 \mathrm{H}, \mathrm{d} ; J=12,4, \mathrm{H}_{1 \mathrm{a}}{ }^{*}\right) ; 6,73\left(1 \mathrm{H}, \mathrm{d} ; J=12,4, \mathrm{H}_{2 \mathrm{a}}{ }^{*}\right) ; 7,18$ $\left(1 \mathrm{H}, \mathrm{d} ; J=9,2, \mathrm{H}_{7}\right) ; 7,32\left(1 \mathrm{H}, \mathrm{dd}, J=9,2 ; 2,2, \mathrm{H}_{6}\right) ; 7,66\left(1 \mathrm{H}, \mathrm{sa}, \mathrm{H}_{4}\right) ; 8,27(1 \mathrm{H}, \mathrm{s}$, $\left.\mathrm{H}_{2}\right)$; 9,98 (1H, s, CHO).

* Asignación intercambiable.

RMN ${ }^{13}$ C: (Fig. LXb) 33,5 $\left(\mathrm{CH}_{3}\right) ; 55,8$ (2) $\left(\mathrm{CH}_{3}\right) ; 60,8\left(\mathrm{CH}_{3}\right) ; 106,2$ (2) (CH); 109,6 (CH); 117,9 (C); 122,4 (CH); 125,1 (CH); 125,2 (C); 129,2 (CH); 130,3 (CH); 132,1 (C); 132,8 (C); 137,0 (C); 137,2 (C); 140,1 (CH); 152,8 (2) (C); 184,3 $(\mathrm{CH})$.

$\begin{array}{cc}\text { HPLC: Columna } \mathrm{C}_{18} & \mathrm{t}_{\mathrm{R}}: 14,66 \mathrm{~min} . \\ \text { Columna } \mathrm{C}_{8} & \mathrm{t}_{\mathrm{R}}: 13,42 \mathrm{~min} . \\ \text { Columna fenílica } & \mathrm{t}_{\mathrm{R}}: 14,24 \mathrm{~min} .\end{array}$


Obtención de $(Z)-\{N$-metil-5-[2-(3,4,5-trimetoxifenil)vinil]indol-3il\}metanol (78).<smiles>COc1cc(/C=C\c2ccc3c(c2)c(C=O)cn3C)cc(/C=C\c2ccc3c(c2)c(CO)cn3C)c1OC</smiles>

Siguiendo el método G, 20 mg de $\mathrm{NaBH}_{4}$ se añaden sobre una disolución de 25 mg (0,07 mmol) de 77 en $10 \mathrm{~mL}$ de $\mathrm{MeOH}$. Tras media hora de reacción, se obtienen $22 \mathrm{mg}$ (89\%) del alcohol 78.

\section{(Z)-\{N-metil-5-[2-(3,4,5-trimetoxifenil)vinil]indol-3-il $\}$ metanol (78):}

IR (película): 3413, 1579, $1124 \mathrm{~cm}^{-1}$.

RMN ${ }^{1} \mathbf{H}$ : (Fig. LXIa) 3,64 (6H, s, $\left.\mathrm{OCH}_{3}\right) ; 3,74$ (3H, s, $\left.\mathrm{CH}_{3}\right) ; 3,84$ (3H, s, $\mathrm{OCH}_{3}$ ); 4,79 (2H, sa; $\left.\mathrm{CH}_{2} \mathrm{OH}\right) ; 6,44\left(1 \mathrm{H}, \mathrm{d} ; J=12,2, \mathrm{H}_{1 \mathrm{a}}{ }^{*}\right) ; 6,57\left(2 \mathrm{H}, \mathrm{s}, \mathrm{H}_{2}, \mathrm{H}_{6}\right)$ ) 6,71 (1H, d; $\left.J=12,2, \mathrm{H}_{2 \mathrm{a}}{ }^{*}\right) ; 7,02\left(1 \mathrm{H}, \mathrm{s}, \mathrm{H}_{2}\right) ; 7,14(1 \mathrm{H}, \mathrm{d}, J=8,6) ; 7,25(1 \mathrm{H}, \mathrm{dd} ; J=8,6 ; 1,8$, $\left.\mathrm{H}_{6}\right) ; 7,67\left(1 \mathrm{H}, \mathrm{d}, J=1,8, \mathrm{H}_{4}\right)$.

* Asignación intercambiable.

RMN ${ }^{13}$ C: (Fig. LXIb) 32,8 ( $\left.\mathrm{CH}_{3}\right)$; 56,0 (2) $\left(\mathrm{CH}_{3}\right) ; 57,0\left(\mathrm{CH}_{2}\right) ; 61,0\left(\mathrm{CH}_{3}\right) ; 106,1$

(2) $(\mathrm{CH}) ; 109,0(\mathrm{CH}) ; 115,0(\mathrm{C}) ; 120,0(\mathrm{CH}) ; 123,4(\mathrm{CH}) ; 127,0$ (C); 128,1 (2) (CH); 128,5 (C); 131,1 (CH); 133,3 (C); 136,6 (C); 137,0 (C); 152,9 (2) (C).
HPLC: Columna $\mathrm{C}_{18}$ $\mathrm{t}_{\mathrm{R}}: 14,82 \mathrm{~min}$.
Columna $\mathrm{C}_{8}$ $\mathrm{t}_{\mathrm{R}}: 13,50 \mathrm{~min}$.
Columna fenílica $t_{R}: 13,96$ min. 
Obtención de $(Z \quad y \quad E)$-1-metil-5-[2-(3,4,5-trimetoxifenil)vinil]-1H-

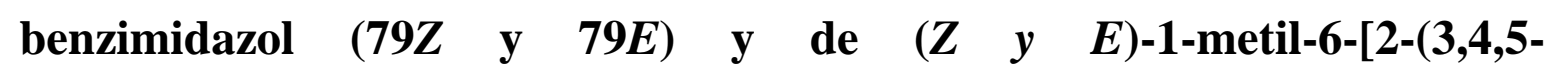
trimetoxifenil)vinil]-1H-benzimidazol (80Z y $80 E)$.<smiles>COc1cc(/C=C/c2cc(OC)c(OC)c(OC)c2)cc(/C=C/c2ccc3c(c2)ncn3C)c1</smiles>

Siguiendo el método B, 1,38 g (2,63 mmol) de bromuro de 3,4,5trimetoxibenciltrifenilfosfonio, 1,8 mL de $n \operatorname{BuLi}(2,88 \mathrm{mmol})$ y $383 \mathrm{mg}(2,39 \mathrm{mmol}) \mathrm{de}$ una mezcla de 7 y 8 en proporción 1:1, reaccionan para dar 1,48 g de crudo de reacción, que se purifican mediante cromatografía en columna de sílice y se obtienen 2 fracciones de 206 mg y de 326 mg de mezclas de los isómeros $\boldsymbol{Z}$ y $\boldsymbol{E}$, que se sometieron a separación mediante HPLC.

(Z)-1-metil-5-[2-(3,4,5-trimetoxifenil)vinil]-1H-benzimidazol (79Z) y (Z)-1metil-6-[2-(3,4,5-trimetoxifenil)vinil]-1H-benzimidazol (80Z):

RMN ${ }^{1} \mathbf{H}$ : Tabla I (Fig.LXIIa).

RMN ${ }^{13}$ C: Tabla II.

HPLC: Columna $\mathrm{C}_{18} \quad \mathrm{t}_{\mathrm{R}}: 13,83$ y 13,93 min. (1:1)

Columna $\mathrm{C}_{8} \quad \mathrm{t}_{\mathrm{R}}: 13,08$ y $13,14 \mathrm{~min} .(1: 1)$

Columna fenílica $\quad t_{\mathrm{R}}: 13,52$ y 13,68 min. (1:1)

(E)-1-metil-5-[2-(3,4,5-trimetoxifenil)vinil]-1H-benzimidazol $(79 E)$ o $(E)$-1metil-6-[2-(3,4,5-trimetoxifenil)vinil]-1H-benzimidazol (80E):

$\mathbf{R M N}{ }^{\mathbf{1}} \mathbf{H}$ : Tabla III (Fig LXIIIa).

$\mathbf{R M N}{ }^{13} \mathbf{C}$ : Tabla IV.

HPLC: Columna $\mathrm{C}_{18} \quad \mathrm{t}_{\mathrm{R}}: 13,79 \mathrm{~min}$.

Columna $\mathrm{C}_{8} \quad \mathrm{t}_{\mathrm{R}}: 12,86 \mathrm{~min}$.

Columna fenílica $\quad t_{\mathrm{R}}: 13,42 \mathrm{~min}$. 



\section{IV.4. SÍNTESIS DE COMPUESTOS MACROCÍCLICOS.}

\section{IV.4.A. Materiales de partida.}

\section{Obtención del 1-(6-bromohexil)-1H-indol-5-carbaldehído (81).}

$\mathrm{OHC}$<smiles>c1ccc2[nH]ccc2c1</smiles><smiles>BrCCCCCCCBr</smiles>

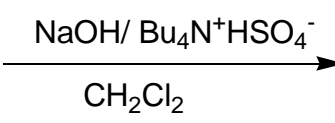

81

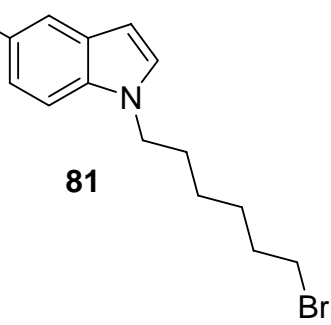

Sobre una disolución de 2.00 g (13,8 mmol) de $1 H$-indol-5-carbaldehído en $40 \mathrm{~mL}$ de $\mathrm{CH}_{2} \mathrm{Cl}_{2}$ se añaden $1,10 \mathrm{~g}(27,6 \mathrm{mmol})$ de $\mathrm{NaOH}$ y $200 \mathrm{mg}$ de $n-\mathrm{Bu}_{4} \mathrm{~N}^{+} \mathrm{HSO}_{4}{ }^{-}$y se mantiene 1 hora en agitación a temperatura ambiente. Posteriormente, se añaden 4,25 mL (27,6 mmol) de 1,6-dibromohexano y se deja en agitación a temperatura ambiente durante $48 \mathrm{~h}$, tras las cuales se evapora el $\mathrm{CH}_{2} \mathrm{Cl}_{2}$. El bruto de reacción se percola sobre gel de sílice, eluyéndose primero con hexano para retirar el exceso de 1,6-dibromohexano y, finalmente, con $\mathrm{CH}_{2} \mathrm{Cl}_{2}$ para obtener 3,04 g (72\%) de producto 81 .

\section{1-(6-bromohexil)-1H-indol-5-carbaldehído (81):}

RMN ${ }^{1} \mathbf{H}$ : (Fig. LXIVa) 1,30 (2H, m); 1,38 (2H, m); 1,76 (2H, m); 1,80 (2H, m); 3,32 (2H, t, $\left.J=6,6, \mathrm{H}_{6}{ }^{\prime}\right) ; 4,09\left(2 \mathrm{H}, \mathrm{t}, J=7,0, \mathrm{H}_{1}\right.$ ) $)$ 6,62 (1H, d; $\left.J=3,3, \mathrm{H}_{3}\right) ; 7,15(1 \mathrm{H}$, $\left.\mathrm{d} ; J=3,3, \mathrm{H}_{2}\right) ; 7,37\left(1 \mathrm{H}, \mathrm{d} ; J=8,4, \mathrm{H}_{7}\right) ; 7,74\left(1 \mathrm{H}, \mathrm{dd} ; J=8,4 ; J=1,5, \mathrm{H}_{6}\right) ; 8,10(1 \mathrm{H}, \mathrm{d}$; $\left.J=1,5, \mathrm{H}_{4}\right)$; 9,99 (1H, s, CHO).

RMN ${ }^{13}$ C: (Fig. LXIVb) 26,1 $\left(\mathrm{CH}_{2}\right) ; 27,7\left(\mathrm{CH}_{2}\right) ; 30,1\left(\mathrm{CH}_{2}\right) ; 32,6\left(\mathrm{CH}_{2}\right) ; 33,8$ $\left(\mathrm{CH}_{2}\right)$; 46,5 $\left(\mathrm{CH}_{2}\right) ; 103,4(\mathrm{CH}) ; 110,0(\mathrm{CH}) ; 121,7(\mathrm{CH}) ; 126,5(\mathrm{CH}) ; 128,4(\mathrm{C})$; 129,3 (C); 129,9 (CH); 139,3 (C); 192,4 (CH). 
Obtención de 1-[6-(4-formil-2-metoxifenoxi)hexil]-1H-indol-5carbaldehído (82).

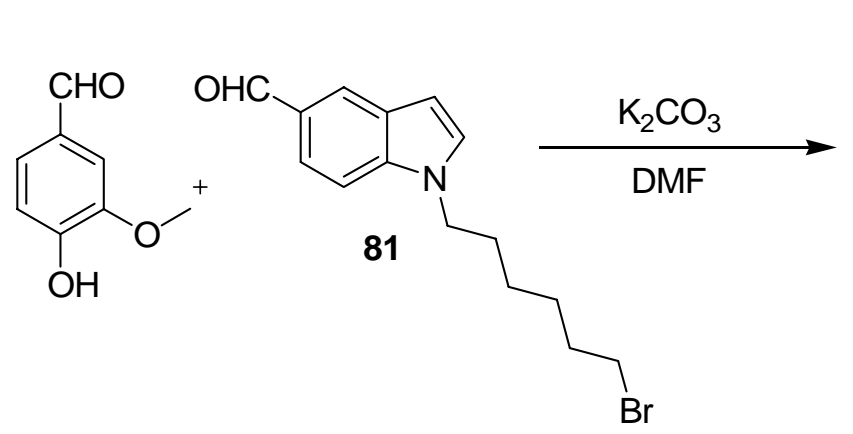

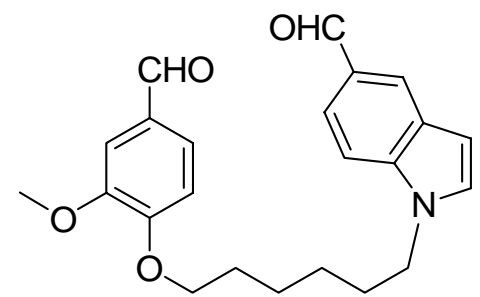

82

A una disolución de 1,72 g (11,3 mmol) de vainillina en $40 \mathrm{~mL}$ de DMF seca, a temperatura ambiente y bajo atmósfera de argón, se le añaden $10 \mathrm{~g}$ de $\mathrm{K}_{2} \mathrm{CO}_{3}$ y se mantiene en agitación durante 30 minutos. A continuación, se añaden 2,90 g (9,44 mmol) de 1-(6-bromohexil)-1H-indol-5-carbaldehído (81) disueltos en $10 \mathrm{~mL}$ de DMF seca y se aumenta la temperatura hasta $70{ }^{\circ} \mathrm{C}$. Transcurridas $48 \mathrm{~h}$, se recoge sobre $150 \mathrm{~mL}$ de hexano, se filtra para retirar las sales y se evapora hasta sequedad. Posteriormente, se redisuelve en $\mathrm{CH}_{2} \mathrm{Cl}_{2}$ y se lava con $\mathrm{NaOH}$ al $4 \%$ y con agua saturada de $\mathrm{NaCl}$ hasta $\mathrm{pH}$ neutro de las aguas de lavado, el conjunto de las fases orgánicas se seca con $\mathrm{Na}_{2} \mathrm{SO}_{4}$ anhidro, se filtra y se evapora hasta sequedad, obteniéndose 3,41 g (95\%) de producto 82.

\section{1-[6-(4-formil-2-metoxifenoxi)hexil]-1H-indol-5-carbaldehído (82):}

IR: 1693, 1596, 808, $\mathrm{cm}^{-1}$.

RMN ${ }^{1} \mathbf{H}$ : (Fig. LXVa) 1,35 (2H, m); 1,45 (2H, m); 1,83 (2H, m); 1,86 (2H, m); 3,89 (3H, s, $\left.\mathrm{OCH}_{3}\right) ; 4,05\left(2 \mathrm{H}, \mathrm{t}, J=6,6, \mathrm{H}_{1}{ }^{\prime}\right) ; 4,17\left(2 \mathrm{H}, \mathrm{t}, J=7,0, \mathrm{H}_{6}\right)$ ); 6,62 (1H, d; $\left.J=3,3, \mathrm{H}_{3}\right) ; 6,91\left(1 \mathrm{H}, \mathrm{d} ; J=8,4, \mathrm{H}_{6}\right.$ "); 7,18 (1H, d; $\left.J=3,3, \mathrm{H}_{2}\right)$; 7,39-7,43 (3H, $\mathrm{H}_{2}$ ', $\left.\mathrm{H}_{5}, \mathrm{H}_{7}\right) ; 7,70\left(1 \mathrm{H}, \mathrm{dd} ; J=8,4 ; J=1,4, \mathrm{H}_{6}\right) ; 8,13\left(1 \mathrm{H}, \mathrm{d} ; J=1,5, \mathrm{H}_{4}\right) ; 9,83(1 \mathrm{H}, \mathrm{s}$, $\mathrm{CHO}) ; 10,00$ (1H, s, CHO).

RMN ${ }^{13}$ C: (Fig. LXVb) 25,4 ( $\left(\mathrm{CH}_{2}\right) ; 26,4\left(\mathrm{CH}_{2}\right) ; 28,7\left(\mathrm{CH}_{2}\right) ; 30,0\left(\mathrm{CH}_{2}\right) ; 46,3$ $\left(\mathrm{CH}_{2}\right) ; 55,8\left(\mathrm{CH}_{3}\right) ; 68,7\left(\mathrm{CH}_{2}\right) ; 103,2(\mathrm{CH}) ; 109,3(\mathrm{CH}) ; 110,0(\mathrm{CH}) ; 111,4(\mathrm{CH})$; 121,5 (CH); 126,4 (CH); 126,6 (CH); 128,3 (C); 129,2 (C); 129,8 (CH); 129,8 (C); 139,2 (C); 149,7 (C); 154,0 (C); 190,7 (CH); 192,2 (CH). 


\section{Obtención de 1-[6-(4-formil-2,6-dimetoxifenoxi)hexil]-1H-indol-5- carbaldehído (83).}

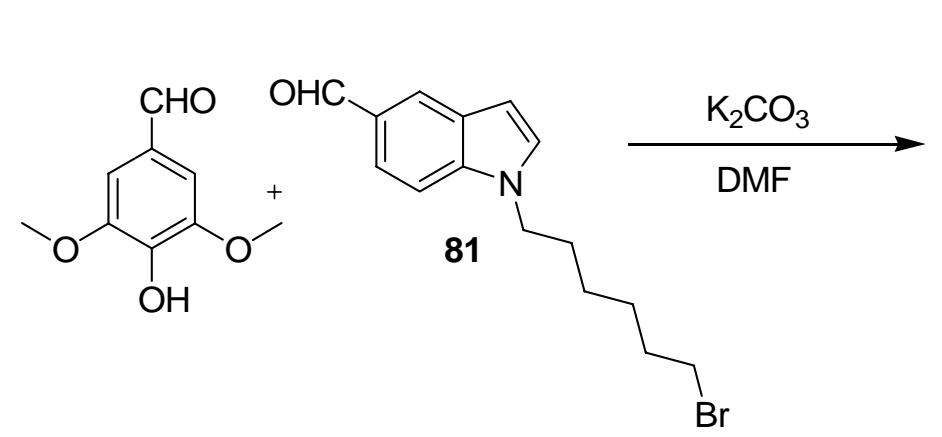

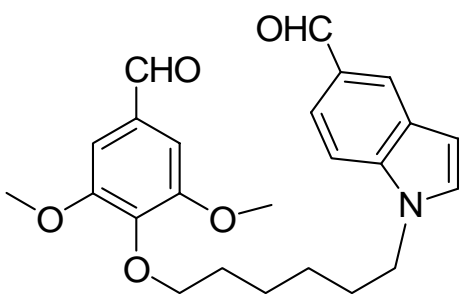

83

A una disolución de 2,16 g (11,87 mmol) de siringaldehído en $40 \mathrm{~mL}$ de DMF seca, a temperatura ambiente y bajo atmósfera de argón, se le añaden 10 g de $\mathrm{K}_{2} \mathrm{CO}_{3}$ y se mantiene en agitación durante 30 minutos. A continuación, se añaden 3,05 g (9,89 mmol) de 1-(6bromohexil)- $1 H$-indol-5-carbaldehído (81) disueltos en $10 \mathrm{~mL}$ de DMF seca y se aumenta la temperatura hasta $70{ }^{\circ} \mathrm{C}$. Transcurridas $48 \mathrm{~h}$, se recoge sobre $150 \mathrm{~mL}$ de hexano, se filtra para retirar las sales y se evapora hasta sequedad. Posteriormente, se redisuelve en $\mathrm{CH}_{2} \mathrm{Cl}_{2}$ y se lava con $\mathrm{NaOH}$ al $4 \%$ y con agua saturada de $\mathrm{NaCl}$ hasta $\mathrm{pH}$ neutro de las aguas de lavado, el conjunto de las fases orgánicas se seca con $\mathrm{Na}_{2} \mathrm{SO}_{4}$ anhidro, se filtra y se evapora hasta sequedad, obteniéndose 3,30 g (81\%) del producto 83.

\section{1-[6-(4-formil-2,6-dimetoxifenoxi)hexil]-1H-indol-5-carbaldehído (83):}

RMN ${ }^{1} \mathbf{H}$ : (Fig. LXVIa) 1,20 (2H, m); 1,40 (2H, m); 1,65 (2H, m); 1,72 (2H, m); 3,71 (6H, s, $\left.\mathrm{OCH}_{3}\right) ; 3,92\left(2 \mathrm{H}, \mathrm{m}, \mathrm{H}_{1}\right.$ ); 3,99 (2H, m, $\mathrm{H}_{6}$ ); 6,48 (1H, d; J=3,3, $\left.\mathrm{H}_{3}\right)$; 6,97 (2H, s, $\mathrm{H}_{2}$,', $\mathrm{H}_{6}$,); 7,07 (1H, d; $\left.J=3,3, \mathrm{H}_{2}\right) ; 7,26\left(1 \mathrm{H}, \mathrm{d} ; J=8,4 ; \mathrm{H}_{7}\right) ; 7,61(1 \mathrm{H}$, dd; J=8,4, $\left.\mathrm{H}_{6}\right) ; 7,96$ (1H, s, H4); 9,70 (1H, s, CHO); 9,85 (1H, s, CHO).

RMN ${ }^{13} \mathrm{C}$ : (Fig. LXVIb) 25,4 $\left(\mathrm{CH}_{2}\right) ; 26,5\left(\mathrm{CH}_{2}\right) ; 29,9\left(\mathrm{CH}_{2}\right) ; 30,2\left(\mathrm{CH}_{2}\right) ; 46,5$ $\left(\mathrm{CH}_{2}\right) ; 56,1$ (2) $\left(\mathrm{CH}_{3}\right) ; 73,2\left(\mathrm{CH}_{2}\right) ; 103,2(\mathrm{CH}) ; 106,6(2)(\mathrm{CH}) ; 110,0(\mathrm{CH}) ; 121,4$ (CH); 126,4 (CH); 128,2 (C); 129,1 (C); 129,9 (CH); 131,6 (C); 139,2 (C); 142,7 (C); 153,8 (2) (C); 191,1 (CH); 192,3 (CH). 



\section{IV.4.B. Macrociclos.}

Obtención de (2Z)-20-metoxi-18-oxa-11-azatetraciclo[17.2.2.1 $\left.1^{4,8} \cdot 0^{7,11}\right]$ tetracosa-1(21),2,4(24),5,7,9,19,22-octaeno (84), (cis)-20-metoxi-18-oxa11-azatetraciclo[17.2.2.1 $\left.{ }^{4,8} \cdot 0^{7,11}\right]$ tetracosa-1(21),4(24),5,7,9,19,22-heptaeno -2,3-diol (85) y (trans)-20-metoxi-18-oxa-11-azatetraciclo[17.2.2.1 $\left.1^{4,8} \cdot 0^{7,11}\right]$ tetracosa-1(21),4(24),5,7,9,19,22-heptaeno-2,3-diol (86).

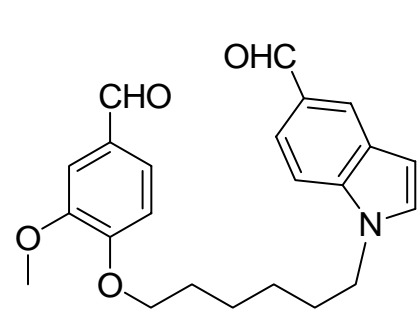

82

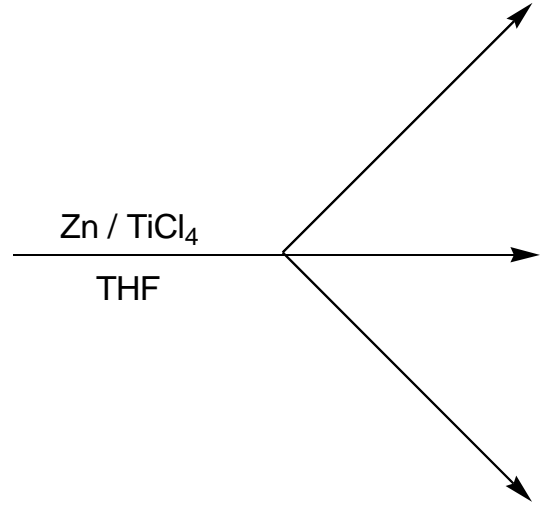<smiles>COc1cc(/C=C\c2ccc3c(ccn3CCCCCCOc3ccccc3)c2)ccc1OC(C)(C)C</smiles><smiles>O=S(=O)(O)Oc1ccc([C@@H](O)[C@H](O)c2ccc3c(ccn3CCCCCCSc3ccccc3)c2)cc1</smiles><smiles>COc1cc([C@H](O)[C@@H](O)c2ccc3c(ccn3CCCCCCOc3ccccc3)c2)ccc1O</smiles>

A una suspensión de 6,43 g (96,8 mmol) de Zinc en $200 \mathrm{~mL}$ de THF seco se le añaden, a $0{ }^{\circ} \mathrm{C}$, 9,16 g (48,2 $\left.\mathrm{mmol}\right)$ de $\mathrm{TiCl}_{4}$ y se mantiene en agitación hasta alcanzar temperatura ambiente. A continuación, se aumenta la temperatura hasta $66{ }^{\circ} \mathrm{C}$ y se adicionan lentamente 1,66 g (4,37 mmol) del dialdehído 82 disueltos en $100 \mathrm{~mL}$ de THF seco. La reacción se mantiene a reflujo y bajo atmósfera de argón durante 5 h, tras las cuales la mezcla de reacción se vierte sobre una mezcla de AcOEt y $\mathrm{HCl} 2 \mathrm{~N}$, se extrae y se lava con agua saturada de $\mathrm{NaCl}$ hasta $\mathrm{pH}$ neutro de las aguas de lavado, se seca la fase orgánica con $\mathrm{Na}_{2} \mathrm{SO}_{4}$ anhidro, se filtra y se evapora hasta sequedad, obteniéndose 1,61 g de producto bruto. Después de cromatografiar en columna de gel de sílice (eluyente Hex/AcOEt 9/1), se obtienen 158 mg (10\%) de olefina 84, 362 mg (21\%) del diol cis 85 y 462 mg (27\%) del diol trans 86. 
(2Z)-20-metoxi-18-oxa-11-azatetraciclo[17.2.2.1.$\left.^{4,8} \cdot 0^{7,11}\right]$ tetracosa-

1(21),2,4(24),5,7,9,19,22-octaeno (84):

IR: $1509,1262 \mathrm{~cm}^{-1}$.

$\mathbf{R M N}{ }^{1} \mathbf{H}$ : Tabla III (Fig. LXVIIa).

RMN ${ }^{13}$ C: Tabla V (Fig. LXVIIb).

EM: $370\left(\mathrm{M}^{+} \mathrm{Na}\right)$.

HPLC: Columna $\mathrm{C}_{18} \quad \mathrm{t}_{\mathrm{R}}: 19,44 \mathrm{~min}$.

Columna $\mathrm{C}_{8} \quad \mathrm{t}_{\mathrm{R}}: 17,45 \mathrm{~min}$.

Columna fenílica $\quad t_{R}: 17,44$ min.

(cis)-20-metoxi-18-oxa-11-azatetraciclo $\left[17.2 \cdot 2 \cdot 1^{4,8} \cdot 0^{7,11}\right] \quad$ tetracosa-

1(21),4(24),5,7,9,19,22-heptaeno-2,3-diol (85):

$\mathbf{R M N}^{1} \mathbf{H}$ : Tabla III (Fig. LXVIIIb).

EM: $404\left(\mathrm{M}^{+} \mathrm{Na}\right)$.

(trans)-20-metoxi-18-oxa-11-azatetraciclo[17.2.2.1 $\left.{ }^{4,8} \cdot 0^{7,11}\right]$ tetracosa-

1(21),4(24),5,7,9,19,22-heptaeno-2,3-diol (86):

RMN ${ }^{1} \mathbf{H}$ : Tabla III (Fig. LXIXb).

EM: $404\left(\mathrm{M}^{+} \mathrm{Na}\right)$. 
Obtención de (2Z)-20,23-dimetoxi-18-oxa-11-azatetraciclo[17.2.2.1 $\left.{ }^{4,8} \cdot 0^{7,11}\right]$ tetracosa-1(21),2,4(24),5,7,9,19,22-octaeno (87), (cis)-20,23-dimetoxi-18oxa-11-azatetraciclo[17.2.2.1.$\left.^{4,8} \cdot 0^{7,11}\right]$ tetracosa-1(21),4(24),5,7,9,19,22heptaeno-2,3-diol (88) y (trans)-20,23-dimetoxi-18-oxa-11-azatetraciclo $\left[17.2 .2 .1^{4,8} \cdot 0^{7,11}\right.$ ]tetracosa-1(21),4(24),5,7,9,19,22-heptaeno-2,3-diol (89).<smiles>COc1cc(C=O)cc(OC)c1OCCCCCCn1ccc2cc(C=O)cc(OC)c21</smiles>

A una suspensión de 2,04 g (30,72 mmol) de Zinc en 200 mL de THF seco se le añaden, a $0{ }^{\circ} \mathrm{C}, 1,80 \mathrm{~mL}(16,29 \mathrm{mmol})$ de $\mathrm{TiCl}_{4}$ y se mantiene en agitación hasta alcanzar temperatura ambiente. A continuación, se aumenta la temperatura hasta $66{ }^{\circ} \mathrm{C}$ y se adicionan lentamente $570 \mathrm{mg}$ (1,39 mmol) del dialdehído 83 disueltos en $100 \mathrm{~mL}$ de THF seco. La reacción se mantiene a reflujo y bajo atmósfera de argón durante 5 h, tras las cuales la mezcla de reacción se vierte sobre una mezcla de AcOEt y $\mathrm{HCl} 2 \mathrm{~N}$, se extrae y se lava con agua saturada de $\mathrm{NaCl}$ hasta $\mathrm{pH}$ neutro de las aguas de lavado, se seca la fase orgánica con $\mathrm{Na}_{2} \mathrm{SO}_{4}$ anhidro, se filtra y se evapora hasta sequedad, obteniéndose $680 \mathrm{mg}$ de producto bruto. Después de cromatografiar en columna de gel de sílice (eluyente Hex/AcOEt 9/1), se obtienen 150 mg (29\%) de olefina 86, 108 mg (18\%) del diol cis 87 y 16 mg (3\%) del diol trans 88. 
(2Z)-20,23-dimetoxi-18-oxa-11-azatetraciclo $\left[17.2 .2 .1^{4,8} \cdot 0^{7,11}\right]$ tetracosa-

1(21),2,4(24),5,7,9,19,22-octaeno (87):

IR: $1577,1126 \mathrm{~cm}^{-1}$.

RMN ${ }^{1} \mathbf{H}$ : Tabla VI (Fig. LXXa).

$\mathbf{R M N}{ }^{13}$ C: Tabla VIII (Fig. LXXb).

EM: $400\left(\mathrm{M}^{+} \mathrm{Na}\right)$.

HPLC: Columna $\mathrm{C}_{18} \quad \mathrm{t}_{\mathrm{R}}: 18,89 \mathrm{~min}$.

Columna $\mathrm{C}_{8} \quad \mathrm{t}_{\mathrm{R}}: 17,14 \mathrm{~min}$.

Columna fenílica $\quad t_{R}: 17,19$ min.

(cis)-20,23-dimetoxy-18-oxa-11-azatetraciclo[17.2.2.1 $\left.{ }^{4,8} \cdot 0^{7,11}\right]$ tetracosa-

1(21),4(24), 5,7,9,19,22-heptaeno-2,3-diol (88):

IR: $3450,1591,1126 \mathrm{~cm}^{-1}$.

RMN ${ }^{1} \mathbf{H}$ : Tabla VI (Fig. LXXIa).

RMN ${ }^{13}$ C: Tabla VIII (Fig. LXXIb).

EM: $434\left(\mathrm{M}^{+} \mathrm{Na}\right)$.

HPLC: Columna $\mathrm{C}_{18} \quad \mathrm{t}_{\mathrm{R}}: 13,34 \mathrm{~min}$.

Columna $\mathrm{C}_{8} \quad \mathrm{t}_{\mathrm{R}}: 12,03 \mathrm{~min}$.

Columna fenílica $\quad t_{R}: 12,53$ min.

(trans)-20,23-dimetoxi-18-oxa-11-azatetraciclo $\left[17.2 .2 .1^{4,8} \cdot 0^{7,11}\right]$ tetracosa-

1(21),4(24),5,7,9,19,22-heptaeno-2,3-diol (89):

IR: 3410, 1592, $1125 \mathrm{~cm}^{-1}$.

$\mathbf{R M N}{ }^{1} \mathbf{H}$ : Tabla VI (Fig. LXXIIa).

RMN ${ }^{13}$ C: Tabla VIII (Fig. LXXIIb).

EM: $434\left(\mathrm{M}^{+} \mathrm{Na}\right)$.

HPLC: Columna $\mathrm{C}_{18} \quad \mathrm{t}_{\mathrm{R}}: 12,60 \mathrm{~min}$.

Columna $\mathrm{C}_{8} \quad \mathrm{t}_{\mathrm{R}}: 11,51 \mathrm{~min}$.

Columna fenílica $\quad t_{R}: 12,00 \mathrm{~min}$. 
Obtención del diacetato de (cis)-20-metoxi-18-oxa-11-azatetraciclo $\left[17.2 .2 .1^{4,8} \cdot 0^{7,11}\right]$ tetracosa-1(21),4(24),5,7,9,19,22-heptaeno-2,3-diol (90).

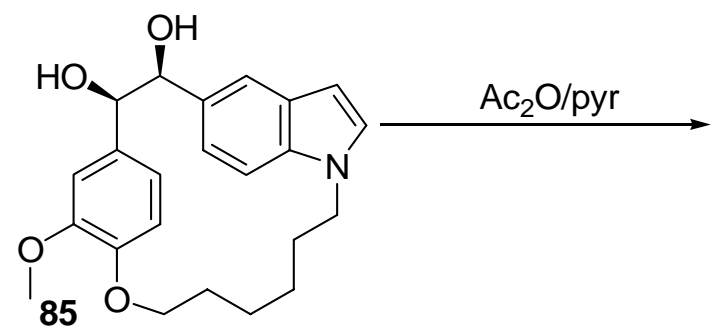<smiles>COc1cc(C(OC(C)=O)C(OC(C)=O)c2ccc3c(ccn3CCCCCCOc3ccccc3)c2)ccc1O</smiles>

Siguiendo el método J, a una disolución de $97 \mathrm{mg}(0,25 \mathrm{mmol})$ de 85 en 4,0 $\mathrm{mL}$ de piridina se añaden 2,0 mL de $\mathrm{Ac}_{2} \mathrm{O}$. Después de 22 horas, se obtienen 86 mg (73\%) del producto acetilado $\mathbf{9 0}$.

Diacetato de (cis)-20-metoxi-18-oxa-11-azatetraciclo[17.2.2.1 $\left.{ }^{4,8} \cdot 0^{7,11}\right]$ tetracosa1(21),4(24),5,7,9,19,22-heptaeno-2,3-diol (90):

IR: 1742, 1594, $1266 \mathrm{~cm}^{-1}$.

RMN ${ }^{1} \mathbf{H}$ : Tabla IV (Fig. LXXIIIa).

RMN ${ }^{13}$ C: Tabla V (Fig. LXXIIIb).

EM: $465\left(\mathrm{M}^{+}\right)$.

$\begin{array}{cc}\text { HPLC: Columna } \mathrm{C}_{18} & \mathrm{t}_{\mathrm{R}}: 16,55 \mathrm{~min} . \\ \text { Columna } \mathrm{C}_{8} & \mathrm{t}_{\mathrm{R}}: 15,14 \mathrm{~min} . \\ \text { Columna fenílica } & \mathrm{t}_{\mathrm{R}}: 16,03 \mathrm{~min} .\end{array}$

Obtención del diacetato de (trans)-20-metoxi-18-oxa-11-azatetraciclo $\left[17.2 .2 .1^{4,8} \cdot 0^{7,11}\right.$ ]tetracosa-1(21),4(24),5,7,9,19,22-heptaeno-2,3-diol (91).<smiles>COc1cc([C@@H](O)[C@H](O)c2ccc3c(ccn3CCCCCCCOc3ccccc3)c2)ccc1O</smiles><smiles>COc1ccc([C@H](OC(C)=O)[C@@H](OC(C)=O)c2ccc3c(ccn3CCCCCCCOc3ccccc3)c2)cc1OC</smiles>

Siguiendo el método J, a una disolución de $72 \mathrm{mg}(0,19 \mathrm{mmol})$ de $\mathbf{8 6}$ en 4,0 $\mathrm{mL}$ de piridina se añaden 2,0 mL de $\mathrm{Ac}_{2} \mathrm{O}$. Después de 24 horas, se obtienen $52 \mathrm{mg}$ (59\%) del diacetato 91. 
Diacetato de (trans)-20-metoxi-18-oxa-11-azatetraciclo[17.2.2.1 $\left.1^{4,8} \cdot 0^{7,11}\right]$ tetracosa-1(21),4(24),5,7,9,19,22-heptaeno-2,3-diol (91):

IR: 1740, 1603, $1266 \mathrm{~cm}^{-1}$.

RMN ${ }^{1} \mathbf{H}$ : Tabla IV (Fig. LXXIVa).

$\mathbf{R M N}{ }^{13} \mathbf{C}$ : Tabla V (Fig. LXXIVb).

EM: $465\left(\mathrm{M}^{+}\right)$.

$\begin{array}{cc}\text { HPLC: Columna } \mathrm{C}_{18} & \mathrm{t}_{\mathrm{R}}: 16,22 \mathrm{~min} . \\ \text { Columna } \mathrm{C}_{8} & \mathrm{t}_{\mathrm{R}}: 14,92 \mathrm{~min} . \\ \text { Columna fenílica } & \mathrm{t}_{\mathrm{R}}: 15,99 \mathrm{~min} .\end{array}$

\section{Obtención del diacetato de (cis)-20,23-dimetoxi-18-oxa-11-azatetraciclo} $\left[17.2 .2 .1^{4,8} \cdot 0^{7,11}\right]$ tetracosa-1(21),4(24),5,7,9,19,22-heptaeno-2,3-diol (92).<smiles>COc1cc([C@@H](O)[C@H](O)c2ccc3c(ccn3CCCCCCCOc3ccccc3)c2)cc(OC)c1O</smiles><smiles>COc1cc(C(OC(C)=O)C(OC(C)=O)c2ccc3c(ccn3CCCCCCO)c2)cc(OC)c1OC</smiles>

Siguiendo el método J, a una disolución de $30 \mathrm{mg}(0,07 \mathrm{mmol})$ de $\mathbf{8 8}$ en $3 \mathrm{~mL}$ de piridina se añaden $1,5 \mathrm{~mL}$ de $\mathrm{Ac}_{2} \mathrm{O}$ y se mantiene en agitación 24 horas. Tras cromatografiar el crudo de reacción, se obtienen 11 mg (32\%) del producto acetilado 92.

Diacetato de (cis)-20,23-dimetoxi-18-oxa-11-azatetraciclo[17.2.2.1 $\left.{ }^{4,8} \cdot 0^{7,11}\right]$ tetracosa-1(21),4(24),5,7,9,19,22-heptaeno-2,3-diol (92):

IR: 1742, 1589, 1236, $1126 \mathrm{~cm}^{-1}$.

$\mathbf{R M N}{ }^{1} \mathbf{H}$ : Tabla VII (Fig. LXXVa).

EM: $495\left(\mathrm{M}^{+}\right)$.

$\begin{array}{cc}\text { HPLC: Columna } \mathrm{C}_{18} & \mathrm{t}_{\mathrm{R}}: 15,88 \mathrm{~min} . \\ \text { Columna } \mathrm{C}_{8} & \mathrm{t}_{\mathrm{R}}: 14,88 \mathrm{~min} . \\ \text { Columna fenílica } & \mathrm{t}_{\mathrm{R}}: 15,70 \mathrm{~min} .\end{array}$


Obtención del diacetato de (trans)-20,23-dimetoxi-18-oxa-11-azatetraciclo $\left[17.2 .2 .1^{4,8} \cdot 0^{7,11}\right]$ tetracosa -1(21),4(24),5,7,9,19,22-heptaeno-2,3-diol (93).<smiles>COc1cc([C@H](O)[C@@H](O)c2ccc3c(ccn3CCCCCCCOc3ccccc3)c2)cc(OC)c1OC</smiles><smiles>COc1cc([C@@H](OC(C)=O)[C@@H](OC(C)=O)c2ccc3c(ccn3CCCCCCOc3ccccc3)c2)cc(OC)c1OC</smiles>

Siguiendo el método J, a una disolución de $23 \mathrm{mg}(0,06 \mathrm{mmol})$ de 89 en $3 \mathrm{~mL}$ de piridina se añaden $1,5 \mathrm{~mL}$ de $\mathrm{Ac}_{2} \mathrm{O}$ y se mantiene en agitación 20 horas. Tras cromatografiar el crudo de reacción, se obtienen 9 mg (30\%) del producto acetilado 93.

Diacetato de (trans)-20,23-dimetoxi-18-0xa-11-azatetraciclo[17.2.2.1 $\left.{ }^{4,8} \cdot 0^{7,11}\right]$ tetracosa -1(21),4(24),5,7,9,19,22-heptaeno-2,3-diol (93):

IR: 1738, 1592, $1266 \mathrm{~cm}^{-1}$.

$\mathbf{R M N}^{\mathbf{1}} \mathbf{H}$ : Tabla VII (Fig. LXXVIa).

RMN ${ }^{13}$ C: Tabla VIII (Fig. LXXVIb).

EM: $495\left(\mathrm{M}^{+}\right)$.
HPLC: Columna $\mathrm{C}_{18}$ $\mathrm{t}_{\mathrm{R}}: 16,29 \mathrm{~min}$.
Columna $\mathrm{C}_{8}$ $t_{R}: 15,12 \min$.
Columna fenílica $t_{R}: 15,74$ min. 



\section{IV.5. ACTIVIDAD BIOLÓGICA: ENSAYOS DE INHIBICIÓN DE POLIMERIZACIÓN DE TUBULINA.}

La parte experimental de la tubulina se ha dividido en tres apartados:

- Aislamiento de la proteína microtubular a partir de cerebros de ternero.

- Ensayos de inhibición de polimerización de tubulina, en el cual se hace un cribado con el fin de seleccionar los compuestos que den mejores resultados.

- Determinación de la $\mathbf{I C}_{\mathbf{5 0}}$, de los compuestos seleccionados en el apartado anterior.

\section{IV.5.A. Aislamiento de proteína microtubular.}

Se parte de 4 cerebros de ternero recién sacrificados, se enfrían a $0{ }^{\circ} \mathrm{C}$ en disolución de transporte (DT) y se llevan a una cámara fría donde se eliminan manualmente las meninges y los coágulos. La parte superficial del córtex se corta tomando la sustancia gris y evitando, en lo posible, coger la sustancia blanca. Se obtienen aproximadamente 300 gramos de tejido. 
Por cada gramo de córtex obtenido se añade $1 \mathrm{~mL}$ de disolución de extracción (DE). A continuación, se homogeniza en varias etapas, con un homogenizador potter. El resultado son unos $450 \mathrm{~mL}$ de homogenado, con aspecto rosado uniforme, que se centrifugan a $4{ }^{\circ} \mathrm{C}$ y 31000 rpm durante 1 hora.

Al sobrenadante, $240 \mathrm{~mL}$, se añaden $24 \mathrm{~mL}$ de tampón 10XAB (1/10 del volumen de sobrenadante), 68,9 mL de glicerol (hasta concentración 3,5 M), 1,7 mL de GTP (hasta concentración 0,5 mM) y $1013 \mu \mathrm{l}$ de PMSF (hasta concentración $1 \mathrm{mM}$ ). Los $335 \mathrm{~mL}$ resultantes se incuban a $37{ }^{\circ} \mathrm{C}$ durante 45 minutos y después se somete a centrifugación a $37^{\circ} \mathrm{C}$ durante 90 minutos a $31000 \mathrm{rpm}$.

El precipitado obtenido (primer ciclo de proteína polimerizada) se resuspende en 12 mL de tampón 1 XAB y 1mM GTP y se homogeniza la muestra. La suspensión se enfría en hielo durante 30 minutos, y posteriormente se centrifuga a 32000 rpm durante 30 minutos a $4{ }^{\circ} \mathrm{C}$. Al sobrenadante obtenido (primer ciclo de polimerización/despolimerización de tubulina), $17 \mathrm{~mL}$, se le añaden $85 \mu \mathrm{l}$ de GTP (hasta 0,5 mM), 51,5 $\mu \mathrm{l}$ de PMSF (hasta 1 $\mathrm{mM}$ ) y la mezcla se incuba a $37^{\circ} \mathrm{C}$ durante 30 minutos. Después se centrifuga a $32000 \mathrm{rpm}$ durante 45 minutos y a $37{ }^{\circ} \mathrm{C}$. Se recoge el precipitado y se enfría en hielo durante 5 minutos (segunda polimerización). El precipitado se resuspende con $2 \mathrm{~mL}$ de tampón 1XAB y $10 \mu \mathrm{l}$ de GTP $(0,5 \mathrm{mM})$.

Las muestras fueron alicuotadas en volúmenes de $200 \mu$ l (obteniéndose un volumen total entre 3,0 y 4,0 mL y una concentración media de $35 \mathrm{mg} / \mathrm{mL}$ ), almacenadas a $-80^{\circ} \mathrm{C}$, previa congelación rápida con nitrógeno líquido, hasta su posterior uso.

El rendimiento promedio de cada purificación (utilizando como material de partida 300 g de tejido) fue de 0,3-0,5 mg de proteína microtubular (MTP) por gramo de tejido. 


\section{IV.5.B. Determinación de la actividad inhibitoria de la polimerización de tubulina de los compuestos a una concentración.}

Las alícuotas de proteína microtubular (MTP) se descongelan rápidamente en un baño de agua a $20{ }^{\circ} \mathrm{C}$ y se resuspenden en $1 \mathrm{~mL}$ de tampón $1 \mathrm{X}$ AB por alícuota. La suspensión se somete, cuidadosamente, a agitación magnética suave en hielo durante 30 minutos, se centrifuga 30 minutos a $4{ }^{\circ} \mathrm{C}$ y 100000 x g (segundo ciclo completo de polimerización/despolimerización). Se recoge el sobrenadante y se realiza el ensayo de Bradford para determinar la concentración de proteína total; típicamente 4,0 mg/mL (valor medio por preparación). Para esta concentración de proteína, se toman $125 \mu$ l de MTP, $5 \mu \mathrm{l}$ de disolución $2 \mathrm{mM}$ de los ligandos en DMSO (para una concentración de compuesto 20 $\mu \mathrm{M}), 15 \mu \mathrm{L}$ de DMSO y $355 \mu$ l de tampón (1XAB + 1,5 mM GTP), hasta completar los $500 \mu \mathrm{L}$ del volumen final.

Las muestras se incuban a $20{ }^{\circ} \mathrm{C}$ durante 30 minutos, permitiendo la interacción de los ligandos con la proteína microtubular. A continuación, se enfrían en un baño de hielo durante 10 minutos y se introducen en el espectrofotómetro. La absorbancia se registra a $450 \mathrm{~nm}$ durante todo el proceso Tras un período de estabilización a $4{ }^{\circ} \mathrm{C}$, aproximadamente 5 minutos, la temperatura se eleva a $37^{\circ} \mathrm{C}$. Cuando la absorbancia se estabiliza, cerca de los 45 min., se vuelve a cambiar la temperatura a $4{ }^{\circ} \mathrm{C}$ y la absorbancia vuelve a disminuir.

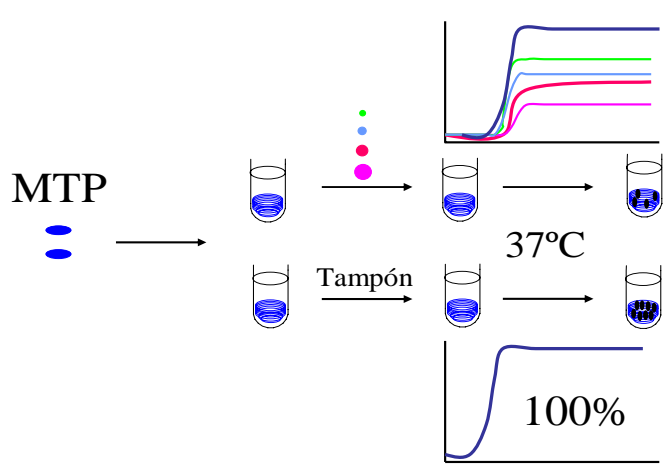

Figura 113. Esquema de ensayo de inhibición de polimerización de tubulina. Cada cubeta contiene proteína microtubular en tampón a concentración de $1 \mathrm{mg} / \mathrm{mL}$, y DMSO (4\%). En cada cubeta se añade el compuesto que se quiere ensayar, a la concentración elegida, exceptuando la cubeta de referencia. A continuación, se aumenta la temperatura $\left(37^{\circ} \mathrm{C}\right)$ y se mide la turbidez generada. La diferencia entre la absorbancia presentada por la muestra de referencia (línea azul oscura, valor considerado como el 100\% de polimerización) y cada una de las muestras que contienen compuesto (resto de líneas de colores) se corresponde con la inhibición que ejerce ese compuesto (\%) a la concentración ensayada. 
En las siguientes tablas se resumen los ensayos de inhibición de polimerización de tubulina y se indican la concentración probada y el porcentaje de inhibición producida. Todos los resultados son para una concentración final de proteína de 1 mg/mL.

\begin{tabular}{|c|c|c|c|c|c|}
\hline COMPUESTO & $\begin{array}{c}\text { CONC } \\
(\mu M)\end{array}$ & $\begin{array}{c}\text { INHIBICIÓN } \\
(\%)\end{array}$ & COMPUESTO & $\begin{array}{c}\text { CONC } \\
(\mu M)\end{array}$ & $\begin{array}{c}\text { INHIBICIÓN } \\
(\%)\end{array}$ \\
\hline$C-A 4$ & $3-4$ & 50 & $C-A 4$ & $3-4$ & 50 \\
\hline 19 & 20 & 20 & 59 & 20 & 97 \\
\hline 20 & 20 & 52 & 60 & 20 & 98 \\
\hline 22 & 20 & 12 & 61 & 20 & 95 \\
\hline 23 & 5 & 81 & 62 & 20 & 32 \\
\hline 24 & 20 & 61 & 63 & 20 & 87 \\
\hline 25 & 20 & 86 & 64 & 20 & 95 \\
\hline 26 & 20 & 0 & 65 & 5 & 97 \\
\hline 27 & 20 & 5 & 66 & 20 & 40 \\
\hline 30 & 20 & 94 & 67 & - & - \\
\hline 32 & 20 & 86 & 68 & 5 & 0 \\
\hline 34 & 20 & 7 & 69 & 20 & 2 \\
\hline 35 & 20 & 16 & 70 & 20 & 22 \\
\hline 37 & - & - & 71 & 20 & 37 \\
\hline 38 & 20 & 12 & 72 & 20 & 37 \\
\hline 39 & 20 & 32 & 73 & 20 & 0 \\
\hline 43 & 20 & 86 & 74 & 20 & 0 \\
\hline 44 & 20 & 68 & 75 & 20 & 95 \\
\hline 45 & 20 & 98 & 77 & 20 & 98 \\
\hline 46 & 20 & 61 & 78 & 20 & 91 \\
\hline 47 & 20 & 96 & $79 Z$ y $80 Z$ & 20 & 93 \\
\hline 48 & 5 & 85 & $79 E$ y $80 E$ & 20 & 49 \\
\hline 49 & 20 & 100 & 84 & 20 & 19 \\
\hline 50 & 20 & $96 / 88$ & 85 & 40 & 0 \\
\hline 51 & 20 & 32 & 86 & 40 & 0 \\
\hline 52 & 20 & 90 & 87 & 20 & 44 \\
\hline 53 & 20 & 93 & 88 & 40 & 0 \\
\hline 54 & 5 & 93 & 89 & 40 & 0 \\
\hline 55 & 20 & 96 & 90 & 40 & 18 \\
\hline 56 & 20 & 12 & 91 & 40 & 0 \\
\hline 57 & 20 & 9 & 92 & 40 & 0 \\
\hline 58 & 20 & 100 & 93 & 40 & 0 \\
\hline
\end{tabular}

Tabla 27. Inhibición (\%) de los compuestos ensayados a 5, 20 ó $40 \mu \mathrm{M}$. En negrita se resaltan aquellos compuestos que presentan un valor de IPT mayor del 50\% para la concentración de prueba (5, 20 o 40 $\mu \mathrm{M}$ ). 


\section{IV.5.C. Deteminación de la $I C_{50}$ de inhibición de polimerización de tubulina.}

La $\mathrm{IC}_{50}$ es la concentración a la cual el compuesto inhibe el 50\% de la polimerización. La determinación se lleva a cabo gráficamente.

Los compuestos seleccionados para la determinación de la $\mathrm{IC}_{50}$ fueron aquellos que, a una concentración $20 \mu \mathrm{M}$ o menor, presentaban una inhibición de la polimerización de la tubulina superior al 50\% (marcados en negrita en la tabla).

El procedimiento seguido es exactamente igual al explicado anteriormente, pero se mide simultáneamente la inhibición de polimerización de tubulina de varias concentraciones del ligando a una concentración fija de proteína $(1 \mathrm{mg} / \mathrm{mL})$. En primer lugar y tras descongelar las alícuotas, se procede al segundo ciclo de despolimerización y se determina, mediante el método de Bradford, la concentración de proteína tras el segundo ciclo de despolimerización.

A continuación, se preparan las cubetas, utilizando distintas concentraciones del mismo compuesto en cada una (generalmente se utilizan al menos las concentraciones 0,5 , 1, 2, 5, 7 y $10 \mu \mathrm{M}$, aunque varían en función del comportamiento de cada compuesto), DMSO hasta $20 \mu \mathrm{L}, 125 \mu \mathrm{l}$ de MTP (4 mg/mL) y $355 \mu \mathrm{l}$ de tampón (1XAB + 1,5 mM GTP).

Tras la preparación de las muestras, la incubación y el resto del proceso se repite del mismo modo que en el ensayo preliminar del apartado anterior.

Como se ha indicado anteriormente, una vez seleccionados los compuestos que mejores resultados de actividad dieron, se calculó la $\mathrm{IC}_{50}$ de estos compuestos, a partir del porcentaje de inhibición de polimerización de tubulina que mostraban a las concentraciones que se muestran en la siguiente tabla: 


\begin{tabular}{|c|c|c|c|c|c|}
\hline COMPUESTO & $\begin{array}{c}\text { CONC } \\
(\mu M)\end{array}$ & $\begin{array}{c}\text { INHIBICIÓN } \\
(\%)\end{array}$ & COMPUESTO & $\begin{array}{c}\text { CONC } \\
(\mu M)\end{array}$ & $\begin{array}{c}\text { INHIBICIÓN } \\
(\%)\end{array}$ \\
\hline \multirow{7}{*}{ (1) } & 5 & 23 & \multirow{7}{*}{ (-) } & 0,5 & 44 \\
\hline & 7 & 25 & & 1 & 48 \\
\hline & 10 & 35 & & 1,5 & 70 \\
\hline & 15 & 36 & & 2 & 83 \\
\hline & 20 & 52 & & 3 & 86 \\
\hline & \multirow[t]{2}{*}{30} & 68 & & 5 & 90 \\
\hline & & & & 10 & 93 \\
\hline \multirow{7}{*}{$\prod_{-0}^{\infty}$} & 0,5 & 30 & \multirow{7}{*}{ - } & 2 & 14 \\
\hline & 1 & 39 & & 5 & 25 \\
\hline & 2 & 61 & & 7 & 20 \\
\hline & 3 & 69 & & 8 & 30 \\
\hline & 5 & 81 & & 10 & 42 \\
\hline & - & - & & 15 & 61 \\
\hline & - & - & & 20 & 86 \\
\hline \multirow{6}{*}{ (1) } & 2 & 0 & \multirow{6}{*}{$\left.\right|_{-0} ^{14}$} & 1 & 26 \\
\hline & 4 & 18 & & 10 & 42 \\
\hline & 5 & 29 & & 15 & 51 \\
\hline & 10 & 48 & & 20 & 68 \\
\hline & 12 & 54 & & 30 & 81 \\
\hline & 15 & 75 & & - & - \\
\hline \multirow{7}{*}{ (- } & 0,5 & 30 & \multirow{7}{*}{ (1) } & 1 & 22 \\
\hline & 1 & 33 & & 5 & $29 ; 30$ \\
\hline & 1,5 & 36 & & 10 & $43 ; 56$ \\
\hline & 2 & 43 & & 15 & 52 \\
\hline & 5 & 65 & & 20 & $78 ; 84$ \\
\hline & 7 & 91 & & 30 & 98 \\
\hline & 10 & 93 & & - & - \\
\hline \multirow{7}{*}{ - } & 0,5 & 9 & \multirow{7}{*}{ (HO } & - & - \\
\hline & 1 & 28 & & 5 & 22 \\
\hline & 1,5 & 34 & & 10 & 35 \\
\hline & 2 & 54 & & 15 & 37 \\
\hline & 5 & 63 & & 20 & 61 \\
\hline & 7 & 85 & & - & - \\
\hline & 10 & 96 & & - & - \\
\hline
\end{tabular}




\begin{tabular}{|c|c|c|c|c|c|}
\hline COMPUESTO & $\begin{array}{c}\text { CONC } \\
(\mu M)\end{array}$ & $\begin{array}{c}\text { INHIBICIÓN } \\
(\%)\end{array}$ & COMPUESTO & $\begin{array}{c}\text { CONC } \\
(\mu M)\end{array}$ & $\begin{array}{c}\text { INHIBICIÓN } \\
(\%)\end{array}$ \\
\hline \multirow{6}{*}{ (1) } & 1 & 65 & \multirow{6}{*}{ (N) } & 0,5 & 28 \\
\hline & 5 & 94 & & 1 & 43 \\
\hline & 10 & 96 & & 1,5 & 45 \\
\hline & 15 & 96 & & 2 & 75 \\
\hline & 20 & 96 & & 4 & 100 \\
\hline & 30 & 100 & & 5 & 93 \\
\hline \multirow{6}{*}{ - } & - & - & \multirow{6}{*}{ (-) } & 0,1 & 0 \\
\hline & 0,5 & 35 & & 0,3 & 58 \\
\hline & 1 & 52 & & 0,5 & 73 \\
\hline & 2 & 65 & & 0,7 & 77 \\
\hline & \multirow[t]{2}{*}{5} & \multirow[t]{2}{*}{85} & & 1 & 95 \\
\hline & & & & 10 & 96 \\
\hline \multirow{7}{*}{ - } & 0,1 & 0 & \multirow{7}{*}{ (1) } & - & - \\
\hline & 0,2 & 27 & & 1 & 8 \\
\hline & 0,5 & 34 & & 2,5 & 18 \\
\hline & 1 & 39 & & 5 & 40 \\
\hline & 2 & 91 & & 10 & 90 \\
\hline & 5 & 100 & & 20 & 97 \\
\hline & 10 & 100 & & - & - \\
\hline \multirow{7}{*}{ - } & 3 & 26 & \multirow{7}{*}{ Сно } & 0,5 & 0 \\
\hline & 4 & 29 & & 2 & 21 \\
\hline & 5 & $52 ; 68$ & & 4 & 40 \\
\hline & 7 & $32 ; 52 ; 81$ & & 5 & 61 \\
\hline & 10 & 45 & & 7 & 78 \\
\hline & 15 & 68 & & 10 & 92 \\
\hline & 20 & 88 & & 20 & 98 \\
\hline \multirow{6}{*}{ - } & 1 & 16 & \multirow{6}{*}{$\underbrace{\mathrm{OHC}_{2}}_{-0}$} & 3 & 40 \\
\hline & 2 & 30 & & 5 & 59 \\
\hline & 4 & 43 & & 7 & 63 \\
\hline & 5 & 71 & & 10 & 83 \\
\hline & 7 & 75 & & 20 & 95 \\
\hline & 20 & 96 & & - & - \\
\hline \multirow{7}{*}{ - } & 0,5 & 17 & \multirow{7}{*}{ (1) } & 1 & 16 \\
\hline & 1 & 26 & & 2 & 29 \\
\hline & 2 & 38 & & 3 & 27 \\
\hline & 3 & 50 & & 4 & 33 \\
\hline & 4 & 62 & & 5 & 52 \\
\hline & 5 & 89 & & 6 & 88 \\
\hline & 20 & 93 & & 7 & 98 \\
\hline
\end{tabular}




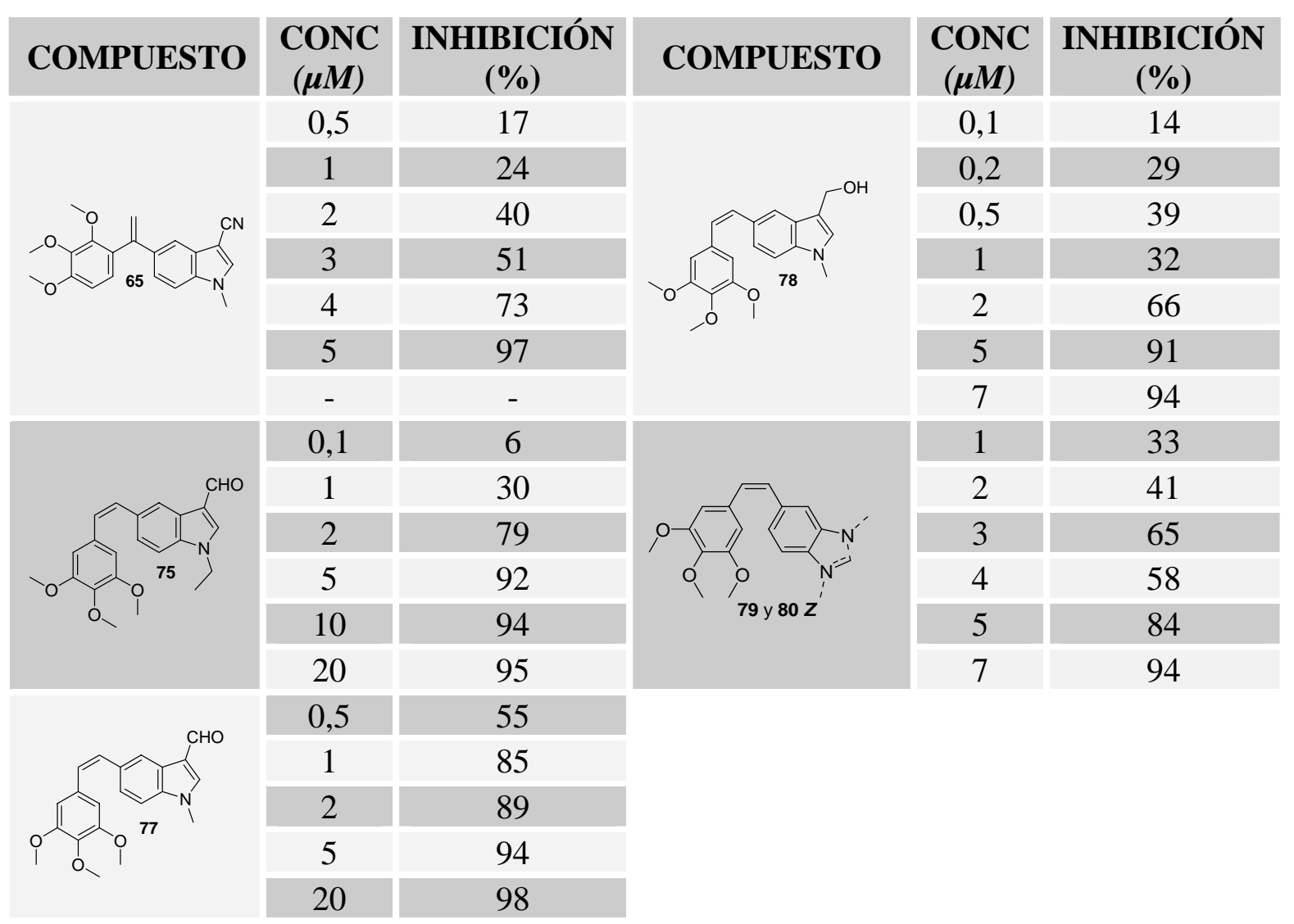

Tabla 28. Inhibición (\%) a varias concentraciones de los compuestos seleccionados para determinar su IC 50. 

Durante la realización de este trabajo de Tesis Doctoral se ha llevado a cabo la síntesis y evaluación de nuevos agentes antimitóticos relacionados con combretastatinas y fenstatinas y de los resultados obtenidos se pueden extraer las siguientes conclusiones:

1. La metodología sintética utilizada permite obtener fácilmente fenstatinas, isocombretastatinas y un gran número de derivados que constituyen una nueva familia de agentes antimitóticos.

2. Se han obtenido decenas de compuestos que combinan restos trimetoxifenilo con restos indolilo a través de puentes diferentes. Su ensayo como inhibidores de la polimerización de tubulina ha permitido la comparación directa de combretastatinas, fenstatinas e isocombretastatinas, que suelen poseer una elevada potencia en dicho ensayo y como agentes citotóxicas cuando poseen las agrupaciones citadas.

3. Para similares potencias de inhibición de polimerización de tubulina, las isocombretastatinas presentan mayor potencia citotóxica que las fenstatinas y semejante a la mostrada por las combretastatinas. 
4. El esqueleto de $N$-metil-5-indolilo ha resultado ser un buen reemplazo del anillo de guayacol, o anillo $\mathrm{Ar}_{2}$, tanto en isocombretastatinas como combretastatinas $\mathrm{y}$ fenstatinas. Sin embargo, su sustitución por otros heterociclos benzofusionados relacionados, como 1,3-benzoxazol y 1 Hbenzimidazol, conduce a compuestos menos activos o inactivos.

5. La presencia del resto 3,4,5-trimetoxifenilo conduce a compuestos más potentes que la presencia del resto 2,3,4-trimetoxifenilo. Sin embargo, la potencia de los compuestos con éste último se ve incrementada cuando se combina con un anillo indólico (en lugar de un segundo resto fenilo).

6. En isocombretastatinas, las modificaciones introducidas en la posición C-3 del indol no han mejorado la actividad presentada por el compuesto con el resto indolilo sin sustituir en dicha posición, aunque la introducción de una oxima, un grupo nitrilo o un grupo formilo ha generado compuestos de potencias comparables.

7. Siguiendo la metodología empleada por el grupo de investigación en trabajos anteriores, se han sintetizado dos nuevas familias de combretastatinas macrocíclicas, cuyo análisis conformacional completa el estudio sobre la movilidad y la disposición que adoptan este tipo de análogos.

8. Se ha confirmado que la existencia de un puente adicional (espaciador), conectando las posiciones para-para de combretastatinas y análogos, hace perder la actividad inhibitoria de polimerización de tubulina y la citotoxicidad de estas familias de compuestos. 



\section{VI.1. TABLAS.}

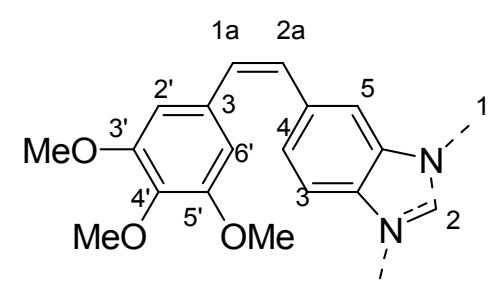

$79 Z, 80 Z$

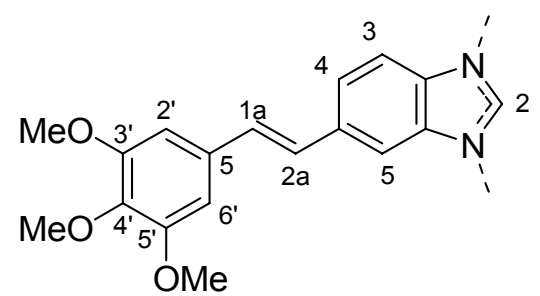

$79 E$ ó $80 E$

\begin{tabular}{|c|c|c|c|}
\hline${ }^{\mathbf{1}} \mathbf{H}$ & Mayoritario70\% & Minoritario30\% & \\
\hline $\mathbf{2}$ & $7,83 s$ & $7,75 s$ & $7,85 s$ \\
\hline $\mathbf{3}$ & $7,22 d 8,6$ & $7,29 d 8,6$ & $7,75 d, 8,4$ \\
\hline $\mathbf{4}$ & $7,66 d 8,6$ & $7,65 m$ & $7,49 d d, 8,4 ; 1,8$ \\
\hline $\mathbf{5}$ & $7,29 s$ & $7,27 s$ & $7,47 s a$ \\
\hline $\mathbf{1}^{\mathbf{a}}$ & $6,72 d 12,1$ & $6,71 d 12,1$ & $7,16 d 16,4$ \\
\hline $\mathbf{2}^{\mathbf{a}}$ & $6,52 d 12,1$ & $6,50 d 12,1$ & $7,05 d 16,4$ \\
\hline $\mathbf{2}^{\prime}, \mathbf{6}^{\boldsymbol{9}}$ & $6,49 s$ & $6,50 s$ & $6,76 s$ \\
\hline $\mathbf{N C H}_{\mathbf{3}}$ & $3,74 s$ & $3,81 s$ & $3,87 s$ \\
\hline $\mathbf{O C H}_{\mathbf{3}}-\mathbf{C}_{\mathbf{3}}$, & $3,60 s$ & $3,61 s$ & $3,92, s$ \\
$\mathbf{O C H}_{\mathbf{3}}-\mathbf{C}_{\mathbf{5}}$, & $3,82 s$ & $3,83 s$ & $3,84 s$ \\
\hline $\mathbf{O C H}_{\mathbf{3}}-\mathbf{C}_{\mathbf{4}}$, & & & $\mathbf{2}$ \\
\hline
\end{tabular}

Tabla I. Señales espectroscópicas de RMN ${ }^{1} \mathrm{H}$ de los compuestos 79 y 80 . 

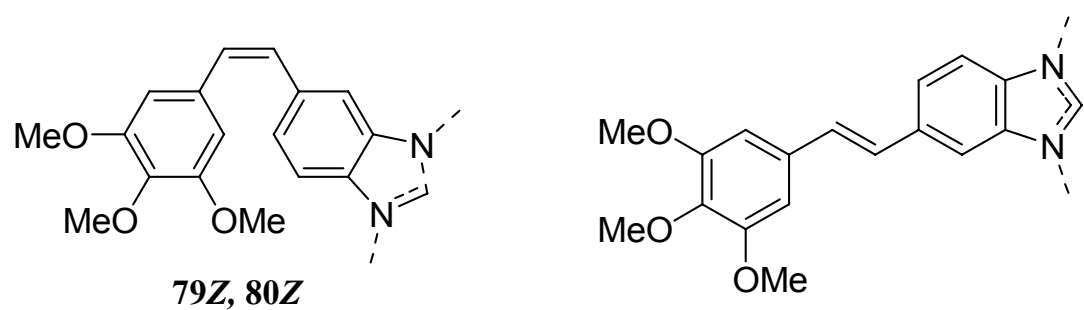

$79 E$ ó $80 E$

\begin{tabular}{|c|c|c|c|c|}
\hline $\mathbf{1 3} \mathbf{C}$ & Mayoritario $70 \%$ & Minoritario30\% & \\
\hline $\mathbf{C}$ & 131,6 & No observado & 132,8 \\
\hline & 132,3 & No observado & 133,3 \\
\hline & 132,6 & No observado & 135,1 \\
\hline & 132,8 & No observado & 137,9 \\
\hline & 137,2 & No observado & 143,4 \\
\hline $\mathbf{C H}$ & $152,8(2)$ & $153,4(2)$ & $153,5(2)$ \\
\hline & $106,0(2)$ & $106,0(2)$ & $106,1(2)$ \\
\hline & 109,6 & 108,8 & 107,4 \\
\hline & 119,8 & 120,7 & 120,2 \\
\hline & 123,7 & 124,4 & 121,2 \\
\hline & 129,6 & 129,1 & 128,0 \\
\hline $\mathbf{C H}_{3}$ & 130,2 & 130,3 & 128,6 \\
\hline & 144,1 & 144,0 & No observado \\
\hline & 30,9 & 31,1 & 31,2 \\
\hline
\end{tabular}

Tabla II. Señales espectroscópicas de RMN ${ }^{13} \mathrm{C}$ de los compuestos 79 y 80 . 


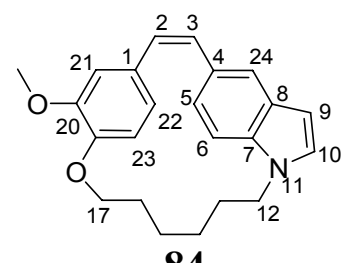

84

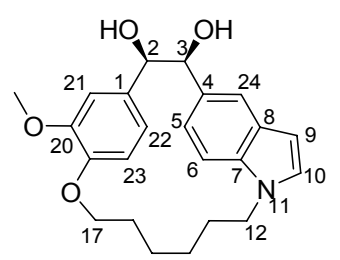

85

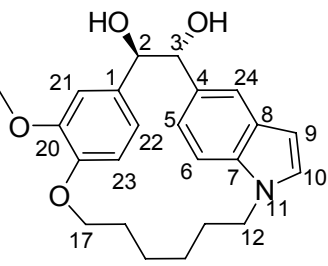

86

\begin{tabular}{|c|c|c|c|c|}
\hline${ }^{1} \mathbf{H}$ & & $\begin{array}{c}\text { Mayoritario } \\
60 \%\end{array}$ & $\begin{array}{c}\text { Minoritario } \\
40 \%\end{array}$ & \\
\hline 2 & $6,92 d 10,2$ & $5,25 d^{t}$ & $5,36 d^{+}$ & $4,73 d 7,8$ \\
\hline 3 & $7,14 d 10,2$ & $4,91 d^{\ddagger}$ & $4,82 d^{\neq}$ & $4,66 d 7,8$ \\
\hline 5 & $6,38 d d 7,9 ; 1,8$ & $6,15 \mathrm{~m}^{\neq}$ & $6,15 m^{\neq}$ & $6,24 b d 8,1$ \\
\hline 6 & $6,83 d 7,9$ & $6,77 d^{+}$ & $6,77 d^{+}$ & $6,78 d 8,1$ \\
\hline 9 & $6,40 d 2,7$ & $6,3-6,5 \mathrm{~m}^{\neq}$ & $6,3-6,5 \mathrm{~m}^{\neq}$ & $6,43 d 2,7$ \\
\hline 10 & $6,96 d 2,7$ & $6,97 \mathrm{~m}^{\neq}$ & $6,97 \mathrm{~m}^{\neq}$ & $6,98 d 2,7$ \\
\hline 12 & $4,05 t 6,2$ & $3,7-4,2 m$ & $3,7-4,2 m$ & $4,10 m$ \\
\hline 13 & $1,62 m$ & $1,1-1,9 m$ & $1,1-1,9 m$ & $1,1-1,9 m$ \\
\hline 14 & $0,93 m$ & $1,1-1,9 m$ & $1,1-1,9 m$ & $1,1-1,9 m$ \\
\hline 15 & $1,18 m$ & $1,1-1,9 m$ & $1,1-1,9 m$ & $1,1-1,9 m$ \\
\hline 16 & $1,33 m$ & $1,1-1,9 m$ & $1,1-1,9 m$ & $1,1-1,9 m$ \\
\hline 17 & $3,98+7,7$ & $3,7-4,2 \mathrm{~m}$ & $3,7-4,2 m$ & $3,6-4,2 m$ \\
\hline 21 & $6,44 s a$ & $6,2-6,4 m^{\neq}$ & $6,7-6,8 m^{\neq}$ & $5,80-6,90 m$ \\
\hline 22 & $6,25 d d 8,1 ; 1,8$ & No observado & No observado & $5,80-6,90 m$ \\
\hline 23 & $6,47 d 8,1$ & No observado & No observado & $5,80-6,90 m$ \\
\hline 24 & $7,40 s$ & $7,76 \mathrm{~s} a^{\neq}$ & $7,41 \mathrm{~s} a^{\neq}$ & $7,65 s$ \\
\hline $\mathrm{OCH}_{3}-\mathrm{C}_{20}$ & $3,55 s$ & $\begin{array}{c}\text { No observado } \\
\text { (ancho) }\end{array}$ & $\begin{array}{c}\text { No observado } \\
\text { (ancho) }\end{array}$ & $3,76 s a$ \\
\hline
\end{tabular}

${ }^{\ddagger}$ Señales poco resueltas

Tabla III. Señales espectroscópicas de RMN ${ }^{1} \mathrm{H}$ de los compuestos 84, 85 y 86. 


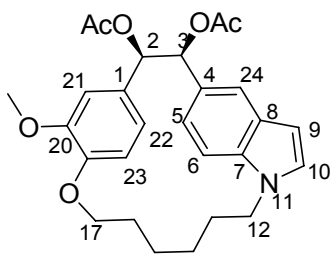

90

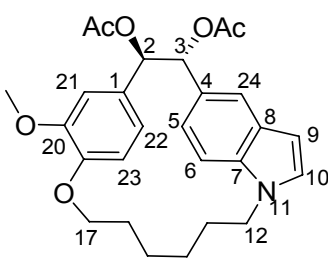

91

\begin{tabular}{|c|c|c|c|c|}
\hline${ }^{1} \mathbf{H}$ & Mayoritario 55\% & Minoritario $45 \%$ & $\sim 50 \%$ & $\sim 50 \%$ \\
\hline 2 & $5,99 d 4,5$ & $5,99 d 4,5$ & $6,08 d 7,9$ & $5,99 d 8,0$ \\
\hline 3 & $6,60 d 4,5$ & $6,60 d 4,5$ & $6,27 d 7,9$ & $6,07 d 8,0$ \\
\hline 5 & No observado & No observado & $6,48 d 8,1$ & $6,19 d 8,1$ \\
\hline 6 & $6,79-6,85 \mathrm{~m}$ & $6,79-6,85 \mathrm{~m}$ & $6,83 * d 8,1$ & $6,79 * d 8,1$ \\
\hline 9 & $6,46 s a$ & $6,39 s a$ & $6,40 d a$ & $6,40 d a$ \\
\hline 10 & $7,00 s a$ & $6,98 s a$ & $6,96 d 3,0$ & $6,90 d 3,0$ \\
\hline 12 & $3,6-4,2 \mathrm{~m}$ & $3,6-4,2 \mathrm{~m}$ & $3,6-4,3 \mathrm{~m}$ & $3,6-4,3 \mathrm{~m}$ \\
\hline 13 & $1,1-1,9 m$ & $1,1-1,9 m$ & $1,1-1,9 m$ & $1,1-1,9 m$ \\
\hline 14 & $1,1-1,9 m$ & $1,1-1,9 m$ & $1,1-1,9 m$ & $1,1-1,9 \mathrm{~m}$ \\
\hline 15 & $1,1-1,9 m$ & $1,1-1,9 m$ & $1,1-1,9 m$ & $1,1-1,9 m$ \\
\hline 16 & $1,1-1,9 m$ & $1,1-1,9 m$ & $1,1-1,9 m$ & $1,1-1,9 m$ \\
\hline 17 & $3,6-4,2 \mathrm{~m}$ & $3,6-4,2 \mathrm{~m}$ & $3,6-4,3 m$ & $3,6-4,3 \mathrm{~m}$ \\
\hline 21 & $6,47 s a$ & $5,88 s a$ & $5,93 s a$ & $6,87 s a$ \\
\hline 22 & $6,26 \mathrm{~m}$ & $6,26 m$ & $6,84 d d 8,4 ; 1,3$ & $5,97 d d 8,4 ; 1,5$ \\
\hline 23 & $6,79-6,85 m$ & $6,79-6,85 m$ & $6,71 d 8,4$ & $6,46 d 8,4$ \\
\hline 24 & $7,74 s a$ & $7,39 s a$ & $7,58 s a$ & $7,58 s a$ \\
\hline $\mathrm{OCH}_{3}-\mathrm{C}_{20}$ & $3,85 s a$ & $3,10 s a$ & $3,89 s$ & $3,10 s$ \\
\hline AcO & $2,30 s ; 2,14 s$ & $2,32 s ; 2,14 s$ & $2,13 s ; 2,13 * s$ & $2,13 s ; 2,04 * 3 s$ \\
\hline
\end{tabular}

* Señales intercambiables.

Tabla IV. Señales espectroscópicas de RMN ${ }^{1} \mathrm{H}$ de los compuestos 90 y 91. 

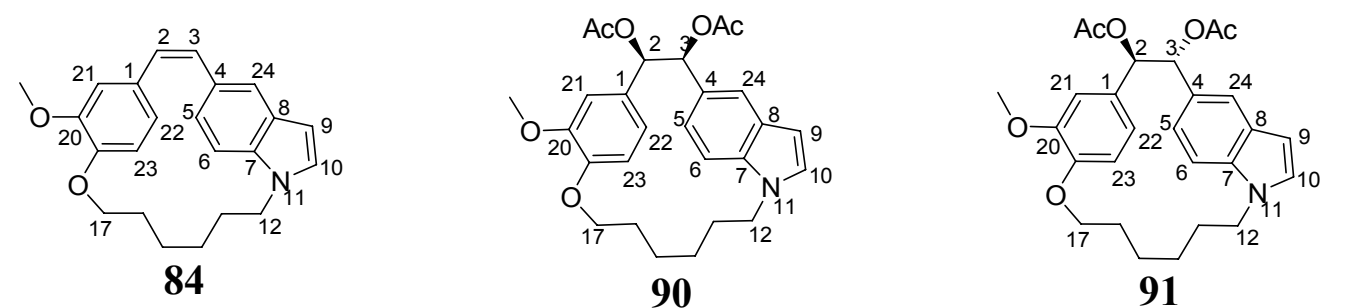

\begin{tabular}{|c|c|c|c|c|c|}
\hline${ }^{13} \mathrm{C}$ & & Mayoritario 55\% & Minoritario 45\% & $\sim 50 \%$ & $\sim 50 \%$ \\
\hline 1 & 133,6 & 129,9 & 129,8 & 131,0 & 129,7 \\
\hline 2 & 132,9 & 73,7 & 74,5 & 79,5 & 79,5 \\
\hline 3 & 134,8 & 77,4 & 77,0 & 79,2 & 78,7 \\
\hline 4 & 129,8 & No observado & No observado & 128,8 & 128,4 \\
\hline 5 & 124,6 & 122,8 & 122,8 & 122,9 & 122,9 \\
\hline 6 & 109,2 & 109,6 & 109,6 & 108,9 & 109,8 \\
\hline 7 & 135,0 & 135,6 & 135,6 & 136,2 & 135,7 \\
\hline 8 & 128,2 & 127,9 & 127,9 & 127,5 & 127,3 \\
\hline 9 & 101,0 & 101,0 & 101,2 & 101,1 & 101,0 \\
\hline 10 & 128,2 & 128,5 & 128,5 & 128,5 & 129,1 \\
\hline 12 & 46,1 & 46,0 & 46,0 & 46,1 & 46,2 \\
\hline 13 & 29,5 & 31,8 & 31,8 & 32,4 & 33,5 \\
\hline 14 & 25,9 & 29,6 & 29,6 & 29,5 & 29,6 \\
\hline 15 & 23,2 & 27,6 & 27,6 & 27,9 & 26,5 \\
\hline 16 & 27,2 & 27,8 & 27,8 & 26,5 & 27,2 \\
\hline 17 & 70,3 & 70,2 & 69,9 & 69,0 & 69,8 \\
\hline 19 & 144,9 & No observado & No observado & 148,1 & 147,0 \\
\hline 20 & 150,3 & No observado & No observado & 150,2 & 150,5 \\
\hline 21 & 113,9 & 108,9 & 108,6 & 115,6 & 113,6 \\
\hline 22 & 122,5 & 119,5 & 119,3 & 122,4 & 120,1 \\
\hline 23 & 117,9 & 118,7 & 118,6 & 118,4 & 118,7 \\
\hline 24 & 120,5 & 118,0 & 118,0 & 117,9 & 118,0 \\
\hline $\begin{array}{c}\mathrm{OCH}_{3-}^{-} \\
\mathrm{C}_{20}\end{array}$ & 55,4 & 56,3 & No observado & 55,8 & 56,1 \\
\hline AcO- & & $\begin{array}{c}171,1 ; 170,0 \\
21,1 ; 21,1\end{array}$ & $\begin{array}{c}170,0 ; 170,0 \\
21,1 ; 21,1\end{array}$ & $\begin{array}{c}170,4 ; \\
170,0 \\
21,2 ; 21,2\end{array}$ & $\begin{array}{c}170,4 ; \\
170,2 \\
21,2 ; 21,0\end{array}$ \\
\hline
\end{tabular}

Tabla V. Señales espectroscópicas de $\mathrm{RMN}{ }^{13} \mathrm{C}$ de los compuestos 84, 90 y 91. 


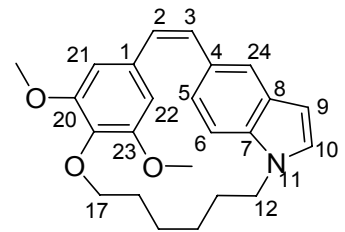

87

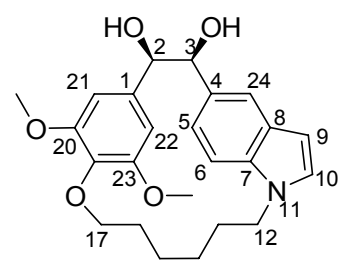

88

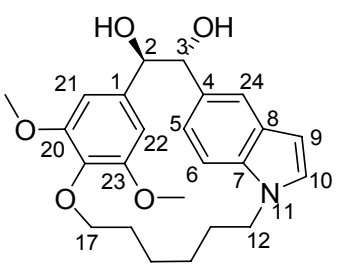

89

\begin{tabular}{|c|c|c|c|c|}
\hline${ }^{1} \mathbf{H}$ & & $\begin{array}{l}\text { Mayoritario } \\
65 \%\end{array}$ & $\begin{array}{l}\text { Minoritario } \\
35 \%\end{array}$ & \\
\hline 2 & $6,92 d 10,1$ & $5,17 d 3,8$ & $5,32 s a$ & $4,64 d 8,1$ \\
\hline 3 & $7,16 d 10,1$ & $4,87 d 3,8$ & $4,76 s a$ & $4,71 d 8,1$ \\
\hline 5 & $6,45 d d 8,2 ; 1,4$ & $6,18 d 8,8$ & $6,39 d 8,4$ & $6,28 d d 8,4 ; 1,4$ \\
\hline 6 & $6,87 d 8,2$ & $6,83 d 8,8$ & $6,80 d 8,4$ & $6,82 d 8,4$ \\
\hline 9 & $6,39 d 3,1$ & $6,44 s a$ & $6,37 s a$ & $6,44 d 2,9$ \\
\hline 10 & $6,97 d 3,1$ & $6,98 s a$ & $6,98 s a$ & $6,99 d 2,9$ \\
\hline 12 & $4,06 t 5,9$ & $4,10 m$ & $4,10 \mathrm{~m}$ & $4,08 m$ \\
\hline 13 & $1,62 \mathrm{~m}$ & $1,1-1,9 m$ & $1,1-1,9 m$ & $1,1-1,9 m$ \\
\hline 14 & $0,91 \mathrm{~m}$ & $1,1-1,9 m$ & $1,1-1,9 m$ & $1,1-1,9 m$ \\
\hline 15 & $1,24 m$ & $1,1-1,9 m$ & $1,1-1,9 m$ & $1,1-1,9 m$ \\
\hline 16 & $1,24 m$ & $1,1-1,9 m$ & $1,1-1,9 m$ & $1,1-1,9 m$ \\
\hline 17 & $3,98 t 6,4$ & $\begin{array}{l}3,95 m \\
3,45 m\end{array}$ & $\begin{array}{l}3,95 m \\
3,45 m\end{array}$ & $4,32 m ; 3,61 m$ \\
\hline 21 & $6,05 s a$ & $6,23 s a$ & $6,77 s a$ & $6,66 d 1,6$ \\
\hline 22 & $6,05 s a$ & $5,89 s a$ & $5,32 s a$ & $5,37 d 1,6$ \\
\hline 24 & $7,40 s$ & $7,79 s a$ & $7,31 s a$ & $7,69 s$ \\
\hline $\begin{array}{c}\mathrm{OCH}_{3-}^{-} \\
\mathrm{C}_{20}\end{array}$ & $3,45 \mathrm{sa}$ & $3,81 s$ & $3,86 s$ & $3,86 s$ \\
\hline $\begin{array}{c}\mathrm{OCH}_{3-}^{-} \\
\mathrm{C}_{23}\end{array}$ & 3,45 sa & $3,00 s$ & $3,00 s$ & $2,97 s$ \\
\hline
\end{tabular}

Tabla VI. Señales espectroscópicas de RMN ${ }^{1} \mathrm{H}$ de los compuestos $\mathbf{8 7 ,} 88$ y 89 . 


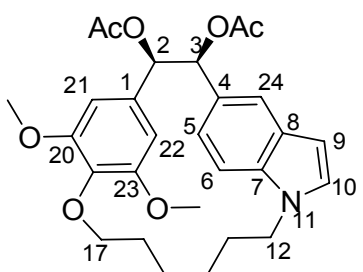

92

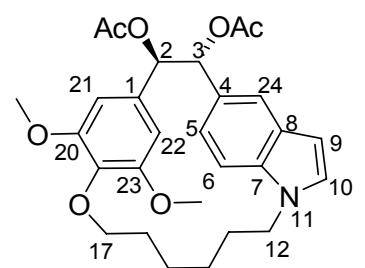

93

\begin{tabular}{|c|c|c|c|}
\hline${ }^{1} \mathbf{H}$ & Mayoritario $60 \%$ & Minoritario 40\% & \\
\hline 2 & $6,40 \mathrm{~m}$ & $6,40 \mathrm{~m}$ & $5,93 d 8,8$ \\
\hline 3 & $6,00 \mathrm{~m}$ & $5,90 \mathrm{~m}$ & $6,02 d 8,8$ \\
\hline 5 & $6,41 m$ & $6,72 m$ & $6,48 d 8,5$ \\
\hline 6 & $6,83 m$ & $6,81 m$ & $6,87 d 8,5$ \\
\hline 9 & $6,47 s a$ & $6,30 s a$ & $6,42 d 3,1$ \\
\hline 10 & $7,00 s a$ & $7,00 \mathrm{sa}$ & $6,99 d 3,1$ \\
\hline 12 & $4,10 m$ & $4,10 m$ & $3,95-4,15 m$ \\
\hline 13 & $1,1-1,9 m$ & $1,1-1,9 m$ & $1,1-1,9 m$ \\
\hline 14 & $1,1-1,9 m$ & $1,1-1,9 m$ & $1,1-1,9 m$ \\
\hline 15 & $1,1-1,9 m$ & $1,1-1,9 m$ & $1,1-1,9 m$ \\
\hline 16 & $1,1-1,9 m$ & $1,1-1,9 m$ & $1,1-1,9 m$ \\
\hline 17 & $\begin{array}{l}3,90 m \\
3,60 m\end{array}$ & $\begin{array}{l}3,90 m \\
3,60 m\end{array}$ & $\begin{array}{l}4,21 \mathrm{~m} \\
3,62 \mathrm{~m}\end{array}$ \\
\hline 21 & $6,60 s a$ & $6,73 s a$ & $6,55 d 1,5$ \\
\hline 22 & $5,70 s a$ & $5,45 s a$ & $5,67 d 1,5$ \\
\hline 24 & $7,80 s a$ & $7,43 s a$ & $7,64 s$ \\
\hline $\mathrm{OCH}_{3}-\mathrm{C}_{20}$ & $3,84 s$ & $3,89 s$ & $3,86 s$ \\
\hline $\mathrm{OCH}_{3}-\mathrm{C}_{23}$ & $3,00 s$ & $3,00 s$ & $3,10 s$ \\
\hline AcO- & $2,34 s ; 2,14 s$ & $2,31 * s ; 2,14 s$ & $2,15^{*} s ; 2,14 s$ \\
\hline
\end{tabular}

* Señales intercambiables.

Tabla VII. Señales espectroscópicas de RMN ${ }^{1} \mathrm{H}$ de los compuestos 92 y 93. 


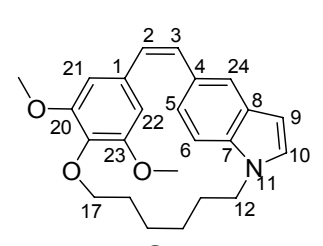

87

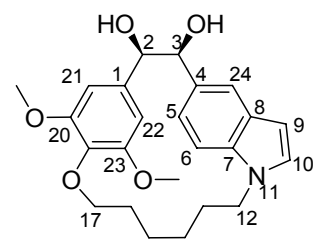

88

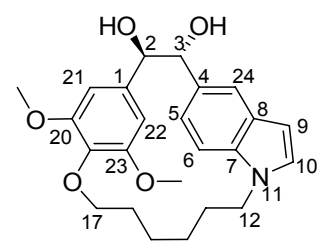

89

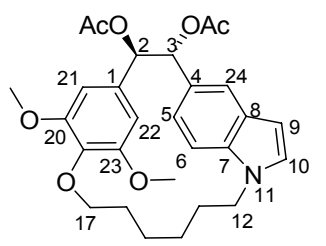

93

\begin{tabular}{|c|c|c|c|c|c|}
\hline${ }^{13} \mathrm{C}$ & & $\begin{array}{c}\text { Mayoritario } \\
65 \%\end{array}$ & $\begin{array}{c}\text { Minoritario } \\
35 \%\end{array}$ & & \\
\hline 1 & 134,5 & 134,5 & 135,1 & 134,9 & 136,1 \\
\hline 2 & 133,4 & 74,7 & 75,3 & 82,6 & 79,5 \\
\hline 3 & 134,9 & 77,7 & 77,7 & 82,0 & 79,1 \\
\hline 4 & 129,8 & 129,8 & 130,7 & 130,8 & 131,4 \\
\hline 5 & 124,2 & 121,7 & 124,4 & 122,1 & 122,6 \\
\hline 6 & 109,3 & 108,6 & 109,5 & 109,1 & 109,2 \\
\hline 7 & 135,1 & 136,0 & 135,9 & 136,2 & 136,6 \\
\hline 8 & 128,0 & 128,5 & 129,1 & 128,6 & 128,6 \\
\hline 9 & 101,0 & 101,4 & 100,6 & 101,2 & 101,1 \\
\hline 10 & 128,1 & 128,1 & 128,0 & 128,3 & 128,7 \\
\hline 12 & 45,7 & 46,2 & 46,2 & 46,2 & 46,1 \\
\hline 13 & 29,9 & 31,4 & 31,4 & 31,5 & 31,0 \\
\hline 14 & 26,0 & 28,6 & 28,6 & 28,6 & 28,4 \\
\hline 15 & 23,4 & 26,9 & 26,9 & 26,7 & 26,3 \\
\hline 16 & 27,8 & 23,6 & 23,6 & 23,6 & 23,4 \\
\hline 17 & 71,8 & 72,2 & 71,9 & 72,2 & 72,2 \\
\hline 19 & 133,9 & 136,1 & 135,8 & 136,3 & 136,7 \\
\hline 20 & 152,4 & 152,4 & 152,4 & 153,0 & 153,0 \\
\hline 21 & 107,2 & 102,7 & 103,2 & 102,1 & 102,7 \\
\hline 22 & 107,2 & 102,3 & 105,1 & 105,7 & 106,8 \\
\hline 23 & 152,4 & 152,3 & 152,0 & 151,3 & 151,6 \\
\hline 24 & 120,4 & 118,1 & 119,0 & 117,6 & 118,6 \\
\hline $\begin{array}{c}\mathrm{OCH}_{3^{-}} \\
\mathrm{C}_{20}\end{array}$ & 55,6 & 56,4 & 56,2 & 56,3 & 56,3 \\
\hline $\begin{array}{c}\mathrm{OCH}_{3^{-}} \\
\mathrm{C}_{23} \\
\end{array}$ & 55,6 & 54,6 & 54,8 & 54,7 & 54,9 \\
\hline
\end{tabular}

Tabla VIII. Señales espectroscópicas de RMN ${ }^{13} \mathrm{C}$ de los compuestos 87, 88, 89 y 93. 


\section{VI.2. ESPECTROS.}

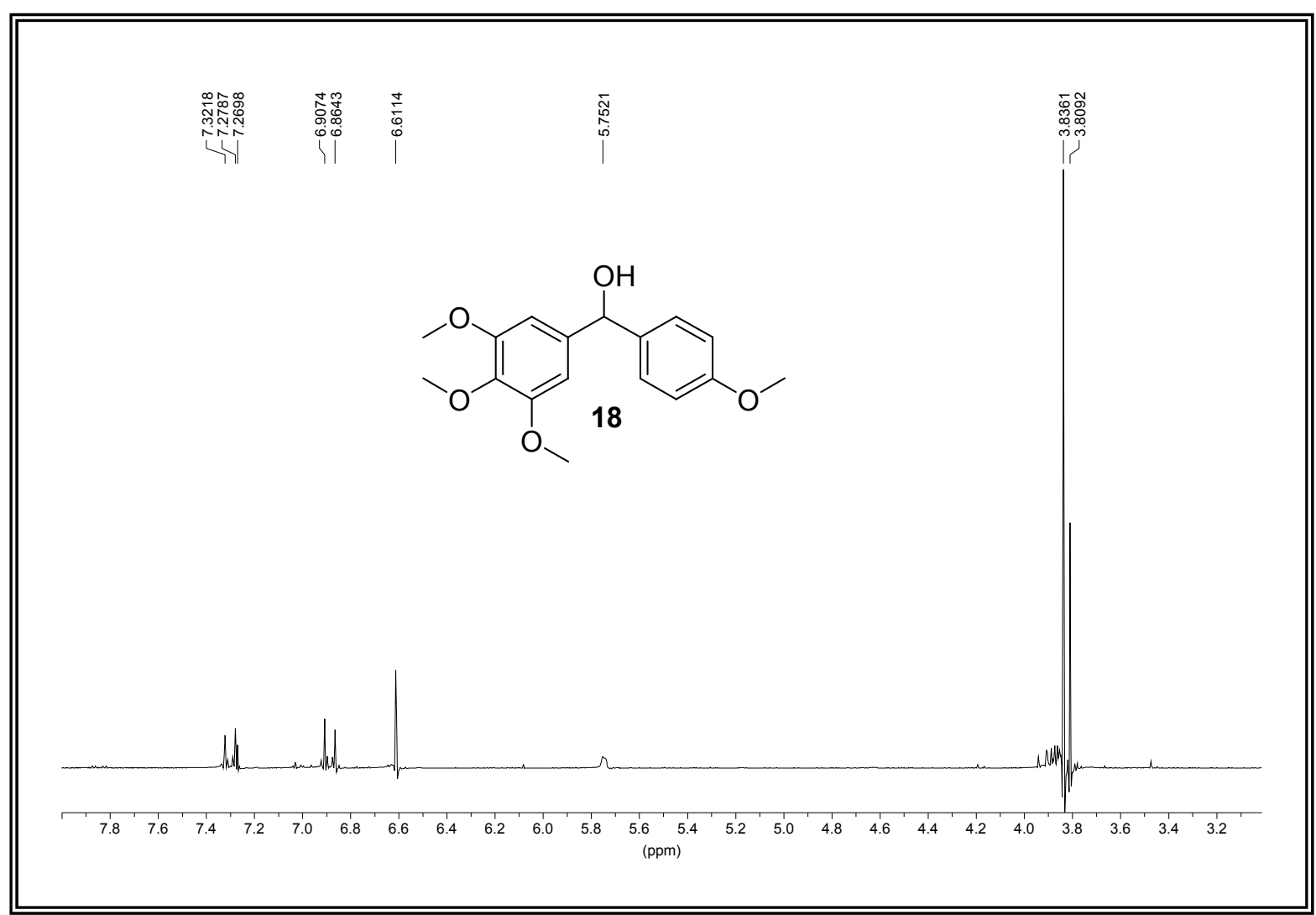

Figura Ia. Espectro de RMN ${ }^{1} \mathrm{H}$ del compuesto 18.

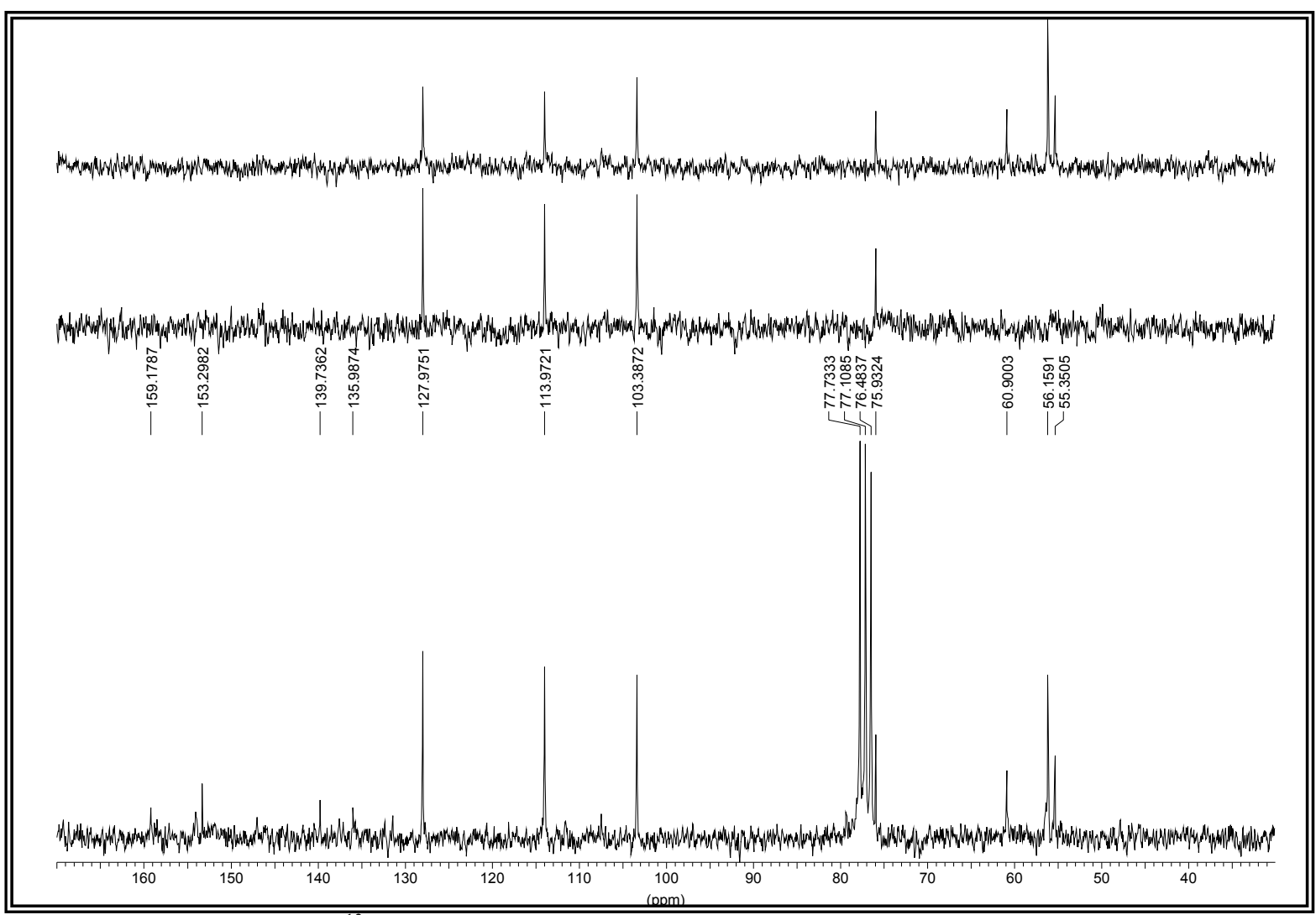

Figura Ib. Espectro de RMN ${ }^{13} \mathrm{C}$ del compuesto 18. 


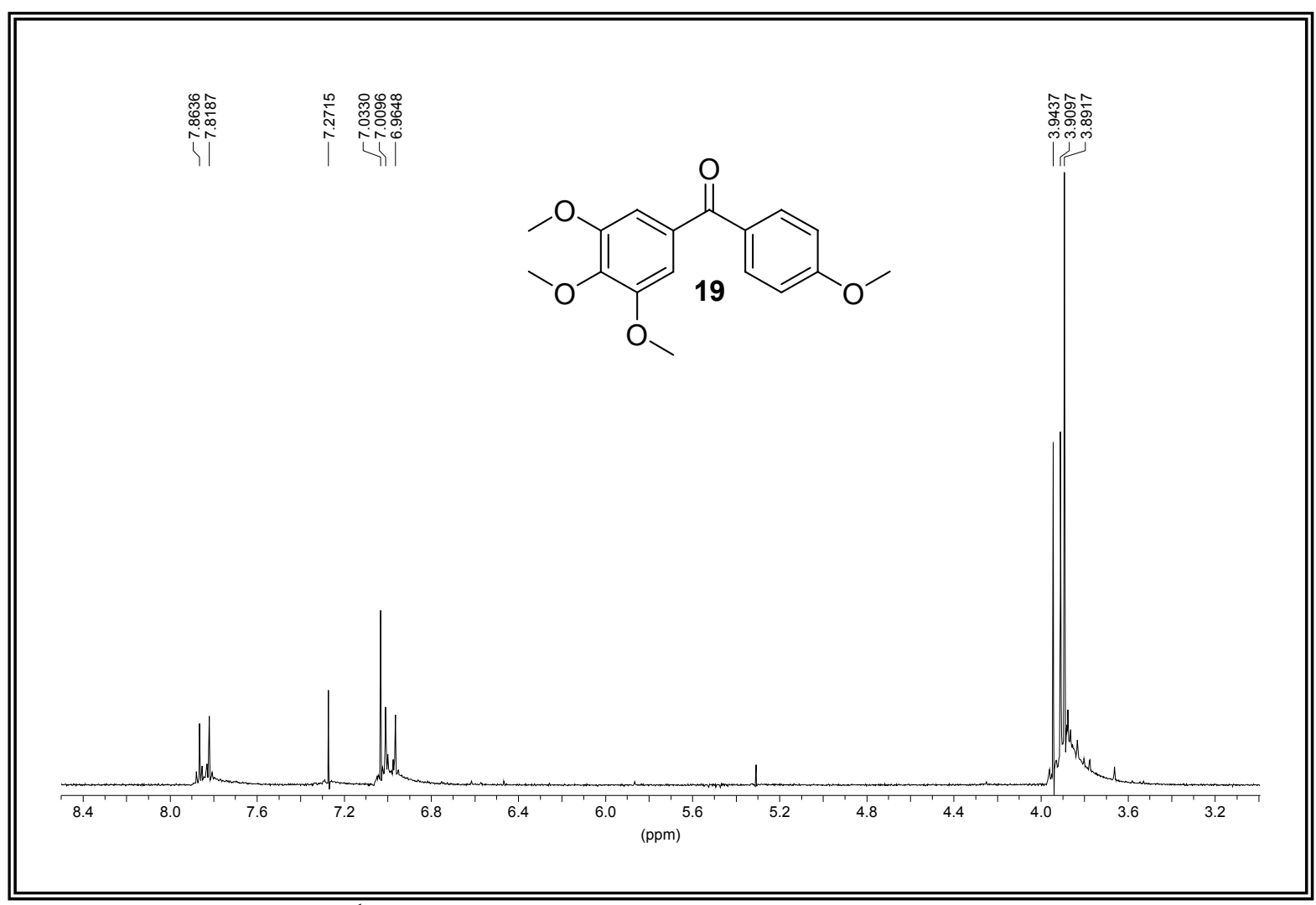

Figura IIa. Espectro de RMN ${ }^{1} \mathrm{H}$ del compuesto 19.

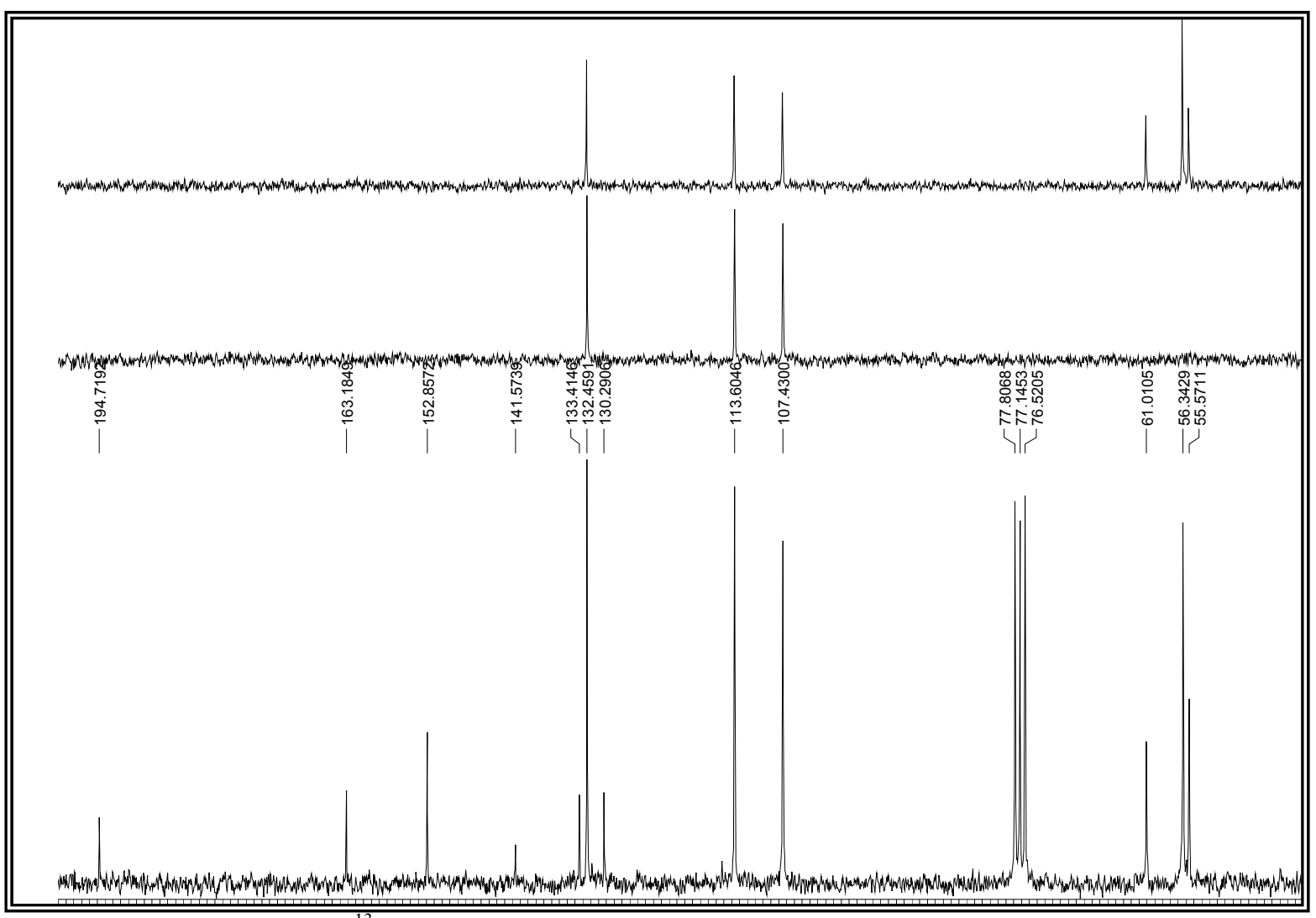

Figura IIb. Espectro de RMN ${ }^{13} \mathrm{C}$ del compuesto 19. 


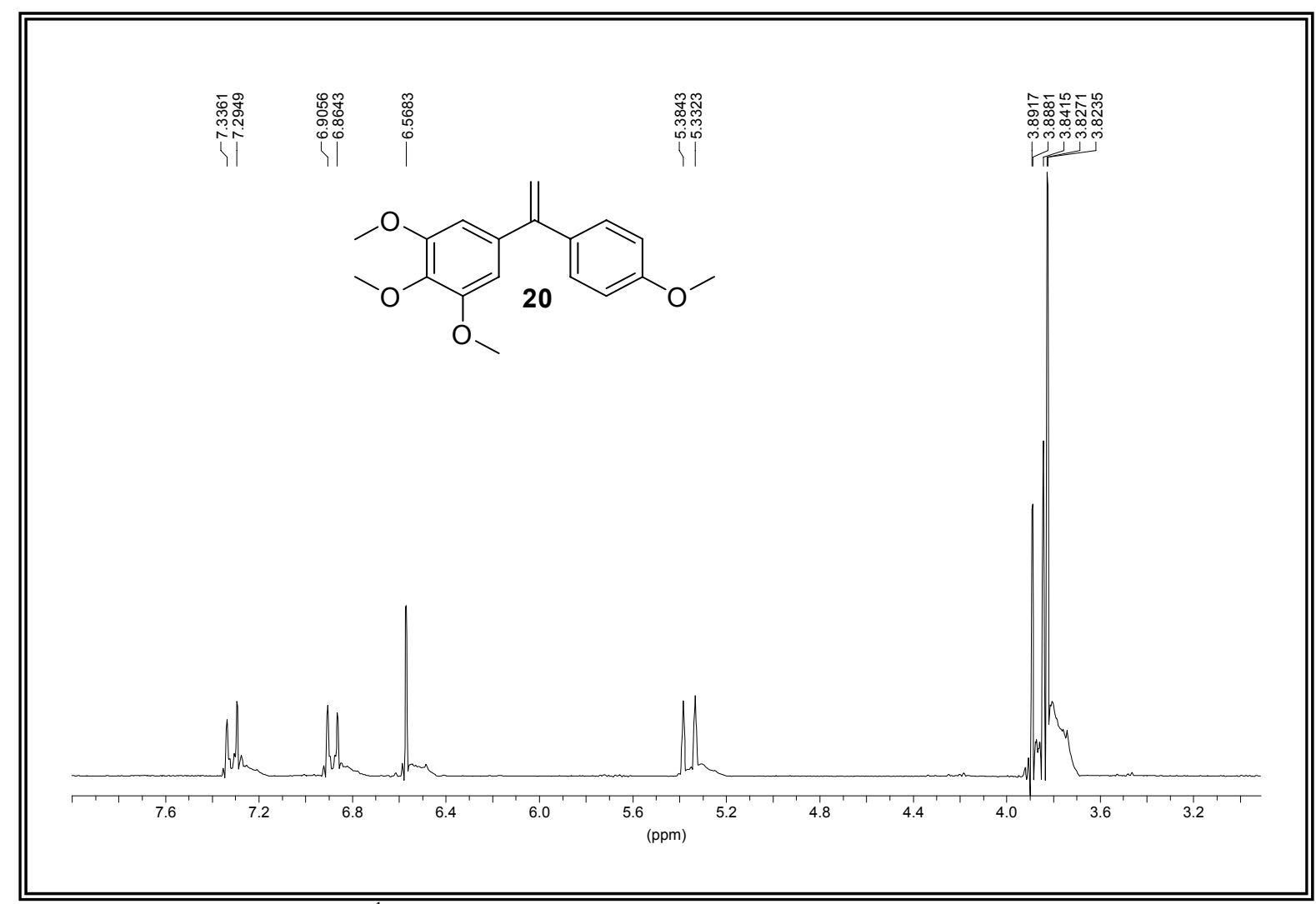

Figura IIIa. Espectro de $\mathrm{RMN}{ }^{1} \mathrm{H}$ del compuesto 20.

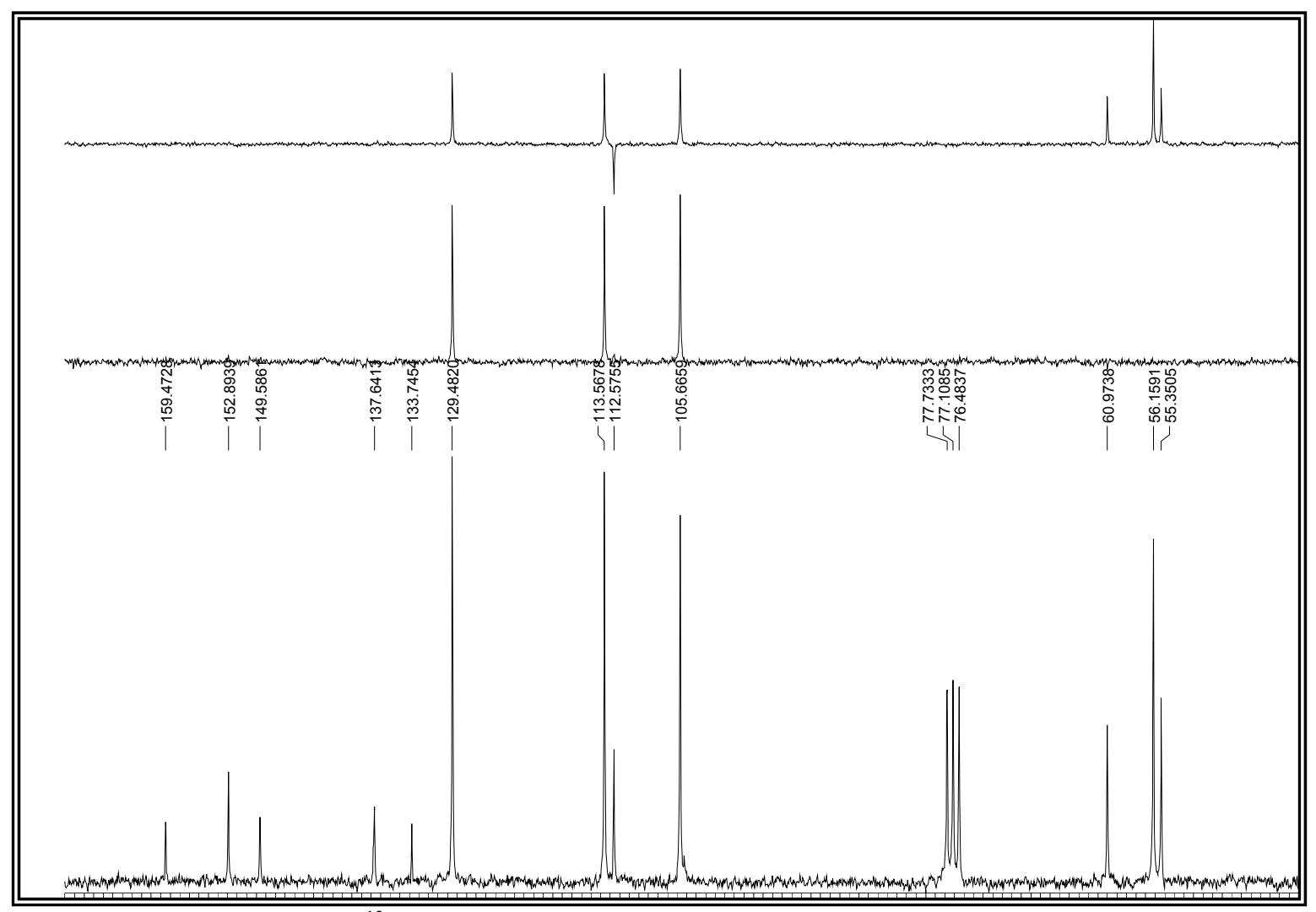

Figura IIIb. Espectro de RMN ${ }^{13} \mathrm{C}$ del compuesto 20. 


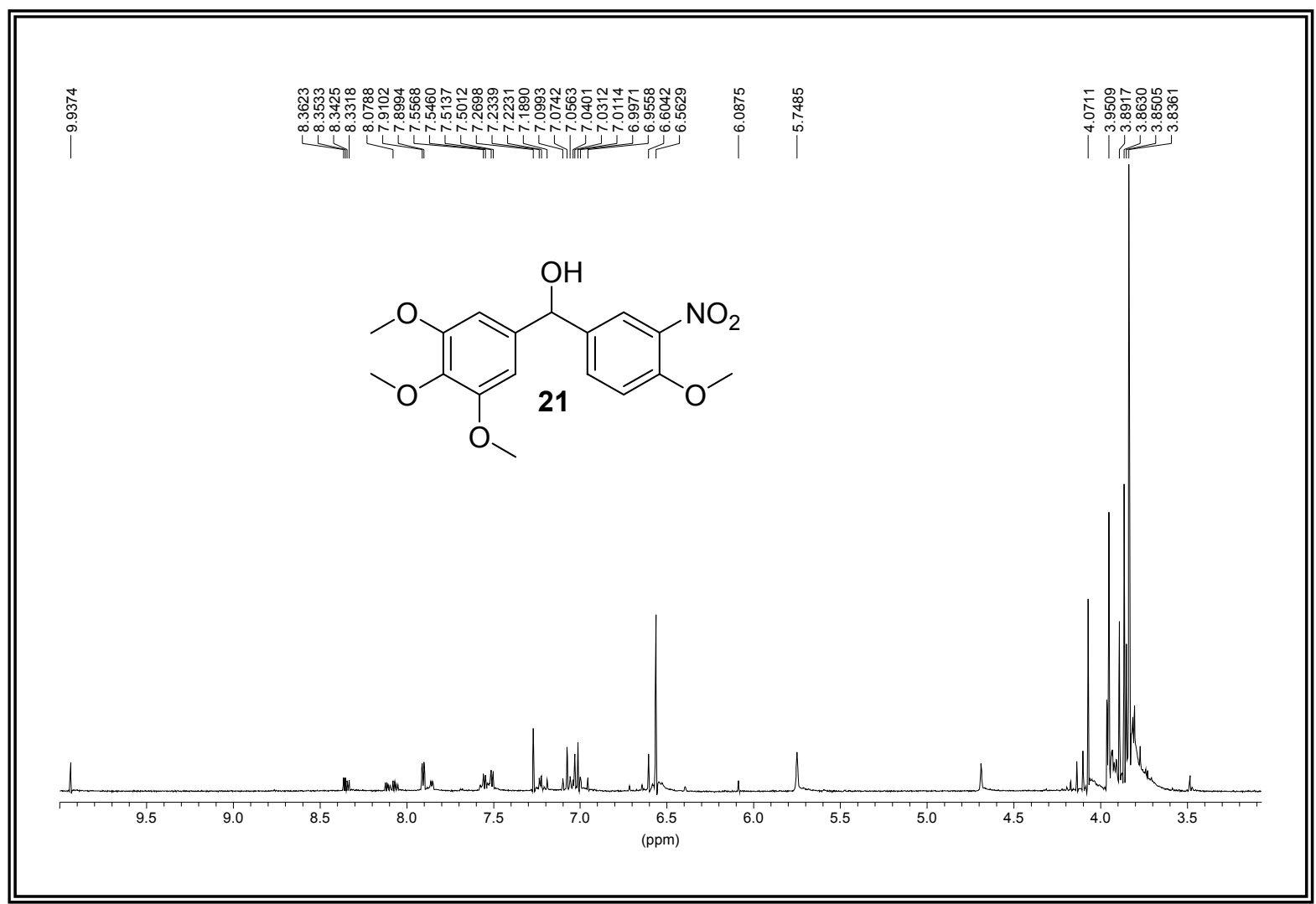

Figura IV. Espectro de RMN ${ }^{1} \mathrm{H}$ del compuesto 21. 


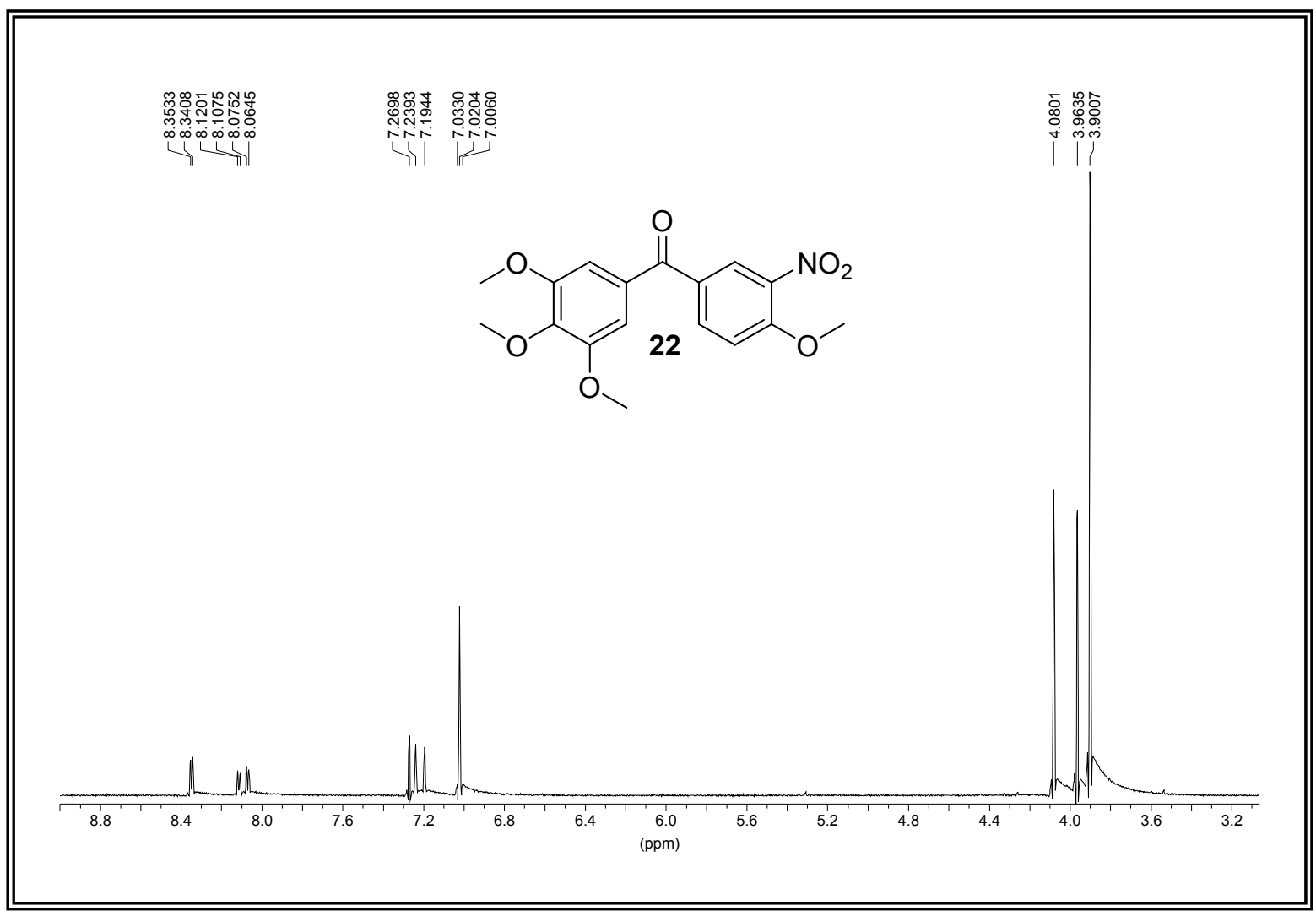

Figura Va. Espectro de RMN ${ }^{1} \mathrm{H}$ del compuesto 22.

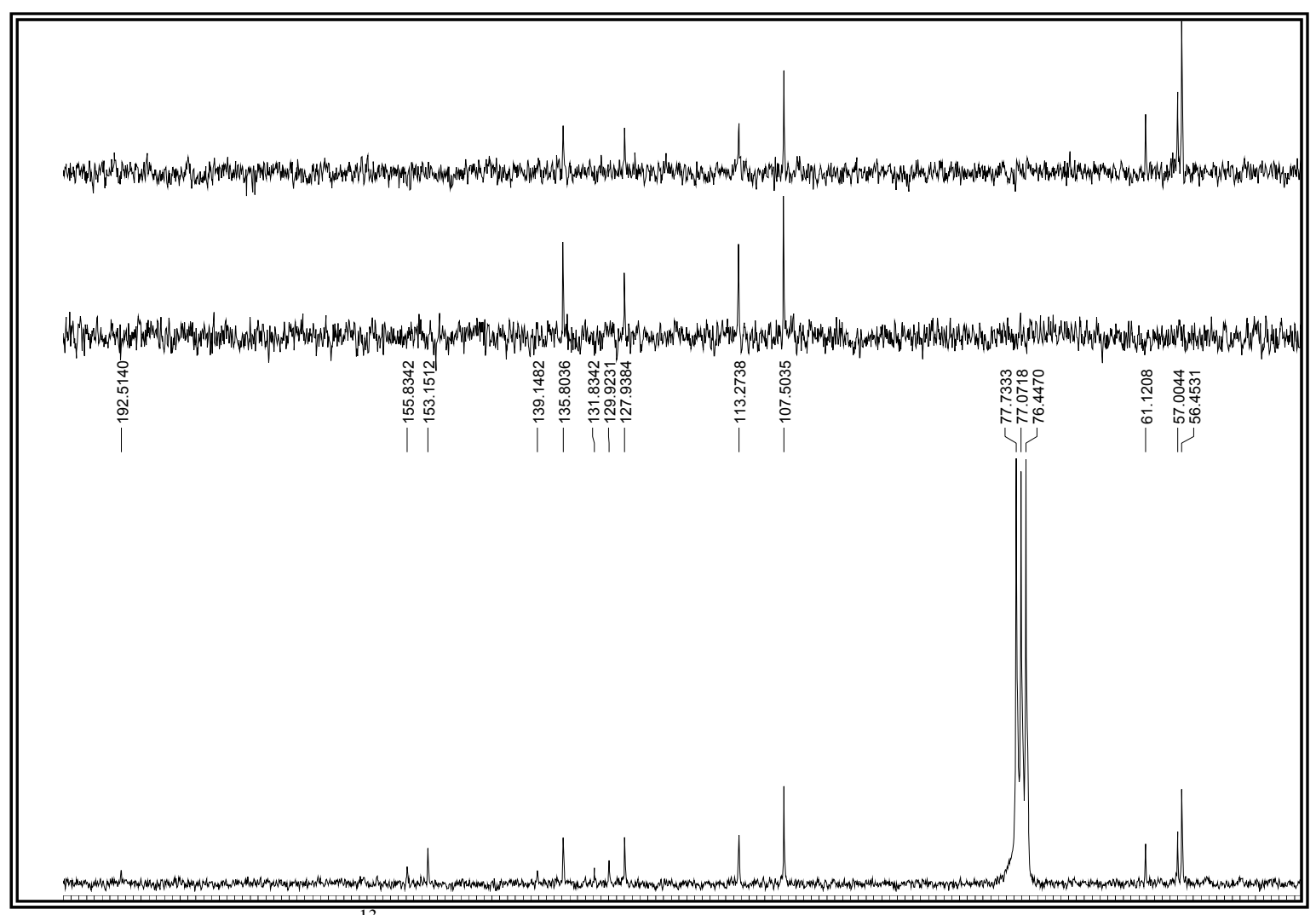

FiguraVb. Espectro de $\mathrm{RMN}{ }^{13} \mathrm{C}$ del compuesto 22. 


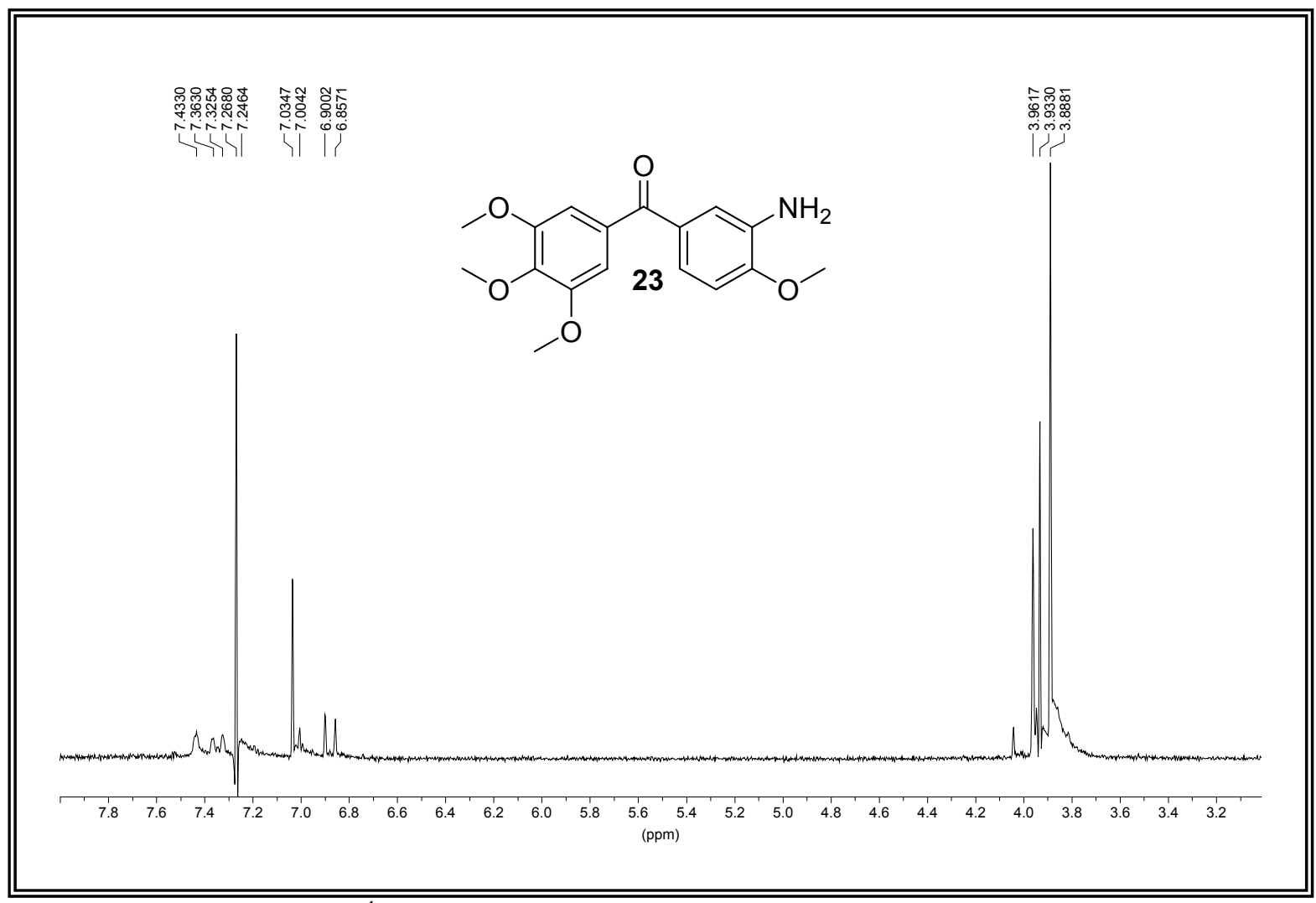

Figura VIa. Espectro de RMN ${ }^{1} \mathrm{H}$ del compuesto 23.

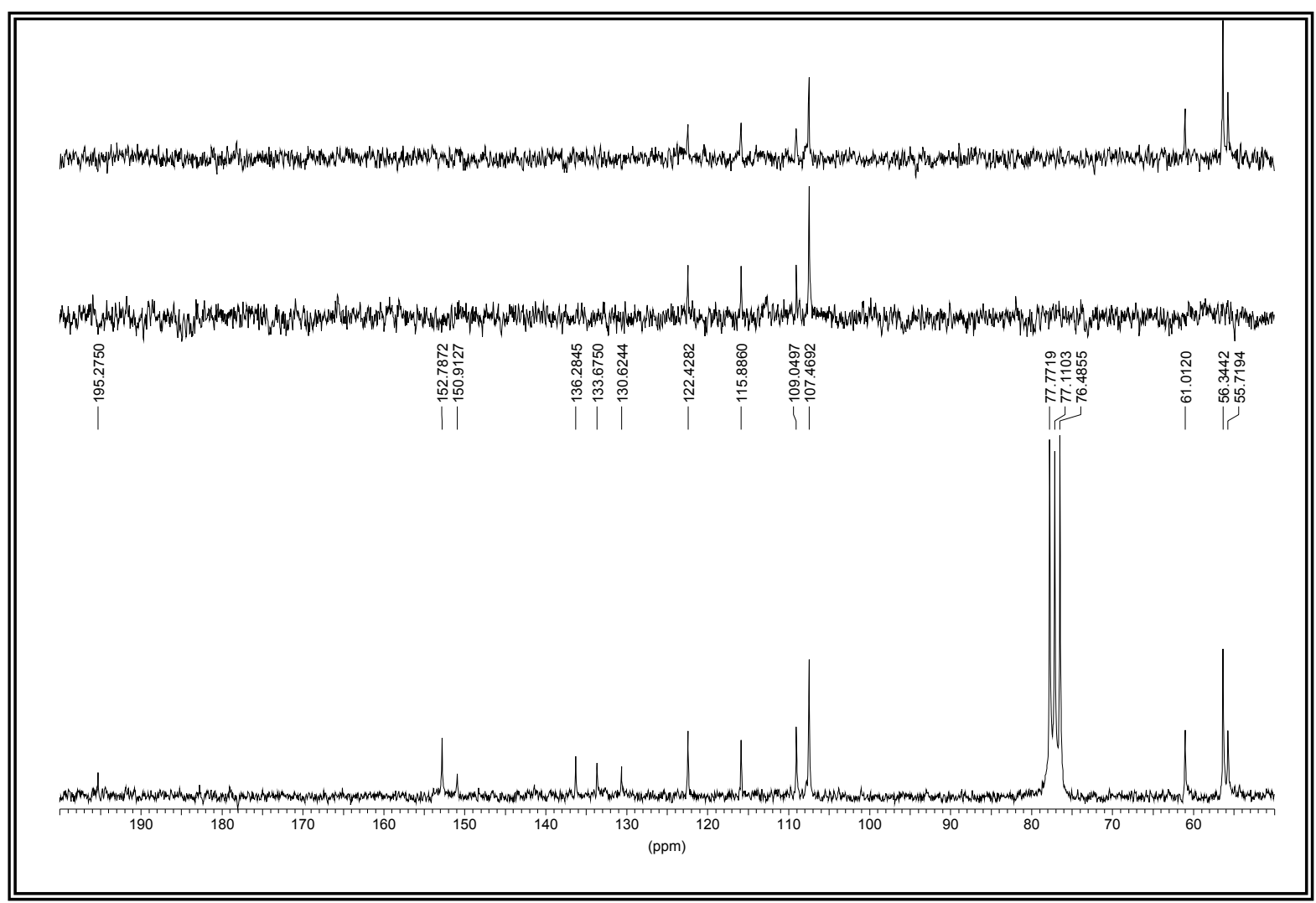

Figura VIb. Espectro de RMN ${ }^{13} \mathrm{C}$ del compuesto 23. 


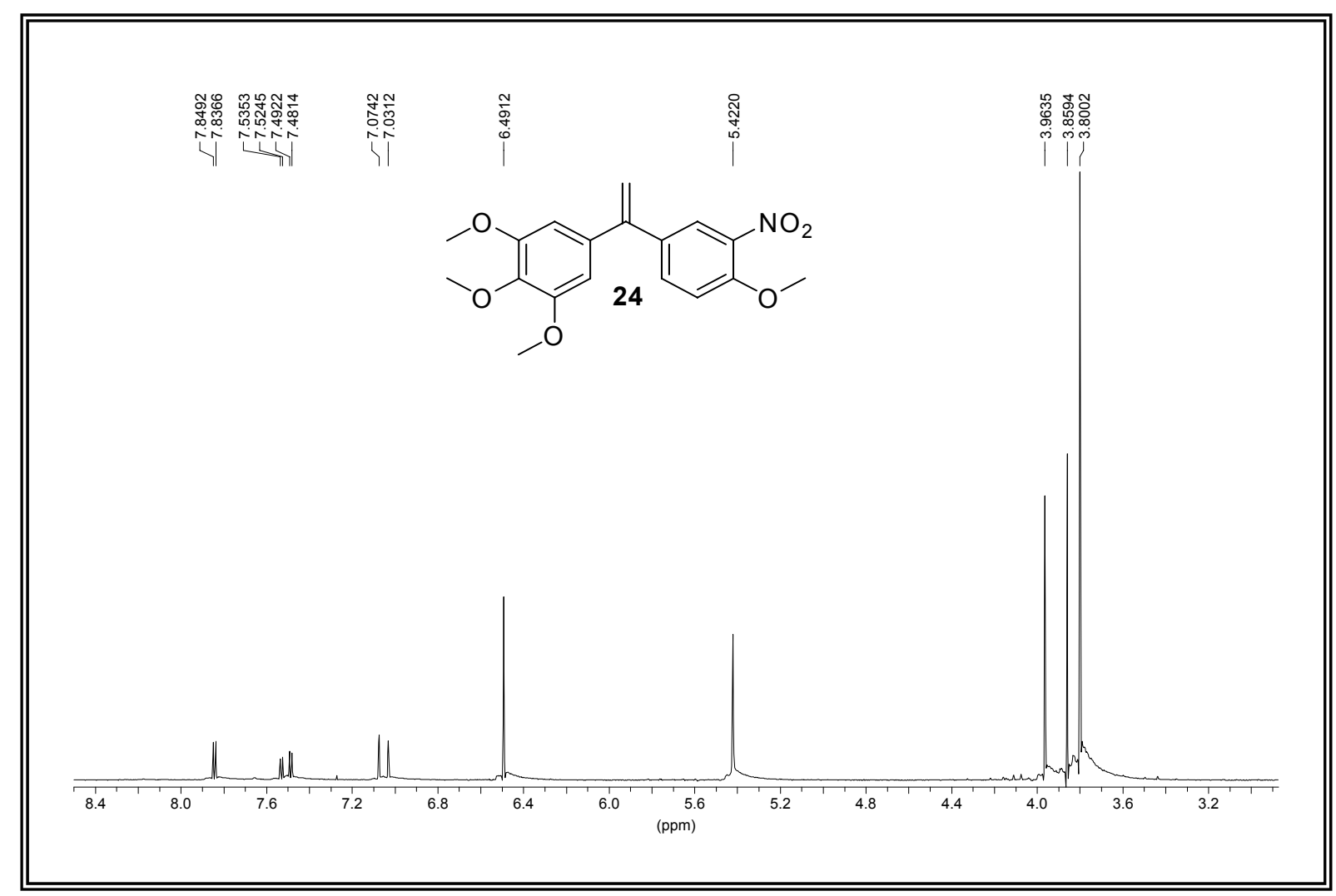

Figura VIIa. Espectro de RMN ${ }^{1} \mathrm{H}$ del compuesto 24.

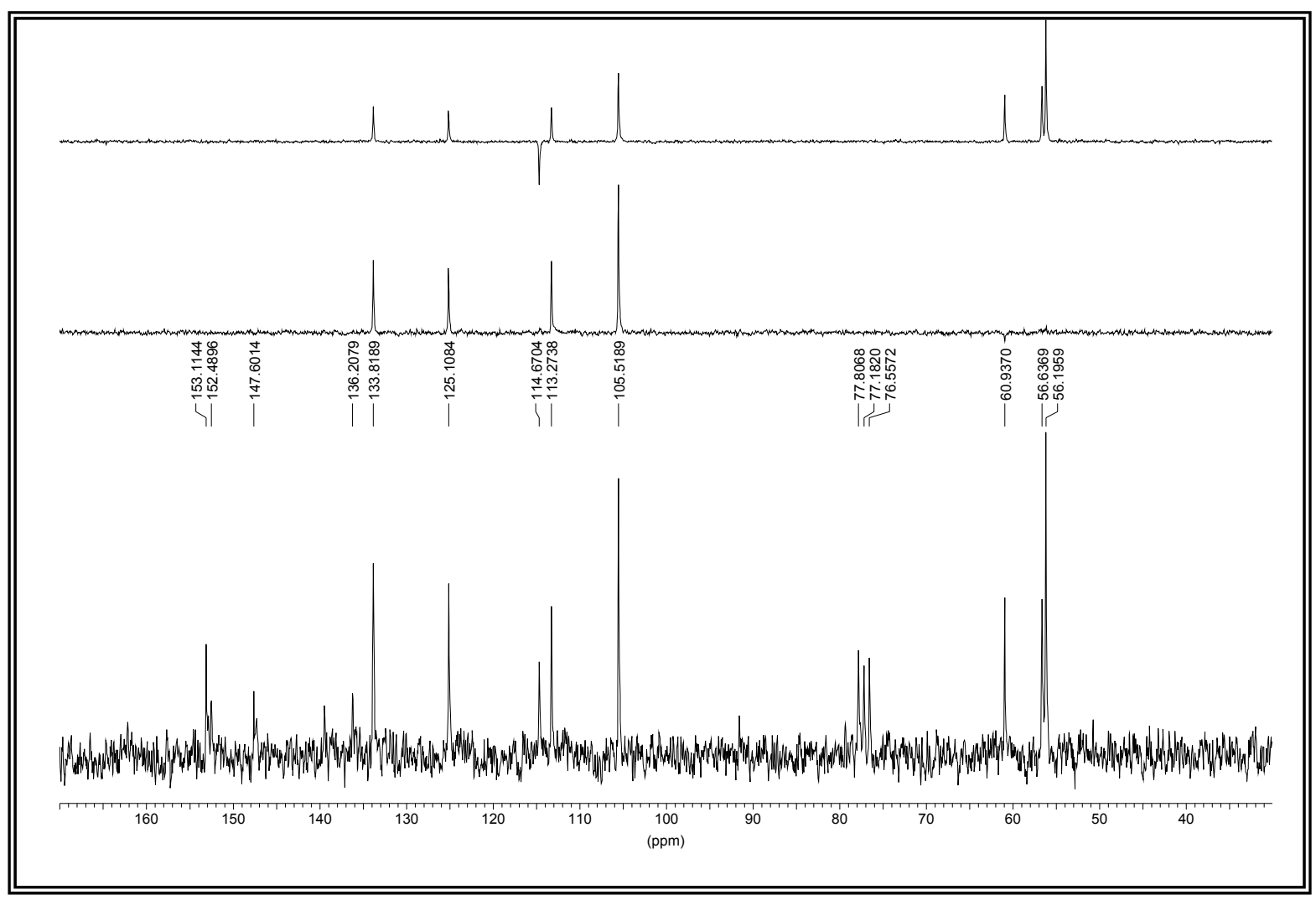

Figura VIIb. Espectro de RMN ${ }^{13} \mathrm{C}$ del compuesto 24. 


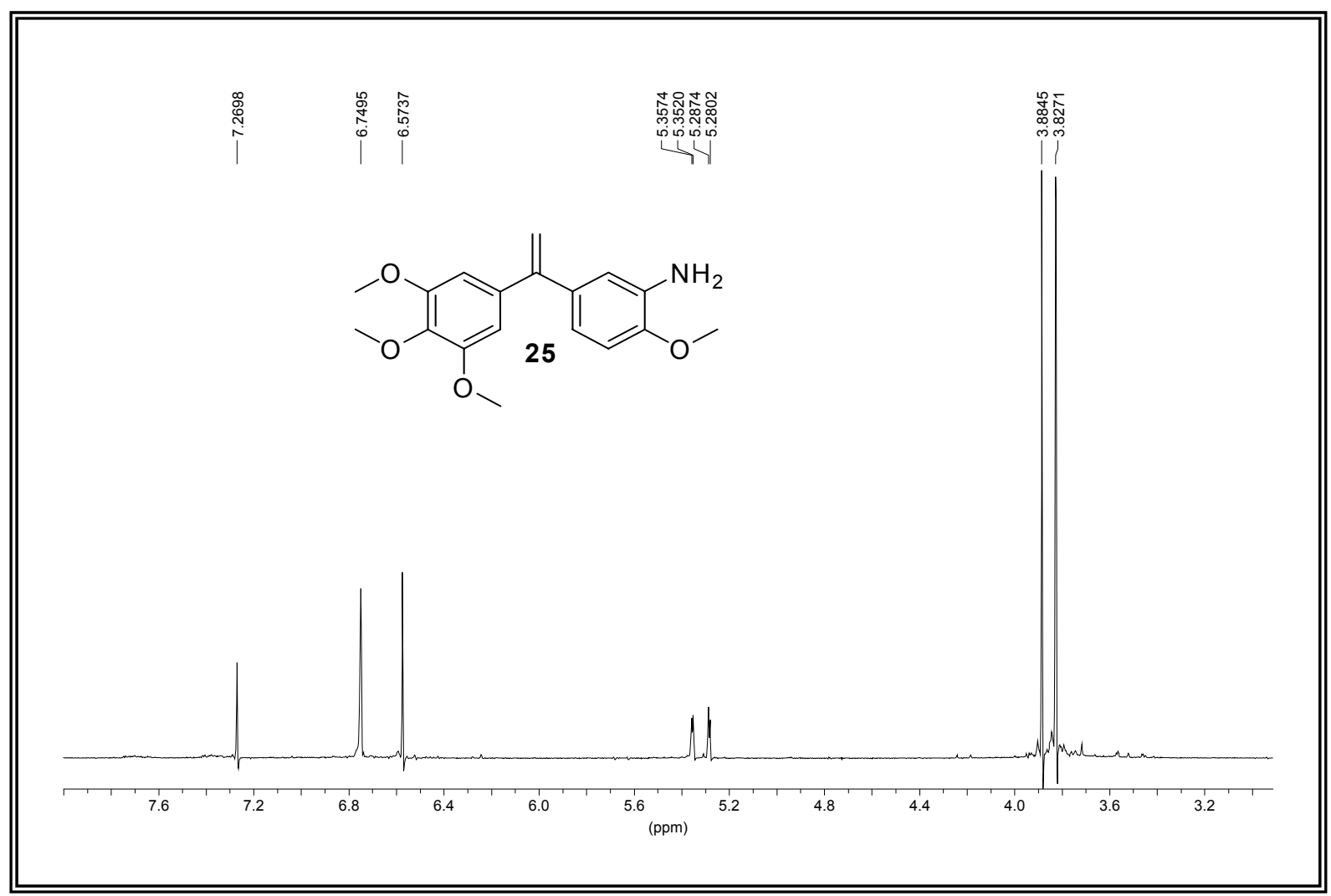

Figura VIIIa. Espectro de RMN ${ }^{1} \mathrm{H}$ del compuesto 25.

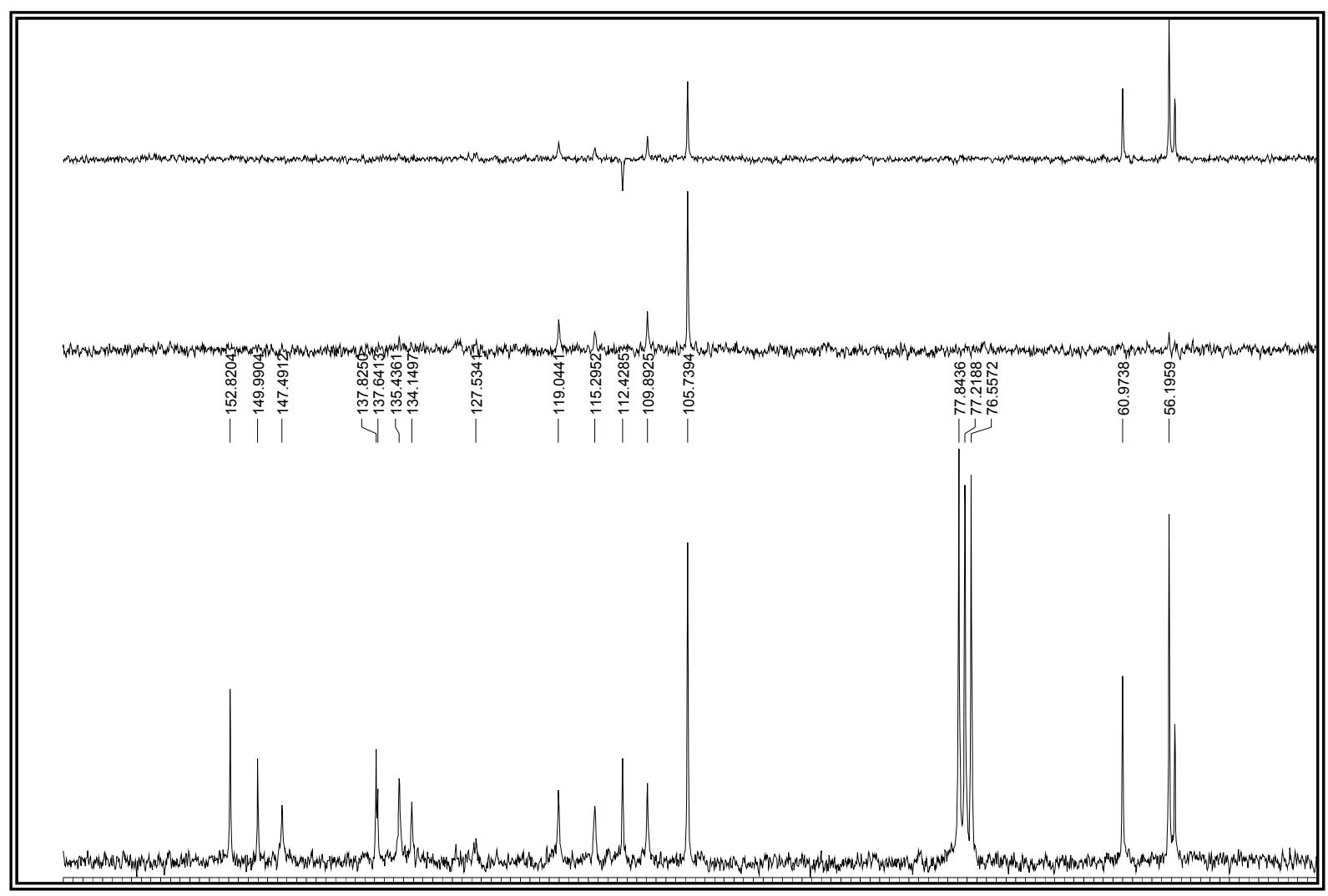

Figura VIIIb. Espectro de RMN ${ }^{13} \mathrm{C}$ del compuesto 25. 


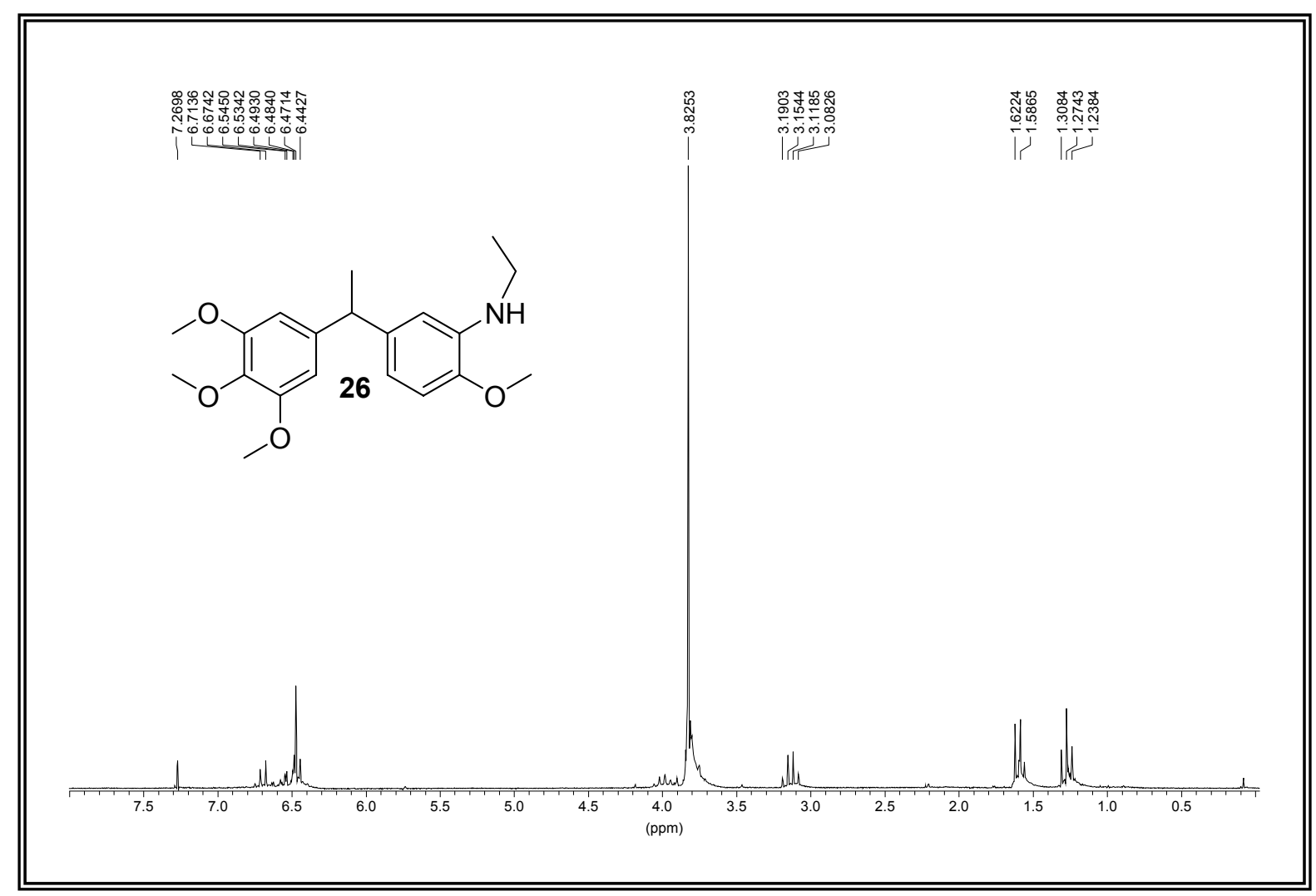

Figura IXa. Espectro de RMN ${ }^{1} \mathrm{H}$ del compuesto 26.

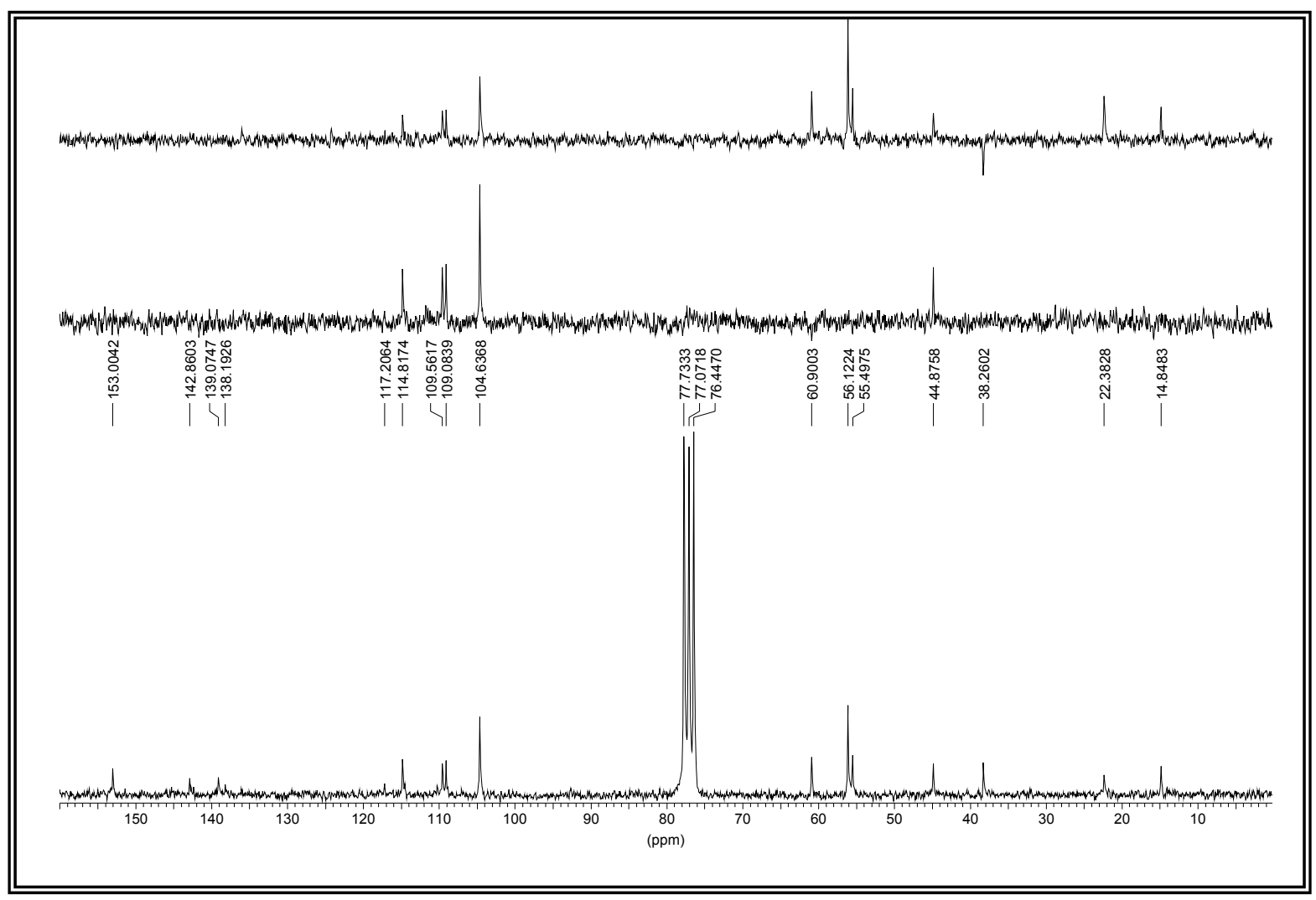

Figura IXb. Espectro de RMN ${ }^{13} \mathrm{C}$ del compuesto 26. 


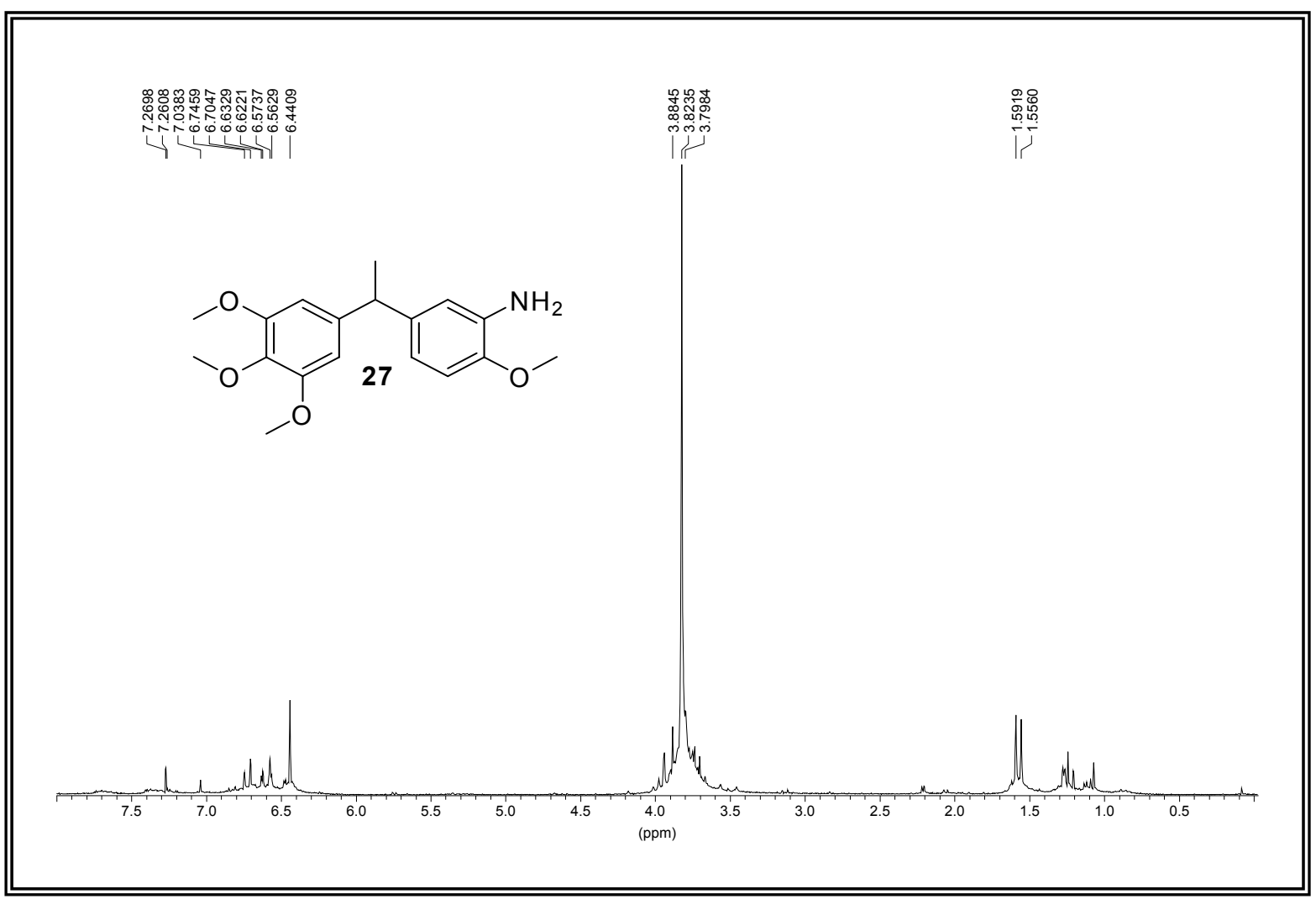

Figura Xa. Espectro de RMN ${ }^{1} \mathrm{H}$ del compuesto 27.

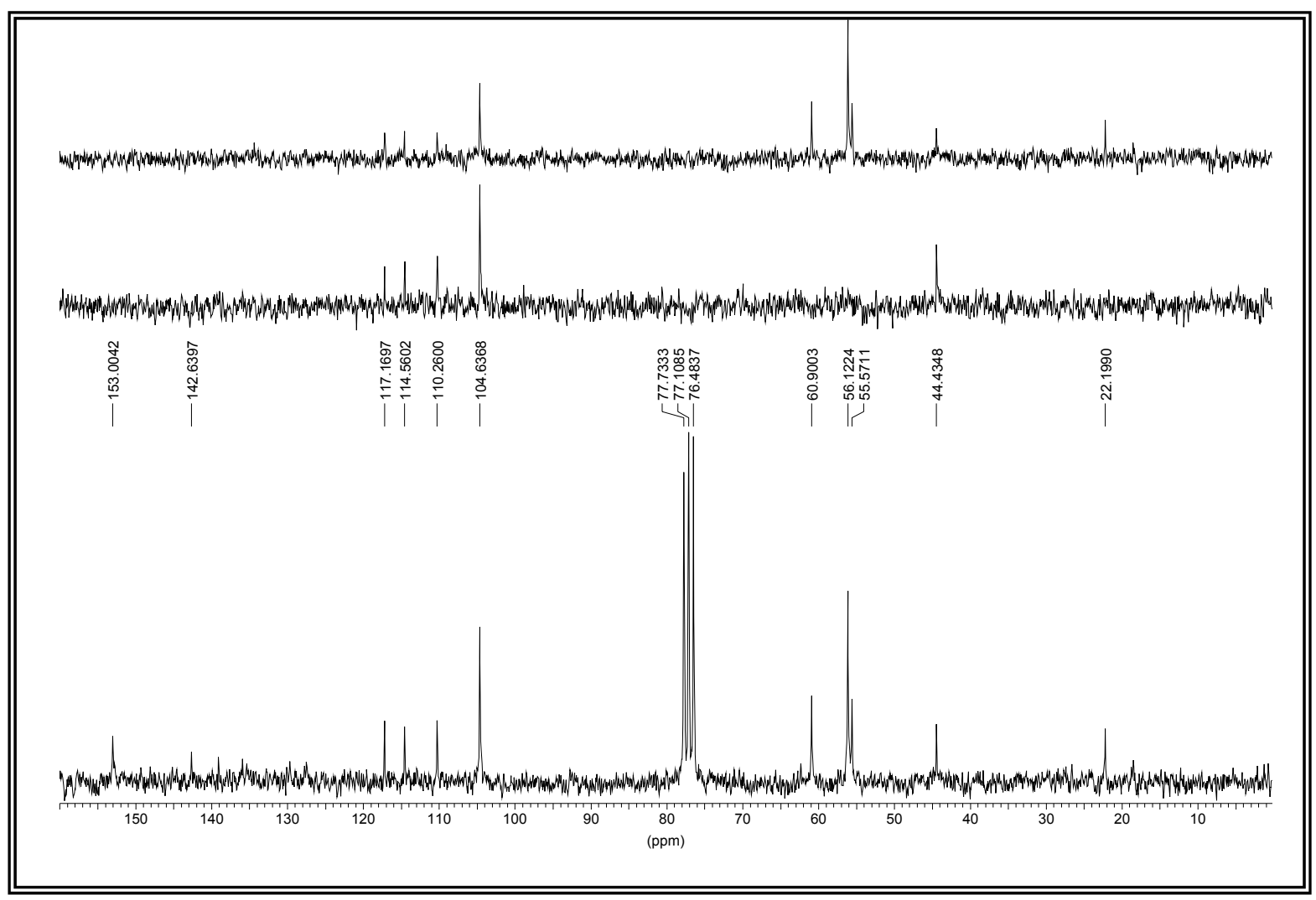

Figura $\mathrm{Xb}$. Espectro de $\mathrm{RMN}{ }^{13} \mathrm{C}$ del compuesto 27. 


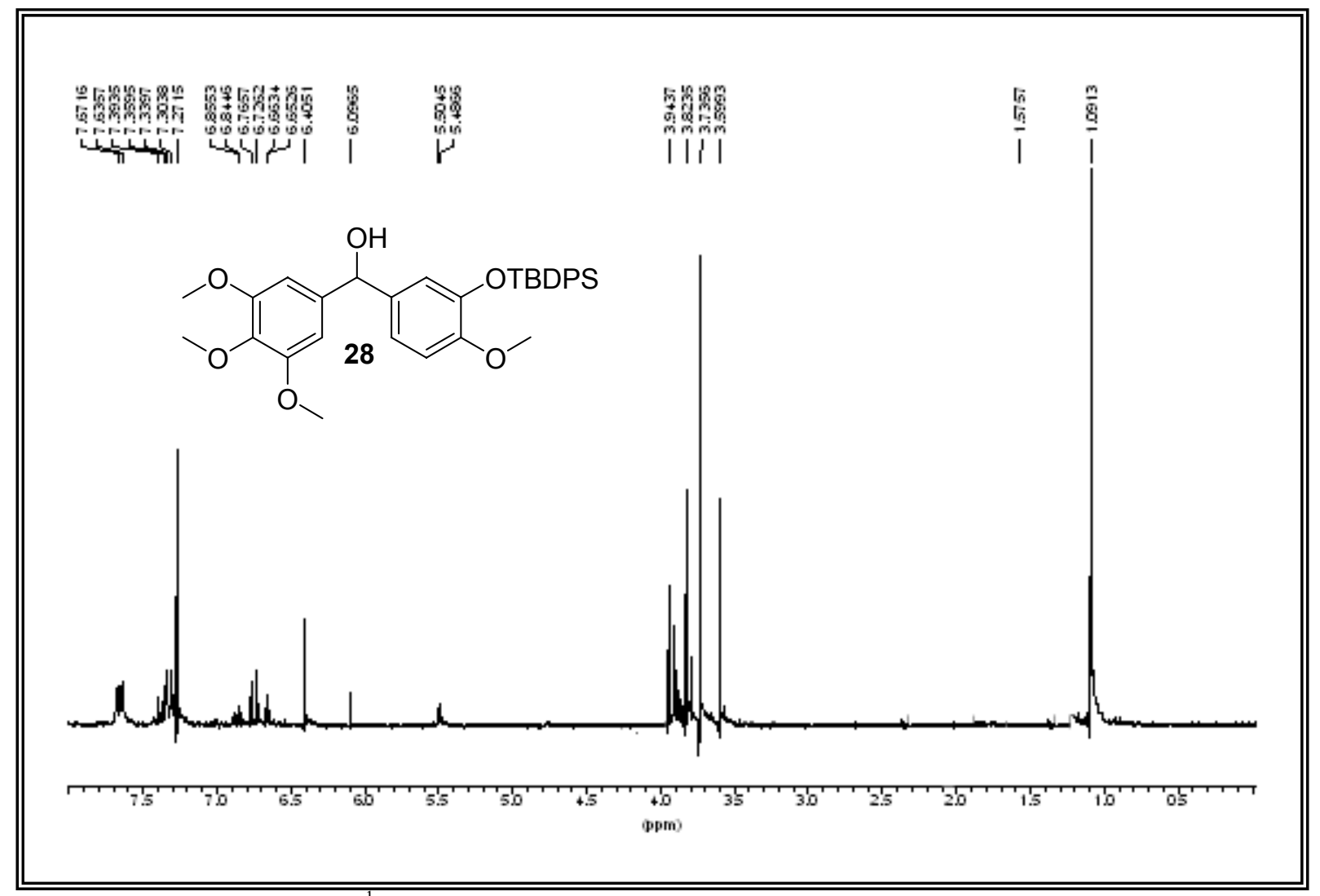

Figura XIa. Espectro de RMN ${ }^{1} \mathrm{H}$ del compuesto 28.

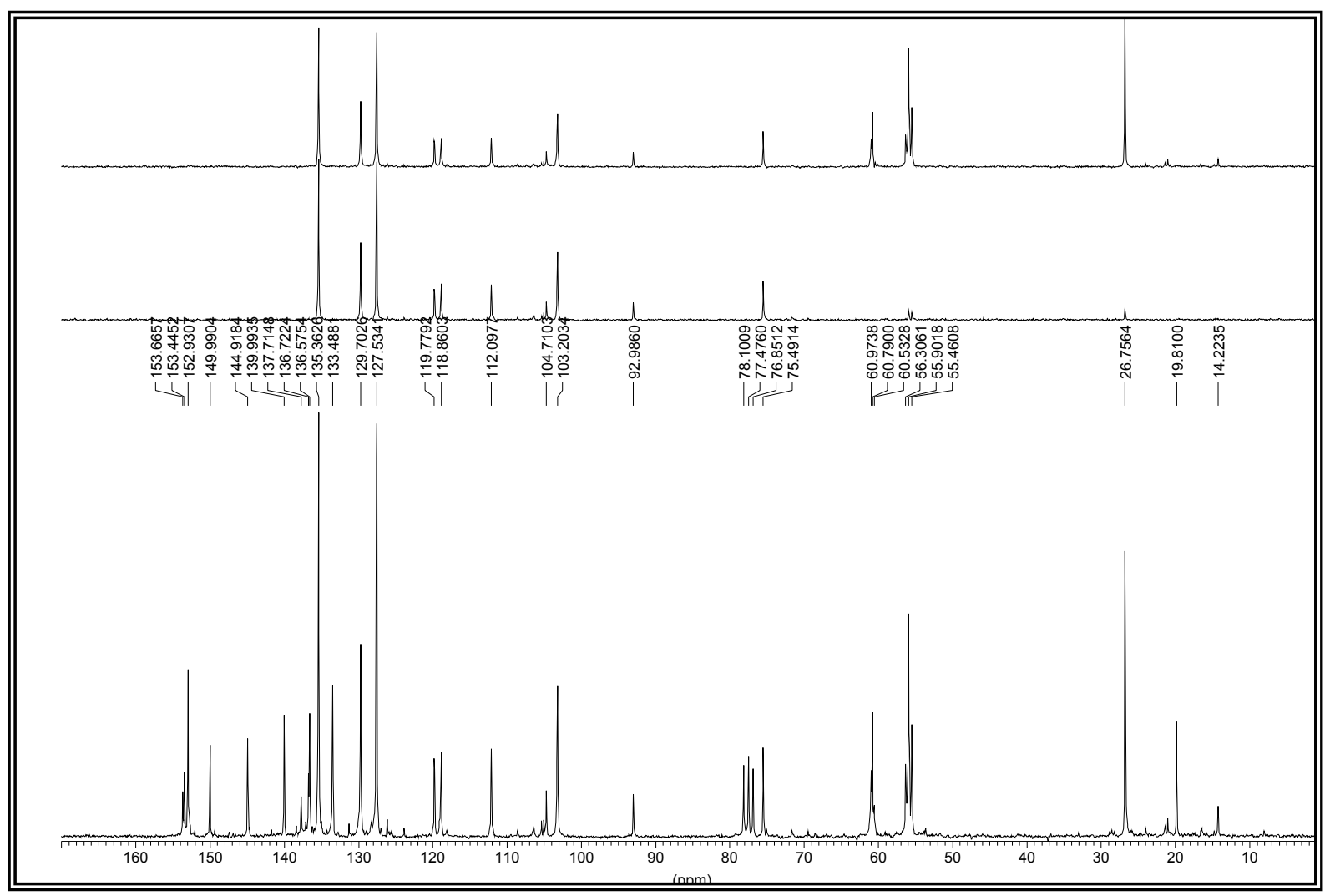

Figura XIb. Espectro de RMN ${ }^{13} \mathrm{C}$ del compuesto 28. 


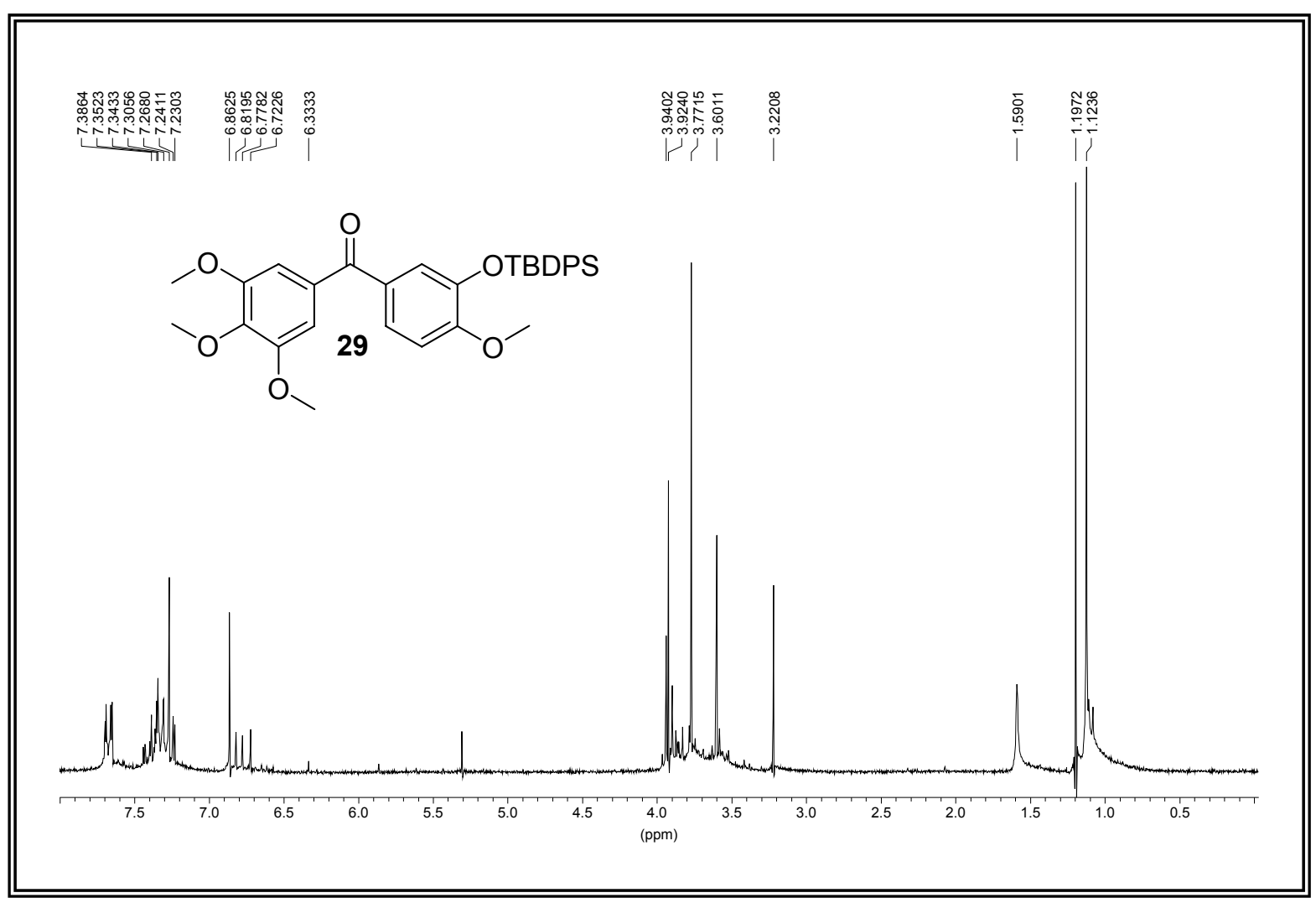

Figura XIIa. Espectro de $\mathrm{RMN}^{1} \mathrm{H}$ del compuesto 29.

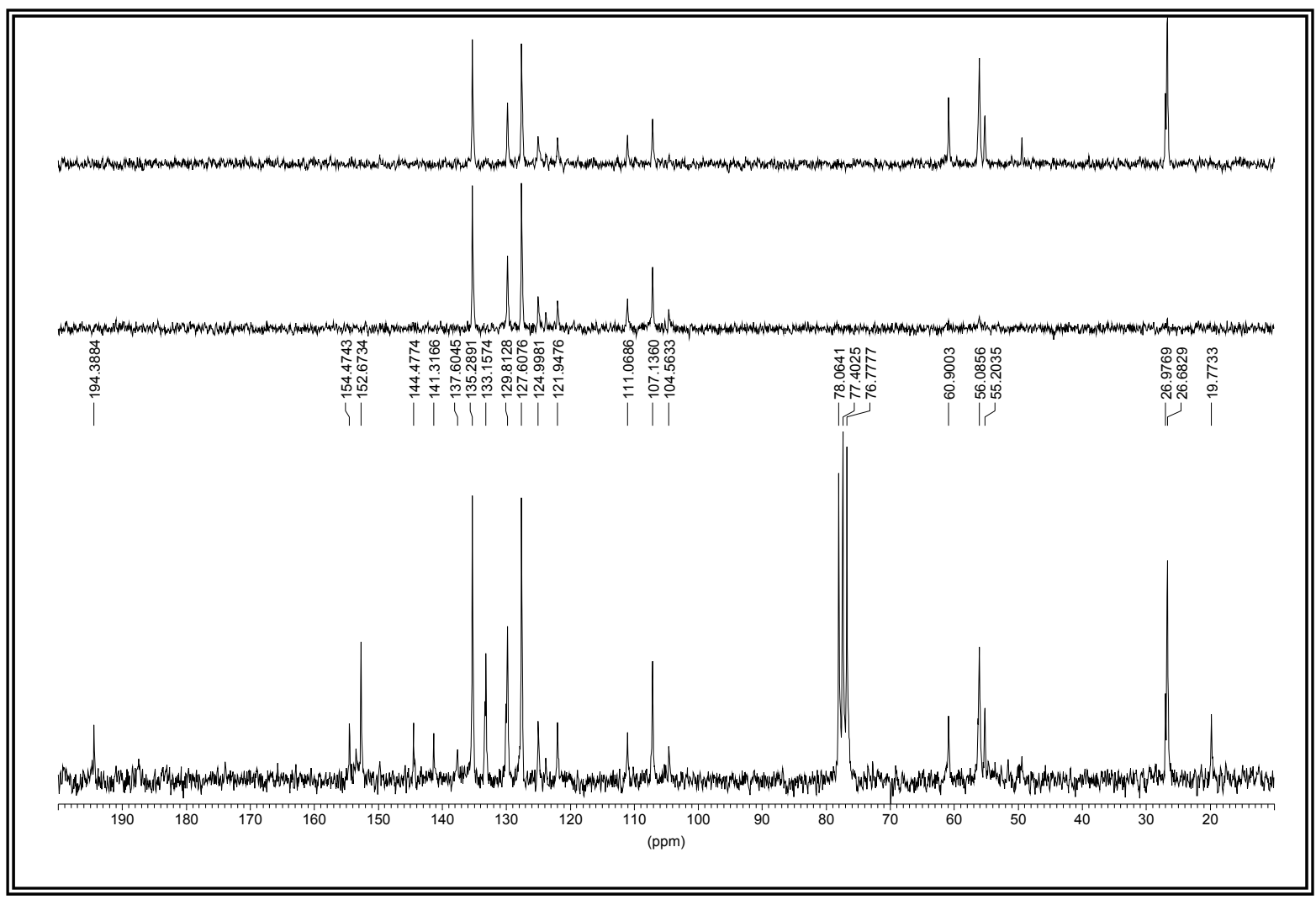

Figura XIIb. Espectro de RMN ${ }^{13} \mathrm{C}$ del compuesto 29. 


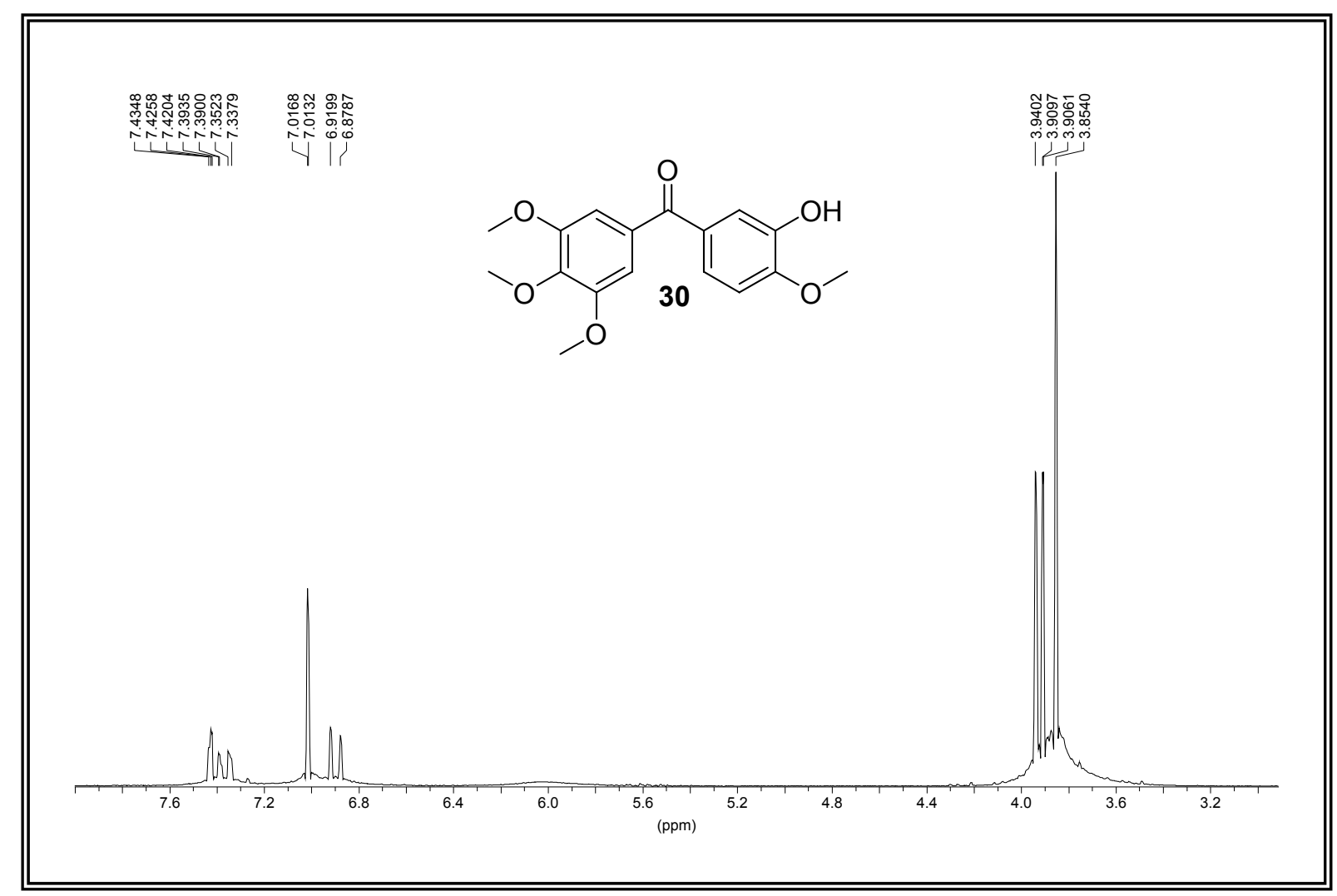

Figura XIIIa. Espectro de RMN ${ }^{1} \mathrm{H}$ del compuesto 30.

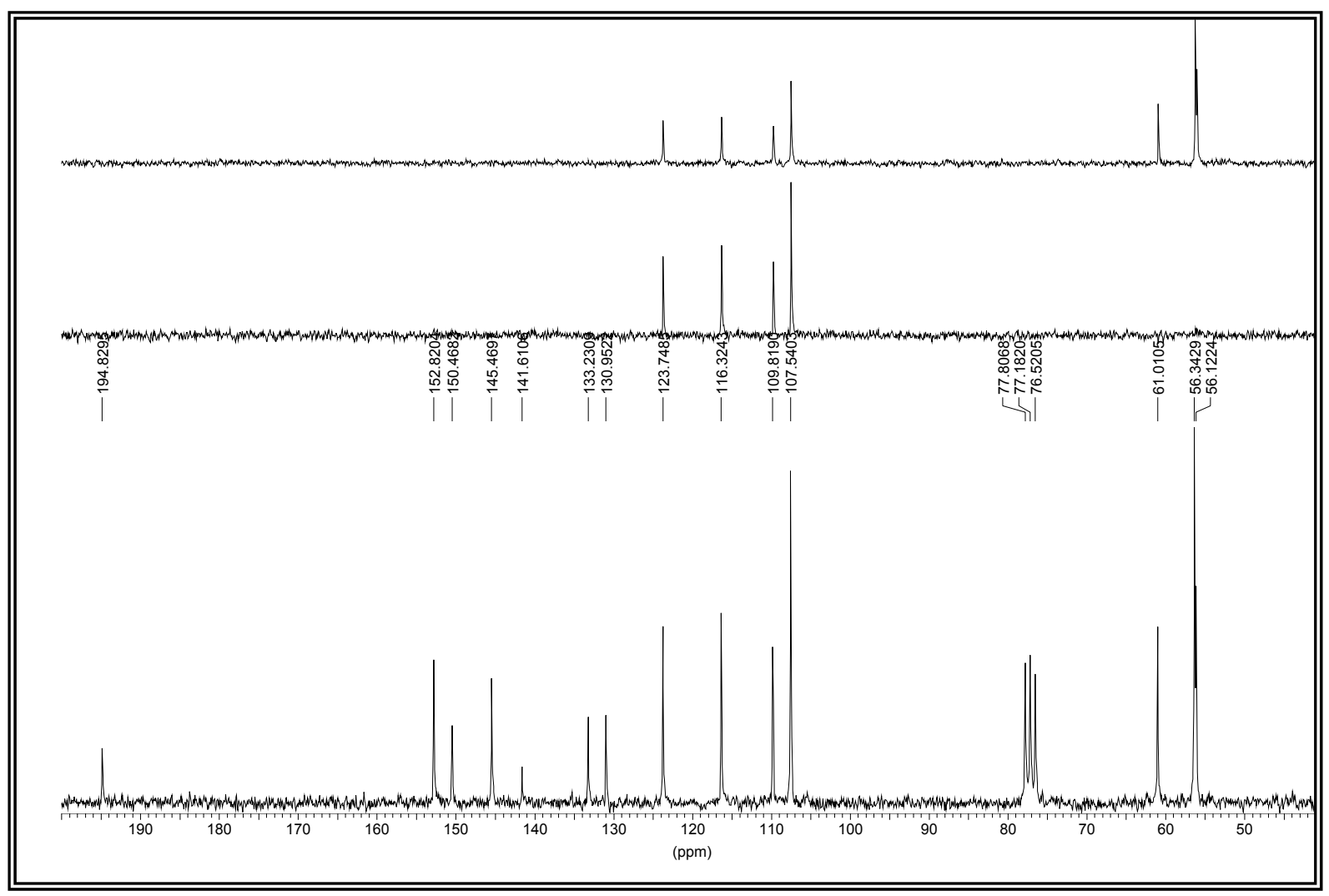

Figura XIIIb. Espectro de RMN ${ }^{13} \mathrm{C}$ del compuesto 30. 


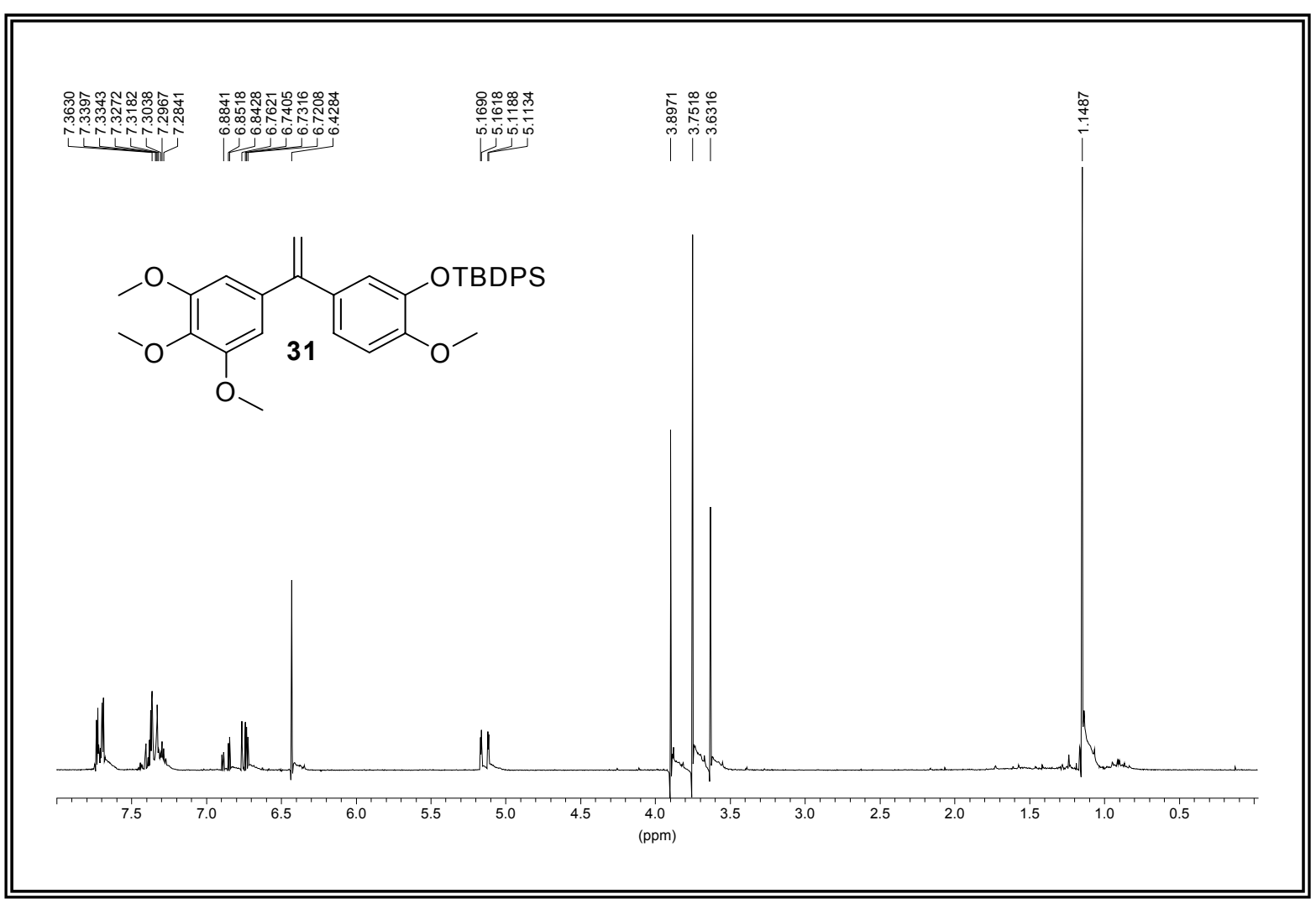

Figura XIVa. Espectro de RMN ${ }^{1} \mathrm{H}$ del compuesto 31.

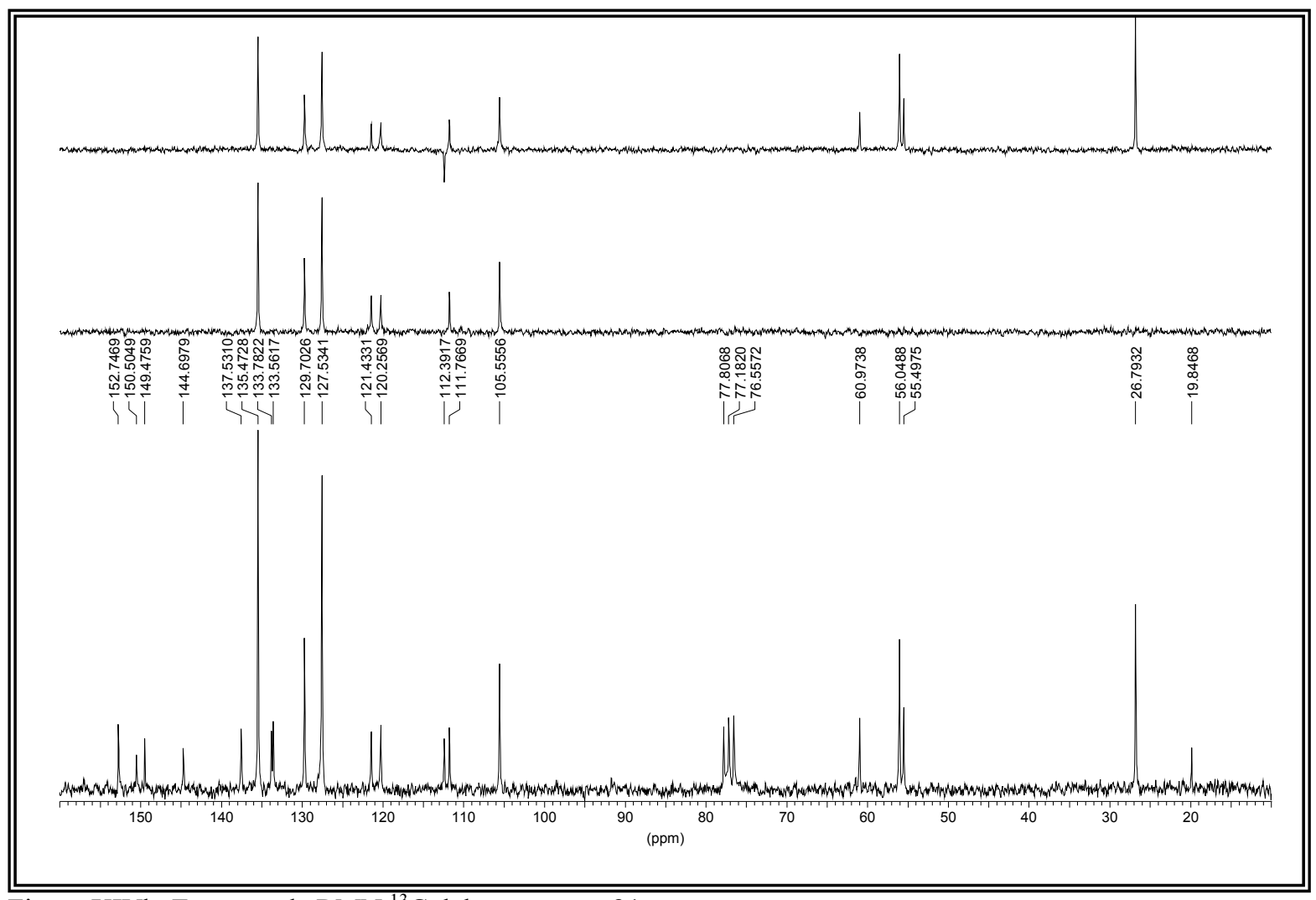

Figura XIVb. Espectro de RMN ${ }^{13} \mathrm{C}$ del compuesto 31. 


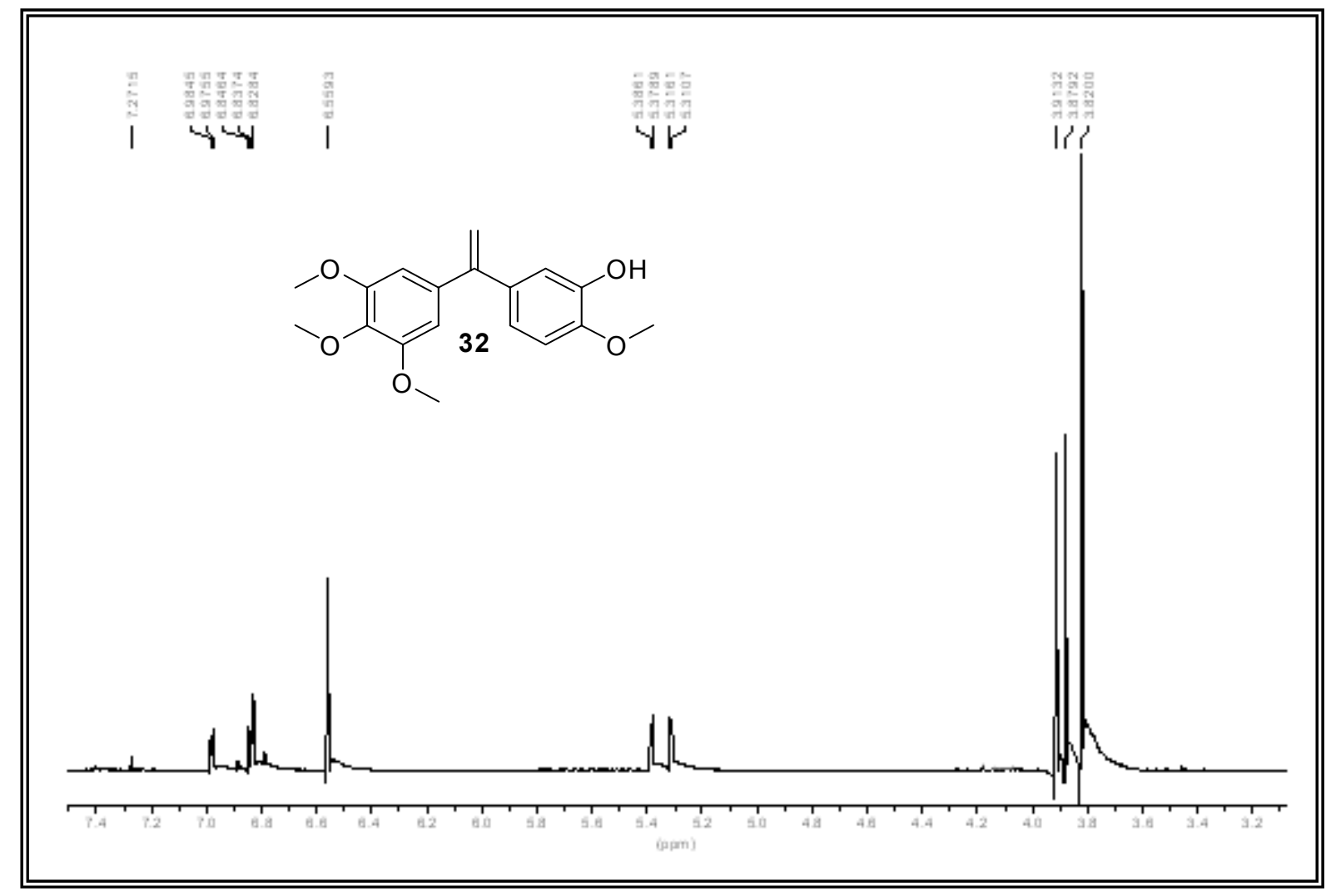

Figura XVa. Espectro de RMN ${ }^{1} \mathrm{H}$ del compuesto 32.

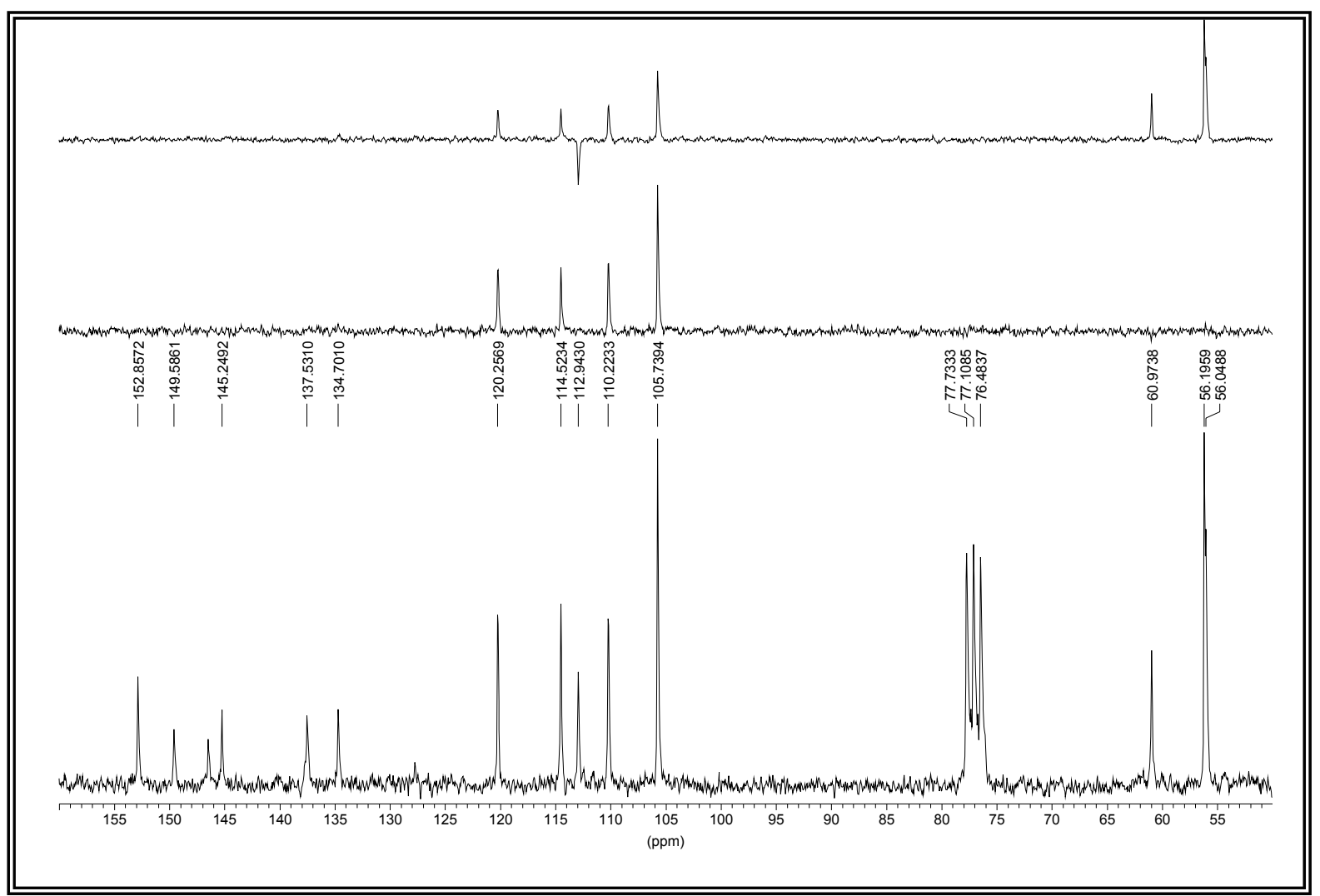

Figura XVb. Espectro de $\mathrm{RMN}{ }^{13} \mathrm{C}$ del compuesto 32. 


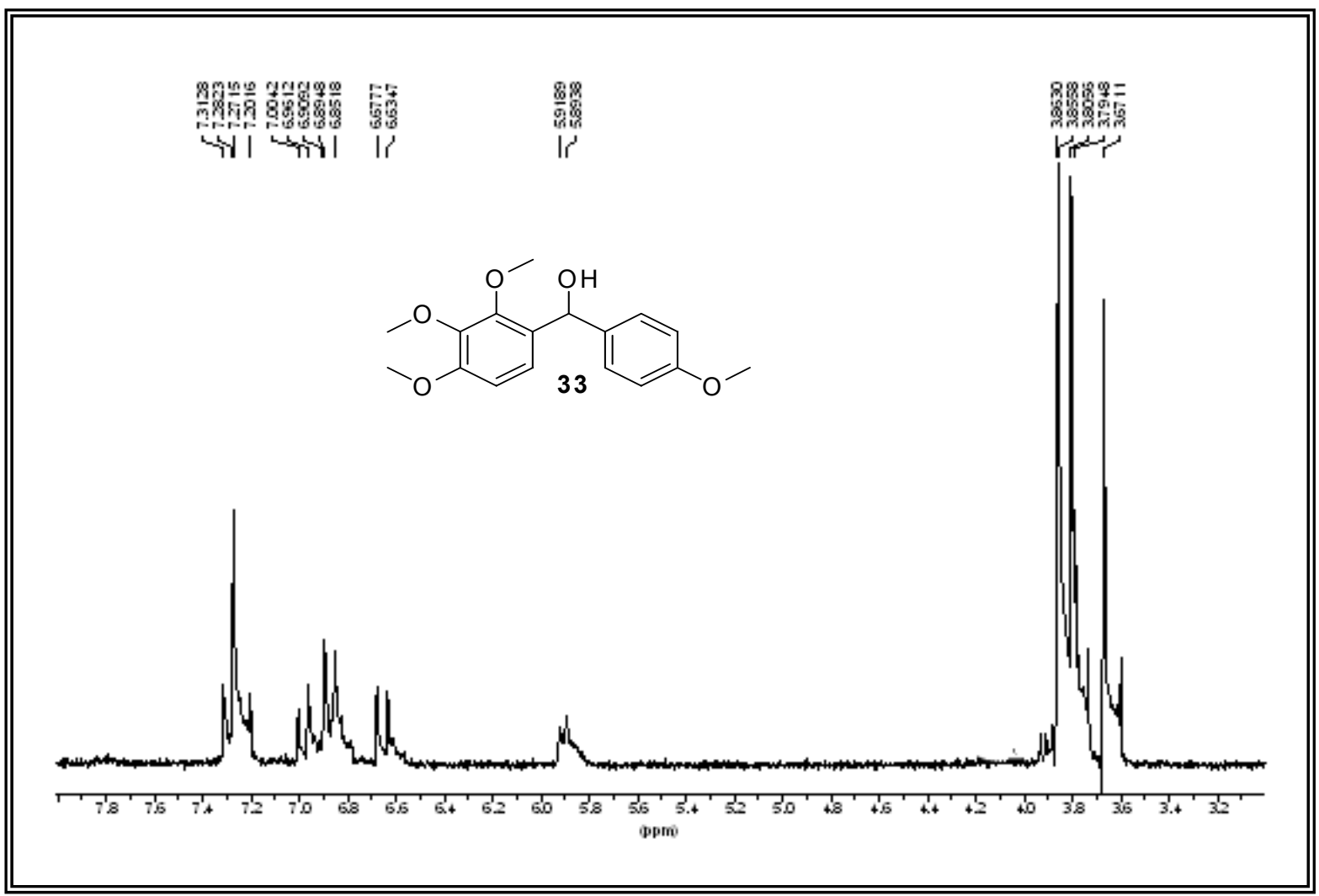

Figura XVIa. Espectro de RMN ${ }^{1} \mathrm{H}$ del compuesto 33.

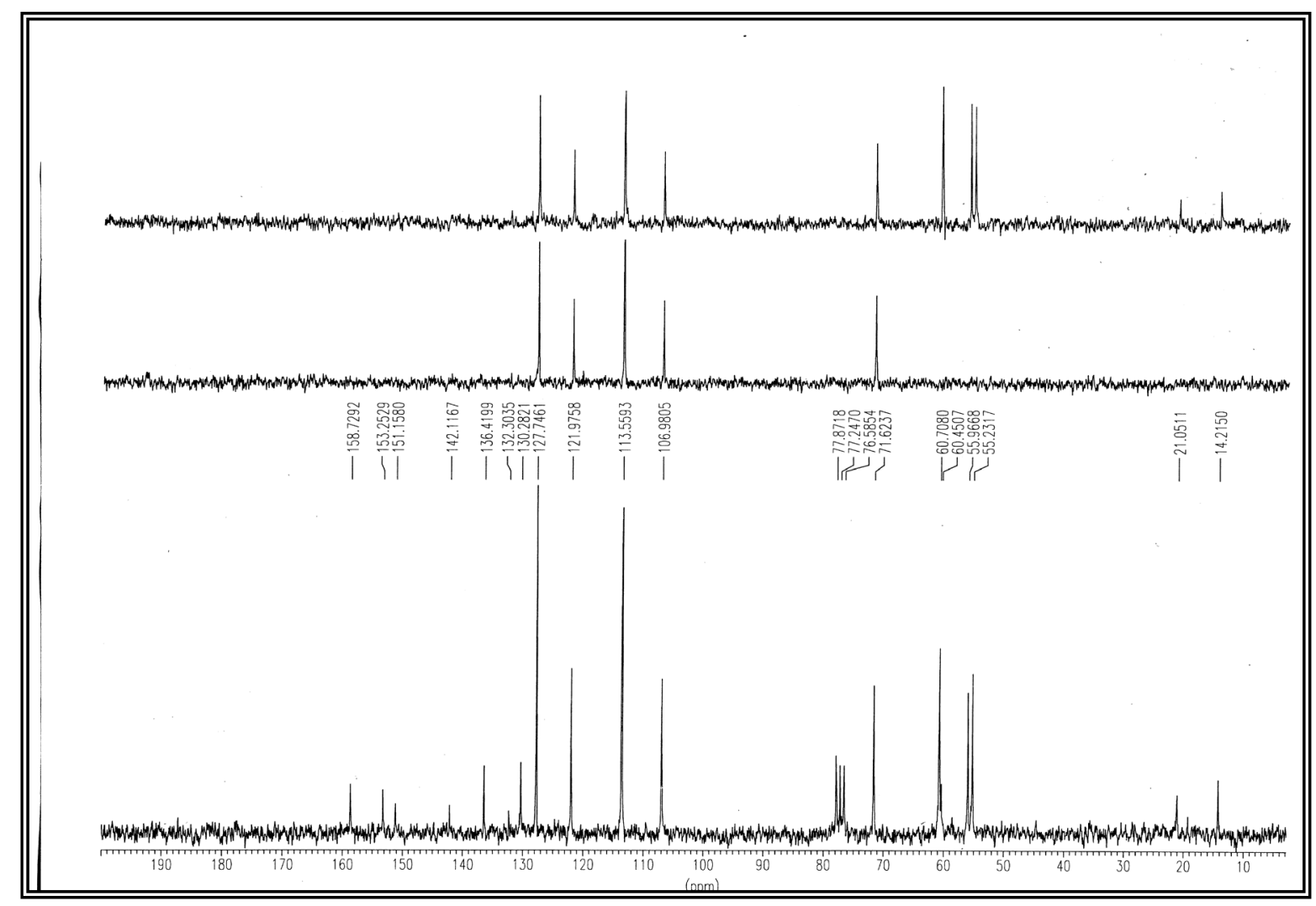

Figura XVIa. Espectro de RMN ${ }^{13} \mathrm{C}$ del compuesto 33. 


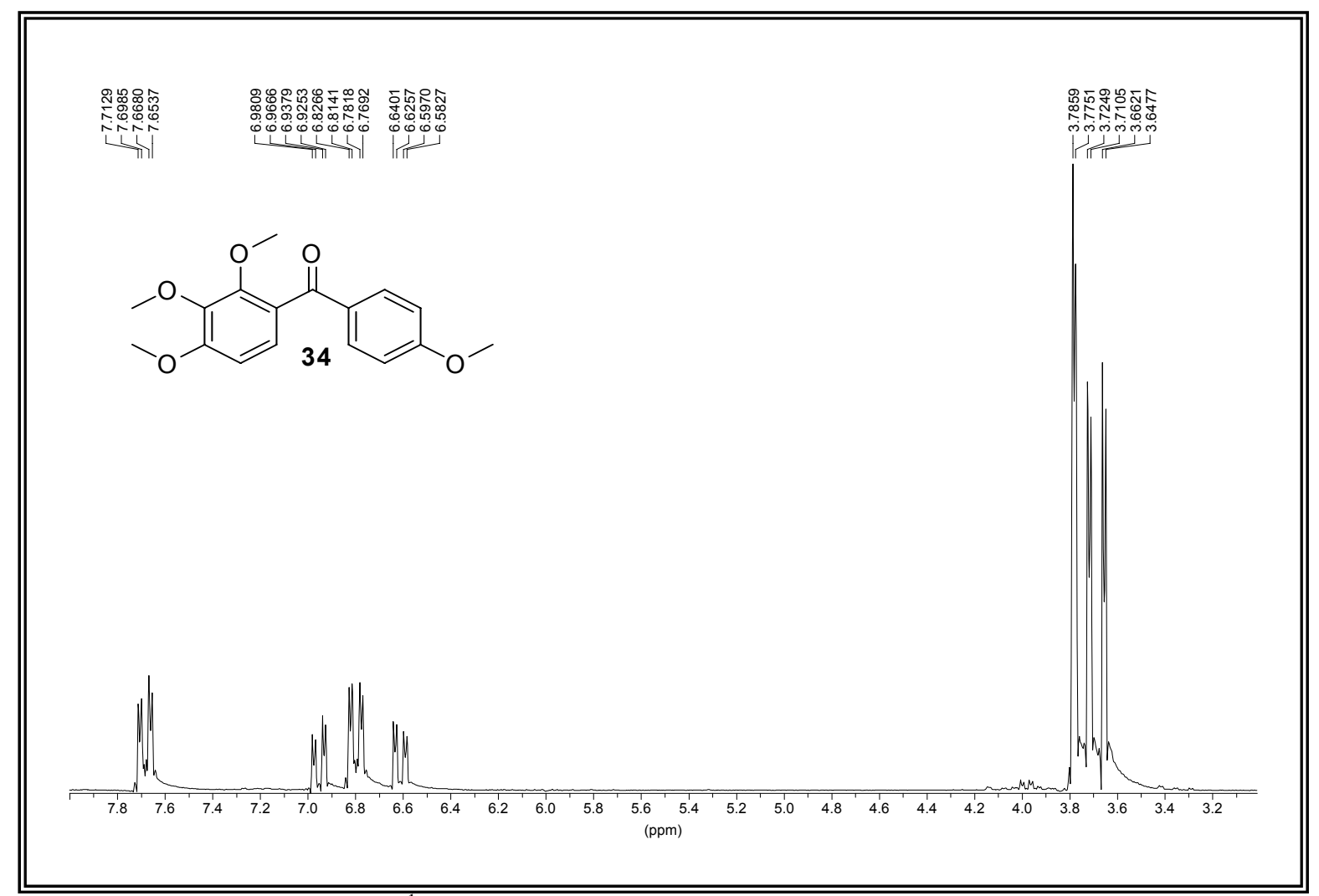

Figura XVIIa. Espectro de RMN ${ }^{1} \mathrm{H}$ del compuesto 34.

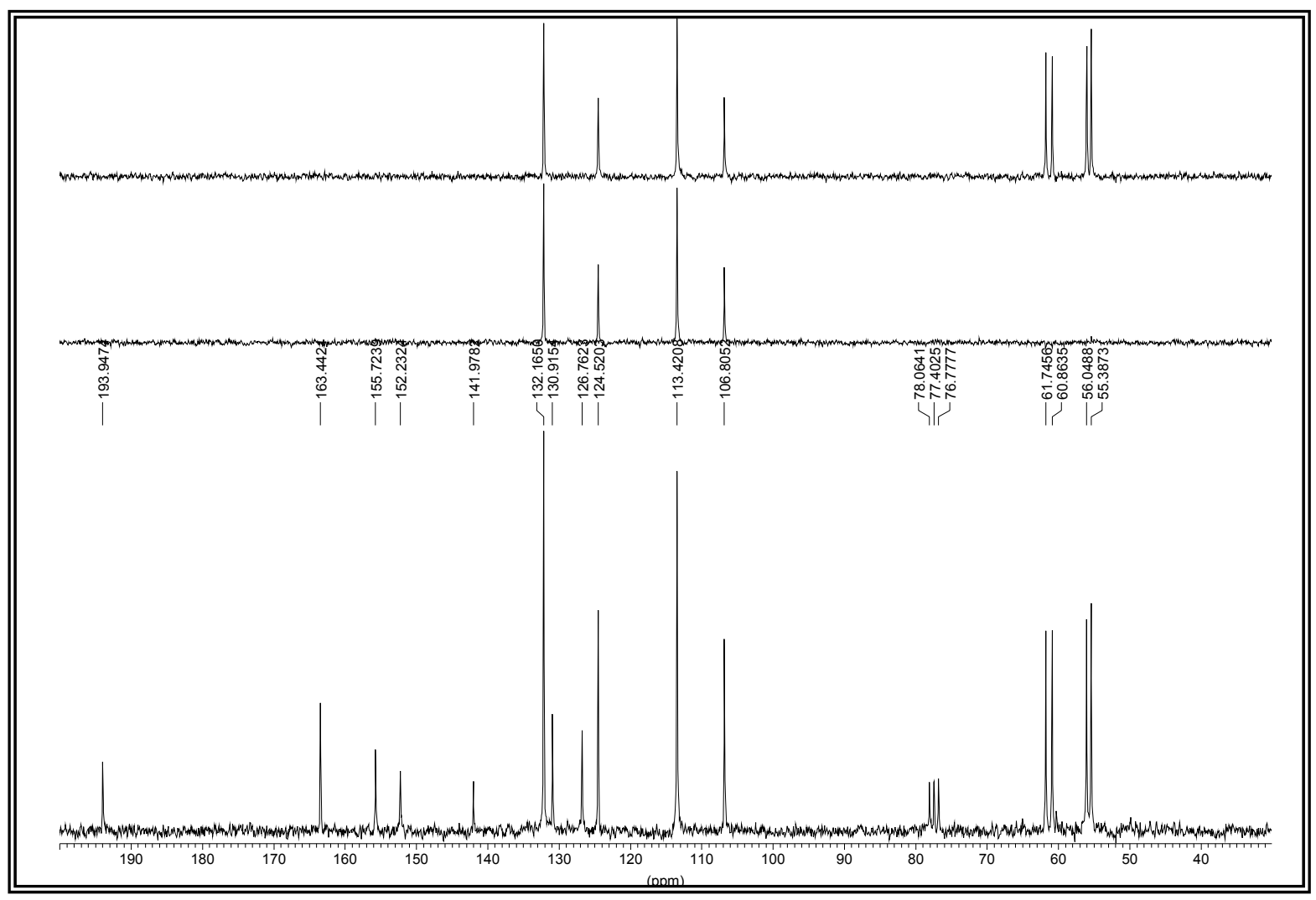

Figura XVIIb. Espectro de RMN ${ }^{13} \mathrm{C}$ del compuesto 34 . 


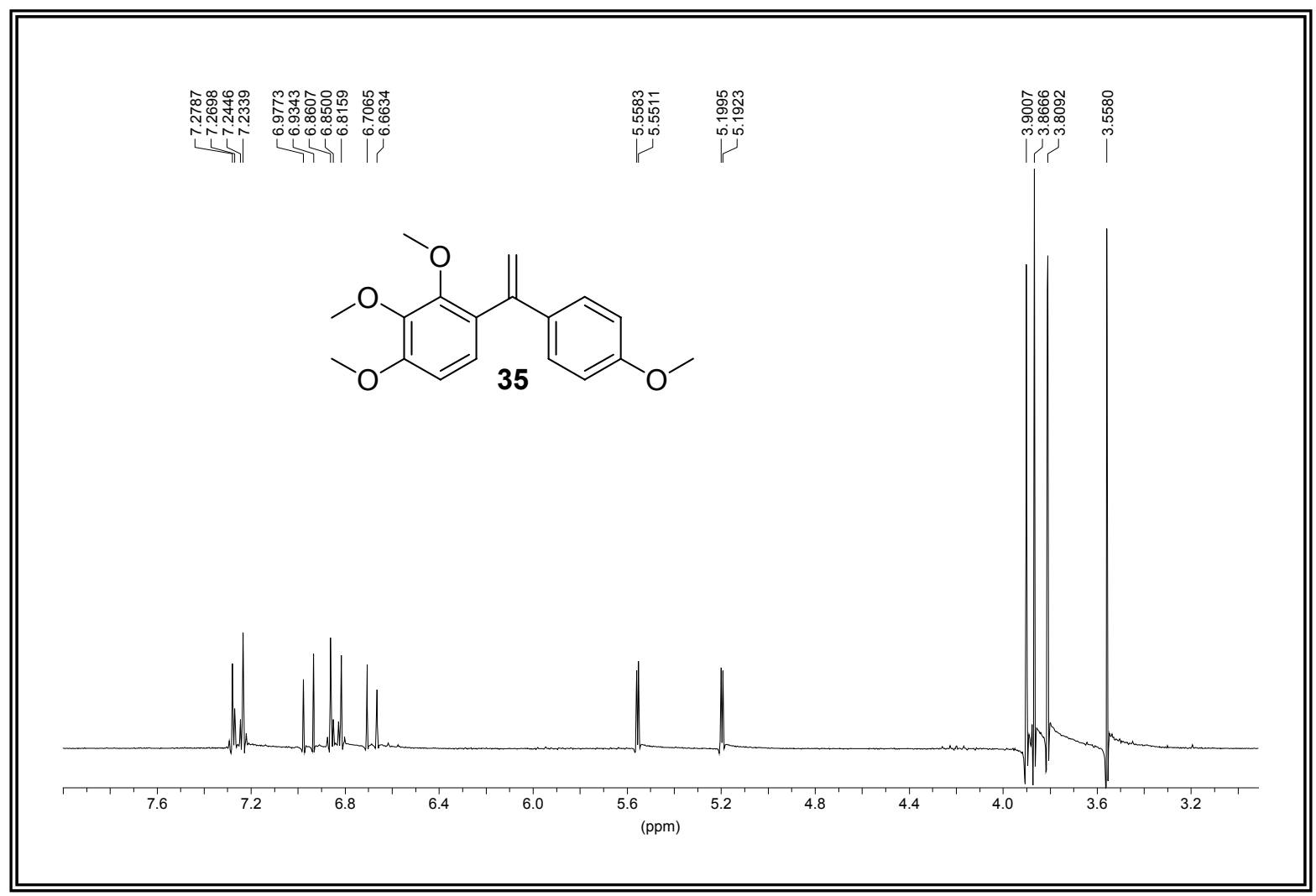

Figura XVIIIa. Espectro de RMN ${ }^{1} \mathrm{H}$ del compuesto 35.

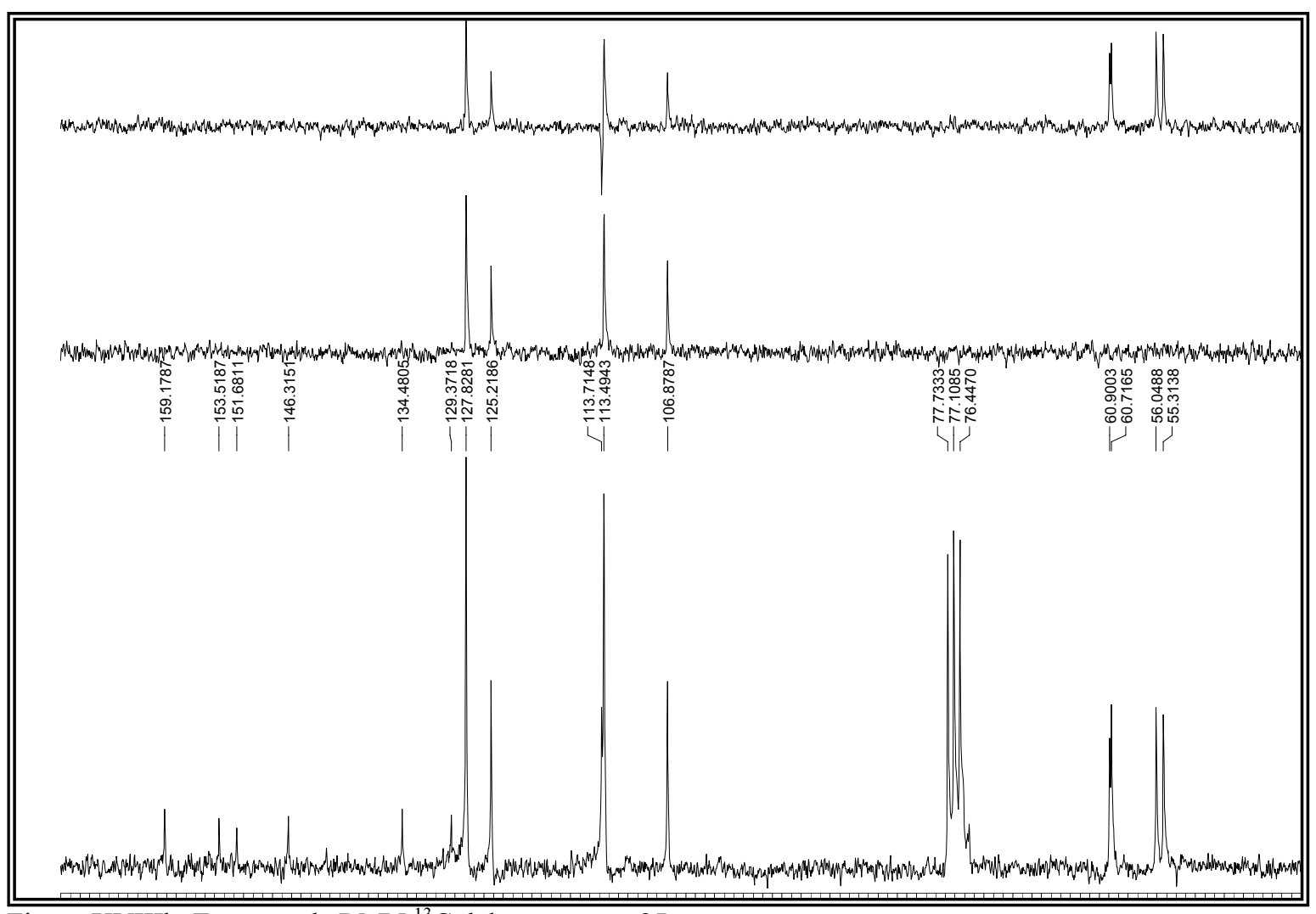

Figura XVIIIb. Espectro de RMN ${ }^{13} \mathrm{C}$ del compuesto 35. 


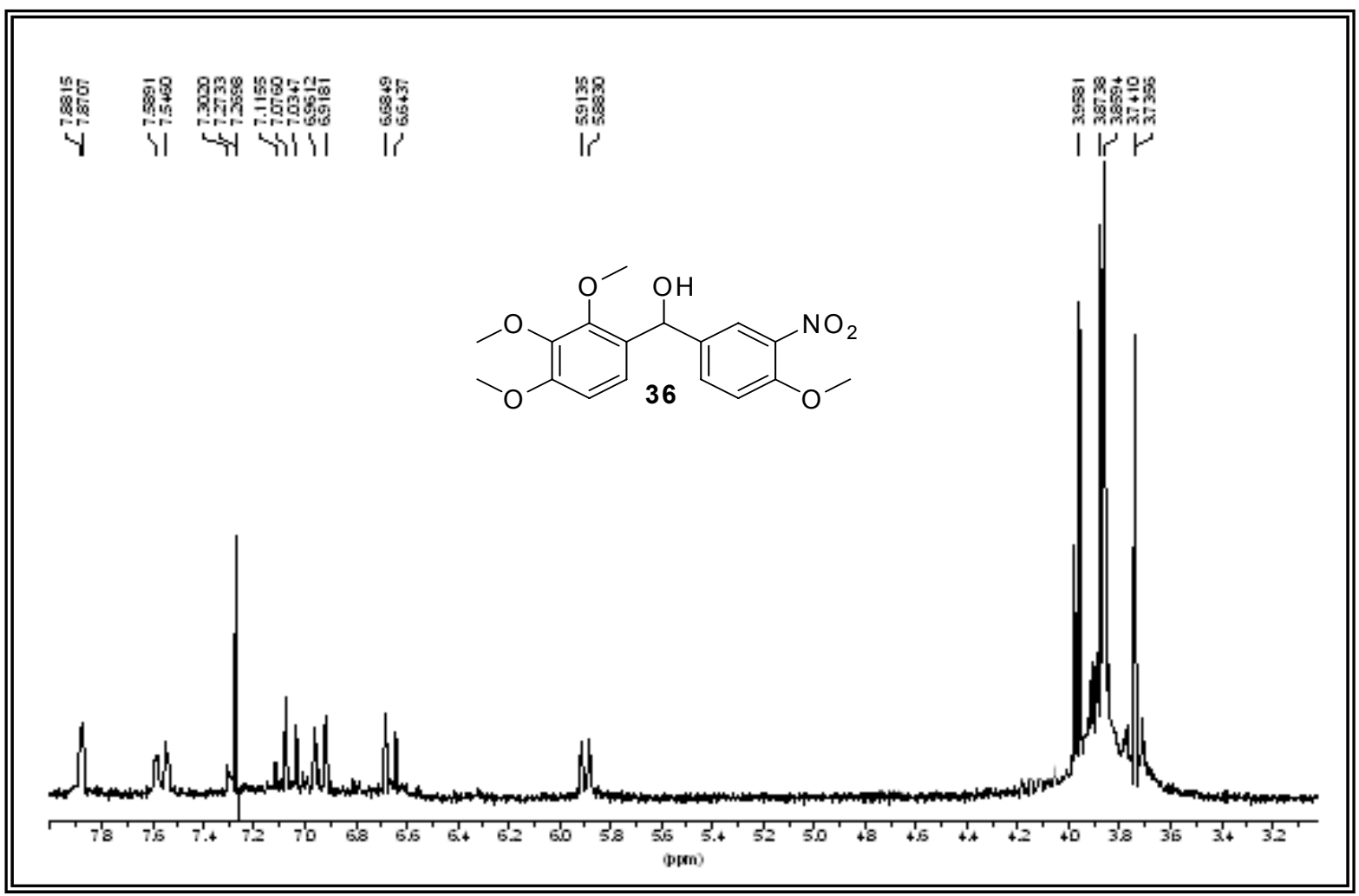

Figura XIXa. Espectro de RMN ${ }^{1} \mathrm{H}$ del compuesto 36.

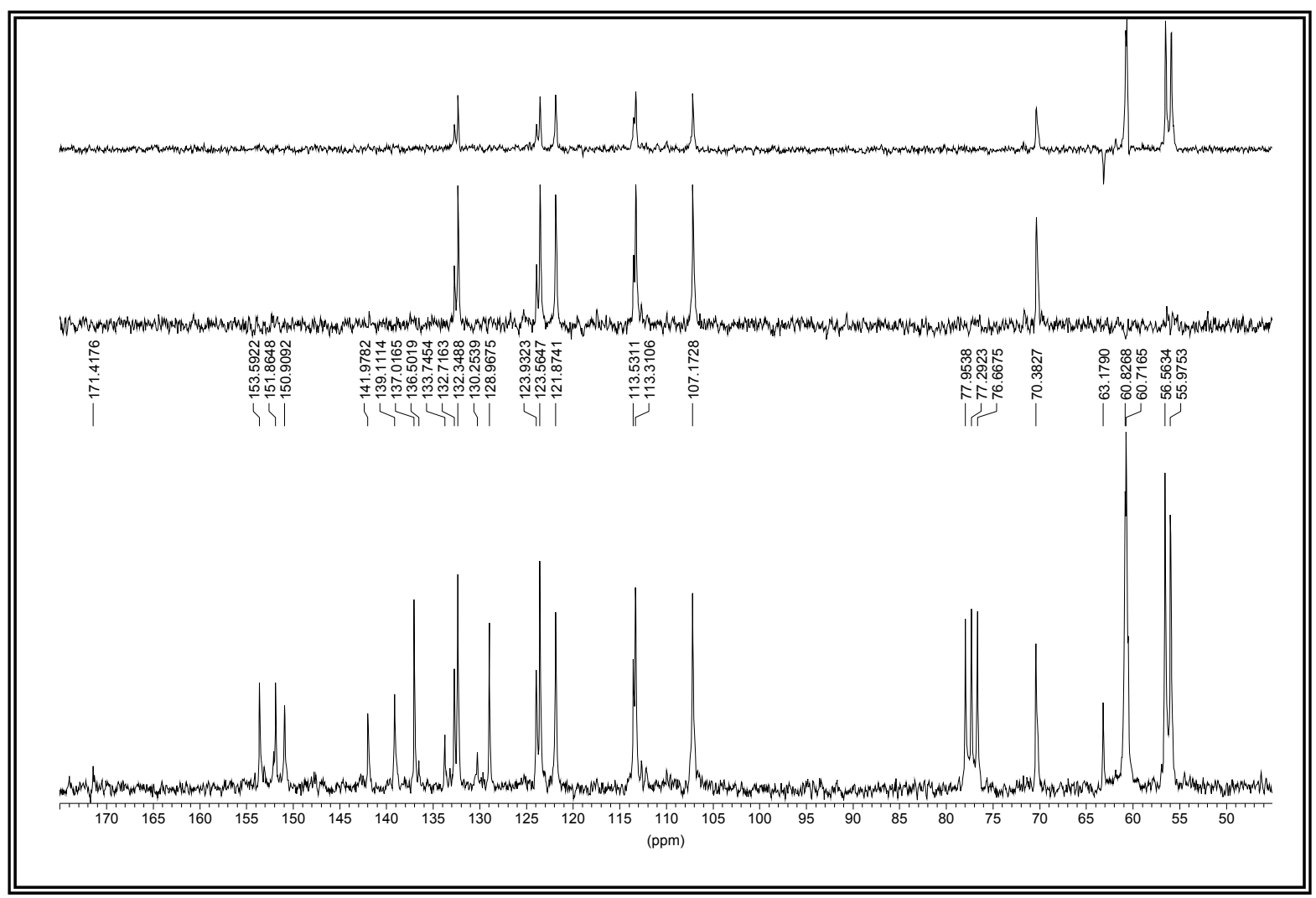

Figura XIXb. Espectro de RMN ${ }^{13} \mathrm{C}$ del compuesto 36. 


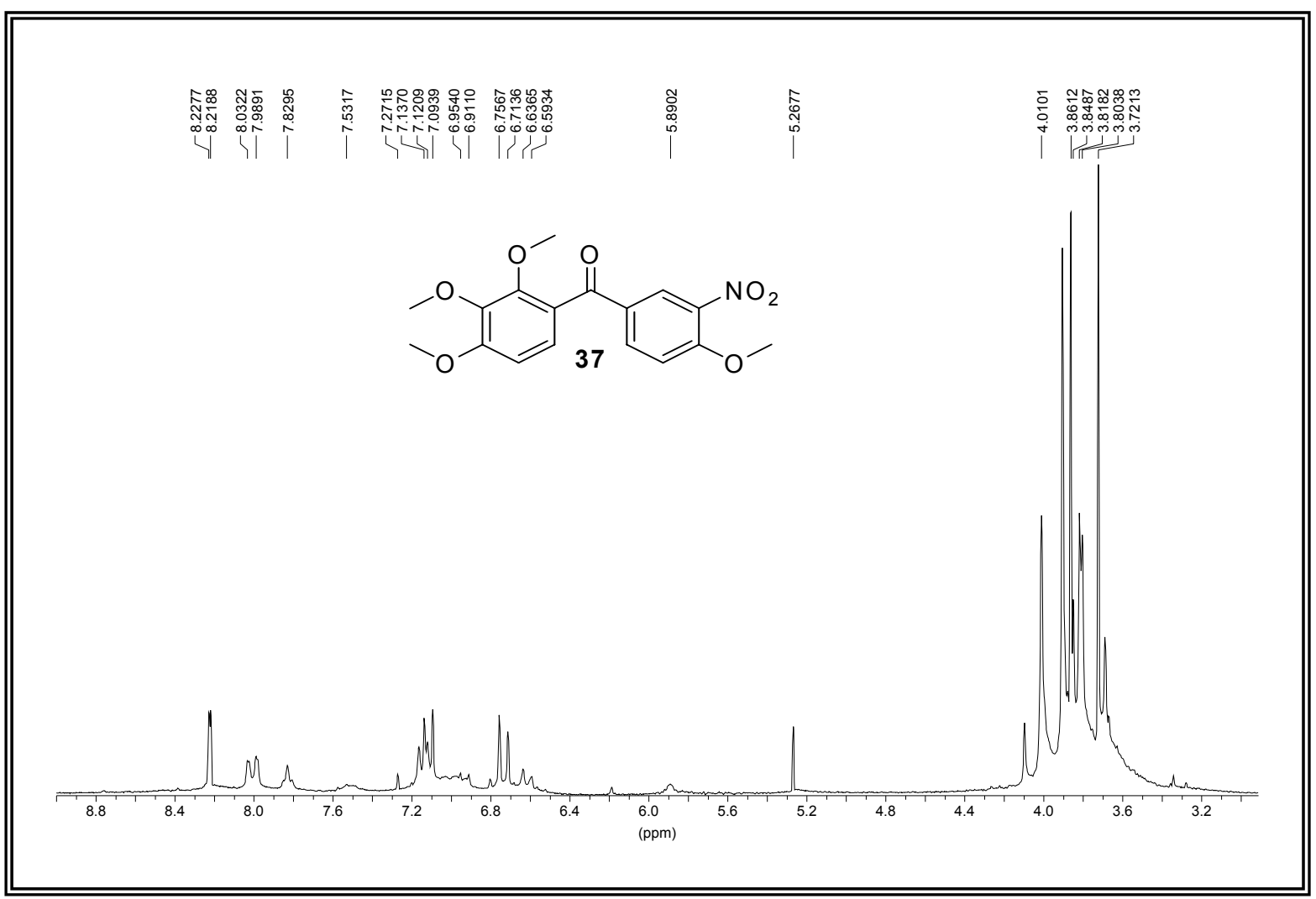

Figura XXa. Espectro de RMN ${ }^{1} \mathrm{H}$ del compuesto 37.

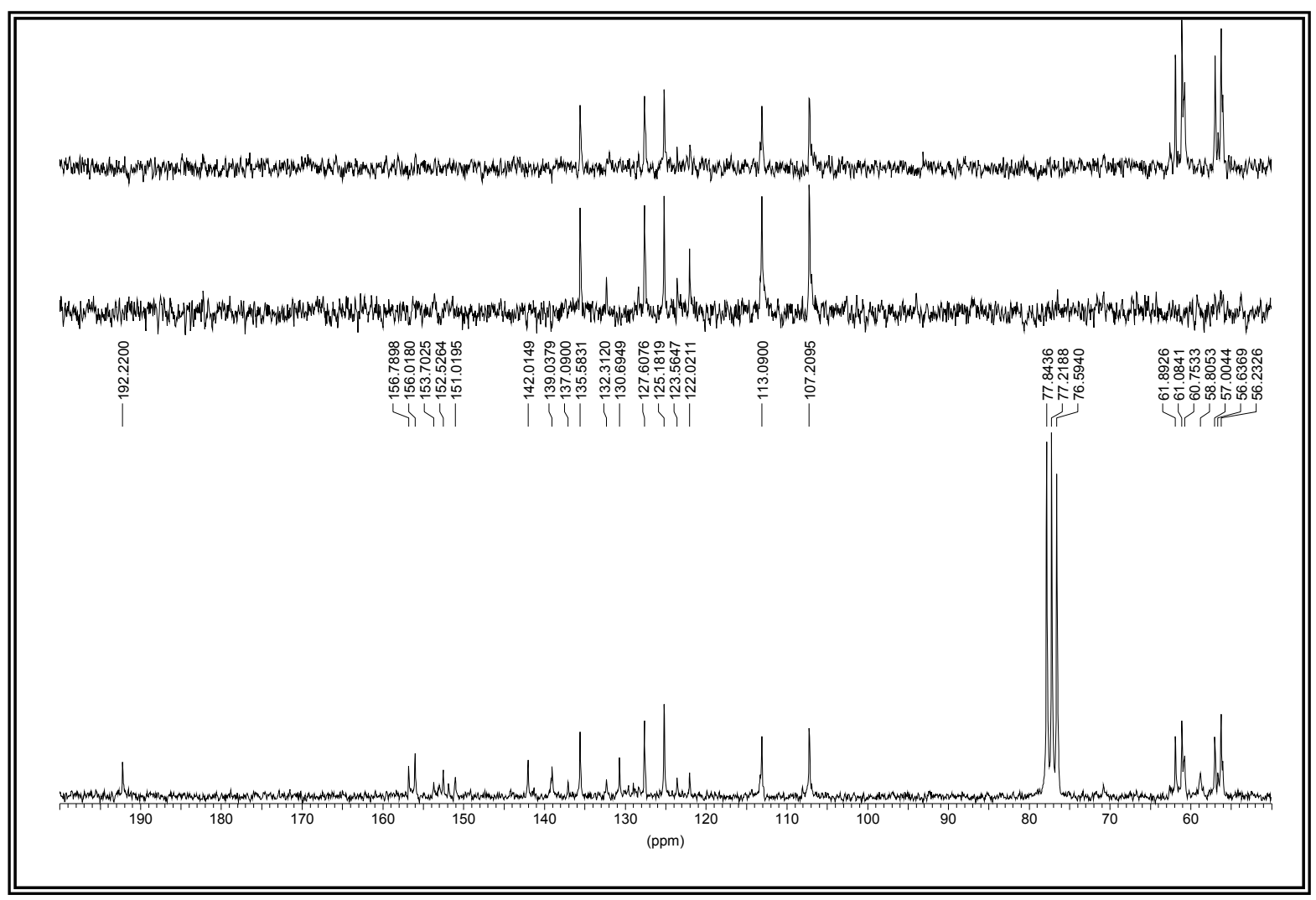

Figura $\mathrm{XXb}$. Espectro de $\mathrm{RMN}{ }^{13} \mathrm{C}$ del compuesto 37 . 


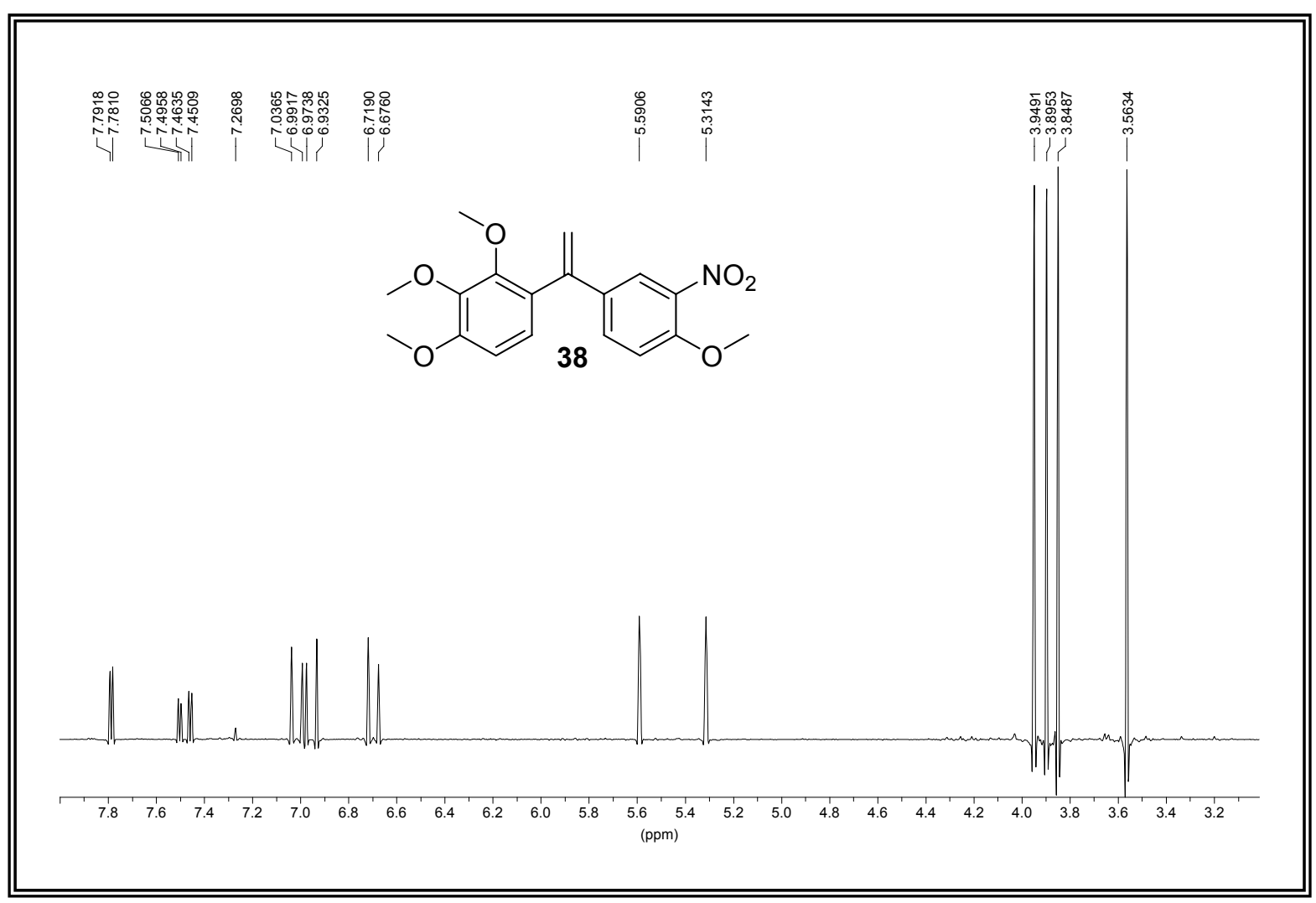

Figura XXIa. Espectro de RMN ${ }^{1} \mathrm{H}$ del compuesto 38 .

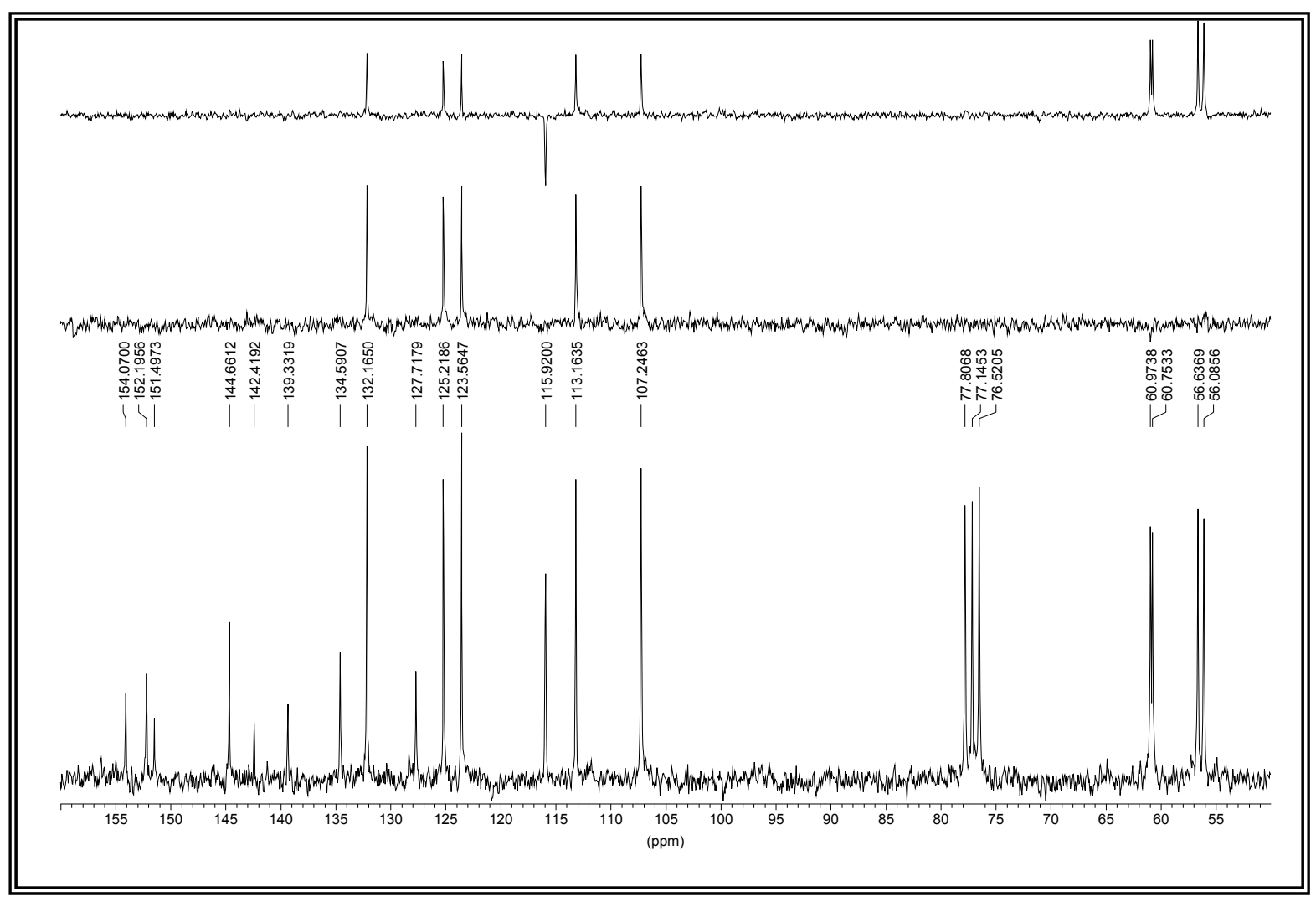

Figura XXIb. Espectro de $\mathrm{RMN}{ }^{13} \mathrm{C}$ del compuesto 38 . 


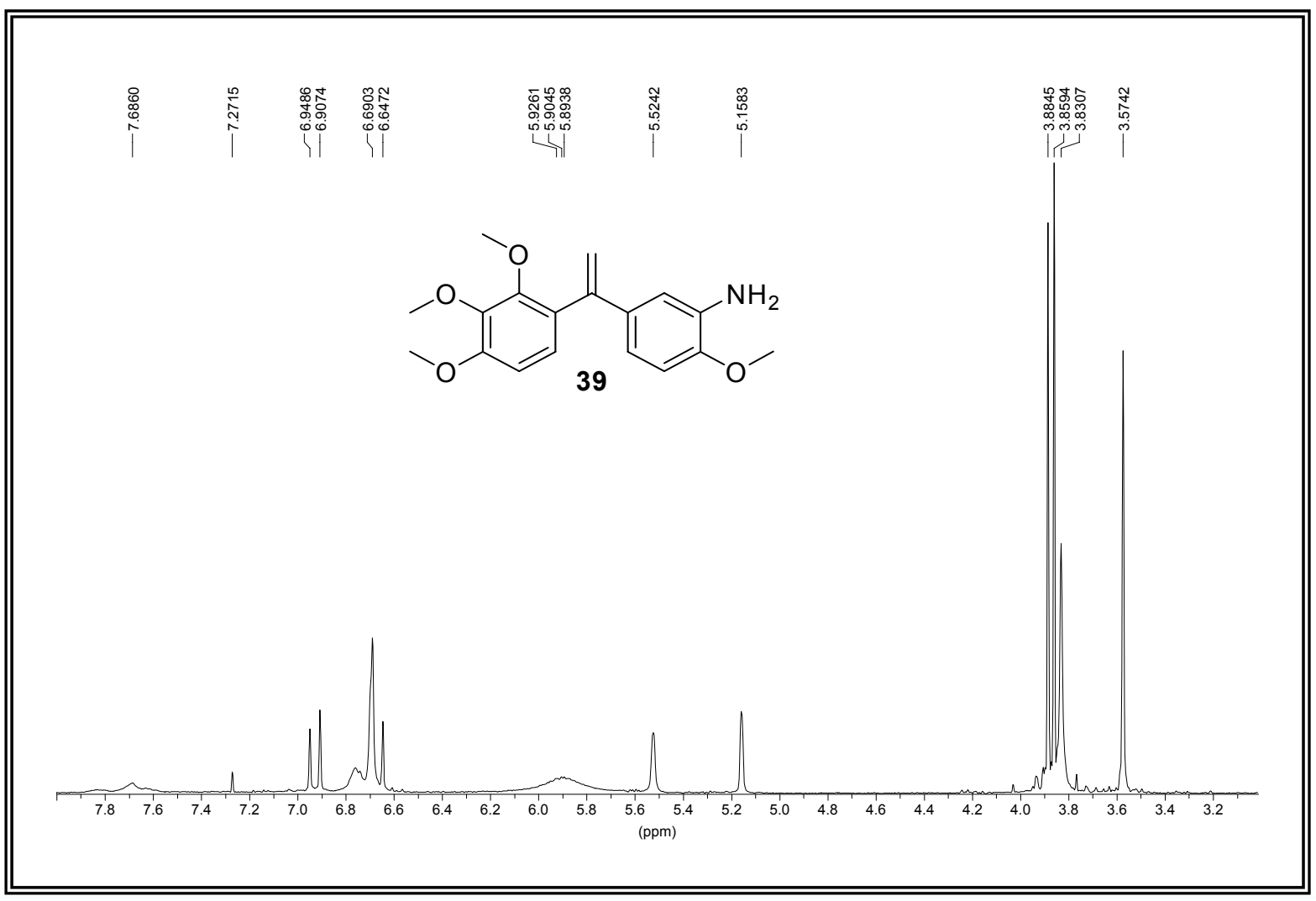

Figura XXIIa. Espectro de RMN ${ }^{1} \mathrm{H}$ del compuesto 39.

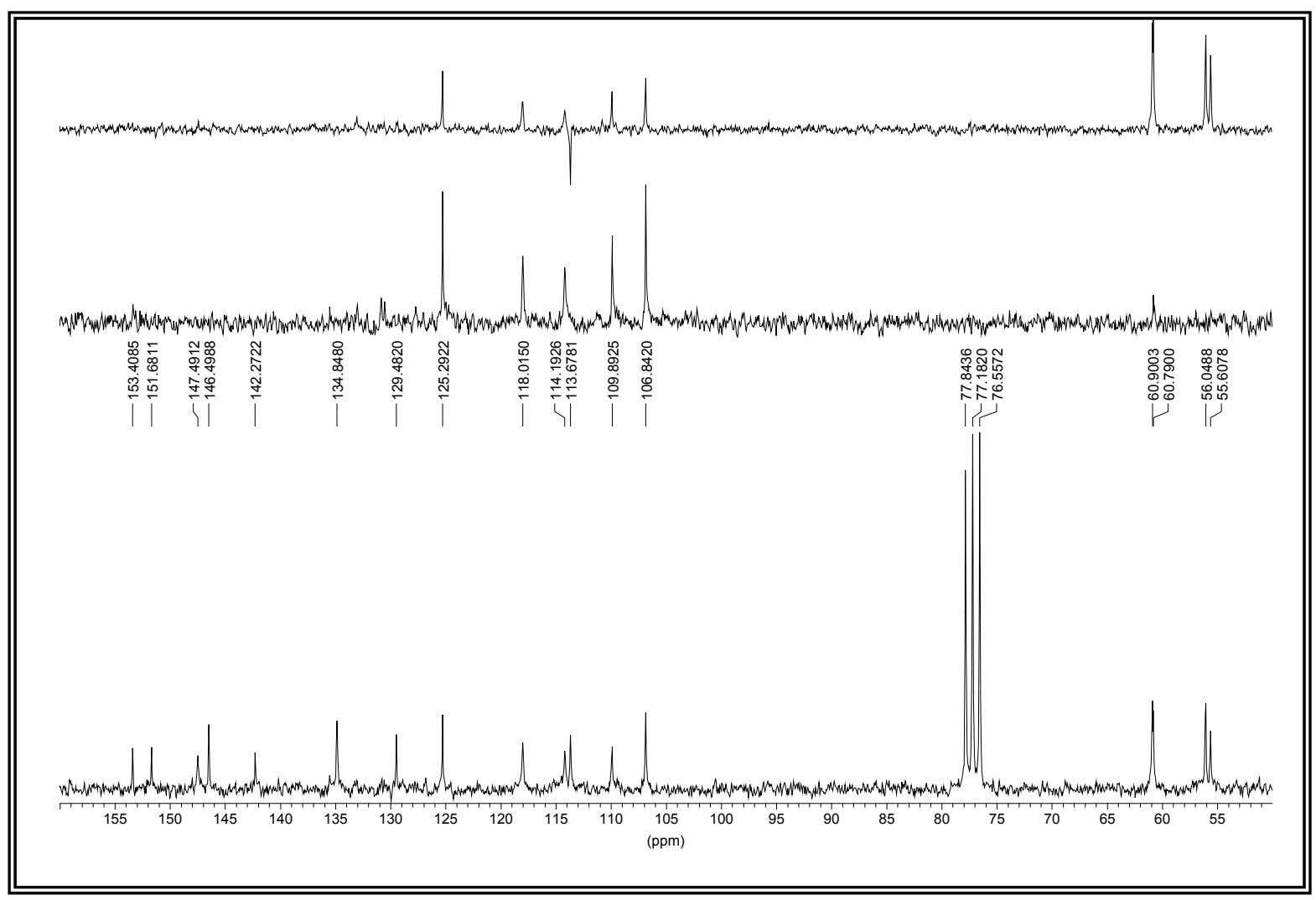

Figura XXIIb. Espectro de RMN ${ }^{13} \mathrm{C}$ del compuesto 39. 


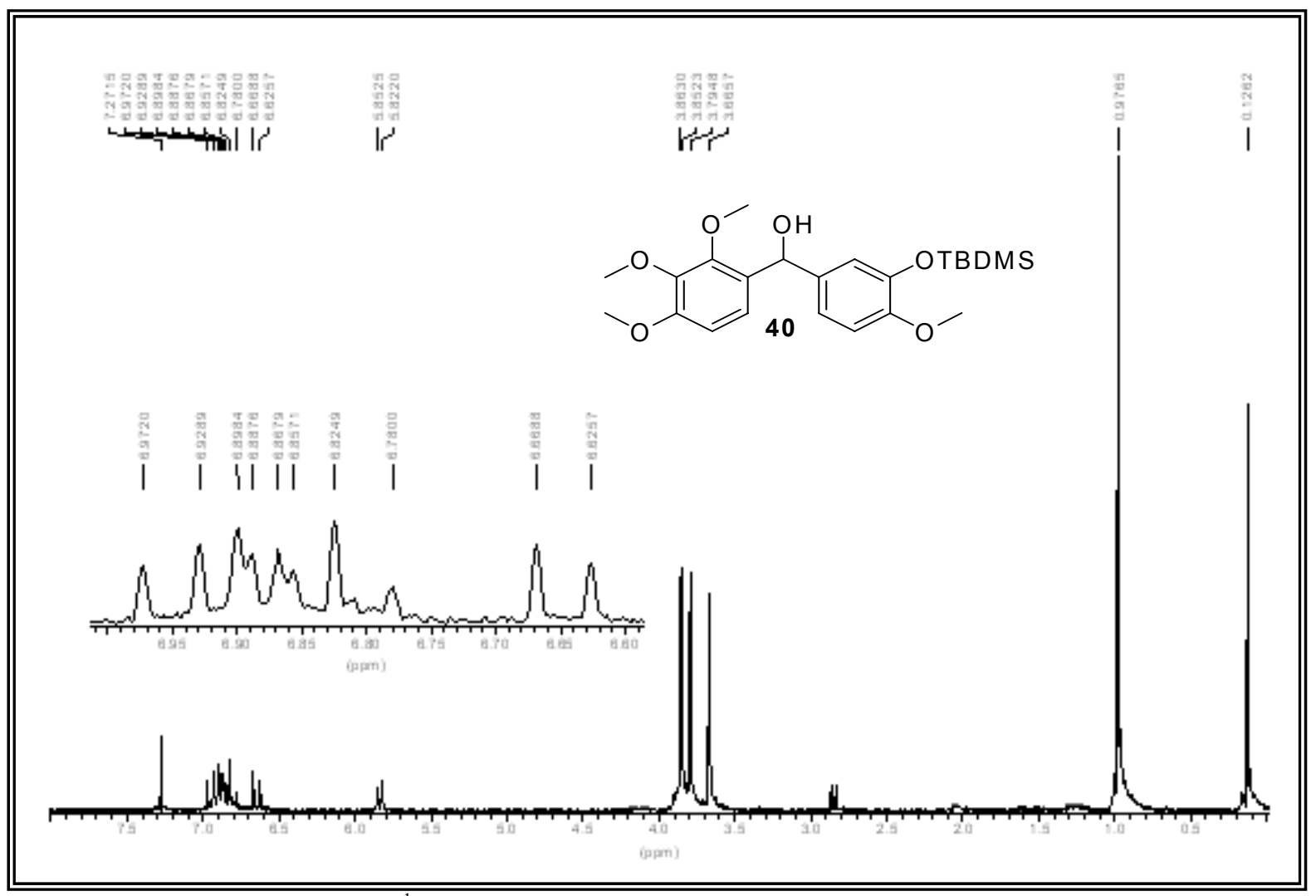

Figura XXIIIa. Espectro de RMN ${ }^{1} \mathrm{H}$ del compuesto 40.

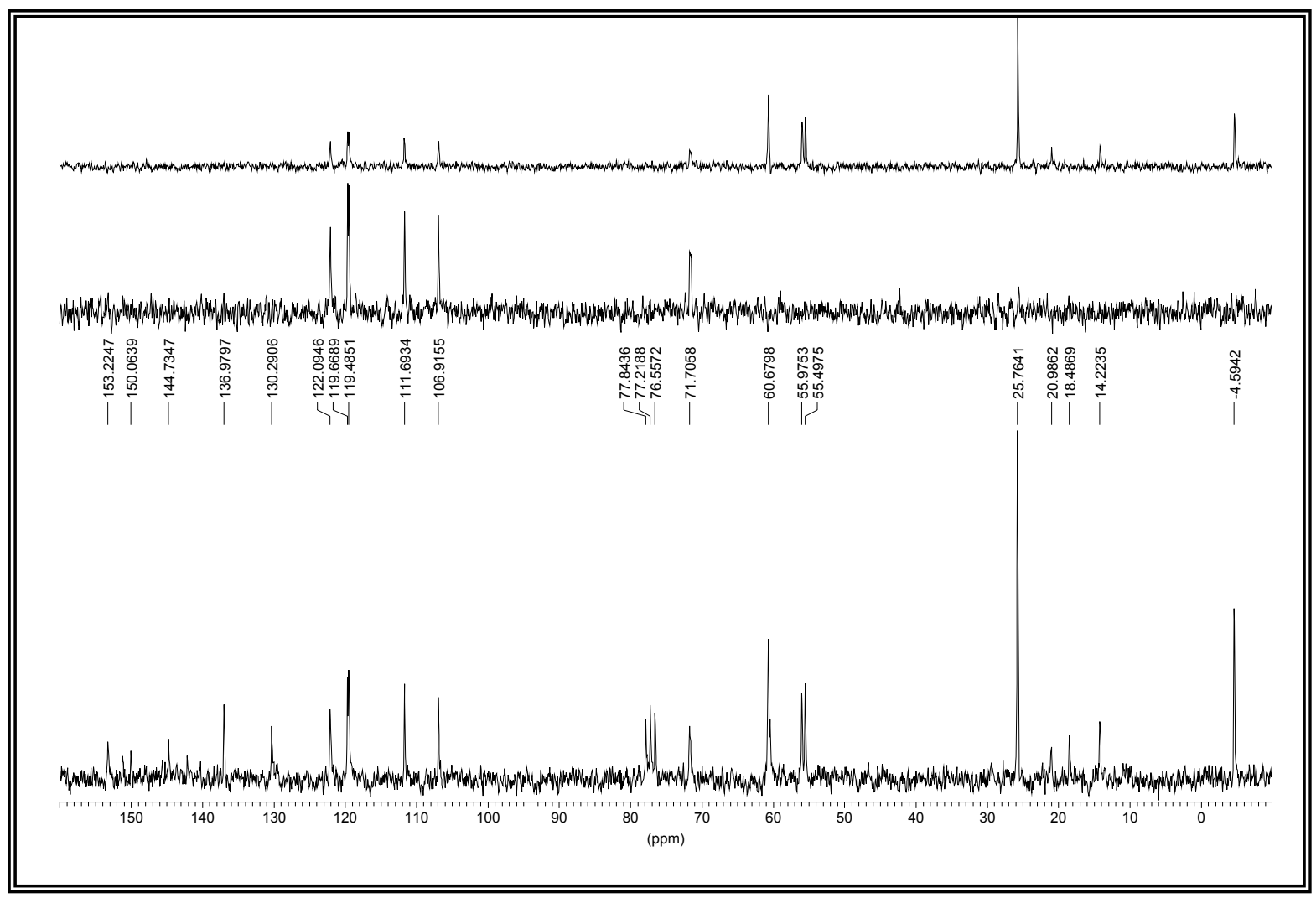

Figura XXIIIb. Espectro de RMN ${ }^{13} \mathrm{C}$ del compuesto 40. 


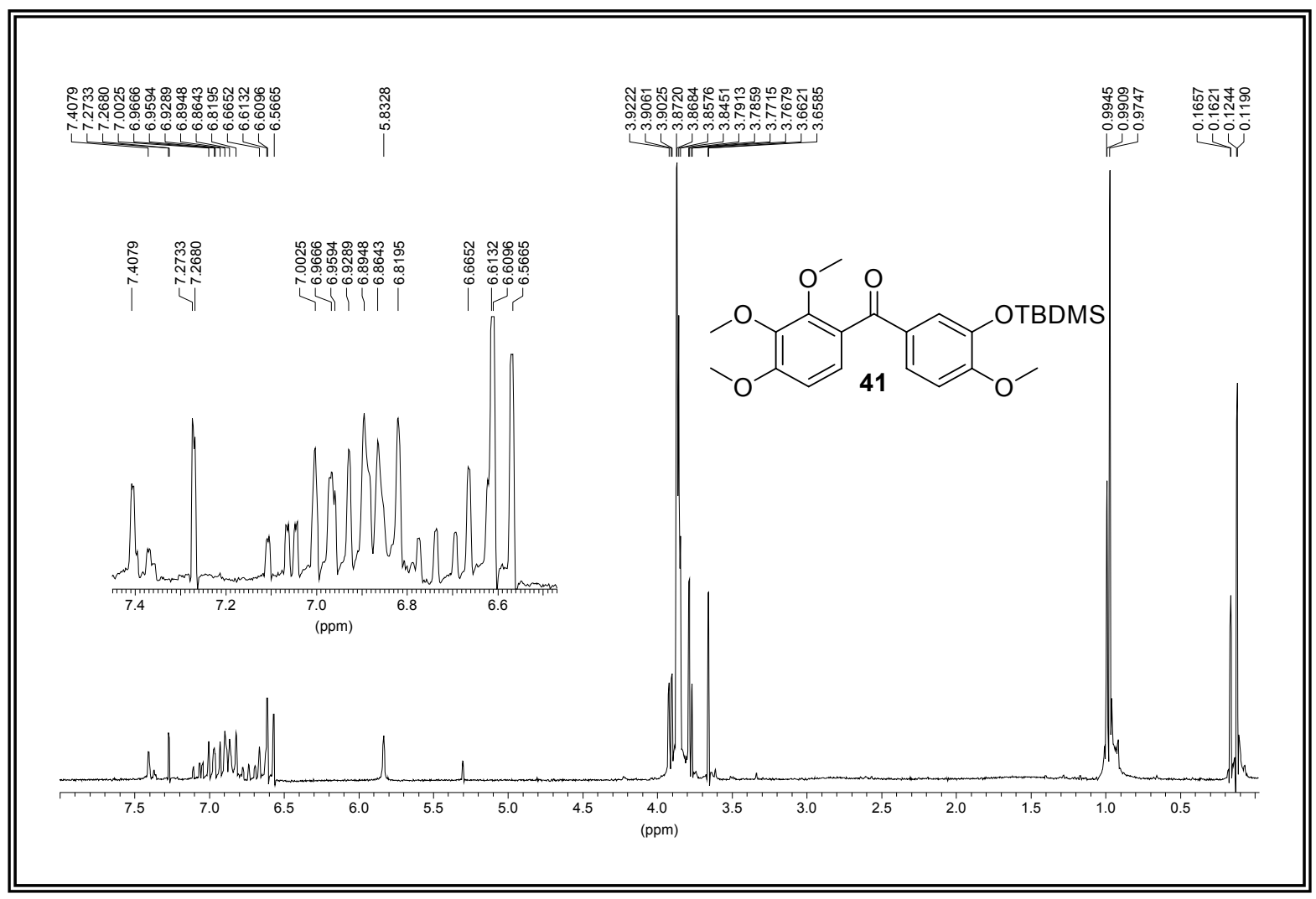

Figura XXIVa. Espectro de RMN ${ }^{1} \mathrm{H}$ del crudo de la reacción para la obtención del compuesto $4 \mathbf{4 1}$ 


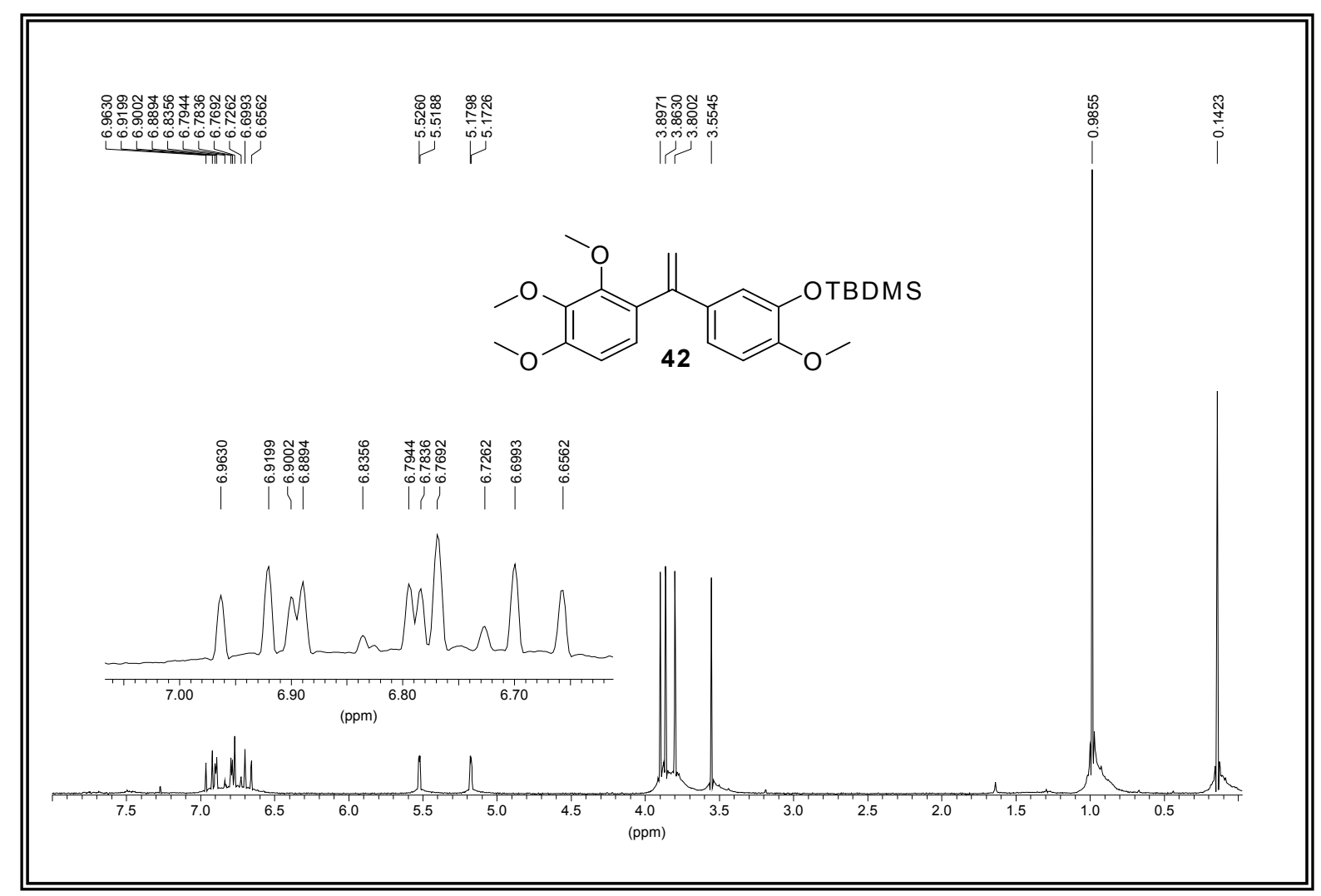

Figura XXVa. Espectro de RMN ${ }^{1} \mathrm{H}$ del compuesto 42.

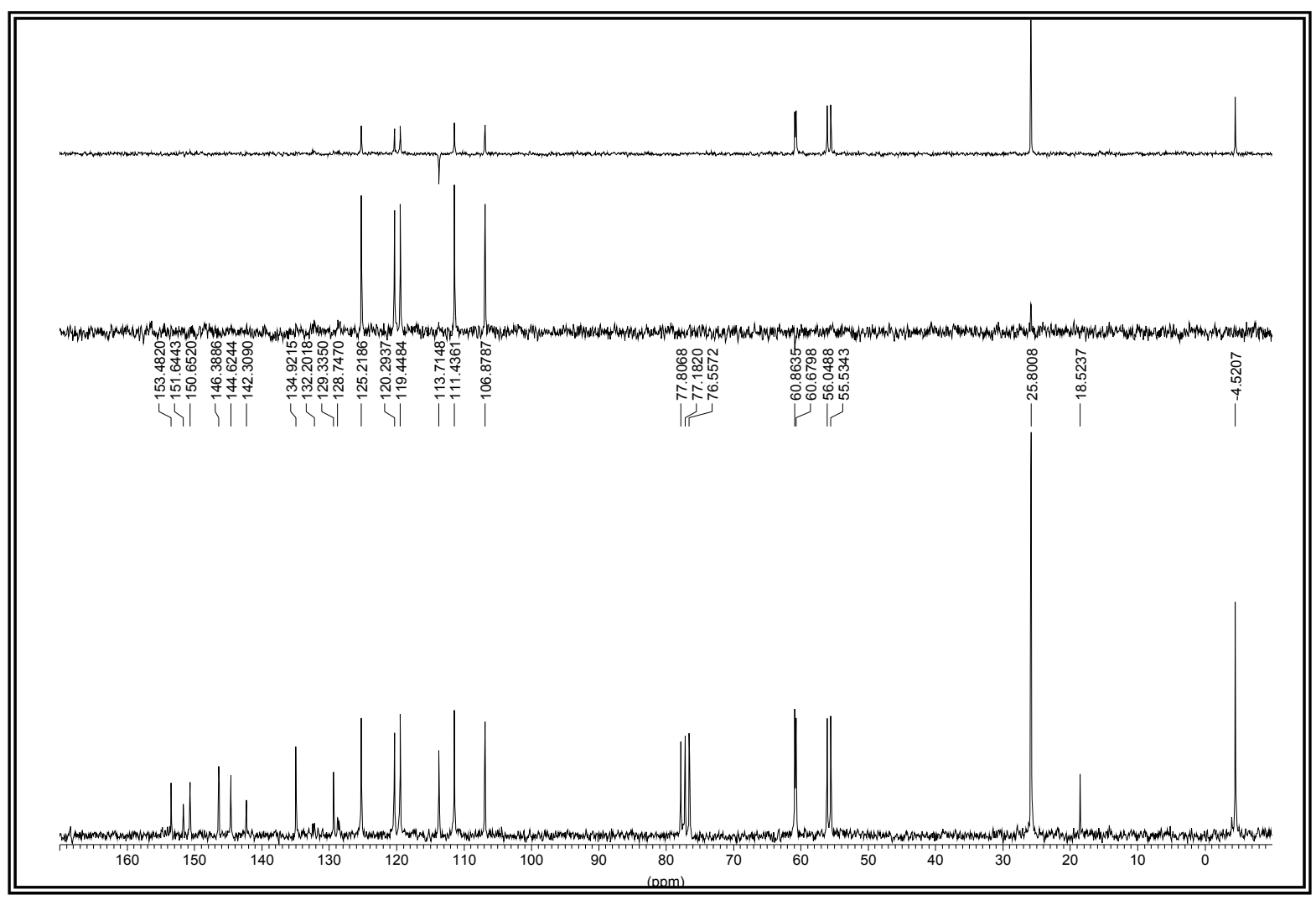

Figura XXVb. Espectro de RMN ${ }^{13} \mathrm{C}$ del compuesto 42. 


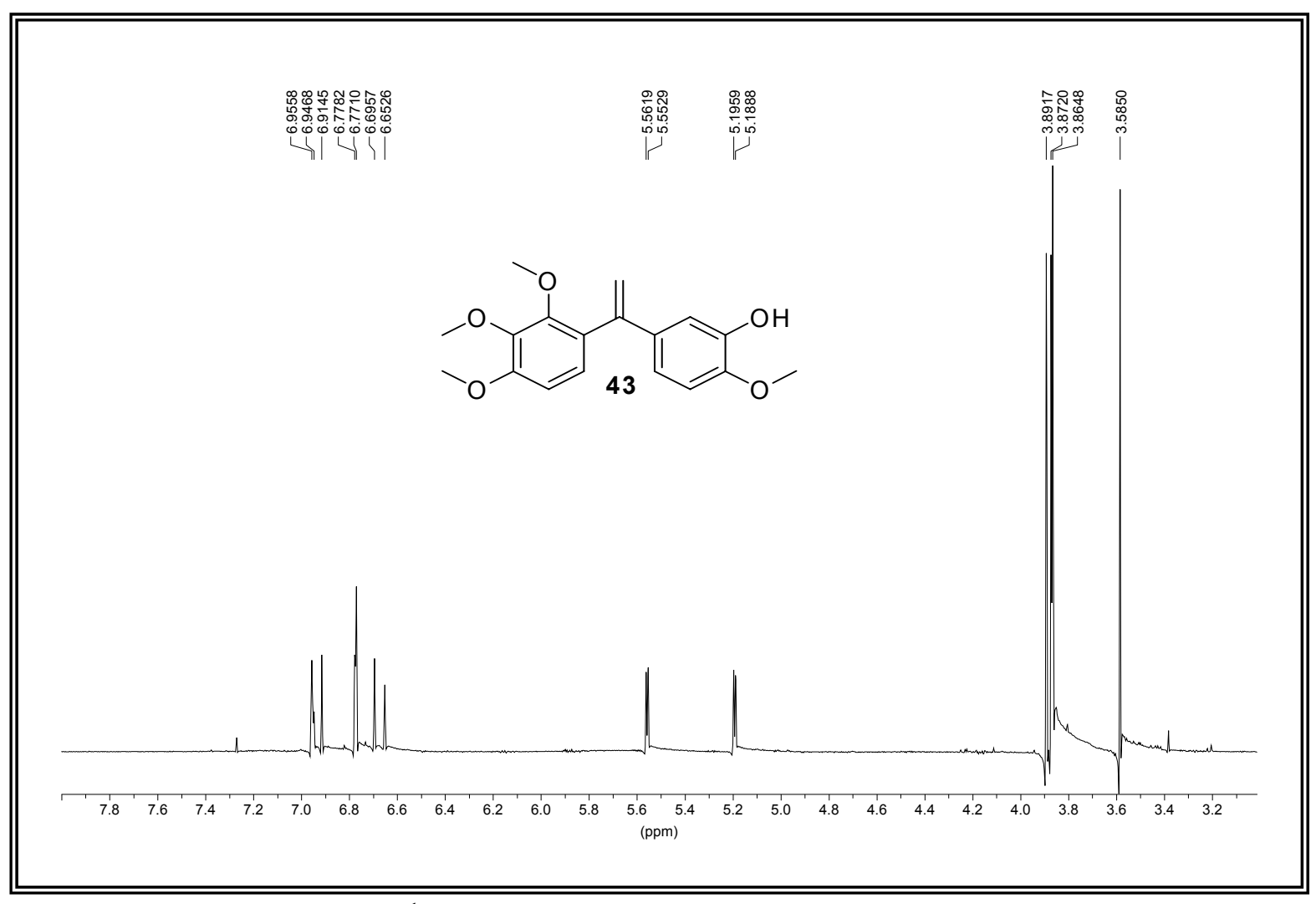

Figura XXVIa. Espectro de $\mathrm{RMN}^{1} \mathrm{H}$ del compuesto 43.

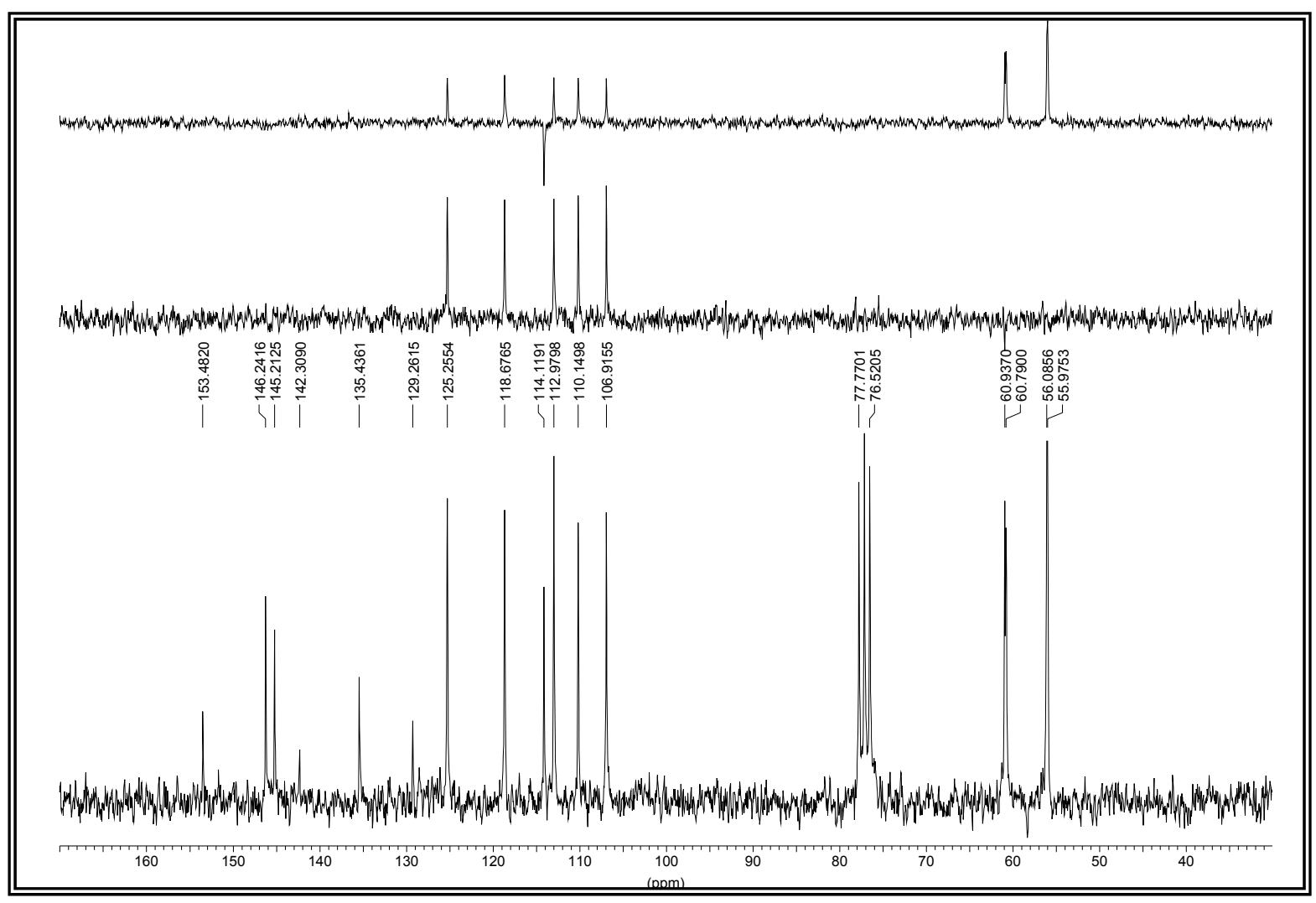

Figura XXVIb. Espectro de RMN ${ }^{13} \mathrm{C}$ del compuesto 43. 


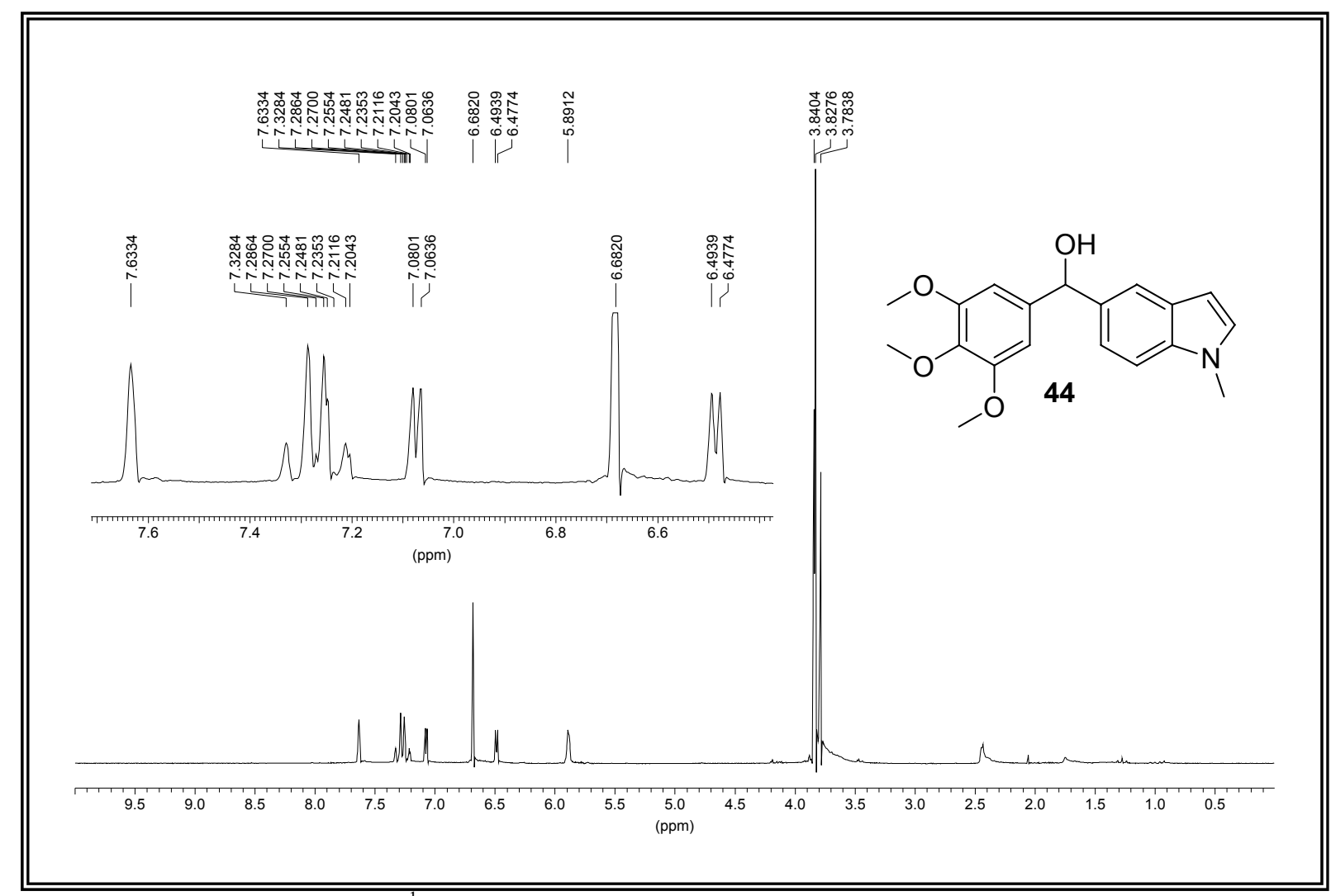

Figura XXVIIa. Espectro de RMN ${ }^{1} \mathrm{H}$ del compuesto 44.

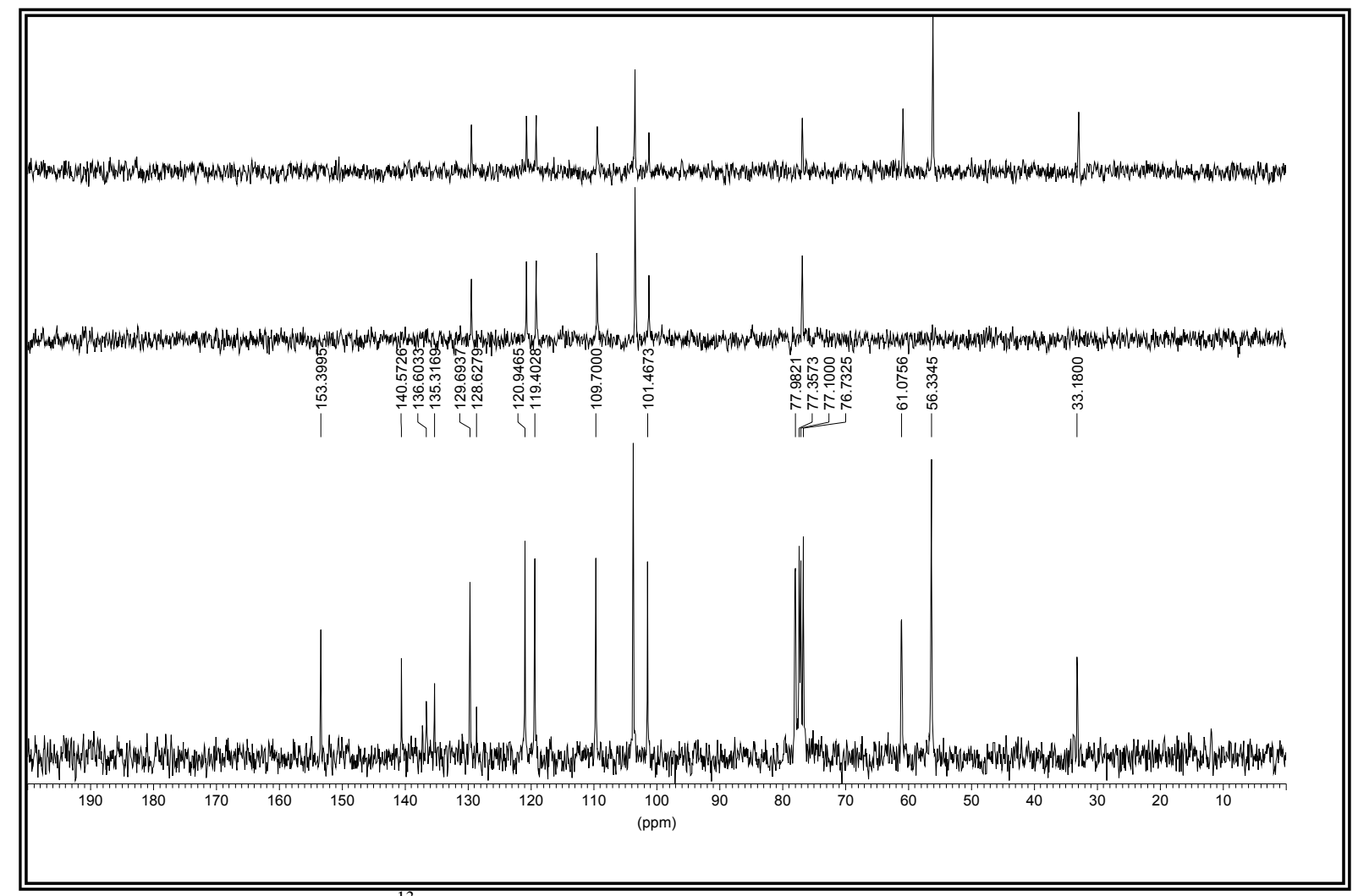

Figura XVIIb. Espectro de RMN ${ }^{13} \mathrm{C}$ del compuesto 44. 


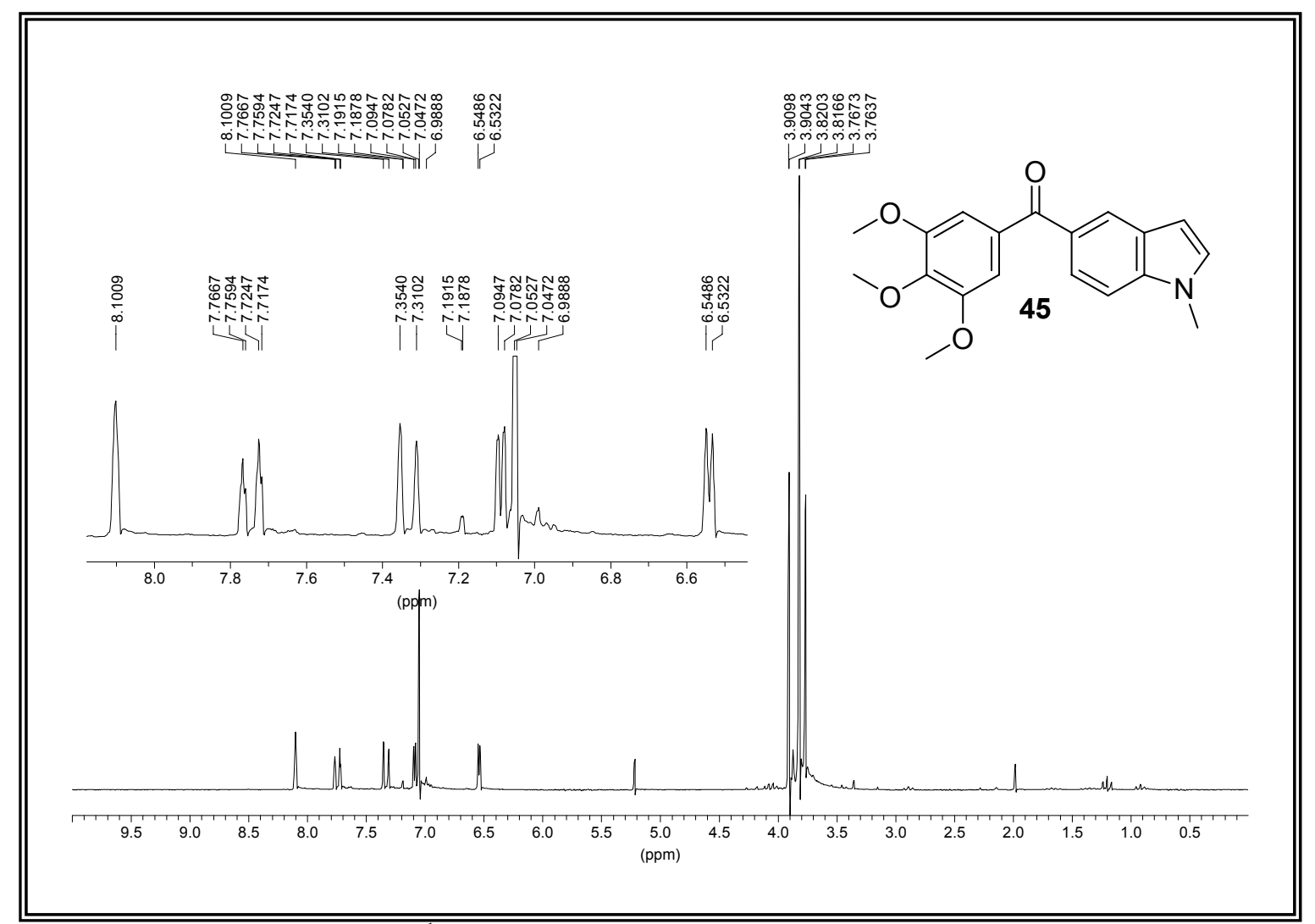

Figura XXVIIIa. Espectro de RMN ${ }^{1} \mathrm{H}$ del compuesto 45.

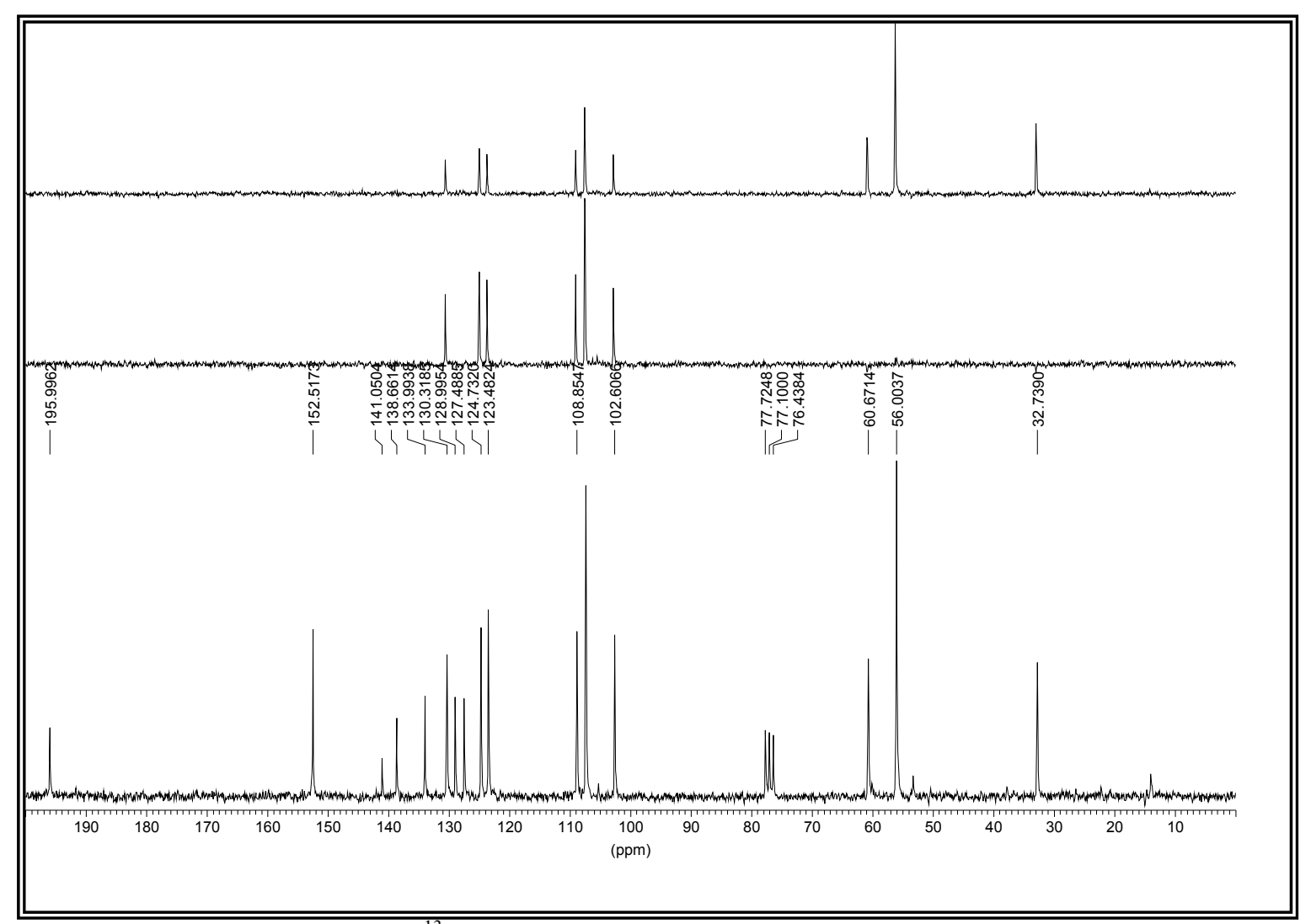

Figura XXVIIIb. Espectro de RMN ${ }^{13} \mathrm{C}$ del compuesto 45. 


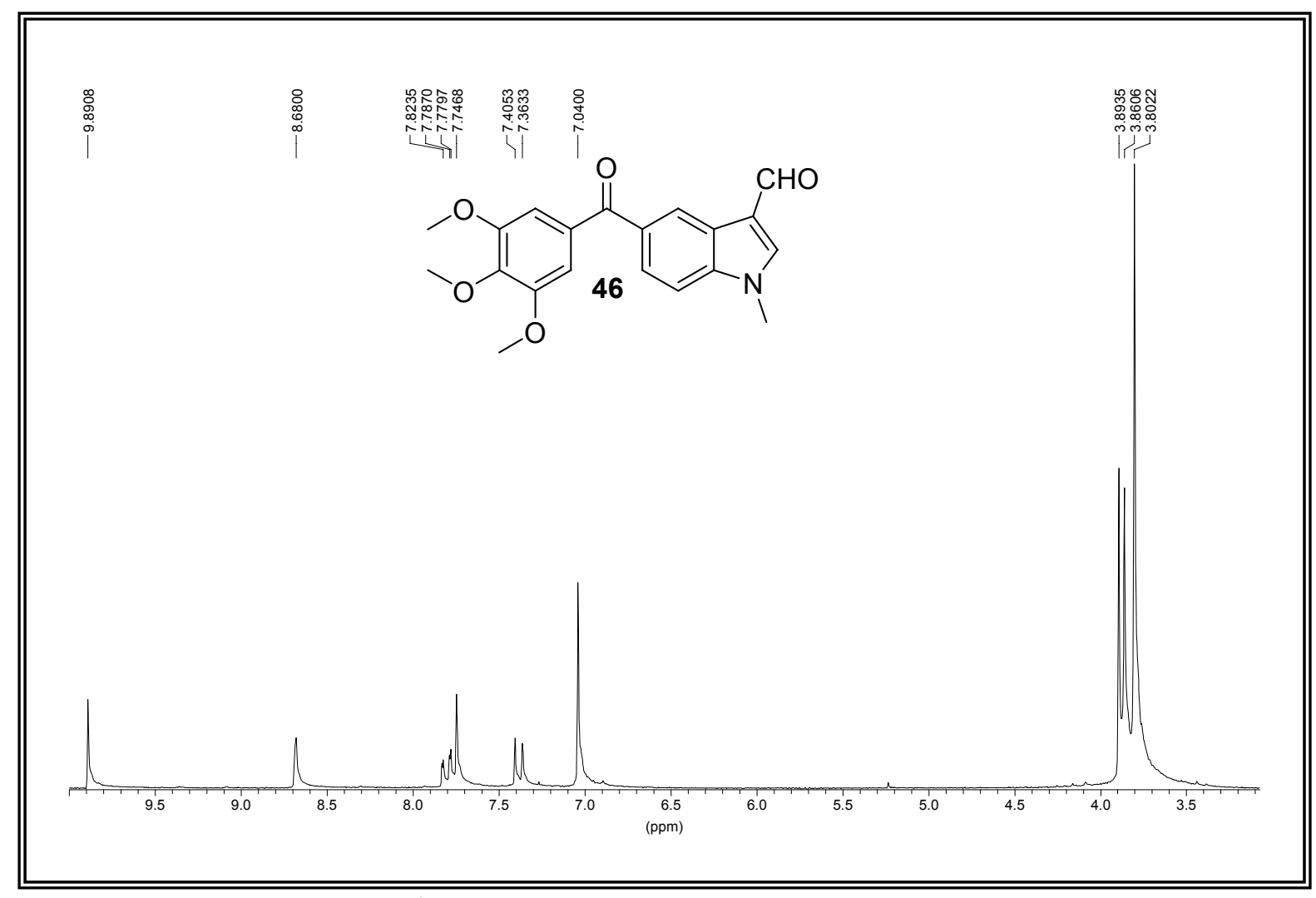

Figura XXIXa. Espectro de RMN ${ }^{1} \mathrm{H}$ del compuesto 46.

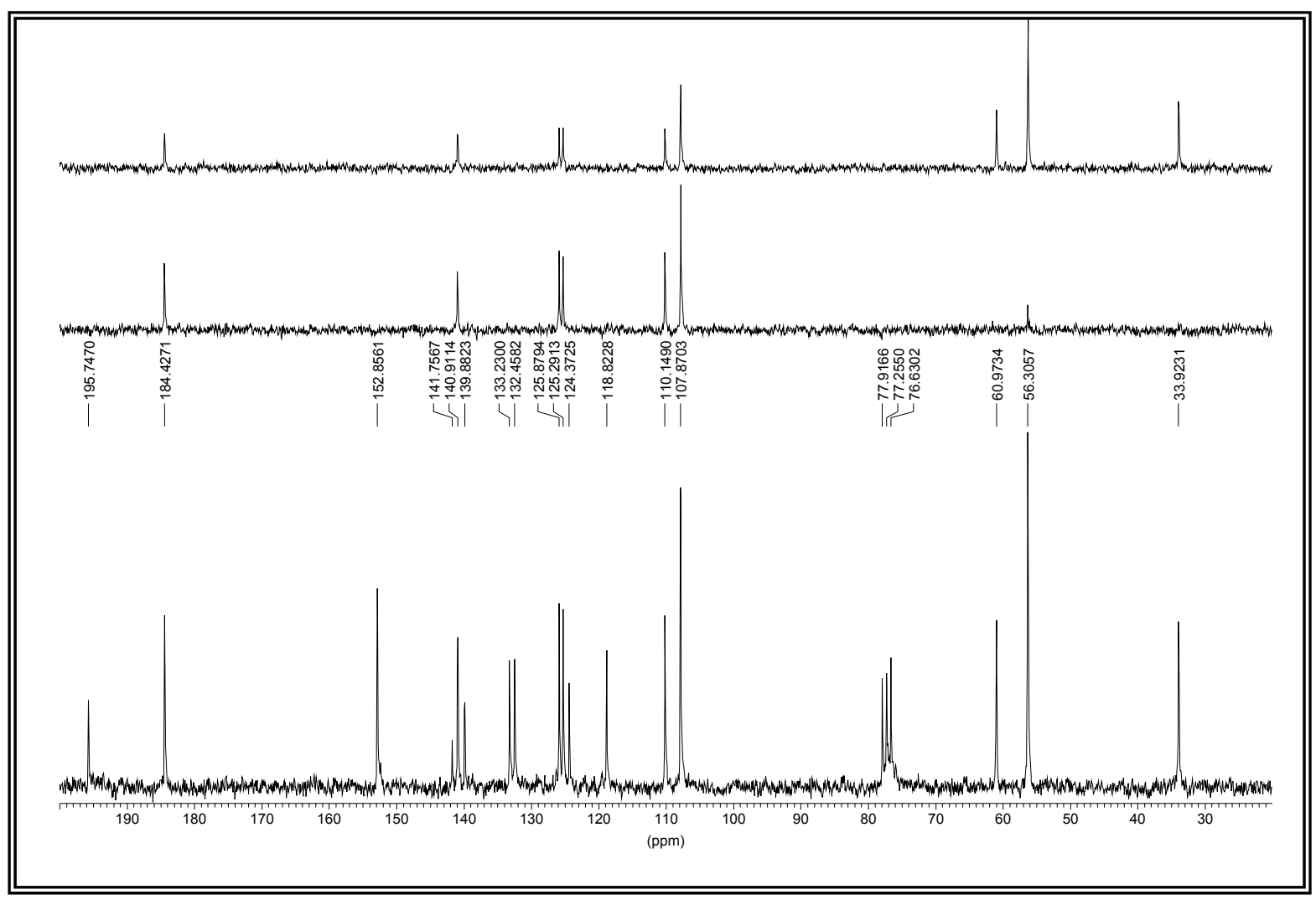

Figura XXIXb. Espectro de RMN ${ }^{13} \mathrm{C}$ del compuesto 46. 


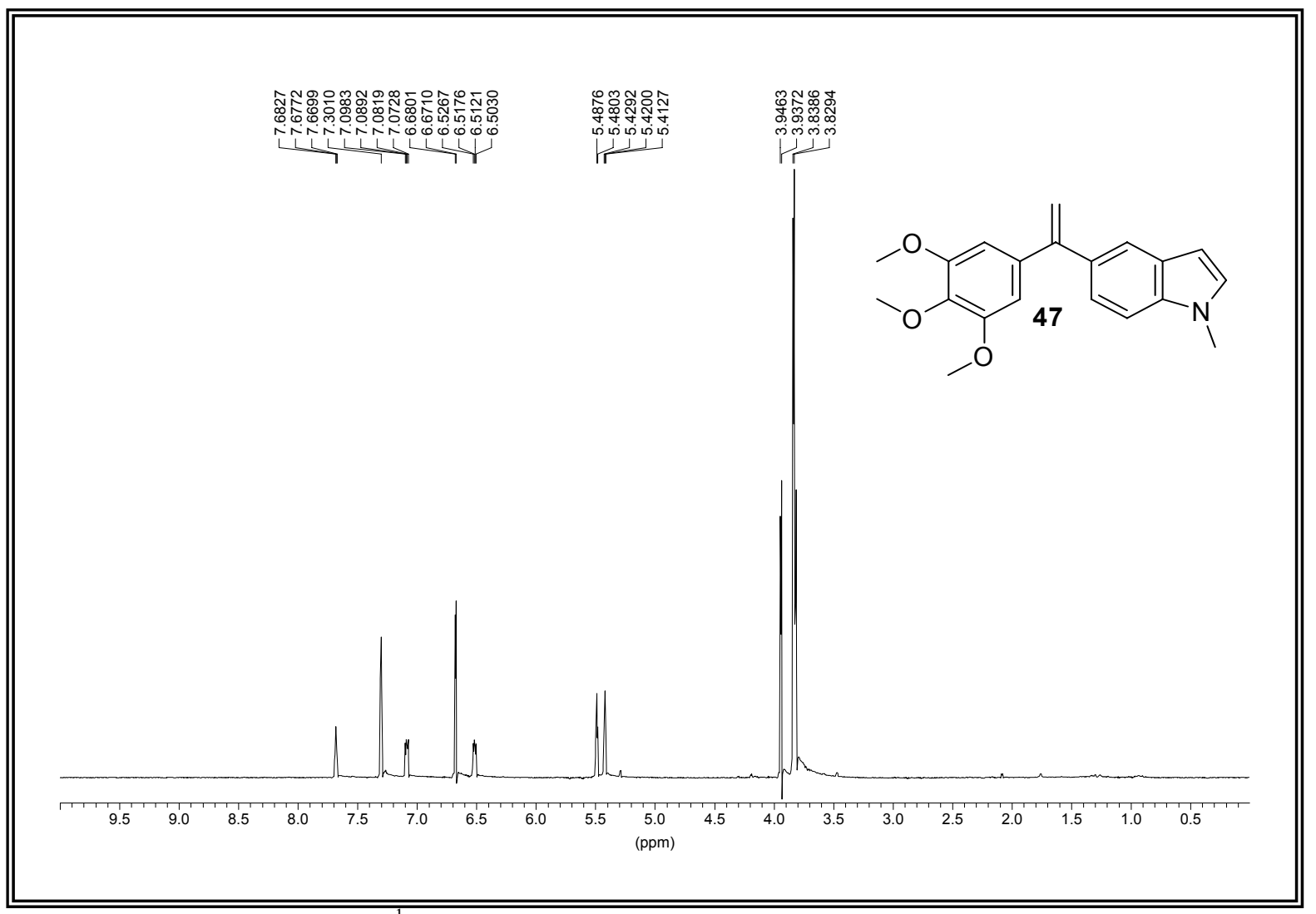

Figura XXXa. Espectro de RMN ${ }^{1} \mathrm{H}$ del compuesto 47.

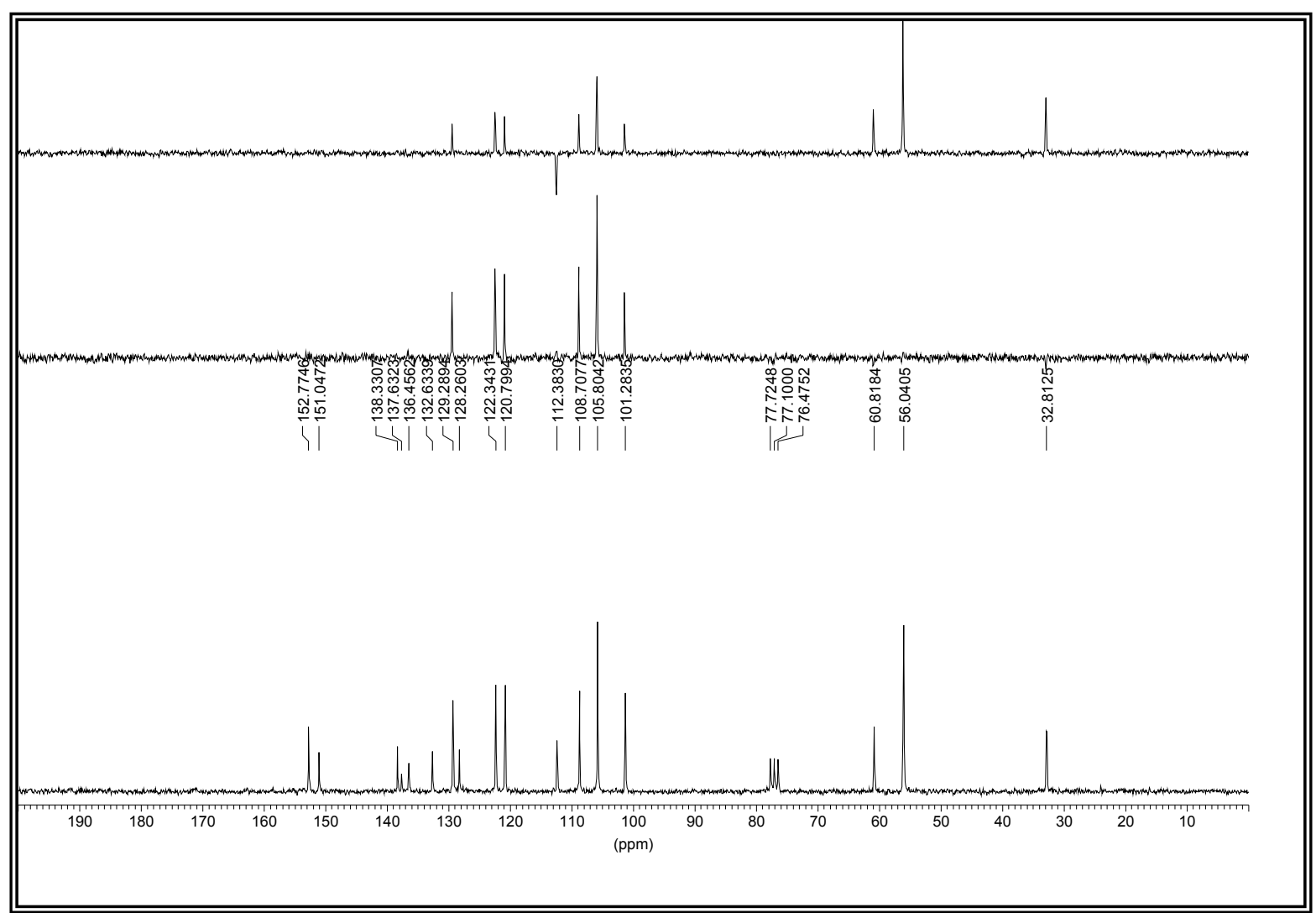

Figura XXXb. Espectro de RMN ${ }^{13} \mathrm{C}$ del compuesto 47. 


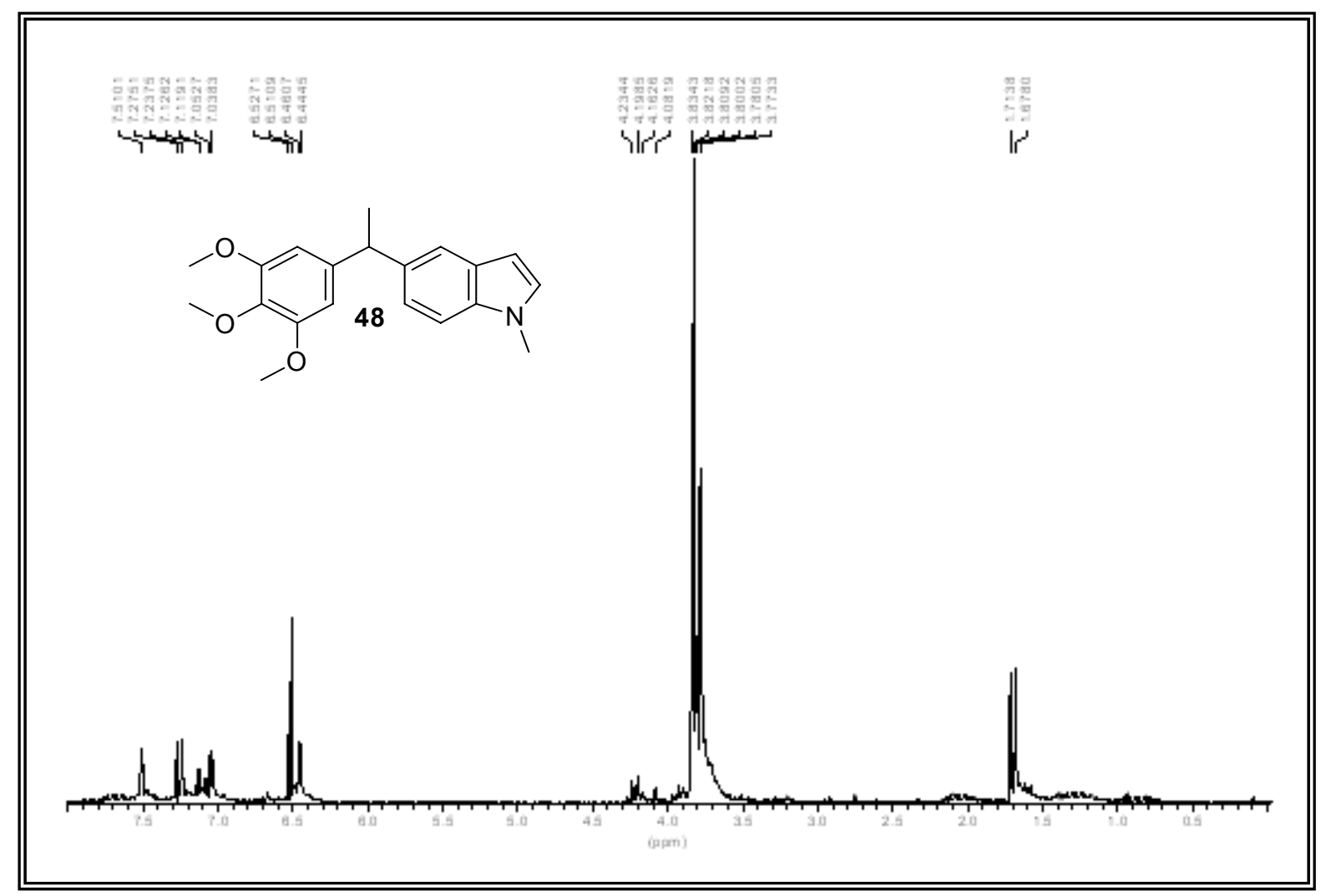

Figura XXXIa. Espectro de RMN ${ }^{1} \mathrm{H}$ del compuesto 48.

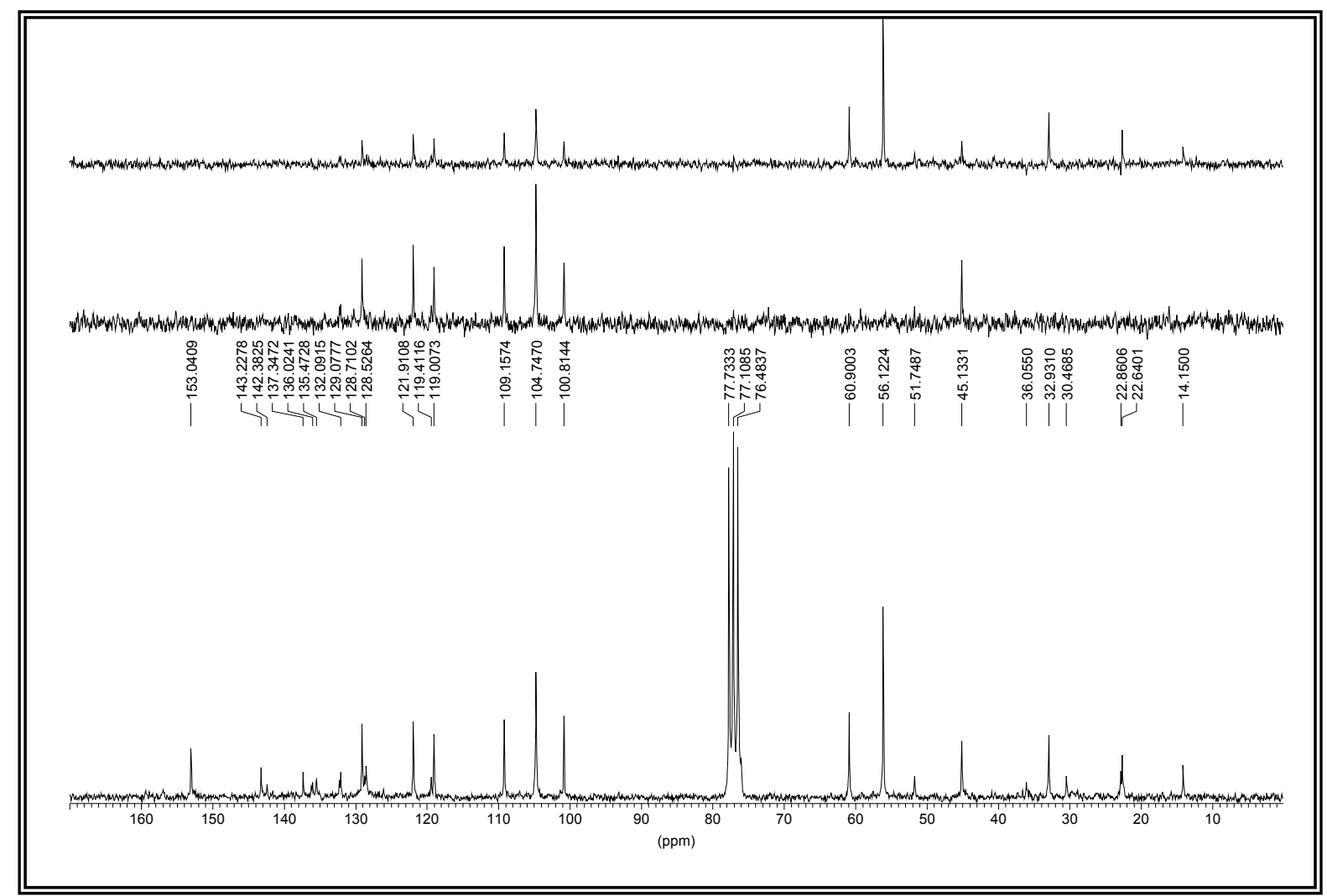

Figura XXXIb. Espectro de RMN ${ }^{13} \mathrm{C}$ del compuesto 48. 


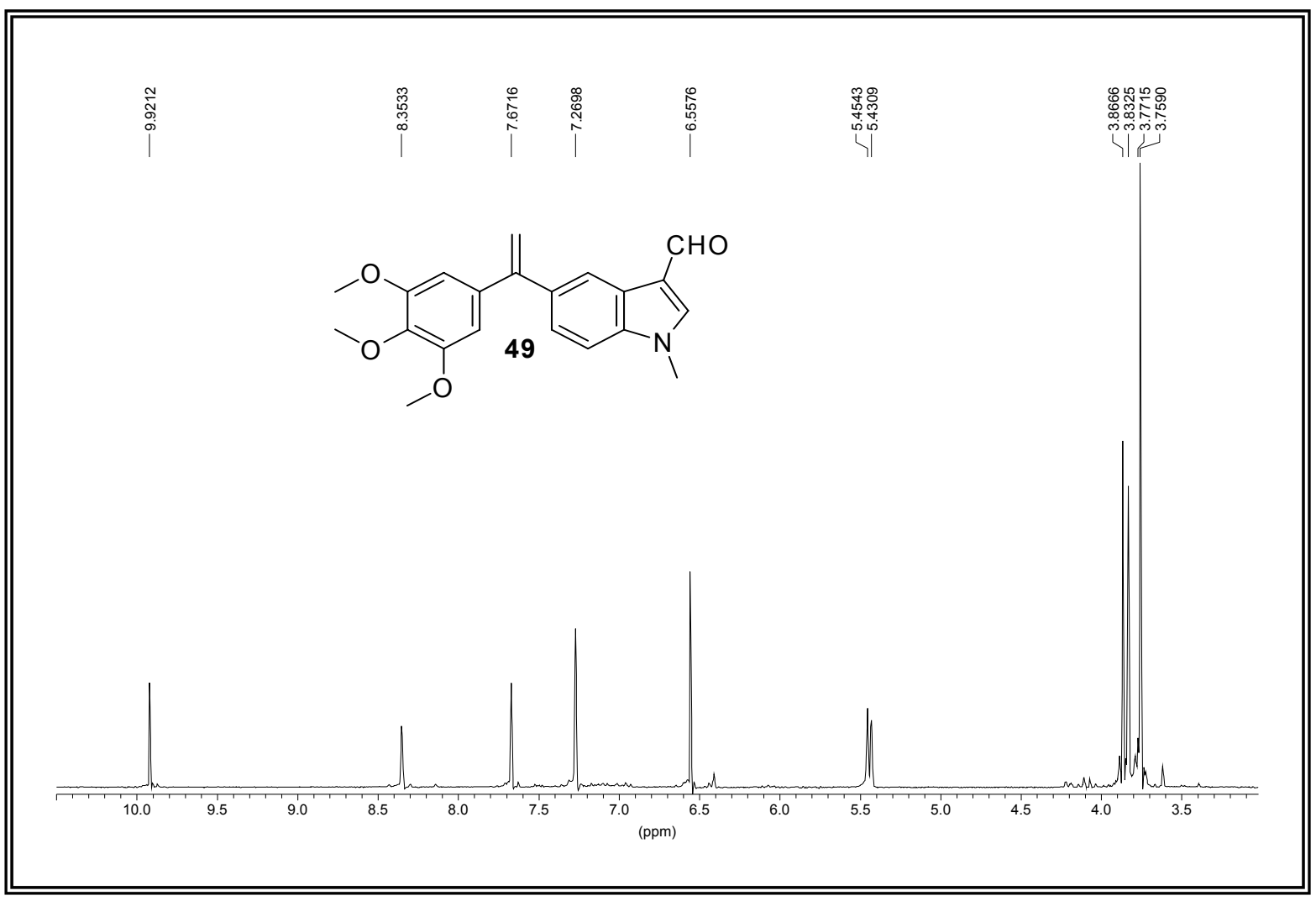

Figura XXXIIa. Espectro de RMN ${ }^{1} \mathrm{H}$ del compuesto 49.

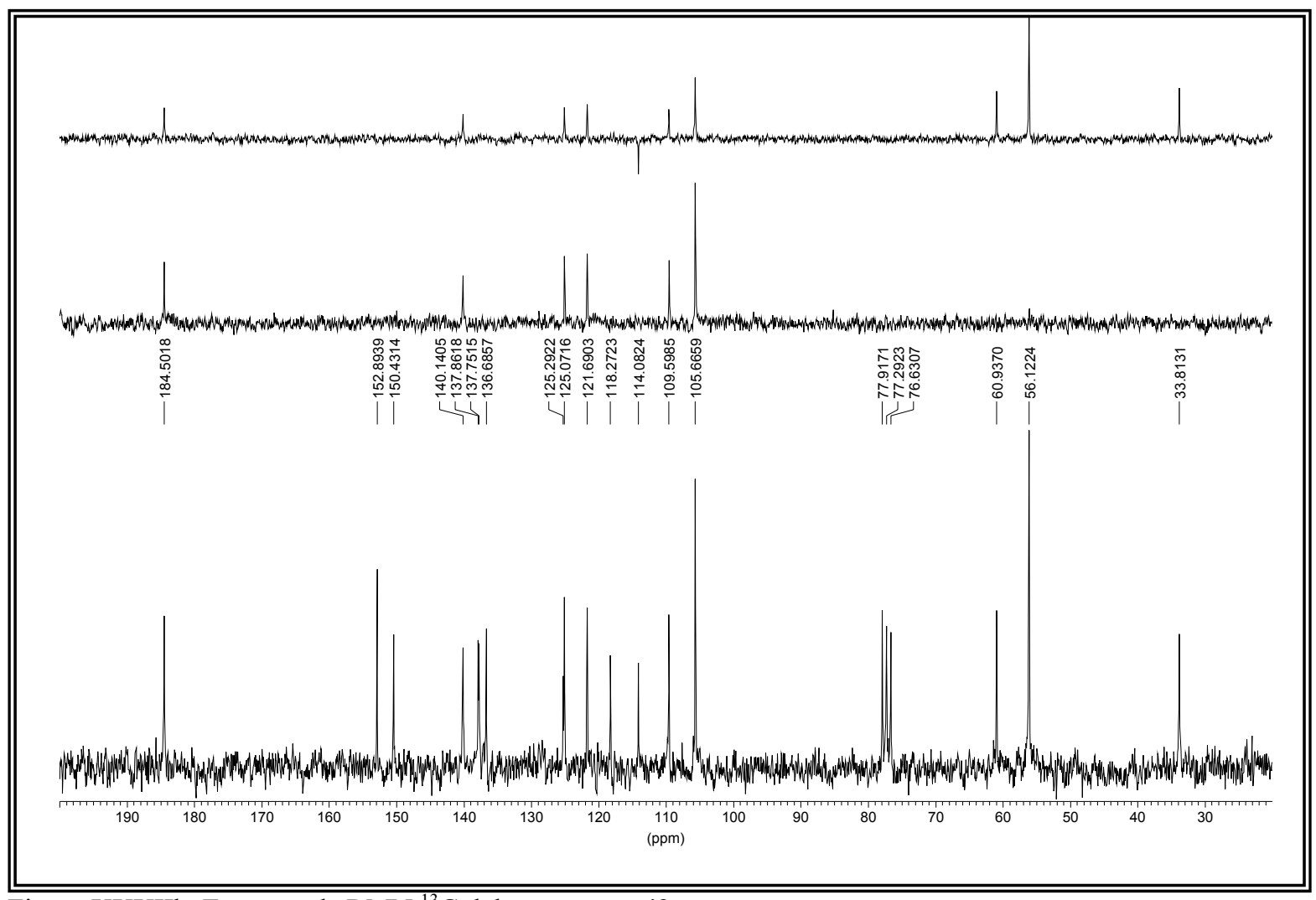

Figura XXXIIb. Espectro de RMN ${ }^{13} \mathrm{C}$ del compuesto 49. 


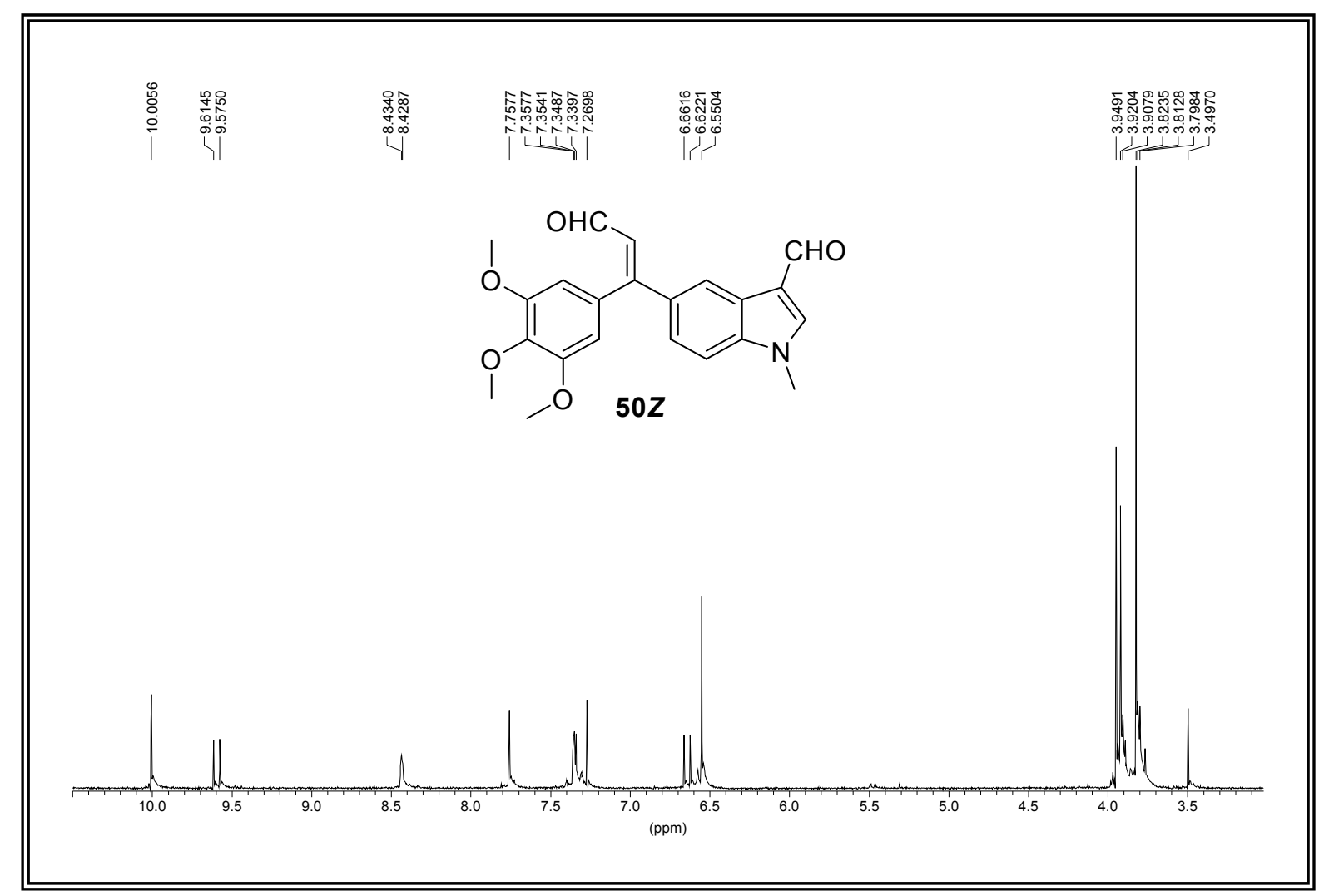

Figura XXXIIIa. Espectro de RMN ${ }^{1} \mathrm{H}$ del compuesto $\mathbf{5 0 Z}$.

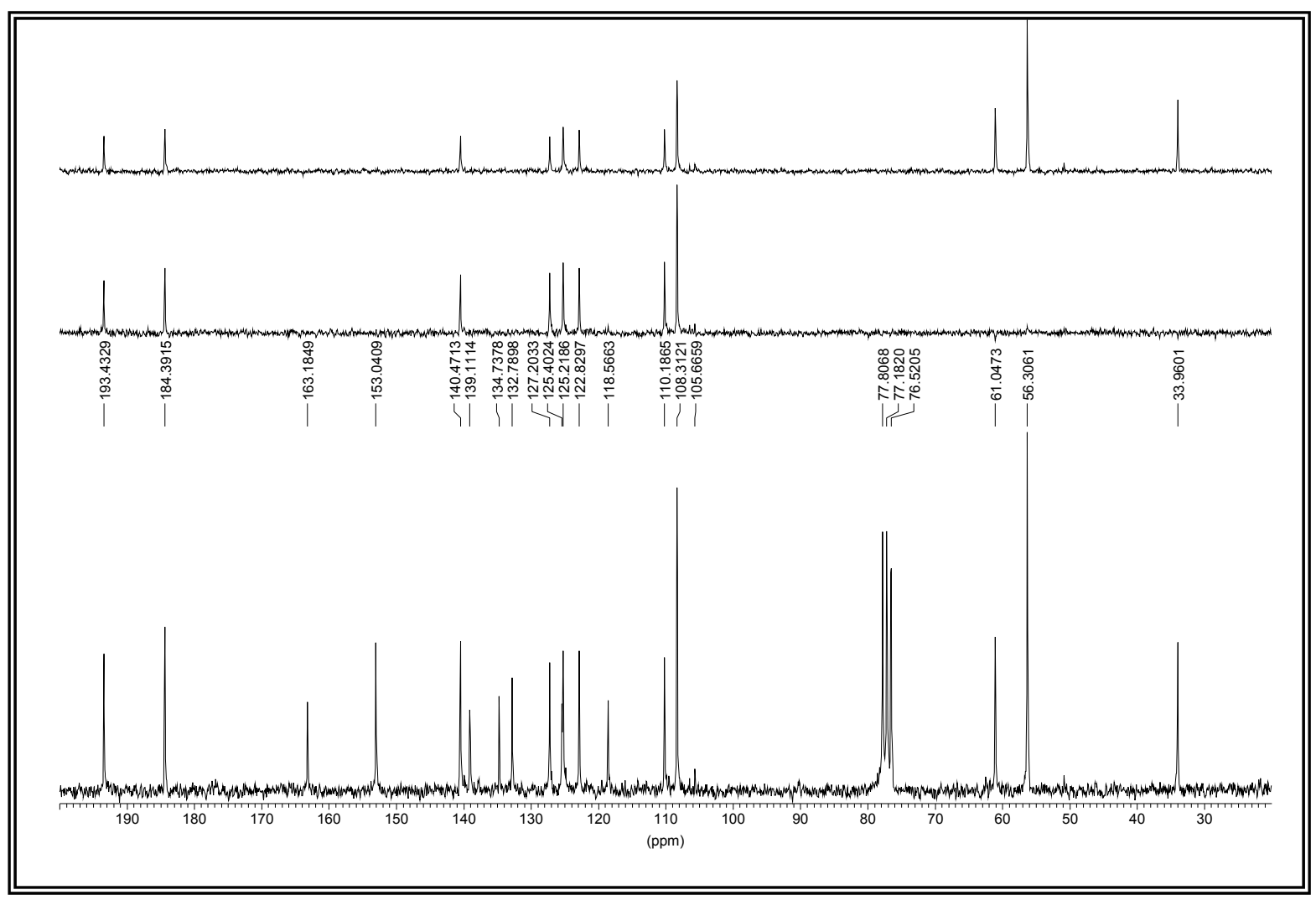

Figura XXXIIIb. Espectro de RMN ${ }^{13} \mathrm{C}$ del compuesto $\mathbf{5 0 Z}$. 


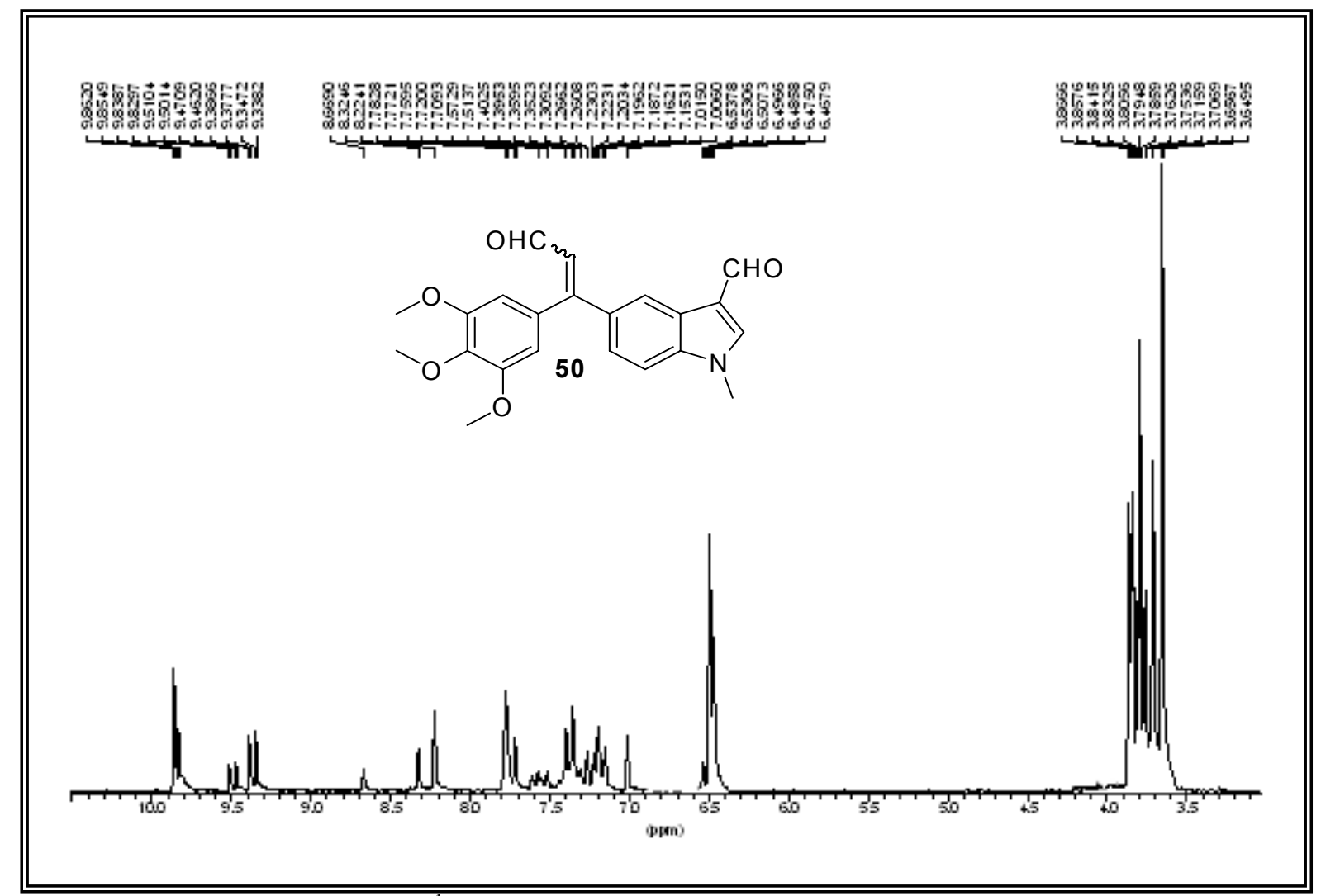

Figura XXXIIIc. Espectro de RMN ${ }^{1} \mathrm{H}$ de los compuestos $\mathbf{5 0 Z}$ y $\mathbf{5 0 E}$.

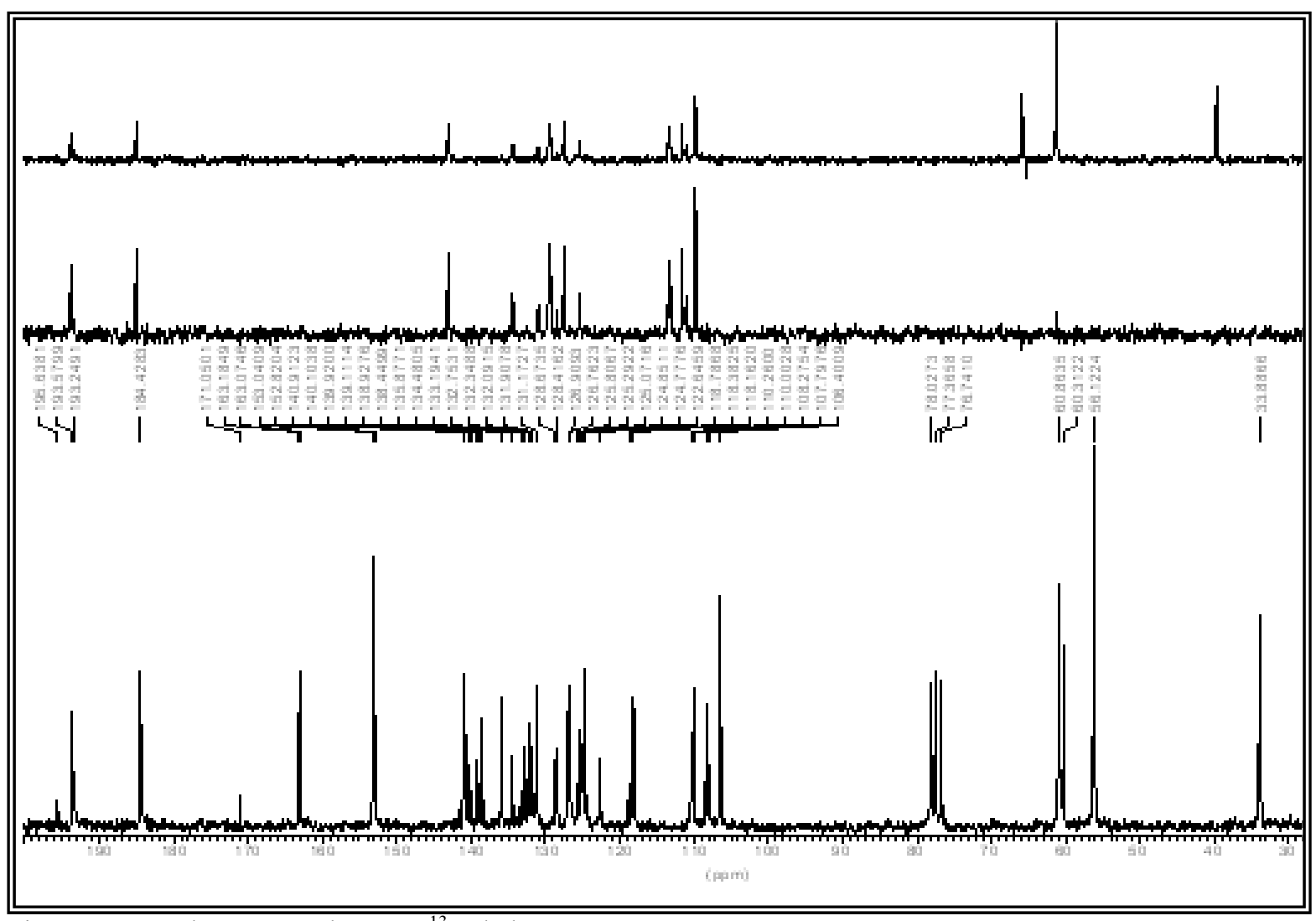

Figura XXXIIId. Espectro de RMN ${ }^{13} \mathrm{C}$ de los compuestos $50 \boldsymbol{Z}$ y $\mathbf{5 0 E}$. 


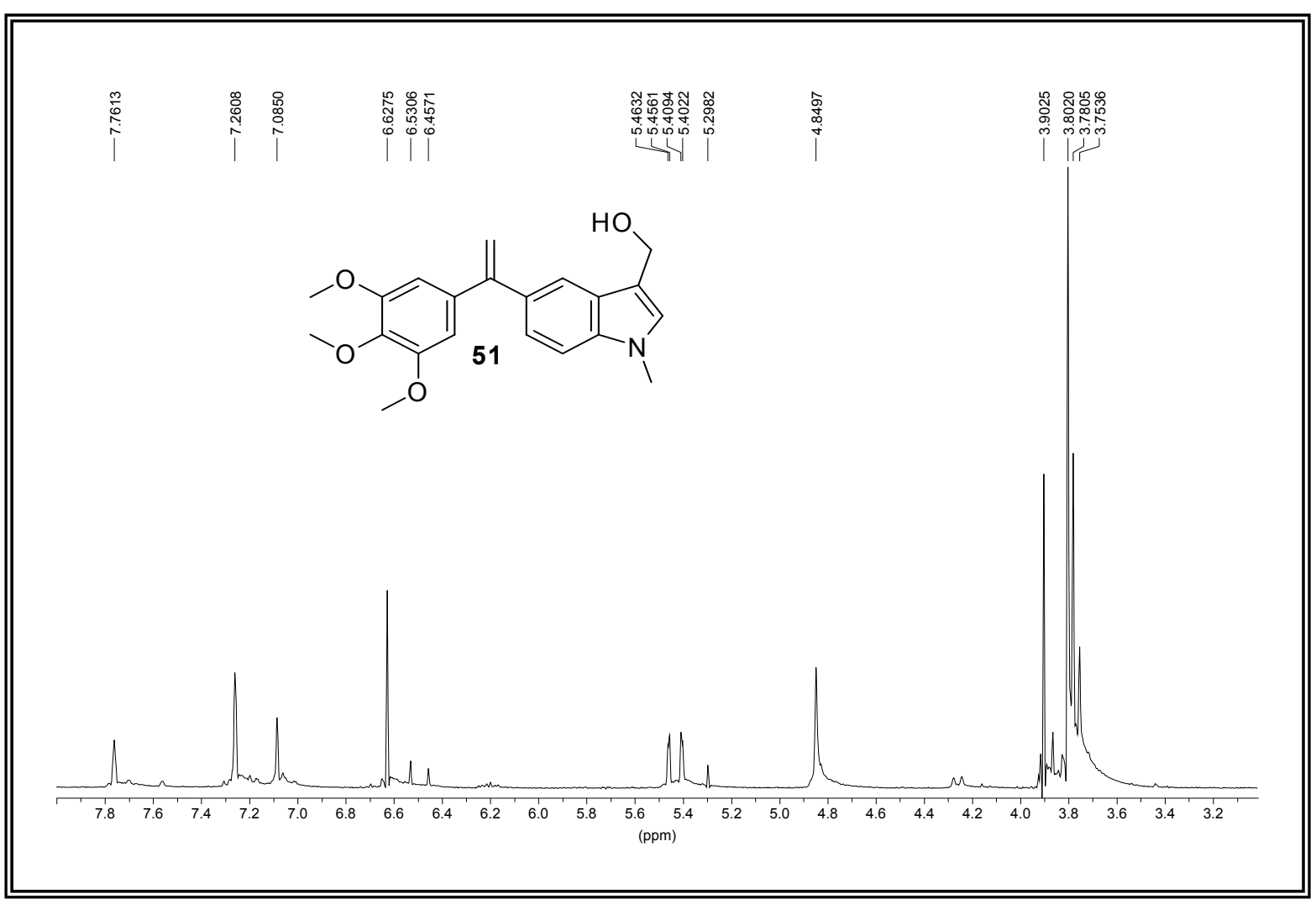

Figura XXXIVa. Espectro de RMN ${ }^{1} \mathrm{H}$ del compuesto 51.

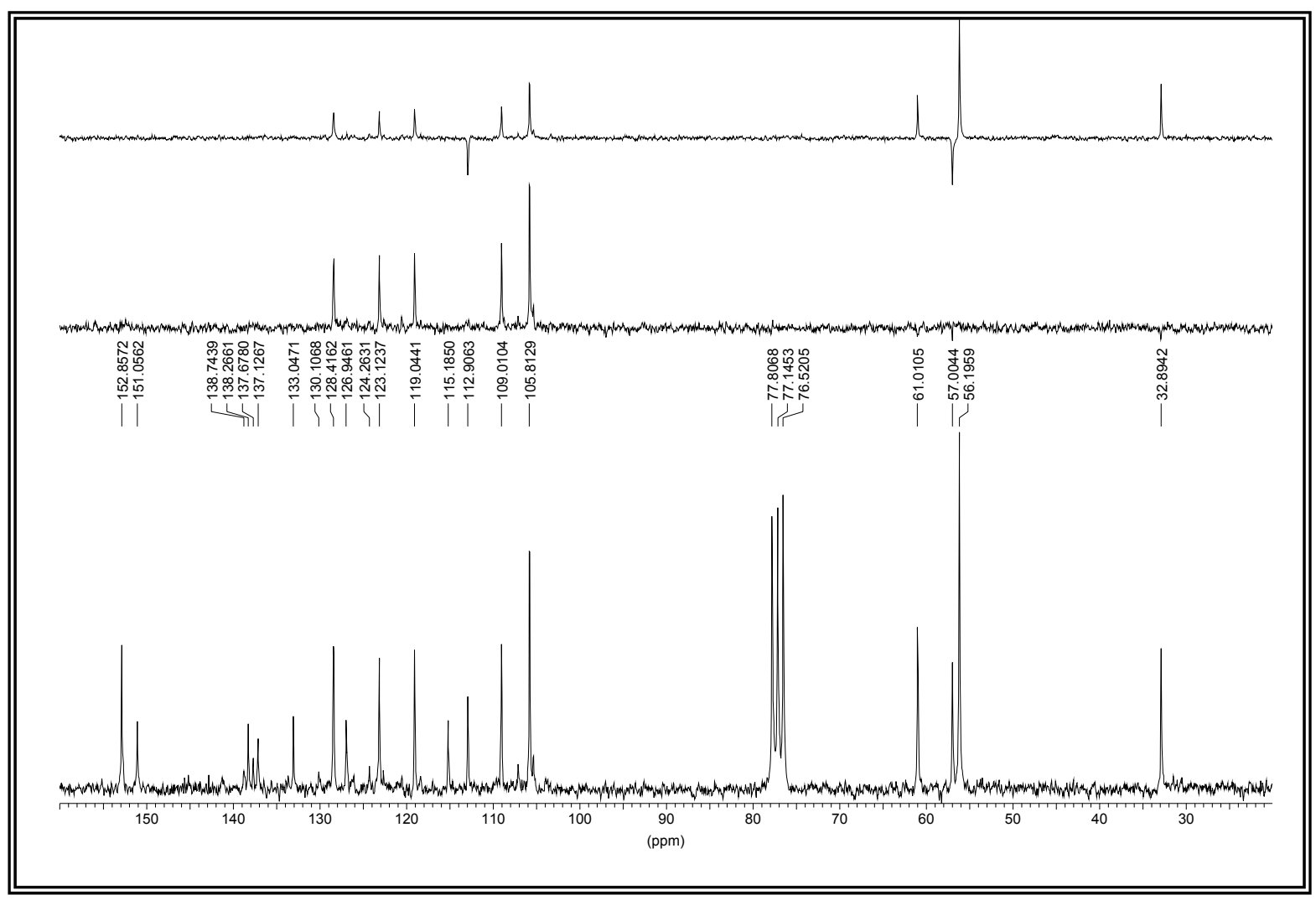

Figura XXXIVb. Espectro de RMN ${ }^{13} \mathrm{C}$ del compuesto 51. 


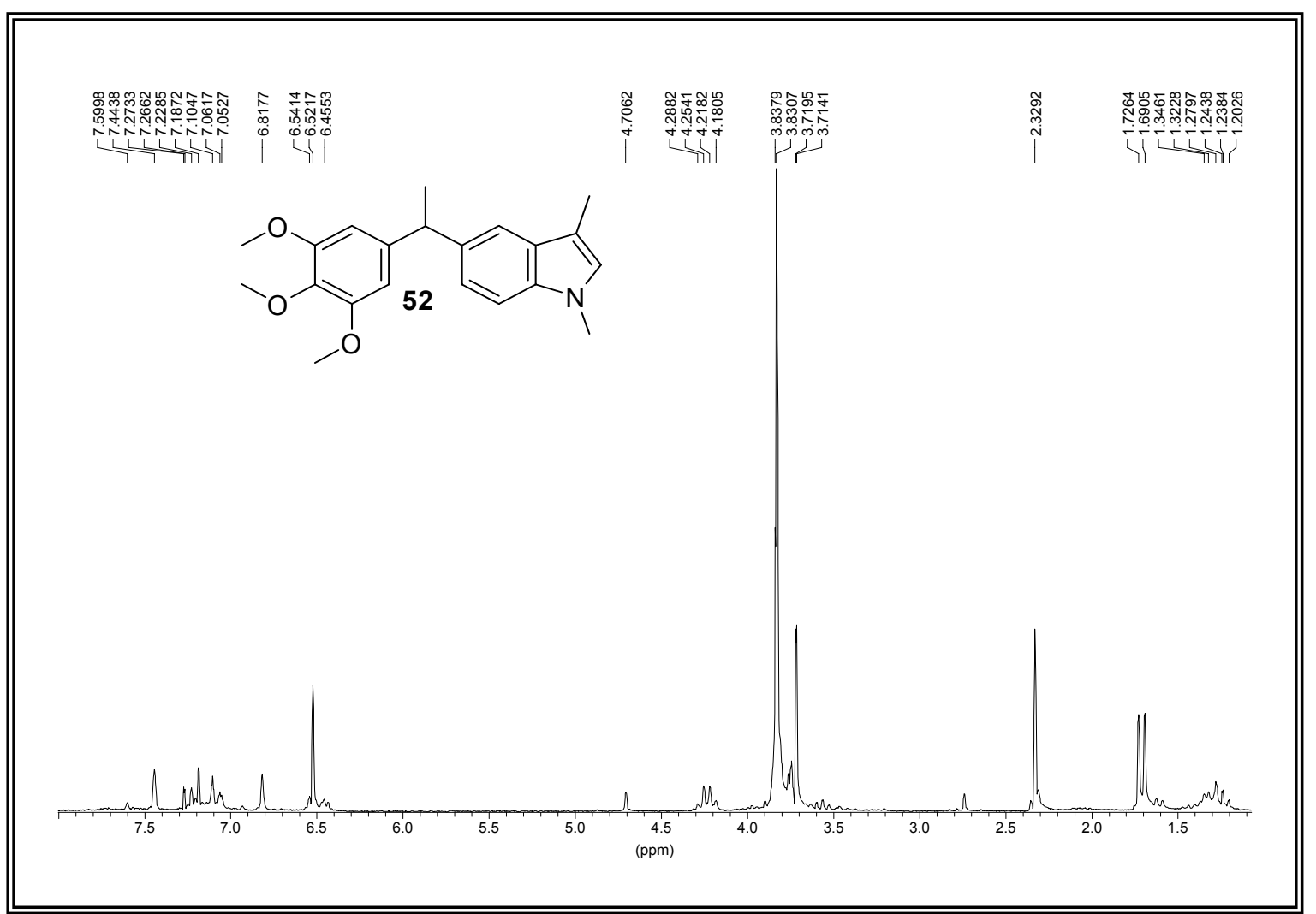

Figura XXXVa. Espectro de RMN ${ }^{1} \mathrm{H}$ del compuesto 52.

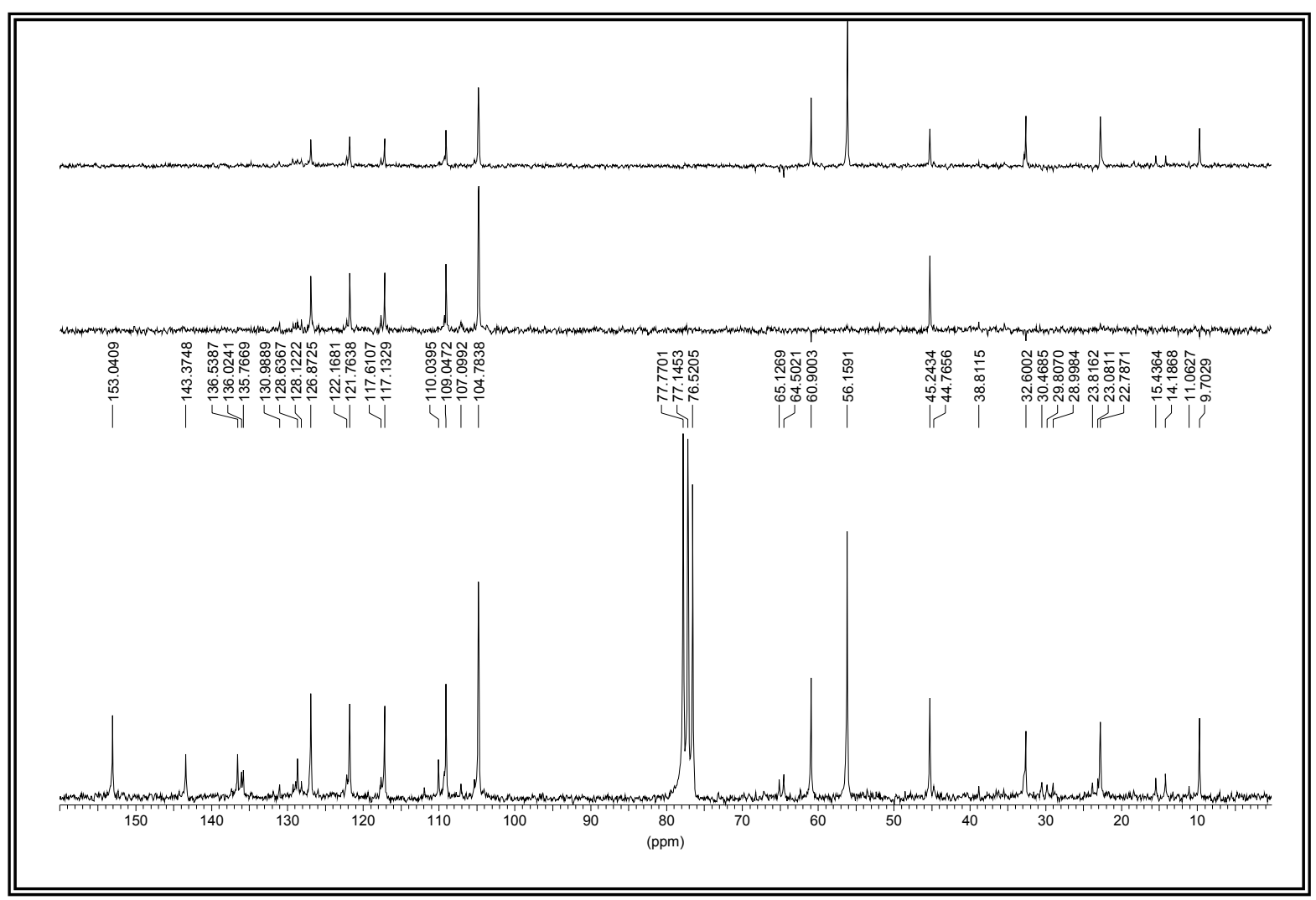

Figura XXXVb. Espectro de RMN ${ }^{13} \mathrm{C}$ del compuesto 52. 


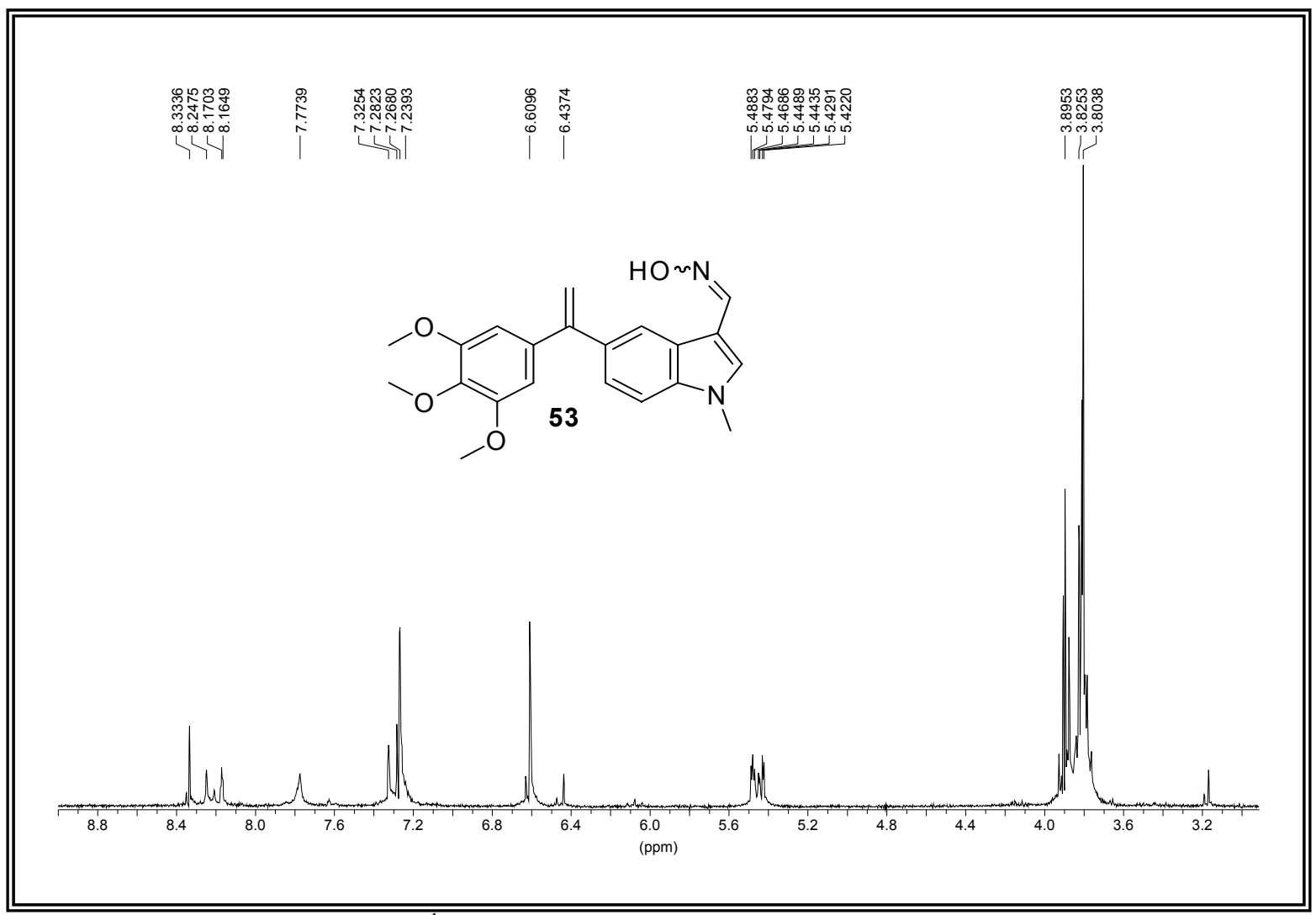

Figura XXXVIa. Espectro de RMN ${ }^{1} \mathrm{H}$ de los compuestos $53 Z$ y $53 E$.

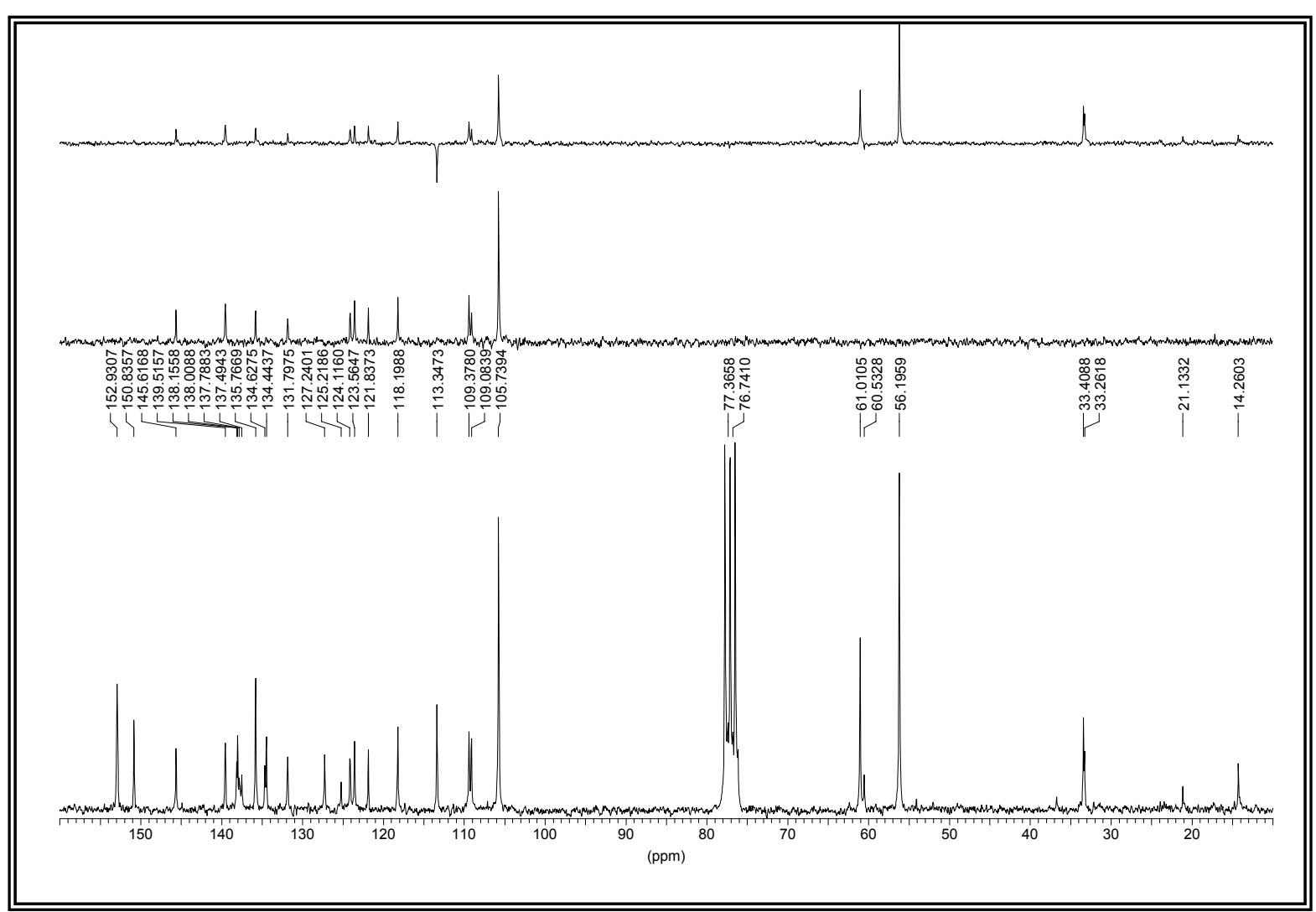

Figura XXXVIb. Espectro de RMN ${ }^{13} \mathrm{C}$ de los compuestos $\mathbf{5 3 Z}$ y $\mathbf{5 3 E}$. 


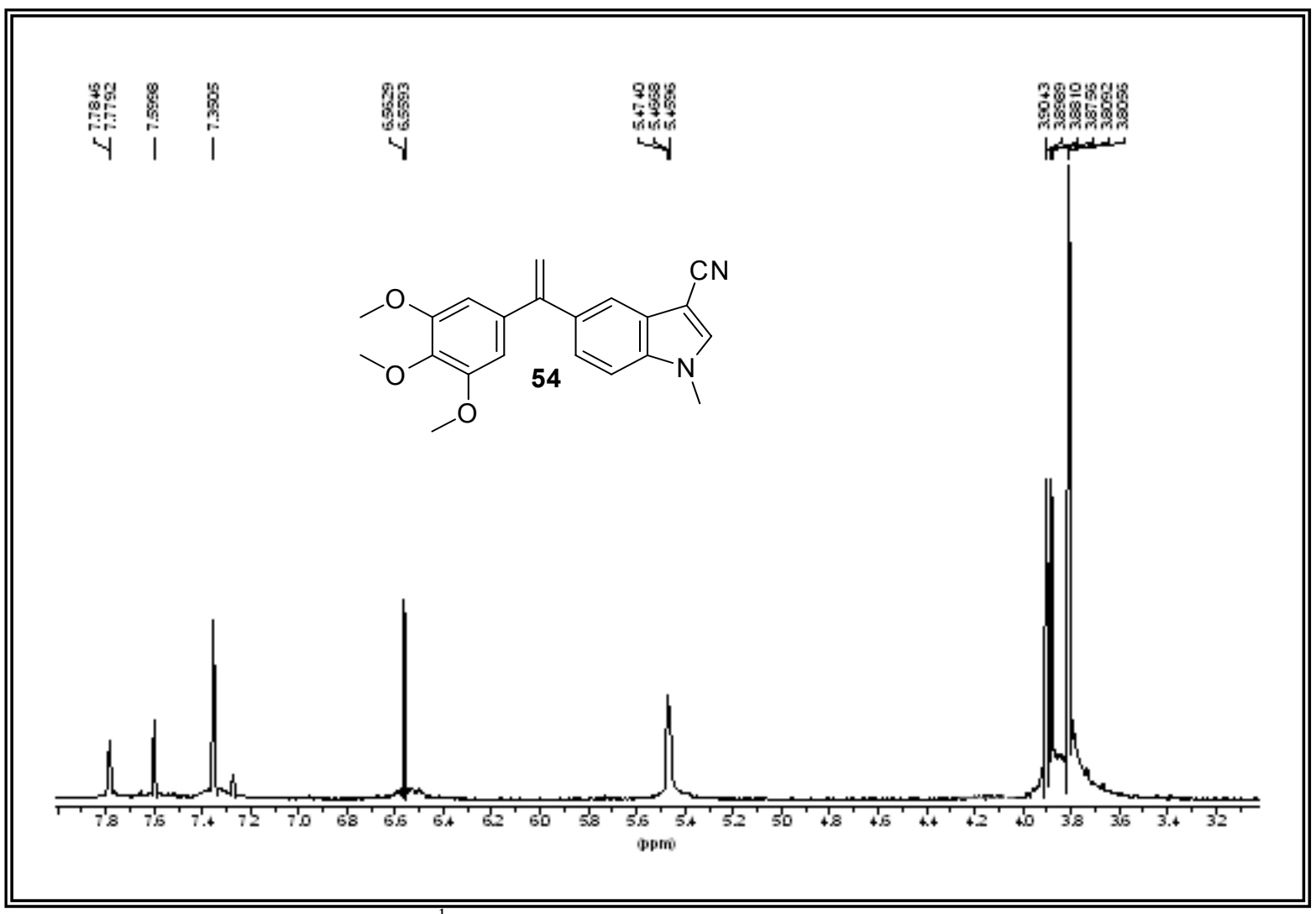

Figura XXXVIIa. Espectro de RMN ${ }^{1} \mathrm{H}$ del compuesto $\mathbf{5 4}$.

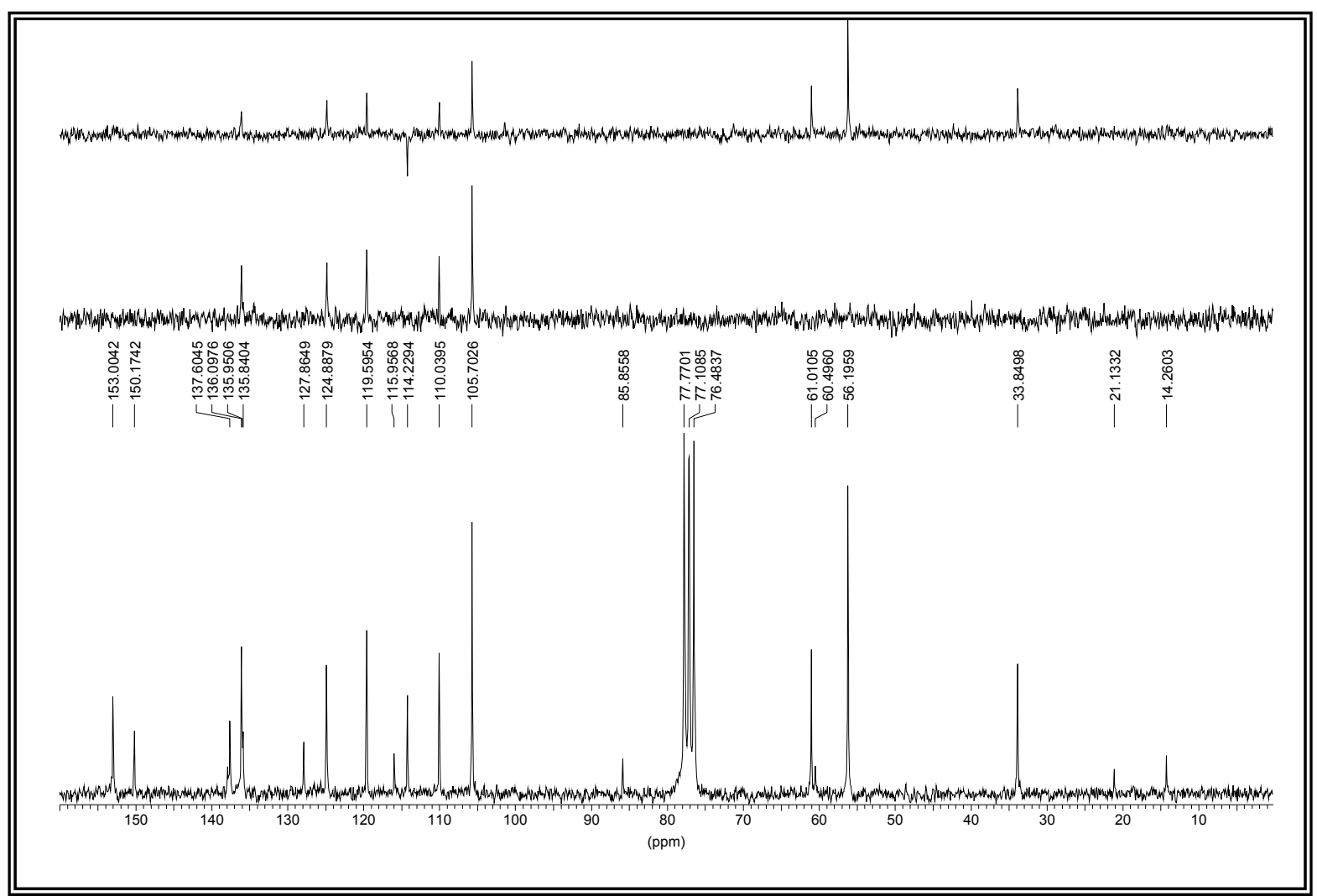

Figura XXXVIIb. Espectro de RMN ${ }^{13} \mathrm{C}$ del compuesto 54. 


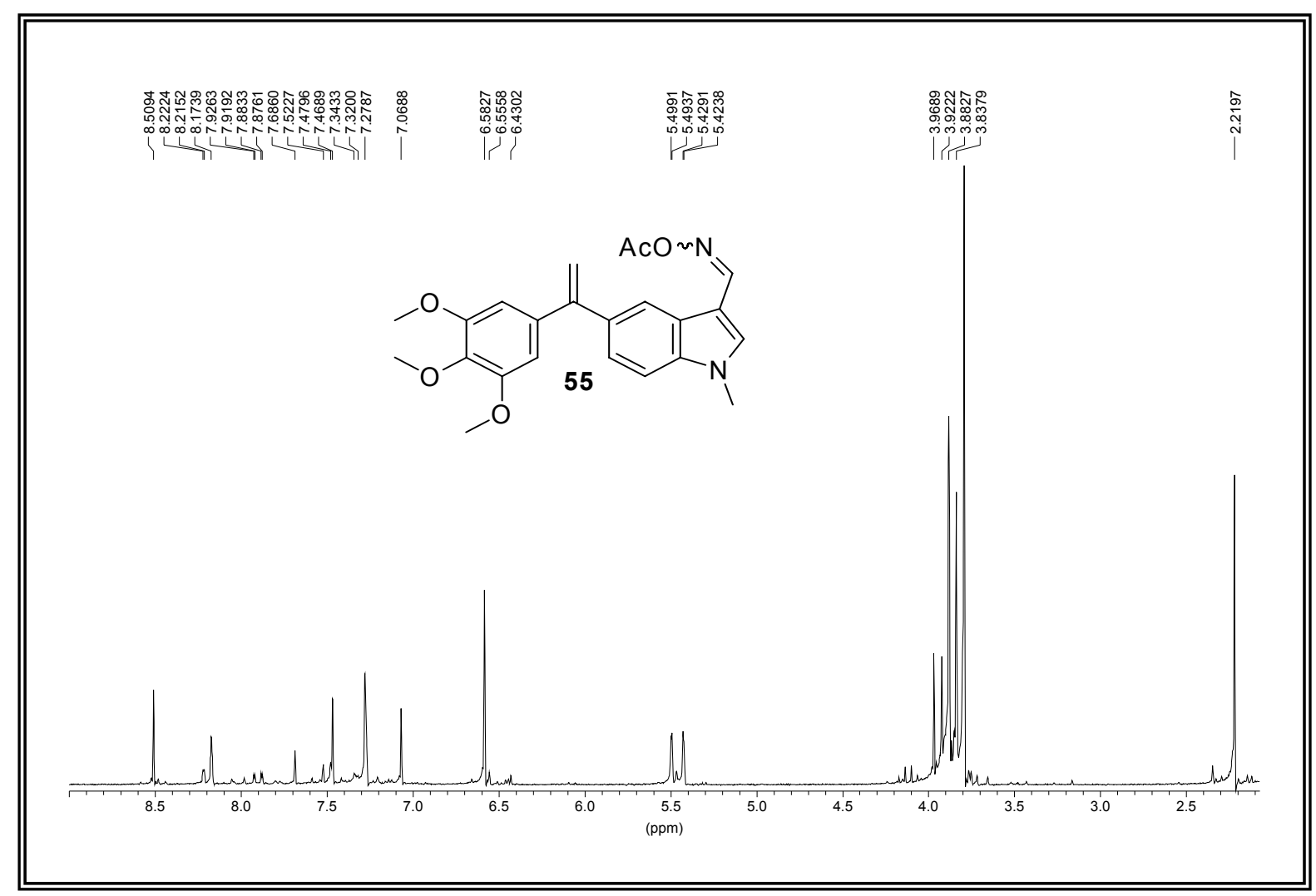

Figura XXXVIIIa. Espectro de RMN ${ }^{1} \mathrm{H}$ de los compuestos $55 Z$ y $553 E$. (un isómero mayoritario)

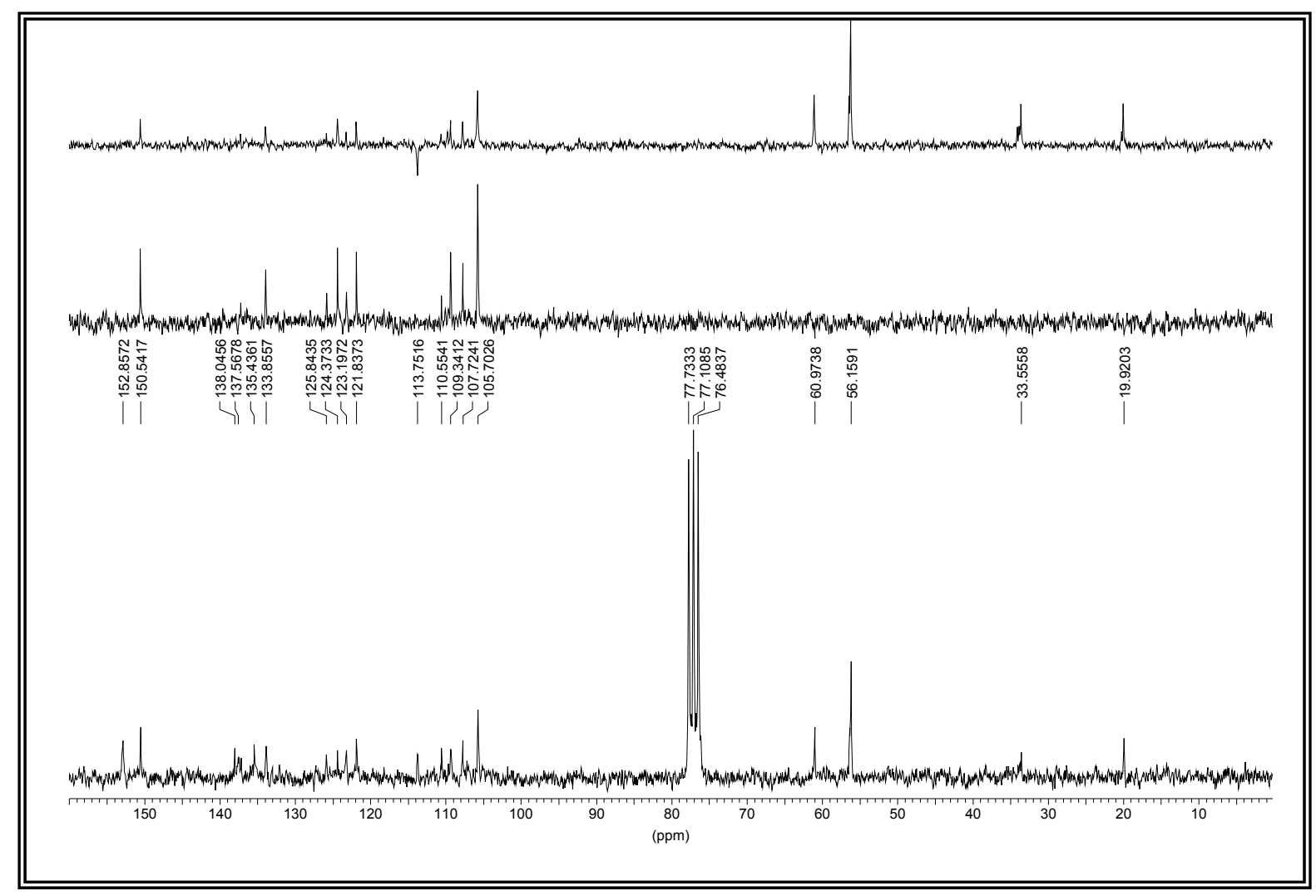

Figura XXXVIIIb. Espectro de RMN ${ }^{13} \mathrm{C}$ de los compuestos $55 Z$ y $55 E$. (un isómero mayoritario) 


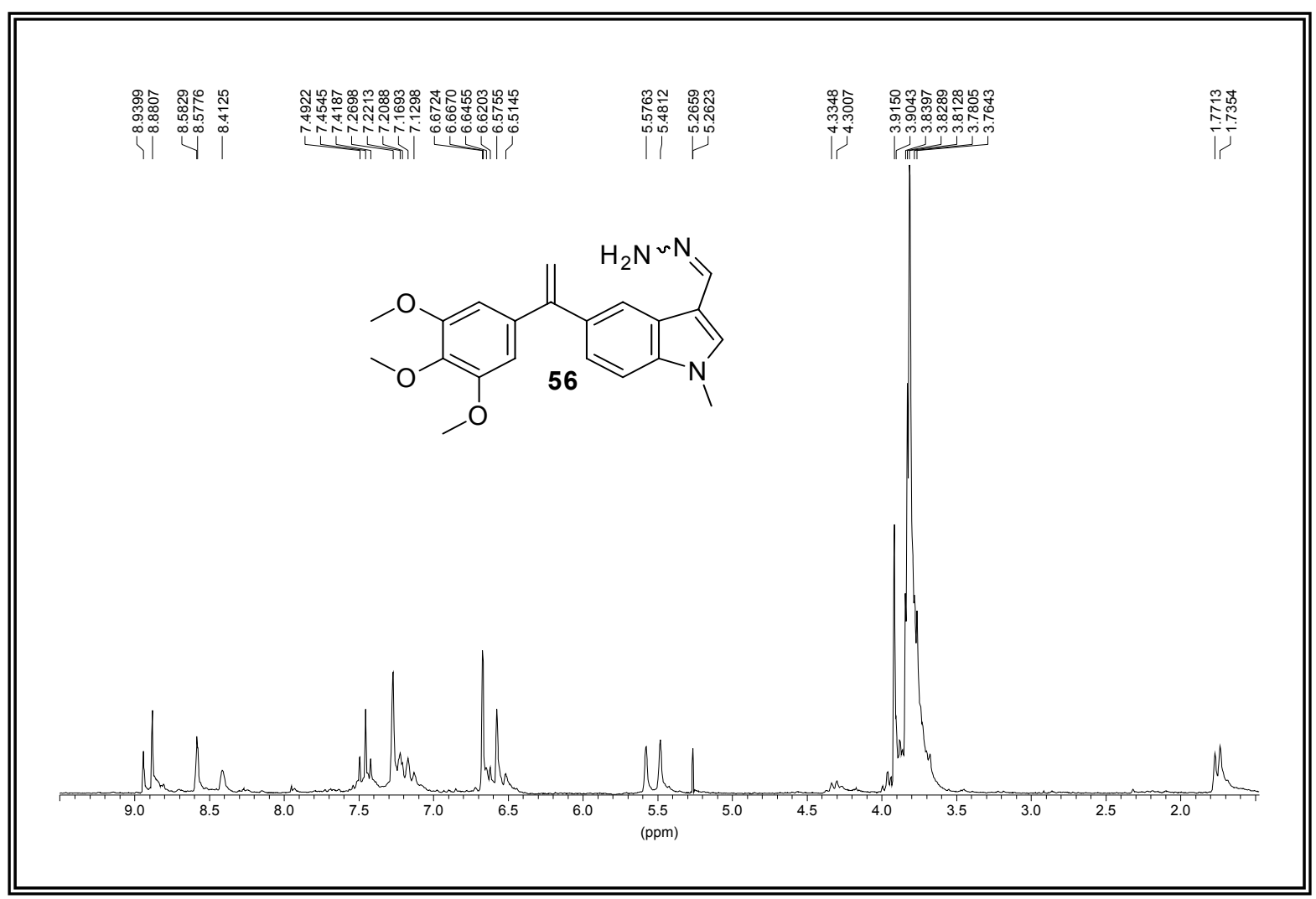

Figura XXXIXa. Espectro de RMN ${ }^{1} \mathrm{H}$ de los compuestos $56 \boldsymbol{Z}$ y $56 \boldsymbol{E}$.

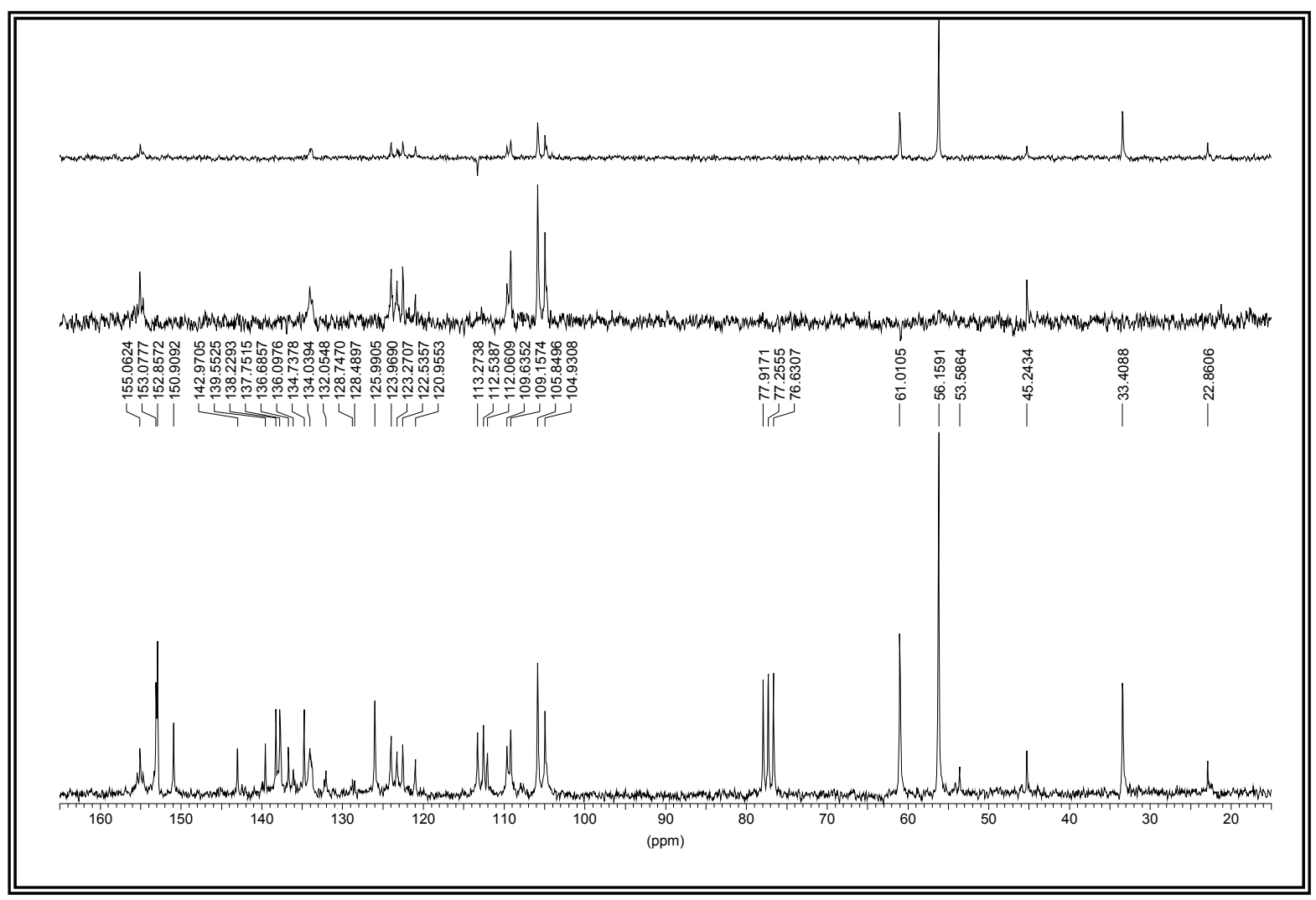

Figura XXXIXb. Espectro de RMN ${ }^{13} \mathrm{C}$ de los compuestos $56 \boldsymbol{Z}$ y $56 \boldsymbol{E}$. 


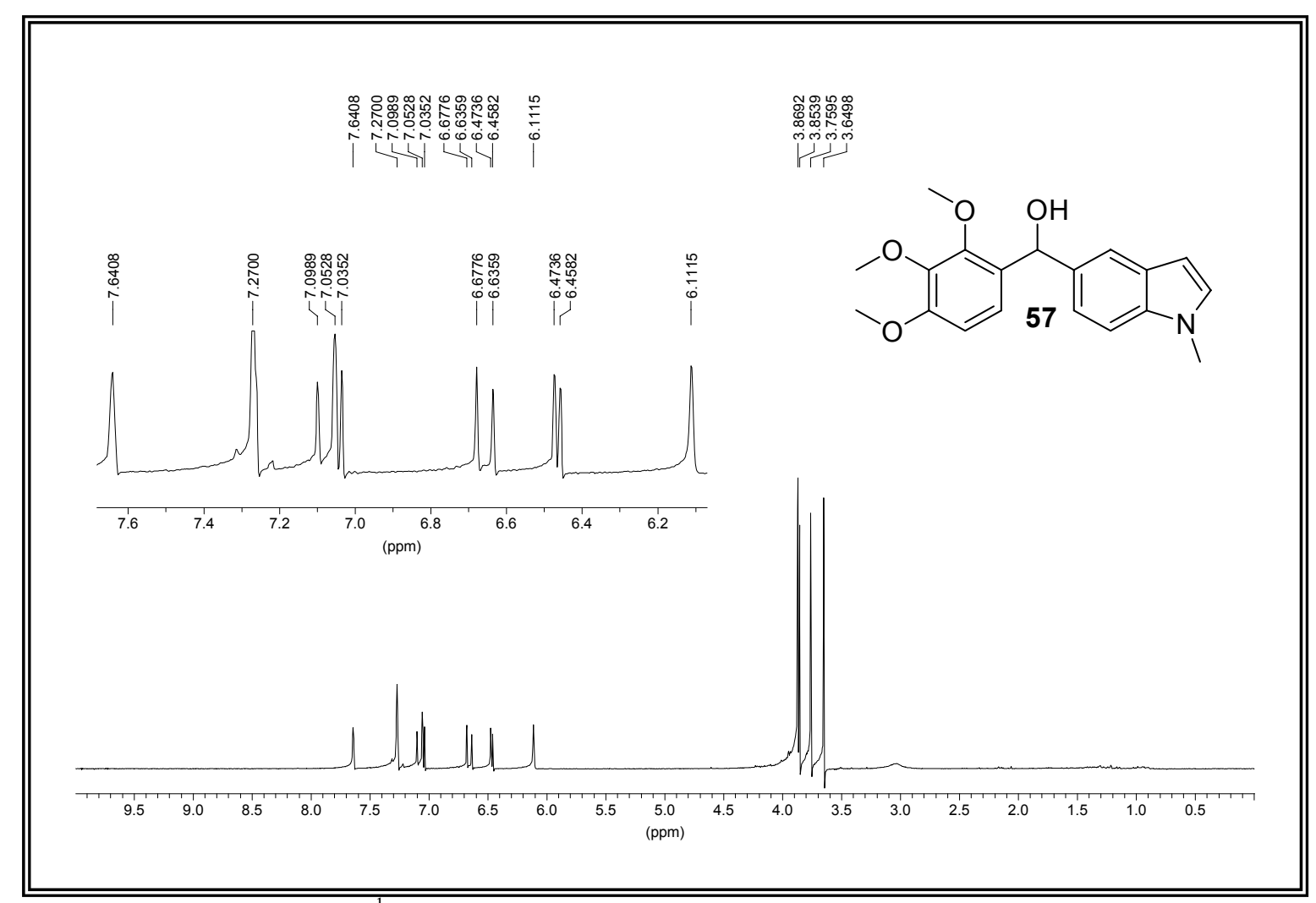

Figura XLa. Espectro de RMN ${ }^{1} \mathrm{H}$ del compuesto 57.

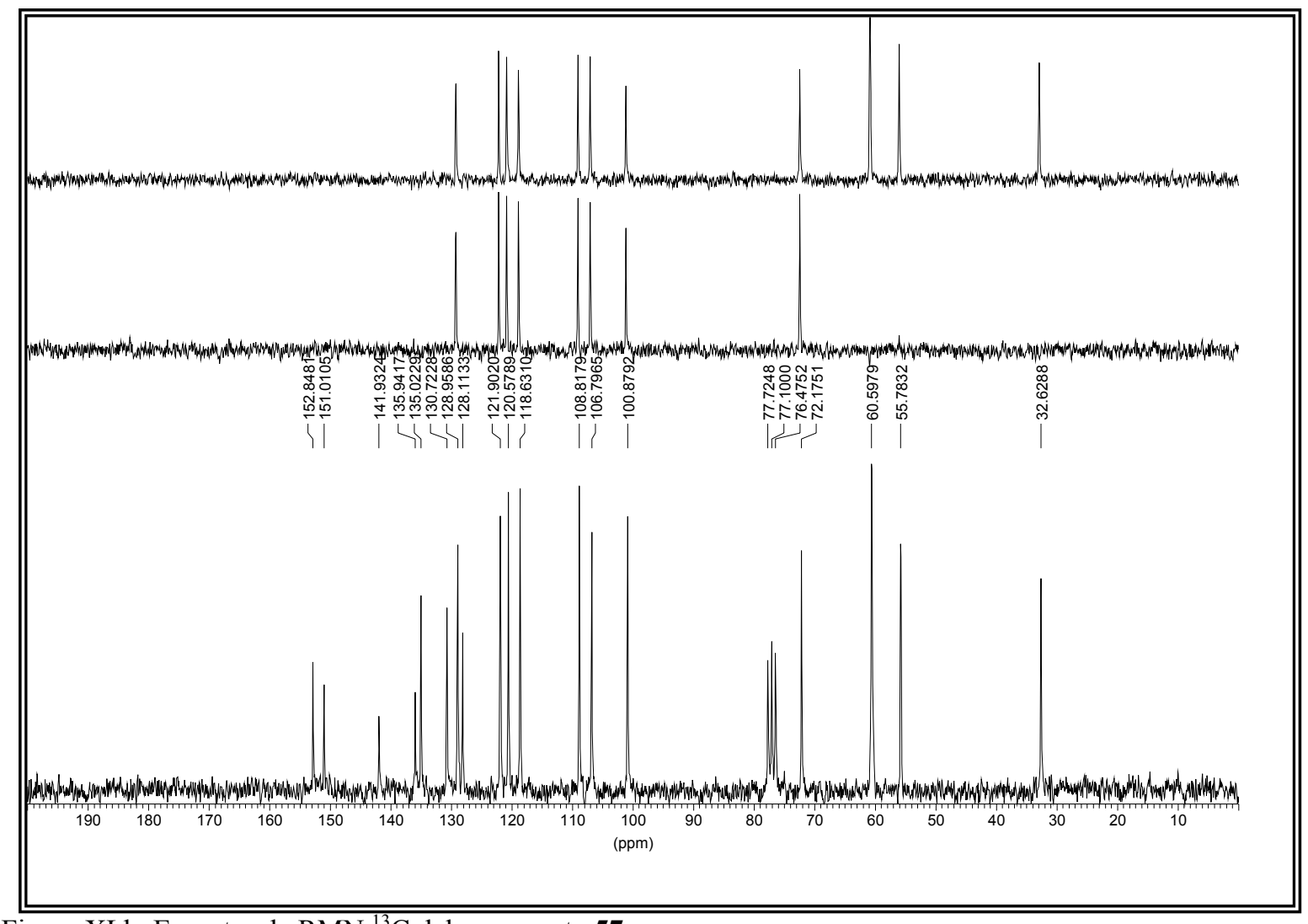

Figura XLb. Espectro de RMN ${ }^{13} \mathrm{C}$ del compuesto 57. 


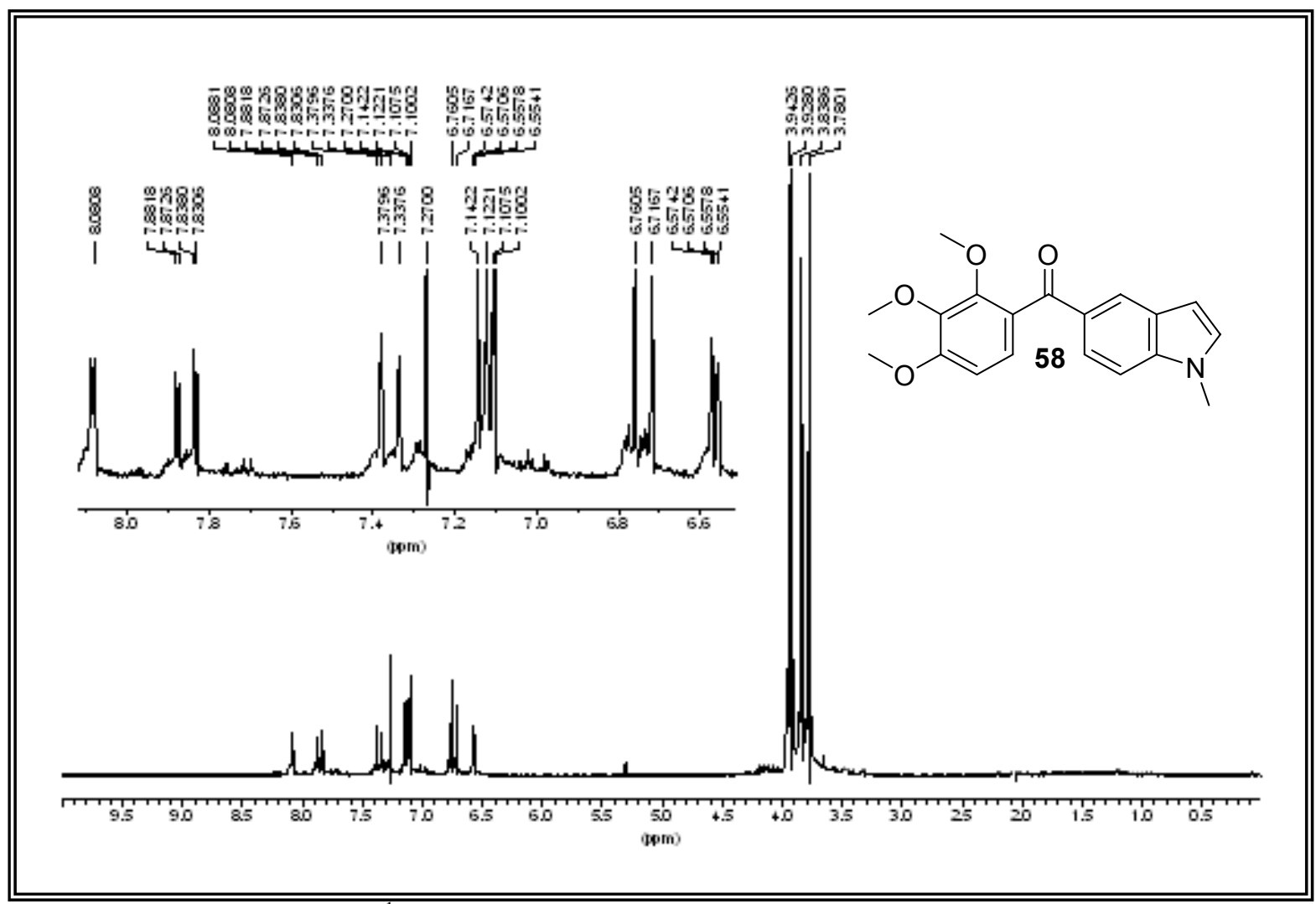

Figura XLIa. Espectro de RMN ${ }^{1} \mathrm{H}$ del compuesto $\mathbf{5 8}$.

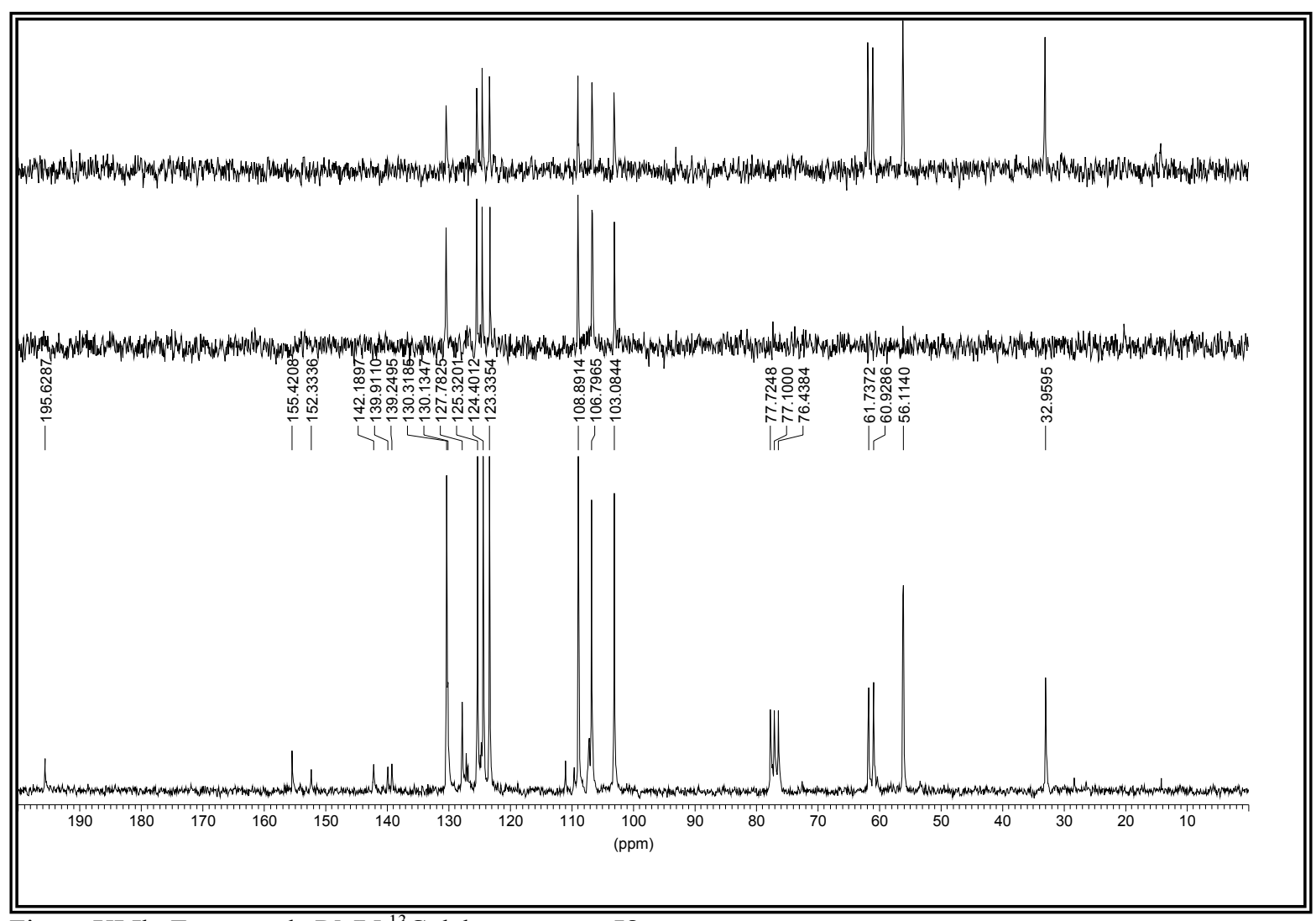

Figura XLIb. Espectro de RMN ${ }^{13} \mathrm{C}$ del compuesto 58. 


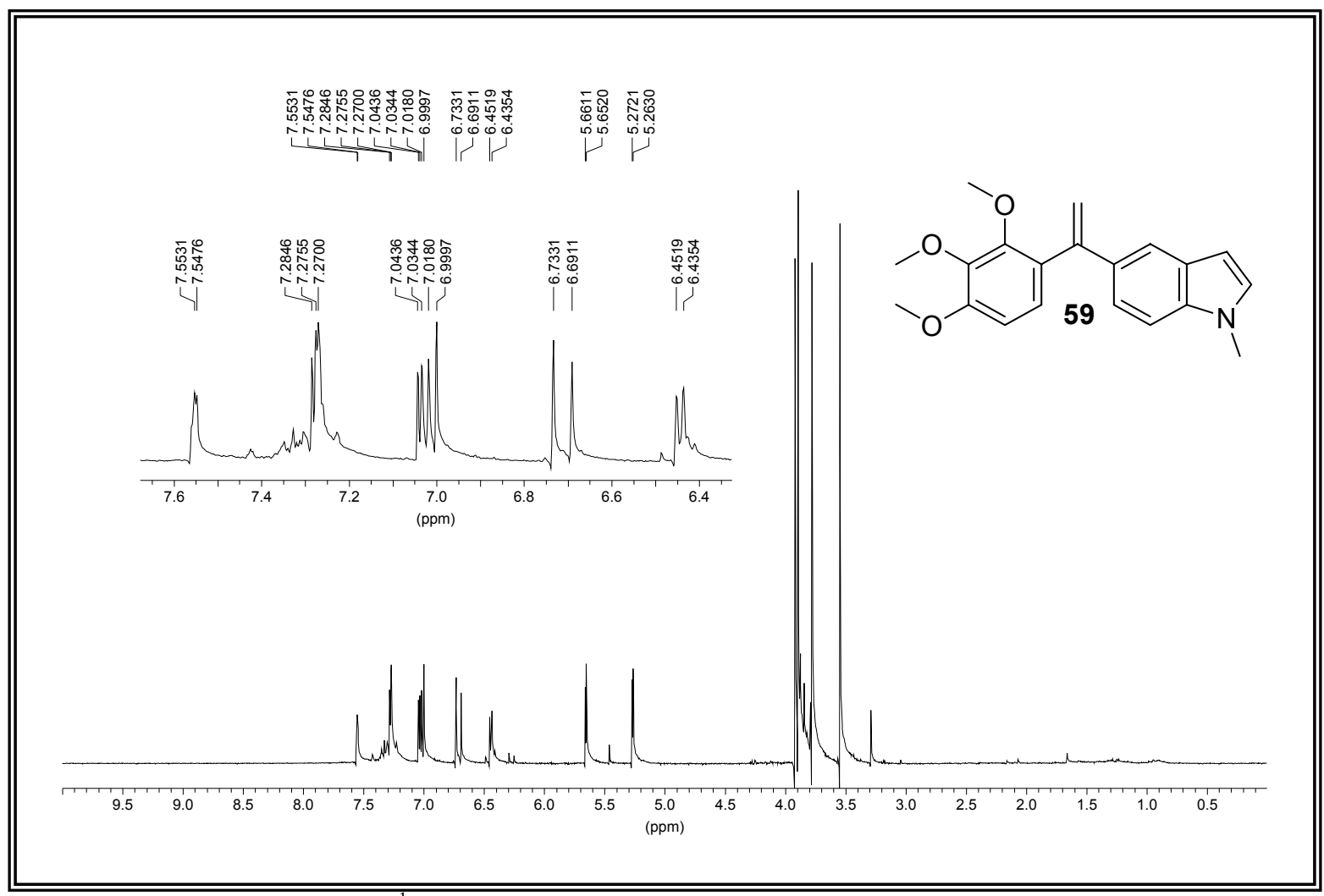

Figura XLIIa. Espectro de RMN ${ }^{1} \mathrm{H}$ del compuesto 59.

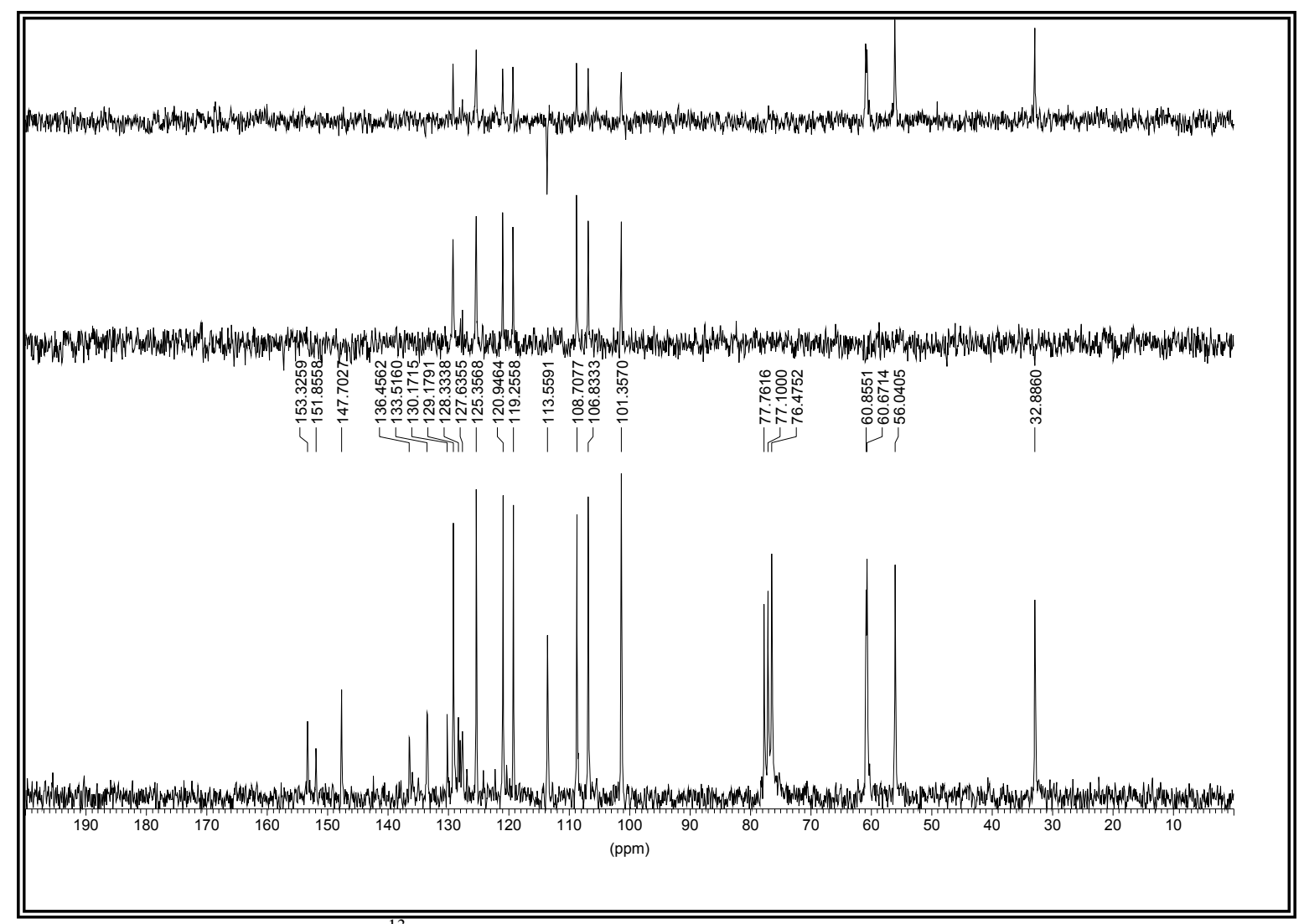

Figura XLIIb. Espectro de RMN ${ }^{13} \mathrm{C}$ del compuesto 59. 


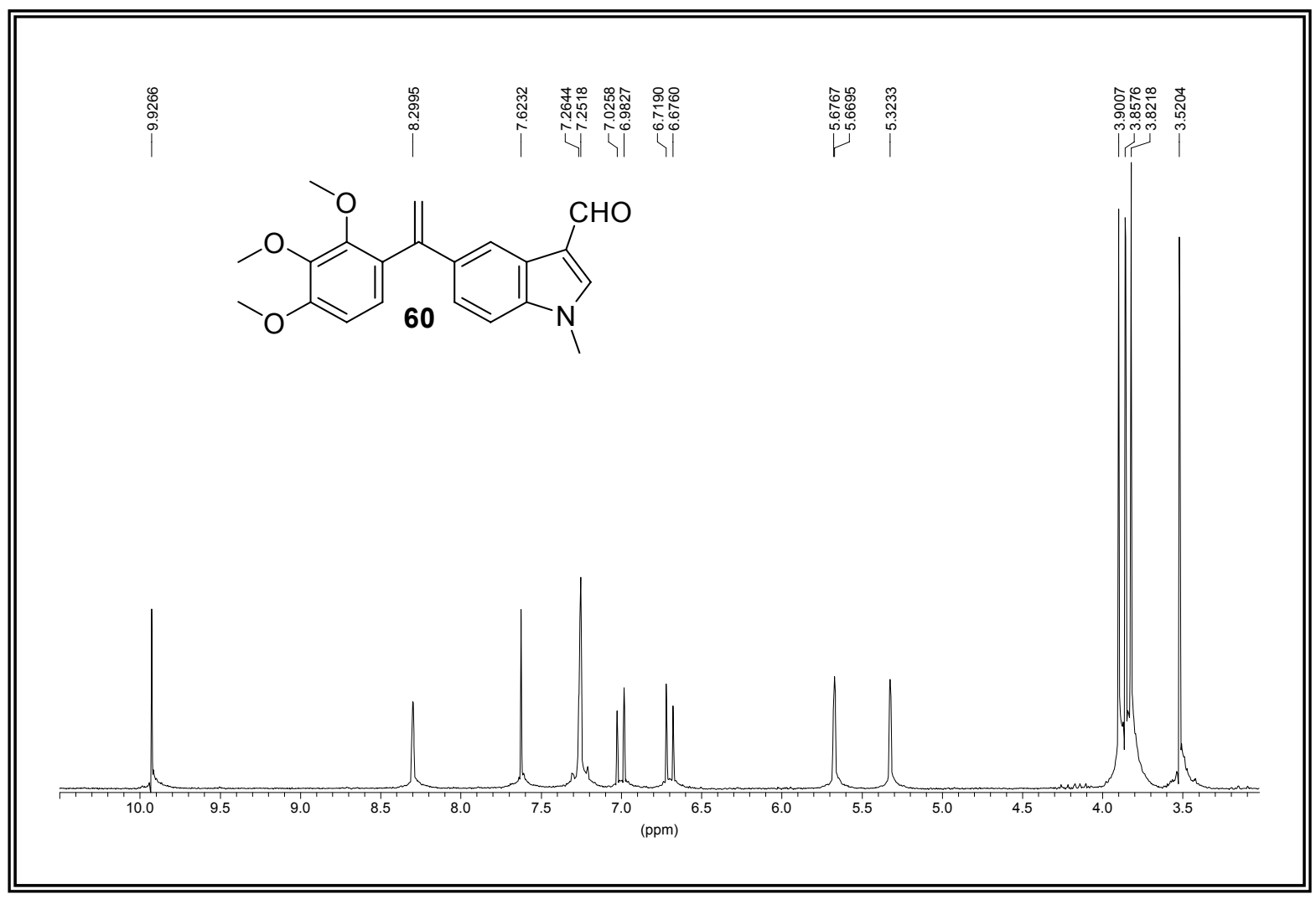

Figura XLIIIa. Espectro de RMN ${ }^{1} \mathrm{H}$ del compuesto 60.

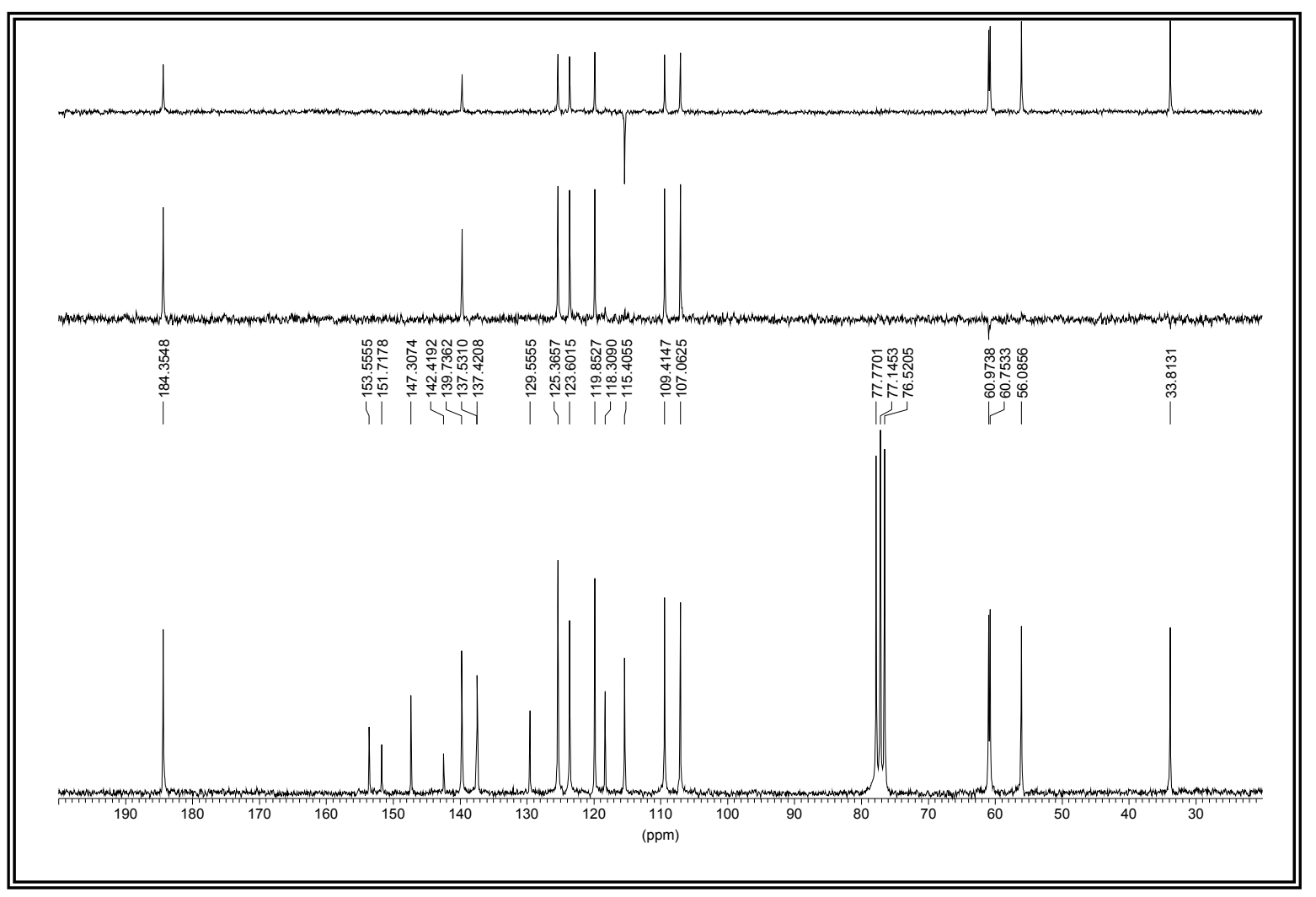

Figura XLIIIb. Espectro de RMN ${ }^{13} \mathrm{C}$ del compuesto 60 . 


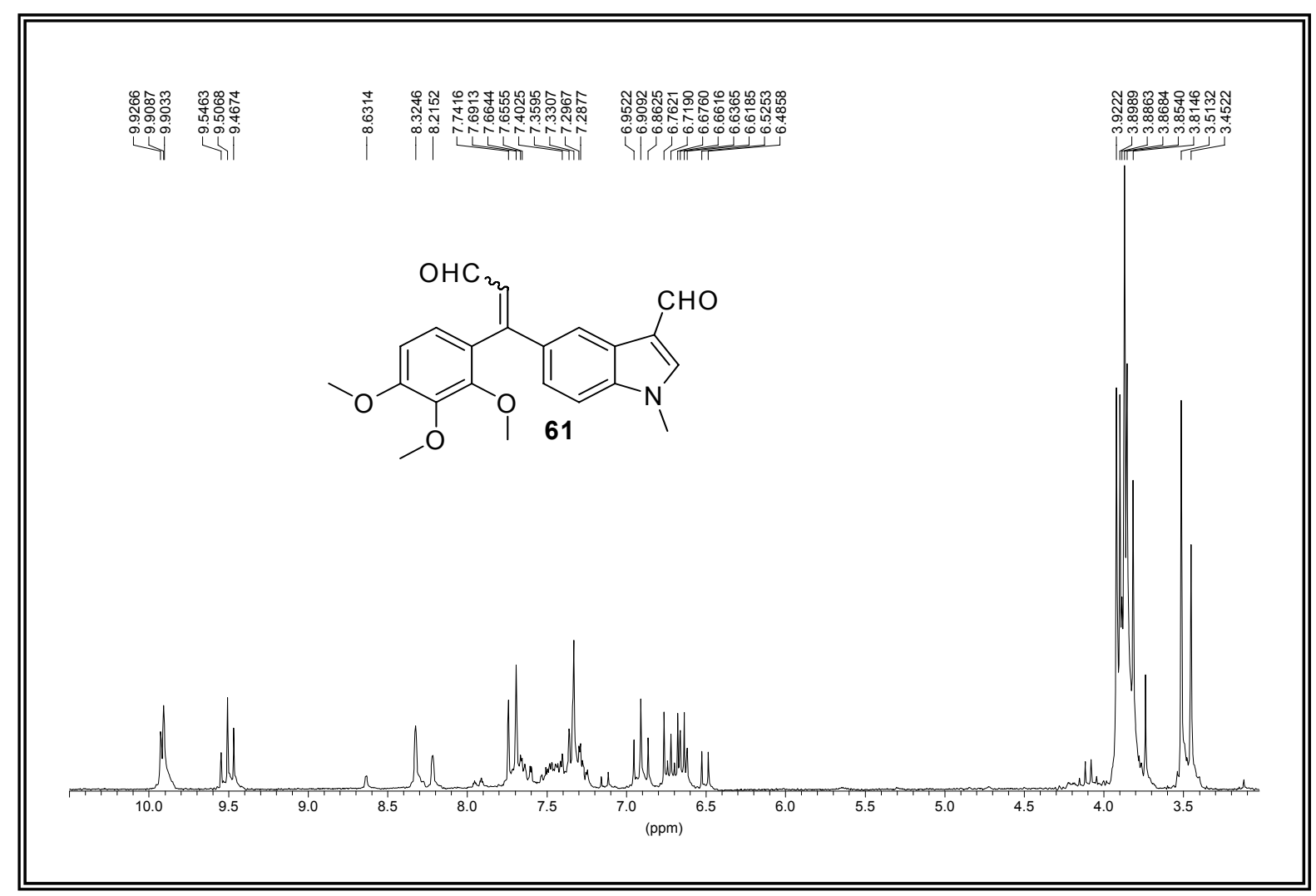

Figura XLIVa. Espectro de RMN ${ }^{1} \mathrm{H}$ de los compuestos $61 Z_{\text {y }} 61 E$.

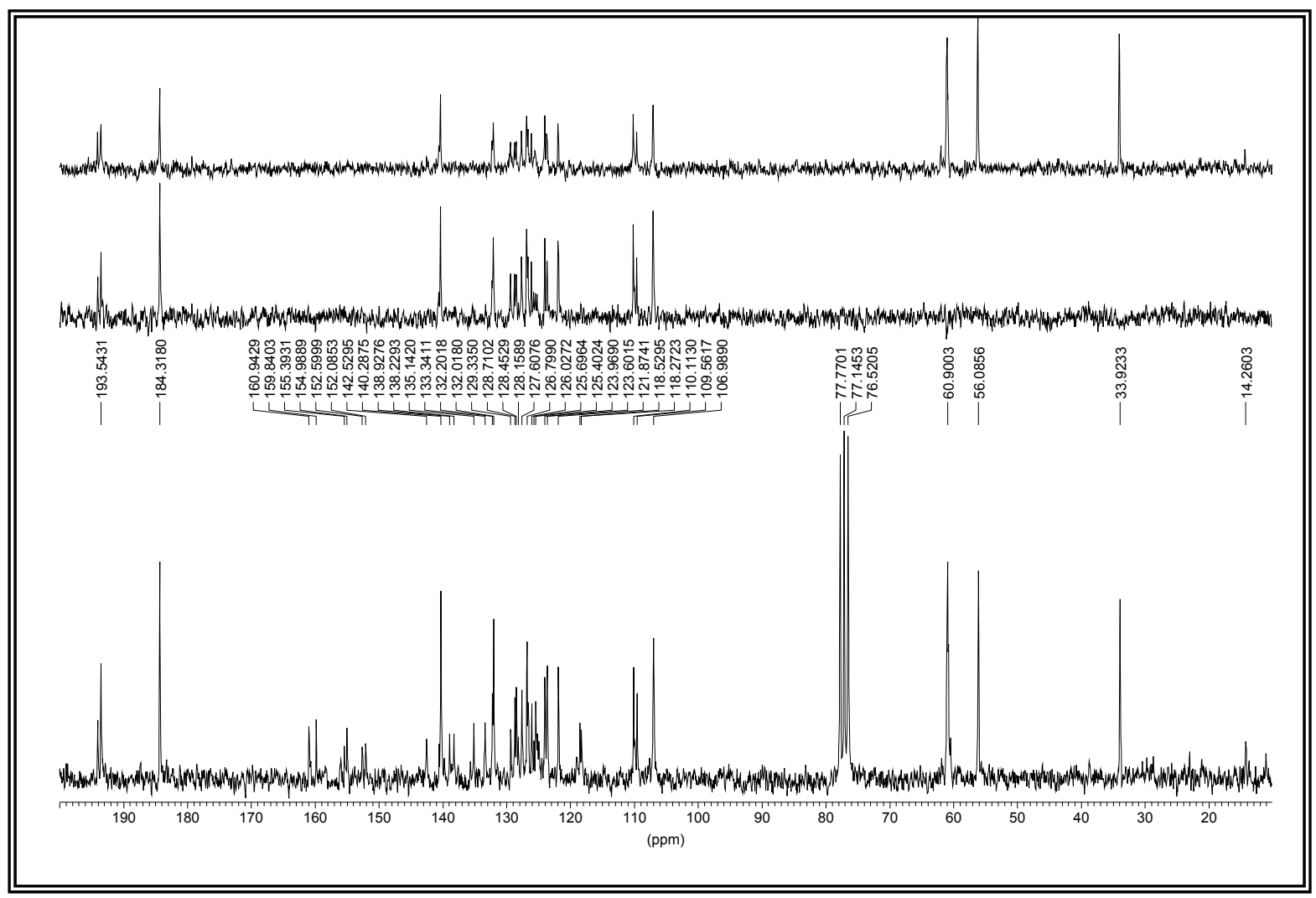

Figura XLIVb. Espectro de RMN ${ }^{13} \mathrm{C}$ de los compuestos $61 Z$ y $61 E$. 


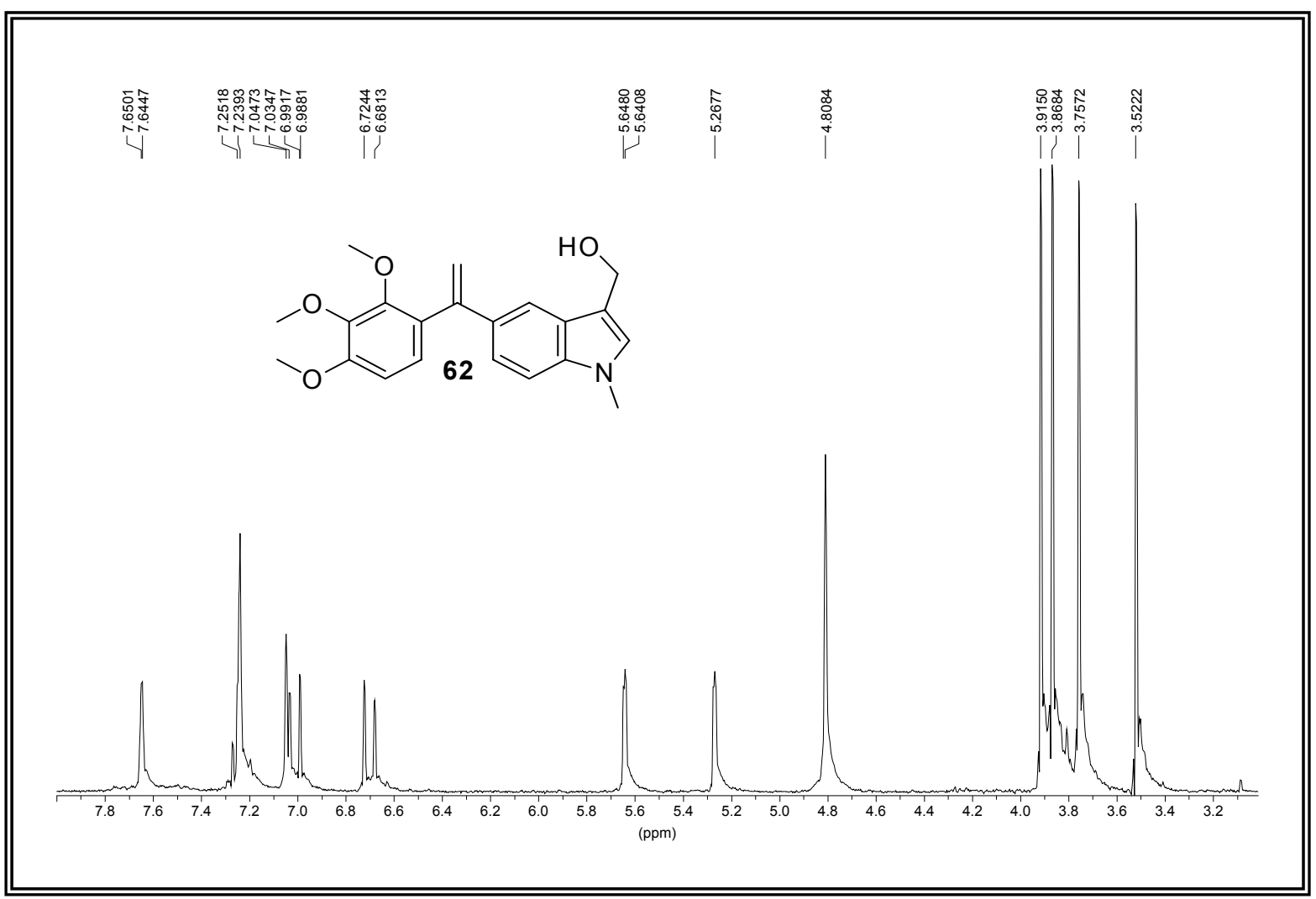

Figura XLVa. Espectro de RMN ${ }^{1} \mathrm{H}$ del compuesto 62.

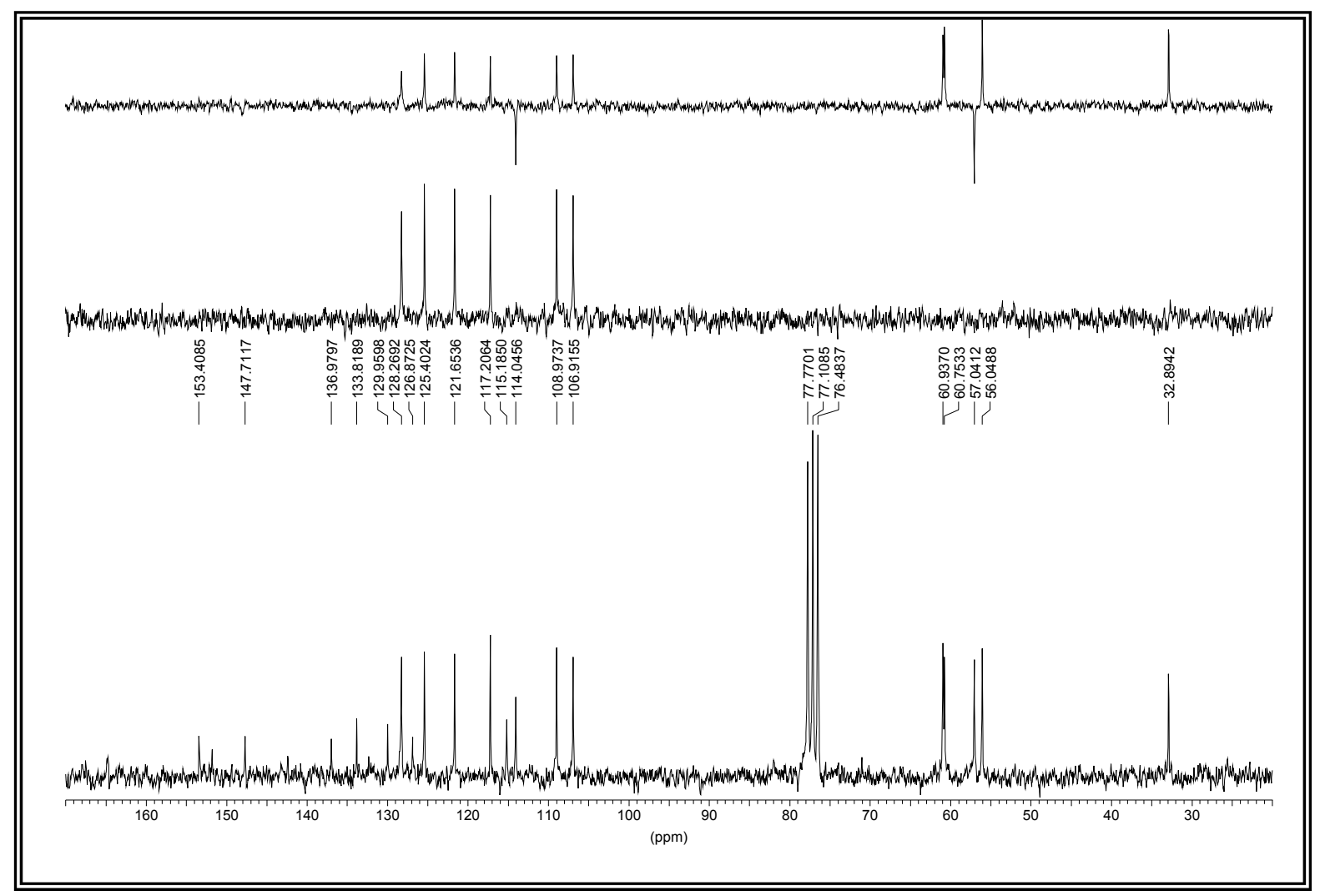

Figura XLVb. Espectro de RMN ${ }^{13} \mathrm{C}$ del compuesto 62. 


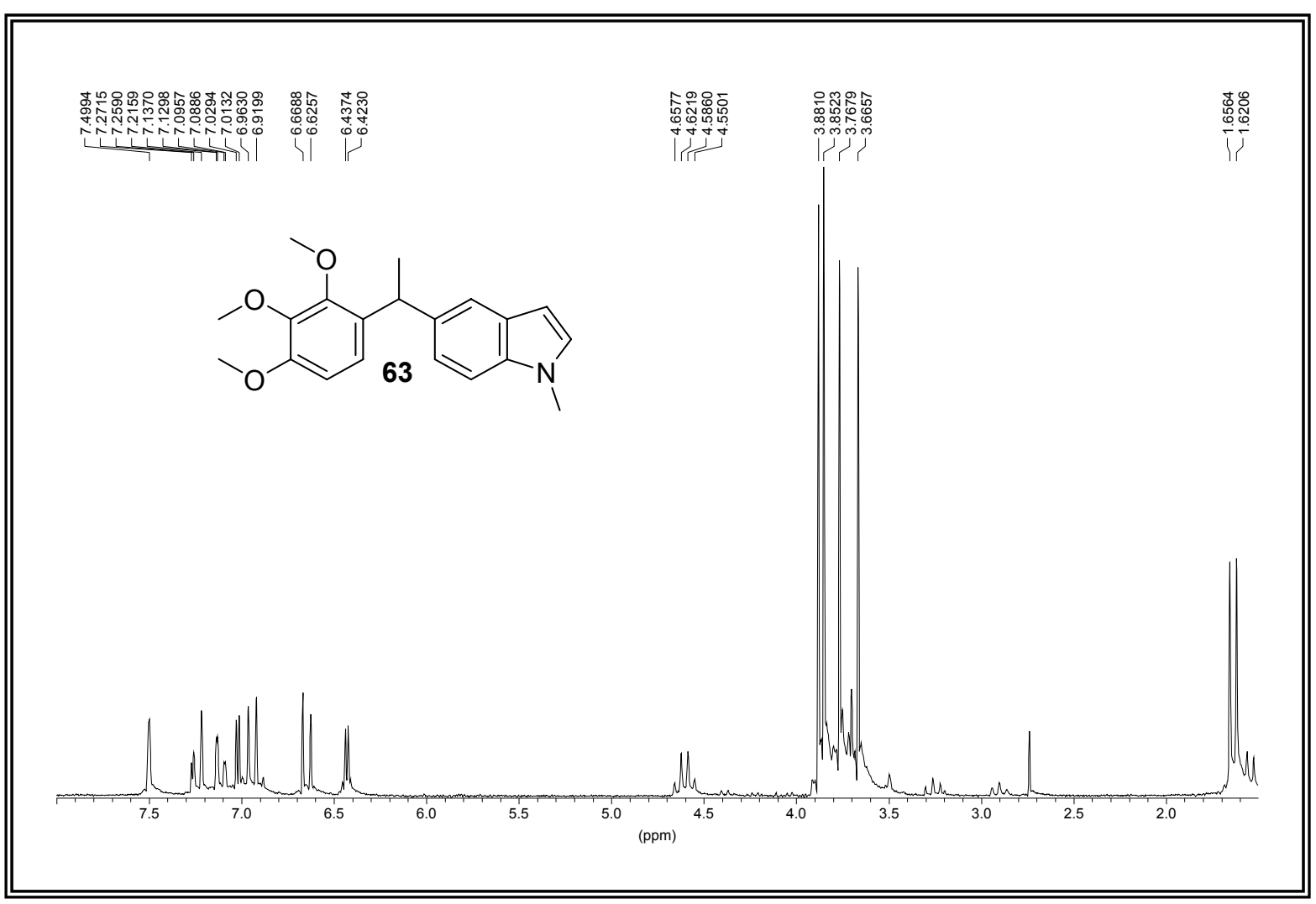

Figura XLVIa. Espectro de RMN ${ }^{1} \mathrm{H}$ del compuesto 63.

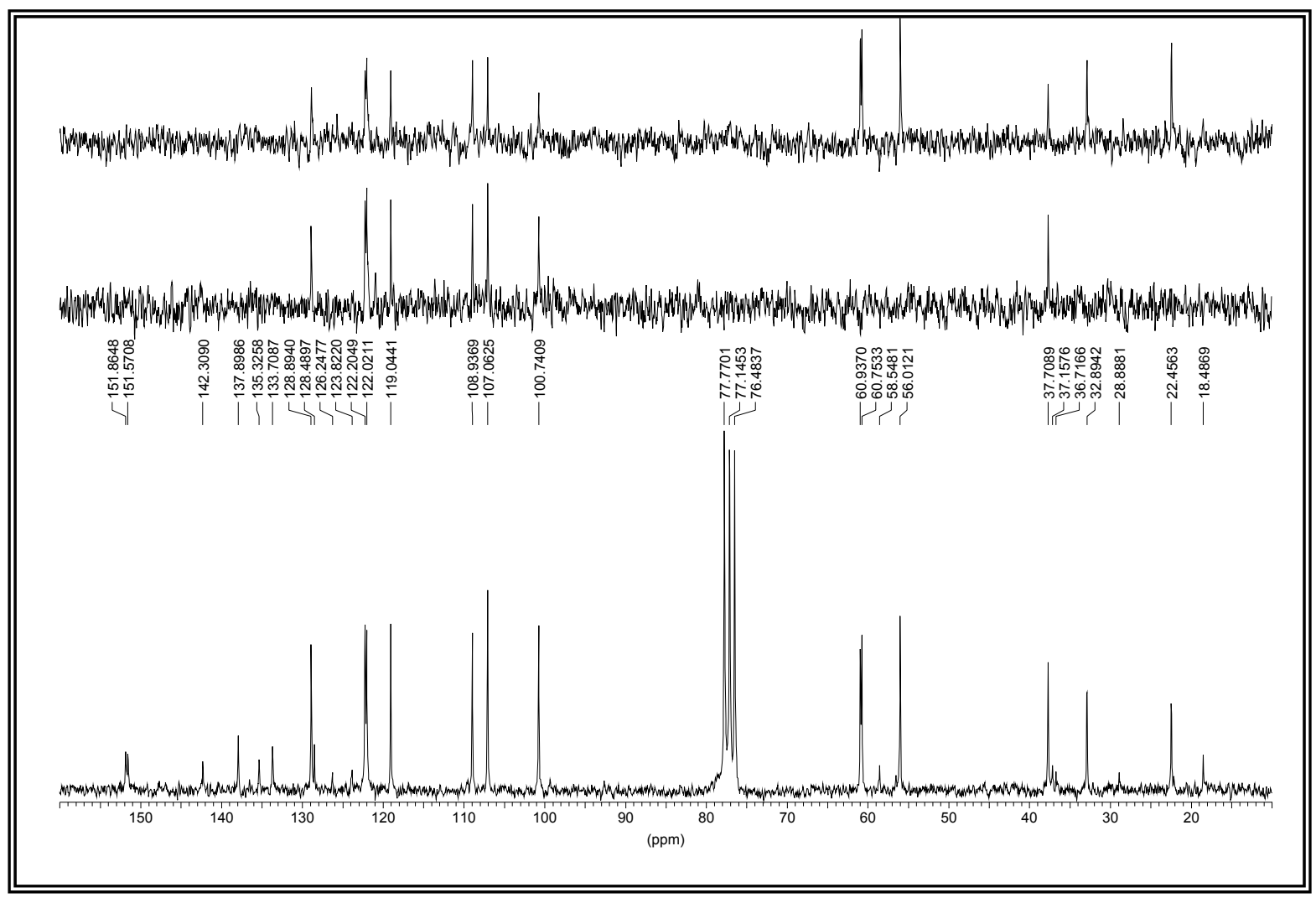

Figura XLVIb. Espectro de RMN ${ }^{13} \mathrm{C}$ del compuesto 63. 


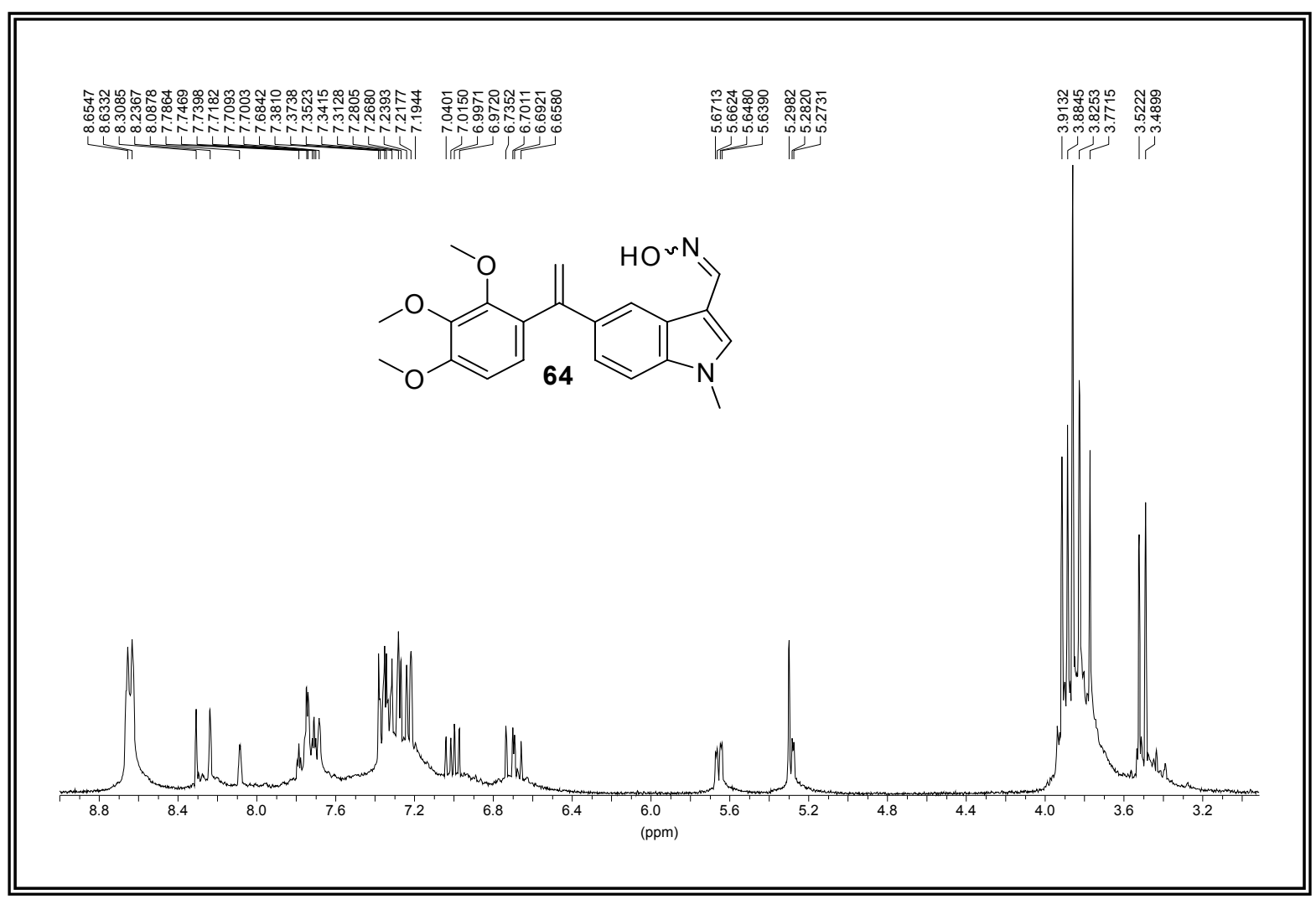

Figura XLVIIa. Espectro de $\mathrm{RMN}{ }^{1} \mathrm{H}$ de los compuestos $64 Z$ y $64 E$.

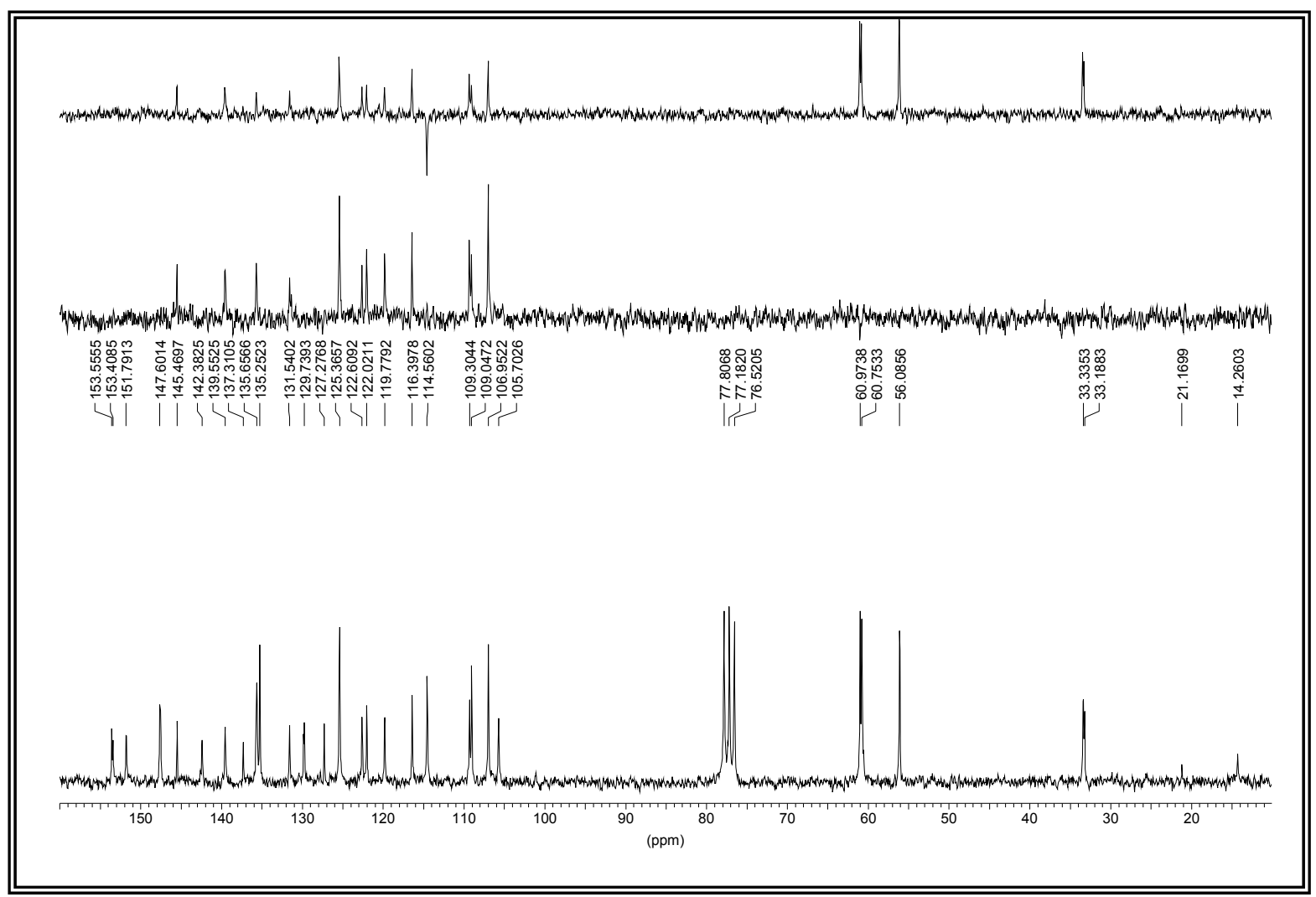

Figura XLVIIb. Espectro de $\mathrm{RMN}{ }^{13} \mathrm{C}$ de los compuestos $64 Z$ y $64 E$. 


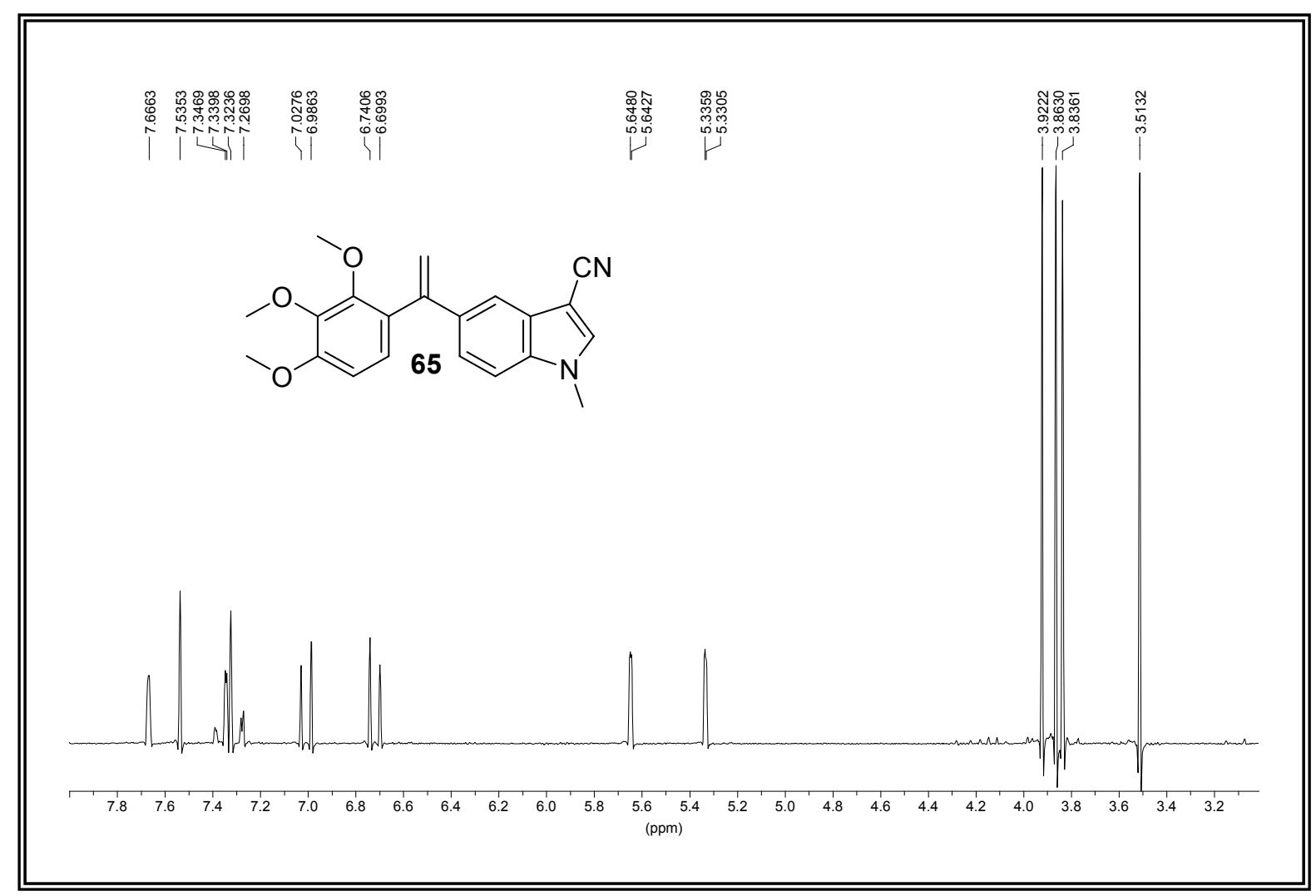

Figura XLVIIIa. Espectro de RMN ${ }^{1} \mathrm{H}$ del compuesto 65.

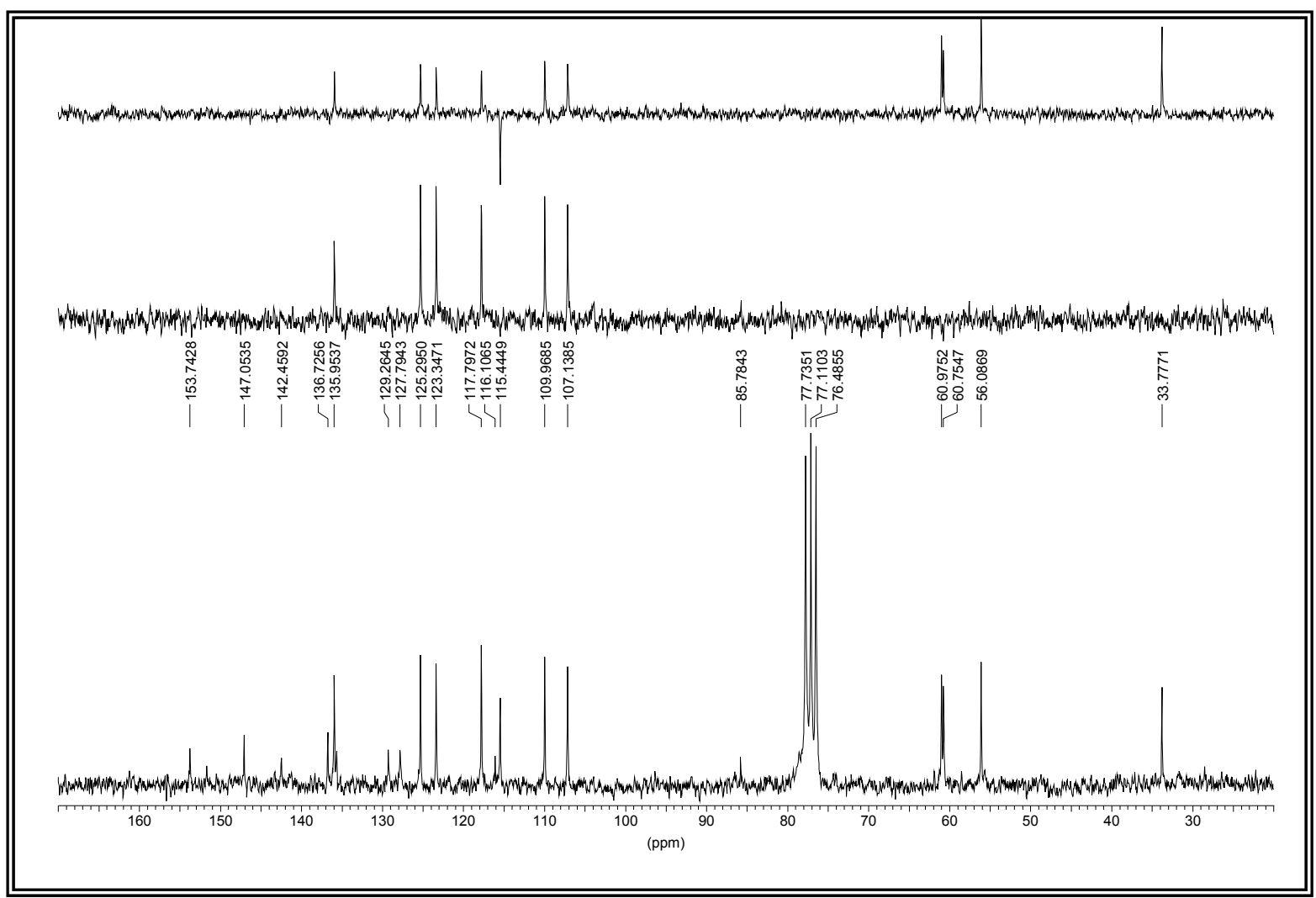

Figura XLVIIIb. Espectro de RMN ${ }^{13} \mathrm{C}$ del compuesto 65 . 


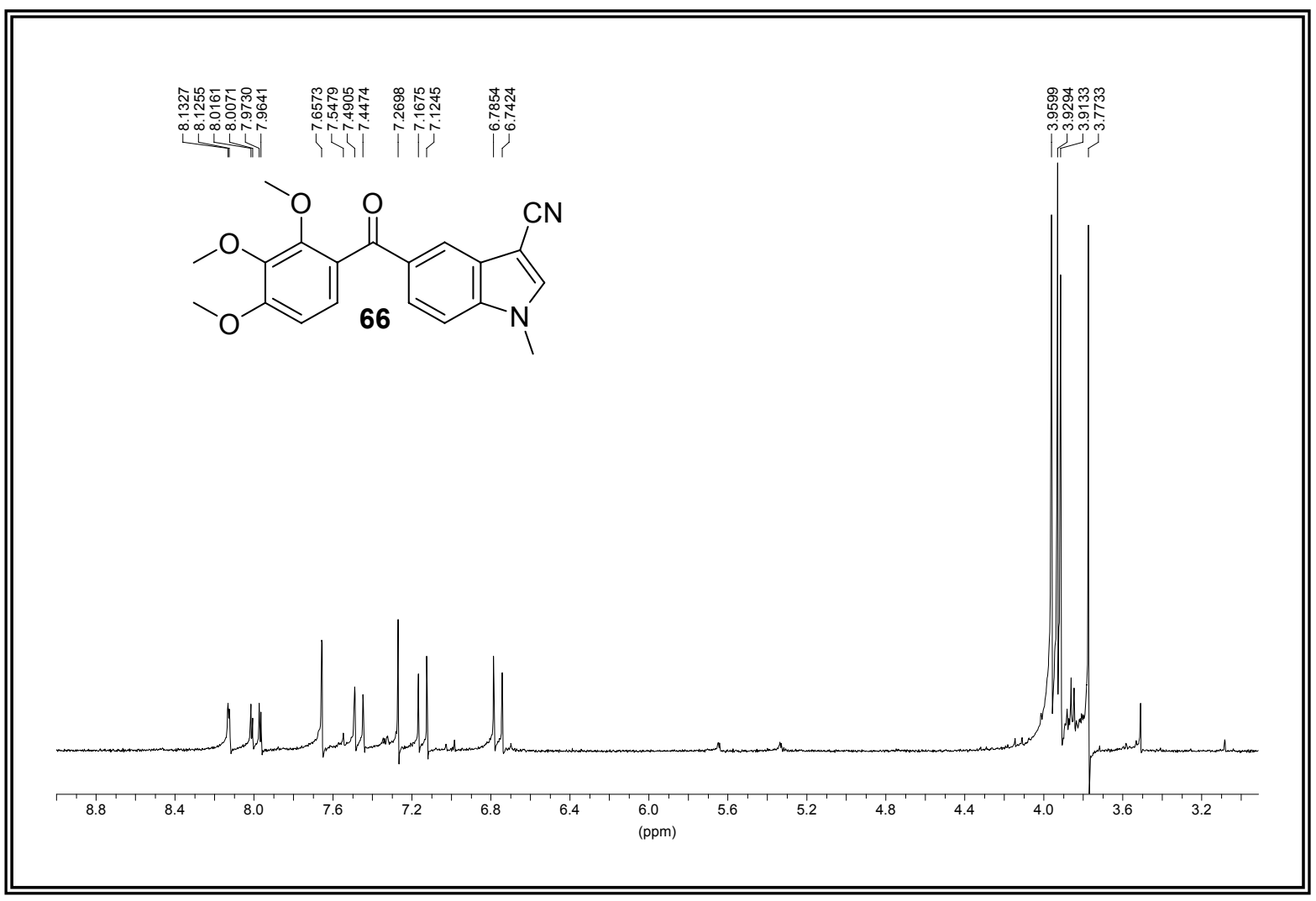

Figura ILa. Espectro de RMN ${ }^{1} \mathrm{H}$ del compuesto 66.

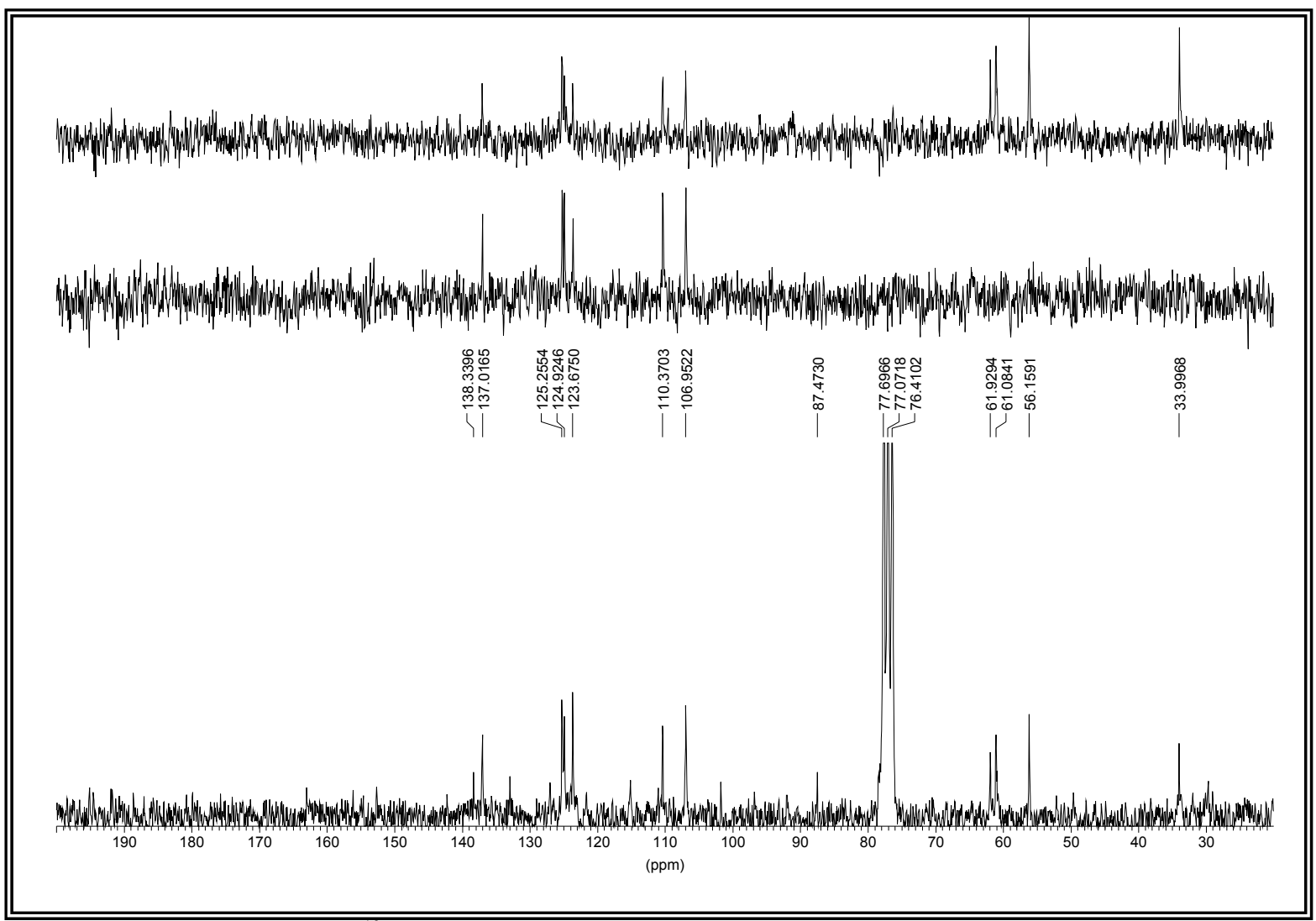

Figura ILb. Espectro de RMN ${ }^{13} \mathrm{C}$ del compuesto 66. 


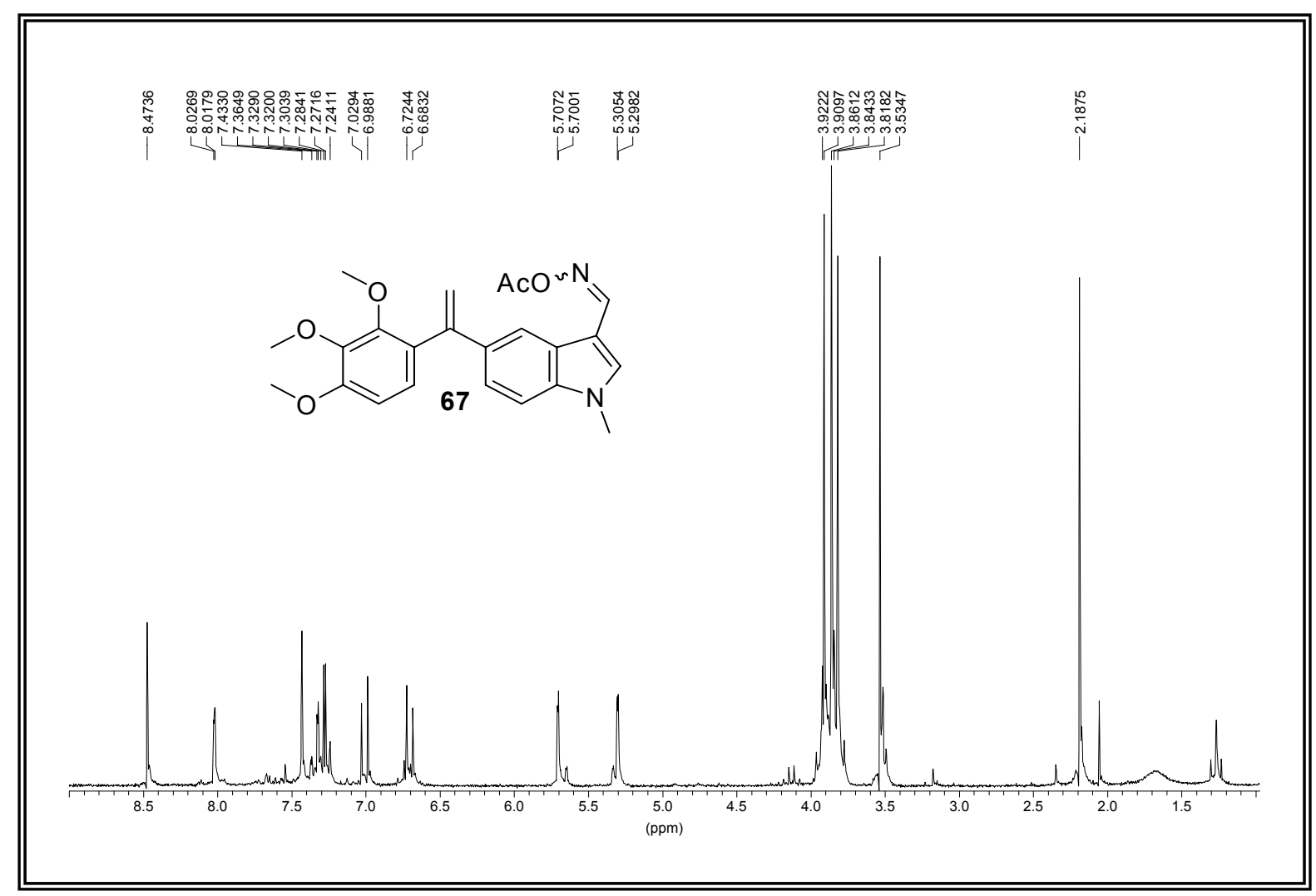

Figura L. Espectro de RMN ${ }^{1} \mathrm{H}$ del compuesto 67. 


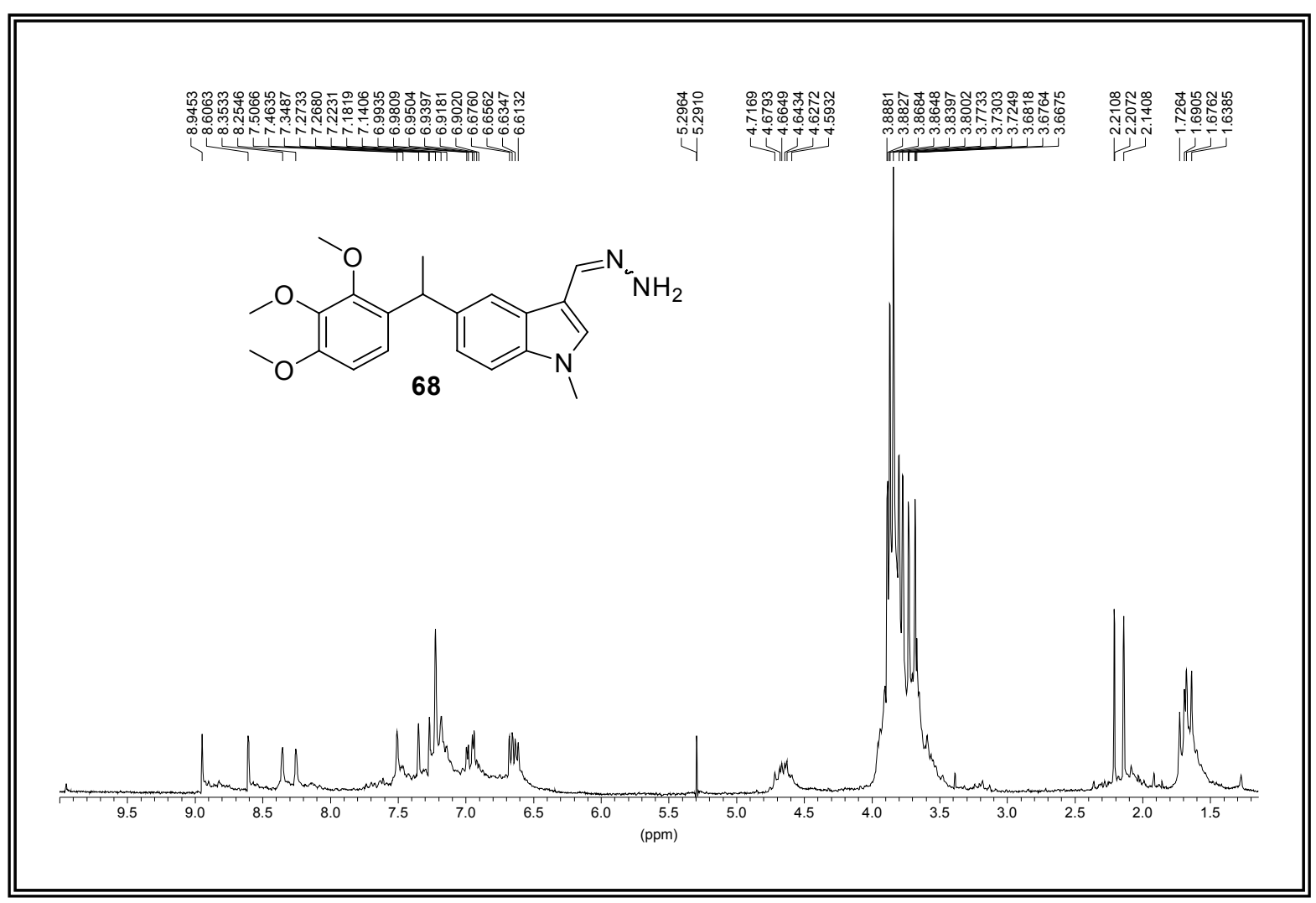

Figura LIa. Espectro de RMN ${ }^{1} \mathrm{H}$ de los compuestos $68 Z$ y $68 E$.

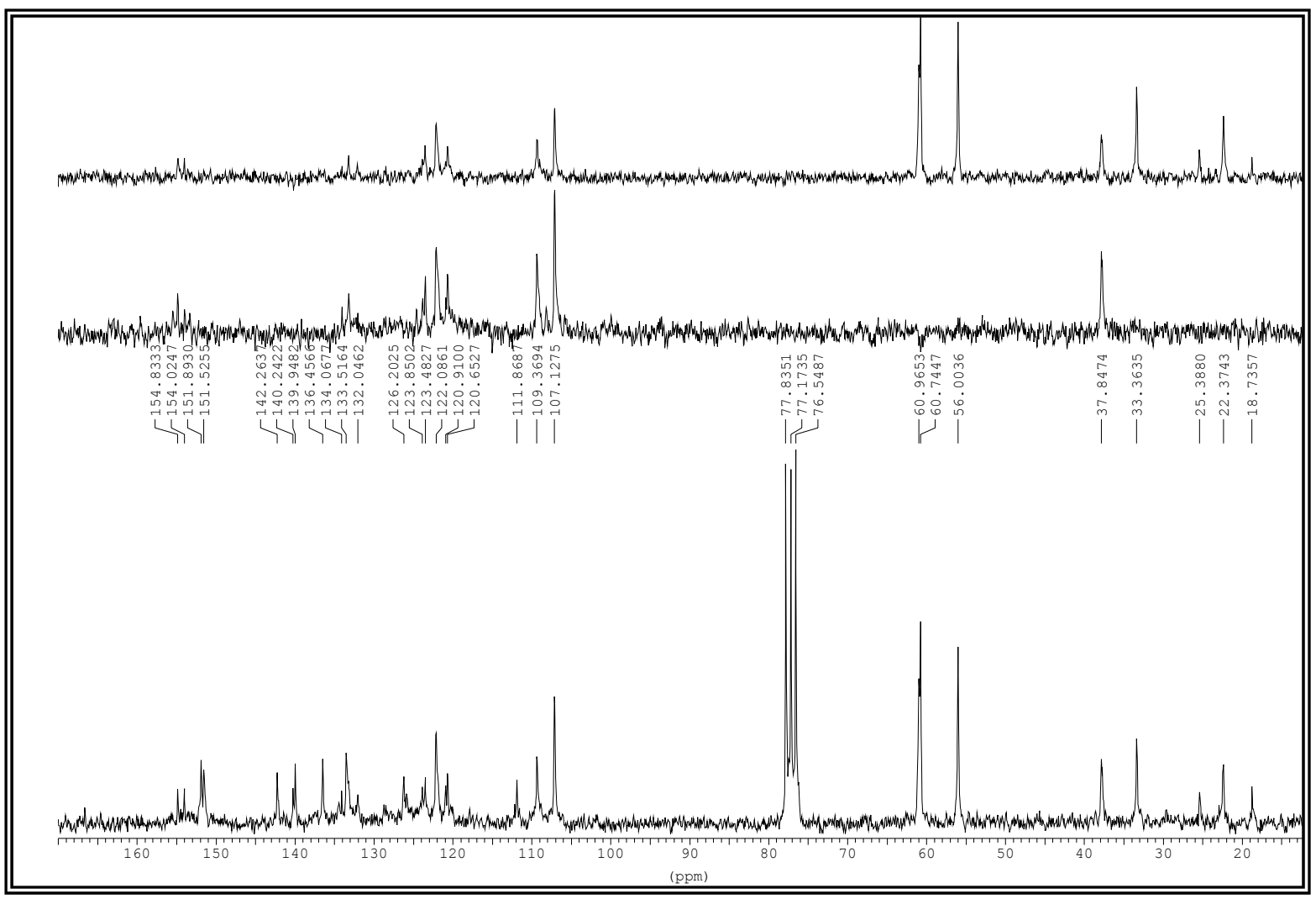

Figura LIb. Espectro de RMN ${ }^{13} \mathrm{C}$ de los compuestos $68 Z$ y $68 E$. 


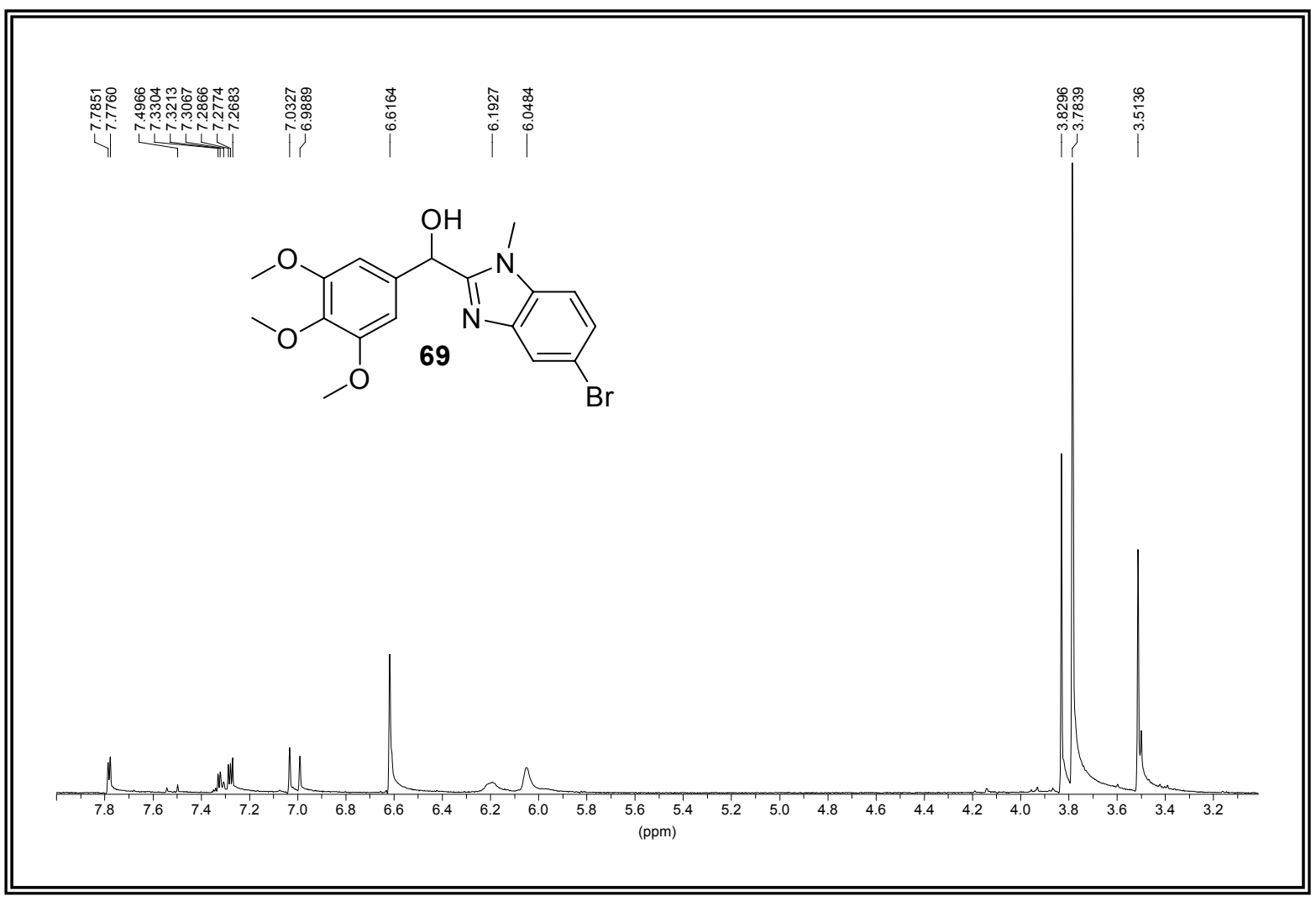

Figura LIIa. Espectro de RMN ${ }^{1} \mathrm{H}$ del compuesto 69.

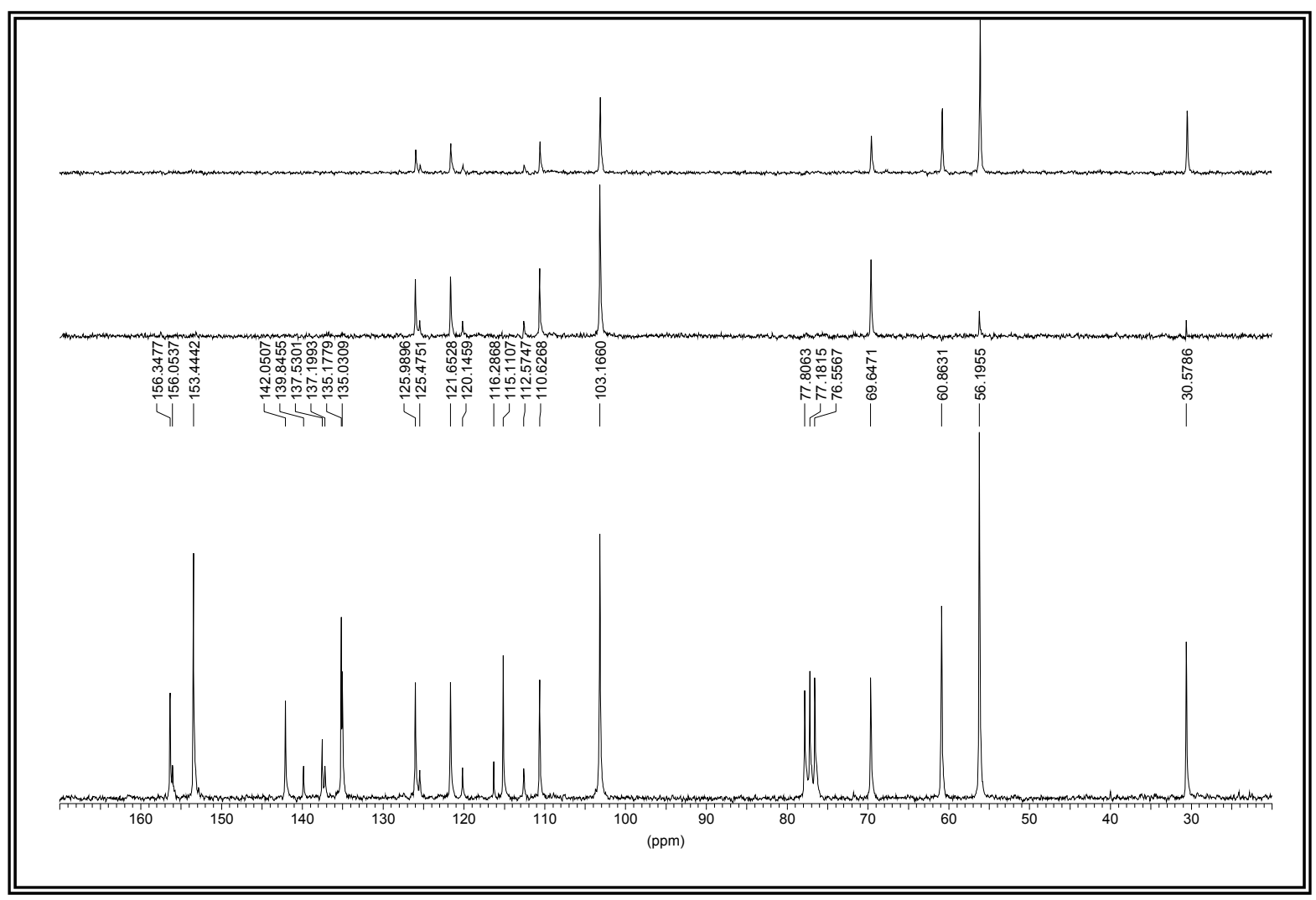

Figura LIIb. Espectro de RMN ${ }^{13} \mathrm{C}$ del compuesto 69. 


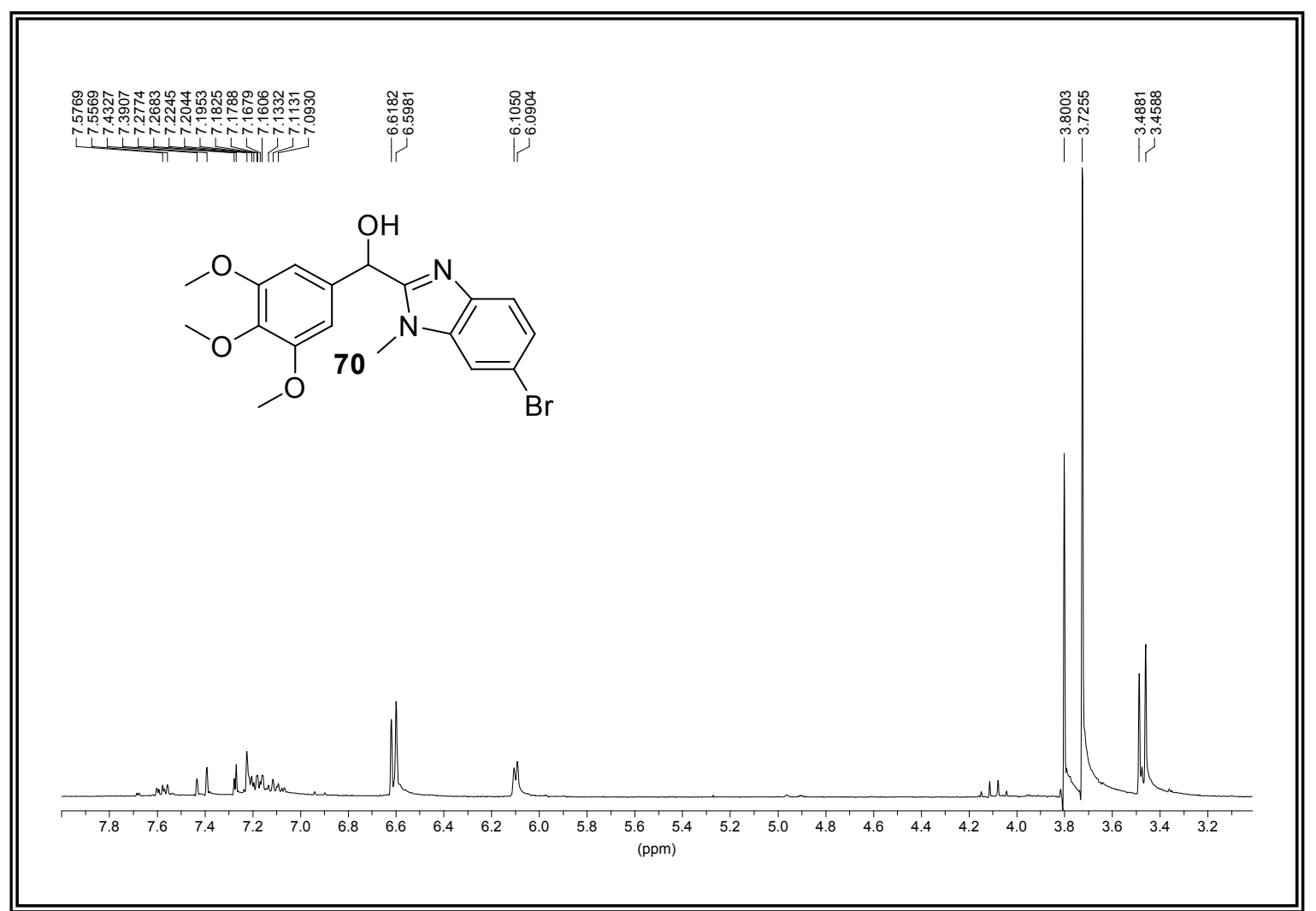

Figura LIII. Espectro de RMN ${ }^{1} \mathrm{H}$ del compuesto 70. 


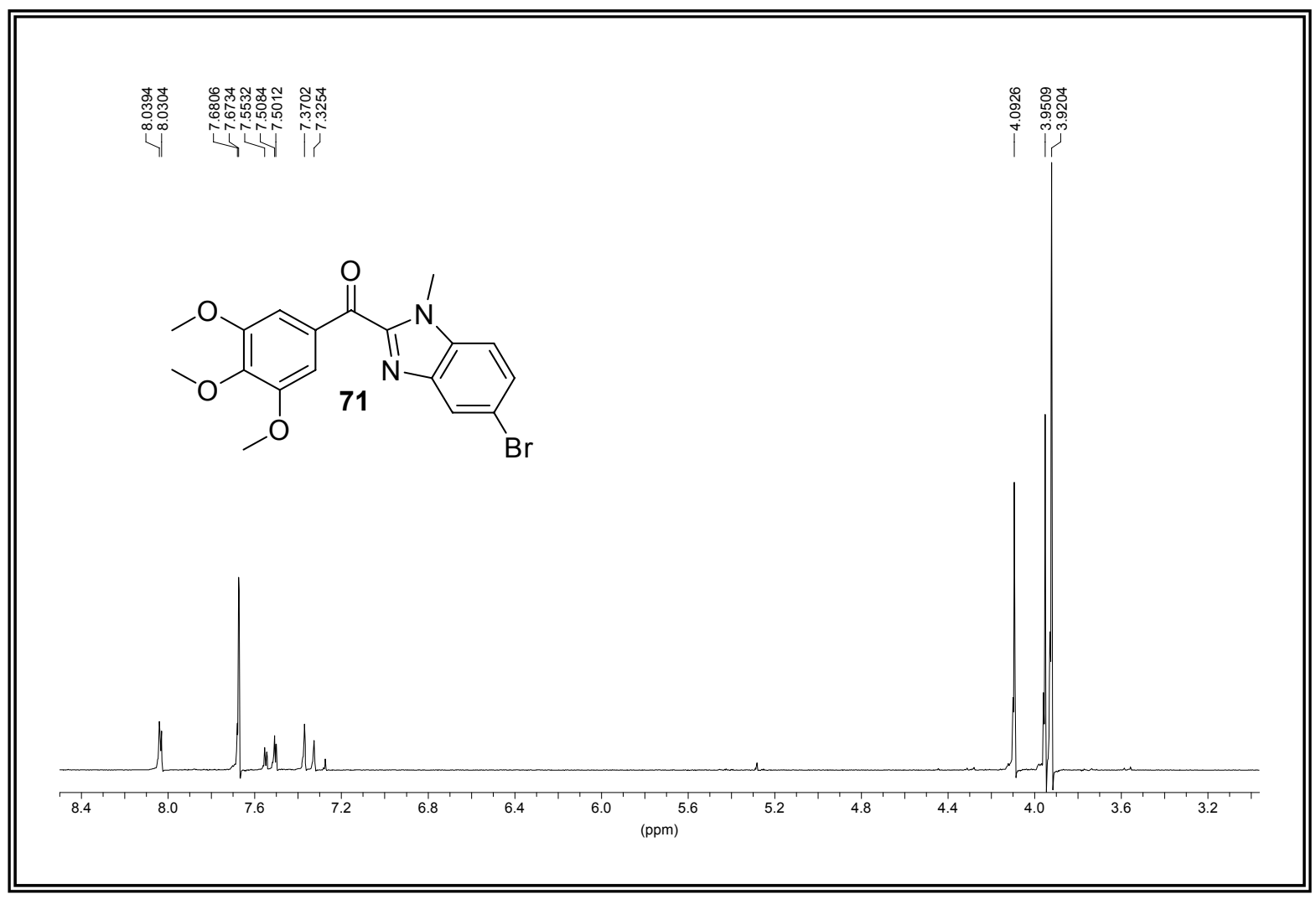

Figura LIVa. Espectro de RMN ${ }^{1} \mathrm{H}$ del compuesto 71.

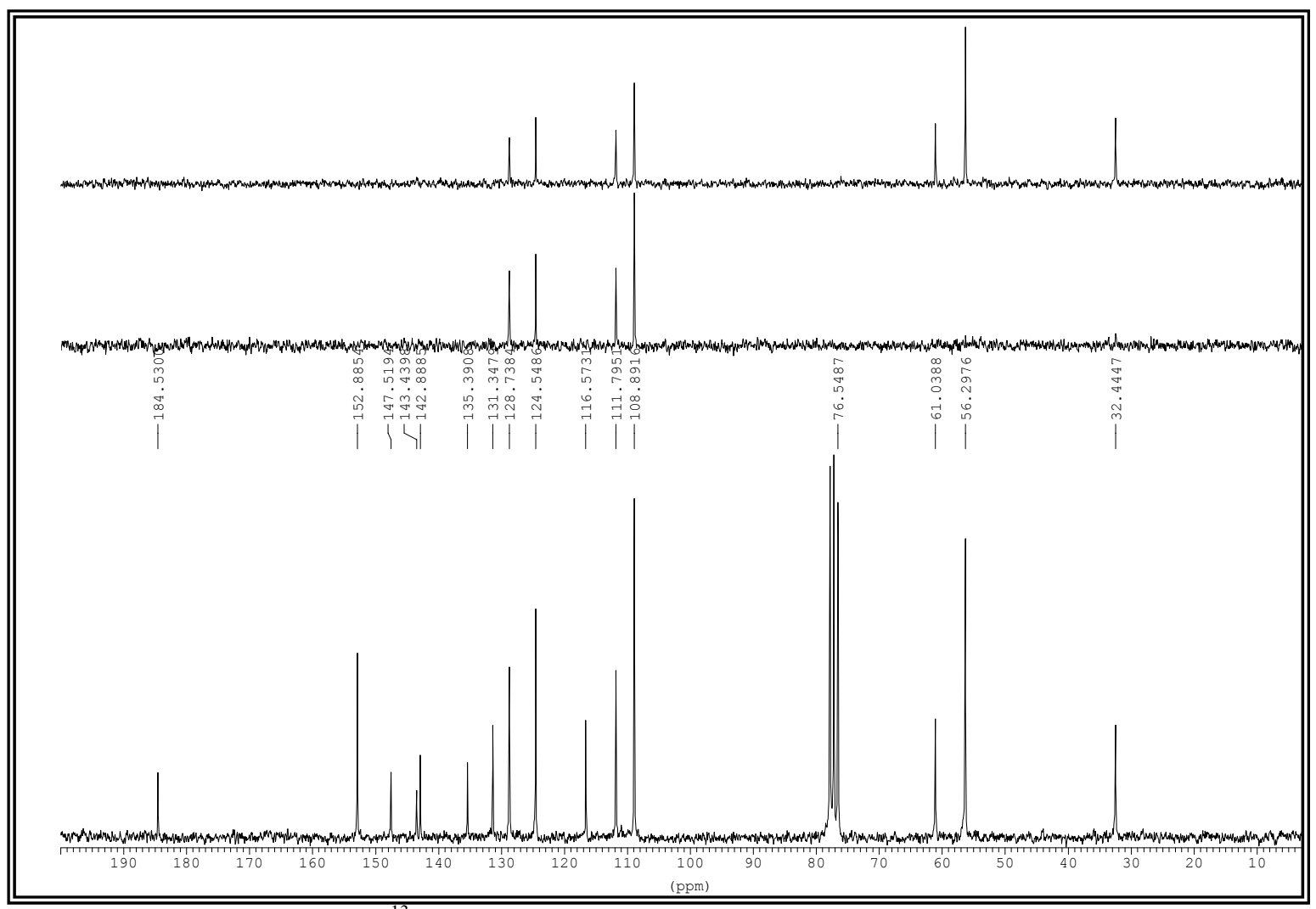

Figura LIVb. Espectro de RMN ${ }^{13} \mathrm{C}$ del compuesto 71. 


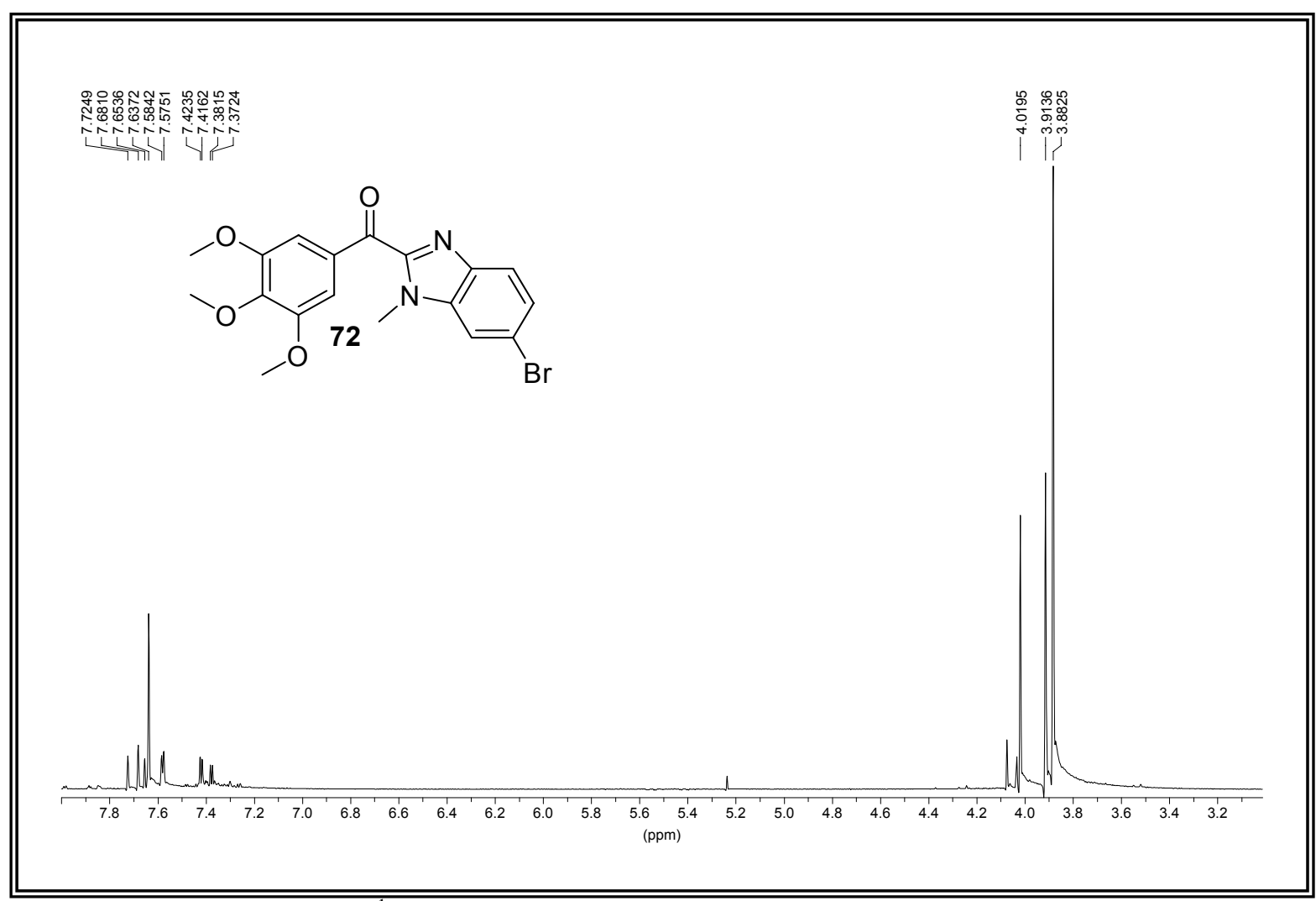

Figura LVa. Espectro de RMN ${ }^{1} \mathrm{H}$ del compuesto 72.

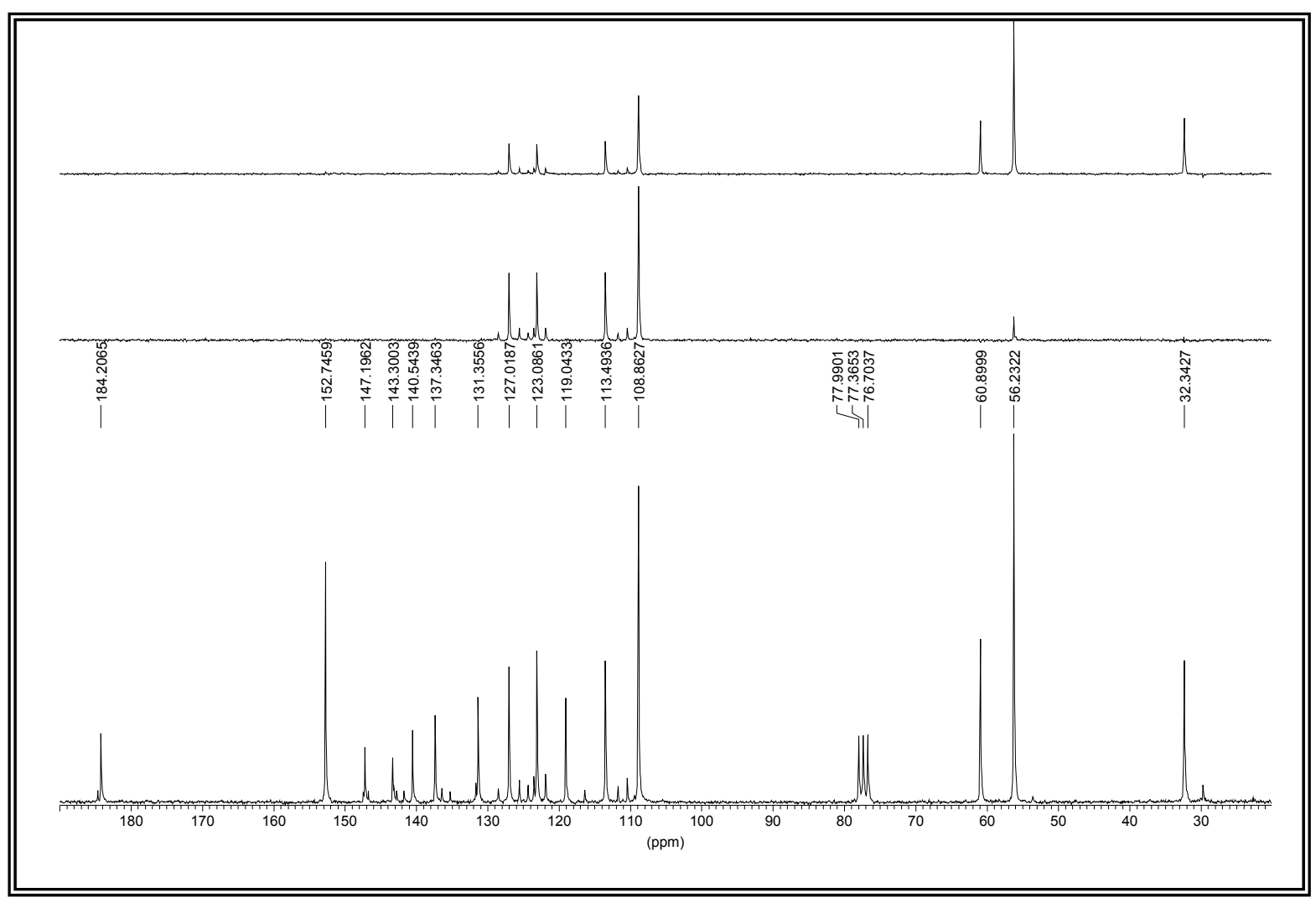

Figura $\mathrm{LVb}$. Espectro de $\mathrm{RMN}{ }^{13} \mathrm{C}$ del compuesto 72. 


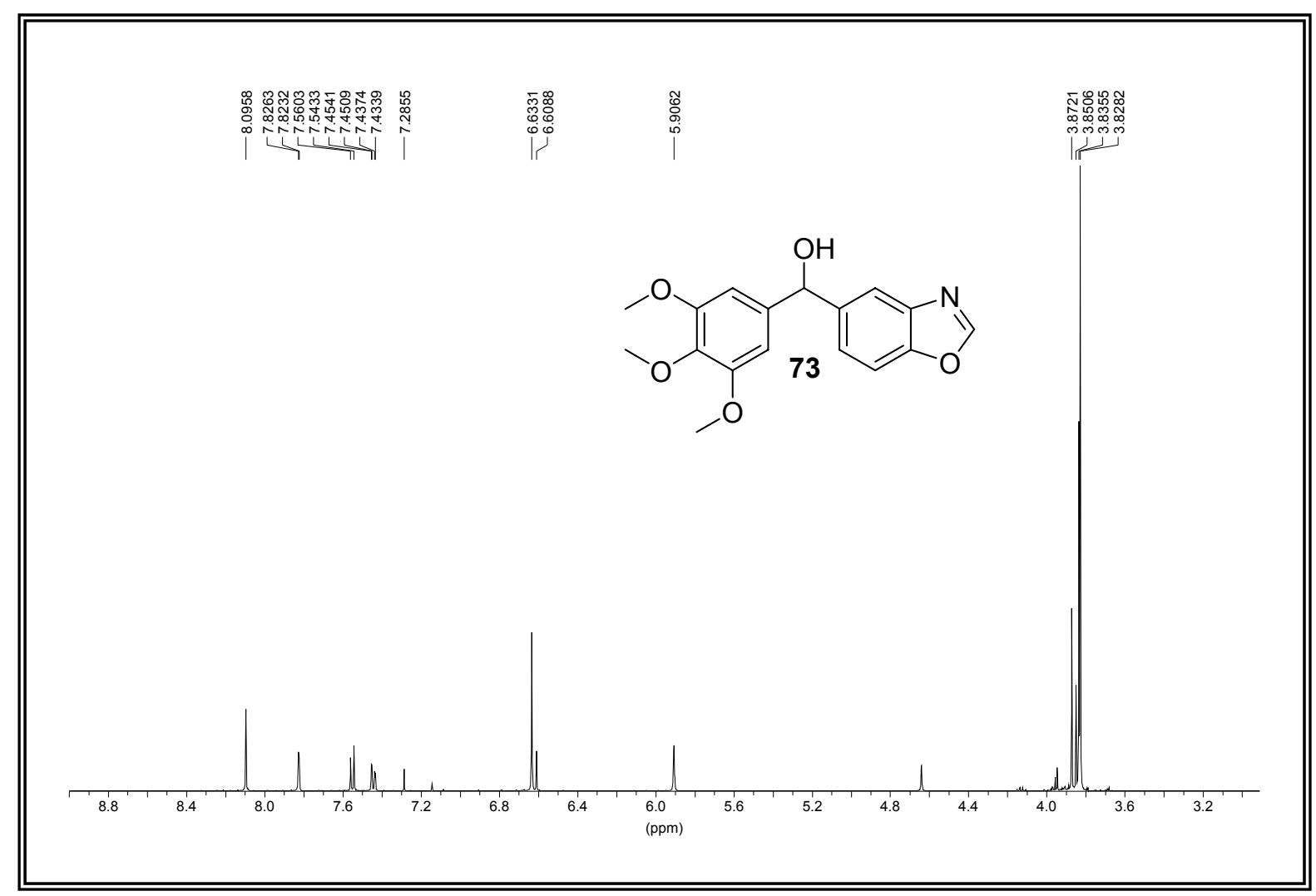

Figura LVIa. Espectro de RMN ${ }^{1} \mathrm{H}$ del compuesto 73.

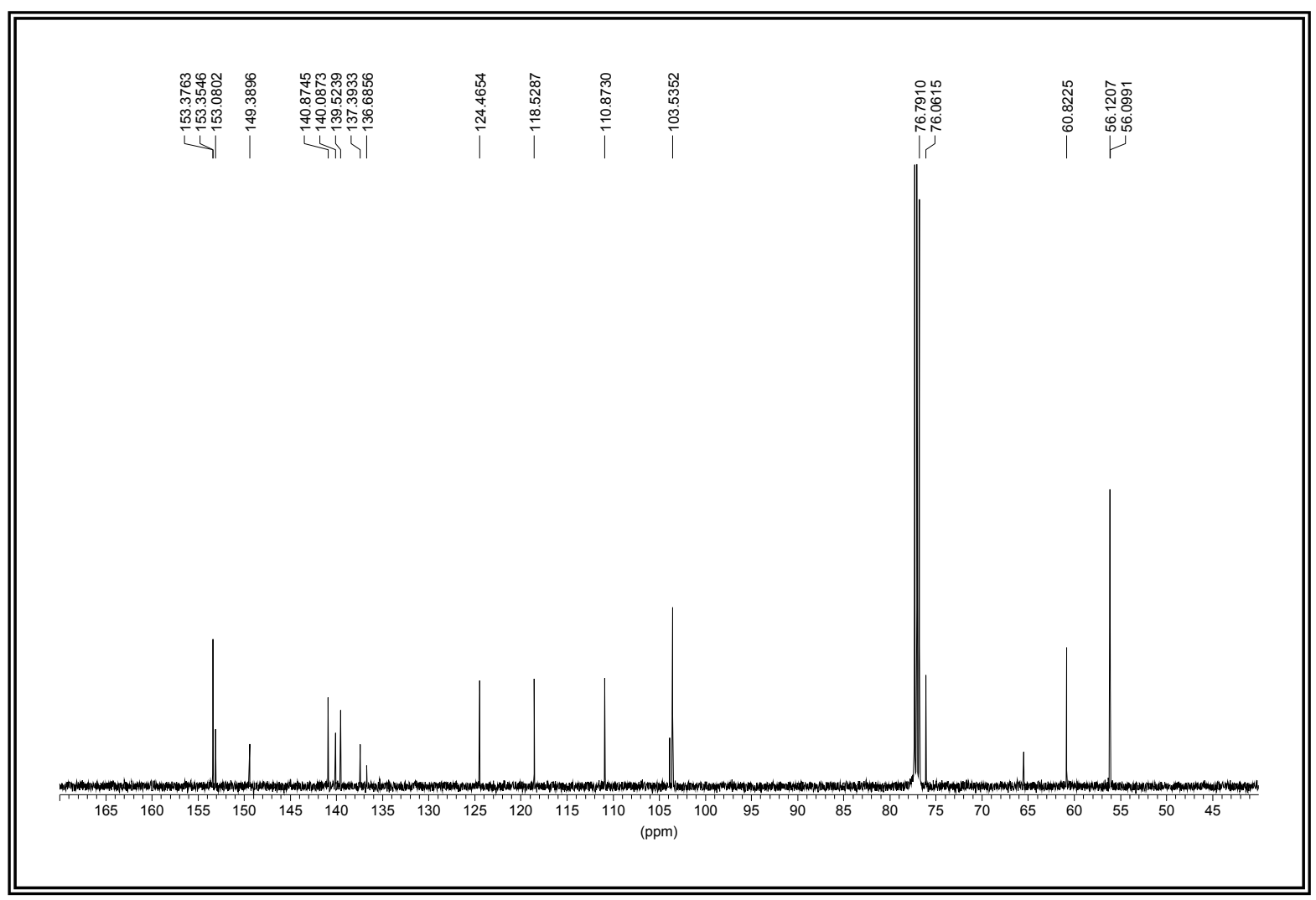

Figura LVIb. Espectro de RMN ${ }^{13} \mathrm{C}$ del compuesto 73 . 


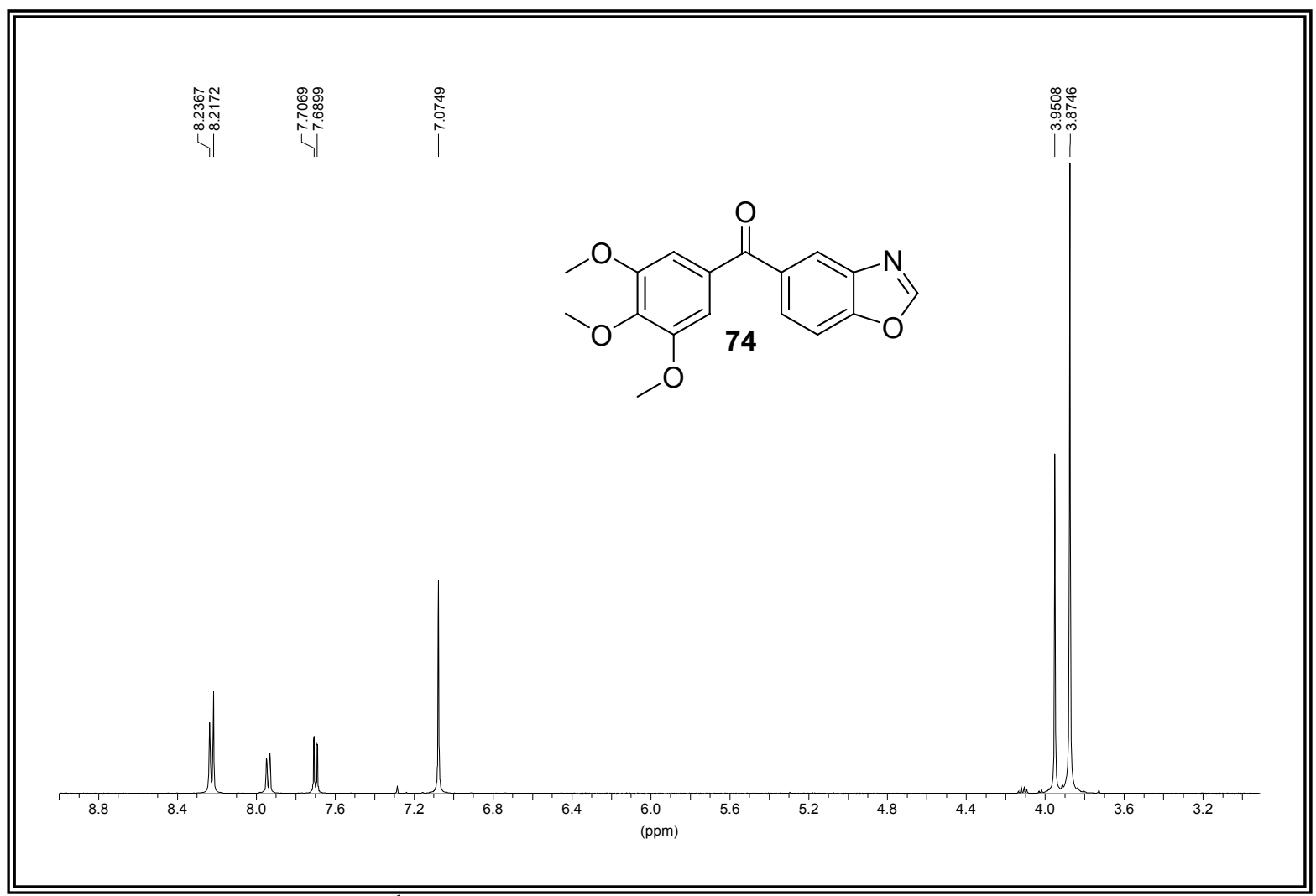

Figura LVIIa. Espectro de RMN ${ }^{1} \mathrm{H}$ del compuesto 74.

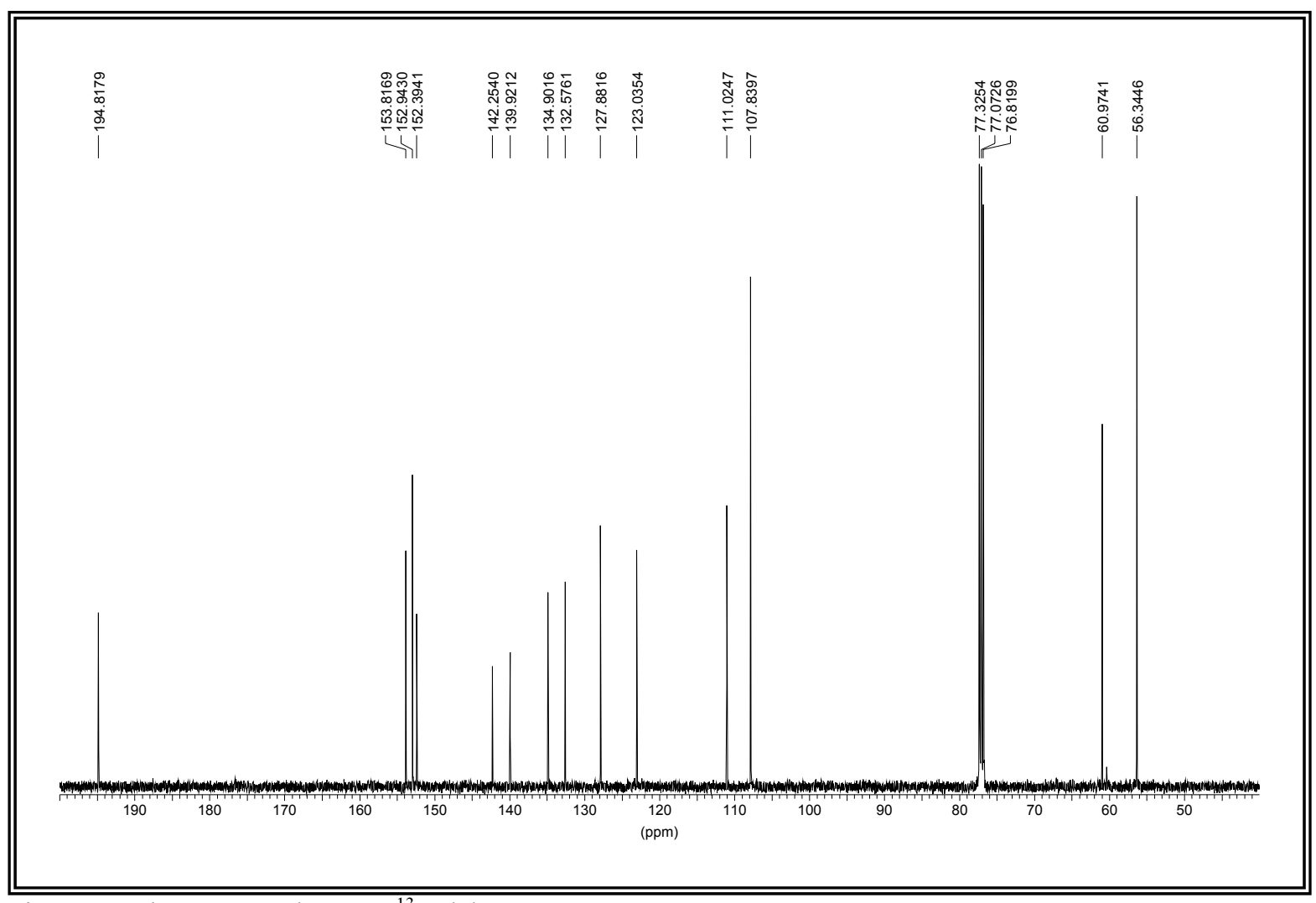

Figura LVIIb. Espectro de RMN ${ }^{13} \mathrm{C}$ del compuesto 74. 


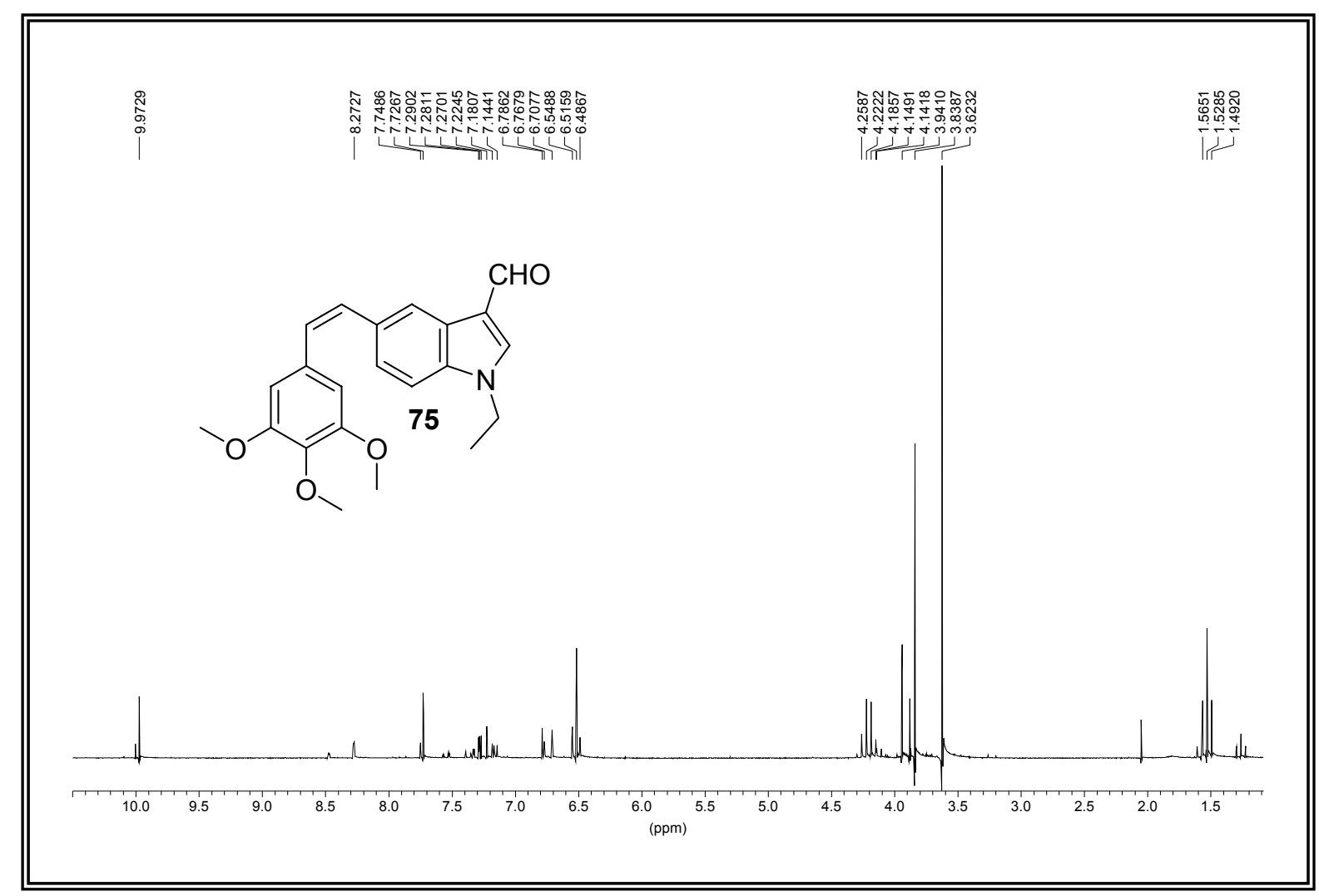

Figura LVIIIa. Espectro de RMN ${ }^{1} \mathrm{H}$ del compuesto 75.

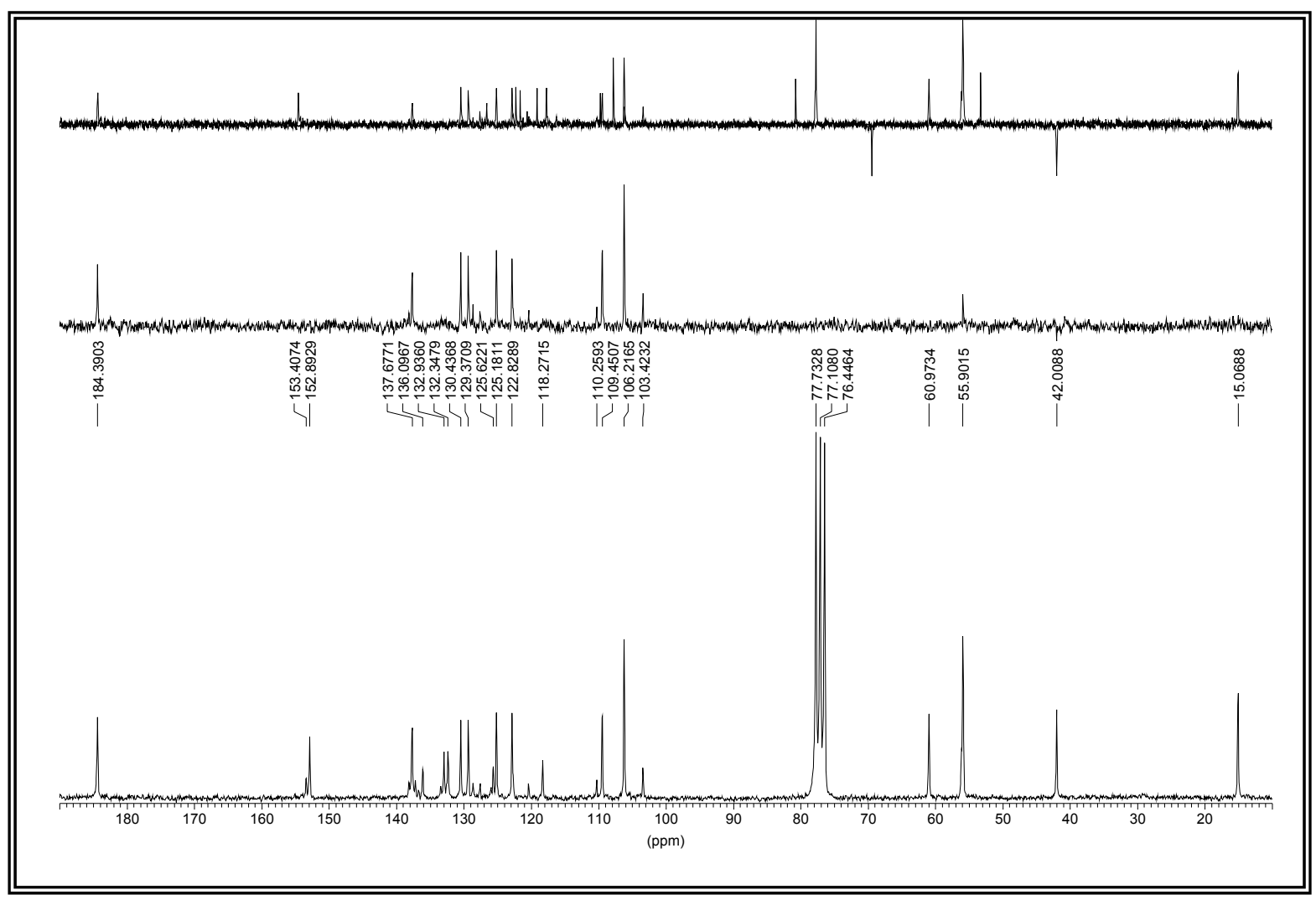

Figura LVIIIb. Espectro de RMN ${ }^{13} \mathrm{C}$ del compuesto 75. 


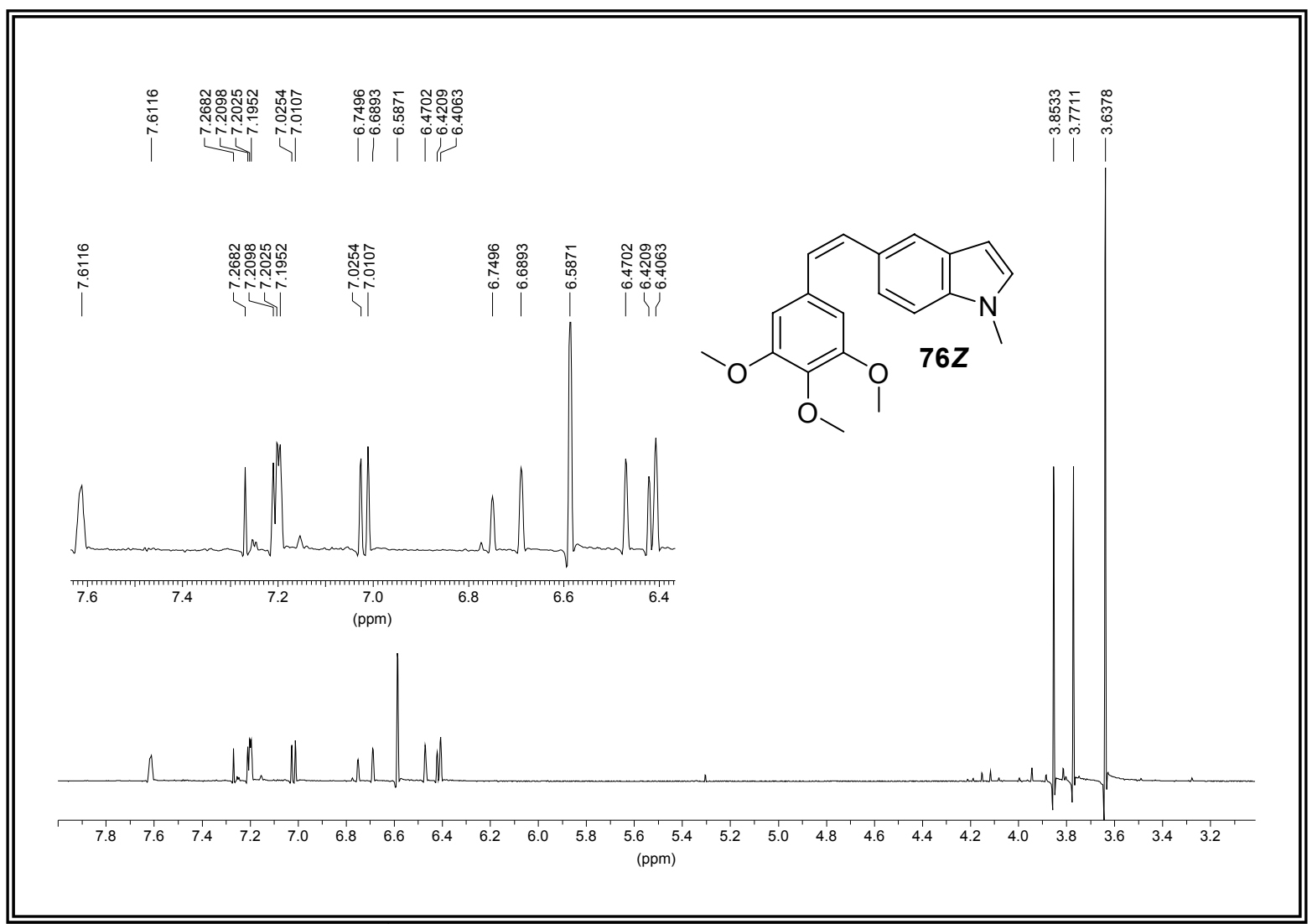

Figura LIXa. Espectro de RMN ${ }^{1} \mathrm{H}$ del compuesto $76 Z$.

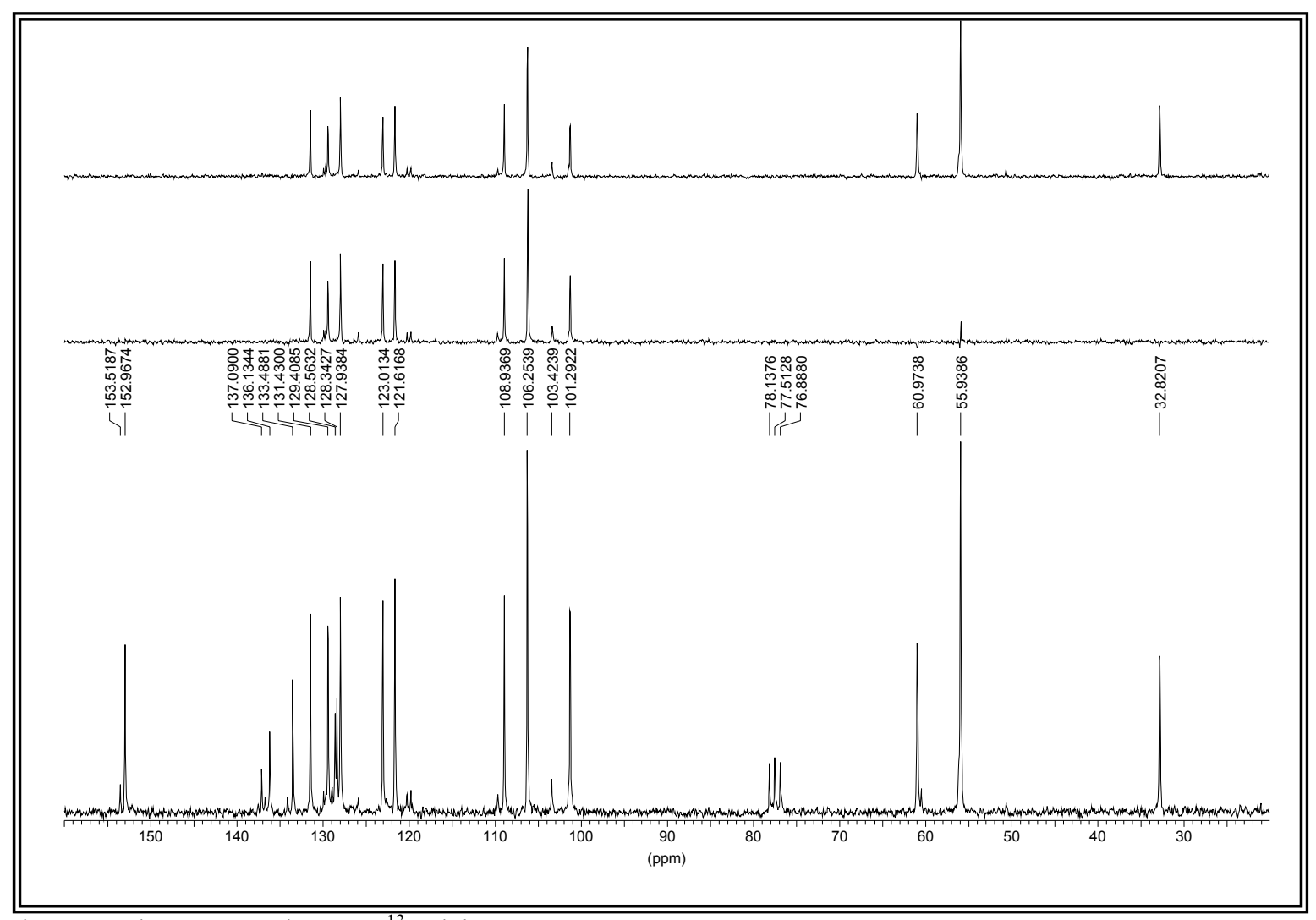

Figura LIXb. Espectro de RMN ${ }^{13} \mathrm{C}$ del compuesto $76 Z$. 


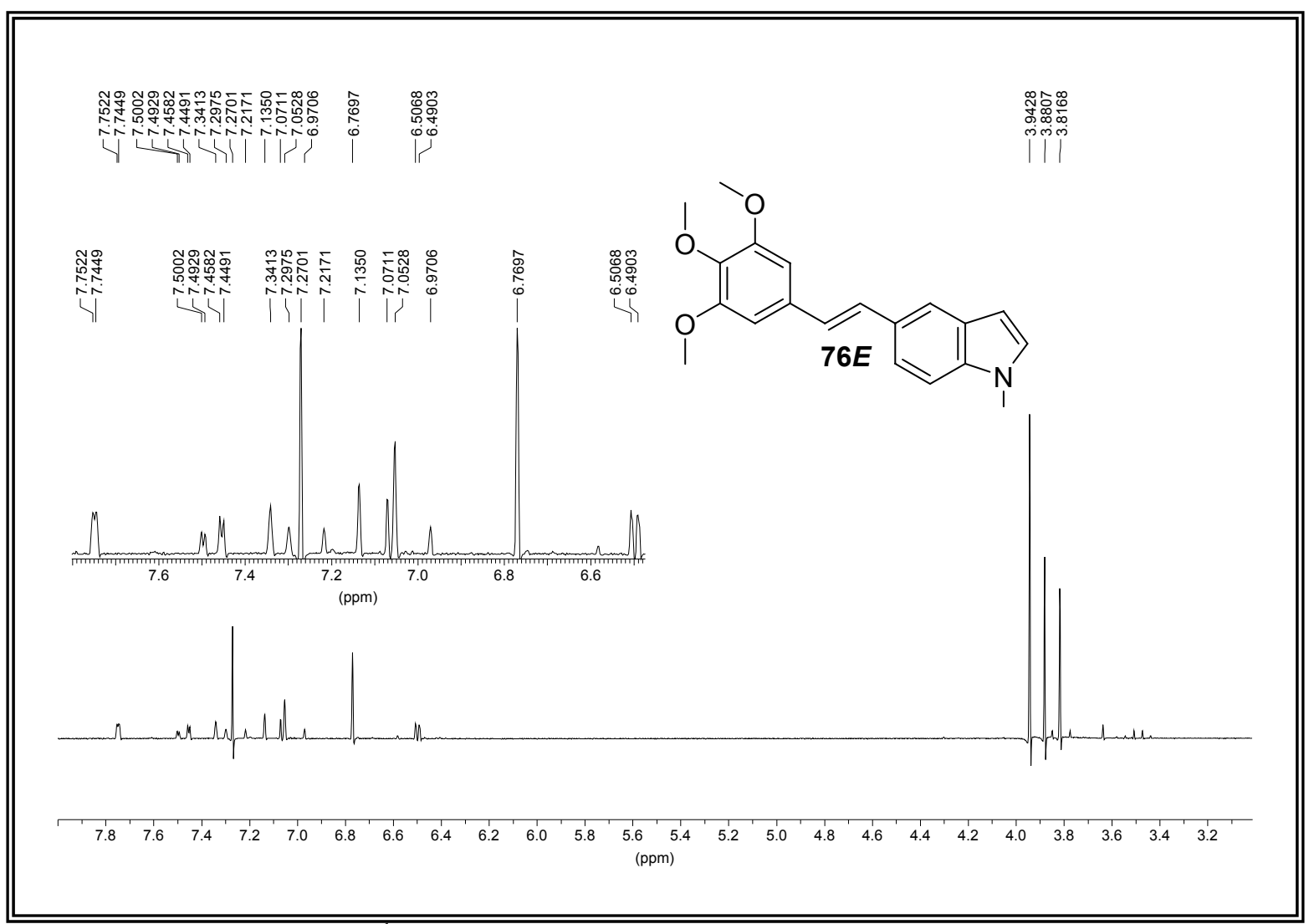

Figura LIXc. Espectro de RMN ${ }^{1} \mathrm{H}$ del compuesto $76 \boldsymbol{E}$.

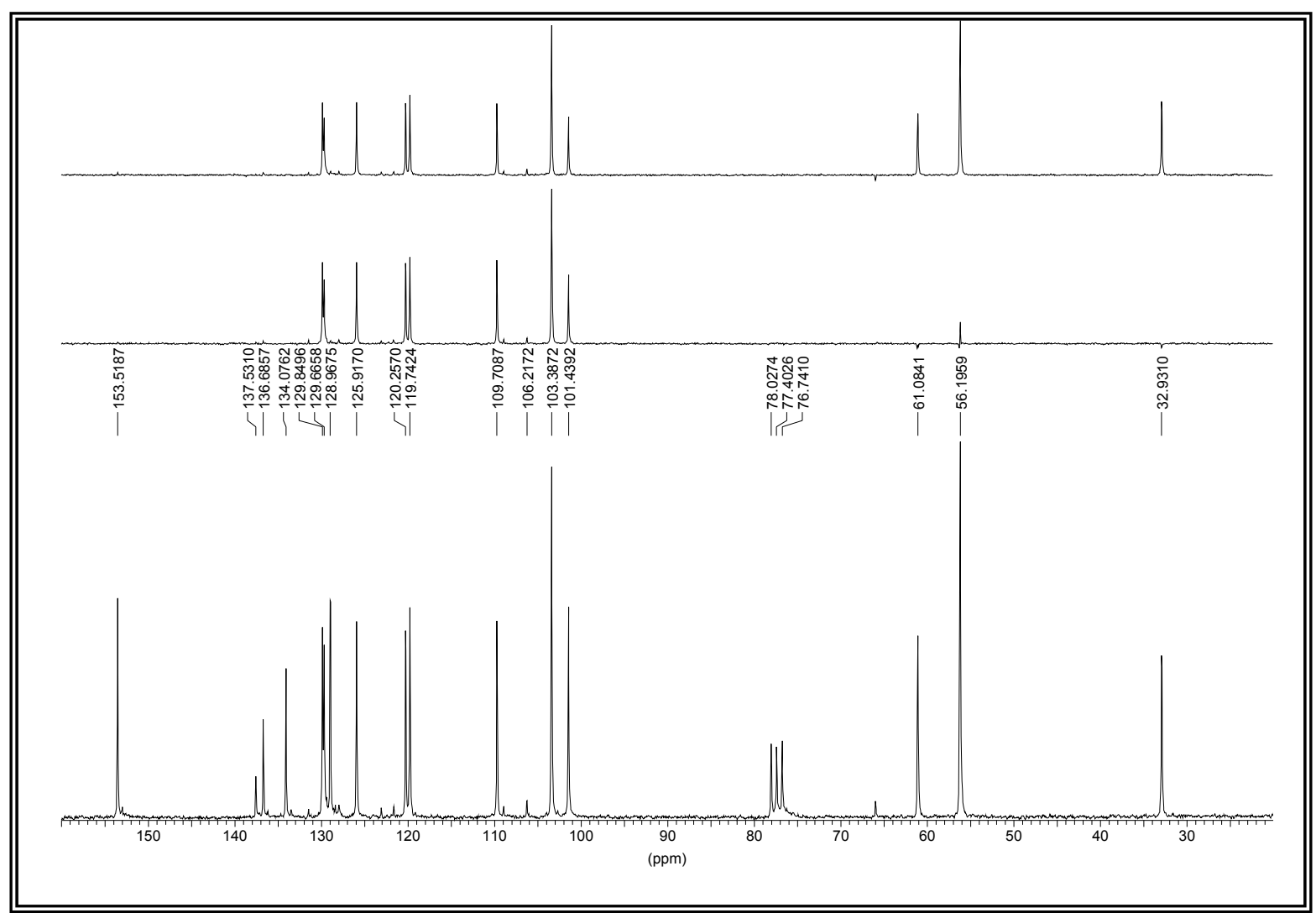

Figura LIXd. Espectro de RMN ${ }^{13} \mathrm{C}$ del compuesto $76 \boldsymbol{E}$. 


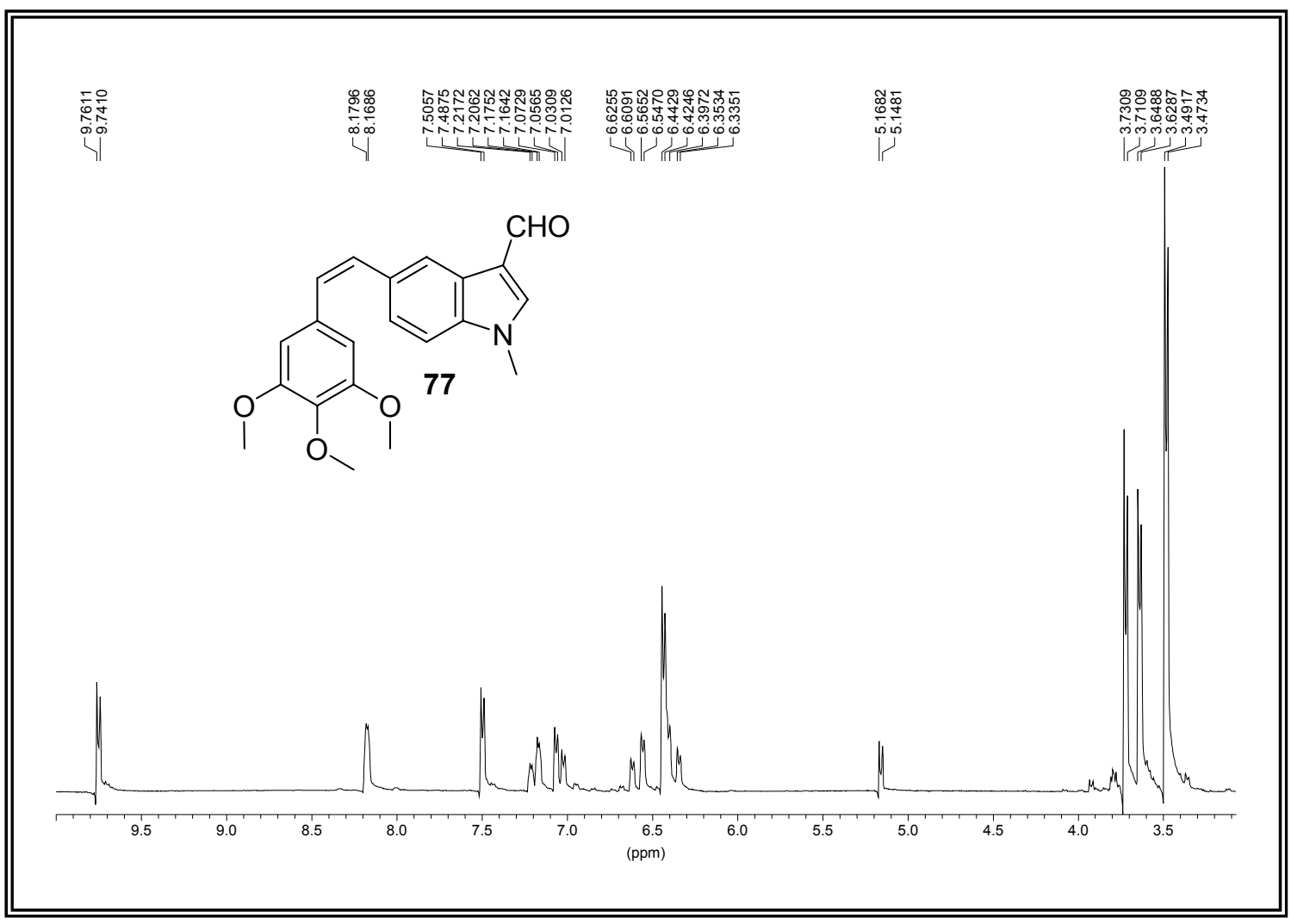

Figura LXa. Espectro de RMN ${ }^{1} \mathrm{H}$ del compuesto 77.

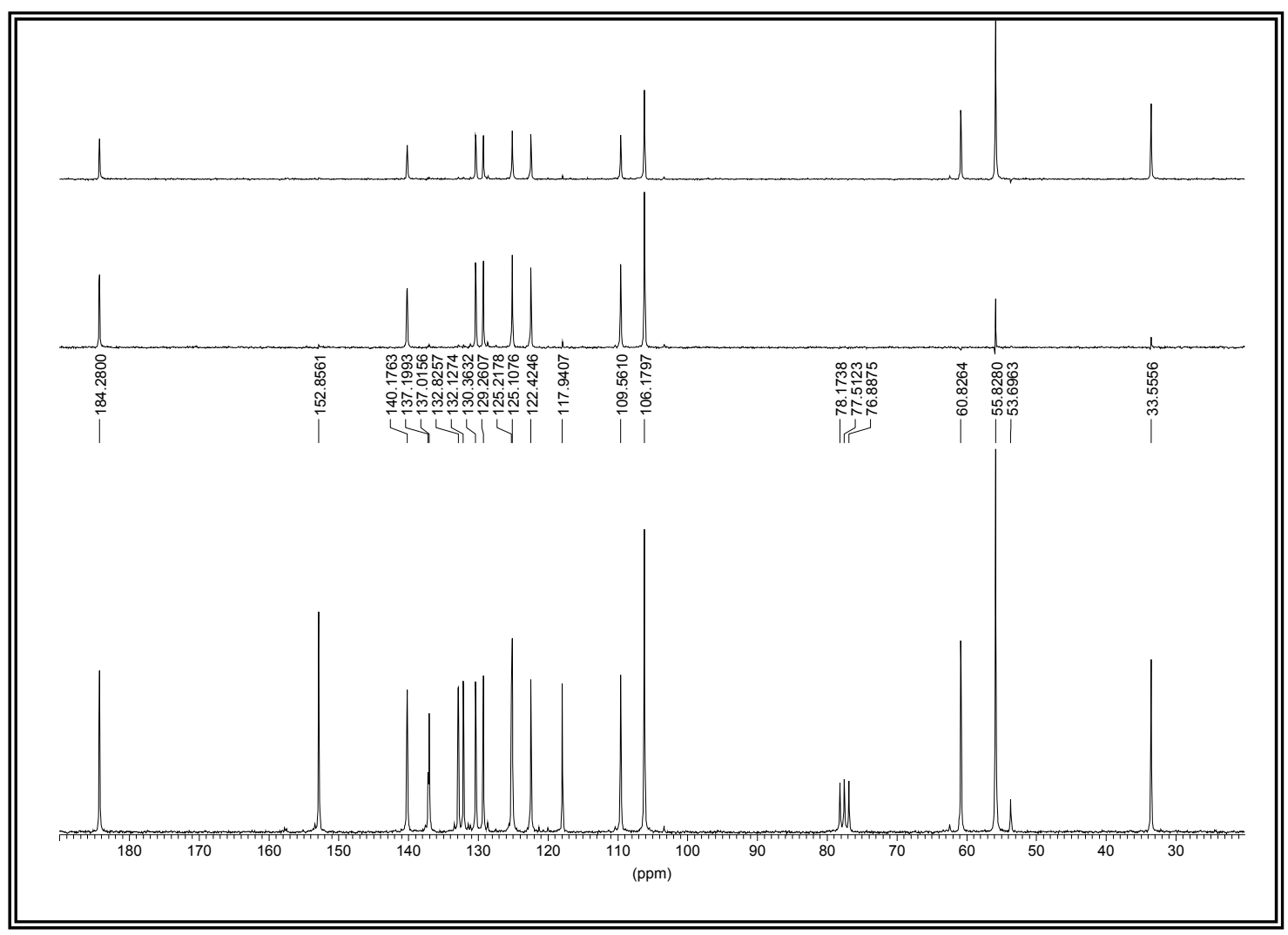

Figura LXb. Espectro de RMN ${ }^{13} \mathrm{C}$ del compuesto 77. 


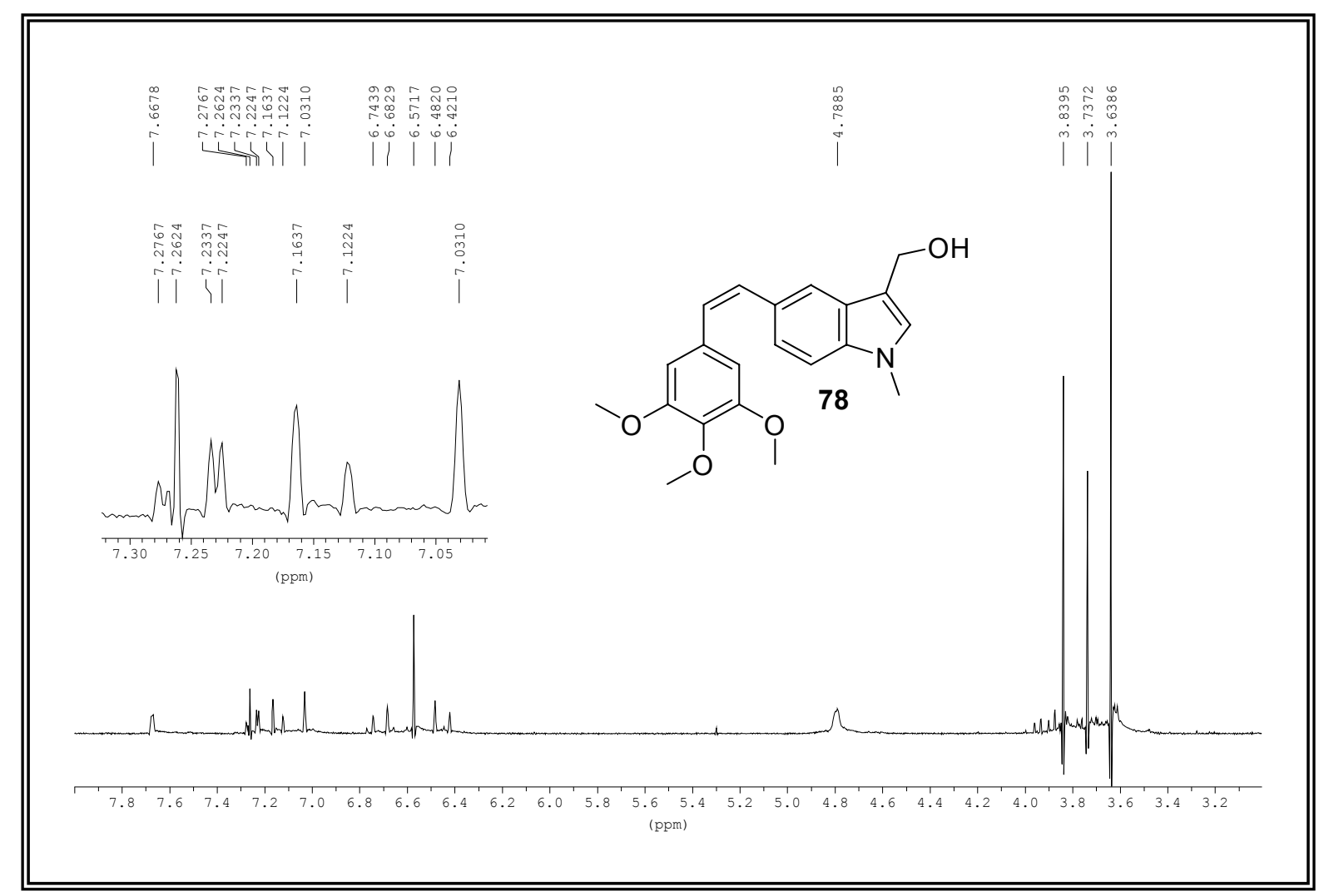

Figura LXIa. Espectro de RMN ${ }^{1} \mathrm{H}$ del compuesto 78.

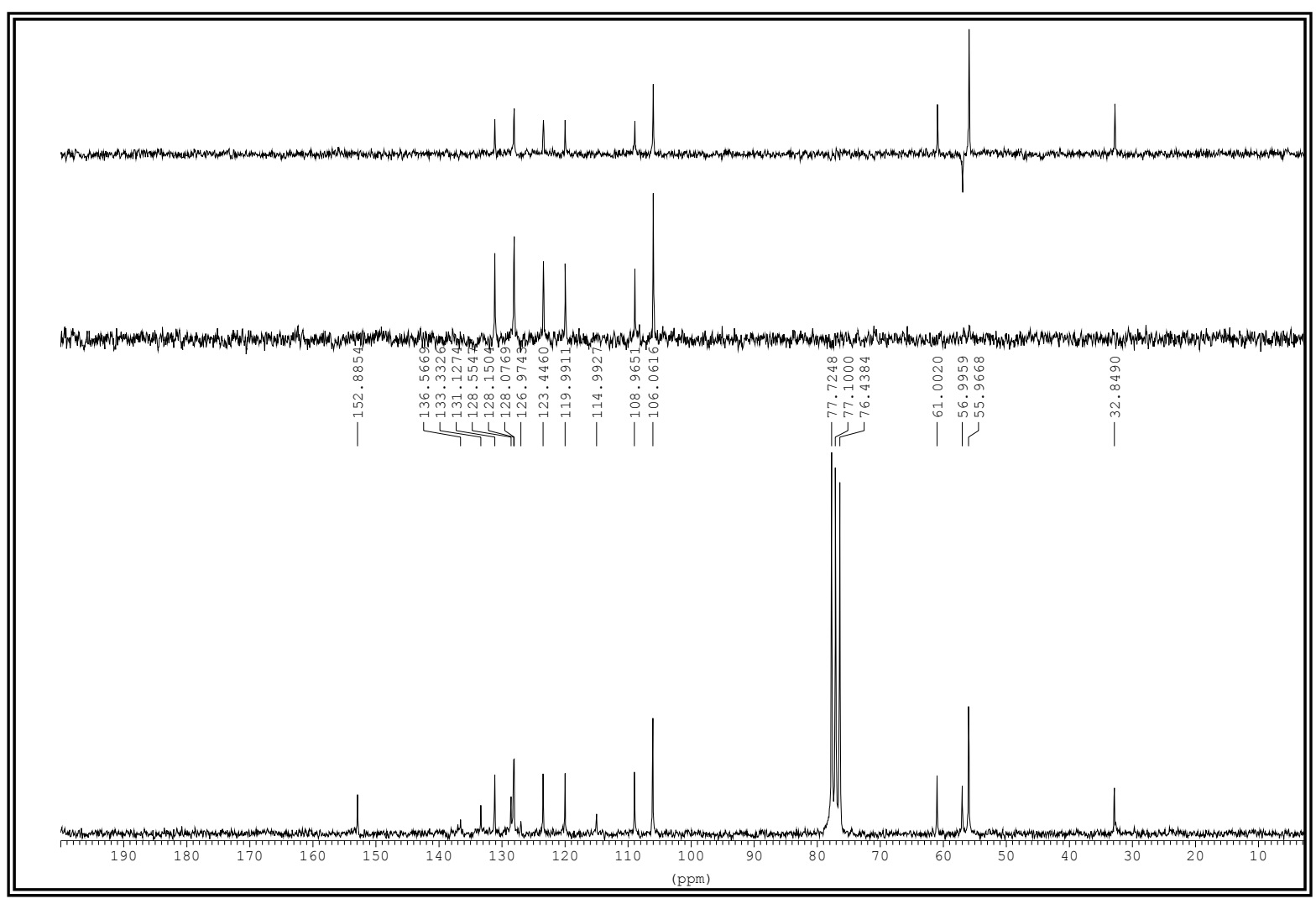

Figura LXIb. Espectro de RMN ${ }^{13} \mathrm{C}$ del compuesto 78. 


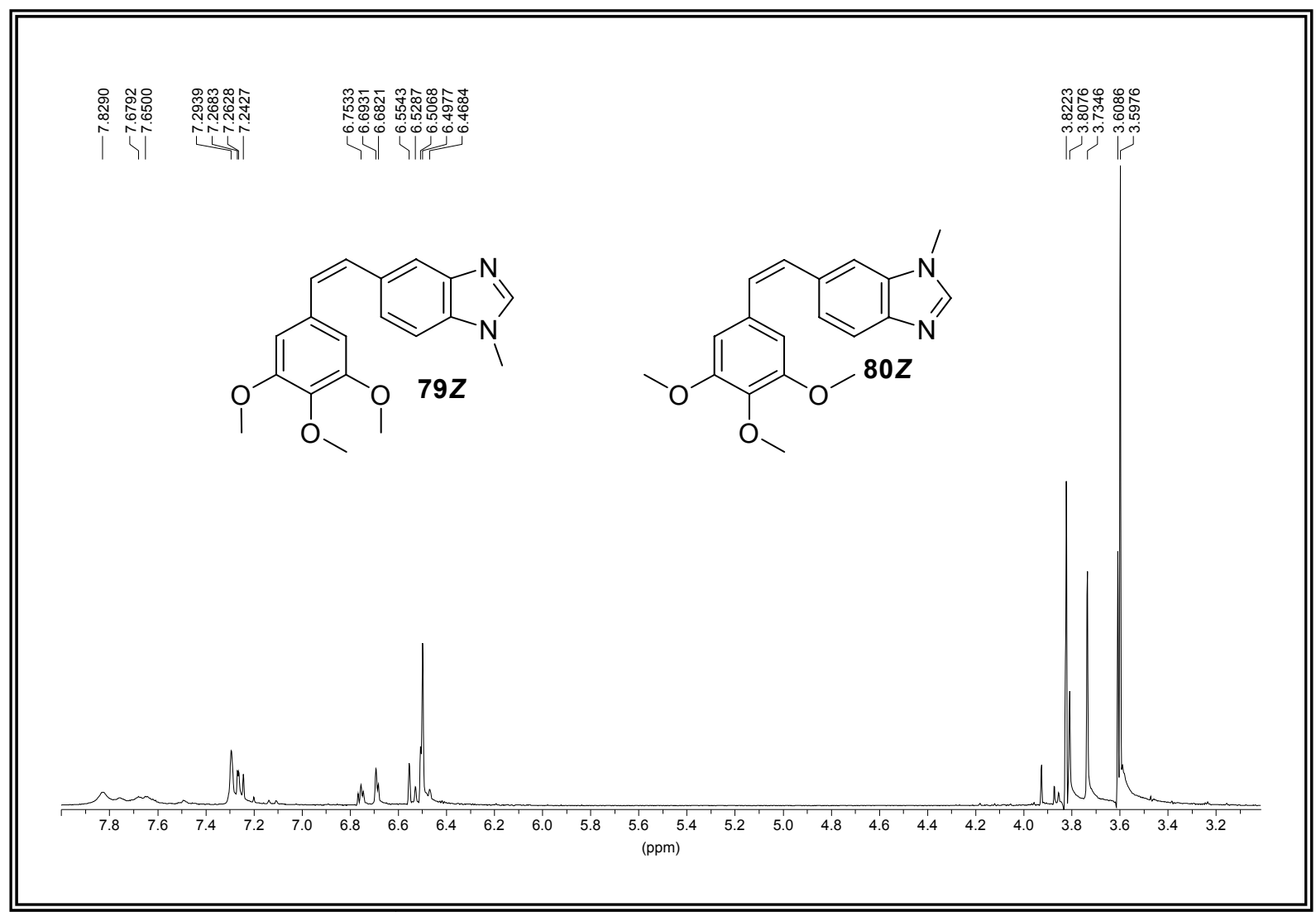

Figura LXIIa. Espectro de RMN ${ }^{1} \mathrm{H}$ de los compuestos $79 Z$ y $80 Z$.

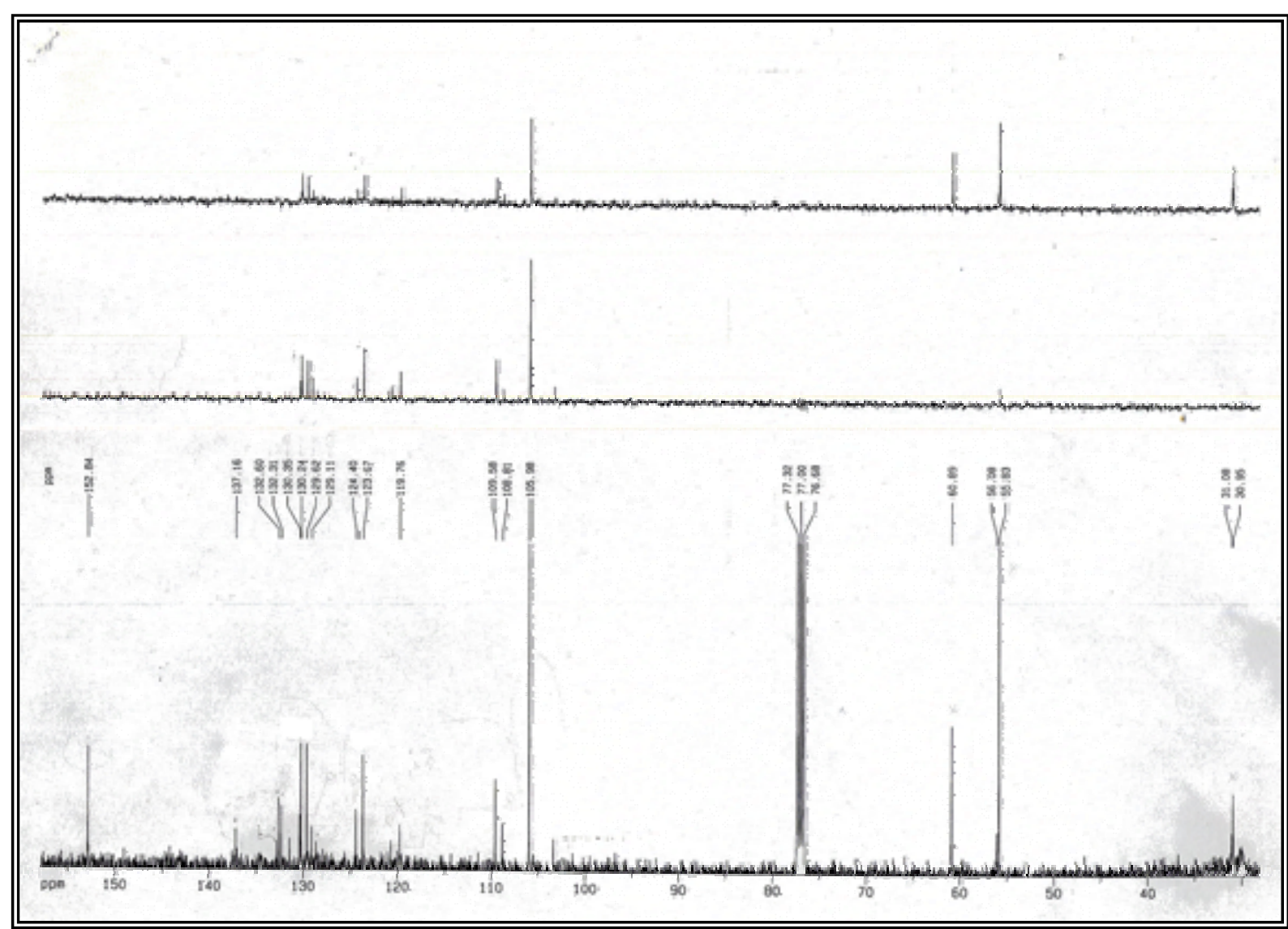

Figura LXIIb. Espectro de RMN ${ }^{13} \mathrm{C}$ del compuesto $79 Z$ y $80 Z$. 


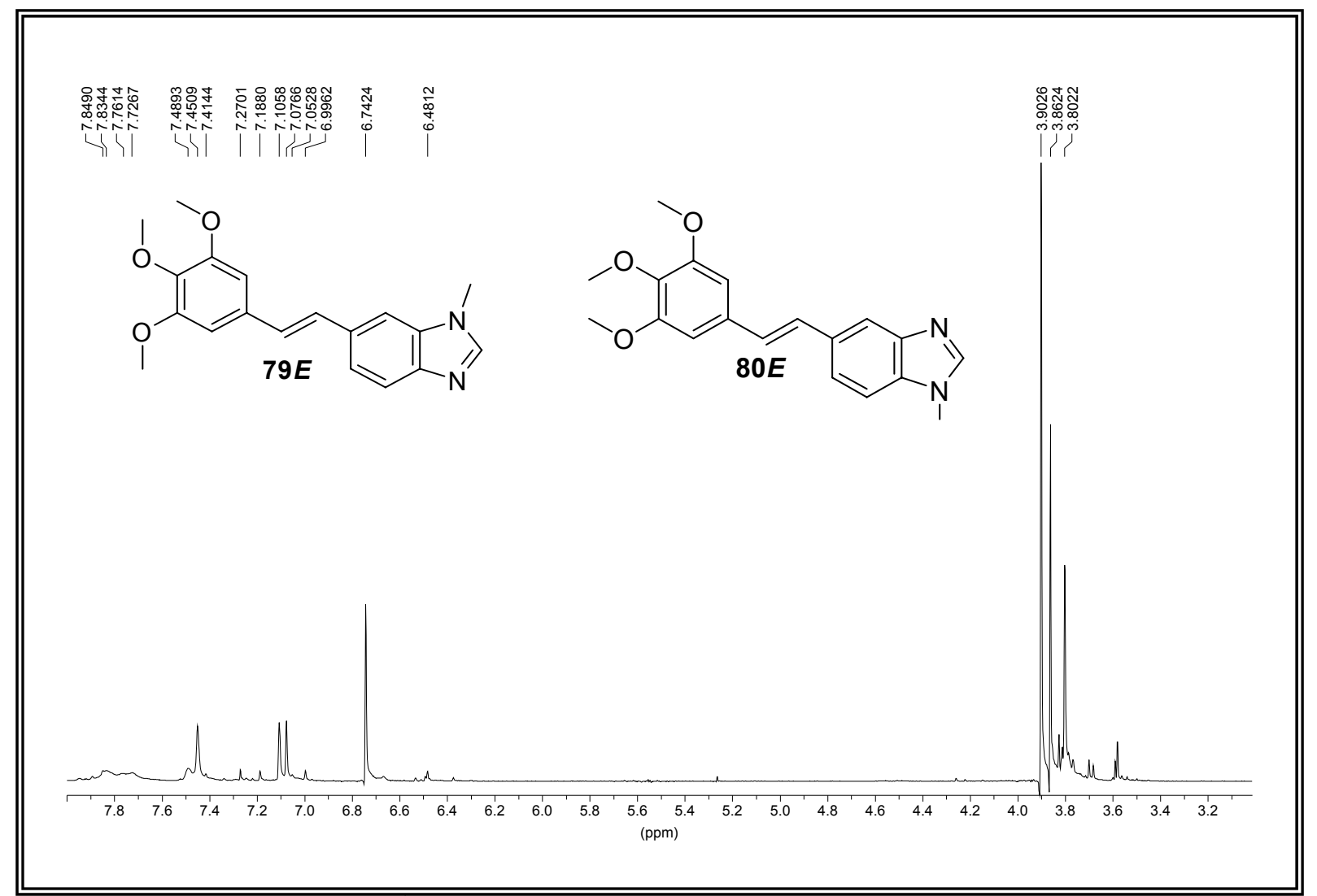

Figura LXIIIa. Espectro de RMN ${ }^{1} \mathrm{H}$ del compuesto $79 \boldsymbol{E}$ ó $80 \boldsymbol{E}$.

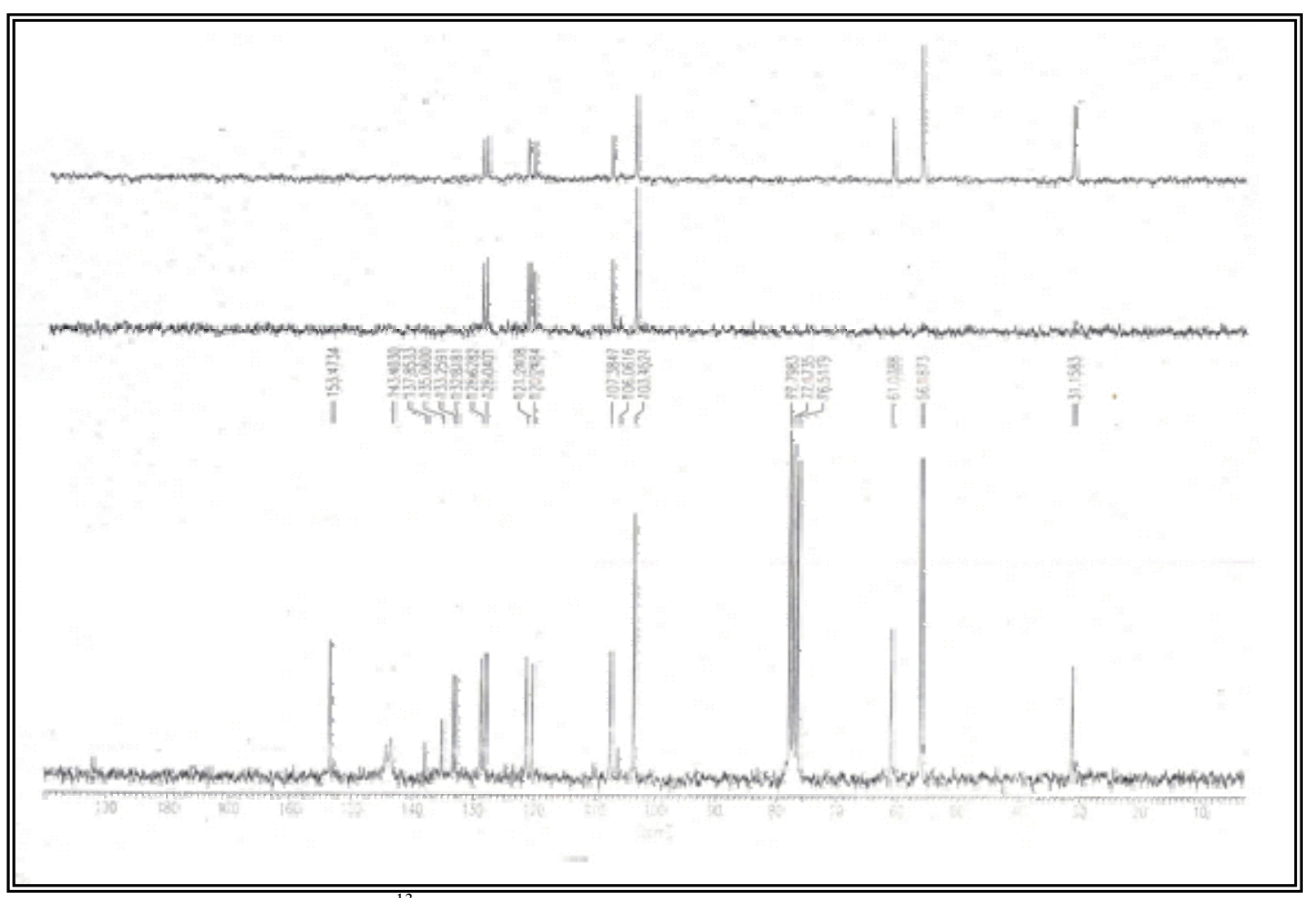

Figura LXIIIb. Espectro de RMN ${ }^{13} \mathrm{C}$ del compuesto $79 \boldsymbol{E}$ y $80 E$. 


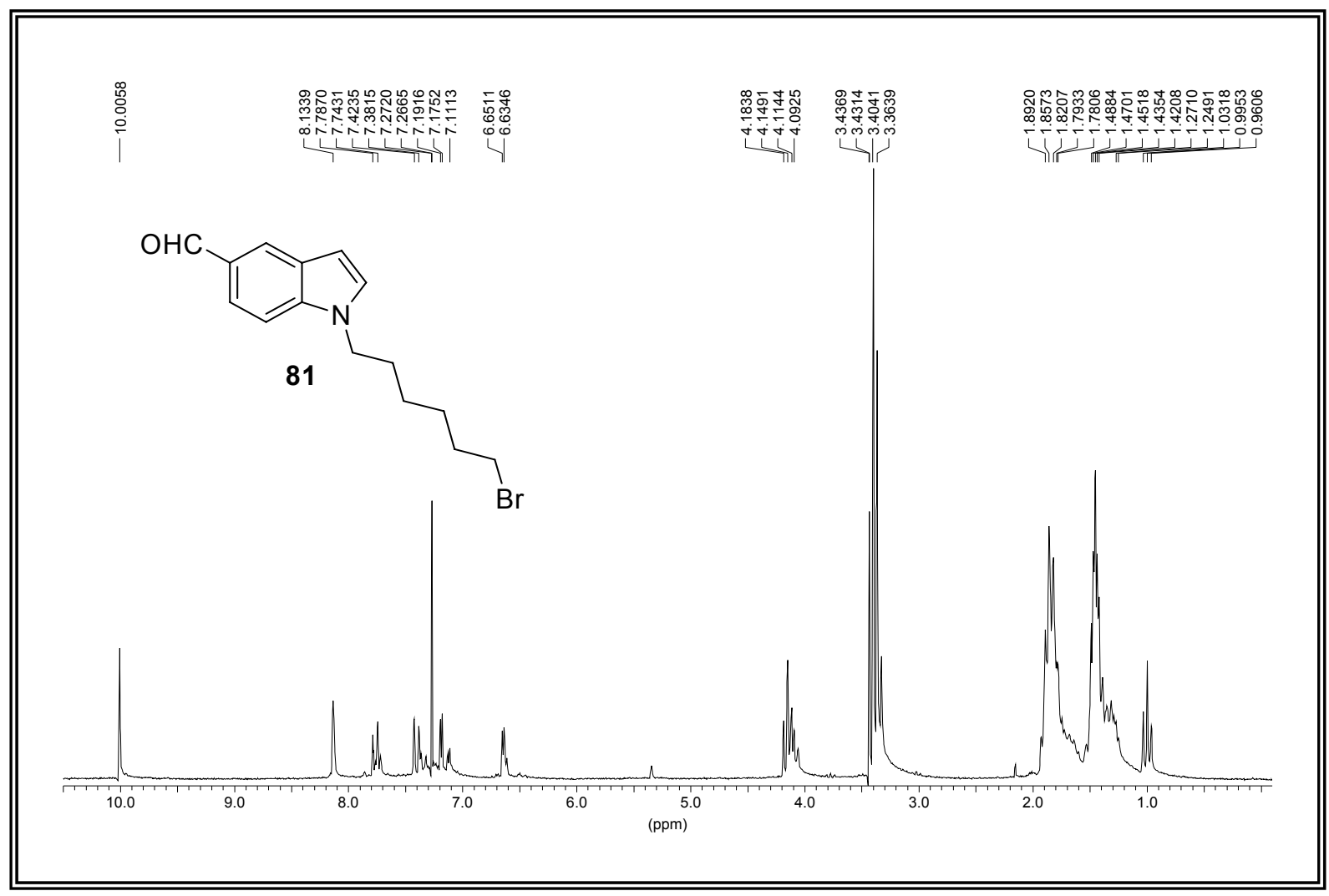

Figura LXIVa. Espectro de RMN ${ }^{1} \mathrm{H}$ del compuesto 81.

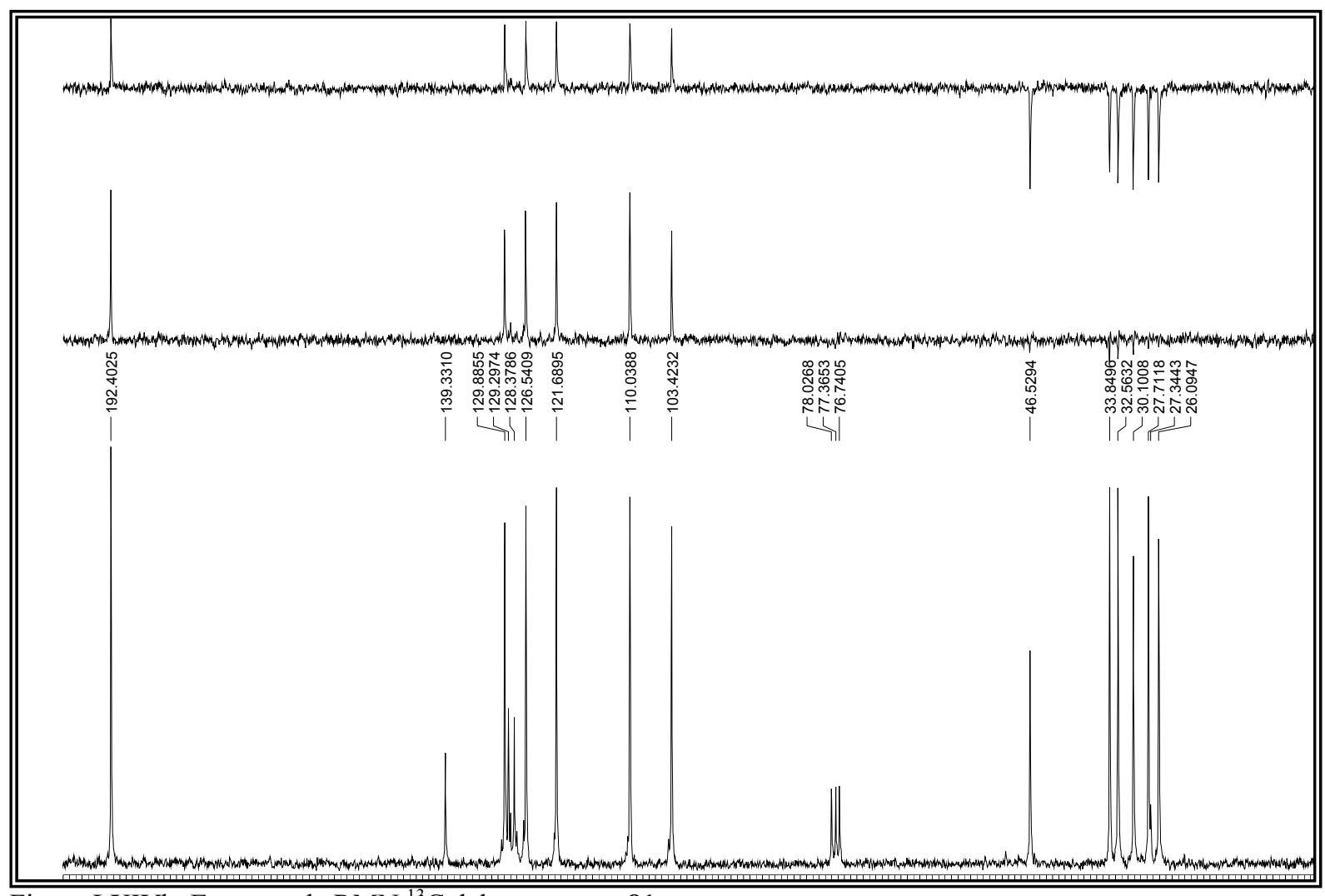

Figura LXIVb. Espectro de RMN ${ }^{13} \mathrm{C}$ del compuesto 81. 


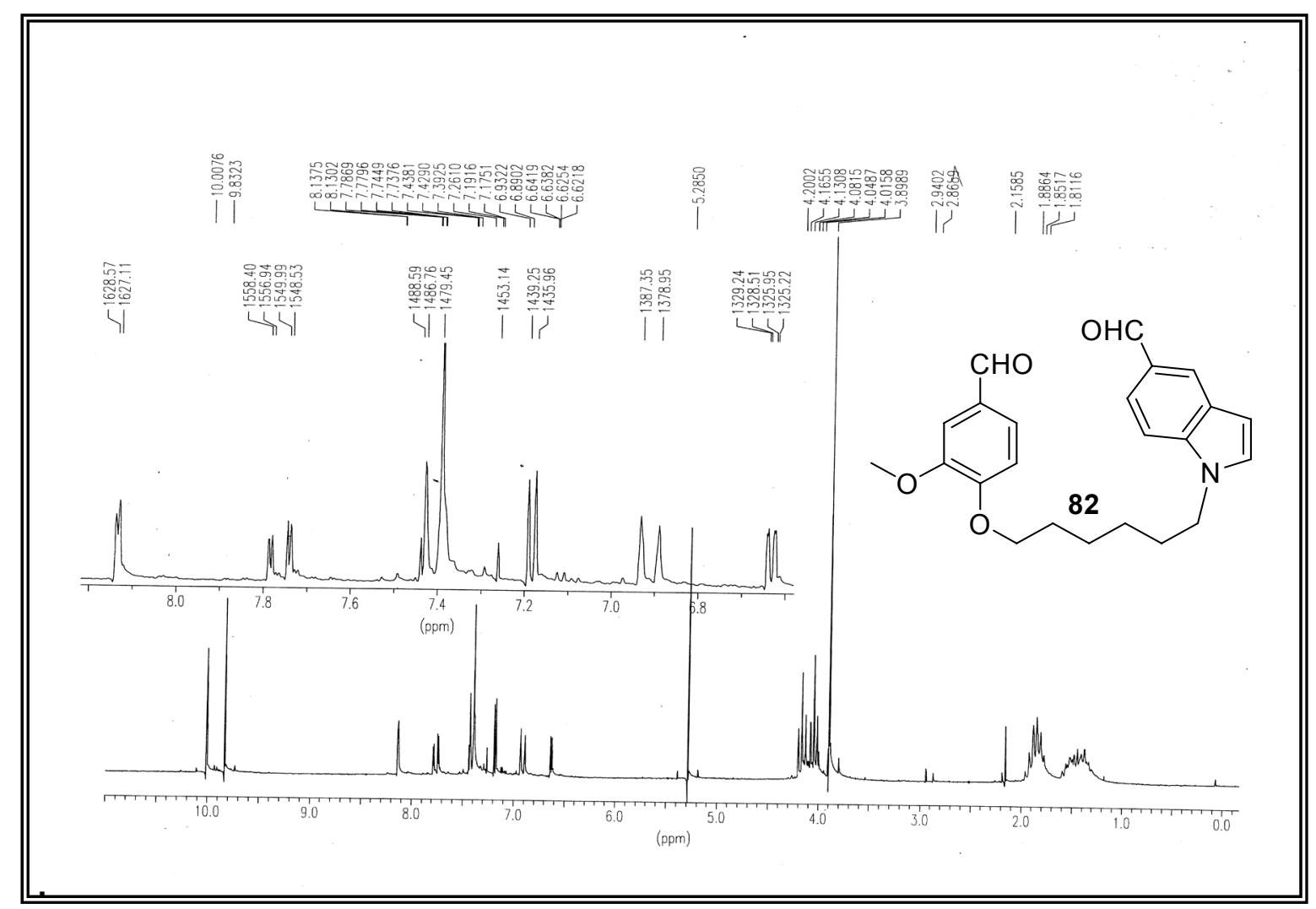

Figura LXVa. Espectro de RMN ${ }^{1} \mathrm{H}$ del compuesto 82.

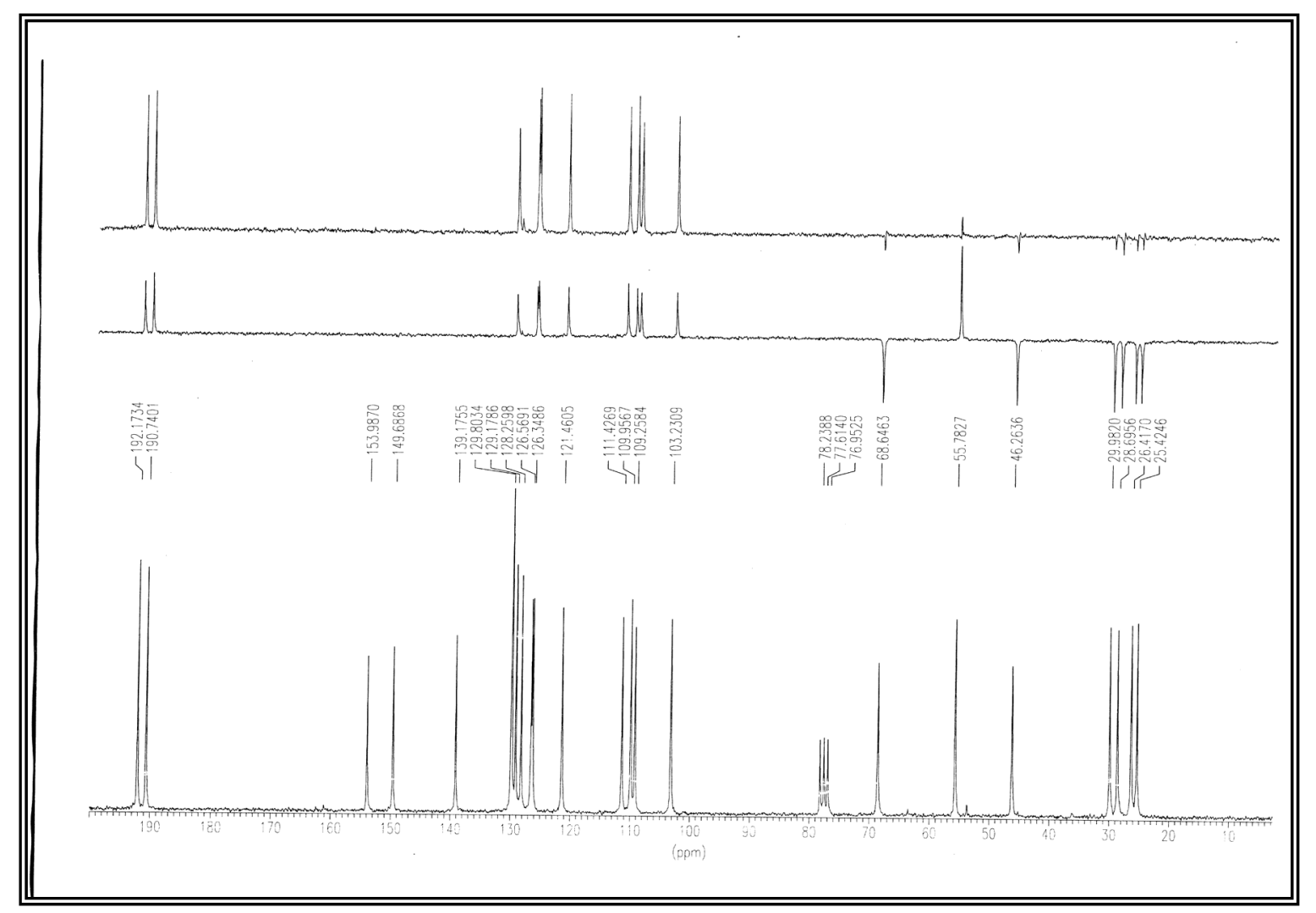

Figura LXVb. Espectro de RMN ${ }^{13} \mathrm{C}$ del compuesto 82. 


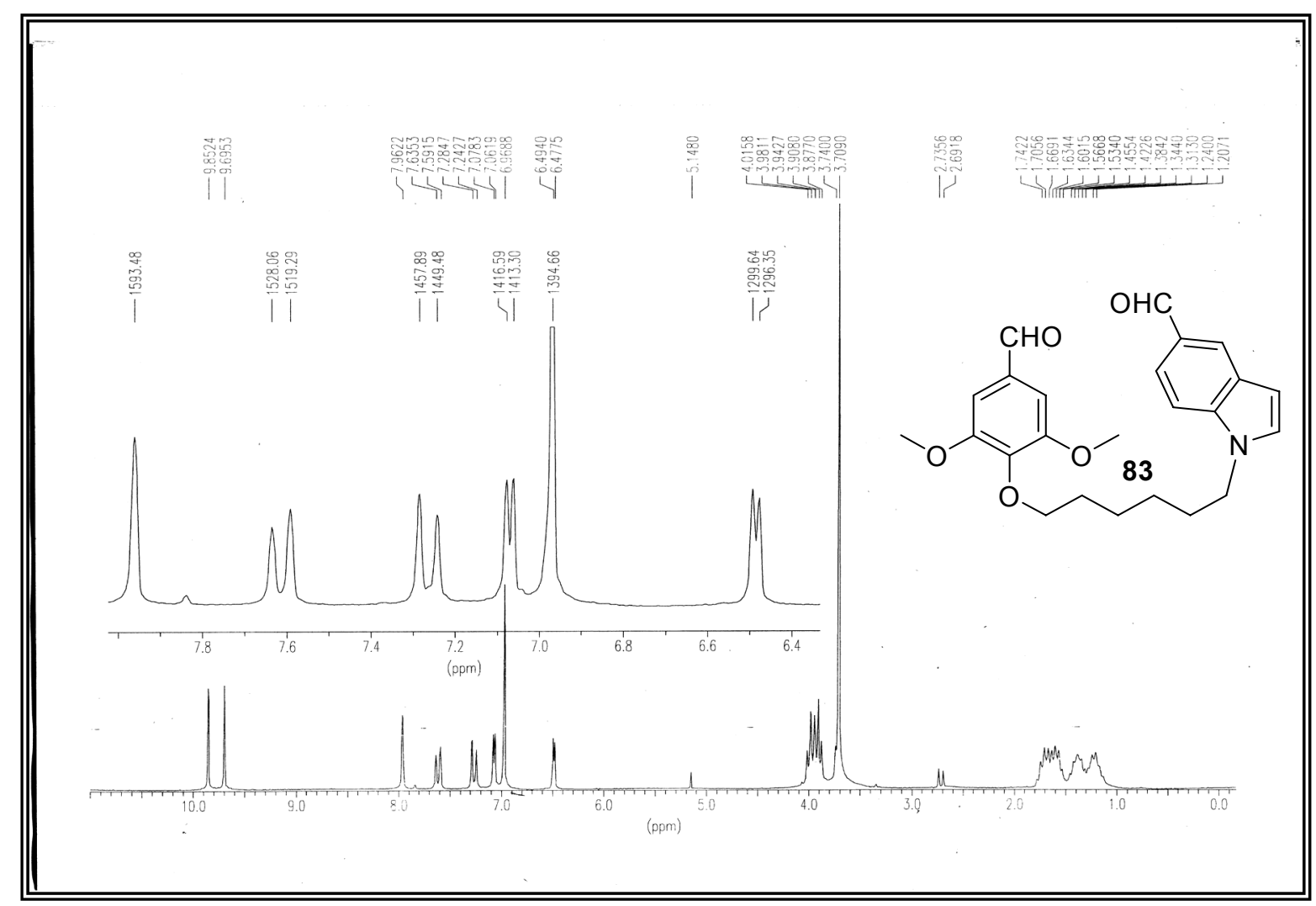

Figura LXVIa. Espectro de RMN ${ }^{1} \mathrm{H}$ del compuesto 83.

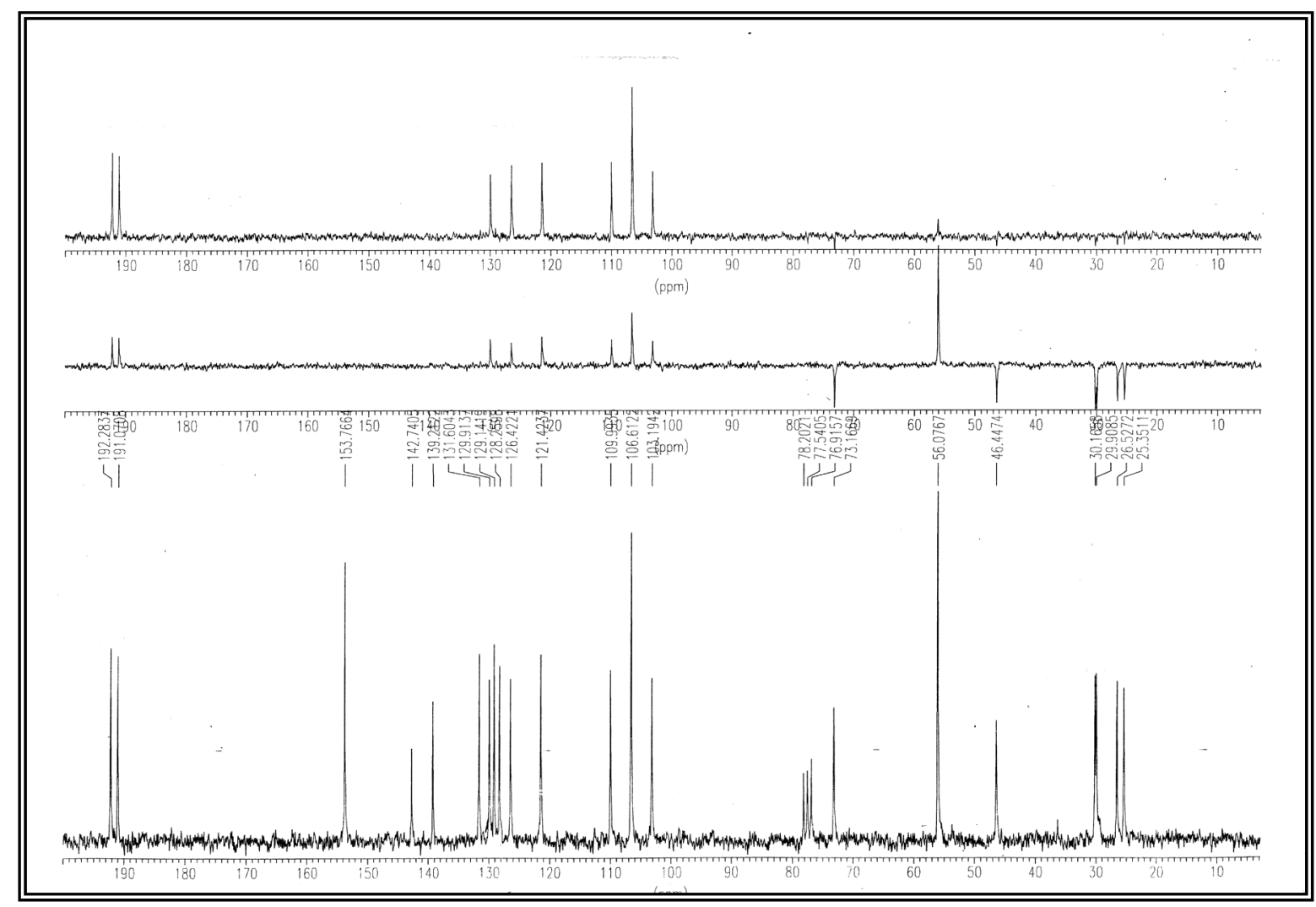

Figura LXVIb. Espectro de RMN ${ }^{13} \mathrm{C}$ del compuesto 83 . 


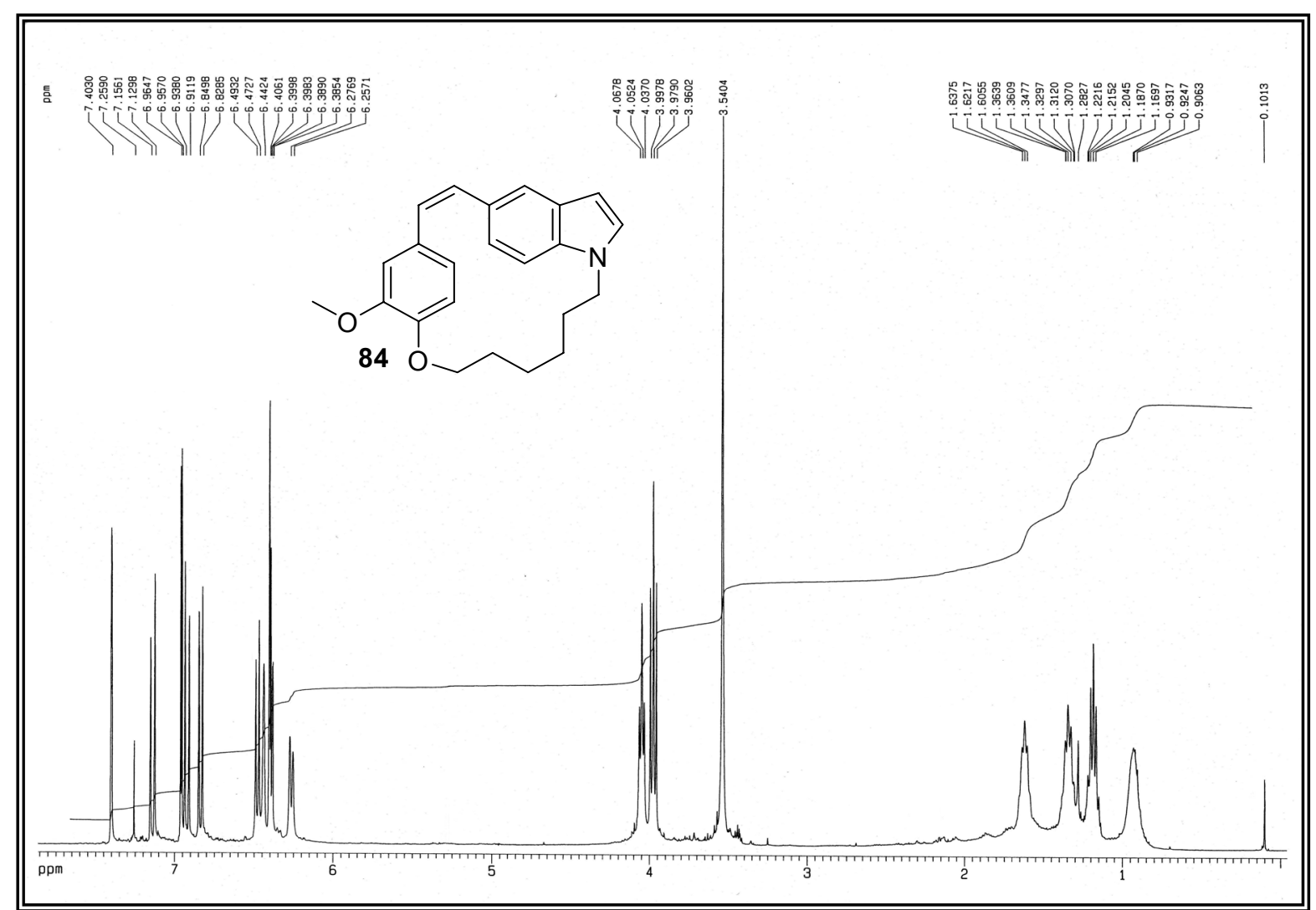

Figura LXVIIa. Espectro de RMN ${ }^{1} \mathrm{H}$ del compuesto 84.

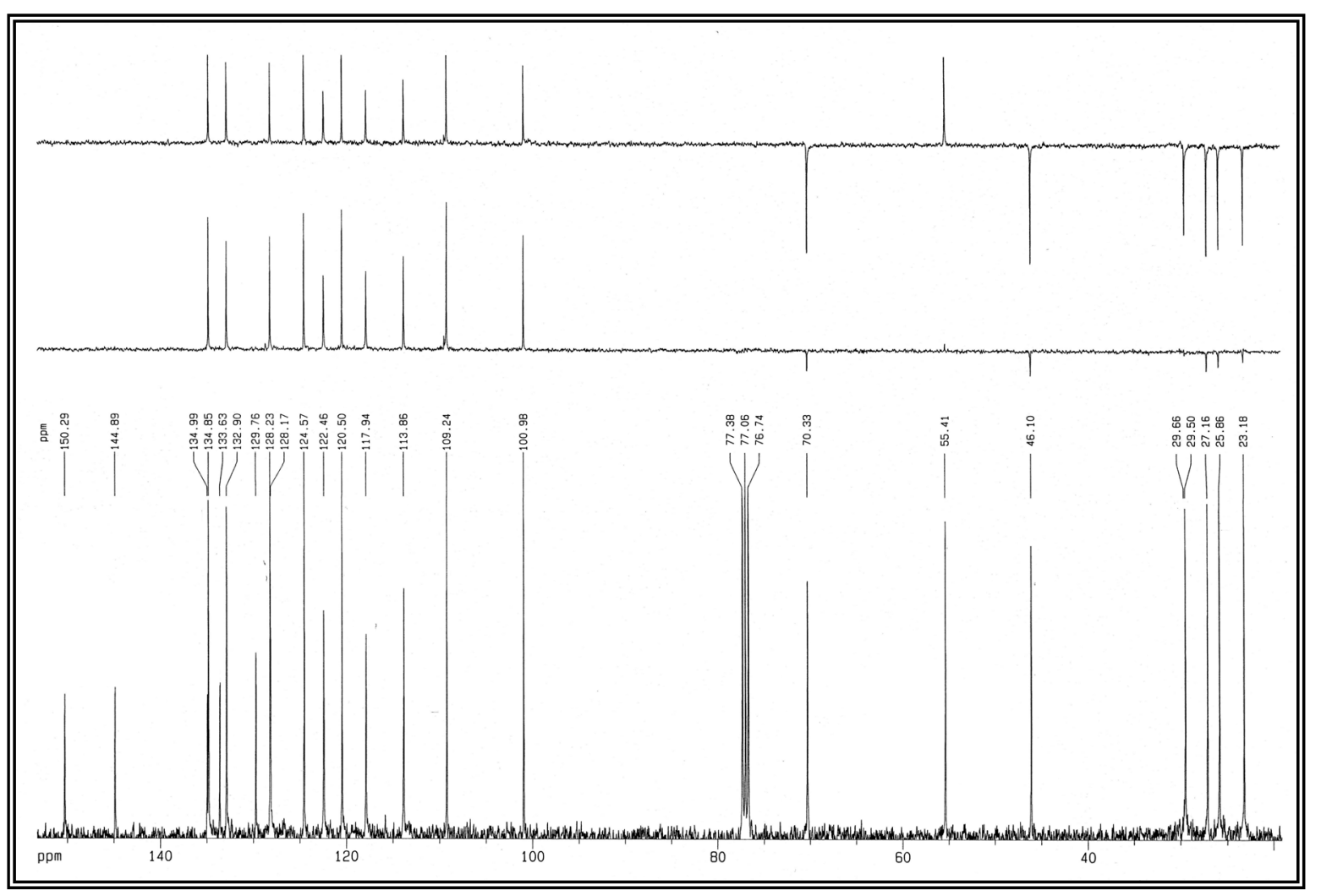

Figura LXVIIb. Espectro de RMN ${ }^{13} \mathrm{C}$ del compuesto 84. 


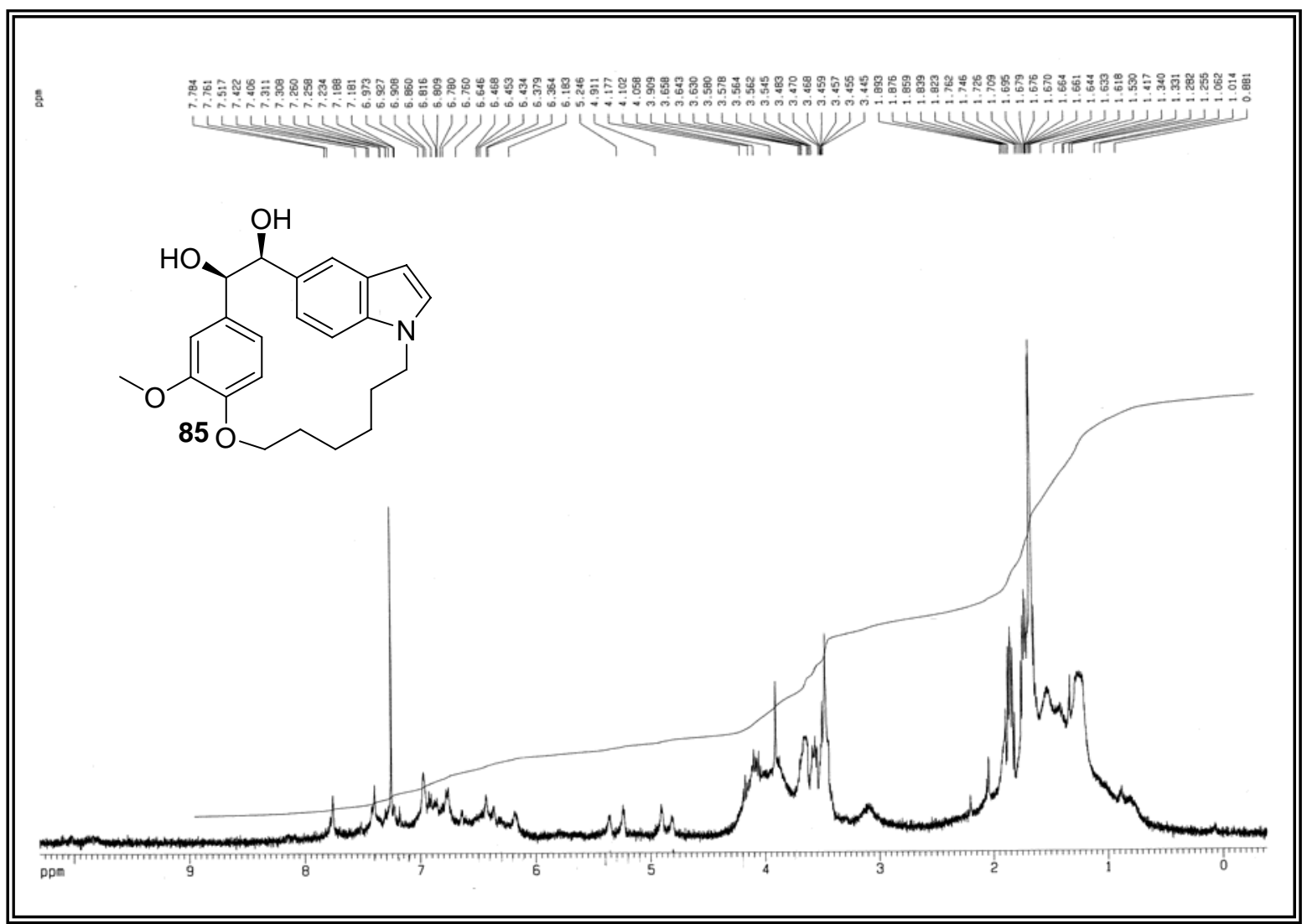

Figura LXVIII. Espectro de RMN ${ }^{1} \mathrm{H}$ del compuesto 85.

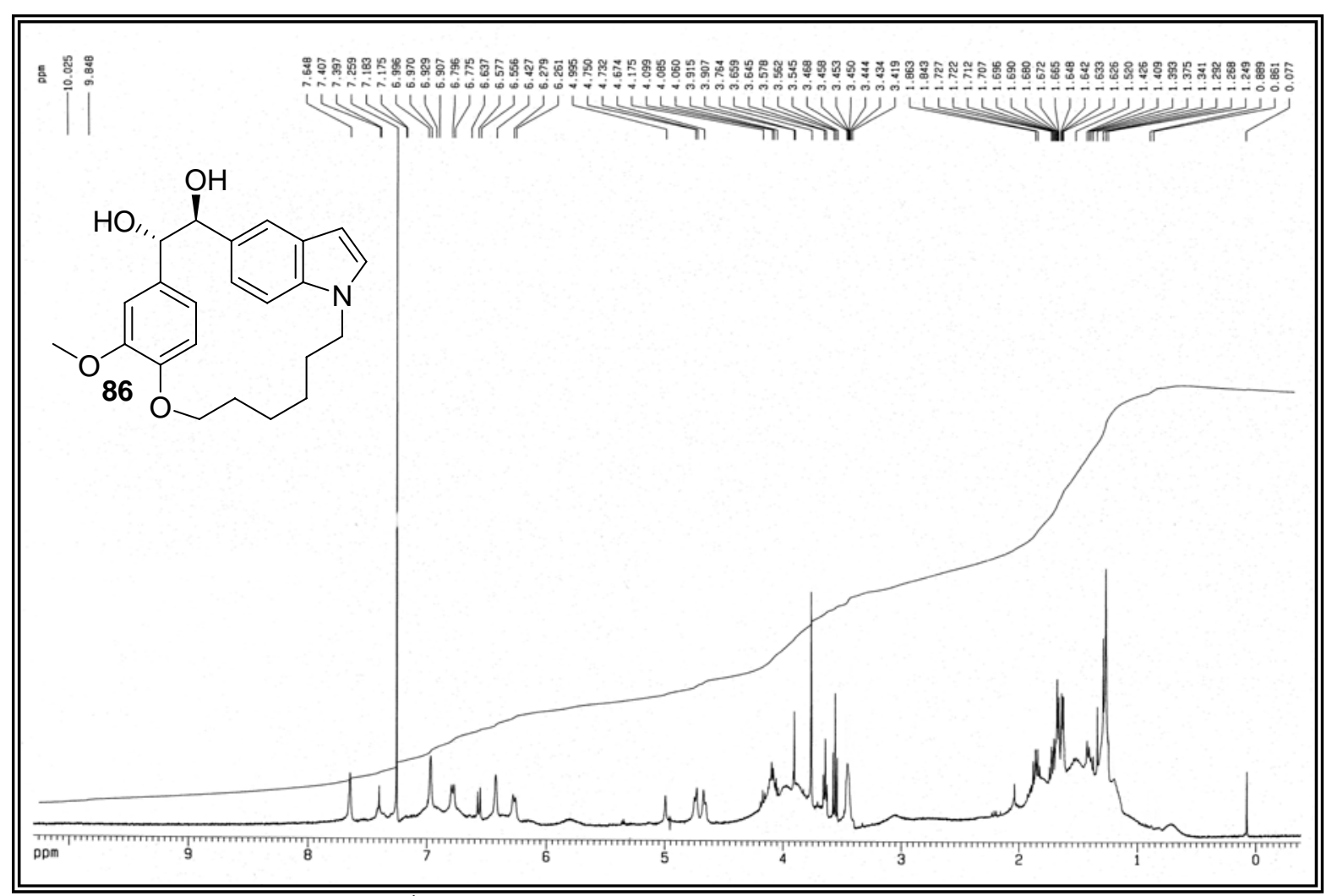

Figura LXIX. Espectro de RMN ${ }^{1} \mathrm{H}$ del compuesto $\mathbf{8 6}$. 


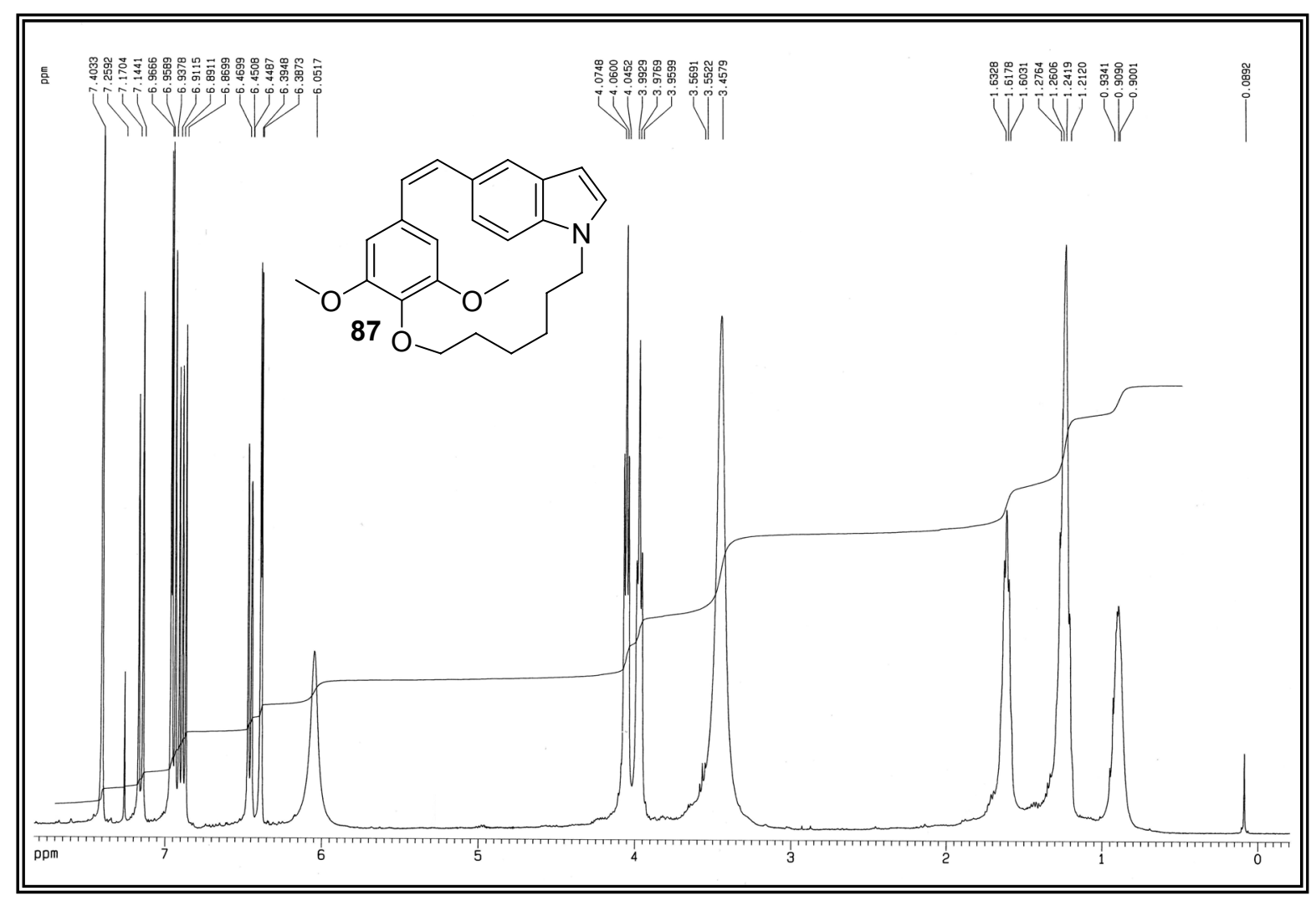

Figura LXXa. Espectro de RMN ${ }^{1} \mathrm{H}$ del compuesto 87.

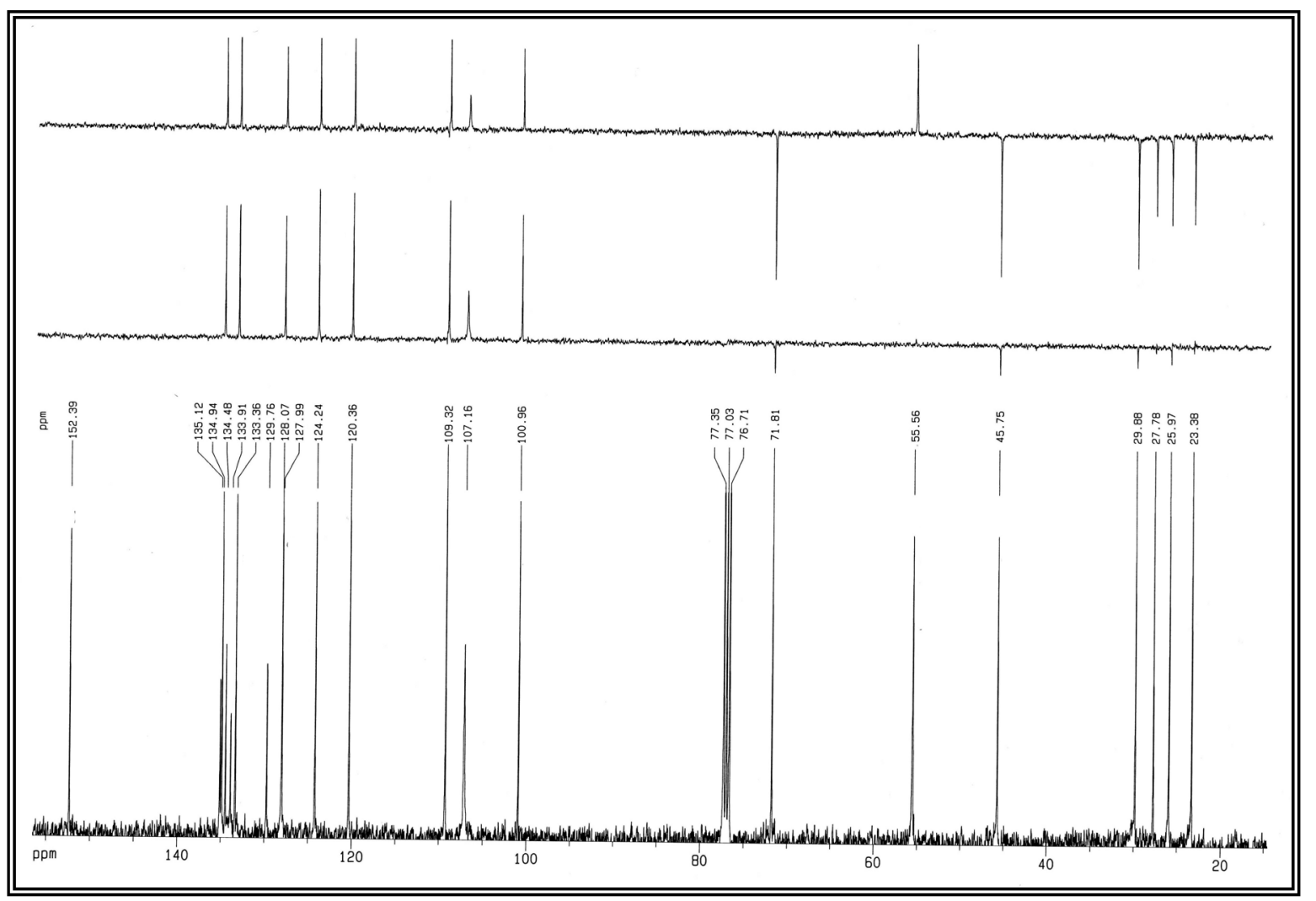

Figura LXXb. Espectro de RMN ${ }^{13} \mathrm{C}$ del compuesto 87. 


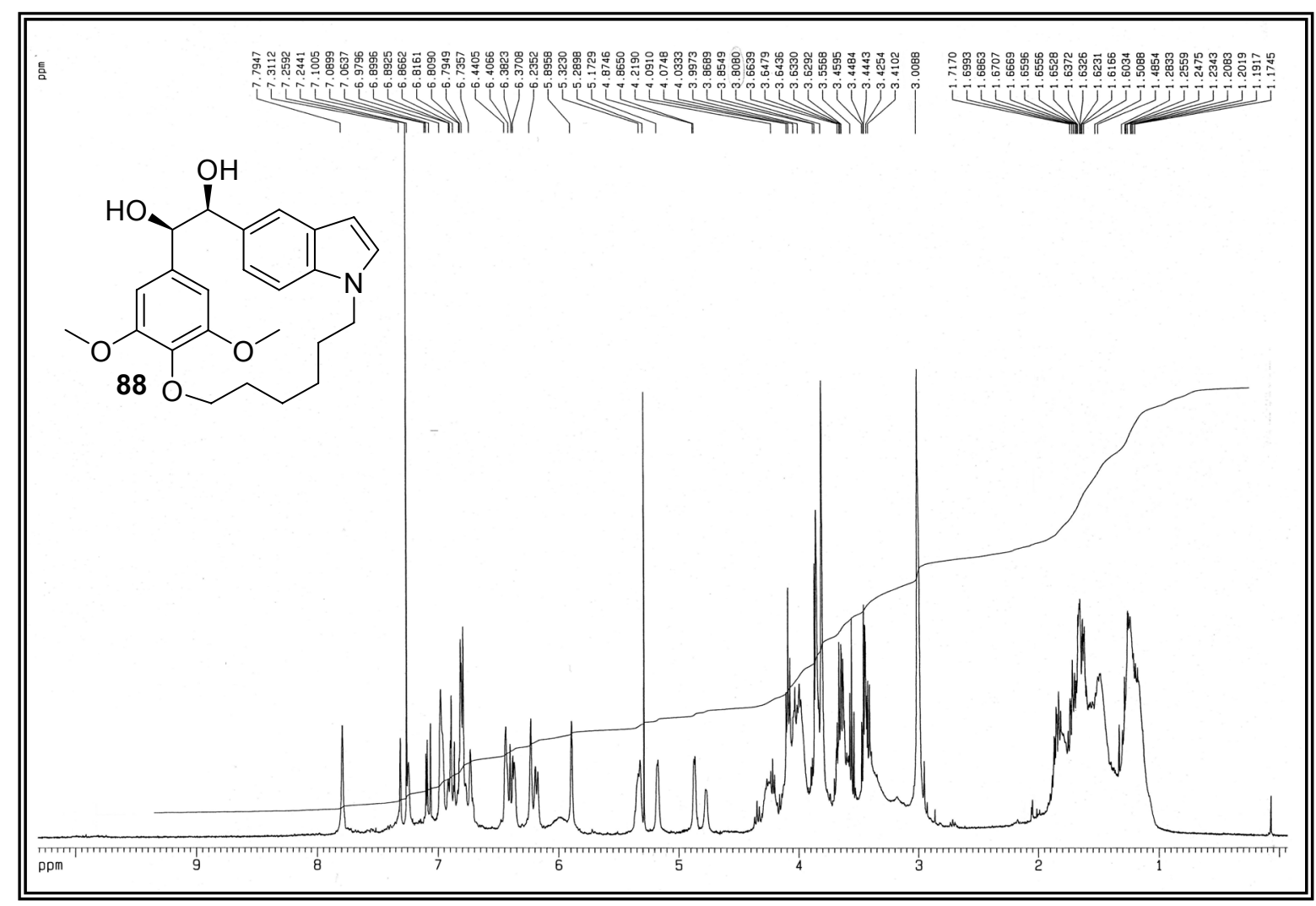

Figura LXXIa. Espectro de RMN ${ }^{1} \mathrm{H}$ del compuesto 88 .

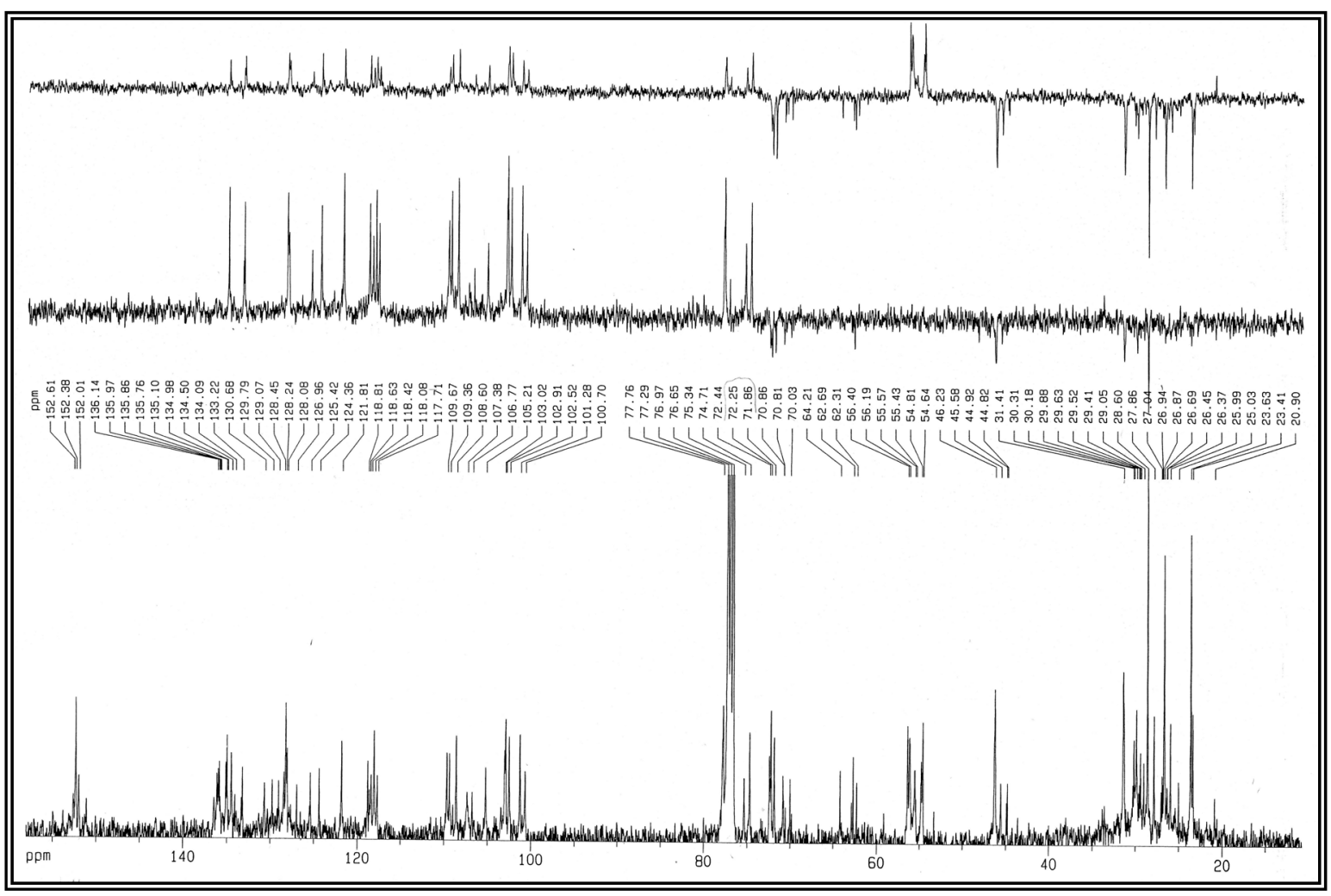

Figura LXXIb. Espectro de RMN ${ }^{13} \mathrm{C}$ del compuesto 88 . 


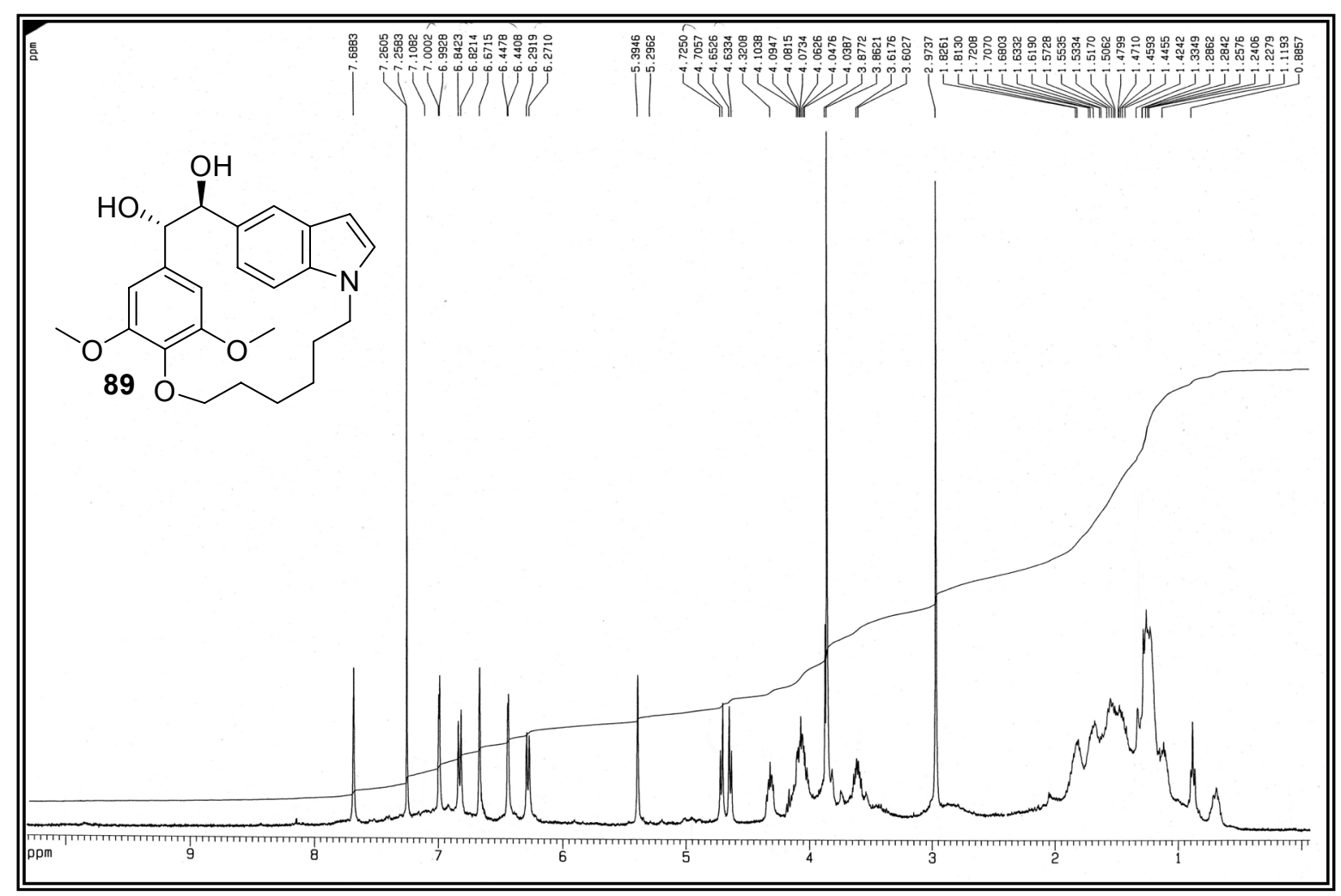

Figura LXXIIa. Espectro de RMN ${ }^{1} \mathrm{H}$ del compuesto 89.

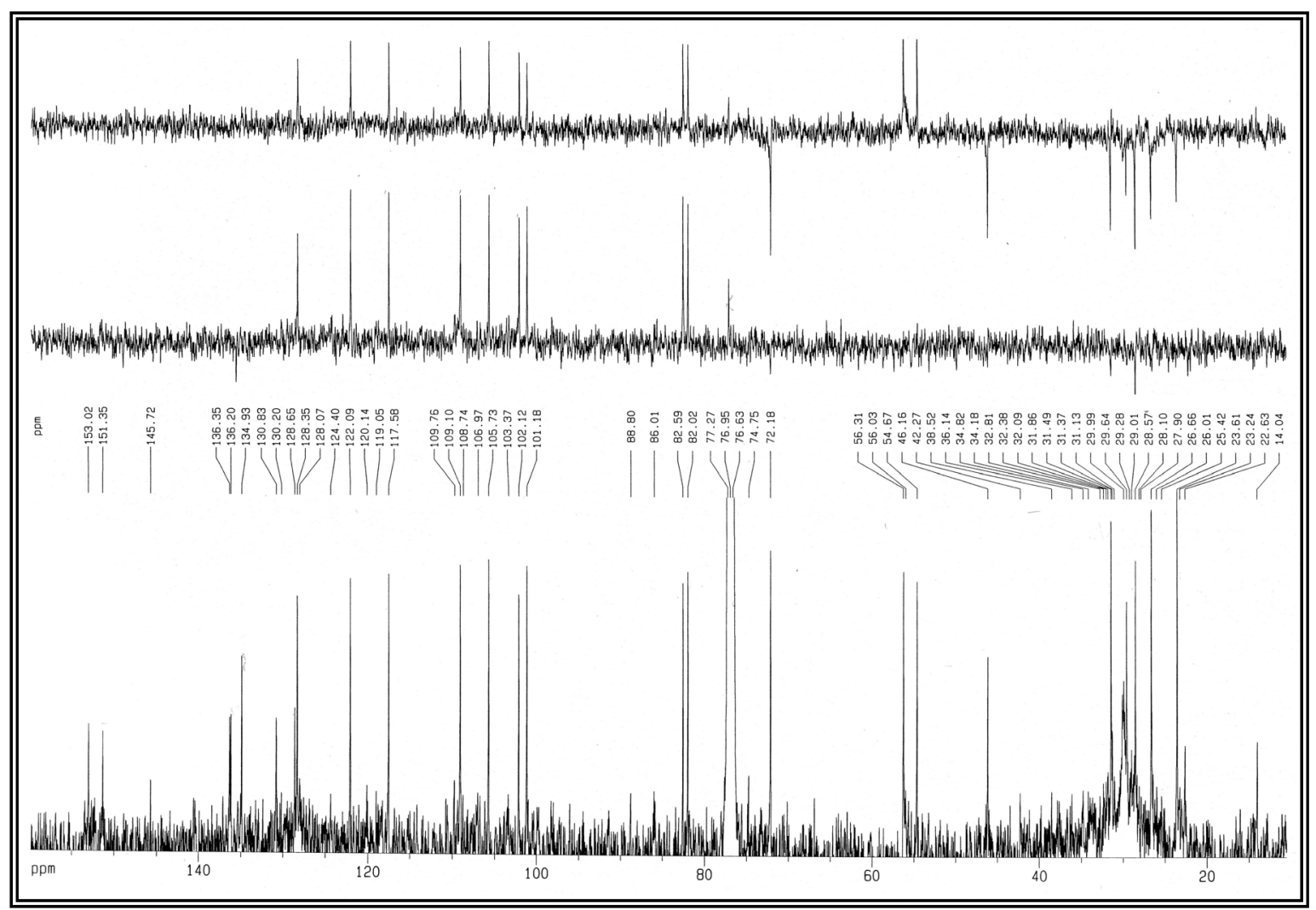

Figura LXXIIb. Espectro de RMN ${ }^{13} \mathrm{C}$ del compuesto 89. 


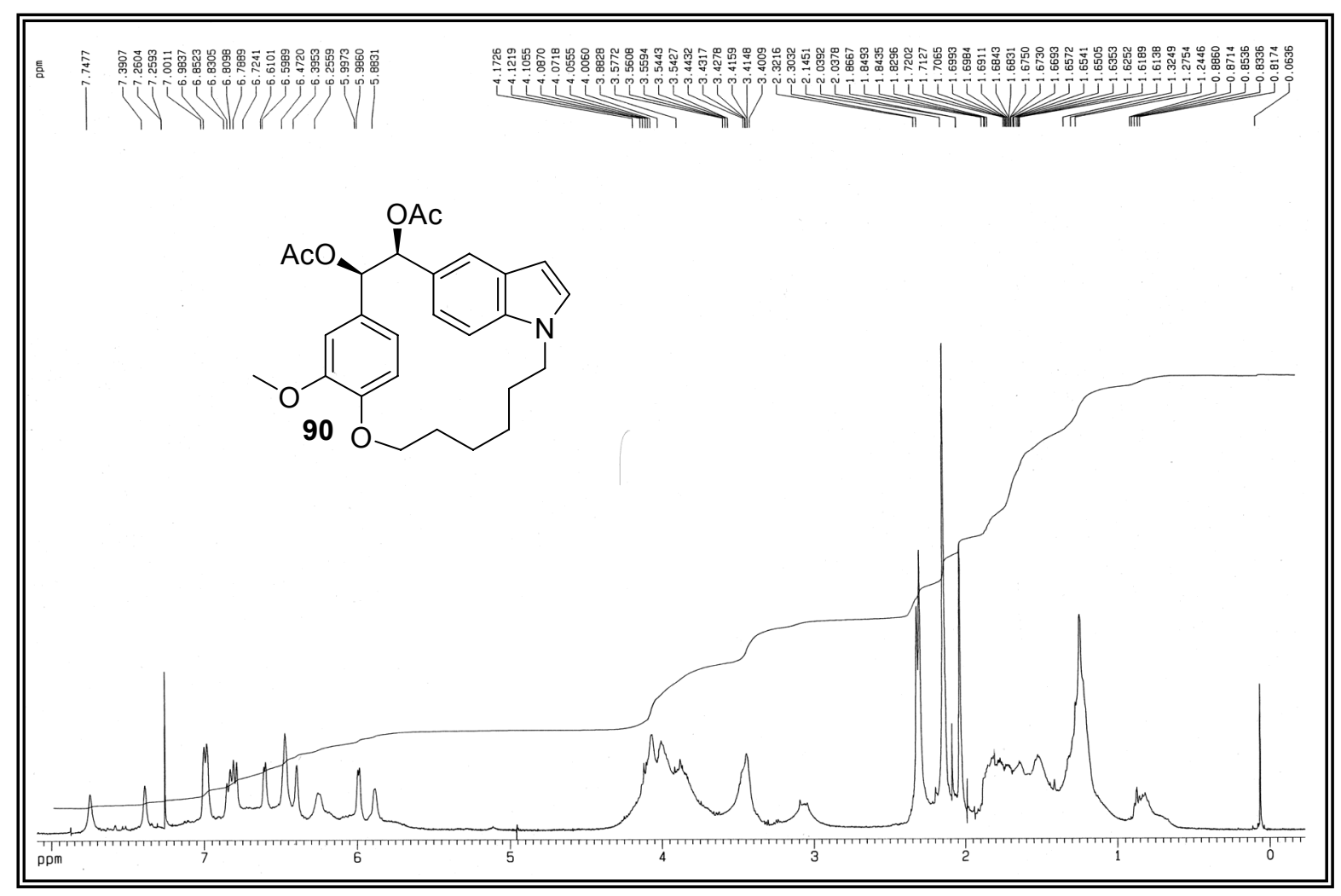

Figura LXXIIIa. Espectro de RMN ${ }^{1} \mathrm{H}$ del compuesto 90.

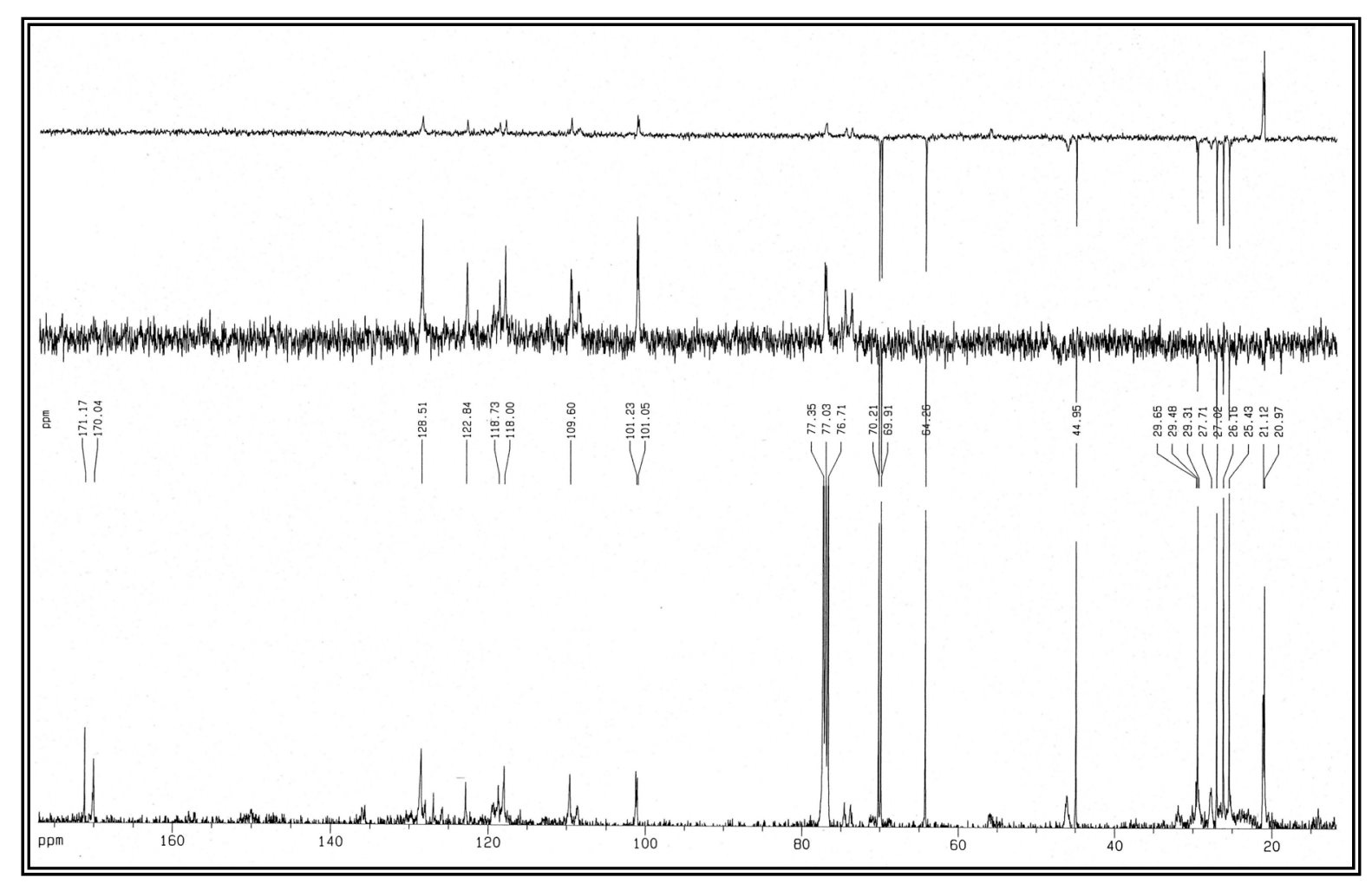

Figura LXXIIIb. Espectro de RMN ${ }^{13} \mathrm{C}$ del compuesto 90. 


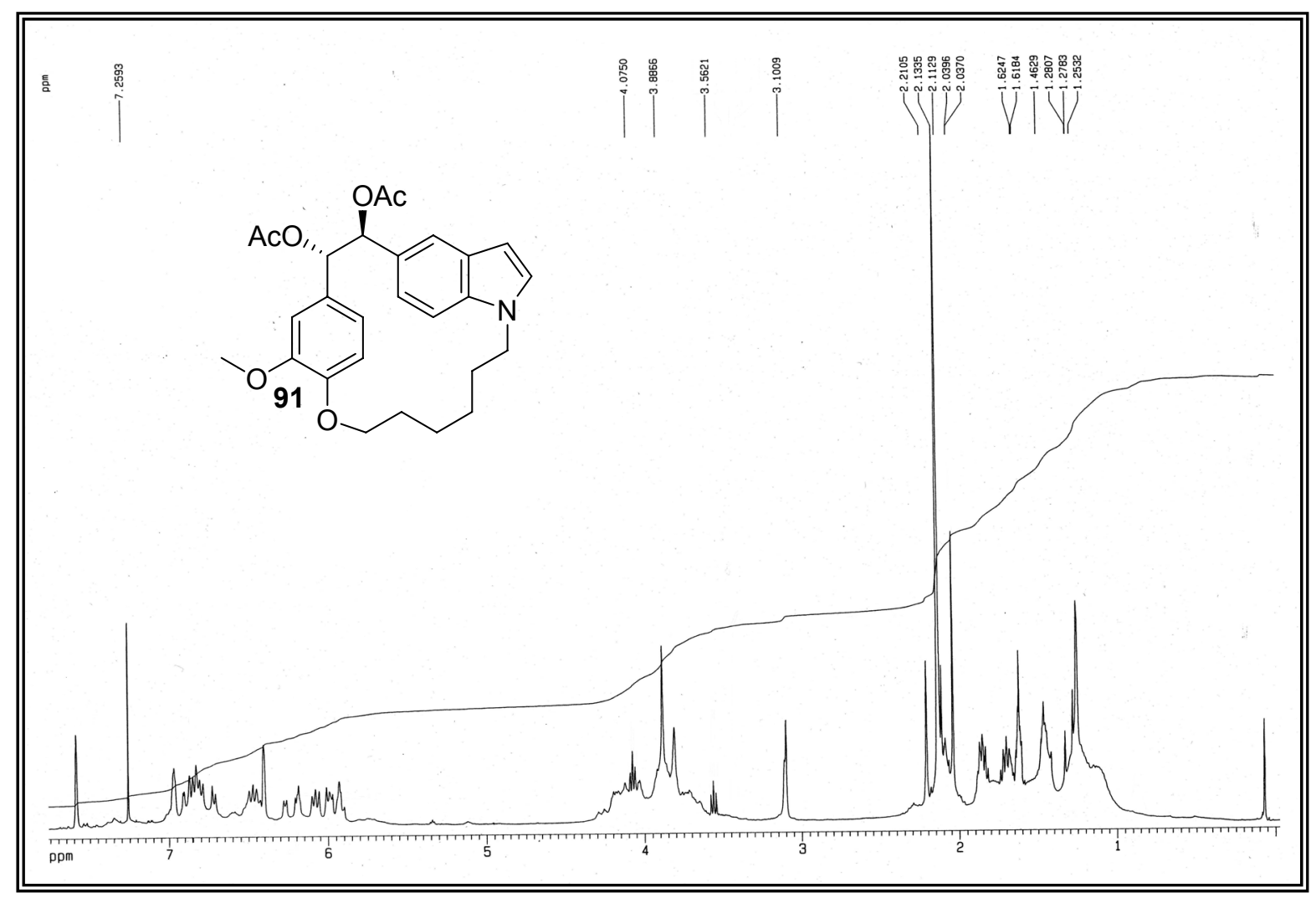

Figura LXXIVa. Espectro de RMN ${ }^{1} \mathrm{H}$ del compuesto 91.

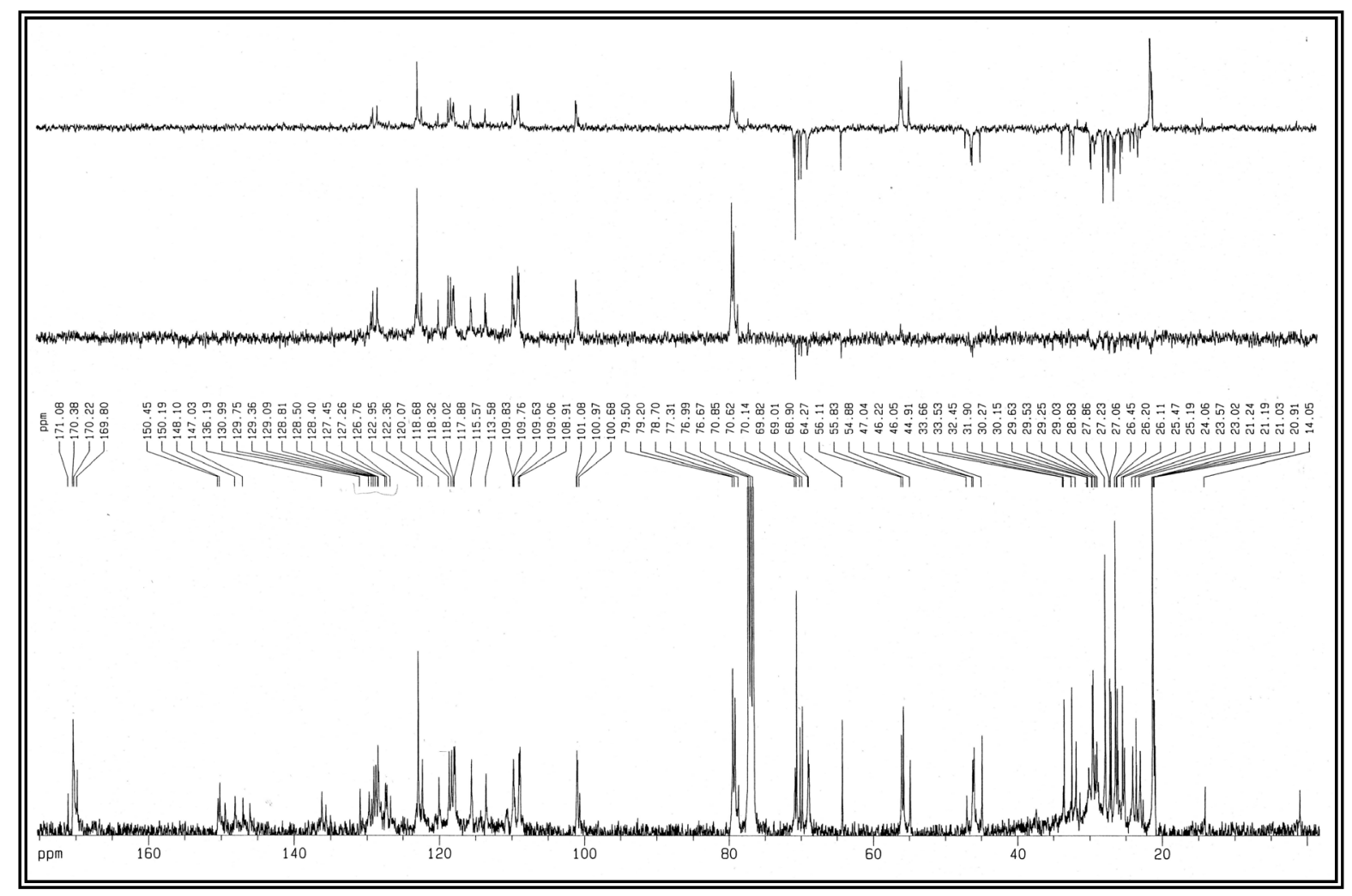

Figura LXXIVb. Espectro de RMN ${ }^{13} \mathrm{C}$ del compuesto 91. 


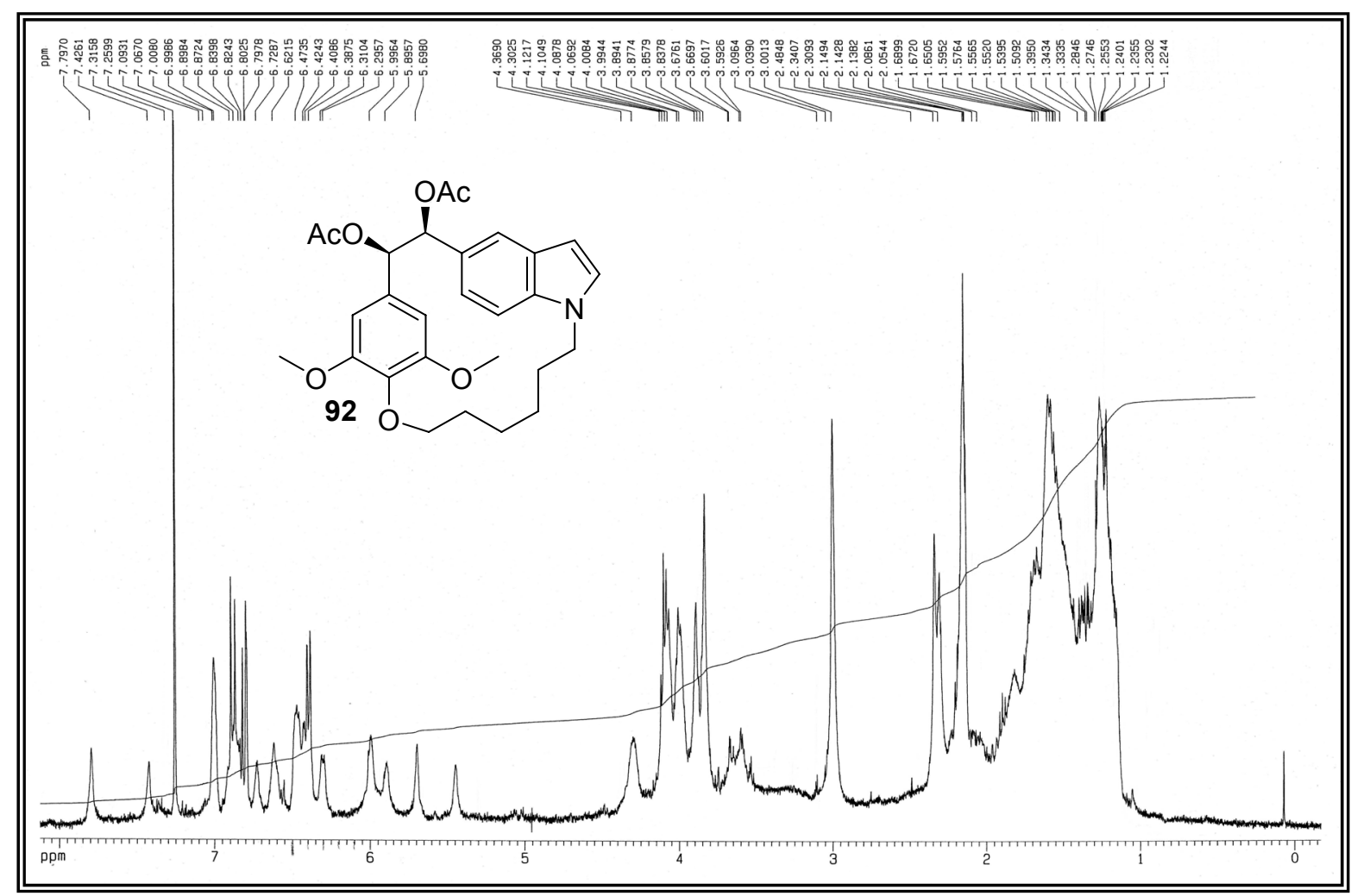

Figura LXV. Espectro de RMN ${ }^{1} \mathrm{H}$ del compuesto 92. 


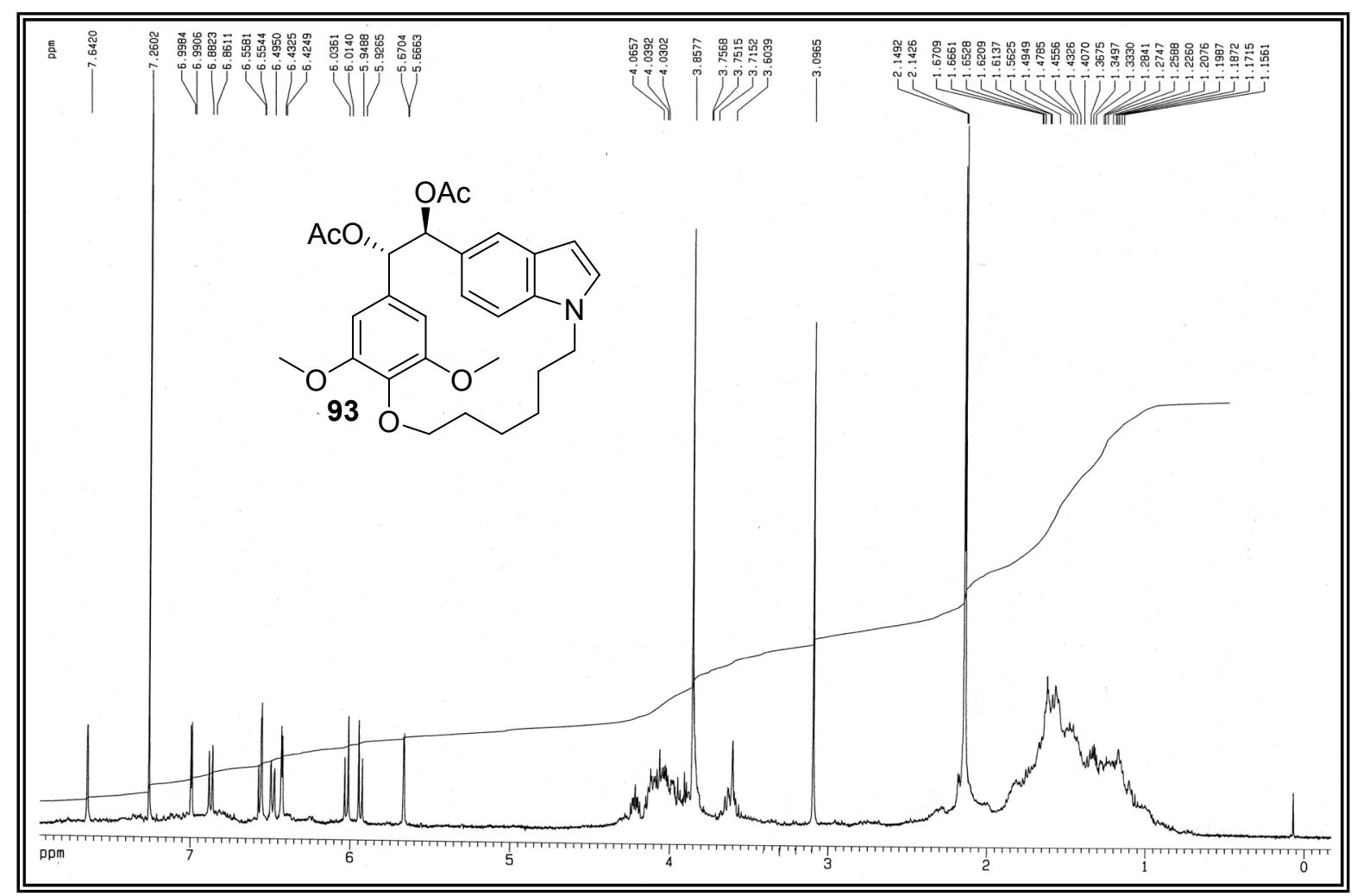

Figura LXXVIa. Espectro de RMN ${ }^{1} \mathrm{H}$ del compuesto 93.

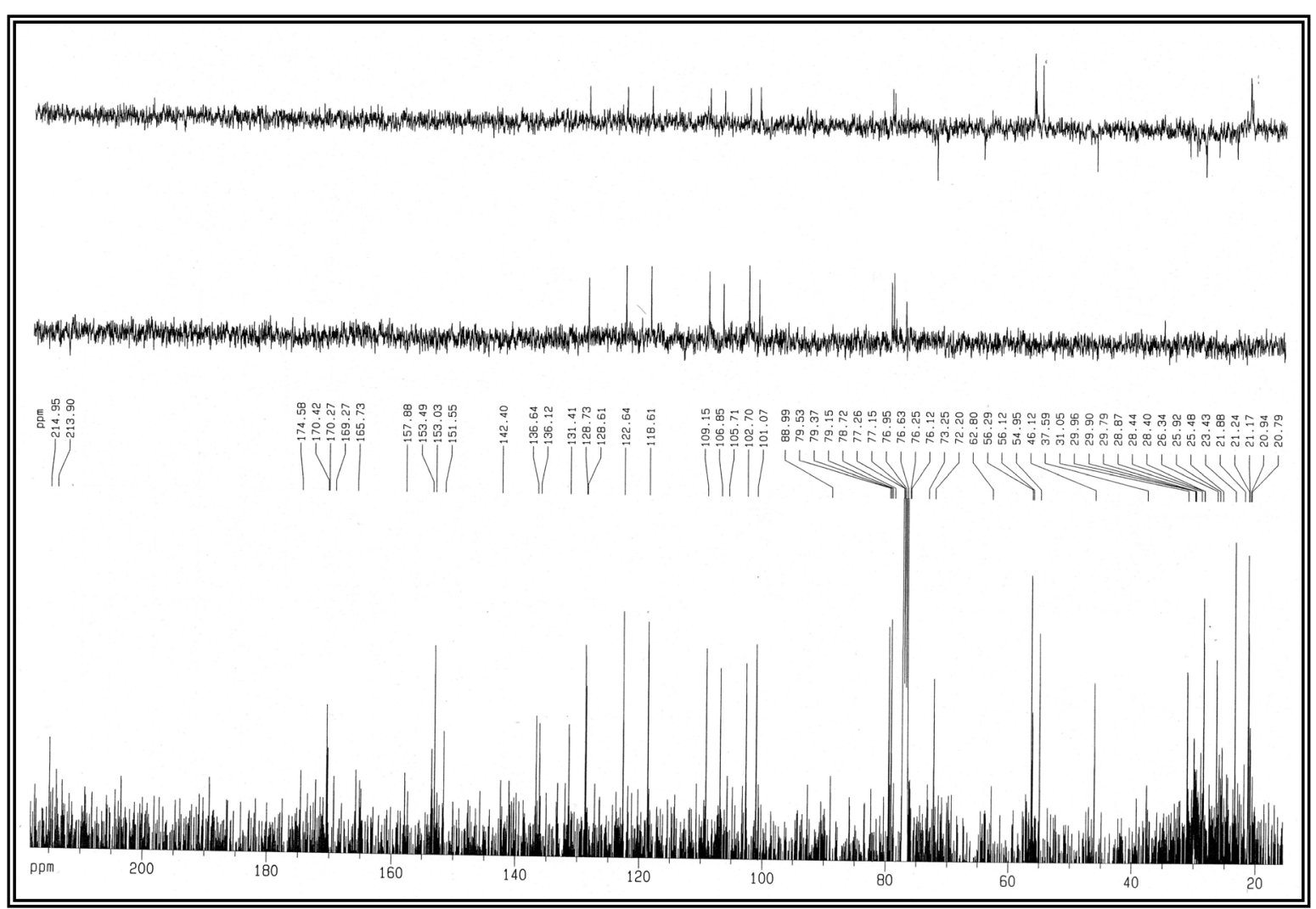

Figura LXXVIb. Espectro de RMN ${ }^{13} \mathrm{C}$ del compuesto 93 